UC-NRLF

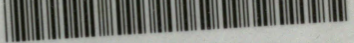

B 3120749

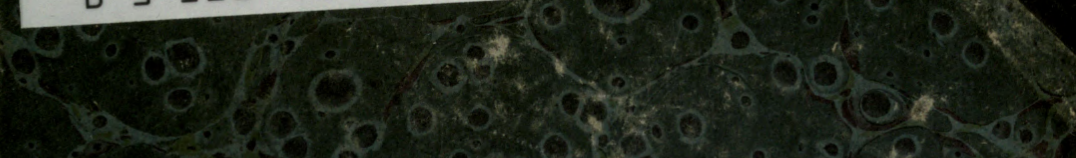

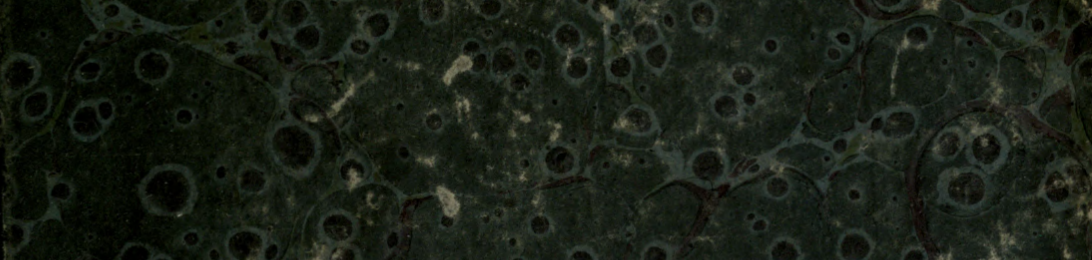
1.

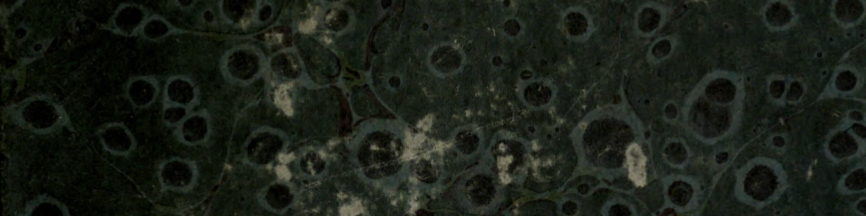

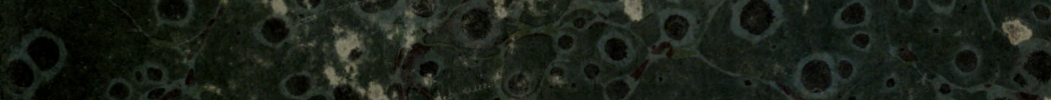

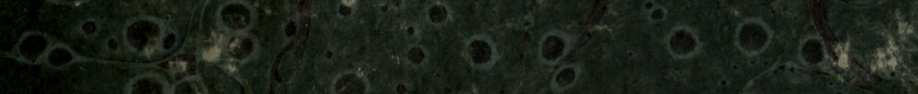

Q.0.7.

:

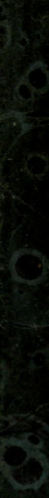

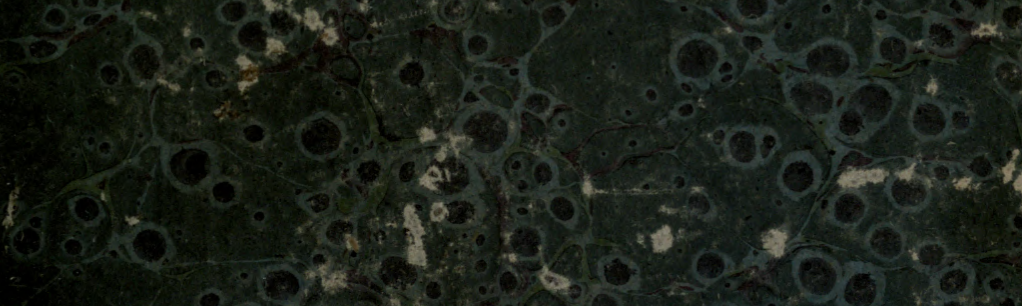

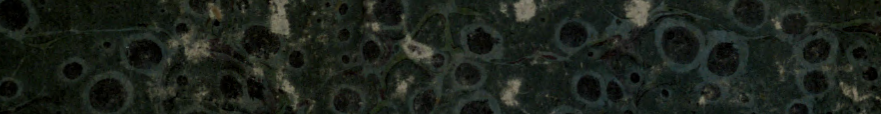

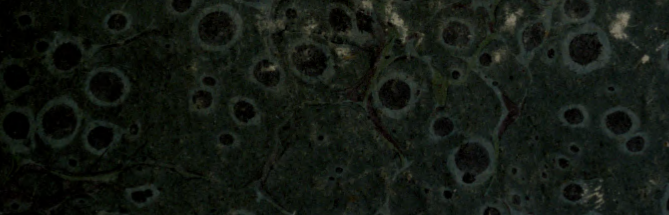

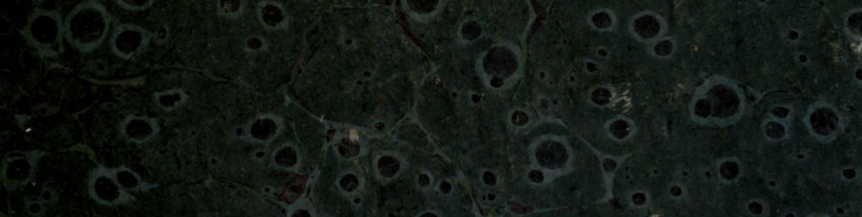

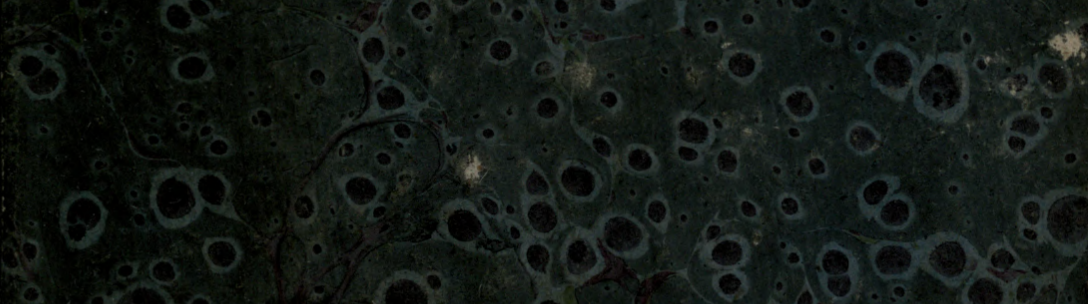

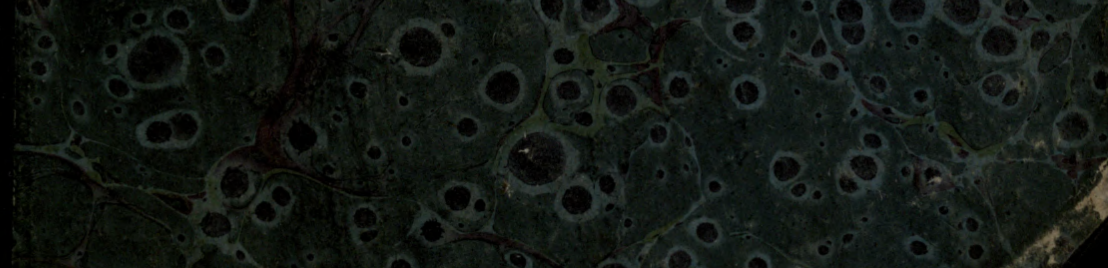

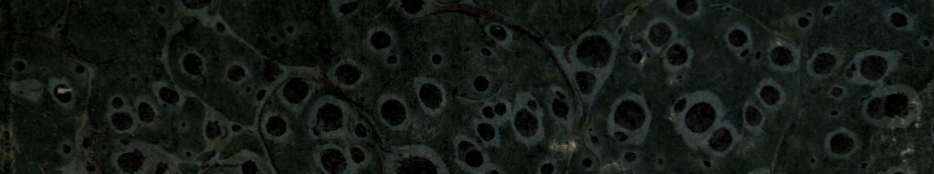




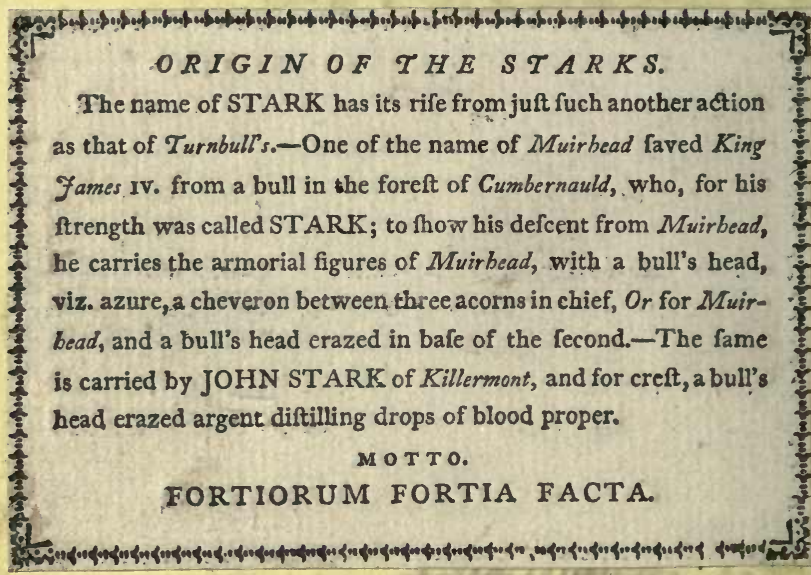




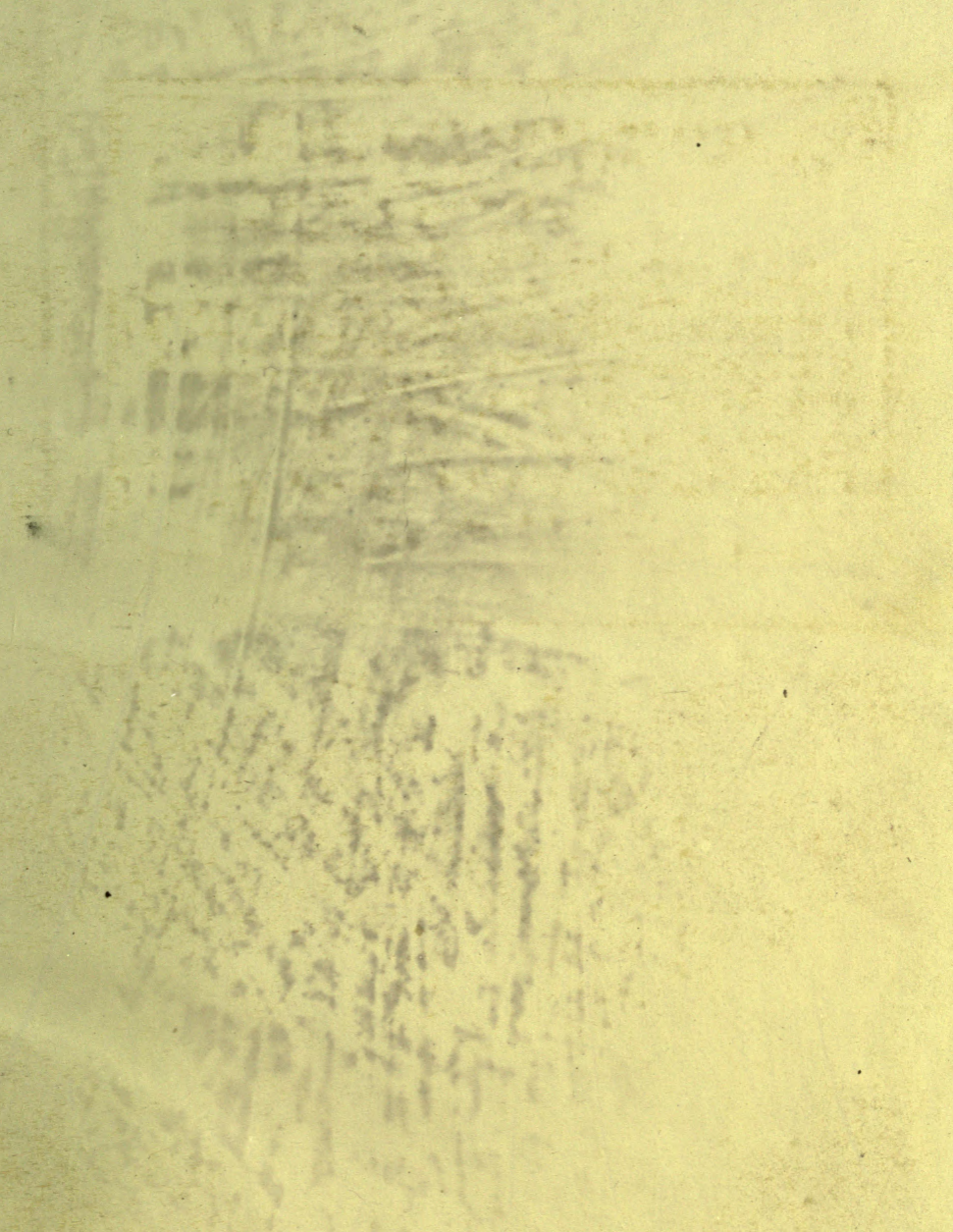





To Ancound to the Pielas perm hisibed frenis

clanes flathl

fo Sames Staits.

fom his affectionale. Fa then.

$28 \mathrm{th}$ Oclober 1828.

$\rightarrow 3$ 


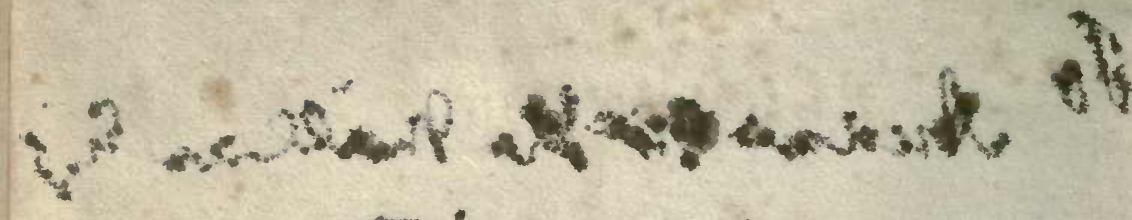
(j) t.t. 


\section{ELEM ENTS}

OF

\section{NATURAL' HISTORY,

ADAPTED TO THE PRESENT STATF OF THE SCIENCE,

CONTAINING

THE GENERIC CHARACTERS OF NEARLY THE WHOLE

\section{ANIMAL KINGDOM,}

A N D

DESCRIPTIONS OF THE PIRINCIPAL, SPECIES.

\section{BY JOHN STARK, F.R.S. E.}

MEMBER OF THE WERNERIAN NATURAL HISTORY SOCIETY OF EDINBURGH, \&c. \&c.

WITH ILLUSTRATIVE ENGRAVINGS.

VOL. I.

VERTEBRATA.

\section{EDINBURGH :}

ADAM BLACK AND JOHN STARK, EDINBURGH :

AND LONGMAN, REES, ORME, BROWN \& GREEN, LONDON. 
-

4.

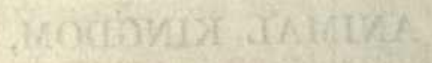

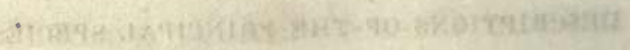
I0\%?

Printed by John Stark. 


\section{ADVERTISEMENT.}

THe following work, though in some measure elementary, will be found to contain considerably more than a mere Introduction to the study of Natural History. It was originally intended, besides observations on the different Classes, detailing generally the structure and classification of the objects they embraced, to give not only the generic characters of the whole Animal Kingdom, but examples of the principal and most interesting species. In all the classes except two, the InsECTA and ENTOzOA, this has been done, and in most cases the indication has not been confined to a single species. But in the class of Insects this was found to be impossible within the limits prescribed, the objects being so extremely numerous, that the recently established generic distinctions would alone have filled a volume.

In the class Mammalia, the Mammalogie of M. Desmarest has been followed, with the addition of the species described since that work was published; and in this department, besides the characters of the recent and fossil genera, room has been found for descriptions 
of the whole ascertained species. In the class of BIRDs Temminck has been taken for the guide; and in addition to the European species described by that celebrated ornithologist, the characters, and at least one typical species, of all the extra-European genera have been given. The arrangement of Baron Cuvier has been followed in the classes of REptiles and Fishes.

The classes Mollusca and Conchifera, including the fossil genera, and the class Tunicata, have been adopted from M. Lamarck; - the CrRrIPEDA and Annelides chiefly from Latreille-the CrustaCEA from the same author, Dr Leach, and Desmarest -the MYRIAPODA from Latreille-and the characters of the INSECTA have been almost wholly taken from the writings of that distinguished entomologist. In this class, however, in place of detailed generic characters, room has only been found for analytical tables. These, with the descriptions of the families and tribes, will, it is hoped, enable the student or traveller to refer any insect met with, if not to its proper genus, at least to the tribe or family to which it belongs. The class Acalepha is adopted from Cuvier-the ENTozoA from the same author and Rudolphi-and the PoLYPI and INFUsoria chiefly from Lamarck.

In the whole work, indeed, it has been a principal object to give, in the arrangement of the different clas- 
ses, the methods adopted by naturalists of the first eminence, and most generally followed,-keeping in view the great outline of Cuvier, founded on the comparative organization of the animal races. The other systems which have been at various periods proposed are noticed in the introductory observations at the head of each class. In most cases the Linnæan name, where it has not been followed as the leading term, is given as a synonym.

As the place of the different classes of animals in the series is determined by their comparative organization, a short sketch of the internal structure as well as of the external characters of each group is given in the respective introductions. The details on this part of the subject, which are chiefly from Cuvier and Dumeril, will be found of material use to the student of Comparative Anatomy, in connecting with his researches the zoological history of the various races.

To complete the plan, a short Introduction to Botany, embracing a general view of the structure of the Vegetable Kingdom, of the system of Linnæus, and the Natural Families of Jussieu, follows the Zoological part of the work; and a brief sketch of the Mineral Kingdom, including Mineralogy and Geology.

In the collection and arrangement of the materials, every accessible source has been consulted; and gene- 
ral remarks have been inserted to lighten the details of scientific arrangement. In the absence of a System of Nature adapted to the present state of knowledge, this work, it is hoped, will form a useful guide to the student of Nature, as, however imperfectly executed, it is the only one in which a consecutive and complete view of the modern classifications of Animals has been offered to the notice of the Public.

Edinburgh, 14th October 1828. 


\section{CONTENTS OF VOLUME FIRST.}

Introduction, . . . . . . . . . . . Page 1

$$
\text { I.-VERTEBRATA. }
$$

Class I. Mammalia, • . • • . • • • • . . . 22 Class II. BrRd, . . . . . . . . . . . . . 166 Class III. Reptiles, • • . . • . . . . . . . 331 Class IV. Fishes, . . . . . . . . . . . . 371

Preparation and Preservation of Objects in Natural History, . . . . . . . . . . . . . . . 495

List of Books, . . . . . . . . . . . 511 


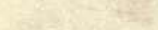

$245 a^{2}+x^{2}$

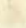

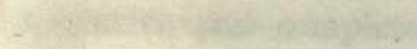

-

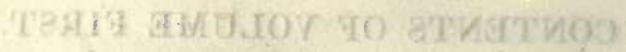

$\sin \sin ^{4}$

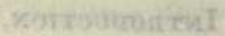

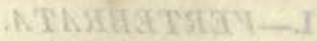

90

079

LR:

178

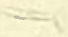

atakicicain at anlo

Hortस -31 ang

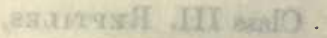

F

36

atest

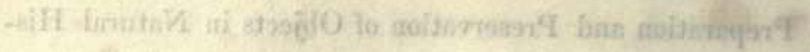

If 


\section{ELEMENTS}

\section{OF \\ NATURAL HISTORY.}

INTRODUCTION.

THE object of Natural History is the Material World, and the various classes of organized and inorganic bodies which form its component parts. To examine and arrange these in connection with the laws by which they are governed, to investigate their structure, their history, and their uses, is the province of the Naturalist. In its most extended sense, Natural History embraces all the visible creation, and includes every object in that creation, from the most magnificent of the celestial bodies to the smallest insect or particle of dust which is found in the globe inhabited by men. A field so extensive, compared with the limited powers of the human faculties, is too vast for the subject of individual research; and in detail its objects are so numerous, that to possess a knowledge of even a small portion of these, has been considered a competent task for a life spent in investigation.

For this reason it has become matter of necessity to subdivide and arrange the objects of the material world into portions, suitable to the powers and the intelligence of those whose province and interest it is to investigate the wonders of Creation. One great branch, termed Natural Phroosopir, has thus been divided into numerous departments, of which Drnamics, or the doctrine of the laws of motion and its effects, and its subsidiary divisions, Statics, Hydrostatics, \&c. offer a wide field to investigation. The observation of the positions and revolutions of the Heavenly bodies has become the province of that branch of Natural Science denominated Astronomy; the nature, vol. $I$. 
motion, and qualities of light form the science of Optics : the changes that take place in the atmosphere, as they are perceived by the senses, or indicated by instruments, is the object of Meteorology : And it is the province of CHEmistry, another great branch of Physical Science, to investigate the mutual agencies of the elementary principles of matter upon one another, their composition, and the laws by which they are regulated. These divisions of the great field of Natural Science have, from the universality of their influence, been called $\mathrm{Ge}$ neral Physics; while Natural. History in its limited sense, and as confined to the examination of what have been called the three kingdoms of Nature, viz. the Animal, Vegetable, and Mineral, has received the name of Particular Physics. Natural History, besides, is distinguished from the other branches of science now named in this, that while Dynamics is a science chiefly of Calculation, and Chemistry of Experiment, the basis of this great science rests chiefly on Observation.

In the limited sense in which Natural History is thus to be understood as confined to the three great divisions of Animals, Vegetables, and Minerals, a System of Nature is a grand catalogue of the objeets in these kingdoms, in which each individual has a distinctive character and an appropriate name. These in. dividuals, for the sake of arrangement, are collected into groups which have something in common, and which are termed Genera; Genera are further combined into other groups, which form in systems what are called $O r$ ders; and Orders are finally arranged under one great head, which is termed a Class. This scale of divisions, of which the highest contains the least, is, as.Baron Cuvier remarks, a kind of dictionary, where the properties of things are investigated to discover their names, and which reverses the usual order of such works, where the names are indicated as detailing the qualities of the things named.

But though method and arrangement form the first step to the knowledge of the numerous objects which claim the attention of the naturalist, Natural History is by no means confined to a list of names. If the method be a good one, and the subdivisions arranged conformably to the fundamental and natural connections of bodies, the very arrangement and classification of names of beings which have something in common, leads to the 
knowledge of their connection and dependence upon one another, and to their comparative importance in the scale of existence. Were it possible to arrange all the classes of organized and inorganic existences in such a manner that the individuals of the same genus should be more nearly connected with that genus than with any other-the genera of the same order more nearly connected with that order than with all the other orders, and so on,-little more would be necessary to make the method, so far as depends on arrangement, complete. But it has not hitherto been found in practice, that characters sufficiently uniform, and at the same time easily cognizable, can be found for arranging all the groups of individuals into closely connected families. Aware of this, Linnæus in his Systema Naturce employed one system of organs in his division of its various objects; while those who attempt to class individual species according to what is called the Natural Method take the whole structure of the objects into consideration. The last of these methods, it is evident, could it be carried into effect, would be the most philosophical; but either system followed exclusively is found to produce the most heterogeneous combinations. That system, then, is to be considered the best, which, in addition to short and clear diagnostic characters, affords the greatest facility in investigating the productions of nature.

The term Nature, it may be remarked, bears various significations. It is sometimes used to signify the properties which a being derives from original conformation, in opposition to those which it has acquired from art; sometimes to express the whole objects which compose the universe; at other times the laws which regulate this universe; and these laws being, in point of fact, the will of that Beneficent and Omnipotent Being who formed all this "gay creation," the word Nature is frequently employed by a figure of speech to designate its great Author.

The first great division of natural objects is into orGANIzED and INORGANIC bodies; the first including animals and plants -the second minerals. These distinctions are easily understood, and have been universally acknowledged to be conformable to nature. Vitality distinguishes the one-the want of vitality characterizes the other.

The objects of Natural History are further arranged into three 
great divisions, which have appropriately enough been called kingdoms, viz. the AvimaL - the VEGETABLE - and the Minerat kingdoms. These divisions are not less proper than convenient; and although some writers believe it possible to trace a continuous but progressive connection from the most perfect animal in the scale to the inert and lifeless rock, yet there seems no good reason for supposing that such a chain exists, or if existing, that all the links shall ever be discovered. The works of the Author of Nature are indeed all in consistent harmony with one another, and there is a mutual dependence, advantageous to all, among the various classes of organized beings: but between the lowest form of vegetable or animal life, and the most symmetrically disposed crystal in the mineral kingdom-between a living body and inert matter-there is an immeasurable distance; and between the highest of the lower animals and Man, of all beings alone endowed with the power of reason and the faculty of speech, a distance still more incalculable.

Animals have been defined to be organized bodies which have life and sensation, and are capable of voluntary motion;-Vegetables organized bodies, endowed with a vital principle, but wanting sensation;-and Minerals unorganized bodies, without life, and of course without sensation.

It has been found impossible to give a satisfactory definition of Life; and physiological writers have therefore limited their efforts to communicate some idea of the vital principle by remarking its effects. Life, where its effects are most easily recognized, seems to consist in the faculty with which certain corporeal combinations are endowed, of existing for a certain period under a determinate form, and assimilating to their substance a part of the surrounding bodies; at the same time restoring to the elements part of their own substance. This vital principle, which, when allied to matter, controls its affinities and directs its forms, is not palpable to the senses in an uncombined shape, and it is only from its effects on material substances that its existence is demonstrated. Baron Cuvier compares the mechanical action of life on matter to a vortex more or less rapid, more or less complicated, where the supply and the waste of particles occasion a constant movement. While this movement subsists, the body which exercises it lives; when the movement is stop- 
ped beyond recal the body dies. After death, the elements which composed it, delivered to the ordinary chemical affinities, soon separate to form other and new combinations.

All living bodies die after a period of which the limit is determinate for each species; and death indeed appears to be a neccssary result of vital action, which insensibly alters the organic structure. The living body, which derives its mysterious birth from another living body which has preceded it, at first enlarges in dimensions, according to certain proportions and limits fixed for each species, and for each of its parts; these parts gradually increase in density; the fibres and vessels which compose them imperceptibly acquire a rigidity which unfits them for the discharge of their functions, the vital impulse ceases, and the body naturally dies. In short, absorption, assimilation, exhalation, developement, and generation, are functions common to all living beings; their birth and their death the universal terms of their existence.

Organisation presupposes life, and the organization of each being implies the life proper to that being. Life indeed is never seen but in connection with an organized body; and all the ingenuity of the materialist has failed to show, that particles of matter can organize themselves, or be organized by any combination known in chemistry. In fact, vitality exercises upon the elements which form at each instant part of the living body, an action contrary to what the ordinary chemical affinities can produce without this master agent; and no power in nature is known capable of reuniting again, in the same manner, the atoms which have been disjoined by death.

Animal life is distinguished from vegetable life by the power of locomotion and sensation; the first is active-the other passive. The nourishment of plants is derived through the medium of their roots; that of animals through a central organ of digestion destined to receive the food. The organization of this cavity and its appurtenances varies according to the nature of the aliments and the alterations which they undergo before furnishing fluids proper to be absorbed; while the atmosphere and the earth supply vegetables with juices ready for absorption. Animal bodies, besides, at least those classes higher in the scale of existence, possess a circulating system, muscles for voluntary move- 
ment, and nerves for sensation. Respiration is another essential function in the animal constitution; and in proportion as the respiratory system is complete, the animal functions are more fully exercised. In addition also to the chemical elements which enter into the composition of vegetables-oxygen, hydrogen, and carbon-a fourth substance, azote, seems almost peculiar to the animal constitution. To complete the distinction between animal and vegetable life, Hedwig has ingeniously remarked, that in vegetables the sexual organs fall each year, or at each production, while animals preserve them through the whole course of their existence.

As nutrition is the most general function of living bodies, under the name of organs of nutrition are comprehended all the parts of the body by which alimentary matters are introduced for its support, or which are employed in preparing the food for that purpose. The materials of nutrition penetrate by various means into organized bodies. They may either be introduced under the form of elastic fluids by the pores or imperceptible interstices in all living bodies, or they may be conveyed by a particular organization for this purpose into an internal organ of digestion. Sometimes this internal canal or digestive cavity has the form of a tube with two orifices, the one for the entrance of food, the,other for the exit of matters unfit for the purposes of life; others have only a single opening destined to this double use; and a few which are found in water absorb their nourishment in the manner of vegetables, with this difference, that the canals which run from these numerous mouths end in a common cavity. The solid matters introduced into the digestive cavity or stomach are converted by an internal process first into a pulpy mass named chyme, and afterwards into a semifluid substance denominated chyle, which is finally taken up or absorbed by appropriate vessels, and conveyed to the great centre of circulation, the heart.

The movement communicated by the action of the heart to the internal fluids, now mixed with other animal liquids and termed blood, by which they are impelled through the body, is known by the name of circulation. The vessels which conduct the blood or chyle to the heart are called veins; those which conduct it from the heart to the other parts of the body 
are called arteries; and the alternate dilatation and contraction of this important organ is the mechanism by which this object is accomplished. In certain classes of animals, in which the circulation is simple, the venous blood terminates in a kind of reservoir or appendage to the heart named an auricle. A muscular apparatus attached to this sinus propels the blood which it receives through an orifice, into the cavity of the heart. The ventricle, composed of thicker and stronger muscular walls, is furnished with moveable valves, which prevent the blood from returning into the auricle, while it is impelled by the contraction of the ventricle into the artery. This arrangement varies much, both in the mechanism and in the number of auricles and cavities in the ventricle, in different classes, and even in families of the same class of animals.

'The liquid prepared by the process of digestion requiring to be submitted to the action of the atmosphere, or water containing air, to absorb the oxygen and deprive it of certain principles, the function by which this is accomplished is called respiration. The organ which performs this service is the lungs, through which the blood is forced by the action of the heart. In animals doomed by their organization to live constantly in water, respiration is effected by means of membranous laminæ called gills (branchio, ) which separate the air from the water as it passes over their multiplied surface.

Among animals which appear to have no true circulation, there exists another mode of respiration by tracheæ or air-vessels, by which the air is conveyed through the body in elastic canals; and in these animals it is through their integuments, which are soft and easily permeable, or on their surface, that the respiratory function is exercised, as in vegetables.

In many animals the mode of generation is not known. Of others fixed to solid bodies, like vegetables by their roots, the power of reproduction seems to be by buds or gemmce, or by means of a separation, which operates naturally or accidentally, of some parts of their bodies, in which are ultimately developed the organs which at first were wanting. In all other animals there are organs specially destined to generation. These organs distinguish the males from the females In the greater part of animals the sexes are distinct and separate in two different indi- 
viduals of the same species; but in some classes the individuals are at once males and females. In this case these beings are termed androgynous. Sometimes the individuals possess both sexes, like the greater number of vegetables, and they are then called hermaphrodites.

The animals which have the sexes separate differ also among themselves. Those are termed oviparous in which the germ of the young individual is separated from the parent for a time before birth under the form of an egg. Viviparous animals, on the contrary, are those in which the young are nourished in an organ termed the uterus, and are not excluded from the mother till they have taken the form which they afterwards preserve.

Other modifications are noticed among the oviparous animals, or those which deposit eggs. In some the egg is impregnated within the animal, and then the shell or covering is generally solid or corneous. In others, such as fishes, frogs, some insects, and many mollusca, the impregnation of the ovum does not take place till after extrusion. Two remarkable circumstances have been further observed among oviparous animals. The one is, that in some species the ova are not truly excluded but hatched in the parent animal, who thus preserves the imperfect beings till they have acquired the requisite solidity for being deposited in a place adapted to their further developement. These species, which are met with in very different classes, are termed ovoviviparous. The other singular fact to be noticed in regard to oviparous animals is, that in a very great number of species the young when hatched have neither the form, the structure, nor the manners of the parent animal, and many live in altogether a different medium. These animals undergo in the course of their limited existence many organic transformations or successive metamorphoses. Such in particular are the frogs and connected genera, and the whole class of insects.

The moving power is another characteristic of animal organization. It is seated in the muscular fibre, which is formed of filaments of excessive tenuity, capable of contraction, and of moving the parts upon which they are fixed. 'I'hese fibres are distributed over the body, and produce all its exterior and interior motions. When they are united in a bundle, of which the mass co-operates in the same action, this bundle is termed a mus- 
cle. In animal bodies there are as many different muscles as there are simple movements; and besides, there are generally, for the purpose of bringing back the parts to their original position, other bundles of fibres destined to produce a contrary effect, and which have been accordingly termed antagonist muscles. The element of the muscular fibre, chemically considered, appears to reside in a matter called fibrine.

The other organs destined to the purposes of movement are altogether passive. Sometimes they are disposed outwardly under the appearance of membranes or integuments more or less solid, sometimes under the form of crusts or sheaths, in the interior of which the muscles are placed. The solidity of these parts, their structure, their articulation, and movements, correspond to the animal's mode of life ; and these crusts, shells, scales, or sheaths, are of a calcarcous or horny nature, and adapted to the efforts they are destined to sustain,-the more soft coverings of this kind, as may be conceived, being only calculated for motion in fluids.

In the higher classes of animals the solid articulated parts which form the frame-work of the body and modify its form are almost always placed internally, and serve the purpose of jointed levers, and as a fulcrum for their muscular coverings. These parts are the bones of animals, and when arranged as a whole they are termed the bony skeleton. All these bones meet in a central stalk, or hollow and moveable column, called the spine, of which the pieces, more or less solid and numerous, are termed vertebra. Among those which are on this account named Vertebrated Animals, the column is terminated at one end by the cranium, a bony cavity inclosing the mass of cerebral matter which gives sensation, and is the seat generally of four organs of sense. In the head is also placed the mouth, an instrument capable of prehension, and provided with organs for mechanically dividing the aliment; and often also in this important part of animals the organs are placed which produce or facilitate the action of respiration. The spine is generally prolonged behind, and forms the tail in many animals.

The mechanical apparatus by which animals acquire the knowledge of what is around them are termed organs of sense, and the impressions made on these by external objects, sensa- 
tions. The medium by which these sensations are conveyed to the brain, the great centre of nervous energy, is through nerves, and the whole apparatus of sensation is termed the nervous system. In animals not possessed of a brain or spinal column, cords or threads of nervous matter, with thickenings or ganglions at certain distances, form their medium of sensation; and although in some groups of animals composed of soft parts, or of extreme tenuity, the presence of nerves has not been satisfactorily traced, yet there seems little reason to doubt the existence, in a greater or less degree, of the faculty of sensation in even the lowest of the animal races.

The material substance of animal bodies, in an anatomical view, may be divided into solids and fluids. The solid portions are named tissues, and are united or combined in various degrees in the animal organs. These tissues have been distinguished by anatomists by their forms, or by the chemical elements which enter into their composition. They are chiefly the following: 1. The cellular tissue, forming in the greater number of animals the connecting medium of all their organs, and enveloping and penetrating them by a reticulation of a spongy nature, which takes the form of cells, capable of distension by the fluids which it includes. 2. The filro-gelatinous tissue is a collection of solid, tenacious, and resisting fibres in their longitudinal direction, flexible and elastic across, whose use seems to be to communicate movement and resist the efforts of exterior force. It is so named from dissolving in boiling water to the consistence of a jelly. 3. The membranous tissue is a disposition of thin membranous flexible laminæ extended like a web, and various in structure and uses. The cutaneous membrane envelopes the superficies of the body and permits absorption and exhalation. It is formed of many layers, and produces the hair, feathers, nails, scales, \&c. of the animal body. Other membranes are called mucous or folliculous, because they secrete a viscid fluid, which lubricates their internal surface; and serous membranes are those so named from their internal smooth and polished surface exhaling a very liquid humour. They form thin and transparent sacs without openings, which facilitate the reciprocal movements of the organs. 4. The vascular tissue is formed of continuous membranous branched tubes, to receive, con- 
tain, and direct the nutritive juices from the organs where they are prepared, till they are required for the purposes of nutrition, respiration, or the secretions. 5. The glandular tissue includes those secreting organs which produce fluids for internal use, or to transmit them out of the body by means of excretory canals. These organs have a granular or lobated form. 6. The bony tissue, or cartilaginous, calcareous, and corneous, is formed by the mucous or gelatinous parenchyma, in which are deposited the hardest and most resisting parts, which protect the body and contribute to its motion. \%. The fibrinous or muscular tissue is composed of filaments disposed in bundles, which, from their power of contraction, produce all the movements which characterize animals. 8. The nervous tissue is a net-work of filaments and tubes, in the interior of which are found prolongations of the cerebral matter. This tissue, extending from the centre to the circumference like radii from a centre, is the medium of sensation, actuates every member through the medium of volition, and connects all the parts of the body by a mutual sympathy.

The animal fluids are found in the body under the form of gases or liquids of various consistence. The first being absorbed or exhaled are but momentarily under this form. 'The fluids are the chyme, the chyle, the lymph, the blood, and the serous, albuminous, mucous, saline, and other humours peculiar to different parts of the body.

The simple chemical elements which are found in the animal structure are, among the imponderable agents, caloric, light, and the electric fluid. Among the simple gases, azote, which enters into the composition of many of the tissues; hydrogen, which is one of the elements of lymph, bile, \&c.; oxygen, which all animals absorb in the act of respiration; carbon, lime, sulphur, iron, \&c. which serve as the base of many salts formed by carbonic and phosphoric acid.

The instincts and habits of the different classes of animals will be hereafter detailed, in the descriptions of the individual species whose manners have been most accurately observed. It is sufficient in this place to state, that all their motives to action, their migrations, and their instincts, may be traced to 
the desire of self-preservation and the impulse of reproduction.

The Vegetable King nom is sufficiently distinguished from the animal, as before remarked, by its passive character, by the want of spontaneous motion, and of sensation. Vegetable life is therefore supported by absorption; and its functions, like those of animals, are exercised in nutrition, developement, and reproduction. The principal part of the nourishment of plants is derived from their roots; and their texture is composed of tissues and vessels formed for absorbing, retaining, and elaborating the nutritive juices drawn from the soil and atmosphere. The vegetable kingdom likewise has this analogy among others with the animal, that the function of reproduction is performed through the medium of sexual organs. These organs are protected by the corolla or flower; and all the display of colour and form in this essential part of vegetables is, like the notes of many birds, connected with the important purpose of the continuation of the species. The number, form, and situation of these organs has afforded to Linnæus the chief characters in his simple though artificial arrangement of the classes and orders of plants, in consequence termed the sexual system; while what is called the natural system, proposed by Jussieu, is founded chiefly upon the presence or absence and the nature of the seed or germ-the relative position of the stamina-and upon the absence or presence and form of the corolla.

The Mineral Kingdom is distinguished from the other two great divisions by the absence of vitality and organic structure. Forming the solid crust of the globe, the mineral kingdom in its various compounds affords support and sustenance to the organized beings existing on its surface. The constitution and arrangement of the mineral strata have given rise to various theories to account for their present appearance; but facts have not yet been sufficiently multiplied to afford a satisfactory solution. . One great line, however, is drawn between those mineral strata which have been termed Primitive, in which no organized remains occur; and those of posterior formation, in which the remains of plants and animals are discovered. The 
principal external characters of the mineral kingdom are taken from their specific gravity, as compared with water, -hardness, - crystallization, when it exists, - and cleavage, or the direction of the lamellæ, which in many minerals is regulated by the relation of the external surfaces to the primary crystal or form. Of a less constant kind are colour, degree of transparency, fracture, and the streak which many minerals show when scratched. The physical characters are fusibility, solubility, phosphorescence, electricity, magnetism, and refraction.

Linnæus in his Systema Naturce arranged the Animal Kingdom into six classes ; the Vegetable Kingdom into twenty-four; and the Mineral Kingdom into three. As this arrangement, though now modified and extended in many of its parts, as will be detailed elsewhere, forms the basis of modern classification, and was the first successful attempt at arranging in intelligible order the various objects of Natural History, its principal divisions are subjoined. *

\section{ANIMAL RINGDOM.}

CLASS I. MAMMALIA.

Order

II. Bruta,

III. Feræ,

IV. Glires,

V. Pecora,

VI. Bellux,

VII. Cete,

CLASS II. AVES.

Order I. Accipitres,

II. Picæ,

III. Anseres,

IV. Grallæ,

V. Gallinæ,

VI. Passeres,

CLASS III. AMPHIBIA.

Order I. Reptilia,

II. Serpentes,

III. Nantes,
CLASS IV. PISCES.

Order I. Apodes,

II. Jugulares,

III. Thoracici,

IV. Abdominales,

CLASS V. INSECTA.

Order I. Coleoptera,

II. Hemiptera,

III. Lepidoptera,

IV. Neuroptera,

V. Hymenoptera,

VI. Diptera,

VII. Aptera,

CLASS VI. VERMES.

Order I. Intestina,

II. Mollusca,

III. Testacea,

IV. Lithophyta,

V. Zoophyta.

- Systema Naturæ, ed. 12. Holmix, 1766. 


\section{THE VEGET ABLE KINGDOM}

is divided into twenty-four classes, according to the number and position of the stamens; the greater part of the orders from the number of the pistils in the flower; others by the situation of the seeds and form of the seed-vessels; in compound flowers from the arrangement of the florets; and the great class of cryptogamic plants, or plants without conspicuous flowers, form four orders, divided into Filices, Musci, Algœ, and Fungi.

\section{THE MINERAL KINGDOM}

is divided into three classes, viz. I. Petre, II. Minene, III. Fossilia, and numerous subdivisions. But as the Mineral Kingdom had attracted but little of the attention of Linnæus, and the progress of Chemistry has since changed the whole science of Mineralogy, it is not necessary here to give the inferior details.

Such is the "field of realities,"as M. Lamarck terms it, which the study of nature offers to the intelligent mind. Life in all its aspects is exhibited in countless forms, and the regular succession of organized beings present the creation in the attractive features of perennial youth. Without herbivorous races, the vegetable kingdom would soon encumber the surface of the globe; without carnivorous animals the others would multiply beyond their means of support; and provision is made in those tribes whose food is decomposing substances, to free the earth from dead animal remains. By no conceivable means could the same amount of existence and happiness be attained; and the whole system is so wonderfully arranged, that among the numberless existences which people the earth, the air, and the waters, there is a constant harmony between the means of existence and the existing beings. While animals useful to others are produced in amazing numbers, the fecundity of others whose physical powers might otherwise give them a superiority are limited, and species apparently the most defenceless are provided with means of protection which insure their perpetuity. To Man alone, as the intelligent head of the whole, is given the dominion over the inferior creatures; his reason has enabled him to apply to his use the whole of the organized and inorganic bodies 
around him, and left him, within certain limits, the accountable master of the creation.

On the utility of a knowledge of the objects of Nature, to a being depending on her productions for the supply of all his conveniences and wants, it is scarcely necessary to insist. No species of human learning is so well calculated to form habits of attention and correct observation as the study of the different branches of Natural History, and none is more admirably adapted to the feelings and capacities of the young. Besides the improvement of the intellectual powers which the examination of the structure and habits of any class of organized beings is calculated to produce, and the associations likely to be thereby awakened, there is something in the study of nature which approaches to philosophy of a higher kind-something that, while it teaches man his place in this Creation of Wonders, infallibly leads him to admire the wisdom, and power, and goodness displayed by its Great Author. 


\section{I.-THE ANIMAL KINGDOM.}

According to Cuvier there are four principal forms after which all living beings seem to have been modelled. The basis of these distinctions is laid in the organization of the creatures themselves. Sensation and movement are the characteristics of animals. The heart and the organs of circulation seem a kind of centre for those functions which may be called vegetative, while the brain and the nervous system form the principal source of the functions more exclusively animal. Descending from the higher to the lower races of animals, both these systems are found gradually to become more imperfect, and finally to disappear altogether. In the lowest tribes in the scale, where nerves are no longer visible, the muscular fibre also ceases to be distinct, and the organs of digestion are reduced to a simple cavity in the homogeneous mass. In insects the vascular system disappears even before the nervous system; but in general the dispersion of the medullary masses is connected with the agents of muscular motion : a spinal marrow upon which knots or ganglia represent as many brains or seats of sensation, corresponding to the structure of a body divided into numerous rings, and supported by pairs of limbs distributed along these annulations. This relative proportion in the structure of general forms, which results from the arrangement of the organs of motion, from the distribution of the nervous masses, and from the energy of the circulating system, constitutes the basis upon which M. Cuvier has founded the principal divisions of the Animal Kingdom.

In the first of these general forms, which is that of Man and the animals which resemble him most nearly, the brain and the principal trunk of the nervous system are inclosed in bony cases, the first called the cranium, the second the vertebra. To the sides of the vertebral column, as to a centre, are attached the ribs, and the bones of the members which form the framework of the body. The muscles in general cover the bones, which they put into action, and the viscera are inclosed in the 
head and trunk. Animals of this form are called VERTEBRATed Animals, (Animalia Vertebrata.)

They have all red blood, a muscular heart, a mouth with two horizontal jaws, distinct organs of vision, hearing, smell, and taste, situated in cavities of the head, and never more than four limbs. The sexes are always separate, and the distribution of the medullary masses and the principal branches of the nervous system is nearly the same in all.

On a close examination of any of the characters of this leading division, some analogy of conformation is always found, even in the species the most remote from each other; and the gradation of the same general plan is to be traced from Man down to the lowest of the fishes.

In the second conformation peculiar to animals there is no internal frame-work or skeleton. The muscles are simply attached to the skin, which forms a soft and contractile covering, from which proceed, in many species, stony plates or envelopes denominated shells, of which the position and production are analogous to that of the mucous body. The nervous system is with the viscera included in this general covering, and is composed of many scattered masses united by nervous threads. The principal of these, placed upon the œsophagus, is denominated the brain. Of the senses, properly so called, the organs of taste and sight are alone to be distinguished, and even these are sometimes wanting. One family alone exhibits the organs of hearing. This division, however, is always characterized by a complete circulating system, and particular organs for respiration; and the organs of digestion and secretion are little less complicated than those of the vertebrated animals. Though the general plan of their organization be not so uniform in regard to external configuration as the preceding division, yet even between these parts there is always an analogous resemblance in structure and functions. This division is termed Moliuscous Animals, (Animatia Mollusca.)

The third general form is that which is observed in insects, worms, \&c. Their nervous system consists in two long cords extending along the belly, and swelled out at intervals into knots or ganglia. The first of these, placed upon the oesophagus, though 
held analogous to the brain, is but little larger than the others. The covering of the body is divided by transverse folds into a certain number of rings, of which the teguments are in some hard, in others soft, but to the interior of which the muscles are always attached. Articulated limbs are often attached to the sides of the annulated portions of the trunk, but it is also frequently destitute of those organs of movement. To these animals Cuvier has given the name of Articulated Animals, (Animalia Articulata.)

In this division is observed the transition from the circulating system in closed vessels, to a nutritive process by simple imbibition; and also a corresponding transition from respiration by circumscribed organs to respiration performed through the medium of tracheæ or air-vessels dispersed through the body. The organs of taste and sight are very evident in the animals of this division. Their jaws, when they have any, are invariably lateral. One family alone possesses the organ of hearing.

The animals comprehended under the fourth general form are usually known under the name of Zoophytes. They approach in structure to the homogeneous character of plants. Neither a distinct nervous system, nor particular organs of sense, are perceptible, and but obscure vestiges of circulation. Their respiratory organs are almost always on the surface of their bodies. The intestines of the greater number consist merely in a cavity without an outlet. The lowest in the series, which are also the last of the animal tribes, exhibit nothing but a homogeneous pulp, possessed of motion and sensibility. In the preceding divisions the organs of movement and sense are disposed symmetrically on both sides of an axis; but in this they have a circular arrangement round a common centre. This form of existence Cuvier arranges under the head of RADIATED ANIMals, (Animalia Radiata.)

The term Zoology includes the whole of the Animal kingdom; besides which different departments have received particular names, such as Ornithology for the birds, Ichthyology for the fishes, Entomology for insects, and Conchology for the testaceous Mollusca. 


\section{First Division.}

\section{VERTEBRATED ANIMALS.}

THE body of vertebrated animals is sustained by a skeleton composed of many pieces connected together, and moveable upon one another. The body is composed of a head, a trunk, and limbs. The head is formed of the cranium, which includes the brain, and of the face, composed of two jaws. In the face are the organs of sense. The trunk is sustained by the spine and ribs. The spine is composed of vertebræ, which move upon one another, all of which have a cylindrical opening in the centre, forming together a canal containing the portion of nervous matter called the spinal marrow. The ribs are semicircular, and protect the sides of the cavity of the trunk. They are generally articulated by one extremity to the vertebral column, and by the other to the sternum. In some species they are scarcely perceptible.

The vertebrated animals have never more than two pair of limbs ; sometimes indeed one or other of these pairs is deficient, and sometimes both. According to the motions to which these limbs are destined to be subservient, the anterior ones assume the form of hands, feet, wings, or fins; the posterior of feet or fins.

The blood of the vertebrated animals is always red, and seems by its composition adapted to sustain energy of sensation and muscular vigour. The correspondence of the blood with the respiration necessary to the several species of these animals has suggested their division into Classes.

The external organs of sense in all vertebrated animals are two eyes, two ears, two nostrils, the teguments of the tongue, and the teguments of the whole body. The nerves unite with the nervous matter in the vertebræ, and terminate in two medullary cavities in the cranium, the volume of which is generally proportioned to the extent of intellectual capacity.

There are always two jaws, an upper and under one. The principal motion exists in the lower, which has the power of elevation or depression. In the greater number the upper jaw is completely fixed and motionless. Both are generally provided with teeth, excrescences of a peculiar nature, similar in chemical 
composition to bone, but which grow from the jaws by a process of secretion. The jaws of one entire class, however, (that of Birds) and the genus Testudo in that of Reptiles, are invested with a horny substance.

The intestinal canal extends from the mouth to the anus in various degrees of expansion or contraction. It possesses certain appendices, and receives liquids of a solvent nature, viz. saliva from the mouth, the secretion of the gland denominated pancreas, and the bile, which is produced by another large gland, the liver.

In the passage of the food through the alimentary canal, the part of it adapted to the purposes of nutrition, and termed the chyle, is absorbed by the lacteal vessels, and conveyed into the pulmonary artery, where, in combination with the blood, it undergoes a certain change; and after each portion of the body has received its proper supply, the remainder is carried back into the veins by a set of vessels analogous to the lacteal, and which together form what is usually called the lymphatic system. The veins carry back to the heart the blood which has served the purposes of nutrition. This blood, however, must pass either wholly or partially into the organ of respiration for the purpose of resuming its arterial character, before it is carried back by the arteries to the different parts of the body. In the three first classes of vertebrated animals the organ of respiration consists of lungs, an assemblage of small cells permeable by the external air. In fishes alone respiration is performed by gills or branchice-a series of laminæ between which the water passes.

In all vertebrated animals, the blood which furnishes to the liver the materials of the bile is supplied from the venous blood which has circulated in the intestines, and which, after being reunited in a trunk called the vena porta, is again divided at the liver, and distributed in ramifications through its substance.

The sexes in this division are always in separate individuals; but the mode in which fecundation is performed is different in the various classes.

Though in all these points the vertebrated animals have a general resemblance, yet the various beings of which this division is composed present peculiarities, which are the foundation of their arrangement into classes. These differences depend upon the nature and energy of their movements, which again 
are always proportioned to the quantum of respiration; for upon the perfection of this function, in a great measure, depend the irritability of the muscular fibre, and the energy of the muscular action. The quantity of respiration depends upon the relative portion of blood contained at every given instant of time in the lungs, and the amount of oxygen which enters into the composition of the fluid. The quantity of blood is altogether determined by the peculiar disposition of the organs of respiration and circulation.

The organs of circulation may be double, so that all the blood conveyed by the veins from the different parts must undergo a process of circulation before it can be returned by the arteries; or they may be simple, in which case only a portion of the blood which returns to the body passes through the lungs. This last is the case with reptiles. The quantity of their respiration, and the qualities depending on it, vary with the relative proportion of blood returned at each pulsation into the lungs.

Fishes have a double circulation, but as they respire through the medium of water, and their blood only receives the portion of oxygen in that medium, their quantity of respiration is perhaps less than that of reptiles.

In the Mammalia the circulation is double, and the respiratory process simple. The quantity of their respiration is superior to that of reptiles and fishes. But the quantity of respiration in birds is still greater than that of quadrupeds, because they also respire by various other cavities as well as the lungs. The air penetrates through their whole body, and acts upon the branches of the aorta with the same efficiency as upon those of the pulmonary artery.

From these circumstances result four different kinds of motion among vertebrated animals. Quadrupeds, in which the quantity of respiration is moderate, are formed for walking and running, and their predominant characteristic is vigour. Birds, whose respiratory system is more extensive, possess the lightness and strength of muscles necessary to support them in their flight. Reptiles, which respire more feebly, creep upon the earth, and many of them pass more or less of their existence in a state of torpor. And fishes, which move in a fluid almost as specifically heavy as themselves, are enabled to execute their movements 
by an arrangement altogether different from the others. Every peculiarity of organization proper to each of these classes, and especially such as belong to motion and external sensation, have a close and necessary relation with the characters now enumerated.

\section{CLASS I.-MAMMALIA.}

Vertebrated animals with red and warm blood, breathing through lungs, viviparous, and suckling their young with milk formed in their breasts or mamma.

The earliest writers on the Mammalia are Aristotle and Pliny, afterwards Elian and Oppian. Elian has a work on the nature of animals, and Oppian a Treatise on Hunting, in which he treats of wild animals. Many other writers, however, incidentally notice the animals known to them, either on account of their use to man, or their ferocity, such as Hippocrates, Cato, Columella, Cæsar, Seneca, Varro, and Athenæus.

It was not till after the revival of letters in Europe that the study of Natural History began to assume a regular form. Conrad Gesner in 1551 published a history of quadrupeds, in which, though he treated of these animals in the alphabetical order of their names, he grouped together some natural genera, as apes, horses, deer, oxen, \&c. He besides made a division of oviparous quadrupeds for the tortoises, lizards, and frogs. Aldrovandus, Johnston, and others followed the steps of Gesner in the following century, without much advancing the progress of the science.

In 1693 our celebrated countryman John Ray published his Synopsis Methodica Animalium Quadrupedum, the first regullar system of mammiferous animals, and the basis of all which have since appeared, in which he divided the Mammalia into two great classes, viz. those which have hoofs and those which have nails.

The first class is subdivided into Solipedes, such as the horse; those which have cloven feet, as the sheep, and animals which 
have their feet divided into more than two parts, as the elephant.

The mammiferæe with cloven feet are subdivided into two sections, those which do not ruminate, as the hog, and those which ruminate:-these last form four genera, the sheep, the goat, the stag, and ox.

Among the Mammalia armed with nails, Ray distinguishes those with broad nails, resembling those of man, such as the apes, and those which have narrow and pointed nails. Among these last he separates those which have the toes divided, which he names fissipedes.

These fissipedes he divides further into, 1. those which have more than two incisors in each jaw, as the lion, the dog, \&c.; or which have only two incisors, as the beaver, squirrel, rat, \&c. 2. those which have no teeth at all, as the tamandua, or which have teeth different in number, form, and position, from those of the other Mammalia, such as the hedgehog, the mole, the sloth, \&c.

To Ray succeeded other writers who endeavoured to improve the study of Natural History by a proper arrangement of its objects. Among these was Seba, whose figures make his work still a desirable addition to the library of the naturalist. But all these were forgotten in the attention which was attracted by the publication of the system of the celebrated Linnæus, whose writings were destined to form an era in the science of Nature. His sagacity enabled him to fix the basis of the classification of its objects upon a proper basis, his genius freed the study of its chief difficulties, and he created a language appropriated to all its wants. The first edition of the Systema Naturce was published in 1735, the second in 1737; and its author lived to see it undergo a twelfth impression, and unite the suffrages of Europe in its favour. As the arrangement of the Mammalia by Linnæus forms the basis of most of the modern systems, it may be proper to give an outline of it in this place.

The Mammalia, which constitute his first class, is divided into seven Orders, the characters of which are derived from the number, situation, and form of the teeth. These teeth in the Mammalia are of three kinds, viz. the incisores or cutting teeth -the canini or dog-teeth-and the molares or grinders. 
I. PRIMATES. Fore-tecth cutting, upper four parallel; tusks solitary ; mammæ two, pectoral ; feet used as hands; nails flattened, oval; food fruits, except a few which use animal food.

II. BRUTA. Fore-teeth in either jaw none; feet with strong hoof like nails; motion slow; food chiefly vegetables.

III. FER E. Fore-teeth conical, usually six in each jaw; tusks longer; grinders with conic projections ; feet with claws; claws subulate; food carcases, and preying on other animals.

IV. GLIRES. Fore-teeth cutting, two in each jaw ; tusks none ; feet formed with claws for running and bounding; food, bark, roots, vegetables, \&c. which they gnaw.

V. PECORA. Fore-teeth cutting, upper jaw none, under jaw many ; feet hoofed, cloven; food, herbs which they pluck; chew the cud; stomachs, four.

VI. BELLU E. Fore-teeth obtuse; feet hoofed; motion heavy; food vegetables.

VII. CETE. Pectoral fins instead of feet; tail horizontal, flattened; claws none; teeth cartilaginous ; nostrils a fistulous opening in the anterior and upper part of the head; food molluscu and fish ; inhabit the ocean.

The example of Linnæus was not without its effect in leading others to attempt the improvement of Natural History. Between the publication of the first and twelfth edition of the Systema Natura, many authors made their appearance, who, emulous of his fame, endeavoured to share or divide the reputation of the author. Among these was the Comte de Buffon, who, while Linnæus described the mammiferous animals in the severe and simple language of science, attracted the attention of all classes of readers to the subject by his less exact but more brilliant colouring. The first volumes of the Natural History of this celebrated author appeared in 1749. Disregarding systematic order, he supplied its place, in detailing the manners of the various races, by an enthusiastic and powerful eloquence, which, however, has too often lèd to exaggeration, and unconsciously seduced him to transfer the passions of men to the actions of animals.

J. T. Klein, in 1751, published his Quadrupedum dispositio brevisque historia naturalis. In this work the Mammalia are divided into two orders, 1 . those which have the foot terminated by one or more hoofs; and, 2. those which have claws or fingers. In 1756, Brisson followed by a work entitled Le Rigne Animal divisé en onze classes, in which the Mammalia are divided 
into eighteen orders and forty-two genera. In 1777, about a year before the death of Linnæus, Erxleben published a work entitled Systema Regni Animalis. The merit of his work is high, both in regard to the discrimination of the species and the synonymous terms. He increased the Linnæan number of genera by ten.

Next followed Gmelin's edition of the Systema Natura in 1788. This work contained all the new objects in Natural History which had been described since the publication of the twelfth cdition; but the compilation was made without sufficient exercise of critical judgment, and the work is in consequence not of much authority.

Gottlieb Conrad Christian Storr, professor, published in 1780 at Tubingen a thesis, under the title of Prodromus $M e$. thodi Animalium, remarkable for its distinct arrangement. The lcading characters are taken from the form of the feet. Boddaert, a physcian in 1785, and Vicq-d'Azyr in 1792, each proposed arrangements for the classification of animals; but as these have not been generally adopted, it is not necessary to enter into the details.

Professor Blumenbach of Gottingen published a Manual of Natural History in 1807, in which he attempted to form a more natural system for the Mammalia, which he divides into nine orders, viz.
I. Bimana,
II. Quadrumana,
III. Chiroptera,
IV. Digitata,
A. Glires,
B. Feræ,
C. Bruta,
v. Solidungula,
VI. Bisulca,
VII. Multungula,
VIII. Palmata,
A. Glires,
B. Feræ,
C. Bruta,
IX. Cetacea,

M. Cuvier, in 1798, published his Tableau Elementaire des Animarux. This sketch contained the basis of classification which he afterwards developed in his Anatomie Comparée and Règne Animal. Two years afterwards appeared the first two volumes of the Comparative Anatomy ; to which were added synoptic tables of all the classes of animals. In 1804, M. Desmarest published, in the 24th volume of the New Dictionary of Natural History, a 
methodical table of the mammiferæ, founded chiefly upon the classification of Storr and Cuvier, and in which he distinguished the natural families, which, like the most part of the families established in zoology, were but the genera of Linnæus.

Between this period and 1811 many new species of mammiferous animals were discovered, for several of which it was necessary to establish new genera. Besides the many memoirs and monographs which had appeared, M. Cuvier had also published great part of his researches on fossil quadrupeds ; and it thus became desirable to place in a complete system the result of all the new discoveries. This was attempted by Illiger, a Prussian naturalist, who published in 1811 a classification of Mammalia and Birds, which attracted attention for the precision of the generic characters. The Mammalia by this arrangement were divided into fourteen orders, thirty-nine families, and 125 genera; but his predilection for changing longestablished and familiar names for others was felt to be an unnecessary load on the memory.

M. Blainville followed Illiger in $\mathbf{1 8 1 6}$ by the prodromus of a new systematic distribution of the animal kingdom; and Baron Cuvier, in his important work entitled Le Règne Animal distribué suivant son organization, published in $181 \%$, brought forward his arrangement, improved by the discoveries which had been made since the interval of its first publication, and by the lights which comparative anatomy threw on the structure of the animal system.

This work was followed, so far as regards the Mammalia, by the Mammalogie of A. G. Desmarest, written for the French Encyclopedie, and published in 1820-1822. This excellent work, founded on the classification of Cuvier, and including every species discovered from the period of the publication of the Règne Animal, leaves little to be desired as far as regards this important class. And finally, an English translation of Cuvier's work, including much valuable matter, and describing many new species, by Mr Edward Griffith and others, and accompanied by excellent figures, appeared in $182 \%$.

As the high character of Baron Cuvier as a naturalist and comparative anatomist, has acquired for his writings the suffrages 
of Europe, in the following elementary summary the arrangement of the Règne Animal is chiefly followed.

The Mammalia are placed at the head of the animal kingdom, not only because it is the class to which man, considered in his animal structure, belongs, but also because the Mammalia enjoy the most numerous faculties, the most delicate sensations, and the most varied powers of motion. As the quantity of respiration is in mammiferous animals moderate, they are generally formed for walking, and in consequence, all the articulations of their frame have defined forms which determine their motions.

Some of the Mammalia, however, can raise themselves in the air by means of elongated limbs connected by extensible membranes; others have their limbs so much shortened that they can move with facility only in water; but these circumstances by no means exclude them from the class to which they are allied by other essential characters.

All the Mammalia have the upper jaw fixed to the cranium; the lower is composed of two pieces articulated by a projecting condyle to a fixed temporal bone. The neck is composed of seven, and in one species of nine vertebræ. The anterior ribs are attached to a sternum, formed of a number of pieces, placed vertically. Their anterior extremity commences at the scapula, which is not articulated to any other bone, but simply suspended in the muscular attachments, and often resting on the sternum by an intermediate bone, denominated the clavicle. This extremity is, continued by an arm, a fore-arm, and a hand, which last is formed of two rows of little bones called the carpus, of another row named the metacarpus, and of fingers, each composed of two or three bones called phalanges.

With the exception of the Cetacea, all this class have the first part of the posterior extremity fixed to the spine. This part, in the form of a girdle or basin, is named the pelvis. In youth it is divided into three pairs of bones, - the os ilium, which is attached to the vertebral column; the os pubis, which forms the anterior part; and the ischium, which forms the posterior portion. At the junction of these three bones is the cavity where the bone of the thigh is articulated, to which again is joined the leg, composed of two bones, the tibia and the fibula. This ex- 
tremity is terminated by the foot, which is composed of parts analogous to the hand, viz. a tarsus, metatarsus, and toes.

The head in the Mammalia is always articulated by two condyles upon the atlas or first vertebra. The brain is composed of two hemispheres, united by a medullary lamina called the corpus callosum, and contains two ventricles, enclosing four pairs of tubercles, called corpora striata, the thalami optici, nates, and testes. Between the thalami optici is a third ventricle communicating with the fourth situated beneath the cerebellum. The crura of the cerebellum form always under the medulla oblongata a transverse prominence called pons Varolii.

The eye, always lodged in its orbit, is protected by two eyelids and a vestige of a third. Its crystalline lens is fixed by the ciliary process and its cellular sclerotic coat.

In the ear there is always found a cavity shut up by a membrane called the tympanum, with four little bones; a vestibule at the entrance of which one of these bones is placed, and which communicates with three semicircular canals; finally, a spiral canal termed the cochlea, which terminates by one of its canals in the tympanal cavity and by the other in the vestibule.

The cranium is divided into three compartments. The anterior part is formed of the two frontal bones and the ethmoid, the intermediate by the parietal and the sphenoid bones; and the posterior by the occipital bone. Between the occipital, the parietal, and the sphenoid, are inserted the temporal bones, which, to a certain extent, belong to the face.

In the fœetus the occiput is divided into four parts, the body of the sphenoid into two, and three of its pairs of alæe are separate; the temporal bone into three, of which one serves to complete the cranium, another to enclose the labyrinth of the ear, the third to form the walls of its cavity, \&c. These portions of the cranium unite more or less quickly, according to the species, and end by perfect union in the adult.

The face is formed by the two maxillary bones, between which the nasal canal passes. Before these are two intermaxillary, behind two palate bones, and between them descends the single plate of the ethmoid bone, named the vomer. At the entrance of the nasal canal are the bones which form the nose. 
The molar or cheek bone of each side unites the maxillary to the temporal, and often to the frontal bone; and finally, the lachrymal cavity occupies the internal angle of the orbit, and sometimes part of the cheek.

The tongue in the Mammalia is always fleshy, and attached to the hyoid bone, which bone is suspended by ligaments to the cranium.

Their lungs, two in number, are composed of a mass of small cells, inclosed without adhesion in a cavity formed by the sides of the diaphragm, and lined by the pleura. Their organ of voice is at the upper extremity of the trachea or windpipe; and a fleshy continuation, named velum palati, establishes a direct communication between their larynx and the back part of their nostrils.

Living on the earth's surface, as do the greater part of the Mammalia, they are exposed to alternations of. heat and cold, and their bodies have in consequence a covering of hair, which is thicker in the colder, and more scanty in the warmer regions. The Cetacea, which inhabit the sea, are, however, totally destitute of this covering.

The intestinal canal of the mammiferous animals is suspended by a fold of the peritonæum, called the mesentery, which contains numerous conglobate glands for the lacteal vessels. Another production of the peritonæum, named the epiploon, hangs before and beneath the intestines.

The generation of the Mammalia is essentially viviparous. The fotus after conception descends into the uterus, to the inner surface of which it is attached by means of an arrangement of vessels termed the placenta, through the medium of which nourishment is derived. The young for some time after birth are nourished by a particular secretion of the mother (milk,) produced in the mammiferous animals after parturition, and drawn by the young from mammce or teats. It is from this last character that the term Mammalia has been applied to this Class -a character exclusively proper to them, and by which they are more easily recognized than by another external distinction.

The total number of mammiferous animals described, according to Desmarest, is about 850 , including, however, many species 
imperfectly ascertained and the fossil Mammalia ; of which belonging to the order Quadrumana are 141,-Cheiroptera 97,Feræ 176,-Marsupialia 47,-Rodentia 149,-Edentata 24,Pachydermata 55,-Ruminantia 97,-Cetacea 62. Of these about 330 are frugivorous or herbivorous, 80 omnivorous, 150 insectivorous, and 240 carnivorous, in a greater or lesser degree. The number of terrestrial species domesticated by Man (but perhaps including all that are really useful) amount only to thirteen.

The essential characters of the Mammalia are taken from the organs of touch and the organs of mastication. On the first depend the power and dexterity of the animal; and from the second may be deduced the nature of its food, and the consequent structure of its digestive apparatus. On these characters are founded the division of mammiferous animals into Orders.

The degree of perfection of the organs of touch may be estimated according to the number and mobility of the fingers, and according to the greater or less depth with which their extremities are covered by the nail or hoof. A hoof, for instance, which envelopes that part of the extremity which would otherwise touch the ground, blunts the feeling, and renders the foot incapable of seizing. The opposite extreme is, when only a single lamina covers the upper surface of the end of the finger or toe, leaving to the other all its sensibility.

The nature of the food may be judged of by the appearance of the molar teeth, to the form of which the articulation of the jaws always corresponds. For cutting flesh the teeth require to be edged like a saw, and the jaws to close vertically like scissors. To bruise grains or roots it is requisite that the molars have a flat crown; that the jaws should move horizontally as well as vertically; and that the teeth should be composed of parts of unequal hardness, to give them the necessary inequalities for this operation. The hoofed animals are all necessarily herbivorous, and possess teeth of this description, since the structure of their feet precludes them from seizing living prey.

Animals with unguiculated toes or fingers, on the contrary, are susceptible of more varicty in their modes of subsistence; 
for besides the form of the molar teeth, they differ materially among themselves in the mobility and delicacy of their toes or fingers. There is one characteristic, however, which exercises a mighty influence on the dexterity of the animals possessed of it, and which multiplies or greatly varies their modes of action. This is the faculty of opposing a thumb to the other fingers, and of thus being enabled to seize with facility the most minute objects. This opposition of a fifth member to the other four constitutes what is properly called the hand, an organ which is carried to the highest degree of perfection in Man, in whom alone the anterior extremities are free.

From these various combinations, which strictly determine the nature of the different mammiferous animals, Cuvier has arranged the Class into the following Orders.

I. Brmana, (with two hands) of which man is the type and only species, is at the head of the unguiculated species, and is distinguished zoologically by possessing hands at the anterior extremities, the posterior being employed to sustain him erect, and three kinds of teeth.

II. QuAdrumana, with four hands at the four extremities, and three kinds of teeth.

III. Carnivora, Carnivorous, or feeding more or less on animal food. This order has no thumb capable of free motion and opposable to the toes; three kinds of teeth. It is divided into four families, viz. Cheiroptera, Insectivora, Carnivora, and Marsupialia.

IV. Rodentia, or Gnawers: (Glives, Lin.) The animals of this order have the extremities little different from those of the carnivora; 'but they want the canine teeth, and their incisors are adapted to a kind of mastication peculiar to themselves.

V. Edentata, without teeth. This order includes animals which have no incisors, or cutting teeth; some of them even want the canine teeth; and others have none at all. Besides this their toes are contracted and buried in large and often crooked nails.

This distribution of the unguiculated animals would be perfect, and would form a regular series, if New Holland had not recently furnished a collateral chain composed of animals with 
abdominal sacs for their young. Though the different genera of these are thus connected in this one particular, yet in the form of their teeth some are found to correspond with the Carnivora, others with the Rodentia, and others resemble the Edentata in the structure of their teeth and the nature of their food.

VI. Pachyderma, or thick-skinned animals. This order includes all the quadrupeds with hoofs, except the ruminating animals, though the elephant is only remotely connected with this group.

VII. Ruminantia, ruminating animals, (Pecora, Lin.) These animals form a very natural family, and are distinguished from all other quadrupeds by their cloven feet, the want of true incisors in their upper jaw, and by their having four stomachs.

VIII. Cetacea, Whales. Mammalia which have no distinct posterior extremities. These are the warm-blooded fishes of the ancients, which, to the strength of the mammifere, unite the advantage of being supported by water, and thus form the most gigantic of animals.

Since the publication of the Régne Animal, Latreille and others have made a separate order of the Cheiroptera, the first of the four families into which Cuvier divides his Carnassiers ; and this separation seems natural and proper, from the other families of the Order having their mammæ ventral, while the Cheiroptera, like the Quadrumana, are distinguished by pectoral mammæ. Cuvier himself suggests the propriety of arranging the Marsupial animals, forming the fourth family of the same order, into a separate group. In the following pages the arrangement will therefore stand thus :-

Order i. bimana,

II. QUADRUMANA,

III. CHEIROPTERA,

IV. FER A,

V. MARSUPIALIA,
Order vi. GLires,

VII. EDENTATA,

VIII. PACHYDERMA,

IX. RUMINANTIA,

X. CETACEA. 


\section{ORDER I.-BIMANA.}

TEETH of three kinds ; the posterior extremities proper for walk. ing ; the anterior furnished with hands ; nails flat ; body vertical; two pectoral mammæ; stomach simple; orbital and temporal fossæ distinct.

Genus, Номо. Incisors $\frac{4}{4}$, canines $\frac{1}{1}-\frac{1}{1}$, molars $\frac{5}{5}-\frac{5}{5}=32$. Species, Homo sapiens. Man.

MAN stands alone in the order and genus to which naturalists have referred his species. Differing widely in physical conformation from all other classes of animated beings, and distinguished by reason and the power of speech, this wonderfully constructed being seems the bond of connection between the material and immaterial worlds. Possessed of mental powers which raise him beyond the level of the surrounding creation, and connect him witl higher orders of existences, Man is the only being who looks forward to futurity, and intuitively perceives his connection with and dependence upon the great Source of Intelligence. While the inferior animals enjoy unalloyed the blessings of life and present enjoyment, Man combines the past, the present, and the future in his calculations of happiness ; and while some parts of his organization connect him with the creatures around him, and sober his rule over beings with animal feelings of pleasure and pain as acute as his own, his intellectual powers, unfettered by the material organs which are their instruments, trace the Divinity in all the parts of creation. Hence has arisen the religious feeling among every tribe of human beings, however rude; and Man alone seems to connect himself with the Great Author of his being through the medium of intellectual homage, and worships, according to his conceptions of that Almighty Being, the Creator and Preserver of all.

While reason places Man at such an infinite distance from the inferior animals, the faculty of articulate speech, and an artificial language, widens the barrier still farther; for although some of the animals possess the power of articulation in a considerable degree, and can communicate by natural signs significant to those of their own species, they totally fail in those powers which enable Man to classify objects, and to employ sounds or signs as an instrument of thought. Brutes possess indeed the powers of sensation, perception, and memory, and seem to be capable of intellectual operations to a certain extent ; but their action is extremely limited, and bounded to the supply of their bodily wants; and though susceptible of a species of education, their imitative powers are neither subservient to the improvement of the individual nor the species.

The faculty which seems to direct the inferior animals in most of their operations, essentially different from any thing like human intelligence, is called instinct. This wonderful faculty, surer in its

vOL. I. 
limited aims than reason, bears, however, no proportion to the general intelligence of the animals which exercise it ; for it has been remarked, that those in whom the instinctive propensity displays the greatest seeming wisdom and contrivance, are upon other occasions remarkably deficient in sagacity.

The physical structure of Man also widely separates him from the other portions of the mammiferous class. But these variations in form and proportion are neither so prominent nor so totally different in character from the other animal structures, as to account for the superiority which he enjoys. Destined to be nourished on substances used in common by other animals, the mechanism of his frame must so far correspond with theirs, as to be able to convert these substances to the fluids which support his animal life ; and his organs of sensation must necessarily be analogous in some degree to those of beings on whom the material world is destined to make similar impressions. But no material organs which Man possesses, abstracted from the mind of which they are but the instruments, can account for his intellectual supremacy; and all those hypotheses which would trace Man's intellectual and moral powers from the absolute or relative size of the brain or other material organs, have miserably failed in connecting mind with matter, or thought with organic structure.

The structure of the human frame, however, is wonderfully adapted to the various purposes for which it is destined ; and even physically considered, seems the worthy habitation of a being placed at the head, and with the control, of animated nature. Man, indeed, considered as an animal, is the only one which walks erect in a vertical position; the only one with hands at the anterior extremity, distinct from the organs of locomotion, and free for executing his purposes; and no other has like him vertical incisive teeth in the lower jaw and a projecting chin. Contrary to what is found in any other mammiferous animal, the structure of his body demonstrates that man is destined to walk erect. The foot is entirely different from the posterior hands of apes, and furnishes a larger and firmer base than that of any other animal. In relation to the foot the leg holds a rectangular or vertical position. The muscles which hold the foot and thigh in an extended state are extremely vigorous, and produce the projection of the calf and the thickening of the buttock. The flexors of the leg are attached very high to allow the extension of the knee. The pelvis is large, which, besides separating the extremities widely, gives a pyramidal form to the trunk favourable to equilibrium; and the articulation of the head is strictly central in relation to its own bulk.

It would be impossible for Man, even if he desired it, to walk on the four extremities, his feet being short and almost inflexible, and the great length of his thigh would bring his knee to the ground. His shoulders, also, being too much separated, and his arms too far extended from the central line, would form a very ineffectual support for the upper part of the body. The great muscle, which, in 
quadrupeds, like a girth, holds the body suspended between the shoulders, is smaller in man than among them. 'The head of man is also heavier, and its means of support weaker ; for there is neither a cervical ligament, nor such an arrangement of vertebræ as would prevent its bending forward. The arteries, besides, which supply the human brain not being subdivided, as in most quadrupeds, the blood necessary for an organ of such volume would be poured in too copiously and rapidly, if he should affect the horizontal position. In short, Man is the only biped and bimanous animal; and his locomotive organs being placed at one extremity, leaves that admirable instrument, the hand, free for the execution of purposes which distinguish him from every other animated being. This instrument, which derives so many advantages from being at liberty, possesses as many more from the wonderful mechanism of its structure. The thumb, longer in proportion than that of apes, affords greater facility for seizing and holding small objects; all the fingers have separate movements; and the nails being placed at one side of the extremity, form a support for the organ of touch without injuring its delicacy. The arms to which those hands are affixed possess a strong point of attachment in the large scapula, the powerful clavicle, and the general arrangement of their articulation.

According to Cuvier, no quadruped is comparable to man for the magnitude of the hemispheres of the brain in proportion to that of the face. The form of the cranium announces this magnitude of brain, while the comparative smallness of the face displays how little that part of the nervous system which influences the external senses is predominant in the human species. Though the external senses of man are less energetic than in some other animals, they are, however, extremely delicate, and admirably balanced amongst themselves. His eyes are directed forwards, and thus, though he does not see on both sides at once like most quadrupeds, there is a greater unity in the result of the visual operation. Though his ear possesses but little mobility or extent, yet of all animals he can best distinguish the various degrees of intonation. His nostrils, though more complicated than those of apes, are less so than those of other animals, -yet man appears to be the only creature whose sense of smell is sufficiently delicate to be affected by unpleasant odours. Lastly, The perfection of his touch results both from the delicacy of his external integuments, the absence of all insensible parts, and the form of his hand, so admirably constructed to adapt itself to the slightest inequalities of surface.

As man, when compared with other animals, displays a striking difference in the relative proportions of the cranium and face, a theory has been formed from these proportions to account for intellectual differences; and it has been remarked, that, among the brute creation, those animals which approach to man in these proportions also combine the largest portion of intelligence and docility. Thus an oblique line drawn from the greatest projection of the forehead to that of the upper maxillary bone, and a horizontal line drawn 
backwards from beneath the base of the nostrils, forms what is called the facial angle, and the number of degrees in this angle gives the measure of the relative prominence of the jaws and forehead. In the human race the facial angle approaches nearly to a right angle, and the obliquity of the line has been observed to increase as we descend the scale of animated beings, till at last the cranium and face form parts of one horizontal line.

This theory of comparative intelligence founded on the facial line, proposed by Professor Camper, corroborates in some measure the idea that the intelligence of animals may be estimated by the comparative size of the brain. At the same time it must be observed, that in many animals the facial line does not measure the actual prominence of the brain but that of the frontal sinuses, which, in the Carnivora, many of the Ruminantia, and the elephant, elevate the facial line considerably. In the human race, however, and the quadrumanous animals, where the frontal sinuses are inconsiderable, this elevation may be conceived to arise for the most part from the greater capacity of the cranium. In man the facial angle varies from. $65^{\circ}$ to $85^{\circ}$ in adults, while in children it reaches to $90^{\circ}$, a sufficient proof, it has been observed, of the inadequacy of this standard as a measure of intellect.

Fruits, roots, and succulent vegetables, appear to be the natural food of man. His hands afford him facility in procuring these, and his short and comparatively weak jaws, his canine teeth not projecting beyond the line of the others, and his tuberculous molar teeth, would not permit him to feed on herbage or devour flesh, unless those aliments were previously prepared by the culinary process. But once in possession of fire, and assisted by the arts of his own invention, to take animals by stratagem or to kill them at a distance, the whole living world is converted to his use, and the means of multiplying his species are infinitely augmented.

The organs of digestion in man are in conformity with those of mastication. The stomach is simple, the intestinal canal of moderate length, the large intestines well-marked, the cœecum thick and short, and augmented by a thin appendage; the liver is divided into two lobes and a smaller one; and the epiploon hangs in front of the intestines, extending even into the pelvis. To complete the anatomical detail as far as necessary in this place, it may be added, that the cranium is formed of eight bones; one frontal, one ethmoid, one sphenoid, and one occipital - all on the mesial plane, and one parietal and one temporal on each side of this plane. The bones of his face are fourteen in number; two maxillary and two malar, each of which is attached to the temporal of the same side by a process called the zygomatic arch; two nasal bones, two lachrymal at the internal sides of the orbits, two palate bones, two inferior turbinated bones within the nostrils, the vomer between the nostrils, and lastly, the single bone of the lower jaw. Each jaw has sixteen teeth; four incisors in the middle, two pointed canine teeth at the corners, and ten molar teeth with tubercular crowns, five on each side, making in all thirty-two. 
The vertebral column or spine is composed of thirty-two vertebræ, seven of which are denominated cervical, twelve dorsal, five lumbar, five sacral, and three coccygeal. Of the ribs seven pair (called true ribs) are attached to the sternum or breast-bone by cartilaginous productions ; the other five pair are called false ribs. The scapula has at the end of its projecting ridges a tuberosity called the acromion, to which the clavicle is attached, and above its articulation a point named the coracoid, for the attachment of certain muscles. The radius turns completely on the ulna, in consequence of the manner in which it is articulated with the humerus. The carpus has eight bones, four in each row ; the tarsus seven; those of the rest of the hand and feet correspond with the number of toes and fingers.

The human race have rarely more than one child at each birth, and twins do not occur in more than a single instance out of five hundred. The period of gestation is nine months. The child at birth is generally eighteen inches long, more than one-fourth of its destined stature ; one-half is attained at two years and a half; and three-fourths at the age of nine or ten. The growth generally ceases about eighteen. The milk-teeth begin to shoot out a few months after birth; at two years old they are twenty in number, and they fall successively towards the seventh year, to be replaced by others. Of the twelve molar teeth which do not drop out, four appear at about the age of four years and a half, four at nine years, and the last four do not appear sometimes till the twentieth year. Puberty is usually manifested by external signs, in girls at the age of ten, twelve, or fourteen, and in boys from twelve to sixteen. The male of the human species seldom exceeds six feet in height, and is rarely under five feet; the female is generally a few inches less.

Scarcely has the body attained its destined height when it begins to increase in bulk. Fat accumulates in the cellular tissue ; the different vessels are gradually obstructed; the more solid parts grow rigid; and after a life more or less long, more or less agitated by physical or moral pleasure and pain, old age arrives, and in its train decrepitude and death. While a few pass the limit of a hundred years, the greater part of the race perish long before this period by diseases or accidents, or even by old age itself.

The greater part of animals are able at the moment of their îirth to provide for their principal wants ; some of them, indeed, as Fishes, Reptiles, almost all Insects, and the Mollusca, never know their parents. The Mammalia in general, and the Birds, remain for some weeks in a state of great helplessness, but towards the eighth or tenth day their senses are all developed, and some of them are even then able to follow their mother. But Man, on the contrary, is at birth the most helpless being imaginable; even his senses, which require a kind of education, are not developed till towards the fortieth day, when the little being also begins to smile, and to know those who approach him : 
When about an year old he begins to lisp the simplest sounds; in about fifteen months he is able to walk; speaks generally in about a year and a half; but it is not till after a long period of training that the infant man is qualified to procure for himself the necessaries of animal life. An intellectual as well as a physical education is therefore necessary, and the foundation is thus laid for one of the most natural as well as permanent bonds of attachment. The equality of the sexes in number point to monogamy as the kind of union most proper and natural for the human species. The long education necessary permits the parents to have other children in the interval; and thus, according to Cuvier, the perpetuity of the conjugal union appears to be a law decreed by Nature. The long period of infantine imbecility gives rise to another natural law, namely, the subordination of each individual family; and this again leads, by a necessary consequence, to the whole system of social order. This family connection, expanded in the progress of time into the bonds of tribes and nations, has wonderfully strengthened the intellectual resuurces of the human race; and has enabled man to subsist under every variety of temperature, and to cover the face of the whole earth with beings similar to himself.

In other respects Man appears to possess nothing resembling the instinct of animals. He is not stimulated to any regular or continuous exertion of industry by an uncontrollable impulse. His knowledge is the consequence of his own sensation and reflection, or of those of his predecessors ; and from these results, transmitted by language or example, and applied to his various wants and enjoyments, have originated all the arts. Language and letters, by affording the means of preserving and communicating acquired knowledge, hold out to the human race indefinite sources of improvement.

Of the numerous varieties of the human race Cuvier mentions three as eminently distinct, viz. the white or Caucasian, the yellow or Morigolian, and the negro or Ethiopian. Blumenbach conceives they may be divided into five distinct varieties, viz. the Caucasian, Mongolian, Ethiopian, American, and Malayan; and other writers have farther subdivided these as their family characteristics were more or less marked.

1. The Caucasian variety includes all the Europeans, with the exception of the Laplanders, and the inhabitants of the western and northern parts of Asia. They have the face oval; facial angle $85^{\circ}$; forehead high and expanding; cheeks coloured red; hairlong, brown, but varying from white to black.

2. The Mongolian variety inhabits eastern Asia, Finland, and Lapland in Europe, and includes the Esquimaux of North America. They have a broad and flat olive-coloured face, with lateral projection of the cheek-bones; facial angle $75^{\circ}$; oblique and narrow eyes ; hair hard, straight, black ; beard thin.

3. The Ethiopian variety, inhabiting the middle parts of Africa, are black in a greater or less degree, with black woolly hair, jaw projecting forward, thick lips, and flat nose; facial angle $70^{\circ}$. 
4. The American variety, comprising all the Americans except the Esquimaux, aremostly tan or reddish copper-coloured, with prominent cheek-bones, short forehead, flattish nose, straight coarse hair, and thin beard.

5. The Malayan variety includes the inhabitants of the islands in the Indian Ocean and Polynesia. They are of a brown colour, from a clear mahogany to the darkest clove or chesnut brown, with thick black bushy hair, a broad nose, and wide mouth.

To one or other of these strongly marked families all the other varieties of the human race may be traced; and these in their turn may be referred to certain hereditary conformations, modified by food, soil, and climate, which have separated the members of one family, long prior to the era of written records.

Some French naturalists have endeavoured to raise the varieties now observable among the human race into different species; but, as Cuvier justly remarks, the indiscriminate sexual intercourse and consequent production of an offspring capable of propagation prove mankind to be but a single species. And it is remarked by Blumenbach, that all national differences in the form and colour of the human body are not more remarkable, nor more inconceivable, than those by which varieties of so many other organized bodies, and particularly of domestic animals, arise as it were under our eyes.

In considering the peculiarities which distinguish man from the brute creation, his capability of inhabiting every climate and sustaining every degree of heat and cold, deserves to be noticed. While the geographical range of most animals is extremely limited, the physical and intellectual powers of man enable him to create a climate of his own in every degree of latitude; and while the Indian of Canada may sleep upon the snow with impunity with the thermometer at $40^{\circ}$ below zero, the natives of Sierra Leone suffer unhurt the heat of a vertical sun with the thermometer above $1000^{\circ}$ And as the physical powers and intellectual resources of Man enable him to occupy the whole surface of the globe, his capacity of living on every species of food renders him in the widest sense of the word omnivorous. The continued use of animal food is as natural and wholesome to the inhabitants of the Arctic regions, where it is impossible to raise vegetables, as a mixed diet is to the Englishman; and vegetable food within the tropics is necessary from the exuberance of this part of the creation, and the comparative scarcity of those gregarious animals on which man subsists in other latitudes.

\section{ORDER II.-QUADRUMANA.}

THRE kinds of teeth, incisors, canines, and molars; four extremities terminated by hands, with the thumb separate from the other fingers, and more or less opposable to them ; fingers long and flexible; two or four pectoral mammæ; clavicles 
complete; bones of the arm and leg distinct, and susceptible of the motions of pronation and supination; male organs of generation external; stomach membranous, simple; intestines of medium length; a little cœcum; orbital and temporal fossæ distinct.

This order feeds on fruits, roots, and insects. They are intelligent, agile, lively, and petulant, destined by their organization to live on trees, where they are almost constantly found. Inhabit the warm parts of Asia, Africa, and America.

\section{FAMILY I.-SIMIAE.}

Form approaching more or less to that of Man; four inclined incisors in each jaw ; nose more or less prominent; nostrils more or less separated from one another; two pectoral manmæ; orbital and temporal fossæ distinct.

If the conformation of the body always implied corresponding intellectual attributes, the Simice or apes should approach the nearest to man. But this is not found to be the case; and though the family of apes lave, like man, their anterior hands free, and opposable thumbs, though in a less degree, yet it is not found that their sagacity is superior or equal to some other tribes of mammiferous animals. The structure of their body, indeed, enables them to perform many movements similar to man, but this, when it approaches the usages of the human race, is in general the mere effect of imitation or education in individuals withdrawn from their kind. Possessed of hands at both extremities, capable, were they directed by intelligence, of turning the soil or the inhabitants of the forest to their use, they are inferior in sagacity to the beaver and many other animals which live in society. The social instinct of theapes indeed seems limited to the tendency which frugiverous animals have in general to live in wandering troops, for the purposes of mutual protection.

The whole structure of apes marks them as essentially formed for climbing trees, and it is in forests, accordingly, that they are chiefly found. Their gait on the ground and on all-fours as quadrupeds is awkward and by leaps; and their head not being placed in equilibrium on the spine as in man, their pelvis being small, and the muscles of the thigh being attached lower in the leg, prevents their assuming the erect position. Their very Jong arms, and hands at both extremities, are, on the contrary, admirably calculated for their mode of life.

The family of apes are lively, petulant, and extremely lascivious. They possess the talent of imitation to a great degree, and bence the ancient generic denomination of Simice from simulare, to imitate. MM. de la Condamine and Bouguer, when making their observations in South America on the Figure of the Earth, were annoycd. by domesticated apes looking through their telescopes, planting signals, running to the pendulum, taking the pen to write, and imitating all the actions of these learned astronomers. Their intelligence is not, however, greater than that of the dog, though their imitative actions appear advantageously from their particular conformation. Their senses of touch, of smell, and of taste, are particularly acute, and seem to direct all their appetites, which are sensual and gross in almost all the specics. The disgusting resemblance to the human countenance which the ape presents, was remarked by Ennius the old Roman poet in the following line:

\section{"Simia quam similis turpissima bestia nobis."}

Apes bring forth one or two young at a birth, after a gestation of from five to seven months, according to the species. The females carry their young in their arms or upon their backs, offer them suck, amuse them, and sometimes strike or bite them when they are dissatisfied. Among the Sapajous or American apes with prehensile tails, the young seat themselves upon the haunches of the mother, preserving their equilibrium by their tail. The males are polygamous in the smaller species, but often monogamous in the largest. Their geographical range is extremely limited, and they are only found under the tropics in both hemispheres. 


\section{1st Tribe.-Apes of the Old Continent.}

\section{(Simice Catarrhini, Geoff.)}

Five molars on each side in both jaws, crowned with blunt tubercles; nostrils approaching, having between them only a thin partition; tail none, or short, or long, never prehensile; often with cheek-pouches and callosities. Inhabits Africa, India, and the neighbouring islands.

Gen. 2. Troglodytes, Geoff.-Pithecus, Cuv.-Simia, Lin.

Incisors $\frac{4}{4}$, canines $\frac{1}{1}-\frac{1}{1}$, molars $\frac{5}{5}-\frac{5}{5},=32$. Canines little projecting, contiguous to the incisors and molars, as those of man; head rounded; muzzle little projecting; superciliary ridge prominent; facial angle $50^{\circ}$; arms almost proportioned to the legs, reaching to the bottom of the thighs; thumbs long and opposable ; no tail, cheek-pouches, intermaxillary bones, nor callosities on the buttocks.

T. niger, Desm. (Simia Troglodytes, Lin.) The Chimpansé. Arms of moderate length ; fur black ; mouth and ears large ; canine teeth scarcely surpassing the incisors ; lips with some stiff hairs ; belly flat and large; buttocks naked and not callous; body covered with long black and thinly scattered coarse hair, that on the shoulders longer than elsewhere; hair on the fore-arm directed towards the elbow; face naked, of a brown colour, with the exception of the cheeks, which have hair similar to that of the body; belly almost naked. About three feet in length.

The Chimpansé, about which so many fables have been related, most resembles man in organization. It lives in troops, and can use a stick to lean upen or for defence. It is very intelligent, and susceptible of considerable education. It is sometimes said to pursue negresses. If there be any truth in the statements of travellers, regarding the great wild man of the woods of Africa, there is little reason to doubt that this formidable animal will turn out to be the adult Chimpansé, as all the specimens brought to Europe displayed their nonage by their teeth and other indications. Inhabits Africa, particularly on the coasts of Angola and Congo.

\section{Gen. 3. Prthkcus, Cuv. Geoff.-Simia, Lin.}

Incisors $\frac{4}{4}$, canines $\frac{1}{1}-\frac{1}{1}$, molars $\frac{5}{5}-\frac{5}{5},=32$. Canine teeth a little longer than the others; molars more square than in man, with tubercles more pronounced; head rounded; no superciliary ridge, at least in young individuals; facial angle $50^{\circ}$ to $65^{\circ}$; arms excessively long; thumbs pretty short; no tail or chcek-pouches; callosities on the buttocks in some species ; ears rounded, similar to those of man.

This genus approaches nearest to man by their intelligence. Inhabits Cochinchina, Malacca, Borneo, and the islands of the Indian Archipelago. 
Sub-Gen. 1.-Orangs, properly so called-No callosities on the buttocks.

P. satyrus, Desm. (Simia satyrus, Lin.-Pongo Wormbii, Desm.) The Great Orang-outang. Fur brownish-red ; face prolonged before, nearly bare, and of a dark lead-colour; eyes small, approaching; nose very flat, with two oblique nostrils ; muzzle projecting, ears small, resembling those of man, but wanting the lower lobe; opening of the mouth large; canine teeth a little projecting; the two middle upper incisors twice the breadth of the lateral ones; arms long; nails similar to those of man, those of the thumb shorter and narrower than the others; thumb reaching to the first joint of the index finger; hair of the head of a reddish brown; beard chesnut colour; hair of the fore-arm directed towards the elbow; breast and belly nearly bare ; no callosities or tail.

The history of this animal, confounded with relations of other species, has hitherto been involved in much obscurity. The animal described by naturalists under the name of $S$. satyrus, specimens of which have occasionally been seen in Europe, and the Pongo of Wurmb, seem only, as Cuvier conjectured, to be the young of the gigantic animal described and partly figured by Dr Clarke Abel. From the measurement of the shrivelled and dried skin, that gentleman makes its height to exceed seven feet and a half, though the youth of the animal was ascertained by the state of its teeth, and by the apophysis of the bones of its hands and feet being incompletely ossified.

" The face of this animal," says Dr Abel, "with the exception of the beard, is nearly bare, a few straggling short downy hairs being alone scattered over it. It is of dark lead-colour, excepting the margins of the lips, which are lighter. The eyes are small in relation to those of man, and are about an inch apart. The eyelids are well fringed with lashes. The ears are $1 \frac{1}{2}$ inch in length, and barely an inch in breadth, are close to the head, and resemble those of man, with the exception of wanting the lower lobe. The nose is scarcely raised above the level of the face, and is chiefly distinguished by two nostrils, $\frac{3}{4}$ of an inch in breadth, placed obliquely side by side. The muzzle projects in a mammillary form. The opening of the mouth is very large. When closed, the lips appear narrow, but are in reality half an inch in thickness. The hair of the head is of a reddish brown, grows from behind forwards, and is five inches in length. The beard is handsome, and appears to have been curly in the animal's lifetime. Its colour is lighter than that of the head, approaching to a light chestnut. The beard is about three inches long, springing very gracefully from the upper lip, near the angles of the mouth, in the form of mustachios, whence descending, it mixes with that of the chin, the whole having at present a very wary aspect. The face of the animal is much wrinkled.

"6 The palms of the hands are very long, are quite naked from the wrists, and are of the colour of the face. Their backs are covered with hair to the last joint of the fingers, and this inclines backwards towards the wrists, and then turns directly upwards. All the fingers have nails, which are strong, convex, and of a black colour. The thumb reaches to the first joint of the fore-finger.

" The soles of the feet are bare, and of the same colour as the hands $\xi$ they are covered on the back with long brown hair to the last joint of the toes. The great toe is set on nearly at right angles to the foot, and is relatively very short. The original colour, however, of the hands and arms, and the soles of the feet, is somewhat uncertain, in consequence of the effect of the spirit in which they have been preserved.

"The skin itself is of a dark leaden-colour. The hair is of a brownish red, but when observed at some distance, has a dull, and in some places, an almost black appearance; but, in a strong light, it is of a light red. It is in all parts very long; on the fore-arm it is directed upwards. On the upper arm its general direction is downwards, but, from its length, it hangs shaggy below the arm. From the shoul. 
ders, it hangs in large and long massy tufts, which, in continuation with the long hair on the back, seems to form a continuous mass to the very centre of the body. About the flanks the hair is equally long, and, in the living animal, must have descended below the thighs and nates. On the limits, however, of the lateral termination of the skin, which must have covered the chest and belly, it is scanty, and gives the impression that these parts must have been comparatively bare. Round the upper part of the back it is also much thinner than elsewhere, and small tufts at the junction of the skin with the neck are curled abruptly upwards, corresponding with the direction of the hair at the back of the head."

This animal was killed on the coast of Sumatra by a party who had landed for the purpose of watering. Captain Cornfoot, the commander of the vessel, in his relation of its capture to Dr Abel, dwelt much " upon the human-like expression of its countenance, and especially on the beautiful arrangement of its beard. He also obliged me with some account of its capture, as reported to him by his officers, and feelingly described the piteous action of the animal on being wounded, and of its apparent tenacity of life. It seens that, on the spot where this animal was killed, were five or six trees, which occasioned his hunters great trouble in procuring their prey ; for, in consequence of the extreme agility and power of the animal in spring. ing from branch to branch, and bounding from one tree to another, his pursuers could not fix their aim, until they had cut down all the trees but one. When thus limited in his range, the orang-outang was shot, but did not die till he had received five balls and the thrust of a spear. One of the first balls probably penetrated his lungs, as he, immediately after the infliction of the wound, slung himself by his feet from a branch, with his head downwards, and allowed the blood to flow from his mouth. On receiving a wound he always put his hand over the injured part, and distressed his pursuers by the human-like agony of his expression. When on the ground, after being exhausted by his many wounds, he lay as if dead, with his head resting on his folded arms. It was at this moment that an officer attempted to give the coup de grace by pushing a spear through his body, but he immediately jumped on his feet, wrested the weapon from his antagonist, and shivered it in pieces. This was his last wound, and last great exertion, yet he lived some time afterwards, and drank, it is stated, great quantities of water. Captain Cornfoot also observes, that the animal had probably travelled some distance from the place where he was killed, as his legs were covered with mud up to the knees."-Brezoster's Journ. iv. I94. "

A young specimen of this animal brought to England from Java, and previously described by Dr Abel in his Account of the Embassy to China, was allowed to wander freely about the ship and became familiar with the sailors. "They often chased him about the rigging, and when pressed he eluded his pursuers by seizing a loose rope and swinging out of their reach. At other times he would patiently wait on the shrouds, or at the mast head, till his pursuers almost touched him, and then sud. denly lower himself to the deck by any rope that was near him. When in a playful humour he would often swing within arm's-length of his pursuer, and having struck him with his hand, throw himself from him." The manners of this animal were gentle, and he romped with the boys of the ship. He would entice them to play by striking them with his hand as they passed, and then bounding from them. But when excited to violent rage, he displayed his teeth, and attempted to bite those who were near him. "If repeatedly refused an orange when he attempted to take it, he would shriek violently, and swing furiously about the ropes; then return and endeavour to obtain it, and if still refused he would roll for some time like an angry child upon the deck, uttering the most piercing screams; and then suddenly starting up, rush furiously over the side of the ship and disappear. On first witnessing this act it was thought he had thrown himself into the sea ; but on a search being made he was found concealed under the chains."

This animal, according to Dr Abel, neither practices the grimaces nor antics of other apes, nor possesses their proneness to mischief. Gravity, approaching to melancholy and mildness, were strongly expressed in his countenance. He soon became attached to those who used him kindly. He was fond of sitting by their side, and getting as close as possible to their persons. From the boatswain of the Alceste, who shared his meals with him, he learned to eat with a spoon; and might be often seen at his cabin door enjoying his coffee, quite unembarrassed by those who observed him, and with a grotesque and sober air that seemed a burlesque on human nature. 
He arrrived in Fngland in August 1817, and survived his transportation till the first of April I819, in the custody of Mr Cross at Exeter-Change. He was shedding his teeth at the period of his death. A figure of the head of this animal, drawn from a cast taken after death, is given by Mr Griffith, (An. King. i. 252), and the head and hands of the adult are figured in Brewster's Journal, iv. pl. 4.

Sub-gen. 2.-Giвbons, - Hylobates, Ill.-Callosities on thebuttocks.

P. lar, Desm. (Simia lar, Lin.) The Gibbon. Fur black; face surrounded with gray hairs. About sixteen inches in height; arms almost reaching the ground when the animal is erect.-Inhabits Coromandel, \&rc.

P. variegatus, Desm. (Simia lar, var. Lin.) Fur variegated with gray brown and deep gray. A third smaller than the preceding.Inhabits the island of Malacca.

P. leuciscus, Desm. (Simia leucisca, Schreb.) Fur gray ash-coloured ; face black; strong callosities.

Similar in form to the preceding, but having the arms longer. They sometimes walk erect, balancing themselves with their long arms upon the high branches of the bamboo in Java and the Moluccas.

P. syndactylus, Desm. (Simia syndactyla, Raffles.) The Siamang. Fur of a deep black, woolly, and very thick, naked under the throat; index and middle finger of the posterior hands united to the second joint.

These animals are common in Sumatra. They are generally found assembled in large troops, conducted, it is said, by a chief, whom the Malays believe to be invulnerable. Assembling at sunrise and sunset, they vie with each other in making the most dreadful cries. At all other times they appear to be perfectly quiet. When any of a troop is wounded it is abandoned to its fate, unless indeed it be a very young one. In this case maternal affection prevails, and the mother of the bleeding young will sacrifice her own life in an ineffectual attack on the enemy. Affection is also often displayed under more pleasing circumstances in the care of the persons of their young, by washing, rubbing, and drying them, in spite of the pettish cries and resistance of the little Siamang. This species is readily tamed ; but, unconquerably timid, it never displays familiarity, and its submission seems rather the result of apathy than of confidence. It displays little intellectual vigour. It drinks by plunging the fingers in water and then sucking them.-Griffith's An. King. i. 256.

P. agilis, Desm. (Hylobates agilis, F. Cuv.) The Active Gibbon. Fur brown, with the back yellow; forehead very low; orbital arches very prominent; face of the male bluish black, that of the female brown.-Mam. 532 .

Jnhabits the forests in Sumatra, living in isolated couples. It is very lively, and climbs with amazing agility, but does not display much intelligence. $-F$. Cuv. Mam. liv. 32.

Gen. 4. Colobus, Geoff.-Simia, Pen. Gmel. \&c. Incisors $\frac{4}{4}$, canines $\frac{1}{1}-\frac{1}{1}$, molars $\frac{5}{5}-\frac{5}{5},=32$. Muzzle short ; face naked; nostrils approaching; hands deprived of thumbs; feet with five fingers, the thumb much separated, and the fingers increasing in length from the first to the third; tail long and slender, tufted towards its extremity; cheek-pouches; callosities on the buttocks; body and legs slender. 
C. polycomos, Geoff. (Simia polycomos, Schreb.) Full Bottom Monkey. With a mane upon the neck, shoulders, and top of the back. About three feet high. Inhabits the forests of Sierra Leone and Guinea._Penn. Quad.i. pl. 24.

C. ferruginosus, Geoff. (Simia ferruginosa, Shaw,) Bay Monkey, Penn. Fur ferruginous; crown of the head, hands, and tail black.-Desm. Mam. 53.

Similar to the preceding species in its slender members, length of the tail, and form of the fingers.

C. Temminckii, Kuhl. Black above, on the shoulders and outside of the thighs. About twenty inches in height.-Desm. Mam. 53.

Gen. 5. Semnopithecus, F. Cuv.-Cercopithecus, Geoff. Cuv. Incisors $\frac{4}{4}$, canines $\frac{1}{1}-\frac{1}{1}$, molars $\frac{5}{5}-\frac{5}{5}=32$. Facial angle $45^{\circ}$; head round; nose flat; ears moderate; limbs very long; thumbs of the anterior hands very short and remote; cheekpouches, and callosities on the buttocks; tail very long and slender.

S. maurus, (Simia maura, Lin.) The Negro Monkey, Penn. Fur black; a white spot beneath, near the origin of the tail; about fifteen inches in height. Inhabits the Island of Java.-Edwards' Glean. pl. 311.

S. melalophus, F. Cuv. (Simia melalophus, Raftles.) The Simpai. Fur of a bright yellowish red above, whitish beneath; a band of black hairs on the forehead; face blue. Inhabits the island of Sumatra.-F. Cuv.

S. pruinosus, Desm. (Simia villosa, Griffith.) Fur blackish, tinged with white; tail brown. Inhabits Sumatra.-Mam. 533.

This animal differs from the S. maurus in the want of a white spot at the insertion of the tail.

S. comatus, Desm. Fur above gray, beneath dirty white; upper part of the head covered with black hair, forming a tuft at the back. Inhabits Sumatra.-Mam. 533.

S. entellus, Geoff. (Simia entellus, Schreb.) Fur yellowish white ; the face and hands black. About three feet and a half in length. Inhabits India.-Audeb. iv, \$ 2, pl. 2.

Gen. 6. Cercoprthecus, Cuv. Geoff. -Simia, Lin.

Incisors $\frac{4}{4}$, canines $\frac{1}{1}-\frac{1}{1}$, molars $\frac{5}{5}-\frac{5}{5}=32$. Canines a little projecting, with intermediate spaces for their reception ; posterior molars with only four tubercles; head rounded; facial angle $45^{\circ}$ to $50^{\circ}$; ears sometimes rounded, sometimes slightly angular; thumbs distinct, more or less approaching to the fingers; cheek-pouches; callosities on the buttocks, with the exception of one species; tail as long at least as the body, often turned up on the back. 
Inhabits Africa, the southern parts of India, and some islands of the Archipelago, living in troops in the forests, but occasionally approaching the cultivated fields. This genus is divided into four sub-genera.

Sub-Gen.1.-LAstopyga, Illig.-Hands longer than the fore-arms ; anterior thumbs very short and slender; no callosities; buttocks bordered with long hair.

C. nameus, Desm. (Simia namea, Lin.) Cochinchina Monkey, Penn. Fur variegated with brilliant colours. About two feet high. Inhabits Cochinchina and Madagascar._Shaw i. pl. 23.

Sub-Gen. 2.-NASALIS, Geoff.-Nose projecting and disproportionately long; ears little and round; body thick; anterior hands with four long fingers and a short thumb; posterior broader, with thick nails; tail longer than the body; callosities.

C. nasicus, Desm. (Simia nasica, Schreb.) Proboscis Monkey, Penn. Fur reddish fawn-coloured; nose very long; face black.

Inhabits the island of Borneo, lives in troops.on trees in the vicinity of rivers, and is savage in its manners.-Share, i. pl. 22.

Sub-Gen. 3.-Cercopithecus, Lin. Cuv. Geoff.-Head round; forehead tapering behind; facial angle $50^{\circ}$; no superciliary ridges; nose flat and open, at the top of the nasalfurrows; callosities on the buttocks; tail much longer than the body; orbitary hollows with smooth borders.

C. auratus, Geoff. Fur of a golden yellow; long hair upon the forehead and cheeks; a black spot on the knee. Inhabits the Moluccas.

C. talapoin, (Simia talapoin, Lin.) Talapoin Monkey, Penn. Fur olive-coloured above; of a pale yellowish below ; tail ash-colour. ed beneath; feet black.-Inhabits Africa.

C. latibarbatus, Desm. (Simia dentata, Shaw.) The Broad-bearded Monkey. A large beard extended laterally; end of the tail tufted; face violet purple. About nine inches in height.Shan, i. pl. 13.

C. cephus, Geoff. (Simia cephus, Lin.) Mustache Monkey. Fur greenish-brown; last half of the tail of a bright red; nose and lips blue.-About a foot high.

C. pileatus, (Simia pileata, Shaw.) Bonneted Monkey. Of a brown fawn colour above, white below, and long hair on the forehead; cheeks covered with white short hair; ears naked, rounded.About a foot in height.

C. mona, Desm. (Simia mona, Lin.) Varied Monkey. Fur chestnut-colour; outer part of the extremities black; two whitish spots upon each buttock. About 15 inches high. Inhabits Africa.-Shan, i. pl. 18.

C. nictitans, Desm. (Simia nictitans, Lin.) White-nosed Monkey. Fur black, dotted with greenish gray; nose white and gibbous; 
anterior extremities entirely black above. About a foot and a half in height. Inhabits the coast of Guinea.-Audeb. Fam. iv. $\S 1$, pl. 2.

C. petaurista, Desm. (Simia petaurista, Lin.) Vaulting Monkey. Fur red above, white below; extremities olive-coloured above, grayish below; lower half of the nose white. About 13 inches in height. Inhabits Guinea.-Schreb. pl. 19.

C. ruber, Geoff. (Simia rubra, Lin.) Red Monkey. Fur red above ; ash-coloured below; a narrow black or white band above the eyes. About 18 inches in length. Inhabits Senegal.Schreb. pl. 16, B.

C. Diana, (Simia faunus, Lin.) Palatine Monkey. Fur of a bright chestnut-colour; slate gray on the flanks, with an oblique line of the same colour upon the thighs. About a foot and a half long. Inhabits Africa.-Audeb. Hist. iv. § 2, pl. 6.

C. albo-cinereus, Desm. Fur gray above, whitish below, with a row of stiff black hairs across the forehead; hands blackish; tail brown.-Inhabits Sumatra.

Sub-Gen. 4.-Cercocebus, Geoff-_Muzzle a little longer than the preceding; facial angle $45^{\circ}$; margin of the orbit projecting.

C. cynosurus, Desm. (Simia faunus, Lin.) The Malbrouck. Fur brownish-olive above, whitish below, with a whitish band above the eyes. About 14 inches long. Inhabits Bengal, \&c.-Audeb.iv. \$2. pl. 5 .

C. sabceus, Desm. (Simia sabca, Lin. The Green Monkey, Penn.) Fur greenish-olive above ; dirty white below; head pyramidal; face black ; cheeks furnished with long hairs; scrotum of a copper-geen colour, surrounded with yellow hairs; end of the tail yellow. About 16 inches long. Inhabits Senegal and the Cape de Verd Islands.-Audeb. iv. \$2, pl. 4.

This is one of the species most frequently imported into Europe. In captivity they display a considerable portion of malice and intelligence. Adanson found them in immense numbers in Senegal. Though in large troops upon the trees, he did not at first notice them, until his attention was roused by their flinging branches of trees toward him. They were not at all frightened by the discharge of fire arms, and preserved the most profound silence even when they were wounded. The individual of which M. F. Cuvier gives a figure was remarkably gentle. He was fond of being handled by those whom he knew, and expressed his satisfaction by a gentle grunt.

C. griseo-viridis, Desm. The Grivet. Fur of greenish-gray ; scrotum copper-green, with the surrounding hairs white; head pyramidal; tail entirely gray.

C. pygerythrceus, F. Cuv. Fur of a greenish-gray colour above; white below; scrotum verdigris green, surrounded with white hairs; hair round the anus deep red; termination of the tail black.-Inhabits the Cape of Good Hope.

f C. fuliginosus, Desm. (Simia AEthiops, Lin.) The Mangabey. Fur 
of a brown slate-gray colour, without spots on the head and neck; upper eyelids white.

About 21 inches long. Inhabits Ethiopia according to Hasselquist, and Madagascar according to Buffon.-Shaw, i. pl. 20.

C. IEthiops, Desm. (Simia AEthiops, Lin.) The Collared Mangabey. Fur of a brown wine-colour; upper eyelids white; a white band separating the eyes, and proceeding on each side to the top of the neck. About a foot and a half high.-Audeb. Fam. iv. $\$ 2$. pl. 10.

C. Atys, Geoff. (Simia Atys, Aud.) Fur entirely white; hands, face, and ears flesh-coloured.

This is conjectured by some naturalists to be only an accidental variety of some other species, like the Albinos among the negroes. About 17 inches in length. Country unknown.

Gen. \%. Macacus, Lacep. Pithecus, Geoff. Cuv. Simia, Lin. \&c.

Incisors $\frac{4}{4}$, canines $\frac{1}{1}-\frac{1}{1}$, molars ${ }_{5}^{5}-\frac{5}{5}=32$. Canine teeth very strong, above all in the males; the first and second molars have two tubercles on their crown; the three others have four, with the exception of the last of the lower jaw, which has five, and which is terminated by a heel; facial angle $40^{\circ}$ to $45^{\circ}$; superciliary ridgés much developed; muzzle broad and projecting; eyes approaching; nostrils oblique; ears naked, close to the head, angular; cheek-pouches; lips thin and extensible; callosities on the buttocks.

Inhabits Africa and India, living in troops, and often doing great damage to the gardens and cultivated fields.

Sub-Gen.1.-Macacus, properly so called.-Tail more or less long.

M. silenus, Desm. (Simia silenus et leonina, Gm.) The Ounderou. Fur black; a mane and large gray beard; tail of medium length, terminated by a tuft of hair.-A About two feet high. Inhabits Ceylon.-Shan, i. pl. 16.

M. Sinicus, Desm. (Simia Sinicus, Lin.) Fur chestnut-brown; hair of the head diverging from the centre to the circumference, and disposed in the form of a cap. Inhabits Bengal, East Indies.Shaw, i. pl. 20.

M. radiatus, Desm. Fur greenish-brown above ; clear ash-coloured below; hair on the top of the head diverging, and dispersed in the form of a cap. Inhabits India.-Ann. de Mus. xix. p. 98.

M. cynomolgus, Desm. (Simia cynomolgus, Lin.) Hare-lipped Monkey. Fur greenish brown or olive above, grayish white below; edges of the orbits projecting in the male; a tuft of hair in the middle of the forehead in the female. One foot eight inches long. Inhabits A frica.-Shaw, i. pl. 16.

M. rhesus, Desm. Pig-tailed Baboon. Upper part of the body of a greenish gray; tail short and wrinkled at its base; buttocks 
of a golden yellow; extremities grayish. About a foot loug. Inhabits forests on the banks of the Ganges.-Shan, i. pl. 25.

11. nemestrinus, (Simia nemestrina, Lin.) Brown Baboon. Colour deep brown above, middle of the head and dorsal band black; tail short and slender, only reaching to the middle of the thigh; head and extremities yellowish. Larger than the last. Inhabits Java and Sumatra.-Shaw, i. pl. 13.

\section{Sub.-Gen. 2. MAGot.-Tail replaced by a simple tubercle.}

M. inuus, (Simia inuus, S. silvanus, Lin. the young.) The Pigmy Ape. Fur of a greenish gray; a cutaneous appendage in place of a tail. Inhabits Barbary, Egypt, and the rocks in the neighbourhood of Gibraltar.-Shaw, i. pl. 7, 8,

\section{Gen. 8. Cynocephalus, Cuv.-Simia, Lin. \&c.- Papio, Bris. \&c.}

Incisors $\frac{4}{4}$, canines $\frac{1}{1}-\frac{1}{1}$, molars $\frac{5}{5}-\frac{5}{5},=32$. Canine teeth very strong; left molar of the under jaw on each side with a heel; head and muzzle much elongated; nostrils placed at the extremity, like the dog; facial angle $30^{\circ} 35^{\circ}$; superciliary, sagittal, and occipital ridges much developed; orbit hollow; maxillary bone much produced; face wrinkled with longitudinal strix; ears flat and angular; cheek-pouches; members of nearly equal length, and very robust ; large callosities.

The Cynocephala arrive at considerable magnitude, and their proportions indicate vigour and agility. Ferocity, though not unmingled with intelligence, is a marked trait in their character. They are in confinement observed to pass in a few moments, and without any apparent cause, from affection to menace, from indifference to rage, and some of them have been known to expire from the consequences of their fury. Their cunning and promptitude in laying waste a plantation are so great, that the utmost vigilance is scarcely sufficient to prevent their devastations. When they eat, they commence by filling their cheek-pouches, and they drink by suction. They are comparatively docile when young, and may be taught little exercises and tricks; but in maturity they refuse obedience, and resume their natural ferocity.

Sub.-Gen. 1. Baboons. - Tail longer or nearly as long as the body.

C. babouin, Desm. (Simia cynocephalus, Lin.) Little Baboon. Fur of a yellowish green; face the colour of raw flesh; cartilage of the nostrils not passing the bone of the upper jaw. Upwards of two feet long. Probably the Cynocephalus of the ancients.-Inhabits Southern Africa.

C. papio, Desm. Guinea Baboon. Fur of a yellowish brown; face entirely black; cartilage of the nostrils surpassing the jaws at their superior extremity; upper eyelids white. Inhabits the Coast of Guinea.-Audeb. iii. \$ 1, fig i.

C. porcarius, Desm. (Simia porcaria, Lin.) Pig-faced Baboon. Fur of a blackish green above; a mane of long hair on the neck; face of a blackish violet; upper eyelids white. Female without a mane.-Inhabits the Cape of Good Hope.

VoL. I. 
C. hamadryas, Desm. (Simia hamadryas, Lin.) Dog-faced Baboon. Fur ash-coloured; mane and beard very long; face fleshcoloured; hands black. Inhabits the environs of Moca on the Persian Gulf.-Shaw, i. pl. 15.

Sub.-Gen. 2. MANDRILLs.-With a very short and slender tail perpendicular to the dorsal spine.

C. mormon, Desm. (Simia maimon, Lin.) The Mandril or Variegated Baboon. Fur grayish brown or olive above; white below; beard yellow; face blue in the adult; nose red in the male.

This is among the largest of apes, since it attains sometimes the height of five feet when on its hind legs. Young males and females have the muzzle shorter, and of a uniform blue. The nose of the males does not become red till their canine teeth are fully developed, when the wrinkles of their face begin to appear. From the Gold Coast and Guinea in Africa._Sharo, i. pl. 10.

C. leucophous, Desm. (Simia leucophoea, Fred. Cuv.) Fur grayish brown, greenish above, white below; face of both sexes at all ages of a deep uniform black. About three feet in length.

The three following species, viz. The wood Baboon, Penn. Simia sylvicola, Shaw; the yellow Baboon, Penn. S. sublutea, Shaw; and the Cinereous Baboon. Penn. S. cinerea, Shaw ; together with the S. apedia of Linnæus, seem in M. Desmarest's opinion to have great affinity with the preceding, and perhaps to have been established from ill-preserved species.

C. Niger, Desm. Fur black; hair woolly, except that on the top of the head, which is lank, and forms a tuft on the occiput; no tail ?-From the Indian Archipelago.

\section{2d Tribe.-Apes of the New Continent. (Simice Platyrrhini, Geoff.)}

Six molars on each side of both jaws, with blunt tubercles, or five only with sharp tubercles. Partition of the nostrils broad; nostrils opening on the sides of the nose; tail always long, often prehensile; buttocks hairy, never with callosities; no cheek-pouches; head generally rounded.

They live in troops as the other apes, feeding on fruits, roots, and sometimes insects : but are less turbulent and lascivious than those of the Old Continent. They inhabit South America from Mexico to Paraguay, particularly the wooded and wellwatered districts situated to the east of the chain of the Andes, Guiana, Brazil, Para, a part of Peru, \&c.

\section{1st Division. SApajous.-Tail long and prehensile.}

\section{Gen. 9. Ateles, Geoff. Cuv.-Simia, Lin.}

Incisors $\frac{4}{4}$, canines $\frac{1}{1}-\frac{1}{1}$, molars $\frac{6}{6}-\frac{6}{6},=36$. Canines little projecting, crossing one another, conical; molars with blunt crowns as those of man; head round; face perpendicular; facial angle about $60^{\circ}$; ears bordered. Extremities very long and slender; the anterior ones generally tetradactyle; thumb none, or only replaced by a wart, or extremely short, and armed with a little sharp nail; posterior pentadactyle; nail con- 
vex and short; tail extremely long, strongly prehensile, having a part without hair, and covered with a delicate skin towards its extremity.

These apes are slow in their movements, and live in monogamy, bringing forth only one young at a time.

* With a very little nailed thumb on the hands, or a rudimentary thumb without a nail.

A. hypoxanthus, Kuhl, Desm. Fur yellowish gray; face fleshcoloured, spotted with gray; base of the tail and anal region sometimes of a ferruginous yellow; a little strong and short thumb with a nail on the hands. About two feet long, and the tail nearly the length of the body.-Inbabits Brazil.

A. subpentadactylus, Geoff. Fur entirely black; a very little thumb without a nail on the anterior hands. About a foot and a half long; tail much longer than the body.-Inhabits Guiana.

** No trace of thumb on the anterior hands.

A. paniscus, Geoff. (Simia panisca, Lin.) The Coaita. Fur entirely black; no thumb on the anterior hands. Inhabits Guiana, Brazil, \&r.-Shaw, i. pl. 28.

Var. A. Orbit projecting above; partition of the nostrils narrow; all the head naked except a few hairs on the middle of the forehead.-From Surinam.

Var. B. Obritary partition little projecting, nostrils widely separated, face black, head furnished with hair.-Cayenne.

In this species the prehensile tail is nearly a foot longer than the body of the animal, and nearly answers all the purposes of a hand. The prehensile part of the tail is naked, and has a covering of very delicate skin. In all its movements the animal entwines this tail round the objects near it, draws things towards him too remote to be reached by his hands, and suspends himself by the same organ from the branches of trees.

A. belzebuth, Geoff. The Marimonda. Fur black; belly of a dirty white or yellow in the males, white in the young and females. About 16 inches in length. Inhabits the banks of the Orinoco, living in troops.-Ann. Mus. vii. pl. 16.

A. marginatus, Geoff. The Chuva. Fur black; a white ruff around the face. About 16 inches in length. In the adult male the ruff of hair yellowish; white in the females. Common on the banks of the rivers Santiago, and Amazons.-Ann. Mus. xvii. pl. 9.

A. arachnoides, Geoff. The Spider Monkey. Fur of a gray fawncolour, very soft; eyebrows long and black; no thumb on the anterior hands. Inhabits Brazil.-Ann. Mus. xiii. pl. 9.

A. melanochir, Desm. Fur gray; top of the head, extremities of the four members, and an oblique spot on each knee of a brown black or gray colour. About 13 inches long.

Gen. 10. Lagothrix, Geoff. Humb.

Incisors $\frac{4}{4}$, canines $\frac{1}{1}-\frac{1}{1}$, molars $\frac{6}{6}-\frac{6}{6},=36$. Head rounded; 
ears very small; facial angle about $50^{\circ}$; muzzle projecting; extremities proportioned to the body; all the hands with five fingers provided with nails; tail long, strongly prehensile, naked and callous below near its extremity ; hyoid bone little apparent externally; hair soft and roolly.

L. Humboldtii, Geoff. (The Capparo.) Fur of a blackish ash-colour; hair long. Body upwards of two feet long; tail a little longer than the body.

Of a gentle nature, frequently standing upon its hind feet.-Inhabits the banks of the Rio Guaviara, South America.

L. canus, Geoff. Silver-haired Monkey. Fur olive gray; head, hands, and tail of a red gray; hair short.-Inhabits Brazil.

Gen. 11. Mxcetes, Illiger.-Stentor, Geoff.-Aluata, Lacep. -Cebus, Erxleb.-Simia, Lin. Schreb. \&c.

Incisors $\frac{4}{4}$, canines $\frac{1}{1}-\frac{1}{1}$, molars $\frac{6}{6}-\frac{6}{6},=36$. Canines well developed, triquetrous; head pyramidal ; countenance oblique ; facial angle $30^{\circ}$. Hyoid bone ventricose, apparent externally and cavernous. Four extremities pentadactyle; tail very long, strongly prehensile, naked under its extremity; nails convex and short.

Savage apes, living in numerous troops, and making the forests resound with their cries particularly at the rising and setting of the sun. They use their tail as an instrument of prehension.- Found from Paraguay to Guiana.

M. seniculus, Desm. (Simia seniculus, Lin.) Red Howling Monkey. Upper part of the body of a fine red; head, extremities, and tail of a deep lively red; face naked and black. Body upwards of two feet long; tail nearly as long as the body. Inhabits French Guiana, \&c.-Audeb. v. fig. 1.

M. ursinus, Desm. The Araguato, Humb. Fur of a uniform golden red; face in part covered with hairs. Form and size of the preceding. Inhabits South America.-Humb. Obs. Zool. fig. 30.

M. stramineus, Desm. The Arabata. Fur of a straw yellow, the hairs being of this colour at their point, and brown at their base. A little less than the preceding.-Inhabits South America.

M. fuscus, Desm. (Simia belzebuth, Lin.) The Guariba. Fur chesnut brown back and head, inclining to chesnut; the extremities of the hairs golden colour. A little larger than the seniculus. A solitary and savage species, inhabiting the most retired deserts. Brazil.-Buff. Suppl. vii. t. 26.

M. flavicaudatus, Desm. The Choro. Fur blackish brown, of a darker tint on the back; tail ornamented on both sides with two jellow stripes.

A little smaller than the M. seniculus. Lives in troops, and is hunted for its skin, which is employed to cover the saddles of the mules on which they travel on the Cordilleras. Inhabits the province of Jaen in New Grenada, and the banks of the river Amazons. 
M. niger, Desm. Araay of Azara. Fur of a very fine black in the male ; sides and under part of the body fawn-coloured in the female and young. About one foot nine inches long; tail the length of the body.

Lives in forests, feeding on leaves and fruits, and making itself be heard at break of day by a strong rough voice, which has been compared to the sound of a number of carriages not greased.-Inhabits Paraguay, Bahia, and the interior of Brazil.

M. rufimanus, Desm. The Red-handed Howler. Fur black; hands red; tail the length of the body.

Gen. 12. Cesus, Erxleb.-Callithrix, Geoff. Cuv. Illig.-Simia, Lin. \&c.

Incisors $\frac{4}{4}$, canines $\frac{1}{1}-\frac{1}{1}$, molars $\frac{6}{6}-\frac{6}{6},=36$. Superior incisors larger than the inferior; canines more or less strong, those of the males being much more so than the females; head round; muzzle short; forehead a little prominent; occiput projecting behind; facial angle about $60^{\circ}$; ears rounded; hyoid bone not projecting; tail prehensile, but entirely covered with hair.

Lives in society in forests, but never quits the trees, feeding on fruits and insects. Inhabits South America from the Guianas to Paraguay. M. Desmarest remarks of this genus that the species are difficult to be characterized. The exterior form is nearly the same in all, and preceding authors vary much in the number of those which they admit into their methods. Brisson describes three; Linnæus four; Gmelin six ; Buffon two; and Baron Cuvier reduces them to one. In these circumstances, M. Desmarest thinks it safer to consider as distinct species all those which have been regarded as such by authors, with the exception of two of Gmelin's. From the researches of Dr Kuhl in the museums of Germany, Holland, and Paris, he is led to think that if all are not separate species they form at least very constant' varieties.

C. robustus, Desm. Fur brown; a black line above the head and neck and surrounding the face ; arms of a bright yellow; fore part of the neck and belly of a reddish chestnut in the male, and of a brown pale yellow in the female and young. About 20 inches in length.-Common in Brazil.

C. apella, Desm. (Simia apella, Lin.) The Weeper. Fur of a pretty deep brown above, fainter below; top of the head, tail, and feet of a blackish-brown; face brown, surrounded with hairs of a blackish brown colour; external side of the arms and under side of the neck of a yellowish brown. About 18 inches in length. Found in French Guiana.-Schreb. t. 28.

C. griseus, Desm. (Cebus barbatus, Geoff.) The Gray Sajou. Fur of a brown fawn-colour, mixed with grayish above; of a clear fawn-colour below; head capped with black; no beard; arms the colour of the back; face surrounded with hair of a blackish brown; sometimes white under the neck and breast. Size of the preceding. Country unknown.-Buff. xv. t. 5.

C. barbatus, Desm. (Cebus albus, Geoff.) The bearded Sapajou. Fur grayish red, varying to gray and white, according to the age and sex; belly red; beard prolonged on the cheeks; hair long and soft. Size of the preceding.-Ann. Mus. xix. fig. 12. 
Var. A. Fur white, with the summit of the head and the hind legs of a pale reddish gray.

Var B. Fur fine, undulated hair of a dirty yellowish uniform white, and colour a little deeper in the feet and tail.-Inhabits Guiana.

C. frontatus, Desm. Kuhl. (Simia trepida, Lin.) The Fearful Monkey. Of an almost uniform black brown colour, with the top of the head and the extremities of the members of a deeper shade; hair of the forehead raised perpendicularly, very erect ; scattered white hairs around the mouth and on the anterior hands. A bout 15 inches long.-Country unknown.

C. niger, Desm. Geoff. The black Sapajou. Fur deep brown; face, hands, and tail black ; forehead and posterior part of the cheeks covered with yellowish hair.

M. Humboldt unites this species with that of the brown Sapajou. Country unknown.-Buff: Suppl. vii. t. 28.

C. variegatus, Desm. Geoff. The Variegated Sapajou. Fur blackish, spotted with golden yellow, belly reddish; hair of the back of three colours, the roots brown, then red, and the apex black; head round; snout projecting; interocular region of a blackish brown. About 15 inches in length.-Country unknown.

C. fulvus, Desm. (Cebus flavus, Geoff. Simia flava, Schreb.) The Yellow Sapajou. Fur entirely fawn-coloured; hair silky and erect, not waved. Inhabits Brazil.-Schreb. t. 31, B.

C. albifrons, Desm. Geoff. White-fronted Sapajou. Fur gray, brighter on the belly; summit of the head black; forehead and orbits white ; extremities of a yellowish brown. About 14 inches long.-Inhabits the banks of the Orinoco.

C. lunatus, Desm. Kuhl. The Spectacle Sapajou. A cross white band upon each cheek, reaching from the eyebrows to the mouth. About the size of the apella.

C. xanthosternos, Desm. Kuhl. The yellow-breasted Sapajou. Fur chestnut-coloured; under the neck and breast of a clear reddish yellow.-Inhabits Brazil.

C. fatuellus, Desm. (Simia fatuellus, Lin.) The Horned Sapajou. Fur on the back chestnut coloured; bright red under the belly; extremities and tail of a brown black; two strong tufts of hair rising from the forehead. About 14 inches long. Inhabits Guiana. -Shaw, i. pl. 28.

C. cirrifer, Geoff. Desm. The Crowned Sapajou. Fur chestnut brown; vertex, extremities, and tail of a chestnut colour, verging to black; a tuft of elevated hair of a horse shoe form on the top of the head; head round. About 16 inches long.-Inhabits Brazil.

C. capucinus, Desm. (Simia capucina, Lin.) Capuchin Monkey. Fur varying from brown gray to olive gray; crown of the head and extremities black; forehead, cheeks, and shoulders of a whit- 
ish gray. Upwards of a foot long; tail longer than the body. Inhabits Guiana.-Buff. xv. t. 8.

C. hypoleucus, Desm. (Simia hypoleuca, Humb.) The white-throated Sapajou. Fur black ; forehead, sides of the head, throat, and shoulders white. About a foot long; tail longer than the body. Inhabits Guiana.-Buff. xv. t. 9.

2d Division. Sagoins.-Tail long, not prehensile. Gen. 13. Callithrix, Cuv. Geoff-_Simia, Lin.-Cebus, Erxl.-Saguinus, Lacep.

Incisors $\frac{4}{4}$, canines $\frac{1}{1}-\frac{1}{1}$, molars $\frac{6}{6}-\frac{6}{6},=36$. Canines of medium size ; inferior incisors vertical and contiguous to the canines; head small, rounded; muzzle short; facial angle $60^{\circ}$; partition of the nostrils not so broad as the row of the upper incisors; ears very large and deformed; tail a little longer than the body, not prehensile, and covered with short hair; body rather slender.

C. sciureus, Desm. (Simia sciurea, Lin.) The Squirrel Monkey. Fur olive gray; muzzle blackish ; arms and legs of a bright red. Nearly a foot long. Inhabits Brazil, Cayenne, \&c.-Shaw, i. pl. 25, Var. A. Back of one colour.

Var. B. Variegated with bright red and black, and larger in size.

C. personatus, Desm. Geoff. The Masked Monkey. Fur gray fawn-coloured; head and fore hands blackish; tail red,-Inhabits Brazil.

C. lugens, Desm. Geoff. (Simia lugens, Humb.) Fur blackish ; throat and anterior hands white; tail scarcely longer than the body. About a foot long.-South America.

C. amictus, Desm. Geoff. (Simia amicta, Humb.) The Ruffed Sagoin. Fur blackish brown; a half collar of white; hands of the anterior extremities of a pale yellow; tail longer by a fourth than the body. Almost double the size of the sciureus._-lnhabits South America.

C. torquatus, Desm. Geoff. The Collared Monkey. Fur chestnut brown, yellow below; a half collar of white; tail a little longer than the body.-Inhabits Brazil.

C. moloch, Desm. Geoff. Fur ash-coloured, with annulated hairs above ; temples, cheeks, and belly of lively red; end of the tail and hands of a clear gray, almost white; tail almost a half longer than the body. Size almost double that of the sciureus. Inhabits Peru.

C. melanochir, Desm. Kuhl. The Black-handed Sagoin. Fur ashcoloured; posterior part of the back and extremity of the tail of a reddish brown; anterior hands fuliginous.-Inhabits Brazil.

C. infulatus, Desm, (Callithrix infulata, Kuhl.) Mitred Sagoin. 
Fur gray above; reddish yellow below; with a large white spot surrounded with black above the eyes; origin of the tail of a reddish yellow colour, its extremity black.-Inhabits Brazil.

\section{Gen. 14. Aotus, Humb. Geoff. Illig.}

Dental formula same as last genus ; head round and very large ; muzzle short ; eyes very large and approaching; nostrils separated by a very thin partition; ears small; tail as long as the body, not prehensile, and covered with hair ; hands pentadactyle, nails flat.

A. trivirgatus, Geoff. Humb. The Douroucouli. Fur ash-coloured; belly of a reddish yellow; with three brown and parallel lines extending from the forehead to the occiput. About nine inches long; tail longer than the body.-Griff. Quad. t. 14.

Inhabits thick forests near Maypura and Esmeralda in South America. It lives solitary upon trees, passes the day in sleeping, and seeks its food during the night. It feeds on insects, which it catches with much address, little birds, and fruits. It is monogamous.

\section{Gen. 15. Prthecra, Desm. Cuv. Geoff.-Simia, Lin.}

Incisors $\frac{4}{4}$, canines $\frac{1}{1}-\frac{1}{1}$, molars $\frac{6}{6}-\frac{6}{6},=36$. Incisors approaching, the upper ones oblique and the broadest; canines strong, triquetrous; partition of the nostrils broader than the row of the upper incisors; head round, muzzle short; facial angle about $60^{\circ}$; ears rounded; tail a little longer than the body, not prehensile, and furnished with long hair; feet pentadactyle; nails short and armed.

These are nocturnal animals living upon trees, which they seldom quit, and which furnish them with fruits and insects, their habitual food. Inhabit Brazil, the Guianas, and Paraguay.

P. Satanas, Geoff. Desm. (Cebus Satanas, Hoffm.) The Couxio. Fur of a brown black in the male; of a reddish brown in the female; thick locks covering all the head and falling upon the forehead; a well furnished beard; tail nearly the length of the body. About 16 inches long.-Inhabits the banks of the Orinoco.-Humb. Obs. t. 27.

P. chiropotes, Desm. Geoff. Fur reddish chestnut; hair of the head thick, separated in the middle, and rising in two distinct tufts on each side of the head; a long and bushy beard. Size of the preceding.-Inhabits the deserts of the Upper Orinoco. Habit solitary. It drinks in the hollow of its hand, from whence the specific name chiropotes given by Humboldt.

P. rufiventer, Desm. (Simia pithecia, Lin.) Fox Tailed Monkey. Fur reddish brown; belly red; the hair brown at its origin, and annulated towards the end with red and brown: locks radiating from the vertex, and falling upon the forehead; no beard; tail nearly the length of the body. Size of the preceding. Inhabits French Guiana.-Shaw, i. t. 25. 
P. miriquoina, Geoff. Desm. (Miriquoina Azara.) Fur gray brown above; cinnamon-coloured below; hair of the back annulated, first with white, with black in the middle, and white at the point; two white spots above the eyes; no beard; tail a little longer than the body. Body about 14 inches in length.-Inhabits S. America.

P. rufibarba, Desm. Kuhl. The red-headed Saki. Body of a brown black above; below of a pale red; pale red above the eyes; tail pointed at the end.-Inhabits Surinam.

P. ochrocephala, Desm. Kuhl. Yellow-headed Saki. Fur of a clear chestnut colour above; red ash-coloured yellowish below; hands and feet of a brown black; hair of the forehead and around the face of an ochre yellow. About ten inches long.-Inhabits Cayenne.

P. monachus, Desm. Geoff. The Monk. Fur variegated with large spots of brown and dirty yellowish white; hair chiefly brown at its origin, and red and golden towards its extremity; hair of the head radiating from the occiput and ending at the vertex; tail nearly the length of the body; no beard. A little smaller than P. rufiventer. Inhabits Brazil.-Büf. Supp. vii. t. 30.

P. leucocephala, Desm. Geoff. (Simia pithecia, Lin.) The Yarke. Fur black, around the head of a dirty white; each hair of one colour; tail nearly the length of the body; no beard. Body about ten inches long. Inhabits Guiana; rare.-Audeb. vi. §. i.f. 2.

P. melanocephala, Desm. (Simia melanocephala, Humb.) The Cacajao. Fur yellowish brown; head black; no beard; tail a sixth shorter than the body. Body about a foot and a half long. Inhabits the banks of the rivers Cassiquiana and Rio Negro in S. America.-Humb. Obs. Zool. t. 29.

Gen. 16. JAcchus, Des. Geoff.-Saguinus, Cuv.-Simia, Lin.

Incisors $\frac{4}{4}$, canines $\frac{1}{1}-\frac{1}{1}$, molars $\frac{6}{6}-\frac{6}{6},=36$. Incisors and canines variable in their dimensions; molars with a crown furnished with sharp tubercles; head round; muzzle short; occiput prominent; tail longer than the body, soft, and entirely covered with hair; feet pentadactyle; thumb of the anterior hands not opposable; nails very long, compressed, arched and pointed.

These animals, always of small size (nearly that of a squirrel,) are of a gentle nature, and their habits are similar to those of the other American apes. They are easily tamed. Inhabit chiefly Brazil and the Guianas.

Sub-Gen. 1. Ourstrit, Jacchus, Geoff.-Intermediate incisors of the upper jan broader than the lateral ones; these last isolated on each side; lower incisors elongated, narrow, vertical, the lateral ones longest, upper canines conical, and of medium length, the two inferior ones very small.

- With annulated tail.

J. vulgaris, Desm. Geoff. (Simia Jacchus, Lin.) Striated Monkey. 
Fur ash-coloured; croup and tail annulated with gray brown and ash-colour; a white spot on the forehead; very long ashcoloured hair before and behind the ears ; remainder of the head and shoulders brown red. Body six inches long.-Shaw, i. pl. 25.

Var. A. Fur red; croup annulated with red and ash-colour.-Inhabits Brazil.

J. penicillatus, Geoff. Desm. The tufted Jacchus. Fur ash-coloured; croup and tail annulated with brown and ash-colour; a white spot on the forehead; a tuft of long black hairs before the ears; head and top of the neck black. About the size of the preceding; but the head smaller and more rounded.-Inhabits Brazil.

J. leucocephalus, Geoff. Desm. The white-headed Jacchus. Fur red; head and chest white; upper part of the neck black; tail annulated with brown and ash-colour; very long hair before and behind the ears. Size of the two preceding.-Inhabits Brazil.

J. auritus, Geoff. Desm. The great-eared Jacchus. Fur black mixed with brown; tail annulated with blackish and ash-colour; a white spot on the forehead; a tuft of very long white hairs covering the interior of the ears. Size of the preceding.

J. humeralifer, Geoff. Desm. The white-shouldered Jacchus. Fur chestnut brown; tail slightly annulated with ash-colour; shoulders, breast, and arms white.-Inhabits Brazil.

Some naturalists regard the five last named as only varieties.

** With tail not annulated.

J. melanurus, Geoff. Desm. The black-tailed Jacchus. Fur brown above, fawn-coloured below; tail of a uniform black, and a fourth longer than the body.-Inhabits Brazil.

J. argentatus, Geoff. Desm. (Simia argentata, Lin.). The fair monkey. Fur white; face, feet, and hands red; tail black or white, but almost double the length of the body.-Inhabits Para in South America.-Shan, i. pl. 26.

Sub.-Gen. 2. Tamarin, Midas, Geoff--Four upper incisors contiguous, the intermediate being broader than the lateral ones; four lower incisors inclined, contiguous; canines conical, pretty strong, and inclining outwards; ears large; forehead rendered very apparent by the projection of the orbital ridge.

J. rufimanus, Desm. (Simia Midas, Lin.) Furblack; croup variegated with gray; hands and feet of a red colour; body seven or eight inches long. Inhabits Guiana, \&c.-Shan, i. pl. 26.

J. ursulus, Desm. (Midas ursulus, Geoff.) Fur black; back undulated with bright red; hands black. Size of the preceding. Inhabits Para in South America.-Audeb. vi. § 2, fig. 6.

J. labiatus, Desm. (Midas labiatus, Geoff.) Fur blackish; ferruginous red below; head black; nose and margins of the lips white-Inhabits Brazil.

J. chrysomelas, Desm. Kuhl. Fur black; forehead and upper side 
of the tail of a golden yellow ; fore-arms, knees, breast, and sides of the head of a red chestnut.-Inhabits forests in Brazil.

J. albifrons. Fur black, slightly variegated with white; face black; tail a little longer than the body.-Act. Stockholm. 1819.

J. rosalia, Desm. (Midas rosalia, Geoff. Simia rosalia, Lin.) Fur golden red; a long mane. About nine inches long. Inhabits Guiana and Brazil.-Shaw, i. pl. 25.

Var. A. Fur varied with red and blackish. Guiana.

Var. B. Fur of a bright red; tail of the same colour. Brazil.

J. leonimus, Desm. (Simia leonina, Lin.) Fur brown olive; a long mane of the same colour ; face black; mouth white ; tail blackish above, brown below; body seven or eight inches long; tail about the length of the body.-Humb. Zool. Obs. t. 5.

A very lively animal, very irascible, and emitting a whistling sound like birds. Inhabits the warmer regions of South America.

J. Edipus, Desm. (Simia Edipus, Lin.) Fur of a brown fawncolour above, white below, with locks of long bristly white hair ; tail red in its first part, and black in the other ; about nine inches long; tail nearly double the length of the body.-Inhabits South America.-Buff. xv. t. 17 .

\section{FAMILY II.-LEMURES.}

General form approaching to the quadrupeds, properly so called; incisors varying in both jaws in number, form, and situation; nostrils at the extremity of the muzzle; posterior extremities longer than the anterior; first finger of the hind feet after the thumb terminated by a sharp turned up nail; two or four pectoral mammæ; tail, when it exists, not prehensile.

The Lemurs may be considered as the link between the Quadrumana and the genuine quadrupeds. These animals being for the most part nocturnal, Linnæus, in reference to the Roman mythology, called them Lemurs or ghosts.

Gen. 17. Indris, Lacep. Cuv. Geoff. Desm.-Lemur, Gmel. -Lichanotus, Illig.

Incisors $\frac{4}{4}$, canines $\frac{1}{1}-\frac{1}{1}$, molars $\frac{5}{5}-\frac{5}{5},=32$. Superior incisors united by pairs; the external inferior ones broadest; molars with a tuberculous crown; two pectoral mammx; head long, triangular; posterior members pretty long; the second toe of the hind feet subulate; tail sometimes very short, sometimes very long; fur woolly.

I. brevicaudatus, Desm. Geoff. (Lemur indri, Lin.) Fur blackish ; tail very short. About three feet long.-Shaw, i. pl. 32.

Its voice resembles that of a child crying. It is trained to hunting by the natives of the south part of Madagascar.

I. longicaudatus, Geoff. Desm. (Lemur laniger, Gm.) Fur fawn- 
coloured ; tail very long. About a foot long. Inhabits Madagascar._Shan, i. pl. 34 .

Gen. 18. Lemur, Lin. Cuv. Geoff. Desm.-Prosimia, Bris.

Incisors $\frac{4}{6}$, canines $\frac{1}{1}-\frac{1}{1}$, molars $\frac{5}{4}-\frac{5}{4},=32$. Superior incisors united in pairs, inferior inclined, long ; superior canines long, compressed, crossing the inferior ones before; inferior canines, or first molars compressed, triangular; molars with blunt tuberculous crown; two pectoral mammæ; head long and triangular; muzzle slender; ears short, rounded; the fourth toe of the feet largest; tail longer than the body, covered with hair, not prehensile; hair soft and woolly.

They live in troops more or less numerous, like the apes, upon trees, and climb with excessive quickness. Feed on vegetable substances, fruits, and roots.

L. macaco, Lin. Geoff. \&c. Ruffed Lemur. Fur variegated with large patches of black and white; tail all black; hair of the cheeks very long. About 20 inches long.-Schreb. t. 49.

Var. A. Black colour replaced by a brown gray.-Inhabits Madagascar.

I. ruber, Peron, Geoff. Cuv. Black and Red Lemur. Fur of a fine reddish chestnut colour; head, hands, abdomen, and tail black; a white spot on the neck. About 16 inches long. Madagascar. -Griff. Quad. t. 33.

L. catta, Lin. Ring-tailed Lemur. Fur reddish ash-coloured above, ash-coloured on the limbs, white below; tail annulated with black. About a foot long. Madagascar.-Shan, i. pl. 35.

L. niger, Geoff. Desm. Black Lemur. Fur entirely black; long hair on the neck. Size of the domestic cat. Inhabits Madagascar.-Edw. Glean. iii. pl. 217.

L. mongoz, Lin. Geoff. Desm. The Mongooz. Fur yellowish gray above, white below; around the eyes and forehead black. About 17 inches long. Inhabits Madagascar.-Shan, i. pl. 33.

The Mongous pass a considerable portion of the day in sleep, rolled up in a ball, having their large tail passed between their hind-legs, and twined round their neck. Like the other Lemurs they are essentially formed for climbing trees. They will leap ten feet from the ground without any apparent effort. They carry their food to their mouth with the hand, and drink by suction. When tranquil their voice is a feeble grumbling, but insupportably loud when alarmed.

L. fulvus, Desm. Fur brown above, gray below ; forehead elevated and prominent.-Inhabits Madagascar.

L. albimanus, Geoff. Desm. White-handed Lemur. Fur gray brown above; sides of the neck of a red cinnamon colour; breast white, belly reddish, hands and feet white. Body 14 or 15 inches long.-Inhabits Madagascar.

L. rufus, Desm. Geoff. Red Lemur. Fur of a golden red above, yellowish white below; all the head white except the face; a black band extending from the face to the occiput. Size of the preceding.-Inhabits Madagascar. 
L. collaris, Desm. Geoff. Collared Lemur. Fur red brown above, fawn-coloured below; a ruff of red hair; face lead-coloured. A little larger than the L. catta.-Inhabits Madagascar.

L. albifrons, Geoff. Desm. White-fronted Lemur. Fur of a gray red above, whitish below; forehead of the male white; female with the same part of a deep gray, and a black longitudinal line on the top of the head. Size of the L. catta.-Inhabits Madagascar.

L. nigrifrons, Geoff. Desm. Black-fronted Lemur. Fur on the upper part ash-coloured before, and grayish red on the posterior parts; a black band on the forehead; abdomen and under side of the thighs red. Size of the preceding. Inhabits Madagascar. -Schreb. t. 42.

L. cinereus, Geoff. Desm. Ash-coloured Lemur. Fur above yellowish gray, beneath dirty white; hair of the tail of a uniform gray. Inhabits Madagascar.-Buff. Sup. vii. t. 84.

Gen. 19. Loris, Geoff. Lacep. Cuv.-Lemur, Gmelin.Stenops, Illig.

Incisors $\frac{4}{6}$, canines $\frac{1}{1}-\frac{1}{1}$, molars $\frac{6}{5}-\frac{6}{5},=36$. Upper incisors very small, separated in their middle; inferior inclined, contiguous, and very small; molars with sharp pointed crowns; head round; muzzle turned up; nose prolonged; eyes very large, separated by a very thin bony partition; ears short and hairy; four pectoral mammæ, from two mammary glands; no tail; bones of the arm and leg distinct; tibia larger than the femur; tarsus and metatarsus of equal length.

L. gracilis, Geoff. Desm. Slender Loris. Fur reddish, with a white spot on the forehead. Body about $7 \frac{1}{2}$ inches long.-Shan, i. pl. 31.

A melancholy and patient animal, very slow in its movement, sleeping during the day, and feeding at night on fruits, eggs, insects; \&c.-Inhabits Ceylon.

Gen. 20. Nycticebus, Geoff.-Lemur, Lin.-Loris, Cuv. Incisors $\frac{2 \text { or } 4}{6}$, canines $\frac{1}{1}-\frac{1}{1}$, molars $\frac{6}{5}-\frac{6}{5}=34$ or 36 . Intermediate incisors separate; lateral small or none; anterior molars with one point; those at the bottom with a large crown, hollow in the centre, and tubercles at the angles; body thick; members robust ; head round; muzzle short, not turned up; eyes very large, approaching, and directed forwards ; ears short and hairy; two pectoral mammæ; a very short tail; bones of the leg and arm distinct; tibia longer than the femur ; tarsus and metatarsus of equal length-Inhabits Bengal, Ceylon, and Java.

N. Bengalensis, Geoff. Desm. (Lemur tardigrada, Lin.) Slow Lemur. Fur red; a brown dorsal line; four upper incisors; tail 
very short. $\Lambda$ bout a foot in length. Inhabits Bengal.-Shaw, $\mathrm{i}$. pl. 29.

A nocturnal animal, very slow in its motions, and emitting a monotonous cry.

N. Javanicus, Geoff. Desm. Javanese Loris. Fur red; with a deeper-coloured dorsal line ; muzzle narrow ; only two upper incisors ; tail short. Size of the preceding.-Inhabits Java.

N. Ceylonicus, Desm. Geoff. (Cercopithecus Zeylonicus, Seba.) Ceylon Loris. Fur blackish-brown, entirely black upon the back. Inhabits Ceylon.

Gen. 21. Galago, Geoff. Cuv. Lacep.

Incisors $\frac{4 \text { or } 2}{6}$, canines $\frac{1}{1}-\frac{1}{1}$, molars $\frac{6}{5}-\frac{6}{5}=34$ or 36 . Superior incisors separated in the middle, and within the canines; the inferior ones inclined, the two external being the largest ; molars with sharp points, the first on each side above and below having but one; two pectoral mamma; head rounded; muzzle short ; ears large, membranous, and naked; eyes very large, approaching; posterior members very long; tail long; covered with hair, not prehensile.

The Galagos are nocturnal animals, and have much of the manner of monkeys and squirrels. They are in general gentle, perch constantly on the branches of trees, where they catch insects with their hands and devour them quickly. They make their nests in the branches of the trees, and cover a bed with grass and leaves for their young. With the ratives of Senegal they are an article of food.

G. Madagascariensis, Desm. Geoff. (Lemur murinus, Penn.) The little Galago. Fur red; ears a half as long as the head ; tail longer than the body, covered with short hair; four superior incisors. body about six inches long.-Brown, Illus. Zool. pl. 44.

G. crassicaudatus, Desm. Geoff. The great Galago. Fur of a grayred; ears two-thirds of the length of the head; tail much tufted; four upper incisors. About the size of a rabbit.-Cuv. Regne Anim. iv. t. 1.

G. Guinensis, Desm. (Lemur potto, Lin.) Fur red, ash-coloured when young; tail of medium length. - Inhabits Guinea.

G. Demidoffi, Geoff. Desm. Fischer. Fur red-brown; ears not so long as the head; tail longer than the body, reddish and tufted. Size less than the common rat; only two upper incisors.-Supposed from Senegal.

G. Senegalensis, Geoff. Desm. Fur gray-red ; ears as long as the head; tail longer than the body, red and tufted; two upper incisors. Size of the rat.-Inhabits Senegal.

Gen 22. Tarsius, Cuv. Geoff.-Lemur, Pallas.-Didelphis, Lin.

Incisors $\frac{4}{2}$, canines $\frac{1}{1}-\frac{1}{1}$, molars $\frac{6}{6}-\frac{6}{6}=34$. Superior incisors contiguous, unequal; the intermediate ones large; the inferior small and crowded by the neighbouring teeth; canines 
less strong than the two intermediate incisors above; anterior molars with one point, the others with a large crown, deeply hollowed; head round; muzzle very short ; eyes excessively large, contiguous ; ears long, naked, and membranous; tarsus three times longer than the metatarsus; tail very long.

T. spectrum, Geoff. Desm. (Lemur spectrum, Pallas. Woolly Gerboa, Penn.) Fur red; ears a half shorter than the head; hind legs larger than the body. Size of the field mouse. Inhabits Amboyna and East India Islands.-Shav, i. pl. 35.

T. fuscomanus, Geoff. Fisch. Yellow Bearded Tarsier. Fur of a clear brown; gray-white below; ears two-thirds the length of the head. A little larger than the preceding.-Madagascar.

T. Bancanus, Horsfield. Fur brown; ears rounded horizontal, much shorter than the head; tail very slender; no intermediate incisors in the upper jaw. Inhabits the island of Banca.-Horsfield, Zool. Research. fasc. ii.

Gen. 23. Cherromys, Cuv. Geoff.-Lemur, Shaw.-Sciurus, Lin.

Incisors $\frac{2}{2}$, canines $\frac{0}{0}=\frac{0}{0}$, molars $\frac{4}{3}-\frac{4}{3}=18$. Incisors very strong, excessively compressed, corresponding perfectly in both jaws like the incisors of the gnawers; molars with a flat crown; foot pentadactyle; anterior members short; hands with the thumb short and free, the other fingers very long; thumb of the posterior hands short, opposable, and furnished with a flat nail; long bushy tail; two inguinal mammæ; muzzle short and pointed; eyes and mouth large.

C. Madagascariensis, Desm. (Sciurus Madag. Lin.) The Aye-Aye. Fur brown, thick ; tail black, formed of large hairs, not distichous, as those of the tails of squirrels. About a foot and a half long.

A nocturnal animal, living on insects and worms. Inhabits Madagascar.-Sharw, i. pl. 34.

The genus Cheirogaleus of M. Geoffroy, established from the drawings of Commerson, M. Desmarest excludes from his series as not being perfectly ascertained. It includes three species, major, medius, and minor.

\section{ORDER III.-CHEIROPTERA.}

Generar form disposed for flight. Incisors variable in number ; canines more or less strong; molars sometimes covered with points, sometimes furrowed longitudinally ; a fold of skin between the four members and the fingers of the anterior 
feet; two pectoral mammæ; very strong clavicles; scapulæe large; fore-arms not capable of rotation.

The distinctive character of this order is the membrane extended between their fore-feet and fingers, which supports them in the air, and permits them to fly when this membrane is sufficiently developed. This arrangement demands powerful clavicles and large shoulder-bladés to give the parts the requisite solidity ; but it is incompatible with the rotation of the fore-arms, which in this order are fixed. All of these animals have four large canine teeth, but the number of the incisors vary. Their pectoral mammæ and male organ of generation connect them with the order Quadrumana, while the other details of their structure equally approach them to the quadrupeds. The early writers seem sufficiently puzzled in what class to arrange this singular group. Aristotle conceived them to be birds with membranous wings; Pliny notices them as viviparous birds; and Aldrovandus made one family of the bat and the ostrich. The Cheiroptera are nocturnal animals, and feed chiefly on insects and fruits. Their power of locomotion on the ground is very limited, and consists in dragging them. selves forward in an awkward manner by the thumbs of their wings. They pass a greater part of the year in a state of lethargy, fastened to the roofs of caverns by their hinder feet.

\section{FAMILY I.-GALEOPITHECI.}

Fingers of the hands furnished with very crooked nails; dental system anomalous; skin of the flanks covered with hair both above and below.

Gen. 24. Galeopithecus, Geoff. Pall. Desm.-Lemur, Gm. Incisors $\frac{4}{6}$, canines $\frac{1}{1}-\frac{1}{1}$, molars $\frac{6}{5}-\frac{6}{5}=36$. Upper intermediate incisors very small; lateral ones long, compressed, edged, with a little tubercle on each side at their base. - Inferior incisors inclined and dentated; posterior molars rough, with points and dentations; muzzle pointed; ears small, rounded; tail of medium length; a membrane enveloping the neck, the extremities, and even the fingers and tail ; fingers of the hands short; nails lunated, very slender; two pectoral mammæ; cœecum much developed.

The Galeopitheci are but imperfectly known. They hing suspended by their hind legs from the branches of trees; feed on insects, and probably small birds. They move with difficulty on the ground, but climb trees with surprising facility, and spring from the one to the other, supported in their flight by the extension of the membrane around their body. The largest species known is not bigger than a young cat. The extremities are entirely enveloped in this singular membrane, which extends even to the nails of the toes. They are nocturnal or crepusculous animals, and suspend themselves during the day as the bats. They inhabit some of the islands of the Indian Archipelago.

G. rufus, Geoff. Desm. (Lemur volans. Lin.) Fur red, without spots. About a foot long. Pelew Islands. - Audeb. Hist. Galcop. pl. 1 .

G. variegatus, Geoff. Desm. Cuv. Fur red-brown, variegated above, spotted with white on the extremities. About six inches long. Supposed by some naturalists to be merely a variety of the preceding. The Moluccas-Audeb. Galeop. pl. 2. 
G. Ternatensis, Geoff. Desm. Fur of a gray red, deeper above than below ; tail slightly spotted. Smaller than the preceding. Isle of Ternate.-Seba, i. t. 58, fig. 2, 3.

\section{Family II.-VESPERTILIONES.}

Fingers of the hands excessively elongated, and supporting very fine membranes, with the thumb alone separate, but not opposable.

This family have their fore-arms and their fingers excessively lengthened, forming with the membrane by which they are connected wings similar to those of birds. Bats fly very high and very quick. Their pectoral muscles have a thickness proportioned to the movements they are intended to execute, and the sternum has a ridge for their attachment, as in birds. The thumb is short, and armed with a crooked nail, by which these animals suspend themselves and climb. The hind feet are feeble, divided into five unequal toes, all furnished with nails. Their intestines have no coecum. Their eyes are excessively small, but their ears are often very large, and form with their wings a large membranous surface, almost naked, and so sensible, that bats are able to direct their flight, probably by the different impressions of the air, even after their eyes have been extracted. Bats are nocturnal animals, which in our climate are torpid in winter. They suspend themselves during the day in dark or obscure places. They bring forth usually two young, which they hold fast to their breast.

\section{1 st Division.-Molar teeth without sharp points.}

Gen. 25.Pteropus, Briss. Cuv. Geoff. Desm.-Vespertilio, Lin.

Incisors $\frac{4}{4}$, canines $\frac{1}{1}-\frac{1}{1}$, molars $\frac{5}{6}-\frac{5}{6}=34$. Molars with the crown truncated obliquely, and marked with a longitudinal furrow; head long and conical; ears short, simple, without auricles; no crest or nasal appendage; tail short or none; interfemoral membrane sloped off. An additional phalange and nail on the index finger of the wings; tongue papillous.

This genus is distinguished by their long and conical head, their slender and pointed muzzle, their small and simple ears, and by the smallness of the interfemo. ral mombrane. They have little or no tail, and the posterior extremities are simply bordered, but not united. They are the only bats which have the second and third finger of the hand provided with a nail, and with the phalanx belonging to it, and the only ones which are deprived of the second external ear. Their tongue is rough and papillous, and their teeth resemble those of apes.

\section{* Without a tail.}

P. Javanicus, Desm. Leschenault. The Javanese Bat. Neck above of a smoky red; remainder of the fur black; white hairs mixed with the black hairs of the back.

The Pteropus Javanicus is the largest of the genus, in adult subjects the spread of the wings being fully five feet, and the length of the body one. It is extremely abundant in the lower parts of Java, and lives in society. Numerous individuals select a large tree for their resort, and, suspending themselves with the claw of their posterior extremities to the naked branches, afford a very singular spectac.e. They pass the greater part of the day in sleep, hanging motionless. Soon after sunset they' gradually quit their hold, and direct their course to the forests, villages, and plantations, devouring indiscriminately every kind of fruit not protected from their incursions.

P. edulis, Geoff. Desm. The Eatable Bat. Entirely blackish; back voL. I. 
covered with close and shining hair. Body ten inches long, the extended wings about four feet.-Indian Islands.

The flesh of this species is white, delicate, and remarkably tender, and is regarded by the inhabitants of Timor as a delicacy.

P. Edwardsii, Desm. (Vespertilio vampyrus, Lin.) Large Bat of Madagascar. Fur red; back of a chestnut-brown.-Edwards' Birds, pl. 180.

P. vulgaris, Geoff. Desm. (Vesp. vampyrus, Lin.) The common Roussette. Body covered, particularly on the belly, with thick and coarse hair, of a deep black; face reddish, as well as the sides of the back. Body about ten inches long; wings extended three feet.-Buff. x. t. 14 .

Var. A. Of a bright chesnut or pale yellow.-Mauritius.

P. rubricallis, Geoff. Desm. (Vesp. vampyrus, Lin.) The redcollared Roussette. Fur of a gray brown; neck red. Body about eight inches long; extended wings two feet. Inhabits Isle of France.-Buffon, x. pl. 17.

P. griseus, Geoff. Desm. The gray Roussette. Fur of a gray red; head and neck red. About six and a half inches long; extended wings about 18 inches.-Inhabits the Isle of Timor.-Ann. Mus. xv. pl. 6.

P. Leschenaultii, Desm. Fur of a fawn ash-colour on the back; a little variegated with white under the belly; whitish points at the base of the membranes of the wings ; extended wings about 18 inches.-Inhabits Pondicherry.

P. rostratus, Horsfield, Desm. The Dog-bat of Java. Muzzle elongated; no tail ; fur of a pale brown. Body three inches long; extended wings 11 inches.-Inhabits Java.

\section{** With a tail.}

P. stramineus, Geoff. Desm. Lesser Ternate Bat, Penn. Fur reddish yellow; tail very short. Body about five inches long; extended wings two feet wide. Inhabits Timor and Ternate.-Penn. Synop. t. 31, fig. 1 .

P. AEgytiacus, Geoff. Desm. Egyptian Roussette. Hair woolly, and of a brown gray-colour. Body about five inches long; extended wings 20 inches.

P. amplexicaudatus, Geoff. Desm. Long-tailed Roussette. Fur reddish gray; tail the length of the thigh, and half enveloped in the interfemoral membrane. Four inches long; extended wings 16 inches. Inhabits Timor.-Ann. Mus. xv. pl. 4.

P. marginatus, Geoff. Desm. Fur olive brown; a white band around the ears. Length three inches; extended wings 11 inches.--Ann. Mus. xv. pl. 5 .

P. minimus, Geoff. Desm. The Kiodote. Hair woolly and of a lively red; tongue extensible. Body three inches long; spread of the wings ten inches.-Inhabits Java. 
*** With wings upon the back.

P. palliatus, Geoff. Desm. Membrane of the wings attached to the dorsal line, having the appearance of a mantle. Body about four inches long; wings 14 inches; length of tail $6 \frac{1}{2}$ inches.

Gen. 26. Cefrhalotes, Geoff.-Vespertilio, Pallas. Gmel.

Incisors $\frac{4}{6}$, canines $\frac{1}{1}-\frac{1}{1}$, molars $\frac{5}{4}-\frac{5}{4},=32$. Superior incisors isolated, lower incisors nearer together; the posterior molars with a large crown without tubercles or ridges; head conical; no crests or nasal leaf; ears short; index finger short, and wanting the nail in one species; tail very short; membrane of the wings rising from the dorsal line; tongue papillous.

C. Peronii, Geoff. Desm. No nail on the index finger of the hand; about six inches long; extended wings about two feet.-Timor.

C. Pallassii, Geoff. Desm. (Vespertilio cephalotes, Lin.) With a nail in the index finger of the hand. Three inches and a half long; spread of the wings 14 inches. Inhabits Moluccas.-Pallas, Spic. Zool. fas. iii. t. 1 and 2.

\section{2d Division. - With pointed molars.}

\section{Gen. 27. Molossus, Geoff. Cuv.-Vespertilio, Lin.}

Incisors $\frac{2}{2}$, canines $\frac{1}{1}-\frac{1}{1}$, molars $\frac{4}{5}-\frac{4}{5}=26$. Superior incisors bifid, converging, inferior very small, crowded before the ca. nines, and each terminated by two little points ; molars large, the crown rough with points; head large ; muzzle naked, gibbous ; nostrils open before, bordered; ears large and united; no crest or nasal leaves; tongue soft; interfemoral membrane narrow and terminated squarely; tail long.

M. rufus, Geoff. Desm. Fur deep chesnut above, lighter below; muzzle short and thick. Body about three inches long; spread of the wings about a foot.

M. ater, Geoff. Desm. Fur black, shining above; muzzle more slender than the preceding. About three inches long.

M. obscurus, Geoff. Desm. Fur blackish brown above, obscure below, the hairs being white at their origin. Nearly four inches long; spread of the wings nearly a foot.-Inhabits Paraguay.

M. longicaudatus, Geoff. Desm. Bull-dog Bat. (Vespertilio molossus, Lin.) Fur fawn ash-coloured; a band of skin extending from the point of the muzzle to the forehead; tail almost as long as the body. About two inches long. Inhabits Martinique.Schreber, t. 59.

M. fusciventer, Geoff. Desm. (Vesp. molossus, Lin. var. $\beta$ ) Fur ash brown above, cinereous below, except the belly, which is brown in its middle. Body two inches long. 
M. castaneus, Geoff. Desm. Fur chestnut above, whitish below ; a band extended from the muzzle to the forehead. Body nearly five inches long; spread of the wings 13 inches.-Paraguay.

M. laticaudatus, Geoff. Desm. Fur obscure brown above, less deep below ; tail bordered on each side by a prolongation of the interfemoral membrane. Body about four inches long.-Paraguay.

M. crassicaudatus, Geoff. Desm. Fur brown cinnamon-colour, brighter below than above; tail bordered on each side by a prolongation of the interfemoral membrane. Three inches and a half long; spread of the wings about ten inches.-Paraguay.

M. amplexicaudatus, Geoff. Desm. Fur blackish, fainter below than above ; tail entirely enveloped in the interfemoral membrane. Size of the common bat. Cayenne.-Buff. Supp. vii. pl.75.

M. acuticaudatus, Desm. Tail long, almost entirely enveloped in the interfemoral membrane; fur brown black. Body about an inch and a half long; wings very long.-Brazil.

M. ursinus, Spix. Body black; jaws robust ; ears falling over the forehead. Inhabits Brazil.-Spix, Braz. t. 35, fig. 4.

M. nasutus, Spix. Nose elongated; ears falling over the forehead; body above brown black, below brown; tail half enveloped in the membrane. Inhabits Brazil. - Spix, Braz. t. 35, fig. 7 .

M. fumarius, Spix. Body blackish brown; face, ears, and wings very black. Inhabits Brazil.-Spix, Braz. t. 35. fig. 5, 6.

\section{Gen. 28. Nycrinomus, Geoff.}

Incisors $\frac{2}{4}$, canines $\frac{1}{1}-\frac{1}{1}$, molars $\frac{4}{5}-\frac{4}{5},=28$. Upper incisors conical and contiguous; inferior very small; molars with pointed tubercles; nose flat, on a level with the lips, which are deeply cleft and wrinkled; ears large, united, and lying on the face ; auricle exterior; tail long, enveloped by the membrane at its base; wings large; thumb very short; index finger without phalanges; hind feet covered with very long hair.

N. Agyptiacus, Geoff. Desm. Fur red above, brown below; tail slender; no muscular bands in the interfemoral membrane, which envelopes the half of the tail. Body about three inches long.

Inhabits Egypt.-Geoff. Egypt.pl. 2, No. 2.

N. Bengalensis, Geoff. Desm. Tail pretty thick; muscular bands in the interfemoral membrane. Size of the preceding. Two incisors in each jaw according to Buchanan.-Lin. Trans. v. t. 13.

N. acetabulosus, Geoff. Desm. Fur of a brown black; interfemoral membrane enveloping two-thirds of the tail. About ten inches long. Island of Mascareigne.

N. dilatus, Horsfield. Blackish brown, paler underneath; wings dilated; tail slender, half enveloped in the interfemoral membrane, which is furnished with a few muscular bands.-Java. 
N. tenuis, Horsfield. Blackish brown; wings of great length, and very narrow; tail slender, half enveloped in the interfemoral membrane, the edge of which is folded and furnished with muscular fibres.-Inhabits Java.

N. Braziliensis, Geoff. Of a cinereous brown colour, lighter on the lower parts, varying also from yellow to black in different individuals. Upper lip not so deeply notched as in the Egyptian species; ears with folds or wrinkles.-Isid. Geoff. Ann. des Sciences, 1824.

N.? murinus. Body blackish above, brown underneath; wings, ears, and head black. Interfemoral membrane destitute of muscular bands. Described by Griffiths from Gray's MSS.

\section{Gen 29. Cherromeles, Horsfield.}

Incisors $\frac{2}{2}$, canines $\frac{1}{1}-\frac{1}{1}$, molars $\frac{4}{5}-\frac{4}{5},=26$. Face conical ; ears distant and spreading; operculum short, semicordate; blunt ; interfemoral membrane short; tail exserted; thumb distinct, claw flat, fringed on the edge with bristles.

C. torquatus, Horsfield. Neck covered with longish hairs ; back naked and dotted. Indian Archipelago._Horsf. Java, No. vii.

Gen. 30. Stenoderma, Geoff.

Incisors $\frac{4}{4}$, canines $\frac{1}{1}-\frac{1}{1}$, molars $\frac{4}{4}-\frac{4}{4},=28$. Nose simple ; ears of medium size, lateral and isolated ; auricle interior; interfemoral membrane rudimentary, bordering the legs; no tail.

S. rufa, Geoff. Desm. Fur red uniform chestnut; ears medium size, oval, a little hollowed at the external border. Body about three inches long; spread of the wings ten inches.

\section{Gen. 31. Noctruro, Geoff. Cuv.-Vespertilio, Lin.}

Incisors $\frac{4}{2}$, canines $\frac{1}{1}-$, molars $\frac{4}{4}-\frac{4}{4},=26$. Canines very strong; molars crowned with pointed tubercles; muzzle short, gibbous, cleft, and furnished with warts or fleshy tubercles; nose without appendages; ears small, lateral; interfemoral membrane very large; tail enveloped at its base; nails of the hind feet very robust.

N. unicolor, Geoff. Desm. (Vespertilio leporinus, Lin.) Peruvian Bat, Shaw. Fur of a uniform reddish fawn colour. Size of a rat. Inhabits Brazil, Paraguay, \&c.-Sham, i. pl. 41.

N. dorsatus, Geoff. Desm. (Pteropus leporinus, Erxleb.) Fur of a yellowish farwn colour, with a whitish band along the back; body four inches long; spread of the wings 16 inches.-S. America.

N. albiventer, Geoff. Desm. Back reddish; belly white. A little smaller than the preceding.

Griffith supposes the last two to be only varieties of the Noctilio unicolor, and makes a separate species of the $N$. albiventer, Spix, on the authority of his figure. 
N. rufus, Spix. Body red; the legs and ears nearly naked. Inhabits Brazil.-Spix, Braz. f. 35, f. 1.

\section{Gen. 32. Phyllostoma, Geoff. Lin. Cuv.}

Incisors $\frac{4}{4}$, canines $\frac{1}{1}-\frac{1}{1}$, molars $\frac{5}{5}-\frac{5}{5}$, or $\frac{5}{6}-\frac{5}{6},=32$ or 34 . Lateral incisors very small, the intermediate ones broader; head long and conical; nose with two nasal crests, one like a leaf, the other of a horse-shoe form; ears large, naked, not united. Auricle internal, dentated; eyes small and lateral; tongue rough with horny papillæ; tail and interfemoral membrane more or less developed.

These bats occasionally suck the blood of animals, but the wounds they make are neither very dangerous nor painful. "Sometimes," says d'Azara, " they will bite the crests and beards of fowls while asleep, and suck the blood. The fowls generally die in consequence of this, as a gangrene is engendered in the wounds. They bite also horses, mules, apes, and horned cattle generally on the buttocks, shoulders, or neck, as they are better enabled to arrive at these parts from the facilities afforded them by the mane or tail. Nor is man himself secure from their attacks. On this point, indeed, I am enabled to give a very faithful testimony, since I have had the end of my toes bitten by them four times while I was sleeping in cottages in the open country. The wounds which they inflicted, without my feeling them at the time, were circular, and rather elliptical, their diameter was trifling, and their depth so superficial as scarcely to penetrate the cutis. It was easy also, on examination, to perceive that these wounds were made by suction, and not by puncture, as might be supposed. The blood that is drawn in cases of this description does not come from the veins or from the arteries, because the wound does not extend so far, but from the capillary vessels of the skin, extracted thence, without doubt, by these bats, by the action of sucking or licking. No one in our neighbourhood fears these animals, or gives himself any trouble about them; notwithstanding a prevalent and most absurd report, that, previously to sucking the blood of their victim, they flap their wings upon the part intended for banquet, for the purpose of lulling and deadening its sensibility.-Hist. Nat. of Paraguay, ii. 273.

* With a tail, but always shorter than the interfemoral membrane.

P. crenulatum, Geoff. Desm. Nasal appendage with dentated margins; end of the tail free. About two inches long; extended wings about a foot.-Ann. Mus. xv. pl. 10.

P. elongatum, Geoff. Desm. Nasal leaf with smooth margins; end of the tail free. About three inches long; spread of the wings 15 inches.-Ann. Mus. xv. pl. 9.

P. hastatum, Geoff. Desm. (Vespertilio hastatus, Lin.) Nasal leaf with smooth borders; tail wholly enveloped in the interfemoral membrane. Nearly four inches long; spread of the wings about a foot and a half. A series of warts in the form of a V on the base of the under lip. Inhabits Guiana.-Ann. Mus. xv. pl. 11.

P. planirostra, Spix. Head thick, depressed above; side of the nose tubercular; front of the nasal leaf free, pendulous; lips annulated on the edges; chin short, flattish. Body nearly four inches long. Inhabits Brazil.-Spix, Braz. 36. f. 1.

** Without a tail.

P. perspicillatus, Geoff. Desm. (Vesp. perspicillatum, Lin.) Spec- 
tacle Bat. Nasal leaf short, hollowed near its point; two white bands from the nostrils to the ears. About three inches long; extended wings 17 inches.-Buff: Supp. vii. pl. 74.

P. lineatum, Geoff. Desm. Nasal leaf entire; four whitish stripes upon the face, and one on the back. Body nearly three inches long; spread of the wings 13 inches.-Inhabits Paraguay.

The number of teeth in this speeies presents an anomaly; according to Azara there are no incisors in the lower jaw.

P. rotundum, Geoff. Desm. Nasal leaf entire, rounded at its extremity; fur reddish brown. About three inches long; spread of the wings nearly 14 inches.-Inhabits Paraguay.

P. lilium, Geoff. Desm. Nasal leaf entire; as high as broad, and narrow at its base; jaws elongated. Two inches three lines long; spread of the wings one foot.-Inhabits Paraguay.

P. spectrum, Geoff. Desm. (Vespertilio spectrum, Lin.) The Vampyre. Nasal leaf entire, less broad than high, jaws elongated. Five inches and a half long.-Inhabits South America.

This species, the largest of the genus, is celebrated in the narratives of travellers for sucking the blood of men and animals while asleep.

\section{Gen. 33. Vampyrus, Spix.}

Incisors $\frac{4}{4}$, canines $\frac{1}{1}-\frac{1}{1}$, molars $\frac{4}{4}-\frac{4}{4},=28$. Incisors conical, the two intermediate in the upper jaw being largest; the first molar with one tubercle, the others with three; mouth rather obtuse, lower jaw verrucose; tail short, involved in the membrane, except the apex.

V. cirrhosus, Spix. Bearded Vampyre. Head oblong; nasal leaf pendulous; lips and chin bearded; spread of wings $4 \frac{1}{2}$ inches. Inhabits Brazil._Spix, Braz. f. 36.

V. soricinus, Spix. Body less robust than the preceding; mousecolour on the back, brownish gray underneath ; chin smooth. Inhabits Brazil._Spix, Braz. f. 36. fig. 2, 6.

V. bidens, Spix. Two incisors in the lower jaw; blackish brown above; mouse-coloured underneath.-Spix, Braz. f. 65.

Gen. 34. Glossophaga, Geoff. Desm.-Phyllostoma, Cuv. -Vespertilio, Pall. Lin.

Incisors $\frac{4}{4}$, canines $\frac{1}{1}-\frac{1}{1}$, molars $\frac{3}{3}-\frac{3}{5},=24$. Incisors regularly arranged; canines of medium size; molars similar to the Phyllostomr; head long and conical; tongue very long, narrow, extensible; nose supporting a little spear-shaped crest; tail more or less long, sometimes wanting; interfemoral membrane very small or none.

G. soricina, Desm. Geoff. (Vesp. soricinus, Lin.) Interfemoral membrane broad; no tail. Body two inches long; spread of the wings eight inches. Inhabits Surinam.-Ann. Mus. xv. pl. 11 .

G. amplexicaudata, Geoff. Desm. Interfemoral membrane broad; 
tail short and terminated by a nodosity; fur blackish brown. Inhabits Brazil and Rio de Janeiro.-Mem. du Mus. iv. pl. 18.

G. caudifer, Geoff. Desm. Interfemoral membrane very short; the tail extending beyond it; fur blackish brown. Inhabits Brazil.-Mem. du. Mus. iv. pl. 17.

G. ecaudata, Geoff. Desm. Interfemoral membrane very short; no tail; colour obscure brown. Inhabits Brazil.-Mem. de Mus. iv. pl. 18.

Gen. 35. Mormoops, Leach.

Incisors $\frac{4}{4}$, canines $\frac{1}{1}-\frac{1}{1}$, molars $\frac{5}{5}-\frac{5}{5},=32$. Two intermediate incisors in upper jaw largest; ears large, close, furnished with auricles; nasal appendage erect, confluent with the cars; index finger two joints, middle finger four, the others three; tail enveloped in membrane except the last joint.

M. Blainvillii, Leach. Nasal leaf plaited; ears bilobed above; labial processes divided. Inhabits Jamaica. - Lin. Trans, xiii. pl. 7.

Gen. 36. Medateus, Leach.

Incisors $\frac{4}{4}$, canines $\frac{1}{1}-\frac{1}{1}$, molars $\frac{4}{5}-\frac{4}{5},=30$. The two intermediate incisors in the upper jaw largest; two nasal appendages, one vertical, the other lunate and horizontal ; no tail ; lips warty.

M. Lewisii, Leach. Blackish; nasal leaf vertical, spear-shaped; ears rounded; spread of wings seventeen inches._Lin. Trans. xiii. 81.

Gen. 3\%. Megaderma, Geoff. Cuv. Desm.-Vespertilio, Lin. Shaw.

Incisors $\frac{0}{4}$, canines $\frac{1}{1}-\frac{1}{1}$, molars $\frac{4}{5}-\frac{4}{5},=26$. Superior canines triangular, the inferior bent backwards ; ears very large, and united upon the forehead; auricle much developed; nasal crests to the number of three, one vertical, one horizontal or folliculated, and the third of a horse shoe form; no tail ; interfemoral membrane truncated; wings very large, with the third finger without the nail joint.

M. trifolium, Geoff. Desm. Nasal leaf oval, follicle large, each the fifth of the length of the ears; auricle of a trefoil shape; body about three inches long; spread of the wings ten inches. Inhabits Java.-Ann. Mus. xv. pl. 12.

M. spasma, Geoff. Desm. (Vesp. spasma, Lin.) Leaf heart-shaped ; follicle large and similar; auricle of a half heart shape. Nearly four inches long. Inhabits Isle of Ternate--Shaw, i. pl. 42.

M. lyra, Geoff. Desm. Leaf rectangular; follicle one half smaller ; body nearly three inches long; spread of the wings about a foot. -Ann. Mus. xv. pl. 12. 
M. frons, Geoff. Desm. Nasal leaf oval, half the length of the ears. Above two inches long.-Inhabits Senegal.

\section{Gen. 38. Rhinolophus, Geoff. Cuv.-Vespertilio, Lin.}

Incisors $\frac{2}{4}$, canines $\frac{1}{1}-\frac{1}{1}$, molars $\frac{5}{5}-\frac{5}{5},=30$. Superior incisors very small, separated, and often falling, inferior bilobed; molars with sharp-pointed crowns; nose with a crest of a horse shoe form before, surmounted by a leaf; ears distinct; interfemoral membrane large ; tail long and entirely enveloped; two pectoral mamma, and two pubial warts, having the appearance of mammæ, but without lactiferous glands.

R. unihastatus, Geoff. Desm. (Vespertilio ferrum-equinum, Lin. Var. A.) Nasal leaf double; the posterior spear-shaped; the anterior sinuous at the margin and extremities. Nearly three inches long; spread of the wings 14 inches. Inhabits old quarries and caves in Europe.-Buff. viii. pl. 20. fig. 1 and 2.

R. bihastatus, Geoff. Desm. (Vesp. ferrum-equinum, Lin. Var. B. Vesper minutus, Mont.) Nasal leaf double, both spear-shaped; ears deeply hollowed. Generally smaller than the preceding. Europe. B.-Leach, Zool. Mis. iii. p. 121.

R. Iridens, Geoff. Desm. Nasal leaf simple, terminated by three points; body about two inches long; spread of the wings nearly nine inches. Inhabits Egypt.-Geoff. Egypt. ii. pl. 2.

R. speoris, Desm. (Rhinolope crumenifère, Peron and LesueurVesp. speoris, Schn.) Nasal leaf simple, with the terminal margin rounded; a purse or cavity on the forehead. Island of Timor. -Peron, Voy. pl. 35.

R. diadema, Geoff. Desm. Nasal leaf simple, terminal border rounded; no purse on the front; tail the length of the leg; body about four inches long. Island of Timor.-Ann. Mus. xx. pl. 6 .

R. Commersonii, Geoff. Cuv. Nasal leaf simple, the terminal margin rounded; no pouch on the forehead; tail one half less long than the leg. A little smaller than the preceding. Near Fort Dauphin, Madagascar.-Ann. Mus. xx. pl. 5:

R. affinis, Horsf. Yellowish brown above, yellow underneath, deeper on the throat and breast; tail shorter than the legs; septum of the nose crooked; ears large, with an accessory lobe at the base.

R. minor, Horsf. Lead-colour or silvery above, gray below ; septum, tail, and ears like the preceding; spread of wings 9 inches.

R. nobilis, Horsf. Brown above varied, with gray underneath; nasal membrane extended across the nose in the form of a shelf; tail as long as the legs; spread of wings $19 \frac{1}{2}$ inches.

R. larvatus, Horsf. Deep-brown above, with a golden lustre; membrane blackish-brown with a yellowish tint, varying according to the disposition of the light; spread of wings $12 \frac{1}{2}$ inches. 
R. vulgaris, Horsf. Brown above, uniform gray beneath; tail a little longer than the leg; upper nasal membrane transverse ; ears patulous, with a hairy lobule at the base; spread of wings $12 \frac{1}{2}$ inches.

R. deformis, Horsf. Brown above, gray underneath; skull elongated and depressed; upper nasal membrane transverse; large, erect, approximate ears. Spread of wings 12 inches.

R. insignis, Horsf. Dark brown above; tail a little longer than the legs; an elongated frontal sinus ; mouth contracted, ascending transversely; ears large and patulous, with the extremity circular. This and the six preceding species inhabit Java.

Gen. 39. Nycteis, Geoff. Cuv.-Vespertilio, Lin.

Incisors $\frac{4}{6}$, canines $\frac{1}{1}-\frac{1}{1}$, molars $\frac{4}{4}-\frac{4}{4}=30$. Superior incisors bilobed, very small, contiguous ; inferior trilobed; molars with pointed tubercles; a deep longitudinal furrow on the forehead ; nostrils covered each by a moveable operculum; interfemoral membrane large, and comprising the tail, which is terminated by a bifurcated cartilage in form of a $\mathrm{T}$.

N. Geoffroyi, Desm. Ears very large ; tragus spiral; under lip with a large wart at its extremity, between two elongated cushions in the form of the letter $\mathrm{V}$; fur of gray brown above, lighter gray below. Nearly two inches long; spread of the wings nine inches. Senegal, \&c. in Africa.-Geoff. Egypt. ii. pl. 1. fig. 2.

N. Daubentonii, Geoff. Desm.(Vespertilio hispidus, Gmel.) Ears pretty

large ; tragus very small ; inferior lip simple ; fur of a reddish brown above, yellowish white below. About $1 \frac{1}{2}$ inch long; spread of the wings about seven inches.-Buff.x. pl. 20. fig. 1, 2 .

N. Javanicus, Geoff. Desm. Fur of a bright red on the upper parts of the body, of a reddish ash-colour upon the inferior. About $2 \frac{1}{2}$ inches long.-Inhabits Java.

Gen. 40. Rhinopoma, Geoff.

Incisors $\frac{2}{4}$, canines $\frac{1}{1}-\frac{1}{1}$, molars $\frac{4}{5}-\frac{4}{5},=28$. Inferior incisors separated; nose long, conical ; truncated at the extremity, and surmounted by a little leaf; nasal openings narrow, transverse and operculated; forehead concave; ears large, united, and lying on the face ; interfemoral membrane narrow and truncated; tail long, enveloped only at its origin.

R. microphylla,Desm. (Vesp.microphyllus, Brunich.) Furash-coloured; tail very long and slender; nostrils with a valve as in seals. Two inches long; spread of the wings seven inches-Egypt.

R. Caroliniensis, Geoff. Desm. Fur brown; tail long, and pretty thick. About two inches long, spread of the wings eight inches. -Inhabits South Carolina.

Gen. 41. Taphozous, Geoff. Desm.-Vespertilio, Schreb.

Incisors $\frac{0}{4}$, canines $\frac{1}{1}-\frac{1}{1}$, molars $\frac{4}{5}-\frac{4}{5},=26$. A furrow on the 
nose, as in the two preceding genera, but not provided with operculi ; upper lip very thick ; tail composed of six vertebræ, free above the membrane ; interfemoral membrane large.

T. Senegalensis, Geoff. Desm. Fur brown above; brown ash-coloured below; auricle rounded. Body $2 \frac{1}{2}$ inches long.-Africa.

T. Mauritianus, Geoff. Desm. Fur chestnut above, reddish below; auricle terminated by a sinuous border. Body $3 \frac{1}{2}$ inches long; spread of the wings above nine inches.-Isle of France.

T. perforatus, Geoff. Desm. Fur gray red above; ash-coloured below; auricle dolabriform. Three inches long, spread of the wings nine inches. Inhabits Egypt at Ombos and Thebes, in the tombs of the kings.-Geoff. Egypt. ii. pl. 3. fig. 1.

M. Desmarest is of opinion that this and the T. Senegalensis are the same.

T. lepturus, Geoff. Desm. (Vespertilio lepturus, Schreb.) Fur gray, paler below than above; auricle very short and obtuse; a fold towards the tail, formed by the membrane of the wings. Body about an inch and a half long. Surinam.-Schreb. Saugh. i. pl.57.

T. rufus, Harlan. Fur of a reddish cream colour; membranes of a dusky red. Four inches long; spread of the wings 12 inches. Inhabits Pennsylvania.-Harlan, Faun. Americ. 23.

\section{Gen. 42. Mropteris, Geoff.}

Incisors $\frac{2}{2}$, canines $\frac{1}{1}-\frac{1}{1}$, molars $\frac{4}{5}-\frac{4}{5},=26$. Inferior incisors bilobed; nose simple; forehead flat, without leaves, membranes, or furrow ; muzzle short and thick; ears large, tail long, half enveloped at its base, free at the extremity.

M. Daubentonii, Geoff. Desm. Upper part of the head and body of a brown colour; below of a dirty white, with a slight tint of fawn colour. Body three inches in length.-Country unknown.

Gen. 43. Celeno, Leach.

Incisors $\frac{2}{2}$, the upper acuminated and simple, the lower formed as it were of four columns; molars $\frac{8}{8}$, the anterior teeth in both jaws acuminated, the three posterior acutely tuberculated.

C. Brooksiana, Leach. Back ferruginous; belly and shoulders yellowish; membrane black; ears acuminated, distinct.-Lin. Trans. xiii. 70.

\section{Gen. 44. Aello, Leach.}

Incisors $\frac{2}{4}$, molars $\frac{8}{1 \overline{2}}$, the two upper acuminated, the third bifid, and the fourth with three edges; in the lower jaw, the three anterior acuminated, the three posterior bifid.

A. Cuvieri, Leach. Isabella ferruginous yellow; wings dark brown; ears short, approximate, broad ; no auricle; tail not reaching beyond the membrane-Lin. Trans. xiii. 71. 
Gen. 45. Scotophirus, Leach.

Incisors $\frac{4}{6}$; in the upper jaw the two lateral teeth shorter; molars $\frac{8}{8}$, furnished with acuminated processes.

S. Kuhlii, Leach. Ferruginous, with the ears, nose, and wings brown; ears distinct, auricle small ; tail reaching to the end of the membrane.-Lin. Trans. xiii. pl. 1.

Gen. 46. Artibeus, Leach.

Incisors $\frac{4}{4}$, the two intermediate in the upper jaw largest; in the lower jaw truncated, the intermediate ones reeded in front; molars $\frac{8}{10}$, the posterior ones small.

A. Jamaicensis, Leach. Dark-coloured above, mouse-coloured below; ears, nasal appendages, and membranes dark brown ; two nasal appendages, the one horizontal, the other vertical and acuminated ; no tail. Inhabits Jamaica.-Lin. Trans, xiii. pl. 1.

Gen. 4\%. Diphylla, Spix.

Incisors $\frac{4}{4}$, canines $\frac{1}{1}-\frac{1}{1}$, scarcely exserted; molars $\frac{4}{4}-\frac{4}{4}$ ? or $\frac{8}{8}-\frac{8}{8}$ ? short, apex erenulated; nose with two short erect truncated leaves placed close together; posterior legs nearly as long as the arms; tail and interfemoral membrane deficient.

D. ecaudala, Spix. Body with woolly, hair back fuscous brown; head and abdomen brownish gray ; wings blackish, nearly naked; face near the ears naked. Brazil._Spix, Sim. Braz. 136, fig. 7 .

Gen. 48. Monophyluus, Leach.

Incisors $\frac{4}{0}$, the two intermediate the largest, canines $\frac{1}{1}-\frac{1}{1}$, molars $\frac{5}{6}-\frac{5}{6}$, the two first in the upper jaw distant, the rest tuberculated on both edges; the second and third in the lower jaw with a space between them.

M. Redmani, Leach. Brown above, mouse-coloured below ; membranes, ears, and nasal appendage brown ; nasal leaf erect, acute ; ears round ; beard elongated. Jamaica.-Lin. Trans. xiii. pl. 1.

Gen. 49. Dysopes, F. Cuv.

Incisors $\frac{2}{4}$, upper close, elongate, elliptical ; canines $\frac{1}{1}-\frac{1}{1}$, molars $\frac{4}{5}-\frac{1}{5}$.

D. mops. Inhabits India.,F. Cuv. Denls. de Mam. 49.

Gen. 50. Nyctophilus, Leach.

Incisors $\frac{2}{6}$, canines $\frac{1}{1}-\frac{1}{1}$, molars $\frac{4}{4}-\frac{4}{4}$. Upper incisors short and conical, the under equal; first molar in the upper jaw acute, with one tubercle; the second and third with four tubercles, and the fourth with three.

N. Geoffroyii, Leach. Back dirty brown, under parts whitish; ears 
broad ; membrane blackish ; two nasal appendages, erect, the posterior one largest; tail as long as the interfemoral membraneLin. Trans. xiii. pl. 1.

\section{Gen. 51. Thyroptera, Spix.}

Teeth......? Body slender; nosesimple ; wings very narrow, extending to the tarsus; interfemoral membrane not extending beyond the feet; tail long, free.

T. tricolor, Spix. Body above fuscous brown, beneath pure white; wings and legs black. Brazils.-Spix, Sim. Braz. t. 36. f. 69 .

$$
\text { Gen. 52. Proboscrdea, Spix. }
$$

Incisors $\frac{4}{6}$, canines $\frac{1}{1}-\frac{1}{1}$, molars $\frac{5}{5}-\frac{5}{5}$. Upper incisors small and diverging, the under ones lobed; the front molar small, the others tuberculated; wings narrow; tail long; half involved in the membrane.

P. saxatilis, Spix. Body above variegated with gray and brown, below mouse-coloured; wings and feet fuscous brown. Inhabits rocky places on the shores of St Francis, Brazil.-Spix, Sim. Braz. t. 35. f. 8.

P. rivalis, Spix. Body smaller; above fuscous brown, beneath pale brown. Inhabits shores of the Amazons; Brazils.-Spix, Sim. Braz. 62.

Gen. 53. Vespertilio, Lin. Pall. Cuv. Geoff.

Incisors $\frac{4}{6}$, canines $\frac{1}{1}-\frac{1}{1}$, molars $\frac{4}{5}-\frac{4}{5}$, or $\frac{5}{6}-\frac{5}{6},=32$ or 36 . Superior incisors separated in pairs, cylindrical and pointed; inferior near together, with a bilobed edge, bent forwards ; canines of medium size; anterior molars simply conical; posterior crowned with points; nose without membranous leaves or furrows, or wrinkles; tongue smooth, not protractile; membranes much extended; tail entirely enveloped in the interfemoral membrane; fur soft and thick; sebaceous glands under the skin of the face of different forms and dimensions, according to the species.

Sub-Gen. 1. Vespertilio, Geoff. Ears of medium size, lateral and isolated; four, five, or six superior molars, and three or six inferior, on each side.

V. murinus, Lin. The Common Bat. Ears oval, the length of the head; auricles falciform; fur of the adults reddish brown above, gray white below; of the young ash-coloured. Body $3 \frac{1}{2}$ inches long; spread of the wings, 15 inches. Inhabits Europe in church towers, \&c. but never in trees.-Penn. Brit. Zool.

V. Bechsteinii, Leisler, Kuhl, Desm. Ears rounded at the extremity, longer than the head; auricle falciform, a little bent outwards towards its point; upper part of the body of a red-gray, 
under part white. Body about two inches long; spread of the wings 11 inches. Inhabits Germany on trees in forests, never in houses.-Kuhl, Deutch. Flederm. pl. 22.

V. Nattereri, Kuhl, Desm. Ears oval, pretty broad; a little longer than the head; fur of a gray brown colour above, white below; members of a smoky gray ; interfemoral membrane festooned. Two inches long, spread of the wings $9 \frac{1}{2}$ inches.-Kuhl, pl. 23.

V. Caroliniensis, Geoff. Desm. Ears oblong, of the size of the head, tragus semicordate; fur chestnut brown above, and yellow below. Body about two inches long; spread of the wings $9 \frac{1}{2}$ inches. Inhabits South Carolina.-Ann. Mus. viii. pl. 47.

V. noctula, Lin. Desm. Ears oval-triangular; shorter than the head, body fawn-colour; membranes brown black. Body about three inches long; spread of the wings $14 \frac{1}{2}$ inches. Inhabits Europe.-F. Cuv. No. 38, t. 3.

V. serotinus, Lin. Desm. (Vespert. noctula, Geoff.) Ears oval-triangular, shorter than the head, auricles semicordate; fur dark chestnut in the males, and lighter in the females; membrane of the wings black. Nearly three inches long; spread of the wings about 13 inches. Inhabits Europe. B.-Ann. Mus. viii. pl. 47, 48.

V. Leisleri, Kuhl, Desm. Ears oval-triangular, short; hair long, of a chestnut colour at the point and deep brown at the base; inferior surface of the membrane of the wings the length of the arm very hairy. Body about $9 \frac{1}{2}$ inches long; spread of the wings 11 inches.-Inhabits Germany.

V. Schreibersii, Kuhl, Desm. Ears small, with an internal hairy border ; fur gray ash-colour, paler below, and often mixed with yellowish white. About $2 \frac{1}{2}$ inches long; spread of the wings 10 to 11 inches.-Inhabits Germany.

V. discolor, Kuhl, Desm. Ears short rounded, oval; hair, of the back brown, with the point white; that of the under part of the body of a dirty white. Body about two inches long; spread of the wings 10 or 11 inches. Inhabits South of Germany.-Kuhl, 43.

V. pipistrellus, Lin. Desm. Ears oval-triangular, shorter than the head; hair blackish brown above, belly of a brown fawn-colour. Body little more than an inch long; spread of the wings upwards of six inches.-Inhabits France, Germany, and Italy.

Var. A. with the points of the hairs ash-coloured.-Geoff. Egyp. i. fig. 3.

V. emarginatus, Geoff. Desm. Ears oblong, size of the head, and furrowed at their exterior border; fur reddish gray above, ashcoloured below. Two inches long; spread of the wings nine inches. Inhabits England.--Ann. Mus. viii. pl. 47. 48.

V. myslacinus, Kuhl. Desm. Ears pretty large, oblong, wrinkled and furrowed exteriorly; hair fine and close set, forming on each side of the upper lip a kind of moustache; fur brown, tipped with brown red. About $1 \frac{z}{2}$ inch long; spread of the wings seven to eight inches. Inhabits Germany. 
V. Kuhlii, Natterer, Desm. Ears simple, almost triangular ; fur of a bright red, brown above, fawn-coloured below ; interfemoral membrane very hairy. A bout $1 \frac{3}{4}$ inch long; spread of the wings $8 \frac{1}{2}$ inches.-Found near Trieste in Germany.

V. Daubentonii, Kuhl, Desm. Ears small ; fur of a red-gray above, and whitish below. Body about two inches long; spread of the wings 9 to $9 \frac{1}{2}$ inches. Inhabits Germany.-Kuhl, t. 25 . fig. 2 .

V. pictus, Lin. Desm. Striped Bat, Penn. Ears oval, shorter than the head; fur of a bright red yellow on the back; two bands of bright yellow along the fingers of the wings, which are of a chestnut colour. Body two inches long; spread of the wings seven inches. E. Indies.-Ann. Mus. viii. pl. 48.

V. lasiurus, Lin. Desm. Rough-tailed Bat, Penn. Ears oval, shorter than the head; fur variegated with yellowish gray and lively red. Nearly two inches long. Cayenne.-Ann. Mus. viii. pl. 47.

V. Borbonicus, Geoff. Desm. Ears oval-triangular, a half shorter than the head; fur red above and whitish below. Body nearly three inches in length. Isle of France-Ann. Mus. viii pl. 46.

V. Nigrita, Geoff. Gmel. Senegal Bat, Penn. Ears oval-triangular, very short ; the third of the length of the head; fur fawn-coloured above, ash-brown below. Body about four incheslong; spread of the wings 18 inches. Inhabits Senegal.-Ann. Mus. viii.pl. 47.

V. maximus, Desm. (V.nasutus, Shaw.) Ears oval, shorter than the head ; muzzle long and pointed; fur chestnut above ; of a bright yellow on the flanks, and of a dirty white on the belly. Body about $5 \frac{1}{2}$ inches long; spread of the wings nearly 18 inches. Inhabits Guiana._Buff. vii. pl. 73.

V.pygmaus, Leach. Brown deeper on the back and head; muzzle short and obtuse; ears shorter than the head, broad at the base, rounded ; tragus linear. Expanded wings about five inches. Inhabits England.-Zool. Journ. iv. f. 22.

V. Braziliensis, Spix. With black wings. Inhabits Brazil.-Spix, Braz. t. 36, f. 8.

V. Hilarii, Isid. Geoff. Ears small and triangular; tail as long as the fore-arm ; interfemoral membrane naked. Inhabits Brazil. -Ann. des Sciences Nat. iii. 440.

V. Polythrix, Isid. Geoff. Ears small, notched at the external margins; tail as long as the fore-arm; interfemoral membrane with scattered hairs on the upper side; face hairy. Inhabits Brazil. - Ann. des Sciences Nat. iii. 440.

V. lavis, Isid. Geoff. Ears long; tail as long as the body; face partly naked. Inhabits Brazil.-Ann. des Sciences Nat. iii. 445.

V. Temminckii, Horsfield. Incisors $\frac{2}{6}$. Head cuneate, top and sides flat; ears shorter than the head, oblong, rounded; tragus elongate, falcate ; fur silky ; hair very short, olive brown, beneath dirty yellow. Inhabits Java.-Horsfield's Java, No. 8. 
V. adversus, Horsfield. Incisors $\frac{4}{6}$, canines $\frac{1}{1}-\frac{1}{1}$, molars $\frac{6}{6}-\frac{6}{6}$. Head wedge-shaped, high behind; muzzle broad; ears erect; tragus linear; fur rather woolly, above shining brown, below whitish ashcoloured. Inhabits Java.-Horsfield's Java, No. 8.

V. Hardwickii, Horsf. Incisors $\frac{4}{6}$, canines $\frac{1}{1}-\frac{1}{1}$, molars $\frac{6}{6}-\frac{6}{6}$. Head globose; tumid; muzzle short, depressed ; ears very broad, concave ; tragus linear, erect ; fur woolly, above brown ash-coloured, below dirty gray. Inhabits Java.-Horsfield's Java, No. 8.

V. tralatitius, Horsf. Incisors $\frac{4}{6}$, canines $\frac{1}{1}-\frac{1}{1}$, molars $\frac{5}{6}-\frac{5}{6}$. Head wedge-shaped ; face bristly ; ears large, flat ; tragus linear, erect, blunt; fore-arm long; fur soft, sooty black. Body three inches long; expanded wings ten inches. Java.-Horsf. Java, No. 8.

V. imbricatus, Horsf. Incisors $\frac{4}{6}$, canines $\frac{1}{1}-\frac{1}{1}$, molars $\frac{4}{5}-\frac{4}{5}$. Head and muzzle short, broad; ears broad, obtuse ; tragus short, semilunar; fur shining, fulvous. Inhabits Java.-Horsf. Java, No. 8.

V. villosissimus, Geoff. Desm. Ears like those of a rat ; interfemoral membrane hairy in its middle; fur of a pale brown. Body about four inches long; spread of the wings 11 inches.-Inhabits Paraguay.

V. ruber, Geoff. Desm. Ears much pointed; hair short, cinnamoncoloured on the upper parts, and fawn-coloured on the inferior parts. Body about three inches long; spread of the wings about nine inches. - Inhabits Paraguay.

V. albescens, Geoff. Desm. Ears sharp pointed; fur almost black, spotted with white above, and obscure below. Body about $2 \frac{1}{q}$ inches long; spread of the wings nearly nine inches. Inlabits Paraguay.-Ann. Mus, viii. pl. 18.

V. Brasiliensis, Desm. Ears medium size, of an elongated form; membranes narrow and black ; fur dark brown, very soft, and silky, shaded with chestnut. Spread of the wings 11 to 12 inches -Inhabits Brazil.

Sub-Gen. 2. Plecotus, Geoff. Ears larger than the head, oflen much developed, united to one another by their base; four or five superior molars, and four to six inferior, on each side.

V. auritus, Lin. Geoff. Desm. The Long-eared Bat. Ears almost as long as the body; fur gray, deeper.above than below. Body nearly two inches long; spread of the wings $10 \frac{1}{2}$ inches. Inhabits Europe. B.-Shaw, i. pl. 40.

Var. A. Smaller than the preceding, with a redder fur. Egypt.

Var. B. Larger than the specimens found in France, and the colour deeper. Austria.

V. barbastellus, Lin. Geoff. Desm. Ears very large, united, triangular, hollowed at their exterior margin ; fur of deep brown; the points of the hairs yellow; membranes of a brown black. Body two inches long; spread of the wings $10 \frac{1}{2}$ inches. Inhabits France and Germany.-Ann. Mus. viii. pl. 46. 
V. Maugei, Desm. Ears very large, united; hollowed exteriorly towards the point, which is rounded; fur of a blackish brown above, and of a clear brown below; posterior parts of the body white; membranes gray. A little larger than the preceding.-Porto-Rico.

V. Timorensis, Geoff. Desm. Ears large, united at their internal base by a little membrane; fur blackish brown above and ash-coloured brown below. About $2 \frac{1}{2}$ inches long; spread of the wings 10 inches. Island of Timor.-Ann. Mus. viii. pl. 47.

V. velatus, Isid. Geoff. Chestnut-coloured above, grayish-brown beneath; tail as long as the body, entirely involved in the membrane; ears long, with two longitudinal plaits hanging over the face ; spread of wings $13 \frac{1}{2}$ inches.-Ann. Sci. Nat. iii. 446.

\section{Gen. 54. Atalapha, Rafinesque-Vespertilio, Gmel. Geoff.}

No incisors; nose simple, without crests or membranes; ears separate, and furnished with auricles; tail long, surpassing the interfemoral membrane a little, or comprised in it.

A. Americana, Rafinesque. (Vesp. Noveboracensis, Penn.) New York Bat. Ears short and broad, rounded; tail comprised entirely within the interfemoral membrane-United States.

A. sicula, Rafinesque. Ears as long as the head; tail projecting by an obtuse point.-Inhabits Sicily.

\section{ORDER IV.-FER E. Carnassiers, Cuv.}

Four extremities proper for walking; three kinds of teeth; mammæ abdominal, varying in number; stomach simple, membranous ; intestines short.

This order is composed of unguiculated quadrupeds, which possess, in common with Man and the Quadrumana, three kinds of teeth. They all live chiefly on animal matter, and this more exclusively as their molar teeth are more or less formed for cutting. Those which have these teeth in part or wholly tuberculous, subsist more or less on vegetable substances; and those which have them covered with conical points live chiefly upon insects. The articulation of their inferior jaw, directed cross-wise, and shutting as a hinge, prevents its having a horizontal movement, the motion being limited to shutting and opening. Their brain, though furrowed, has no third lobe; their orbit is not separated by a temporal depression; their cranium is confined, and the zygomatic arch widened and raised, to give more room and strength to the muscles of the jaws. Their predominating sense seems that of smell, and the pituitary membrane is generally extended upon numerous bony laminæ. Their fore-arm turns with less facility than among the quadrumanous animals. Their intestines are also less voluminous, on account of the substantial na. ture of their aliment, and to avoid the putrefaction which animal matter would experience in remaining too long in an elongated canal.

\section{FAMILY I.-INSECTIVORA.}

Feet short, armed with stout nails; those of the hind feet al. ways with five toes, having their sole entirely bearing upon voL. $\mathrm{I}$. 
the ground; fore-feet generally with five toes; molar teeth crowned with pointed tubercles; canines sometimes very long, sometimes very short; incisors variable in number; body covered with hair or prickles.

1st Division.-Two long incisors in front, followed by other incisors, or false canines, shorter than the molars.

Gen. 55. Erinaceus, Lin. Pall. Geoff. Cuv. \&c.

Incisors $\frac{6}{6}$, canines $\frac{1}{1}-\frac{1}{1}$, molars $\frac{5}{4}-\frac{5}{4},=34$. Intermediate upper incisors separate, cylindrical; canines smaller than the molars; body thick, covered with prickles above and stiff hairs below, capable of rolling up into a ball; muzzle pointed ; ears medium size, or very short and rounded; toes armed with strong nails; tail short, or none; ten mammæ, six pectoral, and four ventral; no cœecum; clavicles complete.

E. Europocus, Lin. Common Hedgehog. Ears short; prickles about an inch long, in diverging clusters, with the points white. About a foot long.-Penn. Quad. tab. 28, fig. 3.

Var. A. - Nose prolonged like that of a hog.

Var. B.-Nose shorter, spinous mantle less extended.

The hedgehogs are nocturnal animals, concealing themselves during the day, and coming out at night to feed. Their food is chiefly insects and their larvæ, snails, eggs, and fruits, and some even eat with impunity the cantharides and other vesicating insects. They become extremely fat towards autumn, and pass the winter in torpidity in holes previously prepared. Their gait is heavy, and their intelligence very limited. Their period of gestation is not exactly known; but the young at birth have their eyes and ears closed. When alarmed they roll themselves up like a ball, and present a surface of erected spines to their enemies. The conmon hedgehog is found in all the temperate parts of Europe.

E. auritus, Geoff. Pallas. Hedgehog of Egypt. Muzzle short; ears two-thirds the length of the head. A little smaller than the hedgehog of Europe. Astracan, Egypt, \&c.-Griff. An. King.170.

E. Malaccensis, Lin. Desm. (Hystrix brachyura Lin.) Muzzle short; ears pretty short, pendant; spines very long, directed parallel to one another. Eight inches long. Java, \&c.-Shaw, i. pl. 121.

\section{Gen. 56. Sorex, Lin. Cuv. Desm.}

Incisors $\frac{2}{2}$, spurious canines, or lateral incisors $\frac{3}{2}-\frac{5}{2}$, or $\frac{4}{2}-\frac{4}{2}$, true molars $\frac{4}{5}-\frac{4}{3},=28$ or 30 . Upper middle incisors hooked and dentated at the hase; molars crowned with points; head much elongated; nose prolonged and moveable; ears short, rounded; eyes small, but perceptible; tail more or less long, often angular; feet with weak toes, separated, furnished with crooked nails; teats six or eight; sebaceous glands on the flanks.

S. araneus, Lin. Shrew Mouse. Ears large and naked, with two folds or lobes within; fur mouse-coloured, paler below; tail square, a little shorter than the body. About two inches long, weighing three drachms. Inhabits Europe. B.-Shav, i. pl. 118. 
S. Daubentonii, Blumenbach, Geoff. (S. fodiens, Pall.) The Water Shrew. Ears provided with three small valves, capable of shutting it entirely; toes of the feet bordered with stiff hairs; tail square-shaped, a little shorter than the body ; fur blackish above, white below. Three inches long. Europe--Shaw, i. pl. 118.

S. tetragonurus, Geoff. Desm. Square-tailed Shrew. Ears short; fur blackish above and ash brown below; tail long, square. Two inches three lines long. France.-Ann. Mus. xvii. pl. 2. fig. 3.

S. constrictus, Hermann, Desm. Flat-tailed Shrew. Ears very small, entirely concealed by the hair; fur of a black ash-colour; tail flattened at its base and point, round in its middle. Two inches seven lines long. Inhabits France.-Ann. Mus. xvii. pl.3. fig. 1.

S. leucodon, Hermann, Desn. Back brown; belly and flanks white; tail slightly tetragonous. Two inches ten lines long. Environs of Strasburg.-Ann. Mus. xvii. 181.

S. lineatus, Geoff. Desm. Tail round, strongly carinated below; fur of a blackish brown, paler below; throat ash-coloured; a spot upon each ear, and a little white line upon the forehead. Two inches long. Inhabits France.-Ann. Mus. xvii. 181.

S. remifer, Geoff. Desm. Tail square at its base, compressed at its point ; fur of a blackish brown above, lighter beneath.-Ann. Mus. xvii. pl. 2. fig. 1.

S. collaris, Geoff. Fur black; a white collar around the neck. Inhabits the islands at the mouth of the Meuse.-Mem. Mus.i.309.

S. Indicus, Geoff. Desm. Tail round, half as long as the body; fur short, gray brown, tinted above with red; ears naked. Six inches long, the largest of the genus. Inhabits India.-Mem. Mus.i. pl.15.

S. Capensis, Geoff. Desm. Tail round, red, half as long as the body; fur ash-coloured, shaded with fawn-colour. Three inches eight lines long. Cape of Good Hope-Petiver, t. 23. fig. 9.

S. myosurus, Pall: Geoff. Tail round, thick, almost naked; muzzle gibbous; fur white. Three inches nine lines long.-Ann. Mus. xvii. pl. 3. fig. 2, 3.

S. parvus, Say. Brownish cinereous above, beneath cinereous; teeth blackish; tail short. About $2 \frac{1}{2}$ inches long. Inhabits Missouri.-Long's Exped. i. p. 163.

S. brevicaudus, Say. Blackish plumbeous above, lighter beneath; teeth blackish; tail short, robust. Inhabits Missouri.-Long's Exped. i. 164.

S. Etruscus, Savi. Ashy gray, white underneath ; ears round; tail large, subquadrate. Inhabits Tuscany.-New Giornal, i. 60.

Gen. 5\%. Mrgale, Cuv. Geoff.-Castor, Lin.-Sorex, Pallas.

Incisors $\frac{6}{8}$, canines $\frac{1}{1}-\frac{1}{1}$, molars $\frac{7}{6}-\frac{7}{6}=44$. Inferior incisors with the two middle ones smallest; canines not distinct in 
their form from the lateral incisors and first molars; muzzle prolonged, moveable, and endowed with great sensibility; no external ears; eyes very small ; toes palmated; nails long and crooked; tail scaly, compressed laterally.

M. Moscovitica, Geoff. (Castor moschatus, Lin.) Musk Rat of Russia. Tail shorter than the body, scaly, almost naked, striated at its base ; fur brown above, white below. Eight inches long. Inhabits Southern Russia._Schreb.t. 159.

M. Pyrenaica. Tail longer than the body, cylindrical for the greater part of its length, but vertically compressed at its extremity; fur brown above and gray below. Body four inches long. Inhabits the Pyrenees.-Ann. Mus. xvii. pl. 4. fig. 1.

\section{Gen. 58. Tupaia, Raffles.}

Incisors $\frac{2}{6}$, canines $\frac{1}{1}-\frac{1}{1}$, molars $\frac{7}{6}-\frac{7}{6},=38$. Body elongated ; head triangular, attenuated, blunt; eyes projecting, and ears large; tail very long; four ventral teats; diurnal.

T. $\operatorname{tana}$, Raffles. Head long; muzzle pointed; fur above reddish brown, spotted with black beneath, and an oblique red line on each shoulder. Inhabits Sumatra._Horsfield's Java, No. 3.

T. Javanica, Raffles. Head long; muzzle slightly pointed; tail very long; fur brown, speckled with gray above, gray below, with a whitish gray oblique line on the shoulder. Inhabits Java.Horsfield's Java, No. 3.

T. ferruginea, Raffles. Muzzle slightly pointed; fur ferruginous. Inhabits Java._Horsfield's Java; No. 3.

Gen. 59. Scalops, Geoff. Cuv.-Sorex, Lin.-Talpa, Penn. Incisors $\frac{2}{4}$, conical teeth $\frac{3}{3}-\frac{5}{5}$, molars $\frac{5}{5}-\frac{3}{3}=30$. Lower incisors conical, straight, with two very small intermediate incisors ; first and third upper conical teeth on each side larger than the second; molars crowned with sharp tubercles; muzzle prolonged and cartilaginous; eyes very small; external ears none; feet short, pentadactyle, the anterior very broad; nails long, flattened, proper for digging; tail short.

S. Canadensis, Desm. (Sorex aquaticus, Lin. Talpa fusca, Penn.) Nose much prolonged, terminated by a cartilaginous button; feet and tail of the mole; fur gray brown. About six inches long. - Inhabits United States from Canada to Virginia.

Gen 60. Chr ysochloris, Cuv. Geoff. Desm.-Talpa, Lin. Incisors $\frac{2}{4}$, conical teeth $\frac{3}{3}-\frac{3}{3}$, molars $\frac{6}{5}-\frac{6}{5}=40$. Intermediate lower incisors very small; fore-feet short, with three toes armed with strong nails; hind-feet pentadactyle; eyes very small; no external ear; no tail.

C. Capensis, Desm. (Talpa Asiatica, Gmel.) Fur brown, with 
under certain aspects brilliant copper and green metallic reflections; five toes on the hind-feet; no tail. About $4 \frac{1}{2}$ inches in length. Inhabits the Cape of Good Hope.-Schreb. tab. 157.

C. rufa, Desm. (Talpa rubra, Lin.) Red Mole. Fur of a reddish approaching to bright ash-colour; hind feet with four toes; tail short. A little larger than the mole of Europe. Inhabits America.-Penn. Quad. 486.

Gen. 61. Condyuura, Illiger, Desm.-Sorex, Lin.-Scalops, Geoff.-Talpa, Cuv.

Incisors $\frac{6}{4}$, conical teeth or spurious molars $\frac{3}{5}-\frac{5}{5}$, true molars $\frac{4}{3}-\frac{4}{3}=40$. Six superior incisors anomalous, the two intermediate very broad; muzzle much prolonged, furnished with membranous crests around the opening of the nostrils; no external ears; eyes excessively small; body thick ; feet pentadactyle; the nails on the fore-feet strong.

C. cristata, Desm. (Sorex cristatus, Lin.) Radiated Mole. Nostrils surrounded by a circular membrane of a stellated form; tail shorter than the half of the body. About four inches long. Inhabits Canada and United States.-Penn. Quad. tab. 28. fig. 1.

C. longicaudata, Desm. (Talpa longicaudata, Erxleb.) Longtailed Mole. No nasal crests; tail half the length of the body. Body from four to six inches long. Inhabits North America.Penn. Quad. tab. 18. fig. 2.

C. macroura, Harlan. Nose surrounded by a circular fringed membrane ; tail nearly the length of the body, strangulated at its base, slightly compressed, tapering. Five inches long.-Faun. Amer. 39.

2d Division.-Four large separated canines with small incisors between them.

Gen. 62. Talpa, Lin. Cuv. Desm. \&c.

Incisors $\frac{6}{8}$, canines $\frac{1}{1}-\frac{1}{1}$, molars $\frac{7}{6}-\frac{7}{6}=44$. Body thick; head elongated, pointed; muzzle with cartilaginous button; eyes very small; no external ears ; pentadactylous ; fore-feet very large, with toes united to the nails, which are strong and slightly arched.

T. Europea, Lin. Desm. The Mole. Fur soft, black, shining; tail short. About five inches long.-Shaw, i. pl. 117.

Var. A. Skin marbled with white and black spots.-Var. B. Fur entirely white. Var. C. Fur yellowish.-Var D. Fur ash-coloured.

Gen. 63. Centenes, Illig. Desm.-Setiger, Cuv. Geoff.Erinaceus, Lin.

Incisors $\frac{6}{6}$ or $\frac{4}{6}$, canines $\frac{1}{1}-\frac{1}{1}$, molars $\frac{6}{6}-\frac{6}{6}=38$ or 40 . Canine teeth very strong; body covered with spines, but not capable of being formed into a ball; feet pentadactyle; no tail.

C. setosus, Desm. (Erinaceus setosus, Lin.) Spines long and flexi- 
ble; four hollowed incisors in each jaw. From ten inches to a foot long. Madagascar and the Isle of France.-Buff. xii. pl. 56. M. F. Cuvier has found in a young individual of this species two small supernumerary incisors in the upper jaw, situated before the canines, which he presumes fall out with age.

C. spinosus, Desm. (Erinaceus ecaudatus, Lin.) Spines short and stiff on the upper parts of the body, bristles and hair on the lower parts; four incisors only in the lower jaw. Inhabits Madagascar.Buff. xii. pl. 57.

C. semispinosus, Desm. (Erinaceus semispinosus, Cuv.) Body covered with bristles and spines, mixed, banded with yellow and black; six incisors above and below ; canines slender and crooked. Four inches long. Inhabits Madagascar.-Buff. Sup. iii. pl. 37.

\section{FAMILY II.-CARNIVORA.}

Six incisors in each jaw; molars generally edged, sometimes tuberculous, never rough with pointed tubercles on their crown; canines very strong.

1st Tribe. Plantigrada. - Sole of the foot entirely resting on the ground.

Gen. 64. Ursus, Lin. Cuv. Geoff., \&c.

Incisors $\frac{6}{6}$, canines $\frac{1}{1}-\frac{1}{1}$, molars $\frac{4 \text { to }}{4 \text { to }} 7=32$ to 44 . Incisors of the lower jaw on the same line; posterior molars very strong, with a square crown and blunt tubercles; feet pentadactyle, armed with strong nails; body thick; tail short; mammæ six, two pectoral and four ventral.

U. Arctos, Lin. Common Brown Bear. Forehead convex above the eyes; muzzle truncated; fur brown. Upwards of four feet long. Inhabits Europe, and temperate parts of Asia.-Shaw, i. pl. 102. The bear lives in solitary places and in the decpest recesses of forests. In winter it retires to caverns or the hollow trunks of large trees, where it exists in a kind of torpidity, occasionally sucking its fore-paws. Its food consists chiefly of vegetable substances; and it never attacks man or animals but when pressed by hunger. In fighting it raises itself upon its hind legs, and presses its enemy by its fore-feet to its breast.

Var. A.-White bear of Europe; an albino variety.

Numerous other varieties of this species are noticed, founded upon shades of colour more or less black, fawn-coloured, or white.

U. cinereus, Desm. (Ursus ferox, Lewis and Clark.) Gray Bear. Fur long, cinereous gray, very thick, especially around the neck and back of the head. About $8 \frac{1}{2}$ feet long.-Inhabits United States.

U. Americanus, Pall. Desm. Cuv. Black Bear. Nose on the same line as the forehead, which is gibbous ; fur black, shining, not curled. Four feet eight inches long. Inhabits North America.

U. maritimus, Lin Desm. The Polar Bear. Head elongated ; cranium flattened; neck long; hair long, soft, and white. About $7 \frac{1}{2}$ feet long. Inhabits coasts of the Polar Sea._Shaw, i. pl. 103. 
U. labiatus, Blainville, Desm. (Bradypus ursinus, Shaw.) Lips extremely long and extensible; hair black; passing in some places to brown. Size of the brown bear. India._Shaw, i. pl. 47.

U. Malayanus, Raffles. Malay Bear. Black, with a large heartshaped patch of yellowish white on the throat. Fur short and smooth. Inhabits India.-Horsfield's Java, No. 4.

U. Thibetanus, F. Cuv. The Thibet Bear. Black, with the under jaw white; pectoral patch forked, and continued to the middle of the belly. Inhabits Thibet.-F. Cuv. Mam.

U. spelceus, (fossil.) Blumen. Cuv. Forehead much elevated above the root of the nose, presenting two convex projections. In calcareous caverns of Germany.-Cuv. Oss. Foss. iv. pl. 3. figs. 1, 2.

U. Arctoideus, (fossil.) Blumen. Cuv. Cranium similar to that of the black bear of America, but with less vertical elevation, and the muzzle more elongated. Found in the same places as the foregoing.-Cuv. Oss. Foss. iv. pl. 3, figs. 3, 4.

Gen. 65. Procyon, Storr. Cuv. Desm.-Ursus, Lin.

Incisors $\frac{6}{6}$, canines $\frac{1}{1}-\frac{1}{1}$, molars $\frac{6}{6}-\frac{6}{6}=40$. Lower incisors on the same line; the three posterior molars tuberculous; feet pentadactyle; nails sharp; muzzle pointed ; ears small ; tail long; six ventral mammæ.

P. lotor, Cuv. Desm. (Ursus lotor, Lin.) The Raccoon. Fur brown gray; muzzle white, with a brown streak across the eyes; tail annulated with brown and white. Body about two feet long. Inhabits N. America, Mexico, and West Indies.-Shaw, i.pl.105.

Var. A. White where the others are gray or yellowish, and lively red where they are black.-Var. B. With a brown spot on the throat.-Var. C. Body covered above with thick white hair; below with whitish yellow.

P. cancrivorus, Geoff. Desm. (Ursus cancrivorus, Cuv.) Fur fawn-coloured, mixed with gray and black, pretty uniform above, of a whitish yellow below; annulations of the tail faintly marked. About $2 \frac{1}{2}$ feet long. Inhabits S. America.-Buff. Suppl. vi. pl. 32.

Gen. 66. Nasua, Storr. Cuv.-Ursus, Briss.-Viverra, Lin.

Incisors $\frac{6}{6}$, canines $\frac{1}{1}-\frac{1}{1}$, molars $\frac{6}{6}-\frac{6}{6}=40$. Lower incisors on the same line; three posterior molars tuberculous ; feet pentadactyle, armed with strong nails; nose much prolonged, and moveable; tail long; six ventral mammx.

N. rufa, Desm. F. Cuv. The Red Coati. Fur generally of a brilliant red; muzzle grayish black, with three white spots about each eye. About a foot long. S. America.-F. Cuv. Mam. liv. 1.

N. fusca, Desm. (Viverra nasica, Lin.) The Brown Coati. Fur brown or fawn-coloured above, of a yellowish-gray or orange yellow; three white spots about each eye; a longitudinal white line along the nose. Size of the preceding. S. America.-Schreb.t.118. Var. A.-Fur more fawn-coloured than brown. The Coati Mondi of Marcgrave. 
Gen. 6\% Poros, Geoff. Desm.-Viverra, Gmel. Schreb.Lemur, Penn.

Incisors $\frac{6}{6}$ canines $\frac{1}{1}-\frac{1}{1}$, molars $\frac{5}{5}-\frac{5}{5}=36$. Lower incisors on the same line; the three posterior molars with tuberculous crowns; pentadactyle; toes armed with crooked nails; muzzle short; head rounded; tail long and prehensile.

P. caudivolvulus, Desm. (Viverra caudivolvula, Schreb.) Yellow 1. Maucoco, Penn. Fur silky, of a brownish very bright fawn-colour. About 19 inches long. S. America.-Penn. Quad.t. 16.

Gen. 68. TAxus, Geoff.-Meles, Storr. Cuv.-Ursus, Lin. Incisors, $\frac{8}{6}$, canines $\frac{1}{1}-\frac{1}{1}$, molars $\frac{5}{6}-\frac{5}{6}=38$. The first molar very small, the second and third pointed, the fourth cutting on the external side, the fifth tuberculous and large; body low upon the legs; pentadactyle; nails robust; tail short; an anal pouch, containing a fetid secretion.

T. vulgaris, Desm. (Ursus meles, Lin.) The Badger. Fur of a A gray brown above, black below; a longitudinal black band on each side of the head, passing around the eye and ear. About two feet three inches long. Irlhabits Europe. B.-Shaw, i. pl. 106.

T. Labradorica, (Ursus Labradoricus, Gm.) Pale yellowish-gray ; belly and throat white, with a longitudinal band on the side of the head, passing over the eye and the ear. Inhabits Hudson's Bay.-Shaw, i. pl. 106.

\section{Gen. 69. Guro, Cuv. Illig.-Mustela, Ursus, Lin.}

Incisors $\frac{6}{6}$, canines $\frac{1}{1}-\frac{1}{1}$, molars $\frac{5}{6}-\frac{5}{6}$ or $\frac{4}{6}-\frac{4}{6}=36$ or 38 . Molars, the three first in the upper, and the four in the lower jaw, small, succeeded by a large carnivorous tooth, and a small tuberculous one at the back; body low, head moderately elongated; ears short and round; tail short; pentadactyle; toes with crooked nails; no anal pouch.

G. arcticus, Desm. (Ursus gulo, Lin. Pall.) The Wolverene, Penn. Body pretty thick; fur of a fine deep chestnut-colour, with a disc, almost black upon the back. About 26 inches long. Inhabits northern Europe and America._Shaw, i. pl. 104.

Var. A. Differs from the preceding in the colours being paler.

The voracity of this animal, though excessive, has been greatly exaggerated. It is about the size of the badger, and the body is heavy. When a sufficient supply of small quadrupeds and birds cannot be procured, it is said to conceal itself on the horizontal branch of some tree, where it will drop on deer or other animals passing beneath, holding its situation and sucking their blood till exhaustion renders them an easy prey. According to Dr Richardson, it is extremely annoying to the hunters, by devouring their stores of provision and carrying off the baits of their marten traps. It has been known to visit daily a line of traps extending upwards of two miles, and to rob the whole of them of the baits, and of such animals as had been caught. 
G. vittatus, Desm. (Viverra vittata, Lin.) Body much elongated; fur black, spotted with white; top of the head and neck gray; a white band running from each side of the forehead to the shoulders. About one foot long. S. America.-Wern. Mem. iii. pl. 19, fig. 5.

G. barbatus, Desm. (Mustela barbata, Lin.) Body elongated; fur of a black brown; a large spot of a yellowish white colour covering the under part of the neck and throat. Inhabits Guiana, Brazil, \&c.-Brown's Jamaica, pl. 49, fig. $1 .^{x_{4}}$

G. Capensis, Desm. (Viverra Capensis, Lin.) Body thick and short; fur gray above, black below, with a longitudinal white line on each side from the ears to the origin of the tail. About three feet four inches long. Inhabits Cape of Good Hope.Sparman, Act. Stockh. 1777, tab. 4, fig. 3.

G. orientalis, Horsfield. Fur glossy reddish brown; white patches about the head and throat, and a long pyramidal white patch from the top of the head to the middle of the spine. Body 16 inches long. Inhabits Java.-Horsf. Java.

G. larvatus, Griff. The Masked Glutton. Fur olive brown and gray; tip of the tail and feet black; white patches about the face. Larger than the polecat._Griffith's Anim. King. ii. 281.

G. ferrugineus, Griffiths. Fur chestnut colour; tail black; head broad and depressed; eyes near the nostrils.-An. King. ii. 282.

\section{2d Tribe. Digitigrada.-Walking on the toes.}

1st Division.-With one tuberculous tooth behind the great carnivorous tooth of the upper jaw.

Gen. 70. Mustela, Lin. Cuv. Illig. Desm.

Incisors $\frac{6}{6}$, canines $\frac{1}{1}-\frac{1}{1}$, molars $\frac{4}{5}-\frac{4}{5}$, or $\frac{5}{6}-\frac{5}{6},=34$ or 38 . Body elongated; head small and oval; ears short and round; legs short; feet pentadactyle, armed with sharp hooked claws; no anal pouch.

Sub.-Gen. 1. Putorius, Cuv.-Two false molars above, and three below; no interior tubercle on the great canine below; muzzle short; emit a fetid odour.

M. putorius, Lin. Desm. The Polecat, Penn. Fur brown; the interior hairs of a yellowish white; some white spots at the head and muzzle. About 18 inches long. Europe. B.-Penn. Quad.p. 213.

M. furo, Lin. Desm. The Ferret, Penn. Fur yellowish; eyes redcoloured. M. Cuvier thinks that the ferret is only a variety of the polecat. Body nearly 14 inches in length.-Penn. Quad. 214.

Var. A. Fur variegated with white, black, and fawn-colour.

Common in Spain, where it was imported from Africa. In Great Britain it exists only in a domesticated state.

M. Sibirica, Pall. Schreb. Desm. Fur of a pale fawn-coloured yellow on the lower parts ; muzzle brown, around the nose white. 
Similar in size to the preceding. Inhabits thick forests in Siberia.-Pallas, Spic. Zool. pl. 4, fig. 2.

M. Sarmatica, Pall. Desm. Fur of a ferruginous brown, spotted with yellow above; throat and belly black. About 13 inches long. Inhabits Poland and Russia.-Pall. Spic. xiv. t. 4, fig. 1.

M. vulgaris, Lin. Desm. The Weasel. Fur of a reddish brown above, white below. Body about $6 \frac{1}{2}$ inches in length. Inhabits Europe, \&c. B.-Shan, i. pl. 98.

Var. A. (M. nivalis, Lin.) White, with some black hairs at the extremity of the tail. A voracious animal, inhabiting the temperate and northern parts of the old world and North America. The while variety is found in Westrobothnia, Sweden, and in Russia and Siberia.

M. Africana, Desm. Body above of a reddish brown; below of a pale yellow, with a longitudinal narrow band of the first colour in the middle of the belly. Ten inches long. Inhabits Africa.

M. erminea, Lin. Desm. The Ermine in winter-The Stoat in summer. Fur in summer of a brown chestnut, paler above, white below; in winter fur white; tail always black at its extremity. About $9 \frac{1}{2}$ inches in length. Common in the north of Europe-Shaw, i. pl. 99.

M. lutreola, Pall. Desm. The Mink. Fur of a blackish brown; upper lip, chin, and under part of the neck white; feet semipalmated. Nearly a foot long. Europe.-Pall. Spic. Zool. xiv. pl.31.

M. alpinus, Gebler. The Alpine Polecat. Fur sulphur yellow, brownish above; chin white. About a foot in length. Inhabits the Altaic Mountains.-F. Gebler. Mem. Moscou, vi. 213.

M. nudipes, F. Cuv. Java Ferret. Fur brilliant golden yellow; forehead and tip of tail yellow white; soles of the feet naked. About 11 inches long. Inhabits Java.-F. Cuv. Mam. No. 32.t. 3.

M. lutreocephala, Harlan. Fur brownish white, paler beneath; tail ferruginous brown. About 20 inches long. Inhabits United States.-Harlan, Faun. Amer. p. 63.

Sub.-Gen. 2. Zonilues.-Muzzle short; two false molars above, three below; nails of the fore feet strong, and proper for digging.

M. zorilla, Lin. Desm. (Mustela zorilla, Lin.) Fur irregularly variegated with longitudinal black and white bands. Cape of Good Hope.-Shaw, i. 391.

Sub.-Gen. 3. MARTES.-A little tubercle on the lower large carnivorous tooth; a false molar above and below more than the Putorius.

M. martes, Lin. The Pine Marten. Fur brown, with a bright yellow spot under the throat. About 18 inches long. North of Europe. B.-Shan, i. 410.

M. foina, Lin. The Beech Marten. Fur brown, below the throat and neck whitish. About 16 inches long. Europe and Western Asia. B.-Buff. vii. pl. 18. 
M. zibellina, Lin. The Sable. Fur brown, whitish on the head, and gray on the throat; feet covered with fur to the ends of the toes. About 18 inches in length. Northern Asia.-Schreb. t. 136.

M. vison, Lin. Fur brown, with the point of the inferior jaw white, and the tail brown black; feet semipalmated. About 15 inches long. Inhabits Canada.-Schreb. t. 127.

M. Canadensis, Lin. Pekan Weasel, Penn. Head, neck, shoulders, and upper part of the back mixed gray and brown; nose, croup, tail, and members of a blackish brown; often a white spot on the throat. About 18 inches long. Canada.-Schreb. t. 134.

M. rufa, Desm. Geoff. Fur of a red chestnut, deeper above than below, and composed of hairs annulated with brown, chestnut, and yellow; tail brown at the tip. Probably a variety of the preceding.

M. Pennantii, Erxleb. The Fisher Weasel, Penn. Fur yellowish, topped with black ; throat, belly, and legs brown ; ears short, lighter at the tips; tail black, shining. About $2 \frac{1}{2}$ feet long. North America.--Penn. Quad. No. 202.

M. leucotis, Griffiths. Fur dark brown; inside of ears white.Griff. An. King. ii. 297.

M. sinuensis, Humb. The Zorra. Fur of a uniform blackish-gray ; belly and interior of the ears white. About two feet two inches in length. Inhabits the warmer parts of New Grenada.

\section{Gen. 71. Mephitis, Cuv.-Viverra, Lin.}

Incisors $\frac{6}{6}$, canines $\frac{1}{1}-\frac{1}{1}$, molars $\frac{4}{5}-\frac{4}{5}=34$. Body elongated, arched; toes of the foot separated and armed with strong nails, the anterior formed for digging; tail long and bushy, or none.

The mephitic weasels are rather clumsy and not nearly so active as their congeners, and as their means of flight are limited, nature has provided them with a singular mode of defence in the ejection of a fetid liquor from their body. Young sporting dogs, unacquainted with the animal, sometimes pounce on them; but the dash of fetid liquid instantly forces them to retire. They whine, rub their noses in the earth, and will never again pursue another of the same species. The smell of this offensive liquor is so penetrating, that washing and baking clothes upon which it has been injected is found insufficient, and the intolerable smell is diffused to a corsiderable distance. Azara declares he was not able to endure the disgusting smell which a dog that had received it from one of the species a week before communicated to some furniture, although the dug had been washed and scrubbed with sand above twenty times.

M. Americanus, Desm. The Chinche. Fur soft, shining, marked with white longitudinal bands upon a blackish-brown ground; tail covered with very long tufted hair. About the size of the domestic cat.-Shaw, i. pl. 94.

Var. A. With many white bands. The Ysquiepalt of Hernandez.

Var. B. W With nine white lines, and digitigrade. The Putois of Catesby.

Var. C. - With six white bands, and said to be plantigrade. Moufette Conepatl, Buff.

Var. D.-With two white bands along the tail. Conepatl, Hernandez.

Var. E._Glauton Mapurito, Humboldt. Fur of a deep-black; back with only one white band, which commences at the forehead and terminates at the half of the body. Its odour is insupportable. 
Var. F.-Mephitis Chiliensis, Geoff. With two white bands on the sides of the body, uniting behind the head and forming a crescent.

Var. G.-Viverra mephitis, Gmel. or Chinche of Buffon. With two very broad white bands posteriorly; forehead marked with a longitudinal white band.

Var. H.-Feulilée's Chinche. With two white bands, which spread and terminate on the sides.

Var I.-Moufette Yagouare of Azara. Fur of a brown-black and two white bands.

Var. K.-Polecat of Kalm. The Skunk. Fur brown-black, with one longitudinal white line on the back and one on each side.

Var. L.-Moufette Zorille. Fur black and white, with a fine tail.

Var. M.-Body spotted with white and black. Mafutiliqui of the Indians.

Var. N.-Male black; female black bordered with white. Louisiana.

Var. O.-White, black, and fawn-coloured. Orthula of Mexico.

Var. P.-Tail with black and white rings. Tepemaxtla, Hernandez.

Var. Q.-Gulo Quitensis, Humboldt. Plantigrade. Body black and marked with two white bands, which extend from the top of the head to the tail.

Var. R.-Mephitis interrupta, Rafinesque. Brown, with two short white bands, parallel to the head; eight bands on the back, of which the four anterior are equal and parallel, and the four posterior rectangular, and disposed in an opposite direction. About a foot long.-Louisiana.

M. Javanensis, Desm. (Telagon, F. Cuv.) Fur deep-brown; forehead with a white spot, extended into a dorsal line; tail very short, and covered with long hair. Body about 16 inches in length. Inhabits Java.-Horsf. Zool. Res. vi.

Made a new genus by Dr Horsfield, under the name of Myadeus.

Gen. 72. Lutra, Desm. Cuv. Shaw, \&c.-Mustela, Lin.

Incisors $\frac{6}{6}$, canines $\frac{1}{1}-\frac{1}{1}$, molars $\frac{5}{5}-\frac{5}{5}$, or $\frac{5}{6}-\frac{5}{6},=36$ or 38 . Head large; and flattened; ears short; body long, low upon the legs, toes webbed; nails crooked; tail long, flattened horizontally.

L. vulgaris, Desm. (Muslela lutra, Lin.) The Otter, Penn. Fur brown above, and whitish below; tail more than half as long as the body. Inhabits Europe. B.-Shan, i. pl. 100.

Var. A. - With a number of small round white spots on the flanks.

L. Brasiliensis, Geoff. Desm. (Mustela lutris Brasiliensis, Lin.) Fur brown, or fawn-coloured, with the throat white or yellowish. Rivers in Guiana, \&c.-Cuv. Reg. Anim. iv. t. 4, fig. 3.

L. Canadensis, Sabine. (Mustela Hudsonica, Lacepede.) Canadian Otter. Fur glossy-brown; chin and throat dusky white; neck and head long; legs short; tail pointed, and as long as the body. Inhabits Copper Mine River.-Franklin, Voy. Ap. 653.

L. insularis, F. Cuv. Hairs scattered; body clear chestnut-brown; throat and chin yellowish-white. Inhabits Isle of Trinity.Dict. Sc. Nat. xxvii.

L. lataxina, F. Cuv. Fur long, twisted, thick ; brown-black above, pale bluish-gray below. Inhabits Carolina.-Dict. Sc. Nat. xxvii.

L. enudris, F. Cuv. Fur above clear bay, paler beneath; throat, and sides of the face nearly white.-Dict. Sc. Nat. xxvii.

L. rair, F. Cuv. Fur long, deep chestnut; lower part of the neck, 
throat, and belly clear reddish-white; a brown band on the cheeks under each eye. Inhabits Pondicherry.-Dict. Sc. Nat. xxvii.

L. inunguis, F. Cuv. Fur chestnut-brown above, deeper on the buttock, tail, and legs; lower parts white ; toes large, semipalmated, without claws. Cape of Cood Hope-Dict. Sc. Nat. xxvii.

L. leptonyx, Horsf. Fur shining fulvous brown; throat dull yellow; claws short, blunt, nearly laminar. Inhabits Java.-Horsf. Jav.vii.

L. marina, Erxleb. Desm. The Sea Otter. Fur blackish, shining; body very long; tail about a third of the length of the body; hind feet very short.-Shaw, i. pl. 101.

Var. A. With white head.-Dr Fleming, in his Philosophy of Zoology, makes a separate genus of this species under the name of Enhydra, and places it and the genus Lutru alongst with the seals.

\section{2d Division.-Tro tuberculous flat teeth behind the great. carnivorous tooth in the upper jaw.}

\section{Gen. 73. Canis, Lin. Cuv. Geoff.}

Incisors $\frac{6}{6}$, canines $\frac{1}{1}-\frac{1}{1}$, molars $\frac{6}{7}-\frac{6}{7}=42$. The three first molars in the upper jaw, and the four in the lower, small, edged; the great carnivorous tooth above bicuspid, with a tubercle on the inner side; two tuberculous teeth behind each of the large carnivorous ones; muzzle elongated; tongue soft; ears erect; fore-feet pentadactylous; hind feet tetradactylous; teats inguinal and ventral.

$$
\text { * Dogs.-Pupils of the eyes round. }
$$

C. familiaris, Lin. Desm. Tail curved upwards; muzzle more or less lengthened; fur varying in the nature of the hair, and of various colours; tail generally tipped with white.

The dog, distinguished by its curved tail, runs into endless varieties in point of size, form, and the colour and quality of the hair. The domestication of this animal is, in Cuvier's opinion, the most complete, the most singular, and the most useful conquest man has ever made. All the species has become his peculiar property; and each individual, devoted to his master alone, accommodates itself to his manners, protects his goods, and remains attached to him till death. This connection arises not from constraint, nor from the want of man's protection; for the dog has natu. rally powers of defence and attack superior to most of the quadrupeds, but from a species of confidence approaching to friendship. Its strength, its speed, and its smell, have made it a powerful ally in the subjugation of the other animals, and it is the only animal which has followed man through every quarter of the globe, and the only one whose existence and propagation does not seem to be determined by certain limitations of latitude.

Some naturalists have thought that the dog is derived from the wolf, and others that it has originated from a domesticated chacal, and there is no doubt but that both of these animals are capable of being tamed and rendered useful; but dogs which have been left in uninhabited islands and become completely wild, neither resemble the one nor the other, The wild dogs, and those of people in the first stage of civilization, such as the inhabitants of New Holland, have their ears erect; which has led to the supposition that the European races nearest the original type are the shepherd's dog and the Pomeranian dog; but the comparison between their craniums approach them more to the matin of Buffon (C. laniarius, Lin.) and the Danish dog, the harrier, the pointer, and the turnspit, which differ but little from them except 
in size and the proportion of the members. The greyhound seems most removed. The shepherd's dog and the Pomeranian wolf dog have the erect ears of the wild dogs, but with a greater developement of the cranium, which is still further developed in the Spaniel family, and with an increase of intelligence. M. Desmarest, from having remarked in an immense number of domesticated individuals, that when white is one of the colours of the tail, the tip is always white, and from having also remarked that all the wild species have the end of the tail white, is inclined to believe that this marked character is derived from the primitive race, and has descended to our domestic varieties. The Antarctic dogs lately brought to Europe were distinguished by the tip of the tail being white.

The young are born blind, and they attain their growth in two years. The period of gestation is two months, and they bring forth from six to twelve young. The $\operatorname{dog}$ is old at 15 years, and seldom lives beyond 20.

M. F. Cuvier divides the varieties of the dog into three groups, each differing materially in the shape of the head, and the length of the jaws and muzzle.

Section 1. Matins.-Head more or less elongated; parietal bones approaching in an insensible manner; condyles of the lower jaw in a line with the upper molar teeth.

Var. A.-C. F. Australasiae, Desm. The Dingo. Size and form of the shepherd's dog, with the head resembling that of the fox.

Var. B.-C. F. Sumatrensis, Hardwicke. Muzzle like the fox : nose pointed, eyes oblique, ears rounded, very hairy ; tail bushy, pendulous.-Shaw, i. t. 78.

Var. C.-C. F. laniarius, Lin. The Matin. Head elongated, forehead flat, ears erect at their base and half drooping. Crossed with the bull-dog the offspring is the English mastiff.

Var. D.-C. F. danicus, Desm. Body generally white, marked with numerous small round black spots.

Var. E.-C. F. grajus, Lin. The Greyhound. Forehead very low ; muzzle much elongated; limbs long and slender, feet frequently wanting the fifth toe.

To this family belong the following subvarieties:-1. The Irish greyhound, of a brownish white colour and of large size.-2. The Scottish greyhound, with the hairs slightly curled and wiry.-3. The Russian greyhound, with long and thick bair, and tail twisted spirally.-4. The Italian greyhound.-5. The Turkish greyhound, with the skin nearly naked.

\section{Section 2. Spaniels.-Head moderately elongated; parietal bones diverging.}

Var. A.-C. F. Extrarius. The Spaniel. Ears large and pendant ; tail elevated; fur of varying length in different parts of the body; colour whitish, with brown or black patches. Employed in the chase as a setter, for which it is qualified by its exquisite powers of smell.

The subvarieties are the Alpine Spaniel, the Newfoundland Spaniel, the Calabrian $\mathrm{dog}$, all of large size, and a number of smaller races: The group of Spaniels seem to have been originally from Spain, whence the name.

Var. B.-C. F. aquaticus, the Barbet Great Water Spaniel, or poodle. Two subvarieties, the Little Barbet and the Griffon.

Var. C.-C. Gallicus. The Harrier. Peculiar for its fine scent.

Var. D.-C. avicularius, the Pointer.

Var. E.-C. vertagus, the Turnspit.

Var. F.-C. domesticus, the Shepherd's dog.

Var. G-C. Pomeranus, the Wolf dog.

Var. H.-C. Sibiricus, the Siberian dog.

Var. I.-C. Borealis the Esquimaux dog.

Var. K.-C. Americanus, the Alco.

Section 3. Muzzle more or less truncated; cranium much clevated; frontal sinuses large; condyles of the lower jaw placed above the line of the upper molars.

Var. A.-C. molossus, the Bull-dog. 
Var. B.-C. Anglicus, the Mastiff.

Var. C.-C. fricator, the Pug-dog.

Var. D.-C. Islandicus, the Iceland dog.

Var. E.-C. variegatus, the little Danish dog.

Var. F,-C. hybridus, the shock dog.

Var. G.-C. Britannicus, the black and tan terrier. Sub-var. the Scottish terrier.

Var. H.-The Artois dog.

Var. I.-C. Andalusia, the Alicant dog.

Var. K.-C. Agyptius, the Egyptian dog.

C. lupus, Lin. Desm. The Wolf. Tail straight ; fur gray fawncoloured, with a black stripe on the fore legs of the adult; eyes oblique. Body about $3 \frac{1}{2}$ feet long, Inhabits the forests of Europe.-Shan, i. pl. 75.

Var. A.-With the fur white. The hair of wolves turns white with age, and those in northern latitudes become white in winter.

However ferocious in its savage state, an instance related by M. F. Cuvier demonstrates that by education the wolf is susceptible of affection. A young wolf, brought up like a dog, became familiar with every person he was in the habit of seeing. He followed his master everywhere, seemed to suffer from his absence, was obedient to his voice, and differed in nothing from the tamest of domestic dogs. His master being obliged to travel made a present of him to the Royal Menagerie at Paris. Here he was shut up in a compartment, and remained for many weeks without exhibiting the least gaiety, and almost without eating. In time, however, he attached himself to his keepers, and seemed reconciled to his fate, when after an absence of eighteen months his master returned. At the first word he uttered the wolf, though it did not see him in the crowd, recognized his voice, and testified his joy by his motions and cries. Being set at liberty he overwhelmed his old master with caresses like the most attached dog. His master being obliged to quit him a second time, the same symptoms of regret appeared. Three years more elapsed, and the wolf was reconciled to his confinement and to the company of a young dog which had been given him for a companion. About this time, whicli would have obliterated in most dogs the remembrance of their master, the gentleman again returned. It was evening, and all was shut up. But the moment the creature heard his former master's voice, he indicated his recognition by the most impatiert cries. The place being opened, the wolf rushed forward, placed his fore-feet on the shoulders of his earliest friend, licked every part of his face, and threatened with his teeth his keepers who approached, and to whom previously he had been testifying the warmest affection. A separation having again taken place the affectionate animal became in consequence sad and immoveable, refused sustenance, and his death was feared as the result. At the end of a week he was so reduced as was scarcely to be known. Time, however, again soothed his feelings, and his keepers gradually acquired his confidence.

C. Lycaon, Lin. Desm. The Black Wolf. Tail straight; body all black. Inhabits the mountainous parts of Europe. and North America.-Griffith's An. King. ii. 318.

Var. A.-Americana. Black, with a white spot on the breast.

C. Javanicus, Desm. Fur of a brown fawn-colour, blackish on the back, feet, and tail ; ears pretty small. Java.-F. Cuv. Dict.Sc. Nat. viii. p, 557.

C. jubatus, Desm. The Red Wolf. Fur of a cinnamon red; a short mane along the back of the spine. Body four feet four inches long. Paraguay.-Cuv. Reg. An. iv. pl. 1.

C. Mexicanus, Desm. Fur ash-coloured, variegated with yellowish spots, and black lateral stripes.-Inhabits South America.

C. pictus, Desm. (Hyena picta, Penn.) Fur variegated with large 
spots of black, brown, and white. Size of the European wolf, -Inhabits the South of Africa.

This species forms the type of a genus, according to $\mathrm{Mr}$ Brookes, under the name of Lycaon.

C. Antarcticus, Shaw, Desm. Fur reddish ; tail at base red, middle black, tip white. Falkland Islands.-Penn. Quad. t. 29.

C. cancrivorus, Desm. Fur ash-coloured, waved with black above, yellowish white underneath. Guiana.-Buff. Sup. vii. pl. 38.

C. aureus, Lin. The Chacal or Jackal. Yellowish gray above, whitish below; tail bristly, black at the extremity. Inhabits the warmer parts of the Old Continent.-Buff. Sup. vi. pl. 16.

C. corsac, Lin. Fur gray fawn-colour above, yellowish white beneath; tail very long, black at the tip. Inhabits deserts of Tartary.-Buff. Sup. iii. pl. 17.

C. mesomelas, Desm. The Cape Chacal. Fur fulvous brown, with a triangular blackish gray patch from the shoulders to the tail; tail touching the ground. Cape of Good Hope._Shaw, i. pl. 79.

C. anthus, Desm. Fur gray, sprinkled with yellow spots; tail fawn-coloured, with a longitudinal black line at its base. Inhabits Senegal.-F. Cuv. Mam. xvii.

* * Foxes._-Pupils of the eyes long; tail long and bushy.

C. vulpes, Lin. The common Fox. Fur fawn-coloured above, white beneath ; behind the ears black ; tail bushy and terminated by black hairs. Inhabits the Northern parts of the Old and New Continent.-Shaw,

Var. A.-C. alopex. Fur thicker, and of a deeper red.

Var. B.-C. crucigera. With a black cruciform mark across the shoulders and down the spine.

The fox is one of the most widely distributed animals, and is found in all the temperate and northern regions of the old and new world. With one exception the structure of the eye, the organization of the fox and dog are similiar. The pupil contracts in a strong light, and assumes a circular form only during twilight or at night. Hence the fox preys by night; and notwithstanding the persecution he undergoes, the extreme cunning of the fox, which has become proverbial, enables him to preserve his race where other animals would have been extirpated. The fox passes the day in his hiding-place, and sallies forth at night along the fields to surprise the partridge on her nest, or the hare in her form. He lies in ambush near the burrows of rabbits, and when game of this description fails, he approaches the farmyards and carries off the poultry, or feeds on tlie refuse of the kitchen. Distrustful to excess, he is not to be deceived by the snares which may be laid for him; and the severest hunger will not prompt him to approach a bait which may lead him into a snare. Gestation continues from sixty to sixty-four days; at three or four months the young foxes quit their burrow; and at two years their growth is completed.

C. lagopus, Lin. The Arctic Fox. Fur very long, thick and soft, uniformly ash-coloured or brown in summer, white in winter. Inhabits the Arctic Regions.-Bewick, Quad.

C. argentatus, Desm. Silvery Fox. Fur soot black, spotted or shaded with white; extremity of the tail white. Inhabits North America and Asia,-F. Cuv. Mam.v. 
C. decussatus, Geoff. Fur variegated with black and white above, with a black cross on the shoulders.-Inhabits North America.

C. Virginianus, Gmel. Gray Fox. Body entirely silvery gray, with a shade of red about the ears. North America-Catesby, ii. t. 78.

C. fulvus, Desm. Fur reddish or fulvous ; breast gray ; face of the fore-legs and feet black, with fulvous toes; tip of the tail white. United States.-Man. p. 203.

C. velox, Say. Fur fulvous; head above ferruginous. About onehalf the size of the preceding.-Long's Exped. i. p. 486.

C. cinereo-argenteus, Lin. Upper part of the body grayish black ; ears and sides of the neck bright red; throat and cheeks white; tail yellow, mixed with black. N. America.-Schreb. tab. 92, A.

C. Niloiicus, Geoff. Body reddish above, gray below, behind the ears black; legs fulvous. Inhabits Egypt.-Desm. Mam. 204.

C. megalotis, Cuv. Fur gray; ears very large, broad and long; a line of longer blackish hairs on the spine; feet black. Cape of Good Hope.-Griff: ii. 374.

C. Brucei, (Fennecus Brucei, Desm.) Bruce's Fennec. Fur dirty white, belly lighter; ears thin, margined with white hairs. Inhabits Abyssinia.-Shaw, i. pl. 80.-M. Desmarest makes a genus of this species under the name of Fennecus.

Gen. 74. Viverra, Lin. Cuv. Geoff. Desm.

Incisors $\frac{6}{6}$, canines $\frac{1}{1}-\frac{1}{1}$, molars $\frac{6}{6}-\frac{6}{6}=40$. Three false molars in the upper jaw, conical and compressed, a large carnivorous bicuspid tooth, and two tuberculous ones; in the lower, four false molars, one bicuspid and one tuberculous; head long; muzzle pointed; feet pentadactyle; claws semiretractile; anal pouch more or less deep.

Sub-Gen. 1. Crvetres, proper. Anal pouch very deep, divided into two sacs, filled with a musky secretion.

V. civetta, Lin. The Civet. Fur gray, with brown or black stripes and spots; a mane along the dorsal line. Inhabits Africa.Shan, i. pl. 95.

The odoriferous substance produced by the Civet forms in the east an object of commerce. This substarce is secreted in a bag or pouch between the anus and parts of generation, and is similar in both sexes. It opens externally by a narrow cleft, which conducts into two cavities, each of which might contain an almond. The internal surface of these bags is slightly covered with hair and porous, and the musk is exuded from these pores into the bag. When the bag is nearly full the animal has the power of compressing it so as to extrude the superfluous part of the secretion.

V. zibetha, Lin. The Zibet. Fur gray; legs transversely spotted with brown; throat white, with two black bands on each side; no mane; tail annulated with black. India._Shan, i. pl. 95.

V. rasse, Horsf. Fur yellowish gray ; neck obscurely banded with black lines; feet brown. Inhabits Java.-Horsf. Java, vi. 
Sub.-Gen. 2. Anal pouches reduced to a simple fold of the skin.

V. genetta, Lin. Fur gray, with small round and elongated black spots; tail annulated with black. Inhabits South of Europe.Shaw, i. pl. 96.

It is probable, from the different synonyms applied to this animal, and the very different parts of the world where it is found, that the individuals described are more than simple varieties, though Baron Cuvier is inclined to consider them as such.

V. fossa, Lin. Fur reddish gray, with yellowish brown spots, and four longitudinal lines on the back. Madagascar.-Shaw, i. pl.96.

V. fasciata, Desm. Fur yellow brown, with brown spots disposed longitudinally.-Shaw, i. pl. 97.

V. musanga, Raffles. The Musang. Fur variegated with ash-colour and black; back with faint black bands; head, feet, and tail black; point of the muzzle white. Sumatra.-Lin. Trans. xiii.253.

V. Indica, Geoff. Desm. Fur yellowish white, with eiglt narrow longitudinal brown bands. India._Shaw, i. pl. 96.

V. gracilis, Desm. (Prionodon gracilis, Horsf.) Fur clear fawncoloured, with four broad brown transverse bands; tail annulated with black; head elongated; muzzle pointed. Inhabits Java._ Horsf. Zool. Res. fas. i.

V. striata, Desm. (Viv. fasciata, Lin.) Fur marked with six brown bands, pretty broad, upon a yellowish bottom. Coromandel.-Buff. Supp. vii. pl. 57.

V. Bondar, Blainv. Fur yellowish, hairs tipped with black; dorsal line, and two narrow parallel lines on each flank black. Bengal. Desm. Mam. p. 210.

V. hyenoides, Cuv. (Proteles Lalandii, Isid. Geoff.) General aspect of the hyena. Fur gray; small mane; narrow transverse black bands on the flanks, thighs and legs, Cape of Good Hope. -Mem. Mus. ii. 5.

Sub-Gen. 3. Paradoxurus, F. Cuv.-No anal pouch, plantigrade, claws half retractile, tail convolute.

V. nigra,'(Paradoxurustypus, F. Cuv.-V.musanga, Raffles.) Body blackish; a white spot above and below the eyes; tail black. India.-Griff. ii. 412.

V. albifrons, (Par. albifrons, F. Cuv.) The Bintourong, Raffles. Fur formed of a mixture of long white and black bristles, except the head and limbs, where it is short; forehead and muzzle nearly white; a black spot inclosing the eye. India.-Lin. Trans. xii..

V. aurea, (Par.aureus, F. Cuv.) Fur uniform golden yellow, hair very long-Griff. Syn. 159.

V. prehensilis, Blainv. (Par. prehensilis. F. Cuv.) Fur yellowish green, with dorsal line, tip of the tail and spots black.-Bengal.

Gen. 75. Herpestes, Illig.-Viverra and Mustela, Lin.Ichneumon, Lacep.

Incisors $\frac{6}{6}$, canines $\frac{1}{1}-\frac{1}{1}$, molars $\frac{5}{5}-\frac{5}{5}=36$. Body elongated; 
anal pouch large ; fect pentadactyle, semipalmated, with nails partly retractile.

H. Mungos, Desm. (Viv. Mongoz, Lin.) Indian Ichneumon. Fur marked on the back with 12 or 13 brown transverse bands, separated by as many reddish bands; tail pointed. India.-Buff. xiii. pl. 19.

H. Edwardsii, Desm. Back and tail olive, annulated with brown; muzzle reddish brown; tail pointed. Inhabits India.-Edwards Birds, t. 199.

H. griseus, Desm. (Viv. Cafra, Lin.) Fur brownish gray and uniformly speckled with reddish brown from the annulations of the hair; tail pointed. Southern Africa.-Buff. Sup. iii. pl. 27.

H. galera, Desm. (Mustela galera, Lin.) Guinea Weasel, Penn. Fur deepish brown, speckled with yellow; fur of the tail of equal thickness its whole length. Madagascar.-Penn. Quad. ii. 53.

H. Javanicus, Geoff. Fur chestnut brown, spotted with yellow white; head and legs chestnut. Java.-Desm. Mam. 212.

H. ruber, Geoff. Fur very bright ferruginous red, especially on the head._Geoff. Hist. Nat. ii. 139.

H. major, Desm. (Ichneumon major, Geoff.) Large Ichneumon. Fur chestnut brown; hair annulated with yellow; tail brown, pointed.-Buff. Supp. iii. pl. 26.

H. Pharaonis, Desm. (Viv. ichneumon, Lin.) The Ichneumon. Fur of chestnut and fawn colour, each hair being annulated alternately with these tints; feet and muzzle black; tail long, tufted. Inhabits Egypt.-Shaw, i. pl.92.

The Ichneumon was well known to the ancients, and was venerated in Egypt for its destruction of the reptile species, and particularly of the eggs of the crocodile. In Egypt it is often seen at the close of the day gliding through the ridges or inequalities of the ground in search of its prey. It never limits itself to the momentary gratification of its appetite, but destroys every living thing within its reach, which is too feeble to offer effectual resistance. In domestication it acquires an attachment to the houses into which it is introduced, never wanders, recognizes the voice of its master, and is pleased with the caresses bestowed on it.

\section{Gen. 76. Suricata, Desm.-Viverra, Lin.}

Incisors $\frac{6}{6}$, canines $\frac{1}{1}-\frac{1}{1}$, molars $\frac{6}{6}-\frac{6}{6}=40$. Body elongated; feet tetradactyle, with strong nails for digging; ears small; pouch around the anus; tail long and slender.

S. Capensis, Desm. (Viv.tetradaclyla, Lin.) Hairs annulated with brown, white, yellowish, and black. About a foot long. Cape of Good Hope-Shaw. i. pl. 93.

3d Division.-Without a tuberculous tooth belind the great carnivorous tooth in the lower jaw.

Gen. 77. Hyana, Cuv. Briss. Geoff-Canis, Lin. Erxleb.

Incisors $\frac{6}{6}$, canines $\frac{1}{1}-\frac{1}{1}$, molars $\frac{5}{4}-\frac{5}{4}=34$. Fect tetradactyle ; nails not retractile ; logs long; eyes projecting; cars large ; a glandular pouch at the anus. 
H. vulgaris, Desm. (Canis hyana, Lin.) The striped Hyæna. Fur dirty gray, striped transversely with brown on the flanks and legs; a ridge of stiff hairs along the dorsal line. Inhabits Barbary, Egypt, \&c.-Shaw, i. pl. 78.

The voracity of this animal, and its preference of the flesh of dead carcasses to living prey, have been often noticed by travellers. But its ferocity has been overrated, for it is capable of being tamed; and according to Barrow the spotted hyæna is used in the district of Sehneeberg at the Cape of Good Hope for the purposes of hunting. In some countries it is by no means uncommon to see chacals, hyænas, dogs, and vultures feeding on the same carcase.

H. Capensis, Desm. (Canis crocuta, Lin.) Spotted Hyæna. Fur dingy gray, with round brown spots on the flanks and thighs; stiff hair on the dorsal line. Inhabits Cape of Good HopePenn. Quad. pl. 17.

H. rufa, Cuv. Fur red, spotted with blackish._-Country unknown.

H fossilis, Cuv. The Fossil Hyæna. About a third larger than the common hyæna. Bones found in various caverns in Europe. B.-Cuv. Rech. iv. part. 4, pl. 1 .

Gen. 78. Felis, Lin. Cuv. Geoff. \&c.

Incisors $\frac{6}{6}$, canines $\frac{1}{1}-\frac{1}{1}$, molars $\frac{4}{3}-\frac{4}{3}$, or $\frac{5}{3}-\frac{5}{3},=30$ or 28 . Five toes on the fore-feet; hind-feet tetradactyle; nails retractile; head short; four molars on each side of the upper jaw, the last tuberculous and very small; three in the lower jaw; ears large pointed.

\section{Fawn-coloured, and vithout spots.}

F. Leo, Lin. The Lion. Fur fawn-coloured, with a tuft at the extremity of the tail; neck of the male furnished with a long thick mane. Body from five to eight feet long. Inhabits Africa and some parts of Asia.

Var. A.-The Senegal lion. Fur lighter and brighter.

Var. B.-South African lion. With a black mane.

Var. C.-Asiatic lion. Rather less than the lion of Africa; mane yellow, and much more scanty.

The bodily strength of the lion, his carnivorous regimen, and predaccous habits, place him at the liead of the beasts of prey. Less savage than the tiger and other carnivorous animals, the lion seems to derive no gratification from the destruction of animal life beyond the immediate cravings of appetite; and hence, compared with the cruel dispositions of many of the minor inhabitants of the forest, he has acquired a character of generosity superadded to his courage, which has long made him be reguarded as the noblest of the feline race. Unlike the tiger, whose social attachment lasts only during the period of reproduction, and whose thirst for blood often leads hin to destroy his own issue, the lion is permanently attached to his mate; while the maternal feeling of the lioness is strikingly displayed in the subsequent fury of this noble animal when by any accident she is " bereaved of her whelps."

The roar of the lion is said to be tremendous, and travellers in Africa have often witnessed its appalling effect on the oxen of their waggons and other animals, though in comparative safety. When in the act of seizing his prey, this roar is heightened into a screan on the fatal leap. This power of voice is said to be useful to the lion, as the terrific sound raises the other animals from their hiding-places, and, as he does not hunt by scent, exposes their distracted flight to their enemy. The mode of his attack is generally, however, by surprise. Approaching slowly and silently till within a leap of his prey, the lion springs with a force which is thought 
in general to deprive its victim of life. The muscular strength of the lion is such, thut he is capable of carrying off a horse or a buffalo; and by the power of his limbs alone he is said to be able to break the spine of a horse.

In confinement the lion shows unequivocal marks of gratitude and affection to the person who serves him with food. The instance mentioned by Seneca, and of which he was personally a witness, of a lion recognizing its former keeper in the Amphitheatre at Rome, where he was exposed for destruction, and protecting him, is well known; and instances are not wanting of their attachment to other animals. To the well-known case of a lion in the Tower of London, which refused all sustenance and died, on the oceasion of the death of a little dog which had long shared his den, many others might be added; and Mr Griffith states on the authority of Major Smitl, that that gentleman " had met with eleven instances of different lions which have protected and fostered dogs, and but a single one of the tiger exhibiting a similar kindness of disposition." The exhibition of a young lion and a lamb in one inclosure of a travelling menagerie, may be mentioned as a proof how far early education can overcome the carnivorous propensity in an animal not cruel bcyond the imperious necessity of supplying itself with food.

The lion is now found chiefly in Africa; in Asia,'excepting some districts between India and Persia, and some parts of Arabia, they are rare. The Asiatic variety is of a uniform yellow colour, and the manc, more scanty than in the African species, is also yellow. The progress of population, and the destruction of game, has diminished the number of species, or extirpated them entirely in countries where they formerly abounded, and few are now seen in Europe in conmparison to the numbers which were exhibited in the Roman Circus. Scylla caused one hundred, all males, to be turned out for the amuscment of the Roman people ; Pompey six hundred, of which one hundred and fifteen were males; and Cæsar four hundred. The numbers seem not to have been much reduced under the first Emperors. Adrian often exhibited one hundred in the Circus; Antonine on one occasion one hundred, and Marcus Aurelius a like number; Gordian the third had seventy which were trained; and Probus liad one hundred of both sexes.

The period of gestation in the lioness is about one hundred and eight days. They are brought forth with the eyes open; but the ear does not become completely erect for two months. They arrive at maturity in five years, and are then nearly eight feet long. When young, the lion has no trace of the mane or of the tuft at the end of the tail. A male lion and tigress confined in one coinpartment, in the menagerie of Mr Atkins, has twice produced cubs, of which excellent figures are given in Griffith's Animal Kingdom, ii. 447.

F. concolor, Lin. The Puma or American Lion. Fur fawn-coloured; without mane or tuft at the end of the tail. About $3 \frac{1}{2}$ feet long. Inhabits the warm and temperate parts of America.Wilson's Illustrations of Zoology, No. i. pl. 1 .

\section{Large, with transverse bands of a darker colour.}

F. tigris, Lin. The Tiger. Fur clear fawn-colour above, white below, striped on the body with irregular narrow Llack bands; hairs about the cheeks very long. Body about five feet long. Inhabits Bengal, \&c.-Griff. i. 440.

Var. A. white, with the stripes of a more opaque white-Griff. An. King. ii. 444.

This animal is the scourge of Asia and the Indian islands. Ferocious in a very high degree, its speed and strength is such as to enable it to seize a man on horseback, and drag or rather carry him in its mouth by bounds or leaps to the nearest jungle or forest. The tiger, unlike the lion, does not confine itself to killing single prey, but attacks, with a cruel avidity for blood, all within its reach. In confinement, however, when taken young, it grows familiar, and exhibits affection and gentleness to its keeper.

3. Large, fawn-coloured, with brown or black round spots. F. onca, Desm. Gmel. The Jaguar. Fur fawn-coloured above, whitish beneath: body marked with open circles of black, containing 
a central spot, the circles disposed in five or six parallel horizontal lines. Inhabits America.-Shan, i. pl. 84.

Var. A. Felis nigra, Gmel. Fur blackish, with the spots deeper black.

The Jaguars are solitary animals, or are met with only in pairs. They inhabit thick forests in the neighbourhood of great rivers, and if driven by their wants to seek for food in the cultivated country they generally do so by night. They will attack cows and even bulls of four years old ; but horses seem their favourite prey. During the residence of D'Azara in Paraguay no less than six men were destroyed by this formidable animal, two of whom were at the time before a large fire.

F. nebulosa, Griff. (F.microcelis, Horsf.) The Clouded Tiger. Head small ; body long, heavy; tail thick and annulated; body covered with large irregular patches, deeper than the ground colour. Inhabits Sumatra.-Griff. An. King. p. 450.

F. pardus, Lin. The Panther. Fur pale fawn-colour above, with six or seven rows of rose-formed spots, forming on the flanks clusters of five or six spots. Inhabits Northern Africa.-Sham, ii. pl. 84.

F. leopardus, Desm. The Leopard. Fur fawn-coloured above, white beneath, with at least ten rows of rose-formed black spots on each flank. Inhabits Africa.-Shaw. i. pl. 85.

F. jubala, Lin. The Hunting Leopard. Fur fawn-coloured, covered with small black round spots, not running into one another; a slight mane. Inhabits Asia.-Shan, i. pl. 86.

The Hunting Leopard, it is said, is conveyed in a corriage, or on a pad behind the saddle of a horseman, with a hood over the eyes, to the field, and when an antelope is started the hood is taken off, and it is dispatched in pursuit. It follows by leaps or bounds, and if unsuccessful in taking its prey after a few efforts, declines the pursuit and returns to its keeper. A tame specimen described by M. F. Cuvier was accustomed to go at large in a park, and associated with children and domestic animals, purring like a cat when pleased, and mewing when he wished to call attention to his wants.

F. venatica, Griff. Brighter yellow than the last; no mane. Inhabits India.-Griff. Syn. 166.

F. uncia, Gm. The Ounce. Body whitish, covered with irregular black spots. Inhabits Persia.-Griff. An. King. ii. 469.

F. chalybeata, Griff. Fur wholly grayish liver colour, with numerous dark brown simple spots. Inhabits Chili._Griff.ii. 473.

\section{Middle-sized, with stripes and spots.}

F. mitis, Desm. (F. chati, F. Cuv.) The Chibigouazou. Fur with a fawn-coloured ground, with four rows of black dorsal spots; spots on the flanks small, bordered. Inhabits S. America.-Penn. Quad.pl. 31, fig. i.

Var. A._-Spots more numerous and smaller, with a large one on each cheek.

Var. B.-Parallel streak from the eye to the ear, with spots within it; tail annulated.

Var. C.-(F. catenata, Griff.) Body with long chain-like markings; belly and throat with black streaks.

F. pardalis, Lin. The Ocelot. Ground colour of the fur gray, with large fawn-coloured spots bordered with black, forming oblique bands on the flank. South America.-Shaw, i. pl. 88. 
F. macrourus, Major Smith. Ground colour ochrey gray, streaked with long patches; two streaks from the eye to the jaw. Inhabits Brazil.-Griff. An. King. ii. 478.

F. colocolo, Major Smith. Head flat and broad; body whitish gray, covered with lengthened streaks of black and tawny. Inhabits America._Griff. An. King. ii. 479.

F. melas, Peron and Lesueur. (Melas, Cuv.) Fur black above and below, spotted with deeper black; eyes of a silvery gray, almost white. Java.-Ann. Mus. xiii. 152.

5. Middle-sized, high on the legs, with broad and long ears, often terminated by a pencil of hairs; three upper molars without tubercles.

F. Lynx, Lin. The Lynx. Fur reddish yellow, with small dark brown spots; tail short, black at the extremity; long pencilled ears. Asia, Africa, and Europe-Buff. ix. pl. 21.

F. Canadensis, Geoff. The Canada Lynx. Fur grayish, with long hair; some black lines on the head. Canada.-Buff. iii. pl. 44.

F. rufa, Gmel. The Red Lynx. Fur reddish yellow, spotted with brown; tail short, white at tip. United States.-Schreb.t. 109, B.

F. fasciata, Desm. (Lynx fasciatus, Rafinesque.) Fur reddish brown, with blackish stripes and spots above.-N. America.

F. montana, Desm. (I ynx montanus, Rafinesque.) Fur grayish, without spots above, whitish with brown spots below; no pencils on the ears. United States.-Mam. 225.

F. Floridanus, Desm. (Lynx Floridanus, Rafinesque.) Fur grayish, flanks varied with spots of yellowish brown, and undulated black stripes; ears without pencils of hair. Florida.-Mam.225.

F. aurea, Desm. (Lynx aureus, Rafinesque.) Fur bright yellow, dotted with black and white spots; belly of a pale yellow without spot. Ears without pencils of hair. N. America.-Mam. 225.

F. caracal, Lin. The Caracal; The Lynx of the ancients. Fur wine-red above, white below; tail reaching to the heels; ears strongly pencilled, black on the outside, white within. Inhabits Africa and Asia.-Shan, i. pl. 91.

There are several varieties of this species, of which the chief are, 1. The Caracal of Algiers, described by Bruce, without pencils of hair at the ears, and with longitudinal stripes. 2. The Caracal of Nubia, of the same author, with the ears black on the outside; and 3. The Caracal of Bengal, of Edwards, with the tail longer than ordinary.

F. chaus, Guldenstadt, Desm. (Felis Lybicus, Oliv.) The Booted Lynx. Fur of a uniform gray yellow; hind part of the legs black; ears terminated by a pencil of black hairs. Inhabits Abyssinia.-Bruce's Travels, pl. 30.

6. Ears without pencils of hair, legs not very long-of small size.

F. Serval, Lin. Fur fawn-coloured above, white beneath, with numerous round black spots disposed in rows on each side; tail annulated. Inhabits Southern Africa._Schreb. tab. 108. 
F. galeopardus, Desm. (Serval, Cuv.) Fur fulvous above, whitish beneath, with black spots, of which those on the middle of the back are in four rows; tail annulated.-F. Cuv. Mam. liv. 1.

F. Capensis, Forster, Desm. Fulvous, with black spots of different sizes, and bands on the shoulders, back, and fore-legs; tail annulated; ears large, without pencils of hair. Cape of Good Hope. -Penn. Quad. i. pl. 1.

F. Cafra, Desm. Fur gray fawn-coloured above, lighter beneath; twenty brown transverse stripes upon each flank; feet banded with black.-Cape of Good Hope.

F. manul, Pallas, Gmel. Fur of a reddish uniform fawn-colour, with two black spots on the top of the head, and two stripes on the cheeks.-Inhabits Tartary.

F. Javanensis, Cuv. Desm. Fur gray-brown above, whitish beneath; four rows of elongated spots along the sides. Inhabits Java.-Horsfield's Java, No. 1.

The F. Bengalensis of Desmarest appears to be a variety of this species.

F. undata, Desm. Fur of a dirty gray, with numerous transverse brown or black bands; convexity of the ears reddish. Java, \&c. -Vosmaer, Monog. t. 13.

Var. A. - Spots much more irregular.-F. Sumatrana, Horsfield.

F. obscura, Fred. Cuv. Fur of a very deep brown black, with transverse numerous stripes, entirely black.-Cape of Good Hope.

F. yagouaroundi, Desm. Fur black brown, spotted with pale white. Inhabits S. America._Azara, Voy. pl. 10.

F. Mexicana, Desm. Fur of a uniform bluish-gray, spotted with black. S. America.--Buff. Sup. iii. pl. 43.

F. pajeros, Desm. Fur bright gray brown above, with reddish transverse bands on the throat and belly, and faint annulations on the feet.-Inhabits S. America.

F. eyra, Desm. Fur bright red, a white spot on each side of the nose; tail more bushy than the domestic cat.-Paraguay.

F. tigrina, Lin. Fur fawn-coloured above, whitish beneath; with five rows of longitudinal spots on the back, and oblique upon the flanks; tail irregularly annulated. Brazil.-Schreb. t. 106.

F. catus, Lin. The Domestic Cat. Ground colour of the fur of a gray more or less marked; with blackish longitudinal bands upon the back and transverse ones upon the flanks; lips and soles of the feet black; tail annulated, with the tip black.

The wild variety has long and tufted hair, particularly on the cheeks ; upper part of the body of a deep yellowish gray or brown, the under parts whitish; the back marked with a longitudinal black line, from which arise numerous indistinct transverse lines, extending parallel to one another to the flanks, the shoulders, and the thighs; similar smaller lines on the face and top of the head, and one across the cheeks from the external angle of the eyes; tail bushy, annulated with black, and with its tip of the same colour ; ears stift and erect ; and the pupils of the eyes contracting longitudinally. The wild cat lives in woods isolated or in pairs; climbs trees with facility, and 
preys on birds, leverets, rats, and other small quadrupeds. Numcrous varicties occur in domestication, distinguished by the arrangement of the colours, spots, or stripes. The most remarkable are those totally white or completely black; but the varieties most valued are those where the stripes are well-marked, hence called the tiger cat, and the spotted eat of Spain. The fur of this last is short and brilliant; the feet and lips flesh-coloured; and the fur spotted with irregular patches of pure white, lively red, and deep.black. Desmarest, however, has remarked in a number of instances that the females of this race are alone spotted with the three colours.

\section{FAMILY III.-AMPHIBIA.}

Feet short, enveloped in the skin, in form of fins; the posterior in the direction of the body; number of incisors variable; often six and sometimes four above, more generally four; and sometimes two below.

Gen. 79. Proca, Lin. Cuv. Geoff.-Otaria, Peron.

Incisors $\frac{6}{4}$ or $\frac{6}{2}$ or $\frac{4}{4}$, canines $\frac{1}{1}-\frac{1}{1}$, molars $\frac{5}{5}-\frac{5}{5}$ or $\frac{6}{5}-\frac{6}{5}$ or ${ }_{6}^{6}-\frac{6}{6},=30$, $32,34,36$, to 38. Molars all cutting or conical; five toes on all the feet; tail short; eyes large; nostrils closing at the will of the animal; head round; external ears wanting; four abdominal mammæ.

In arranging the seals as a family of his Carnassiers, Cuvier seems to have been led by the structure of their teeth rather than their general form and habits, which seem to connect them with the Cetacea. The structure of the seal is admirably adapted to its aquatic life. The nostrils are habitually closed, and the ears are shut when the animal dives. All its movements on land are slow and painful. In walking, or rather crawling, it presses the fore and hind parts of the body alternately on the ground, bending its back upwards. The claws of the anterior extremities assist it in climbing, but the hind feet are only used in swimming. Seals are easily tamed; and one of the individuais of the species $\boldsymbol{P}$. vitulina, preserved alive in the Menagerie at Paris, lived familiarly with two young dogs which were slut up with him; and when they leaped upon his back, barked and run from him, used to share in their anusement, trailing himself with painful effort along the stones and mud to approach them. In cold weather the dogs and seal lay closely together to keep each other warm.

Scals bring forth annually one or two young, which they suckle on land with much apparent tenderness. They live. in numerous flocks, and in the coupling season furious battles are fought by the males for the possessior of the females. They inhabit every sea, but chiefly those of the polar regions, and are killed in numbers for their skins and oil. The appearance of the seal on a desolate rock suckling its young has perhaps given rise to the fable of the Mermaid.

Sub-Gen. 1.-Proca, Peron. No external ears; incisors with a simple edge; molars edged; toes of the hind feet terminated by pointed nails, placed on the border of the membrane.

* Head furnished with cutaneous appendages, or a kind of trunk.

P. proboscidea, Peron. The Sea Elephant. Hair very thinly scattered, gray; claws of the fore-feet small ; occipital and sagittal ridges very prominent; incisors $\frac{4}{2}$. Twenty to thirty feet in length. Seas of New Holland.-F. Cuv. Mem. Mus. vi. t. 3, fig. 1.

P. Ansonii, Desm. (Phoca leonina, Lin.) Hair short, clear yellow; feet and tail black; claws of the fore-feet strong; incisors $\frac{6}{6}$. From 12 to 20 feet long. Pacific Ocean,-Schrel, tab. 83, A. 
P. Byronii, Blainville. The occipital and sagittal ridges and the mastoidal apophyses very prominent ; incisors $\frac{6}{2}$, the upper ones next the canines larger than the others.-Island of Tinian.

P. cristata, Desm. (Phoca leonina, Fab.) The Crested Sea Lion. Top of the forehead furnished with a moveable hood, susceptible of erection, and of covering the eyes and muzzle; incisors 4. Seven or eight feet long. Northern Seas.-Shan, i. pl. 73.

** Species without trunk or hood.

P. albiventer, F. Cuv. (P. leptonyx, Desm. P. bicolor, Shaw.) Fur above gray, variegated with yellow; yellowish white beneath; whiskers rigid; claws, especially those of the hind feet, small.Shaw, i. pl. 71.

P. Gronlandica, Muller, (P. oceanica, Cuv.) The Greenland Seal. Fur of the adult males whitish, marked with a large brown spot on the shoulders; claws strong, black; females and young covered with unequal, distant, angular spots. Inhabits the North Sea.-Shaw, i. pl. 71.

P. leporina, Desm. Fur yellowish; head and body covered with long and soft white hairs; claws of the fore-feet very strong. Inhabits the Northern Ocean.-Mam. 243.

P. lagura, Cuv. Fur gray, clearer on the sides and belly; whiskers black; tail long, thin, white.-Oss. Foss. v. 206.

P. vitulina, Lin. The Common Seal. Fur yellowish gray, thick, more or less waved or spotted with brown, according to the age; incisors ${ }_{4}^{6}$; claws strong. North Seas. Shav, i. pl. 70.-There are numerous varieties of colour in this species.

P. fotida, Mull. Fur of a pale brown, variegated with white above, dirty white beneath; hair rough; claws strong; incisors $\frac{6}{4}$. Inhabits the North Seas.-Buff. Sup. vi.pl. 45.

P. barbata, Mull. The Bearded Seal. Fur blackish; thumb of the hand shorter than the fingers; incisors $\frac{6}{4}$. Inhabits the North Seas.-Buff. vi. pl. 45.

Sub.-Gen. 2.-Otaria, Peron. Incisors $\frac{6}{4}$, canines $\frac{1}{1}-\frac{1}{1}$, large ; molars $\frac{6}{5}-\frac{6}{5}$, root simple, and a prominent conical point; external ears distinct.

P. jubata, (Otaria jubata, Desm.) Sea Lion. Fur yellow; neck of the male with a large mane; hind feet with the termination lobed. Inhabits the Pacific Ocean.-Shaw, ii. pl. 174.

P. ursina, Lin. (Otaria ursina, Desm.) Common Sea Bear. Fur brown; males maneless; the hind-feet furnished with long flaps of skin. Kamtschatka. This is the type of M. F. Cuvier's genus Arctocephalus.-Buff. Sup. vi. pl. 47.

P. Peronii. (Otaria Peronii, Desm.) Fur soft, blackish; the hind feet having only three claws apparent in the middle, ending in a five lobed membrane. Cape of Good Hope.-Buff. xiii. t. 53. 
P. coronata, Blain. (Otaria coronata, Desm.) Fur black, with yellow spots; a yellow band on the head and a spot on the muzzle; hind feet with five claws.

P. cinerea. (Otaria cinerea, Peron, Desm.) Fur ash-coloured, thick and rigid. Coast of New Holland.

P. albicollis. (Otaria albicollis, Peron, Desm.) Fur with a large white spot on the top of the back.-New Holland.

P. flavescens, Shaw. (Otaria flavescens, Desm.) Fur of a pale yellow; no nails apparent on the fore-feet; the hind feet with claws. Straits of Magellan.-Shaw i. pl. 73.

P. Falklandica, Shaw. (Otaria Falklandica, Desm.) Fur ash-coloured, shaded with white ; fore-feet clawless ; hind feet with four claws.-Inhabits Falkland Islands.

\section{Gen. 80. Trichecus, Lin. Cuv. Desm.}

Incisors $\frac{2}{0}$, canines $\frac{1}{0}-\frac{1}{0}$, molars $\frac{5}{5}-\frac{5}{5}=24$. Incisors small, deciduous; superior canines or tusks of large size, longer than the head, compressed laterally and arched; molars cylindrical, crown truncated obliquely; body elongated; head round ; muzzle large ; no external ears ; tail very short ; forefeet like fins, with five toes; hind feet horizontal ; toes enveloped in the skin.

T. rosmarus, Gmel. (T. manatus, Lin.) The Morse. Lips very thick; bristles rigid; hair very thin, short, reddish ; two enormous canines projecting downwards. Northern Ocean.-Shaw, i. pl. 78.

The Morses or Walruses are animals of very large size, sometimes eighteen feet long, and closely resemble the Phoca in their mode of life. They inhabit similar places, and are generally found together. They are gregarious animals, and are sometimes seen in vast multitudes on masses of floating ice in the Northern Seas. "They lie," says Captain Cook, " ir herds of many hundreds upon the ice, huddling one over the other like swine, and roar or bay very loud, so that in the night, or in foggy weather, they gave us notice of the ice before we could see it. We never found the whole herd asleep, some being always on the watch. These, on the approach of the boat, would wake those next to them, and the alarm. being gradually communicated, the whole herd would be awake presently. But they were seldom in a hurry to get away till after they had been once fired at. Then they would tumble one over the other into the sea in the utmost confusion."- " The female will defend her young to the very last, and at the expence of her own life, whether upon the water or upon the ice. Nor will the young one quit the dam though she be dead, so that if you kill one, you are sure of the other. The dam when in the water holds the young one between her fore-fins." These animals are killed for the sake of their oil.

\section{ORDER V.-MARSUPIALIA.}

Teeth different in the different genera. Young brought forth prematurely, often in a pouch formed by a fold of the skin of the abdomen of the females, inclosing the mammr; marsupial bones in both sexes; thumb of the hind feet sometimes 
wanting, sometimes very distinct, without nail, opposable to the other toes; scrotum of the males before the organ. of generation.

The general character of this Order is the marsupial pouch in the abdomen of the female, in which the imperfect germs of the young are deposited till their further developement. In this pouch the mammæ also are placed. Linnæus arranged all the species which he kncw under one genus, Didelphis, and their general resemblance afforded sufficient grounds for this arrangement. But on the discovery and examination of new species from Australasia, it was found that no common character could be formed from their teeth, fect, and organs of digestion, and that the differences in structure of these made it impossible to include them in any of the existing Orders. The presence of the abdominal pouch, therefore, and marsupial bones in both sexes, separating them from all the other quadrupeds, Cuvicr arranged these singular animals in a separate family of his Carnossicrs, but suggested their forming the type of a larger division; and we have accordingly followed Latreille in arranging the species as a separate Order.

\section{Gen. 81. Didelfhis, Lin. Cuv. Geoff. Desm.}

Incisors $\frac{10}{8}$, canines $\frac{1}{1}-\frac{1}{1}$, molars $\frac{7}{7}-\frac{7}{7}$, or $\frac{6}{7}-\frac{6}{7},=50$ or 48 . Two superior intermediate incisors larger than the others; lower incisors equal; canines strong, compressed; molars, the three first in the upper jaw triangular; the others crowned with points; head long and conical, muzzle pointed, mouth much cleft; ears large, rounded, almost naked; five toes on all the feet, nails long and bent; hind feet plantigrade, with the thumbs opposable, but destitute of nails; tail long, scaly, mostly deprived of hair.

\section{* Females with an abdominal pouch.}

D. Virginiana, Desm. Gmel. Virginian Opossum, Shaw. Fur woolly, fine, mixed black and white, with white lines; head nearly white; size of a rabbit. America.-Shaw, i. pl. 107.

D. Azarce, Tem. Fur of two sorts, one cottony underneath, and black at the tip; the other rigid and white; black round the eyes; the legs black; half of the tail hairy, the rest scaly. South America.-Tem. Monog. Mam. p. 30.

D. cancrivora, Lin. Desm. The Crab-eating Opossum. Fur yellowish, mixed with brown; forehead brown. Surinam.-Buff. Sup. vi. pl. 54.

D. Quica, Tem. Fur above blackish yellow; upper part of the head blackish, with three white bands; chin white; belly reddish. Size of a polecat. Brazil,-Tem. Mam. p. 36.

D. Opossum, Lin. Fur fawn-coloured above, whitish below; a pale white spot above each eye ; tail partly hairy. S. America. -Shan, i. pl. 108.

D. Philander, Schreb. Fur spotted with brown; head very short, muzzle blunt; head with a red central longitudinal band; eyes placed in a gray spot; tail naked.-Schreb. vii.t. 147. 
** Females without a pouch.

D. nudicaudata, Geoff. Desm. Fur gray, brown above, whitish underneath; a pale yellow spot over each eye; tail longer than the body, naked.-Inhabits Cayenne.

D. crassicaudata, Desm. Fur fawn or cinnamon-coloured, brighter over the eyes; tail thick at its origin, covered for a third of its length.-Paraguay.

D. cayopollin, Lin. Desm. Mexican Opossum. Fur yellowish gray above, whitish underneath, round the eyes and upon the nose ; tail brown, spotted with blackish, much longer than the body. Mexico. -Buff.x. pl. 55 .

D. lanigera, Desm. Fur woolly, almost the colour of tobacco above, whitish below; tail nearly triangular at its base, longer than the body, partly naked on its upper side. Eight inches long.-Paraguay.

D. murina, Lin. Desm. Fur yellowish gray above, paler underneath; eyes surrounded with brown; tail naked, as long as the body. Surinam.-Buff.x. pl. 52, 53.

D. cincrea, Tem. Fur short, ash-gray in the males, yellowish gray in the females, white beneath; tail much longer than the body. Brazils. - Tem. Mon.

D. dorsigera, Tem. Fur of a uniform brown colour; head long; tail hairy at the base-Tem. Mon.

D. tricolor, Geoff. (D. brachyura, Pallas.) Fur of a blackish brown on the back, reddish on the flanks, and white below; tail very short, all hairy.-Pall. Ac. Petrop. ii. t. 5.

D. brachyura, Geoff. Gmel. Fur deep red, brown above, and on the flanks, whitish below; tail half as long as the body.-Seba, i. t. 31 .

D. pusilla, Desm. The Dwarf Opossum. Fur mouse-colour, whitish below; tail longer than the body, naked, and of a white colour. Body three inches long.-Paraguay.

Gen. 82. Chrronectes, Illiger-Didelphis, Geoff. Cuv.

Incisors $\frac{10}{8}$, canines $\frac{1}{1}-\frac{1}{1}$, molars $?-?,=$ ? probably 50 , as in the Didelphi. Anterior molars pointed and cutting; muzzle pointed; ears naked; feet pentadactyle, the posterior plantigrade and palmated; thumb without a nail; nails of the toes sharp and bent; tail long, cylindrical, naked, scaly, and prehensile; abdominal pouch in the female.

C. palmata, Geoff. The Yapock. Fur brown above, with three gray transverse patches or bands; white beneath. Guiana.Griff An. King. iii. 35.

Gen. 83. Dasyurus, Geoff. Cuv. Desm.-Didelphis, Shaw.

Incisors $\frac{8}{6}$, canines $\frac{1}{1}-\frac{1}{1}$, molars $\frac{6}{6}-\frac{6}{6}=42$. Two first molars compressed and cutting, the others rough with points; head 
conical ; five toes on the fore-feet, with crooked nails; four on the hind-fcet, and short thumb without a nail ; tail long, covered with hair; an abdominal pouch in the females.

D. cynocephalus, Geoff. Desm. Fur yellowish brown; crupper marked with transverse black bands; tail compressed. Nearly four feet long. Van Dieman's Land._Lin. Trans. ix. pl. 19.

M. Temminck makes a new genus of this species under the name of Thylacynus.

D. ursinus, Geoff. Desm. Shaw. Fur black; tail not very long, slightly prehensile, naked below. Van Dieman's Land.-Lin. Trans. ix. pl. 19.

D. macrourus, Geoff. (Viverra maculata, Shaw.) Fur chestnut-cop loured, spotted with white; tail also spotted. About the size of a cat. New Holland.-Peron, Allas, pl. 33.

D. Maugei, Geoff. Fur olive-coloured, spotted with white; tail without spots.-New Holland.

D. Viverrinus, Geoff. Fur black, spotted with white; tail without spots. About the size of a rat. New Holland.-Shaw, i. pl. 111.

D. tafa, Geoff. (Viverrine Opossum, Shaw.) Fur uniform grayish brown, without spots. New Holland.-Shaw, i. pl. 111.

D. penicillatus, Geoff. (Didelphis penicillata, Shaw.) Fur ash-coloured, not spotted; tail black and tufted. New Holland.-Shan, i. pl. 113.

D. minimus, Geoff. Fur red, not spotted, with tail of the same colour.-Van Lieman's Land.

The last two species form the genus Phascogale of Temminck.

Gen. 84. Perameles, Geoff--Didelphis, Shaw.

Incisors $\frac{10}{8}$, or $\frac{10}{6}$, canines $\frac{1}{1}-\frac{1}{1}$, molars $\frac{7}{7}-\frac{7}{7}$, or $\frac{8}{6}-\frac{8}{6},=50$. Crowns of the molar teeth acutely tubercular; head very long; muzzle pointed; eyes lateral ; fore-feet with five toes, the three middle ones largest; the thumb rudimentary ; hindfeet very long, with four toes, two internal and very small, the third very robust; tail long, pointed; base thick and naked beneath, not prehensile.

P. nasuta, Geoff. Desm. Head very long; muzzle slender; nose prolonged; fur grayish brown, white beneath. Incisors $\frac{10}{6}$. New Holland.-An. Mus. iv. pl. 44.

P. Bougainvillii, Gaimard. Head long ; ears ovate, acute; body red above, gray beneath.-Griff. Syn. 195.

P. obesula, Geoff. (Didelphis obesula, Shaw.) Incisors $\frac{10}{8}$; head rather short ; forehead convex; fur reddish yellow, white below. New Holland.-An. Mus. iv. pl. 45.

Gen. 85. Phalangista, Geoff. Cuv.-Didelphis, Shaw, Gmel. Incisors $\frac{6}{2}$, canines $\frac{1}{0}-\frac{1}{6}$, or $\frac{0}{0}-\frac{0}{0}$, false molars or false canines 
$\frac{2}{3}-\frac{2}{5}$, or $\frac{8}{2}-\frac{8}{2}$, molars $\frac{5}{5}-\frac{5}{5}$, or $\frac{6}{5}-\frac{6}{5},=38$ or 40 . Forehead convex; feet pentadactyle, not united to the body by the skin of the flanks; anterior toes separate, armed with strong crooked nails; posterior with a large nailless thumb; tail naked, or covered with hairs; abdominal pouch in the females.

* Tail naked, scaly, and prehensile.

P. maculata, Geoff. (Didelphis orientalis, Lin.) Fur whitish, spotted with brown or black; size of a cat. Java.-Buff. xiii.t.11.

P. rufa, Geoff. (Did. orientalis, Lin.) Fur reddish or whitish, with a darker dorsal line. Java.-Buff. xiii.t. 10.

P. Papuensis, Desm. Fur gray, yellowish, white beneath; ears very small, hairy.-New Guinea.

P. ursina, Tem. Fur thick, black, with a yellowish shade.-Tem. Mam. t. 8.

P. Chrysorrhos, Tem. Fur blackish gray, with a black line on each flank, thick, cottony ; head pale ash-gray; rump and tip of the tail golden yellow. Island of Celebes.-Tem. Mam. p. 12.

\section{** Tail hairy.}

P. vulpina, Desm. The Lemurine Opossum. Fur grayish brown above; yellow gray on the head and shoulders; grayish beneath; tail tufted; tip black. New Holland.-Shaw, i. pl. 110.

P. Cookii, Cuv. Desm. Fur brown, or reddish gray above, white beneath; tail brown; the tip white; size of the polecat. Van Dieman's Land.-Cool's Voy. iv. pl. 8.

P. nana, Geoff. Desm. Fur reddish gray above, white below; tail brown. Van Dieman's Lảnd.-Desm. 268.

Gen. 86. Petaurista, Cuv. Geoff-Didelphis, Shaw.

Incisors $\frac{6}{2}$, canines $\frac{1}{0}-\frac{1}{0}$, or $\frac{1}{2}-\frac{1}{2}$, molars $\frac{6}{6}-\frac{6}{6}$, or $\frac{7}{6}-\frac{7}{6},=32$ or 34. Head rather long; eyes small; ears long; feet short, pentadactyle; the hinder ones with a large nailless thumb, and the two first toes short and united; nails compressed, arched, and very strong; skin of the sides extended, and uniting the extremities, so as to form a kind of parachute; tail long, hairy, not prehensile.

\section{* Tail round.}

P. taguanoides, Desm. (Didelph. petaurus, Shaw.) Fur very soft, gray brown above; throat and breast white ; tail brown, paler at the base. New Holland.-Shaw, i. t. 112.

P. macroura, Desm. (Did. macroura, Shaw.) Fur grayish brown above, whitish beneath; tail slender, longer than the body. New Holland.-Shaw, i. pl. 113.

P. flaviventer, Geoff. Desm. Fur chestnut brown above, yellowish white beneath; tail round, a little longer than the body. New Holland.-Desm. 269. 
P. sciurca, Shaw. Fur ash-gray above; edges of the membrane and dorsal line deep brown, beneath white; tail reddish gray at the base, blackish at the extremity. New Holland.-Shaw, i. pl.113.

P. Peronii, Desm. Body brown above, white beneath; menbrane of the flanks brown; legs and end of tail white. New Holland. -Shaw, i. p. 500 .

\section{** Tail featlery.}

P. pygmaca, Desm. Fur uniform, mouse-gray, with a reddish cast on the back, whitish below. New Holland.-Shaw, i. pl. 114.

Gen. 87. Pororous, Desm.-Macropus, Shaw.

Incisors $\frac{6}{2}$, canines $\frac{1}{6}-\frac{1}{0}$, molars $\frac{5}{5}-\frac{5}{5}=30$. Four posterior molars in either jaw with blunt tubercles; head long and pointed; ears large ; upper lip cleft ; fore-feet short, with five toes; hind-feet long, with four toes, two of which united and small ; tail long, robust ; hair woolly ; an abdominal pouch in the female.

P. murinus, Desm. (Macropus minor, Shaw.) Fur brownish above, gray beneath. New Holland.-Shaw, i. pl. 116.

Gen. 88. Kangurus, Geoff. Lacep. Desm.-Macropus, Shaw.

Incisors $\frac{6}{2}$, canines $\frac{0}{0}-\frac{0}{0}$, molars $\frac{5}{5}-\frac{5}{5}=28$. Ears large, pointed; eyes large ; fore-legs very short, with five toes and strong nails; hind legs long, robust, with four toes; the two internal united and small, the central large with a strong claw like a hoof, plantigrade; tail very strong, with powerful muscles, not prehensile, but serving for locomotion; an abdominal pouch.

K. labiatus, Geoff. (Macropus major, Sharv.) Large Kangaroo. Fur ash gray above, white beneath ; a gray line across the chin; legs and upper part of the tail blackish. New Holland._Shaw, i. pl. 115.

K. fuliginosus, Peron, Geoff. Fur sooty brown above, grayish below; the legs and tail blackish. New Holland.-Desm. p. 273.

K. rufus, Desm. Fur woolly, clear red above, white beneath. New Holland.-Mam. 541.

K. rufo-griseus, Desm. Geoff. Fur reddish gray above, paler beneath; legs and end of the tail passing into brown; tail reddish. New Holland.-Mam. 273.

K. ruficollis, Geoff. Fur hare gray above, pure white beneath; neck and upper part of the shoulders red mixed with gray. King's Island.-Mam. 274.

K. Eugenii, Desm. Fur grayish brown above; front of the forelegs reddish, whitish below. New Holland. Perhaps the young of the former species?-Mam. 274.

K. fasciatus, Desm. Fur gray with a brown band across the back and loins. New Holland.-Peron. Voy. t. 27. 
K. Billardierii, Desm. Ears short, oval, rounded; fur gray brown above, reddish beneath; upper lip reddish.-Van Dieman's Land.

K. Brunii, Desm. Fur brown above, fawn-coloured beneath. Aroe Islands.-Shav, i. 402.

IK. pencillatus, Geoff. Fur above gray, with darker tints, beneath rufous brown; tail as long as the body, and tufted at the end. New Holland.-Griff. An. King. iii. 48.

Gen. 89. Phascolarctos, Blainville.

Incisors $\frac{6}{2}$, false canines $\frac{2}{0}-\frac{2}{0}$, molars $\frac{4}{4}-\frac{4}{4}=28$. Four intermediate teeth between the incisors and the upper molars; molars with four tubercles; ears large and pointed; feet pentadactyle; toes of the fore-feet in two groups, the thumb and index finger on one side, the three others on the opposite; thumb of the hind-feet large, nailless; the two next toes united.

P. fuscus, Desm. The Koala, Cuv. Fur of an uniform chocolate colour, long and thick. Size of a moderate dog. New Holland. -Cuv. Reg. An. iv. t. 1.

Gen. 90. Phascolomys, Geoff. Cuv.-Didelphis, Shaw.

Incisors $\frac{2}{2}$, canines $\frac{0}{0}-\frac{0}{0}$, molars $\frac{5}{5}-\frac{5}{5}=24$. Incisors strong and thick; molars with oval crown, divided by a furrow; body thick; head large, flat; ears short; eyes much separated; feet with five toes, the anterior armed with crooked and robust nails for digging; thumb of hind-feet very small, nailless; tail scarcely apparent; an abdominal pouch in the female.

P. vombat, Peron, Desm. The Wombat. Fur uniform grayish colour. Size of the badger. New Holland.-Desm. Mam. 276.

ORDER VI. GLIRES, Lin.-Rosores, Storr--Rodentia, Cuv.

Two large incisors in each jaw, separated from the molars by a vacant space; no canine teeth; molars with flat crowns or blunt tubercles; extremities, the posterior longest, terminated by unguiculated toes, the number varying according to the species; mammæ variable in number; stomach simple; intestines very long.

Section 1.-With complete clavicles.

Gen. 91. Castor, Lin. Cuv. Geoff.

Incisors $\frac{8}{2}$, canines $\frac{0}{0}-\frac{0}{0}$, molars $\frac{4}{4}-\frac{4}{4}=20$. Molars composed of a flat crown, with sinuous and complicated ridges of ena$\mathrm{mel}$; five toes on each foot, the anterior short and close, the voL. $I$. 
posterior longer and palmated; tail broad, thick, flattened horizontally, of an oval form, naked, and covered with scales.

C. fiber, Lin. The Beaver. Fur consisting of two sorts of hair, one coarse and brownish, the other downy, more or less gray. About two feet long. North America and Europe.-Penn. Brit. Zool. i. pl. 9.

The Beaver has been long celebrated for its intelligence and social instinct. It is found on the banks of rivers and lakes in North America, living in troops more or less numerous in a kind of huts, constructed near the margin of the water. They intercept the water, to form ponds attached to their dwellings, by strong arched dikes, of which the convexity is opposed to the current. These dikes are formed of stones, mud, and branches of trees. Their huts, composed of the same materials, are situ. ate on the margin of the ponds, and generally of an oval form, with a rounded top, the diameter of which is proportioned to the number of individuals who are its inmates. The entrance to this cabin is from the lowest part, descending into the water, through which alone they enter, the principal part of the dwelling being above its level. The beaver uses its teeth to cut the branches of trees necessary for its purpose, as well as to transport the different materials of its structure; and the combination of means to this end in a number of individuals has approximated in the minds of some the social instinct of animals to something approaching to reason. But in captivity the beaver shows nothing of the social instinct, and very little intelligence. The period of gestation in the beaver is four months, and it brings forth two or three young. They are at their full size in two years, and the duration of their life is about fifteen.

The beaver is subject to considerable variety of colour, and individuals have been noticed from totally black to different shades of yellow or fawn-colour and white.

A fossil species, the $\boldsymbol{C}$. trogontherium of Fischer, resembles in its characters the present species, though its dimensions seem to have been much larger.

\section{Gen. 92. Frber, Cuv. Geoff.-Mus. Gmel.}

Incisors $\frac{2}{2}$, canines $\frac{0}{0}-\frac{0}{0}$, molars $\frac{3}{3}-\frac{3}{3}=16$. Molars with a flat crown, and scaly angular zigzag plates of enamel; fore-feet with four toes and the rudiment of a thumb; posterior with five, edged with stiff and close bristles; tail long, compressed laterally, naked, except a few scattered hairs, and granular.

F. Zibethicus, Desm. (Castor Zibethicus, Lin.) The Ondatra or Musk Rat. Fur clear brown, tinged with red above, cinereous beneath. About the size of a rabbit. Canada.-Buff.x. pl. 1 .

Gen. 93, Arvicola, Desm.-Mus, Lin.-Lemmus, Geoff.

Incisors $\frac{2}{2}$, canines $\frac{0}{0}-\frac{0}{0}$, molars $\frac{3}{3}-\frac{5}{3}=16$. Molars with a fat crown and angular plates of enamel; ears large ; anterior toes with nails; tail round, hairy, almost the length of the body.

A. amphibius, Desm. (Mus amphibius, Lin.) The Water Rat. Fur blackish gray, slightly mixed with yellowish, lighter beneath; tail black. A little larger than the common rat. Old and New Continents. B.-Buff. vii. pl. 43.

Var. A. All black.-Var. B. With a large white spot on the shoulders.-Var. C. Black, feet covered with white hairs.

A. Argentoratensis, Desm. Fur of a brownish black, mixed with gray; tail brown, almost naked. Six inches long. Found near Strasbourg.-Buff. Sup. vii. pl. 70. 
A. Niloticus, Desm. Egyptian Arvicola. Fur brown, mixed with yellow, above yellowish, gray beneath; earslarge, naked. Mam.281.

A. albicaudatus, Desm. Fur brown, with the feet and upper side of the tail white.-Mam. 281.

A. vulgaris, Desm. (Mus agrestis, Lin.) The Field Mouse. Of a reddish ash-colour above, paler below; ears small and round. Furope and Northern Asia.-Buff. vii. pl. 47.

A. fulvus, Desm. (Lemmus fulvus, Geoff.) About four inches long; reddish yellow; belly and feet paler; tail not half the length of the body. France.-Mam. 282.

A. xanthognatus, Desm. Fur fawn-coloured, variegated with black above, cinereous beneath; cheeks yellowish. Hudsons Bay.Leach, Nat. Mis. i. t. 26.

A. cconomus, Desm. (Mus ceconomus, Gmel.) Fur brown above, passing into yellow on the flanks ; throat and belly white; tail onefourth the length of the body. Siberia.-Pall. Glir. pl. 14, A.

These little animals construct their burrows below the surface of the turf in the form of an arched chamber about a foot in diameter. To this chamber they make numerous small holes or entrances, and near this principal apartment they form magazines, in which they deposit in some cases from twenty to thirty pounds of roots, collected by the females during sunmer for their winter provision. The migrations of this species, like the Lemming, take place in vast phalanxes at uncertain periods, is conducted in the same manner, and is probably caused by excessive production and want of food. The natives of Kamtschatka often rob the hoards of these provident little animals, leaving a ridiculous present at the place in return.

A. saxatilis, Desm. Fur brown, mixed with gray above, deep gray on the sides, cinereous below; tail as long as the body. Siberia. -Pall. Glires, pl. 23, B.

A. alliarius, Desm. About four inches long; fur ash-coloured above, white beneath; ears large, almost naked. Siberia.Pall. Glires, pl. 14, C.

A. rutilus, Desm.. Rather less than the preceding; fur reddish above, dirty white below ; tail a third of the length of the body. Siberia._Pall. Glires, pl. 14, B.

A. gregalis, Desm. Fur pale gray on the back, mixed with long black hairs ; belly white; tail blackish, one-fourth the length of the body. Three inches long. Siberia.-Pall. Glir. pl. 17.

A. socialis, Desm. (Mus gregarius, Lin.) Fur pale gray above, white underneath; ears short, broad, almost naked. About three inches long; tail one inch. Deserts near the Caspian Sea.Pall. Glir. pl. 13, B.

A. Astrachanensis, Desm. Fur yellowish above, cinereous below. Four inches long; tail one inch. Astracan.-Mam. p. 285.

A. pumilio, Desm. Fur bright brown above, with four longitudiP. nal black bands. Cape of Good Hope.-Shaw, ii. pl. 133.

A. hortensis, Harlan. Fur above ferruginous brown, sides lead-coloured, yellow beneath; hair coarse; ears broad, oval. Inhabits Florida.-Faun. Amer. 138. 
A. palustris, Harlan. Fur dark grayish brown above, lead-coloured below; ears slightly edged with hair; tail short, slightly hairy. Inhabits the shores of the Delaware-Faun. Amer. 136.

A. Pennsylvanica, Ord. Fur brownish fawn-coloured above, grayish white beneath; eyes very small; ears short and round. Pennsylvania.-Wilson, Ornith. vi. t. 50, fig. 3.

A. Floridanus, Harlan. Fur lead-colour, mixed with black on the dorsal line, yellowish on the flanks ; ears large and membranous. Body about eight inches long. Florida.-Faun. Amer. 142.

This is the type of the genus Neotoma of Messrs Say and Ord, which differs from the Arvicolo in the teeth being furnished with roots.

Gen. 94. Lemmus, Cuv. Geoff.-Mus, Lin.

Incisors $\frac{2}{2}$, canines $\frac{0}{0}-\frac{0}{0}$, molars $\frac{3}{3}-\frac{3}{5}=16$. Molars with a flat crown and angular plates of enamel ; ears very short ; forefeet in some species with five, in others four toes, proper for digging; tail short and hairy.

L. Norvegicus, Desm. (Mus Lemmus, Lin.) The Lemming. Fur of a red fawn-colour, variegated with black and brown; five toes on the fore-feet. Norway and Lapland.-Pall. Glir.t. 12, A, B.

The migratory habits of these animals are very remarkable. They inhahit the alpine or mountainous parts of Lapland and Norway; nnd at particular but uncertain periods they descend into the plains in immense troops, devouring every thing in their passage. Their migrations are continued in a direct line, and no obstacles in their way have any effect in altering their route; neither ravines, torrents, marshes, or lakes, nor even fires, make them deviate from their line of march. If a rick of hay or corn occurs in their passage they eat through it; and insurmountable objects make them only deviate till the obstacle is passed. The grass is destroyed to the very roots in the line of their march, and the ground appears as if ploughed. The cause of these periodical migrations is not known. They seldom happen more than once in ten years. Want of food and excessive multiplication have been assigned as the probable causes; and it has been remarked that their migrations take place in the autumn of such years as are followed by a severe winter. If the instinctive propensity arises from the numbers being too great for the supply of food, the object is amply attained ; for the greater part of these immense hosts is destroyed by various enemies, owls, hawks, weasels, \&cc. and numbers perish in the waters which their blind instinct impells them to cross. Few survive to return to their native mountains.

L. zokor, Desm. (Mus aspalax, Pall.) The Daurian Rat, Penn. Body reddish gray; tail short; fore-feet pentadactylous; the three intermediate nails very long; eyes very small. Inhabits the Altaic Mountains.-Pall. Glir. t. I0.

L. Talpinus, Desm. Fur gray brown above, whitish underneath; fore-feet pentadactyle, with pretty strong nails; eyes small; tail very short. Inhabits Southern Russia.-Pall. Glir. t. 11, A.

L. Hudsonius, Desm. Fur cinereous, with a dusky stripe down the middle; fore-feet with four toes and the rudiment of a thumb; the two middle nails very large, and apparently divided. Inhabits Labrador._Pall. Glir. t. 26. fig. A, B, C.

L. torquatus, Desm. Fur ferruginous, with a black dorsal line and a white collar; fore-feet pentadactylous; nail of the thumb short and rounded. Inhabits Siberia._Pall. Glir. t. 11, B. 
L. lagurus, Desm. Fur cinereous, with a black dorsal line and no collar; fore-feet pentadactyle; tail very short. Inhabits Siberia.-Pall. Glir. t. 13, A.

L. terrestris, F. Cuv. Fur blackish gray, slightly variegated with yellow, paler beneath; tail black. Europe.-F. Cuv. Mam.

Gen. 95. Eснimys, Geoff. Cuv.

Incisors $\frac{2}{2}$, canines $\frac{0}{0}-\frac{0}{0}$, molars $\frac{4}{4}-\frac{4}{4},=20$. Molars simple, with transverse plates united by twos at the end, or isolated; four unguiculated toes and the vestige of a thumb on the fore-feet, five on those behind; tail long, scaly; the back more or less covered with flat spines.

E. cristatus, Desm. Fur chestnut-coloured above; head deep brown, with a narrow white stripe down the middle; tail longer than the body, black, with its last half white or yellowish. Surinam. -Buff. Sup. vii. pl. 72.

E. dactylinus, Geoff. Fur of the back deep brown, mixed with gray and yellow, reddish on the flanks; two middle toes of the forefeet longest; tail longer than the body.-S. America.

E. spinosus, Desm. Fur dark brown, mixed with reddish above, white beneath; hairs on the back mixed with strong spines. Seven inches long. South America.-Mam. 291.

E. hispidus, Geoff. Fur reddish brown, lig'ter underneath; head reddish; tail as long as the body, scaly; hairs of the back very rough. S. America.-Desm. Mam. 292.

E. didelphoides, Geoff. Fur brown upon the back, yellowish below; tail the length of the body, the greater part naked and scaly. S. America.-Desm. Mam. 292.

E. Cayennensis, Geoff. Fur red, passing to brown on the back, white below ; hind-feet with long tarsi, and three middle toes equal. S. America.-Desm. Mam. 292.

E. setosus, Geoff. Fur red, soft, with few spines, whitish below; end of the feet white; tail rather longer than the body.-S. America.

Gen. 96. Mroxus, Cuv. Geoff.-Mus, Lin.

Incisors $\frac{2}{2}$, canines $\frac{0}{0}-\frac{0}{0}$, molars $\frac{4}{4}-\frac{4}{4},=20$. Molars simple, with transverse projecting lines; fore-feet with four toes and the rudiment of a thumb; tail very long, round, with hair tufted or depressed.

M. glis, Desm. (Sciurus glis, Lin.) The Fat Dormouse. Fur brownish ash-coloured above, whitish below, with brown round the eyes ; tail hairy. Six inches long. Europe-Buff. viii. pl. 24.

The M. dryas of Schreber is considered a variety of the M. Glis.

The Dormouse resembles the squirrel in its manners and food. It couples in spring, and the female brings forth four or five at a birth. On the approach of winter this little animal retires into the crevices of rocks or cavities of trees, rolls itself up into a ball and passes the winter in torpidity, awaking, however, to take food when the temperature is raised. It is used for food in Italy, as it was by the ancient 
Romans, who fattened them for the table in receptacles called Gliraria. The common Dormouse has the same habits.

M. nitela, Desm. Garden Dormouse. Fur gray brown above, whitish below; a black spot round the eyes extending to behind the ear; tail long, black, with a white luft at the end. Inhabits Europe.-Buff. viii. pl. 24.

M. avellanarius, Desm. The Common Dormouse. Fur clear fawncolour above, whitish below; tail the length of the body, flattened horizontally, the hairs distichous. Europe. B.-Schreb. pl. 227.

M. murinus, Desm. Fur gray, paler beneath; tail as long as the body, flattened, with distichous hairs. Cape of Good Hope.F. Cuv. Mam. No. 17 .

M. Africanus, Shaw. Fur pale ferruginous above, whitish beneath, with a white line above each eye; tail black in the middle.Shaw, ii. 172.

Gen. 9\%. Hydromys, Geoff. Cuv.-Mus. Gmel.

Incisors $\frac{2}{2}$, canines $\frac{0}{0}-\frac{0}{0}$, molars $\frac{2}{2}-\frac{2}{2},=12$. Molars with flat crown, the plates of enamel having the appearance of the figure 8, with two hollows; ears small and round; feet pentadactyle, the toes of the hind-feet united by a membrane; tail cylindrical, covered with hair and pointed.

H. chrysogaster, Geoff? Fur chestnut above, orange-coloured below. One foot long. Van-Dieman's Land.-An. Mas. vi. pl. 36.

H. leucogaster, Geoff. Fur brown above, white below. Van-Dieman's Land. One foot long-An. Mus. vi. pl 36.

H. Coypus, Geoff. The Coypou. Fur brown chestnut on the back, red on the flanks, and light brown on the belly. 'Twenty inches long. Inhabits South America.-An. Mus. vi. pl. 35.

This species is the type of M. F. Cuvier's genus Myopotamus. It is nearly allied to the beaver, and its fur is known in trade by the name of Racoonda, and used in the manufacture of hats.

\section{Gen. 98. Mus, Lin. Cuv.-Rattus; Penn.}

Incisors $\frac{2}{2}$, canines $\frac{0}{0}-\frac{0}{0}$, molars $\frac{5}{3}-\frac{5}{3},=16$. Molars with tuberculous crowns; four toes and rudimentary thumb on the fore-feet; hind-feet with five unguiculated toes; ears oblong or round, naked; taillong, naked and scaly ; fur with scattered hairs, longer and stiffer than the others, sometimes forming a kind of spines.

\section{* Spineless rats of the Old Continent.}

M. giganteus, Hardwick. The Malabar Rat. Fur of an obscure brown on the back, gray under the belly; feet black. Body above a foot long. Inhabits Malabar.-Lin. Trans. vii. t. 8.

M. Javanus, Desm. Fur brown red above, extremities of the feet whitish; tail shorter than the body; feet not palmated. Nine inches long. Inhabits Java.-Mam. 298. 
M. caraco, Pallas. Fur mixed with reddish and gray, deeper on the back than the sides; feet and belly whitish; tail rather more than half the length of the body; feet semipalmated. Seven inches long. Inhabits Siberia.-Pall. Glir. t. 23.

M. decumanus, Desm. Norway Rat. Fur gray brown above, whitish below; tail almost the length of the body; toes free. Nine inches long._Shaw, ii. pl. 130.

This well-known animal is originally from Persia or India, and was not known in England previous to the year 1730. It is now naturalized in all the countries of Europe, and in America, and in Britain has almost expelled the black rat.

M. Indicus, Geoff. Fur reddish gray above, gray below; legs reddish; tail a little shorter than the body; feet not palmated. Inhabits India._Desm. Mam. 299.

M. Alexandrinus, Geoff. Fur reddish gray above, cinereous below ; tail one-fourth longer than the body; feet not webbed. Inhabits Egypt._Geoff. Egyp. pl. 3. fig. 1.

M. rattus, Lin. The Black Rat. Fur blackish above, deep ashcoloured below ; tail longer than the body. Seven or eight inches long. Originally from India, but spread over the civilized world. -Shan, ii. pl 130.

M. sylvaticus, Lin. The Field Mouse. Fur reddish gray above, whitish below; tail shorter than the body. Five inches long. Europe. B.-Shaw, ii. pl. 132.

M. campestris, F. Cuv. The Dwarf Mouse. Ears short, rounded ; fur fawn-gray above, white below. About two inches and a-half long. France.-Desm. Mam. 543.

M. musculus, Lin. The Mouse. Dusky gray above, cinereous below; tail about as long as the body. About four inches long. Sometimes found all white. Europe. B.-Shaw, ii. pl. 131.

M. messorius, Shaw. The Harvest Mouse. Fur mouse gray, mixed with yellowish above; belly and feet white ; tail a little shorter than the body. Two inches and a-half long. Inhabits England.-Shaw, ii. frontispiece.

This is the smallest of British quadrupeds, two of them weighing about the third of an ounce. They build their nests amidst the straws of corn, and sometimes in thistles, and are often carried into the barn-yard with the sheaves.

M. agrarius, Pall. Fur reddish gray, with a black dorsal line; tail half the length of the body. About three inches long. Russia. -Pall. Glir. pl. 24, A.

M. subtilis, Pall. Fawn-coloured, with a black dorsal line, ears folded; tail rather longer than the body. About three inches long. Inhabits Tartary and Siberia.-Pall. Glir.t. 22. fig. 2.

There are several varieties in colour of this species. They live in trees, which they climb with ease. They have some analogy with the dormice, and like them want the gall-bladder, but differ from them in having a coecum. Mr Gray has formed them into a separate genus under the name of Sicista.

M. striatus, Lin. Fur reddish gray above, with lines of longitudinal white spots. East Indies.-Shaw, ii. pl. 133. 
M. Barbarus, Lin. Fur brown, with ten longitudinal whitish lines ; three toes on the anterior feet. Northern Africa._Shaw, ii. 70

M. soricinus, Desm. Fur yellowish gray above, whitish below; muzzle elongated ; ears orbicular, hairy; tail as long as the body. $2 \frac{1}{2}$ inches long. Vicinity of Strasbourg.-Shan, ii. pl. 133.

M. minutus, Pall. Fur ferruginous above, whitish below ; muzzle slightly elongated. Body about two inches long. Inhabits Russia. -Pall. Glir. pl. 24, B.

M. frugivorus, Raf. Fur reddish brown, with scattered long hairs, white below; ears naked, rounded ; tail as long as the body. Inhabits Sicily, on trees.-Griff. Syn. 229.

M. dichrurus, Raf. Fur gray and brown; head with a brown band; tail as long as the body. Inhabits Sicily.-Griff. Syn. 229.

M. setifer, Horsf. Fur bristly, back gray, blackish brown beneath ; ears large, rounded, nearly naked; tail long. Java._Horsf. Jav.

M. Islandicus, Thienemann. Iceland Rat. Fur black above; red gray, spotted with yellow on the sides; tail nearly naked, scaly, a little longer than body. N. of Europe.-Natur. Bemerk. i.t. 22.

M. Donovani, Griff. Fur blackish gray, with three small dorsal bands ; tail rather hairy. Cape of Good Hope-Nat. Rep. t. 35.

\section{** American Spineless Rals.}

M. Angouya, Desm. Fur yellow brown above, whitish bencath; tail rather longer than the body; ears rounded.-Paraguay.

M. rufus, Desm. Reddish fawn-colour, darker on the head and back; belly yellowish; tail rather more than half the length of the body. About six inches long. Inhabits Paraguay.-Mam.305.

M. cephalotes, Desm. Head very large; muzzle short; fur brown above, whitish below; tail as long as the body. Four inches long. Inhabits Paraguay.-Mam. 305.

M. auritus, Desm. Head thick; ears long; fur mouse-colour, lighter beneath; tail shorter than the body. Four inches and a-half long. Inhabits Buenos Ayres-Mam. 306.

M. nigripes, Desm. Head thick; ears short and round; yellow brown above, white below; feet deep black. Three inches and a-half long. Inlabits Paraguay.-Mam. 306.

M. Laucha, Desm. Muzzle pointed; fur lead-colour, paler below ; tail shorter than the body. $2 \frac{1}{4}$ inches long.-Buenos Ayres.

M. leucopus, Desm. Brownish yellow above, white beneath; ears large; feet white, tail as long as the body. Five inches long. Inhabits United States.-Mam. 307.

M. nigricans, Desm. Fur black above, gray below; tail black, longer than the body. Six inches long.-United States.

M. Perchal, Shaw. Fur reddish brown, mixed with spiny hairs, 
grayish below ; tail not so long as the body. Body 18 inches long. India.-Buff. Supp. vii. pl. 69.

M. Cahirinus, Geoff. The Egyptian Rat. Fur ash gray, deeper above than below, composed of rough spiny hairs; tail as long as the body. Four inches long. Egypt._Geoff. Egyp.pl. 5. fig.2.

Gen. 99. Cricetus, Lacep. Cuv.-Mus, Lin.

Incisors $\frac{2}{2}$, canines $\frac{0}{0}-\frac{0}{0}$, molars $\frac{3}{3}-\frac{3}{3}=16$. Crown of the molars with blunt tubercles ; fore-feet with four toes and a rudimentary thumb; hind-feet pentadactyle, with strong nails ; tail short and hairy ; cheek-pouches.

C. vulgaris, Desm. (Mus cricetus, Lin.) The Common Hamster. Fur reddish gray above, black below; with three large yellowish spots on each side; a white spot on the throat and another under the breast. Inhabits the northern and central parts of Europe and Asia. Eight inches long.-Shan, ii. pl. 137.

The Hamster forms complicated burrows or excavations of a circular form from one to five feet in diameter, communicating by horizontal passages. In one of these is the retreat of the animal, furnished with dry herbs for its bed-the others are magazines for its winter provisions, which frequently contain many bushels of corn or other grain. These burrows are frequently sought, both to destroy the animal which robs the agriculturist of so much produce, and to appropriate their supplies. In the environs of Gotha it is said that in a single year 80,000 hamsters have been killed. The hamster is larger than the common rat; is provided with cheekpouches; brings forth frequently, and from six to twelve young. On the approach of winter the entrances to their burrows are closed up, and they are supposed to pass this season partly in a state of torpidity.

C. migratorius, Desm. (Mus accedula, Pall.) Fur ashy gray above, white on the muzzle, round the nostrils and feet; ears notched; Length four inches. Siberia.-Pall. Glir. pl. 18, A.

C. arenarius, Desm. (Musarenarius, Gmel.) Sand Hamster. Whitish ash-coloured above, pure white beneath; feet and tail white; ears round. Four inches long. Siberia.-Pall. Glir. pl. 16, A.

C. phous, Desm. (Mus phoeus, Gmel.) Fur brownish ash-coloured above, whitish below; ears oval and large. Inhabits Persia.Pall. Glir. pl. 15, A.

C. songarus, Desm. (Mus songarus, Pall.) Fur ash-coloured on the back, with a black dorsal line; sides varied with white and brown. Length three inches. Siberia._-Shaw, ii. pl. 139.

C. furunculus, Desm. (Mus furunculus, Pall.) Fur ashy above, with a black dorsal line; belly and feet white--Pall. Glir. tab. 15, B.

C. bursarius, Desm. (Mus bursariks, Lin. Trans.) Canada Hamster. Fur gray; fore-feet pentadactylous, with long digging nails ; ears short. Length 11 inches. Canada._Shaw, ii. pl. 138.

C. laniger, Desm. (Mus. laniger, Gmel.) The Chinchilla. Fur gray and white, the hair soft and downy; ears large and round; tail short, with long stiff hairs. 11 inches long. Chili.-Griff. iii. 138.

C. anomalus, Desm. Fur chestnut brown above, white below, some 
flat spines on the back; tail nearly as long as the body, scaly and black. Isle of Trinity, Gulf of Mexico.-Mam. 313.

Gen. 100. Dipus, Cuv. Geoff. Gmel.

Incisors $\frac{2}{2}$, canines $\frac{0}{0}-\frac{0}{0}$, molars $\frac{3}{3}-\frac{3}{3}$ or $\frac{4}{3}-\frac{4}{3}=16$ or 18 . Molars simple, with tuberculous crowns; eyes large ; ears long, pointed; posterior extremities much elongated, with the number of toes variable, but having only one metatarsal bone; tail very long, tufted.

These singular animals, approaching something in form to the Kangaroo, but very different in other particulars, were formerly supposed to walk solely upon their hind-feet; but subsequent observation has proved this to be wrong. They usually walk on all-fours, but when alarmed endeavour to escape by prodigious leaps, springing from their hind-feeet by the assistance of their tail, their fore-feet being pressed close to their breast on these occasions.

D. maximus, Blainv. The Great Jerboa. Fur bright gray above, with a black line over each eye, uniting on the forehead; four toes on the fore-feet, and three on those behind. Size of a rabbit.

D. gerboa, Desm. (Mus jaculus, Lin.) The Jerboa. Fur bright fawn-colour above, white underneath; tail tufted; three toes on the hind-feet, the middle one longest. About six inches long. Barbary, Egypt, \&c.-Shaw, ii. pl. 157.

D. jaculus, Desm. (Mus jaculus, Pall.) Pale fawn-coloured above, white below; muzzle white, and a white band across the buttocks; five toes on the hind-feet; ears long. Seven inches long. Tartary.-Shaw, ii. pl. 158.

D. brachyurus, Desm. Pale fawn-coloured above, white below; a white crescent-shaped spot on the buttocks; muzzle white at its extremity, brown above; tail and limbs thick; ears short; hind-feet pentadactyle. Four inches and a-half long.-Siberia.

D. minutus, Desm. Fur pale yellowish gray, whitish underneath ; the extremities and transverse stripe on the buttocks white; hindfeet pentadactyle. Four inches long.-Shores of the Caspian sea.

\section{Gen. 101. Gerbillus, Desm. F. Cuv.}

Incisors $\frac{2}{2}$, canines $\frac{0}{0}-\frac{0}{0}$, molars $\frac{3}{3}-\frac{3}{3}=16$. Molars tuberculous; posterior extremities very long, with five toes, each with its proper metatarsal bone; tail long, covered with hair.

G. tamariscinus, Desm. (Mustamariscinus, Pall.) Fur grayish yellow above, white below; tail nearly as long as the body, annulated with brown. Six inches and a-half long. Shores of the Caspian Sea._Shaw, ii. pl. 160.

G. meridianus, Desm. (Mus longipes, Lin.) Fur grayish fawncolour above, white below, with a central line of red brown on the belly. Body four inches long. Deserts near the Caspian Sea.-Shaw, ii. pl. 160.

G. Indicus, Desm. Fur chestnut above, sprinkled with small brown 
spots longitudinally, white below; tail a little longer than the body, with a tuft of brown hair. Hindostan.-Desm. Mam.p.321.

G. AEgytius, Desm. (Dipus pyramidum, Geoff.) Upper part of the body bright yellow, under part pure white; tail a little longer than the body, brown, and terminated by a few long hairs. About the size of a mouse. Egypt.-Oliv. Voy. pl. 28. A, B, C.

G. Canadensis, Desm. Canadian Gerbo, Shaw. Fur yellowish above, white below; ears short; tail almost naked, rather longer than the body. Inhabits Canada.-Shaw, ii. pl. 161.

G. Labradorius, Sabine. Fur brown above, white beneath, without a dividing line; toes four before, five behind; tail more than half the length of the body. Labrador.-Faun. Amer. p $15 \%$.

M. Rafinesque has named six other species of Gerbilli as natives of North America. These are the G. soricinus, megalops, leonurus, Hudsonius, macrourus, and brachyurus.

\section{Gen 102. Aspalax, Desm. Oliv.-Spalax, Cuv.}

Incisors $\frac{2}{2}$, canines $\frac{0}{0}-\frac{0}{0}$, molars $\frac{3}{3}-\frac{3}{3},=16$. Molars simple, with blunt tubercles; body long, cylindrical ; eyes very small, and concealed by the skin; no external ears ; feet short, pentadactylous; no tail.

A. typhlus, Desm. (Mus typhlus, Pall.) Fur ash-coloured, tinted with reddish. Eight inches long. Asia Minor, \&c. The Aspalax or mole of the ancients.-Pall. Glir. pl. 8.

Var. with large irregular white spots.

Gen.103. Bathrergus, Cuv.-Mus, Pal.-Orycterus. F.Cuv.

Incisors $\frac{2}{2}$, canines $\frac{0}{0}-\frac{0}{0}$, molars $\frac{4}{4}-\frac{4}{4},=20$. Incisors very long, broad ; molars slightly tuberculous, notched on the edges; body thick and cylindrical; head thick; muzzle truncated; eyes small ; no external ears; feet short, pentadactyle, with strong nails; tail very short.

B. maritimus, Desm. (Mus maritimus, Gmel.) Fur whitish gray; tail flat, covered with stiff hairs. About a foot long. Cape of Good Hope.-Shaw, ii. pl. 140.

B. Capensis, Desm. (Mus Capensis, Pall.) Fur brown, with white round the eyes and ears, on the tip of the head, and at the end of the muzzle. About six inches long. Cape of Good Hope.Shaw, ii. pl. 140.

Gen.104. Pedetes, Desm.-Dipus, Gmel--Helamys, F. Cuv.

Incisors $\frac{2}{2}$, canines $\frac{0}{0}-\frac{0}{0}$, molars $\frac{4}{4}-\frac{4}{4},=20$. Molars with a cylindrical crown and a circle of enamel divided into two parts ; head short, broad, and flat between the ears ; muzzle obtuse; ears long, thin, narrow, pointed; eyes large; no cheek-pouches; whiskers large; fore-feet short, with five toes and long nails; hind-feet very long, four-toed ; tail long, thick ; an abdominal pouch, but not inclosing the teats. 
P. Capensis, Desm. (Mus Cafer, Pallas.) Fur bright fulvous, mixed with black above, white below ; legs brown ; tail slender, black at the end. Cape of Good Hope-_Buff. Supp. vi. pl. 41.

Gen. 105. Arctomys, Geoff. Cuv.-Mus, Lin.

Incisors $\frac{2}{2}$, canines $\frac{0}{0}-\frac{0}{0}$, molars $\frac{5}{4}-\frac{5}{4},=22$. Incisors very strong; molars with ridges and blunt tubercles; body thick and heavy; head large; no cheek-pouches; ears short and rounded; eyes large; feet robust, those before with four toes and a rudimentary thumb; those behind with five toes, the nails strong, compressed, and crooked.

\section{* No cheek-pouches.}

A. Bobac, Desm. (Mus arctomys, Pallas.) Fur yellowish gray, with a red tint near the head; under part of the body reddish. 15 inches long. Poland and Northern Russia._Shaw, ii. pl. 144.

A. marmotta, Desm. (Mus alpinus, Pliny.) The Marmot. Fur yellowish gray, top of the head and end of the tail black. Eighteen inches long. Mountains in Europe and Asia.-Shaw, ii. pl. 143.

The Marmots live on the elevated sides of the highest mountains, near the limit of perpetual snow. They are found in families of from six to fifteen : and towards the month of September dig a hole on a southern exposure, which at five or six feet from its entrance divides into two branches, leading to chambers of from three to seven feet in diameter, stored with hay and moss, where they hybernate. When they leave their retrcat to seek food, a centinel is placed upon a height to give the alarm, which he does by a kind of whistle, when they retire to their holes. They store up no provisions, their long torpor rendering this unnecessary; but at the end of autumn they are very fat, and are then taken in great numbers to be used as food.

A. monax, Desm. (Mus monax, Lin.) Fur brown above, paler on the sides and belly; muzzle bluish gray; tail half as long as the body, black. 16 inches long. N. America.-Shaw, ii. pl. 143.

A. empetra, Desm. Quebec Marmot, Penn. Fur blackish brown, dotted with white above, red ferruginous below; tail short. $\mathrm{Ca}$ nada.-Penn. Quad. ii. pl. 74, fig. 1.

A. brachyura, Rafinesque. Cinereous brown above, light red below; tail short, flat, reddish.-Missouri.

Several other animals said to belong to this genus are excluded by Desmarest as not being sufficiently ascertained.

** With large cheek-pouches. Spermophilus, F. Cuv.

A. citillus, Desm. (Mus citillus, Pall.) Fur gray brown above, waved or spotted with white; white below; cheek-pouches.-Europe and Asia.

There are three varieties of this species, distinguished by the undulations or spots on the fur.

A. Franlilinii, Sabine. Head broad; earssmall; snout blunt; tail elongated; body variegated, fuscous. Canada._Lin.Trans. xiii.t. 27.

A. Richardsonii, Sabine. Ears short; snout acute; body fuscous. Canada._Lin. Trans. xiii. t. 28.

A. Parryii, Richardson. Snout blunt; ears short; tail elongate, tip 
black ; body marbled above with confluent black and white spots; beneath ferruginous. One foot long; tail tour inches. Canada. -App. Franklin's Voy.

A. tridecimlineata, Harlan. (S. tridecimlineatus, Desm.) Fur deepchestnut above, striped with six white lines, alternating with an equal number of longitudinal rows of white spots; white below. - Faun. Amer. 164:

\section{Gen. 106. Sciurus, Lin. Cuv.}

Incisors $\frac{2}{2}$, canines $\frac{0}{0}-\frac{0}{0}$, molars $\frac{5}{4}-\frac{5}{4}=22$. Inferior incisors compressed laterally; molars tubercular; body elongated; head small ; ears erect, rounded; eyes large ; fore-feet with four long toes with compressed crooked nails and a tubercular thumb; hind-feet very large, with five toes; tail long, often with hair disposed in two rows; two pectoral and six ventral mammæ.

\section{* Tail distichous.}

S. vulgaris, Lin. The Common Squirrel. Fur reddish above, white below; ears pencilled with long hairs.-Europe and North of Asia.

Several varieties of the squirrel have been noticed, varying in different shades of colour and markings from fawn-colour to black. The colour sometimes changes with the season.-Buff. vii. pl. 32.

S. Alpinus, F. Cuv. Fur deep brown, varied with yellowish white above, white beneath ; feet yellow, with a yellow band separating the white of the neck and the gray of the limbs from the brown of the back ; ears pencilled. Pyrenees.-F. Cuv. Mam.

S. cinereus, Desm. The Gray Squirrel. Fur ash-coloured, white below; ears without pencils of hair. Ten inches long. N. America_-Shaw. ii. pl. 147.

Var. With a red line on the back. S. rubrolineatus. Desm.

S. capistralus, Bosc. Body ashy; head black; muzzle, ears, and belly white. S. Carolina.-Brown, Illust. pl. 47.

Var. A.-Colour all black. Var. B.-With a black belly. Var. C.-Variegated with red, orange colour, and white.

S. rufiventer, Geoff. Fur gray above, bright red below; feet brown; tail shorter than the body. Size of the European Squirrel.North America.

S. Ludovicianus, Curtis. Body and upper part of the tail dark gray ; belly, legs, thighs, and under part of tail reddish brown; tail longer than the body, very broad. N. America.-Barton's Journal, vi. 47 .

S. grammurus, Say. Body cinereous ; fur very coarse ; three black lines on each side of the tail. N. America._Suy and Long, vi.72.

S. lateralis, Say. Fur brownish cinereous above; sides marked with dull yellowish stripes. N. America.-Say and Long, vi. 46.

S. quadrivittatus, Say. Head brownish, with four white lines; sides fulvous, whitish beneath. N. America._Say and Long, vi. 45. 
S. magnicaudatus, Harlan. Fur mixed gray and black ; sides of the head and orbits pale ferruginous; tail large. Canada.Faun. Amer. 178.

S. Clarkii, Griff. Fur silvery gray above; shoulders, flanks, and belly white, with an ochry tint; tail flat, terminating in a point. N. America.-Griff. Syn. 255.

S. maximus, Desm. Upper part of the head, flanks, and legs purple chestnut colour, with a black transverse stripe on the shoulders; lower part of the back, loins, and tail black; under part of the body and interior of the limbs pale yellow. Fifteen inches long. Malabar.-Shaw, ii. pl 146.

S. Ceylonensis, Desm. Fur black above, yellow below ; tail gray. Ceylon.-Penn. Ind. Zoól. pl. 1.

S. Madagascariensis, Shaw. Fur deep black above ; throat and belly yellowish-brown; tail black. Eighteen inches long. Madagascar.-Buff. Supp. vii. pl. 63.

S. Prevostii, Desm. Fur black above, yellow on the flanks, chestnut below; tail brown.-India.

S. Leschenaultii, Desm. Fur clear brown; head, throat, and belly yellowish white; tail brown above, yellowish below. About a foot long. There is a darker coloured variety. Java.-Mam. 335.

S. bicolor, Desm. Fur deep brown or blackish above, clear fawncoloured below; eyes surrounded with a black circle; ears not pencilled. Java.-Schreb. t. 216.

S. bilineatus, Geoff. Fur gray, with a longitudinal white line on each side. Seven inches long.-Java.

S. affinis, Raffles. Fur ash gray above, nearly white beneath, with a reddish brown line on each side. Sumatra.-Lin. Trans. xiii.

S. nigrovittatus, Horsfield. Fur gray brown above; edges of the abdomen and circle round the eyes paler; gray beneath, with a lateral black line ; tail longer than the body, annulated with black. Java.-Zool. Jav.

S. tenuis, Horsfield. Fur variegated with deep-gray and black; lateral edge gray, yellowish gray below ; tail annulated with black. India._Zool. Jav.

S. Finlaysonii, Horsfield. Fur milk white ; back yellowish ; eyes, whiskers, and soles of the feet black. Java._Horsf. Zool. Java.

S. getulus, Desm. Brown above, with four longitudinal white lines reaching to the tail. Five inches long. N.Africa._Sham, ii.pl.148.

S. palmarum, Desm. Fur gray brown, with three longitudinal bands of a pale white, the two lateral terminating at the eyes. India.Buff. x. pl. 26.

*. Tail round, distichous only at the extremity.

S. cestuans, Desm. Fur olive gray above, reddish beneath; tail 
round, longer than the body, shaded with brown black and yellow. Nine inches long. Brazil.-Shaw. ii. pl. 156.

S. pusillus, Desm. Fur gray olive brown above, paler below ; tail round, shorter than the body. Cayenne. Four and a-half inches long.-Shaw, ii. pl. 156.

S. albovittatus, Desm. Fur reddish above, with a white line on each side ; tail round at its base, distichous at the extremity, and varied with black and white; nails long, compressed. One foot long. Cape of good Hope.-Sonnerat, Voy. ii. t. 89.

S. bivittatus, Desm. Fur of a brown black, spotted with yellowish on the back, and a brilliant red below; a white and black line meeting on each flank; tail round, the termination red. A little larger than the common squirrel. Sumatra.-Lin. Trans. xiii.

S. annulatus, Desm. Fur greenish gray above, white below ; tail longer than the body, annulated with black and white.-Mam.546. *** With cheel-pouches, tail distichous.

S. striatus, Desm. Fur brown above, with five longitudinal brown stripes, and two white ones; whitish below ; tail blackish above, red, bordered with black below. Southern Asia.-Buff. x. pl. 28.

S. Hudsonius, Desm. Fur of a reddish brown above, whitish ashcoloured below, with a black line on each flank.-Penn. Syn. Quad. t. 26, fig. 1.

Several other species of Sciurus have been noticed ; but as their characters are not well established their names are merely given._S. Persicus, anomalus, Gmel.; erythrous, Horsf; Abyssinicus, Indicus, and flavus; the Plantain Squirrel of Pennant ; the Mexican Squirrel of Seba ; and Rafinesque has described five North American species, viz. S. ruber, Felenus, Phaiopus, Melanotus, and lateralis,

\section{Gen. 10\%. Pteromys, Cuv. Desm.-Sciurus, Lin.}

Incisors $\frac{2}{2}$, canines $\frac{0}{0}-\frac{0}{0}$, molars $\frac{5}{4}-\frac{5}{4},=22$. Head round; ears rounded; eyes large; fore-feet with four elongated toes with compressed sharp claws and the rudiment of a thumb; hindfeet with five toes much divided; tail long, hairy, sometimes distichous; skin of the sides extended, forming a kind of parachute.

\section{* With round tail, hairs not distichous.}

P. petaurista, Desm. (S. petaurista, Pall.) The Sailing Squirrel. Fur brown, tipped with white above, whitish gray below; thighs red; feet brown ; tail blackish. Seventeen inches long. E. Indies. -Shaw, ii. pl. 152.

P. nitidus, Desm. Fur deep-chestnut above, brilliant red below; tail deep brown. Size of the preceding. Java._Mam. 342.

** With flattened tails, hairs distichous.

P. sagitla, Desm. Fur of a deep-brown above, white beneath; tail bright brown, as long as the body. Six inches long. Java.Shaw, ii. 15 ]. 
P. Sibiricus, Desm. (S. volans, Lin.) The Flying Squirrel. Fur ashy-gray above, white below; tail half the length of the body. About six inches long. There is a white variety. Northern Europe.-Shaw, ii. pl. 149.

P. volucella, Desm. Fur of a reddish gray above, white below; tail nearly as long as the body. About five inches long. United States.-Shaw, ii. 150.

P. genibarbus, Horsf. The Kechubu. Fur gray above, white beneath ; vibrissæ on the cheeks and sides of the head, tail flat and distichous. Java._Griff. An. King. Syn. 261.

P. lepidus, Horsf. Fur blackish brown, white beneath; head and middle of back gray; tail longer than the body, flat; ears naked; vibrissæ very large.-Griff. An. King. Syn. 261.

Section 2.-With incomplete clavicles or none.

Gen. 108. Hystrix, Lin. Cuv.-Coendu, Lacep.

Incisors $\frac{2}{2}$, canines $\frac{0}{0}-\frac{0}{0}$, molars $\frac{4}{4}-\frac{4}{4},=20$. Molars with flat crown, but with ridges of enamel; head strong; muzzle gibbous; ears short, rounded; tongue with spiny scales; forefeet with four toes, and a rudimentary thumb; hind-feet pentadactyle; spines more or less long on the body, sometimes intermixed with hairs; tail sometimes prehensile.

M. F. Cuvier has divided this genus into five genera; but as the species bear no comparison to this excessive subdivision, no confusion can arise from retaining the old name.

H. cristata, Lin. Crested Porcupine. With very long spines on the back, annulated with black and white; a mane of long stiff hairs on the head and neck; tail short. About two feet long. Africa.-Shaw, ii. pl. 122.

The Potcupine burrows in the ground, and feeds on vegetable substances, coming out at night to feed. When it is irritated, it erects the spines on its body, rattles those on its tail, and strikes with its feet on the ground like hares and rabbits. Its voice resembles the grunting of a pig. Its flesh is eaten.

H. dorsata, Desm. Spines short, partly concealed in the brown hair ; tail elongated ; no mane; hair on the head and neck long. Two feet long. Canada.-Shaw, ii. pl. 125. Type of M. F. Cuvier's genus Erethizon.

H. fasciculata, Lin. (Mus fasciculatus, Desm.) Spines like strips of parchment; those on the body flat, black. Less than the common porcupine. Inhabits India. This is the type of M. F. Cuvier's genus Acanthion.-Shaw, ii. pl. 124.

H. Javanica. (H. longicauda, Marsden.) Like the last, but the tail shorter. Sumatra.-Marsden, Sum. t. 17.

H. macroura, Gmel. (Mus macrourus, Desm.) Upper part of the body covered with strong rounded spines; tail half the length of the body, tufted with spines formed like grains of rice. India. -Shav, ii. pl. 124. 
H. spinosa, Griff. Spines rather long, dark at the end ; tail naked beneath. Paraguay.-Type of M. F. Cuvier's genus Sphiggurus.

H. villosa, Griff. Spines hid in the long thick hairs_-Brazil.

H. Couiy, Desm. (H. prehensilis, var $\gamma$ Gmel.) Body covered with numerous short spines, yellowish at their base and point, brown in the middle; tail thick, pretty short, the latter half naked.-Mexico.

H. Cuandu, Desm. (H. prehensilis, Shaw.) Bady covered with short spines, annulated black and white, without any mixture of hair in the upper part; tail nearly the length of the body, pointed and prehensile. Two feet long. Brazil.-Shaw, ii. pl. 123.The type of M. F. Cuvier's genus Sincthere.

Gen. 109. Lepus, Lin. Cuv. Geoff, \&c.

Incisors $\frac{4}{2}$, canines ${ }_{0}^{0}-0,0$, molars $\frac{6}{5}-\frac{6}{5}=28$. Centre upper incisors large and wedge-shaped, with a longitudinal furrow in front, lower incisors square; molars crowned with transverse laminæ of enamel; ears and eyes large ; fore-legs short, with five toes; the hind-feet long, with only four, covered with hair; tail short, erect; teats from six to ten; coecum very large.

L. timidus, Lin. The Hare. Fur brownish-red gray; chin and belly white; ears black at the point ; tail white beneath, black above. Nearly two feet long. Europe. B.-Shaw, ii. pl. 162.

L. variabilis, Pall. Fur fawn-coloured in summer, white in winter ; ears shorter than the head, and black at the tip at all seasons. Larger than the common hare. Mountainous parts of Europe and Asia. B.-Penn. Quad. t. 96, fig. 1.

L. glacialis, Sabine. The Snowy Hare. Fur white; ears black at the tip, longer than the head; nails strong, broad and depressed. Larger than the preceding.-Inhabits within the Arctic Circle.

L. cuniculus, Lin. The Rabbit. Fur gray, mixed with yellowish; reddish about the neck and belly; tail white, brown above. Fifteen inches long. Originally from Africa and Spain. B.-Shaw, ii. 162. There are numerous varieties of this species in colour and markings.

L. Tolai, Pall. Fur gray, mixed with brown and yellow; belly white; feet yellowish; ears a little longer than the head in the males, shorter in the females. Mongolia and Tartary.-Pall. Glir. t. 4, fig. 2.

L. AEgyplius, Geoff. (Lepus Capensis, Lin.) Fur reddish-brown; breast and feet red fawn-colour; tail black above, white below; ears longer than the liead, black at the tip. Fifteen inches long. Inhabits Africa.-Geoff. Egyp.

L. Americanus, Desm. Fur yellowish gray, varied with brown; VOL. $\mathrm{I}$. 
throat and belly white; ears shorter than the head, without black tips. Size of the rabbit. N. America.-Schreb. 234, B.

L. Braziliensis, Lin. Fur brown and yellowish above ; a half collar of white on the throat; ears much shorter than the head. South America.-Marcg. Braz. 223.

L. uigricollis, F. Cuv. Head sprinkled with yellow; sides red; throat white; a grayish white band from the muzzle to the ear; upper part and sides of neck and shoulder bright black.-Java.

L. saxatilis, F. Cuv. Fur reddish-gray, under parts white; ears red behind, black brown at the tips. - Cape of Good Hope.

Gen. 110. Lagomys, Geoff. Cuv.-Lepus, Pall.

Incisors $\frac{4}{2}$, canines $\frac{0}{0}-\frac{0}{0}$, molars $\frac{6}{5}-\frac{6}{5}=28$. Teeth and toes similar to the hare; ears short, rounded; no tail ; clavicles almost perfect ; teats four or six.

L. alpinus, Pall. Fur reddish; ears and soles of the feet brown. Northern mountains of the Old World. Ten inches long.Shaw, ii. pl. 163.

L. ogotona, Pall. Fur pale gray; ears oval, slightly pointed, the colour of the body. Seven inches long. Mongolian Tartary.Shaw, ii. pl. 163.

L. pusillus, Desm. (Lepus pusillus, Pall.) Fur gray brown; ears almost triangular, edged with white. Seven inches long. S. E. parts of Russia.-Shaw, ii. pl. 163.

Gen. 111. Hydrocherus, Cuv.-Sus, Lin.-Cavia, Pall.

Incisors $\frac{2}{2}$, canines ${ }_{0}^{0}-0$, molars $\frac{5}{4}-\frac{5}{4},=22$. Molars composed of laminæ; eyes large ; ears rounded ; fore-feet with four, the hinder ones with three, palmated toes; no tail; two mammæ; hair scattered and bristly.

H. capybara, Desm. (Cavia capybara, Gmel.) Fur reddish brown, fawn-coloured below; head very large. Nearly three feet in length. Inhabits South America._Shaw, ii. pl. 127.

Gen. 112. Cavia, Desm.-Mus, Lin.-Cobaya, Cuv.

Incisors $\frac{2}{2}$, canines ${ }_{0}^{0}-0,0$, molars $\frac{4}{4}-\frac{4}{4}=20$. Body thick ; muzzle short, compressed; eyes large; ears round; legs short; four toes on the fore-feet, three on the hind-feet, not palmated; no tail; two ventral teats.

C. cobaya, Desm. The Guinea Pig. Fur reddish-gray in the wild variety, or varied with black, yellow, and white in the domestic races. Nearly a foot long. Brazil, \&c.-Shaw. ii. pl. 126.

Gen. 113. Dasyprocta, Illig:-Mus, Lin.-Cavia, Gmel.

Incisors $\frac{2}{2}$, canines $0_{0}^{0}-0$, molars $\frac{4}{4}-\frac{4}{4},=20$. Head rather elongated, forehead flat; muzzle thick; eyes large. and pro- 
jecting; fore-feet with four toes and rudimentary thumb; hind-legs longer than those before, with three toes and strong nails; sole of the foot naked and callous.

D. Acuti, Desm. The Agouti. Fur brown, sprinkled with yellow or reddish ; ears short ; tail rudimentary; twelve teats. Nearly two feet long. Brazil-Shaw, ii. pl. 126.

D. cristata, Desm. Fur blackish, sprinkled with red; hair on the occiput long, and forming a sort of crest; hair on the croup also long; belly brown; ears and tail short.-Mam. 358.

D. Acuschy, Desm. The Akouchy. Fur brown, spotted with yellow ; croup blackish; belly red. Twenty inches long. Guiana. -Shav, ii. pl. 126.

D. Patagonica, Desm. Fur brownish gray, dotted on the back, black on the croup, white on the thighs and belly; tail very short. Two feet six inches long. Patagonia.-Shaw ii. pl. 165.

D. Viscacha, Desm. Fur dirty white; sides of the head black; moustache seven inches long; body thick and cylindrical; tail naked at tip, but with bristly hairs on the upper part of the remainder. As big as a hare ; tail nine inches long.-Brazil.

\section{Gen. 114. Calogenus, F. Cuv.-Cavia, Lin.}

Iricisors $\frac{2}{2}$, canines $\frac{0}{0}-\frac{0}{0}$, molars $\frac{4}{4}-\frac{4}{4}=20$. Five toes on all the feet, the external and internal toe behind being nearly rudimentary ; nails conical, strong, for digging; cheek-pouches; a naked tubercle in place of a tail ; two pectoral and two inguinal mammæ.

C. subniger, Desm. The Brown Paca. Fur short, blackish-brown, marked on each flank with four or five longitudinal bands of white spots ; head large ; neck short ; ears round. Twenty-one inches long. S. America.-Buff. Sup. iii. pl. 35.

C. fulvus, Desm. (Cavia paca, Geoff.) Like the preceding, but with the ground colour yellowish. S. America.-An.Mus. x. pl.9.

\section{ORDER VII.-EDENTATA.}

No incisors in either jaw; sometimes canines and molars, or molars only, often no teeth at all; extremities terminated with toes in number variable, armed with strong nails; orbital and temporal fossæ united.

The Edentata are quadrupeds without incisive teeth, and form the last order of unguiculated animals. Although united together only by a negative character, they possess some positive connection in the large nails which cover the extremities of the toes, which approach more or less to the nature of hoofs, and a want of agility, a certain slowness of motion, occasioned by the disposition of their members. 
1st Tribe.-Tardigrada.-Face short; with canine and molar teeth, or molars only; nails long and bent.

Gen. 115. Bradypus, Lin. Cuv.

Incisors $\frac{0}{0}$, canines $\frac{1}{1}-\frac{1}{1}$, molars $\frac{4}{3}-\frac{4}{3}=18$. Canines higher than the molars, pyramidal and pointed; molars cylindrical; head small, rounded; muzzle truncated; neck short; nostrils at the extremity of the muzzle; anterior extremities longer than the posterior, with two or three united toes, terminated by very long robust nails; fur thick and harsh, with the hair of the fore-arms directed upwards ; stomach membranous, divided into many sacs; intestines short; no cœecum.

B. tridactylus, Lin. The Three-toed Sloth. Three nails to all the feet; lower jaw truncated before; fur of a gray, more or less brown, mixed with whitish; soles of the feet hairy. S. America. -Shaw, i. pl. 45.

The extreme slowness of locomotion in the Sloth is the result of its peculiar con formation. It possesses, however, a great degree of muscular power, and will hang for days upon trees with its body downward by its strong claws. It feeds upon the leaves, buds, and fruits, and never leaves the tree upon which it is located till the supply is completely exhausted; then rolling itself up as a ball the animal drops to the ground, and drags itself heavily along in search of fresh food. The apathy of these animals is such that they may be taken attached to the branch of the tree upon which they, are found, and testify neither astonishment nor uneasiness at any treatment they may receive. They emit a plaintive cry, noted by the vowels $a, i$, from whence the American name, $\boldsymbol{A} i$.

B. didactylus, Lin. Two long nails only on the fore-feet; lower jaw projecting and pointed; hair very long, of a brownish gray colour; soles of the feet naked. S. America._Shaw, i. pl. 46.

Gen. 116. Megatherium, Cuv. (Fossil.)

Incisors $\frac{0}{0}$, canines $\frac{0}{0}-\frac{0}{0}$, molars $\frac{4}{4}-\frac{4}{4}=16$.

M. Cuvieri. Molar teeth marked with transverse furrows on the crown. Body, estimated from the skeleton, 12 feet long.-Found in Paraguay, South America.

2d Tribe.-Efrodientia.-Muzzle elongated; with molar teeth only, or none at all.

Gen. 11\%. Dasyrus, Lin.-Armadillo, Briss.

Incisors $\frac{0}{0}$ or $\frac{2}{4}$, canines $\frac{0}{0}-\frac{0}{0}$, molars varying in the several species from 28 to 68 , simple, cylindrical, separate, without enamel on the inner side; head long, mouth and eyes small; body enveloped in a hard scaly shell in three compartments, covering the head, the body, and the tail, with moveable transverse bands between them; five toes on the hind-feet, four or five on the fore-feet, with long nails for digging.

* Four toes on the fore-feet ; two or four mamma.

D. Apar, Desm. (Dasypus tricinctus, Lin.) The Three-banded Ar- 
madillo. Molars $\frac{8}{8}-\frac{8}{8}$; tail short, flattened; three moveable transverse bands to the body ; two pectoral mammæ. Rolls itself into a ball. Inhabits South America.-Shaw, i. pl. 57.

The D. quadricinctus of Linnæus, and the Armadillo Indicus of Brisson, appear to be allied to this species, which M. F. Cuvier makes the type of his genus Tatuises.

D. Peba, Desm. (D. novemcinctus, Lin.) The Nine-banded Armadillo. Molars $\frac{8}{8}-\frac{8}{8}$; tail round, almost as long as the body, annulated nearly its whole length; body with seven, eight, or nine mobile bands ; plates of the shield small, rounded, those of the bands rectangular; ears very long; four teats. Two feet long. Inhabits Brazil, \&c.-Shan, i. p1. 57.

D. hybridus, Desm. Tail round, nearly half as long as the body; muzzle elongated; ears large; legs short; shield with five, six, or seven moveable bands. About a foot long.-Inhabits Brazil.

* * Five toes on the fore-feet, and two pectoral mamma.

D. giganteus, Desm. Molars $\frac{17}{17}-\frac{17}{17}$; tail round, half as long as the body, covered with plates; shield with 12 or 13 bands, composed of long scales; ears small; head gibbous; muzzle long; claws very strong. 'Three feet long. Paraguay.-Shaw, i. pl. 59.

D. Tatouay, Desm. The Twelve-banded Armadillo. Molars $\frac{8}{7}-\frac{8}{7}$; tail round, less than half the length of the body, covered with scattered tubercles; shield with 12 or 13 moveable bands, formed of broad rectangular plates; ears large ; muzzle long. Eighteen inches long. Inhabits Brazil.-Schreb. t. 75.

D. sexcinctus, Desm. Incisors $\frac{2}{4}$, molars $\frac{8}{8}-\frac{8}{8}$; six or seven moveable transverse bands; tail round, half as long as the body. Inhabits Paraguay.-Shaw, i. pl. 58.

D. villosus, Desm. Hairy Armadillo. Molars $\frac{8}{8}-\frac{8}{8}$; tail half as long as the body, annulated at the base; shield edged with serrated scales, furnished with six or seven moveable bands of rectangular plates; hair brown, abundant. Fourteen inches long.Inhabits South America.

D. minutus, Desm. Tail round, annulated at the base, nearly half as long as the body; shield notched on the sides, with six or seven bands of rectangular plates; bands dentated on their margin. Ten inches long. Buenos Ayres.-F. Cuv. Mam. i.

Gen. 118. Orycteropus, Geoff. Cuv.-Myrmecophaga, Pall.

Incisors $\frac{0}{0}$, canines $\frac{0}{0}-\frac{0}{0}$, molars $\frac{6}{6}-\frac{6}{6}=24$. Molars separate, without root or distinct crown, formed of bony substance, traversed longitudinally by parallel tubes; head elongated; four toes before, and five behind, the hind-feet plantigrade; nails very thick, approaching to hoofs.

O. Capensis, Desm. (Myrmecophaga Capensis, Gmel.) Fur pale gray, inclining to red on the flanks. Three feet five inches long. Inhabits Cape of Good Hope.-Griff. An. King. iii. 296. 
Gen. 119. Myrmecophaga, Lin. Cuv. Desm. \&c.

Perfectly toothless; head elongated; muzzle tapering to a point; tongue long, protractile ; toes united, four before and five behind, or two before and four behind, armed with strong nails; two pectoral and two ventral mammæ; tail long, sometimes prehensile.

M. jubata, Lin. The Great Ant-eater. Fore-feet with four toes ; hind-feet with five; tail not prehensile, with long hair; fur brown, with an oblique black line on the shoulders. Four feet long. Inhabits South America._Shaw, i. pl. 49.

M. Tamandua, Desm. (M. tridactyla, Lin.) Four toes before, five behind; tail round, naked at its point, prehensile; fur varying much in colour, but mostly pale gray, with a band on the shoulders. Two feet long. Inhabits South America._Schreb. t. 66.

Var. A. Yellowisk, gray.-Var. B. With black before the eyes.-Var. C. Dirty yellow, with a brown line on the shoulders.-Var. D. Of the same colour, but with the croup, flanks, belly, and shoulders brown.-Var. E. Uniformly yellow.Var. F. Black-Var. G. Pale yellow, sides and croup brown.-Var. H. With an annulated tail, $\boldsymbol{M}$. annulata, Desm.-Var. I. With a triangular brown spot above the eyes; tail arnaulated.

M. didactyla, Lin. Desm. Only two nails on the fore-feet, one of which is very large; four on the hind-feet; tail long and prehensile, naked below at the extremity; fur fawn-coloured, woolly, with a reddish dorsal line. Seven inches long. S. America.-Shan, i. pl. 52.

\section{Gen. 120. Manis, Lin. Cuv. Geoff.}

Entirely toothless; body elongated, covered with strong corneous triangular and imbricated scales, and capable of rolling into a .ball; muzzle long; tongue protractile; feet with five toes formed for digging; tail long.

M. crassicaudata, Geoff. (M. macroura, Desm.) The Short-tailed Manis. Tail shorter than the body, thick at the base; scales of the back forming eleven longitudinal rows. Nearly two feet long. Inhabits the India Islands.-Shan, i. pl. 56.

M. longicaudata, Geoff. (M. Africana, Desm.) Long-tailed Manis. Tail twice the length of the body, turned upward, compressed; eleven rows of longitudinal scales. Smaller than the preceding. Inhabits Central Africa.-Shaw, i. pl. 55.

M. Javanicus, Desm. Tail a little shorter than the body, depressed; 17 longitudinal rows of scales on the back. 16 inches long.-Java.

Gen. 121. Chramyrhorus, Harlan, Griff.

Incisors $\frac{0}{0}$, canines $\frac{0}{0}-\frac{0}{0}$, molars $\frac{8}{8}-\frac{8}{8}$, the two first pointed, the rest flat and cylindrical ; shell composed of a series of trans. verse plates; toes, five before and behind, with compressed nails; tail short, turned downwards.

C. truncatus, Harlan. Body covered with a leather-like shell, 
abruptly truncated behind, with white silky lair beneath. Five inches long. Inhabits North America._Zool. Journ. ii.

\section{3d Tribe.-Monotrema. Mamma not observed; marsupial bones.}

Gen. 122. Echidna, Cuv. Geoff.-Myrmecophaga, Shaw.

Toothless, but the palate aculeated; head small, conical ; muzzle prolonged; tongue protractile; eyes very small; no external ears; feet short, with five toes; and a moveable spur on the inner side of the hind-legs of the male, through which an acrid fluid is ejected; tail short ; body covered with spines; large marsupial bones; body capable of a spherical shape.

E. hystrix, Desm. (Myrmecophaga aculeata, Shaw.) Spiny Echidna. Body covered with thick spines, without a mixture of hairs. Size of a hedgehog. New Holland.-Shan, i. pl. 54.

E. setosa, Desm. Bristly Echidna. Body covered with hair, among which are found short spines. A little larger than the preceding. New Holland.-Home, Phil. Trans. 1802. pl. 13, B.

Gen. 123. Ornithorynchus, Blumenbach,-Platypus, Shaw. Incisors $\frac{0}{0}$, canines $\frac{0}{0}-\frac{0}{0}$, molars $\frac{2}{2}-\frac{2}{2},=8$. Molars fibrous, fixed only in the gum; a horny beak resembling a duck's bill; nostrils contiguous, opening at the end of the upper mandible ; cheek-pouches; feet webbed, pentadactyle, with a spur on the hind ones in the male; tail short, broad at its base.

O. rufus, Desm. (O. paradoxus, Blum.) Fur reddish brown above, silvery white below. 14 incheslong. New Holland.-Shaw, i.pl.66.

O. fuscus, Desm. Fur blackish brown; hair flat and curled. Size of the preceding. Inhabits New Holland.-Leach, Zool. Mis. t. 111.

\section{ORDER VIII. PACHYDERMA.}

Three or two kinds of teeth; four extremities, with the toes variable in number, and furnished with strong nails or hoofs ; no clavicles; organs of digestion not disposed for ruminating.

Unable to use their feet for the purpose of seizing objects, this Order commences the series of hoofed quadrupeds. Their feet serving only as means of support, they possess no clavicles, their fore-arm remains always in a state of pronation, and they are thus necessarily reduced to feed on vegetables. Their forms and their modes of life present fewer varieties than those of the unguiculated animuls; and Cuvier has accordingly arranged the whole series in two Orders-those which ruminate and those which do not. The last of those, or Pachyderma, including the largest terrestrial animals, form two families.

\section{FAMILY I.-PROBOSCIDEA.}

Upper incisors in form of clongated tusks; molars compound 
and in small number; five toes on all the feet; nose prolonged into a proboscis.

Gen. 124. Elephas, Lin. Cuv. Geoff. Desm.

Incisors or tusks $\frac{2}{0}$, canines $\frac{0}{0}-\frac{0}{0}$, molars $\frac{2}{2}-\frac{2}{2},=10$. Tusks slightly arched toward their extremity, composed of ivory, cased in a crust of enamel; molars composed of vertical and transverse laminx covered by enamel; five toes on all the feet; nose elongated into a cylindrical proboscis, moveable in all directions, with a moveable appendix at the termination, serving the purpose of a finger; head very large ; neck short, eyes small, lateral; ears extremely flat, and very large; body large and massive; tail short, tufted at the end; two mammæ.

The Elephant is the largest of existing quadrupeds, and has been known from the earliest ages. The Asiatic species is found throughout the whole of Southern Inclia and the neighbouring islands; but though extensively employed it can scarcely be considered as a domestic animal, as it does not breed in captivity. The supply is therefore kept up by the capture of wild ones, and elephant-hunting forms a princely sport among the inhabitants of Asia. The elephant inhabits forests in the neighbourhood of rivers, and swims with great ease. It is a gregarious animal, and is generally found in herds, sometimes to the amount of hundreds together. Its extreme docility renders it easy to be tamed; and numerous facts have been related of its sagacity in a state of domestication. The specimen long in Mr Cross's collection at Exeter Change, and which he was forced to kill to preserve the building, was between 10 and 11 feet in height, and weighed by computation between four and five tons. Its daily allowance of food was three trusses of hay, about $200 \mathrm{lbs}$ of carrots and other fresh vegetables, and from 60 to 80 gallons of water. A strong elephant can carry 2000 pounds weight and travel 60 miles a-day; though in long marches its feet are apt to become tender. The period of gestation is twenty months. At birth the young elephant is about three feet long, and it sucks with its mouth, putting back the proboscis when doing so. It arrives at full growth in about twenty years; and lives, according to the opinion entertained in India, for three centuries, witnessing the successive rise and decay of the ephemeral generations of men. The tusks, an object of commerce, are changed but once during the life of the animal, but the molar teeth are renewed as often as detrition renders it necessary. These teeth, however, are not renewed in the usual manner, by the new teeth pushing out the old ones, but by a lateral succession from back to front. The most wonderful part of the structure of the elephant is its proboscis, which to it serves all the purposes of a hand; and while it is able with this powerful instrument to lift the greatest weights, its lip possesses all the delicacy of a finger, and is capable of seizing the smallest substances.

E. Indicus, Cuv. (E. maximus, Lin.) The Asiatic Elephant. Head oblong; forehead concave ; ears large, but less than those of the African species; four hoofs on the hind-feet; crown of the molar teeth marked by transverse undulating lines of enamel. Height about ten feet. Inhabits Southern Asia and the larger Islands. - Shaw, i. pl. 63.

Var. The white Elephant. This variety is rare, and is held in much esteem by the eastern sovereigns. Horace alludes to its exhibition in ancient Rome, Epist. i. B. ii.

E. Africanus, Cuv. Desm. The Afriçan Elephant. Head round, forehead convex; ears very large; three hoofs to the hind-feet; crown of molar teeth marked by lozenge-shaped lines of enamel. Smaller than the Asiatic species. This is probably the elephant of the Greeks and Romans.-Griff. An. King. iii. 349.

E. primogenius, Blumen. The Mammoth, Cuv. (fossil speciesa) 
Head oblong; forehead concave; tusks very large ; molar teeth with close parallel ridges of enamel. Larger than the Indian elephant. Found fossil in Northern Europe-Cuv. Ossem. Foss. $2 \mathrm{~d}$ edit. i. p. 75, pl. 11.

An individual of this species discovered in Siberia, with the flesh and skin entire, upon the melting of the ice in a hot summer, was found covered with two kinds of hair, viz. a red and thick tufted wool, and stiff black bristles upon the neck and spine, that upon the neck long enough to have formed a kind of mane. From this circumstance, and the numerous remains of fossil elephants found all over Europe, M. Cuvier conceives it to be probable that this species has formerly existed there, its covering of hair protecting it from the rigours of a northern winter. Other isolated bones, from having the remains of marine animals attached to their surface, seem to imply that they had been exposed to the action of the sea.

\section{Gen. 125. Mastodon, Cuv. (Fossil.)}

Incisors $\frac{2}{0}$, canines $\frac{0}{0}-\frac{0}{0}$, molars $\frac{2}{2}-\frac{2}{2},=10$. Molar teeth rectangular, without cortical substance, the crown with points disposed in pairs, of which the number varies.

M. giganteum, Cuv. Mammoth of the Americans. Molars very broad relatively to their length, the crown presenting, when its points have been worn down by use, lozenges of enamel. Height to the withers 11 feet; tusks nine feet long; molar teeth weighing 11 or 12 lbs.-Fossil in N. America.

M. angustidens, Cuv. Molars narrow and elongated, their crown by use presenting dises of enamel of a trefoil form. A third less than the gigantic Mastodon.-Found fossil in the South of Europe, and at Santa Fe de Bogota, 1300 toises above the level of the sea.

M. Cordillerarum, Cuv. Intermediate molars as large as those of the great Mastodon, with crown nearly square, and trefoil-shaped discs of enamel.-Found fossil in S. America by Humboldt.

M. Humboldtii, Cuv. Intermediate molar tooth a third smaller than those of the great Mastodon, covered with trefoil-shaped discs.Found fossil in Chili.

M. minus, Cuv. Intermediate molar tooth narrow and elongated, with trefoil-shaped dises. A third smaller than the Mastodon angustidens. - Found fossil in Saxony.

M. tapiroides, Cuv. Intermediate molar tooth with eminences crenulated at their summit, and scarcely perceptibly divided into two parts.-Found fossil near Orleans.

FAMILY II.-PACHYDERMA, properly so called.

Three kinds of teeth in the greater number; two at least in the others; feet terminated by four or two toes.

1st Division.-With the toes equal.

Gen. 126. Hippopotamus, Lin. Cuv. Desm. Geoff.

Incisors $\frac{4}{4}$, canines $\frac{1}{1}-\frac{1}{1}$, molars $\frac{7}{7}-\frac{7}{7}=40$. Lower canines much developed, forming strong tusks curved upwards; head 
thick and square; muzzle very large and gibbous; body very thick and heavy; legs short, with four toes on the feet; eyes and ears small; tail short; two ventral mammæ; skin very thick, almost without hair.

The Hippopotamus is one of the largect of quadrupeds, reaching to twelve feet long, and from five to six in height. Its body is very massive, and denuded of hair; its legs short, the belly almost touching the ground, and the head excessively large. It inhabits the muddy banks of rivers, which it quits in the night in search of pasture, and at the least noise or indication of danger dives to the bottom of the water, from time to time raising itself to the surface to breathe. The hippopotami are gregarious in their habits, and are found throughout Africa. Anciently they were common in Egypt, and the latter Roman Emperors often brought then to Rome, and exhibited them in the Circus. The skin is very thick, and is cut into strips at Senaar, where they are numerous, and made into whips. The flesh is eatable, and the fat thought a delicacy by the colonists at the Cape. The name of the River Horse, which it has popularly received, seems not inapplicable, Mr Burchell conceives, when merely the upper part of the head is seen above the water; but M. F. Cuvier conjectures that this ancient name has reference to its voice, which Adanson informs us is like neighing. The hippopotamus is alluded to in the Sacred Writings.-Job, xl. 15. H. amphibius, Lin. Body very massive; belly almost touching the ground; mouth much cleft; ears far back. About 13 feet long. Inhabits the great rivers of Africa.-Shaw, ii. pl. 219.

Desmoulins has divided this species into two, H. Capensis and $\boldsymbol{H}$. Senegalensis, distinguished by the character of the skulls of specimens from different parts of Africa.

H. antiquus, Cuv. (fossil.) Size of the preceding; occiput very elevated.-Found fossil in Italy.

H. minor, Cuv. (fossil.) Adult individuals, as indicated by the state of the teeth, about the size of the wild boar.

H. medius, Cuv. Of a size intermediate between the two preceding; last lower molar tooth one inch long; the penult one 11 lines.-Found fossil in France.

H. minimus, Cuv. Size smaller than the H. minor.-Found fossil with the remains of crocodiles in limestone near Blaye, France.

Gen. 12\%. Sus, Lin. Cuv. Geoff. Desm.

Incisors $\frac{4}{6}$ or $\frac{6}{6}$, canines $\frac{1}{1}-\frac{1}{1}$, molars $\frac{7}{7}-\frac{7}{7}=42$ or 44 . Canines bent upwards and laterally; molars tuberculous; lower incisors bent forward; four toes on all the feet, the two middle ones only touching the ground, armed with strong hoofs; nose elongated, cartilaginous; body covered with bristles; twelve teats.

S. scrofa, Lin. The Hog. Tusks strong, triangular, directed laterally; no protuberance under the eyes; colour blackish gray in the wild animal, but varying much in the domesticated races.Inhabits all the habitable world.

The English variety acquires an extraordinary bulk, and sometimes weighs 1200 lbs. It is generally of a whitish colour, and the body much elongated. The Jutland race has an elongated body and pendant ears, back bent, and limbs long. The Zealand race is smaller, and has the ears slightly raised, and the back furnished with strong bristles. The races of Poland and Russia are of a reldish colour; and the South 
of Europe possesses a black race with short limbs. The races of France have the bones generally small, and the head pointed; and there is a solidungulous variety, but in which traces of the hoofs may be observed. There is, besides, the Turkish pig, the Siamese pig, and other varieties more or less characterized by family likenesses.

The fecundity of the hog is very"great. A hog belonging to Mr Thomas Richdale, Leicestershire, had produced, in the year 1797, three hundred and fifty young ones in twenty litters; four years before it brought forth two hundred and five in twelve litters; and in Vauban's opinion in twelve generations the produce of a single pair would produce as many as Europe could support. Among the ancients the hog was in much esteem; it was the peculiar sacrifice to Ceres; and in the Island of Crete it was regarded as sacred. In ancient Rome the art of rearing and fattening them was much studied, and a dressed hog was among the most expensive of the imperial dishes. The Jews and Mahometans do not eat the flesh of the hog.

S. babyrussa, Lin. Tusks long, slender, turned up vertically; the upper ones bent behind; legs long. Inhabits India Islands.Griff. An. King. iii. p. 408.

S. larvatus, Desm. Tusks moderate, angular and lateral ; a large fleshy tubercle on each cheek. Size of the European wild boar. Inhabits Madagascar._Schrcb. t. 327.

Gen. 128. Phascocherus, Cuv. Desm.-Sus, Lin. Geoff.

Incisors $\frac{2}{6}$, canines $\frac{1}{1}-\frac{1}{1}$, molars $\frac{5}{4}-\frac{5}{4}=30$. Tusks very strong, lateral, and directed upwards; molars composed of cylinders of enamel, inclosing the osseous substance; large warts on the cheeks; toes like the hog.

P. Africanus, Desm. (Sus AEthiopicus, Lin.) Tusks rounded, very thick, directed laterally and vertically; a large fleshy lobe on each cheek. Nearly five feet long. Africa.-Griff. iii. p. 410.

Gen. 129. Dicotyles, Cuv. Desm.-Sus, Lin. Geoff.

Incisors $\frac{4}{6}$, canines $\frac{1}{1}-\frac{1}{1}$, molars $\frac{6}{6}-\frac{6}{6}=38$. Canines or tusks not projecting from the mouth; the other teeth like those of the hog; four toes before, three behind, only two of which lean upon the ground; a glandular opening on the back, from which exudes a fetid humour; no tail.

D.torquatus, F. Cuv. Desm. The Peccari. Hair of the fur annulated with dirty white and black; a large whitish oblique line descending from the shoulders over the sides of the neck. About two feet and a half long. S. America.-Shaw, ii. pl. 224.

D. labiatus, F. Cuv. Desm. Fur of a uniform blackish brown; lips white. Three feet long. S. America._Griff. iii. 413.

Cuvier has mentioned two genera of fossil quadrupeds, the Choropotamus, the general form and size of the head of which is similar to the bog; found in the gypsum quarries near Paris; and the Anthracotherium, which includes a large species, of which the remains have been found at Genes.

\section{Gen. 130. Axoplotherium, Cuv.-(Fossil.)}

Incisors $\frac{6}{6}$, canines $\frac{1}{1}-\frac{1}{1}$, molars $\frac{7}{7}-\frac{7}{7}=44$. Teeth all in one line; general form intermediate between the rhinoceros and horse; feet terminated by two toes; molar teeth in crescentformed lines or tuberculous.-Oss. Foss. 2d edit. 
A. vulgaris, Cuv. Size of the ass.-Found fossil near Paris.

A. secundarium, Cuv. Size of the hog.

A. medium, Cuv. Size and form of the goat.

A. minus, Cuv. Size of the hare.

A. minimum, Cuv. Size of the Guinea pig.

\section{2d Division.-Toes always unequal in number on the hind- feet, and often on those before.}

Gen. 131. Rhinoceros, Lin. Cuv. Desm.

Incisors $\frac{0}{0}$ or $\frac{2}{2}$ or $\frac{4}{4}$, canines $\frac{0}{0}-\frac{0}{0}$, molars $\frac{7}{7}-\frac{7}{7}$ or $\frac{6}{6}-\frac{6}{6}=32$ or 36. Incisors unequal among themselves when they cxist; anterior molars small, the posterior increasing progressively; eyes small, lateral; ears long, narrow; three toes on all the feet; one or two horns, placed on the nose, above the nasal cavity ; skin very thick, naked, and rugous, tail short; laterally compressed.

R. Indicus, Desm. Cuv. (R. unicornis, Lin.) One horn on the nose ; two strong incisors in each jaw, with a small tooth on each side of those in the upper jaw ; skin forming several deep folds. Length upwards of ten feet. Inhabits India.-Griff. iii. 424.

The Rhinoceros with one horn, the unicorn of the Sacred Writings, and the type of the fabulous animal of heraldry, approaches to the elephant in size, and like it feeds on vegetable substances. Its body is heavy, and the skin, which is very thick, forms rugous folds in different parts. The knowledge of this circumstance among the older naturalists led them to multiply these folds, and to figure this animal completely encased in native armour. According to Mr Burchell, whose opportunities of examination were abundant, the horns of this genus do not envelope a bony core like those of the ruminating animals, nor do they partake of the osseous nature of the horns of stags, but appear to be formed of horny fibres, growing from the skin, like thick hairs closely cemented together. The smell of the rhinoceros is so keen that it can perceive at a great distance the approach of men, and it is only by advancing against the wind that the hunter can get within musket shot. Their power of hearing is equally acute. In a specimen lately exhibited in Britain, the colour of the nearly naked skin was gray with a violet tint, and under the folds of the skin fleshcoloured. He was habitually gentle, knew those who supplied him with food, and opened his mouth and put out his tongue for it. His long upper lip seemed peculiarly useful in collecting his food. He was about eight feet long.

R. Sondaicus, Cuv. One horn on the nose; skin rugous, covered with thinly scattered brown hairs; margin of the ears and tail with numerous short hairs. Nearly six feet long. - Sumatra. $X$

R. Africanus, Desm. (R. bicornis, Lin.) Two horns upon the nose; no folds of the skin; no incisors in either jaw. About the size of the Indian species. Inhabits Southern Africa._Shaw, i. pl. 61.

R. Sumatrensis, Cuv. Two horns on the nose; skin almost without folds ; two incisors in each jaw. Sumatra.-Shan, i. pl.62.

R. Camus, Griff. Horns two; muzzle truncated; skin without folds. Nearly double the size of the common two horned rhinoceros of Africa. Southern Africa.-Burchell's Travels, ii. 75.

R. Pallassii, Cuv. (fossil.) Head elongated, supporting two long 
horns; bones of the nose forming a large arch, consolidated by a vertical partition, which is wanting in the living species; body covered with thick hair. Size larger than the African rhinoceros.Found fossil in Siberia, Germany, France, and England.

R. Cuvieri, Desm. (R. leptorhinus, Cuv.) Form approaching that of the African species; head with two horns. Cuv. Reg. An. i. 240.- Found fossil in Italy.

R. minimus, Cuv. About the size of the hog; incisive teeth in both jaws.--Found fossil in France.

Gen. 132. Hyrax, Hermann, Cuv. Geoff-_Cavia, Pall. Incisors $\frac{2}{4}$, false molars $\frac{1}{0}-\frac{1}{0}$, molars $\frac{6}{6}-\frac{6}{6}=32$. Two strong bent incisors in the upper jaw, and two very little canines in youth ; four inferior incisors without canines; body covered abundantly with hair of two kinds, one woolly and short, the other long and silky; four toes on the fore-feet, and three on those behind; nails small, flat, and scarcely covering the upper part of the toes; head large; nostrils oblique; upper lip cleft; ears large and rounded; no tail; two pectoral and four ventral mammæ.

II. Capensis, Desm. Fur thick, of a grayish brown above, and whitish below. About two feet long. Inhabits the Cape of Good Hope.-Shaw, ii. pl. 164.

This singular little animal, the Coney of the Sacred Writings, inhabits holes in rocks, and feeds on vegetables, roots, and fruits. It is found in the neighbourhood of the Cape of Good Hope, in Abyssinia, and on Mount Libanus. The H. Syriacus of Gmelin does not seem to differ from the present species.

\section{Gen. 133. Paleotherium, Cuv.-(Fossil.)}

Incisors $\frac{6}{6}$, canines $\frac{1}{1}-\frac{1}{1}$, molars $\frac{7}{7}-\frac{7}{7}=44$. Incisors ranged in the same line, wedge-shaped; canines conical, crossing each other; molars of a square form, separated from the canines by an empty space, with four roots, ridged with enamel ; general form of the head like that of the tapir.-Oss. Foss.

* Paleotheria, proper.-Inferior molars in double crescents.

P. magnum, Cuv. Size of the horse.

P. medium, Cuv. Size of the hog; feet long and slender.

P. crassum, Cuv. Size of the hog; feet shorter and broader than the preceding.

P. curtum, Cuv. Size of a little sheep; legs very short and thick.

P. minus, Cuv. Size of a small sheep; legs slender.-All found fossil in the gypsum quarries near Paris.

** LOPHIODON.-Inferior molars crowned with transverse eminences.

L. giganteum, Cuv. Size of the rhinoceros. About eight feet long.-Found in the fresh water formations. 
L. tapiroides, Cuv. Size of the ox.-Found in the fresh water formations.

L. Buchsowillanum, Cuv. Size of the hog.-Found near Buchsweiller on the Lower Rhine.

L. tapirotherium, Cuv. Size of the tapir.-France.

L. Aurelianense, Cuv. Size of the hog. France, near Orleans.

L. occitanicum, Cuv. Size of the sheep.-Found fossil at Issel.

Gen 134. Tapirus, Cuv. Geoff.-Hippopotamus, Lin.

Incisors $\frac{6}{6}$, canines $\frac{1}{1}-\frac{1}{1}$, molars $\frac{7}{7}-\frac{7}{7}=44$. Intermediate incisors shorter than the exterior; nose terminating in a little moveable proboscis, but not by a kind of finger like the elephant; eyes small ; ears long and moveable; fore-feet with four toes, the hind ones with three, with short round hoofs; tail very short; two inguinal mammæ.

T. Americanus, Desm. (Hippopotamus terrestris, Lin.) The Tapir. Fur brown or fawn-coloured; a little mane on the neck of the male. Nearly six feet long. S. America.-Shaw, ii. pl. 220.

The tapir sleeps during the day in the most sequestered places, and goes forth at night in search of water melons, gourds, and pasture. If taken young it may be almost immediately tamed, and, like the hog, will feed on any thing.

T. Malayanus, Raffles, (T. Indicus, Desm.) Fur black or dirty brown, with a large white patch on the posterior part.-Griff. An. King. iii. 434.

T. giganteus, Cuv. (fossil.) Size equal to that of the largest elephants. Found in France, in alluvial soil.-Oss. Foss. $2 \mathrm{~d}$ edit.

\section{Family III.-SOLIDUNGULA.}

Three kinds of teeth; only one apparent toe, and one hoof on each foot.

Gen. 135. Equus, Lin. Cuv. Geoff. \&c.

Incisors $\frac{6}{6}$, canines $\frac{1}{1}-\frac{1}{1}$, or $\frac{0}{0}-\frac{0}{0}$ in the females of some species, molars $\frac{6}{6}-\frac{6}{6}=40$. Molars furrowed on each side, with flat crowns, and several ridges of enamel; a void space between the canines and molars; upper lip capable of considerable motion; eyes large; ears rather large, pointed erect, and moveable; feet terminating in a solid hoof; tail with long hair, or a tuft at its extremity ; two inguinal mammæ.

E. Caballus, Lin. The Horse. Tail long, covered with long hair throughout its whole length; ears of medium size; long mane.

The horse is not known in its pristine state. Of those which have returned to the wild state, such as the numerous herds of South America, the appearance is not prepossessing, according to the ideas wlich have been formed of the symmetry of the domestic varieties.

The different races of the horse are numerous, most of the principal countries in 
the world possessing breeds peculiar to themselves. But the Arabian race has long been considered as the noblest of the species, and as combining the qualities of endurance, vigour, and temper, in a higher degree than any of the other varieties. As breeders of horses have ascertained that the qualities of the Arabian horse may be perpetuated in his descendants, in the countries of Europe where attention is paid to the raising of this valuable animal for various purposes, the deterioration which a northern climate induces in a native of warmer latitudes is counteracted by crossing with the original breed. From the importation of the pure breed of Arabia into Europe, and the different crossinge of these and their descendants with the native breeds, has arisen all that variety in appearance and qualities of the horse, which fits them for heavy draughts, the plough or the saddle.

It is in England chiefly, however, that the cultivation and education of the horse has been carried to its greatest refinement, and in this country are local races, admirably adapted to the different purposes which agriculture, or commerce, or luxury may demand. The first is the race-horse, immediately proceeding from an Arabian or Barbary stallion, with an English mare already crossed with a Barb or Arab in the first degree, or the result of two crossings in the same degree. This breed is termed first blood, or the nearest possible to the original stock; and in the quality of speed it is not probable that it can ever be exceeded. The next is the Hunter, the result of crossing a stallion of the first blood with a mare of a degree less near the original source. The third is the cross between the hunter and the more common mares, which, uniting the stronger limbs and heavier bodies of the indigenous races to the qualities of the Arabian, produce the British carriage-horses; and the great dray horse, whose gigantic proportions and immense power of draught can scarcely be surpassed, are the produce of this last with the strongest mares of the country breed. And it is a curious circumstance, that, in the mixture of all these races, the influence of the Arab blood is observable, either in the conformation of some peculiar parts, or the preservation of some peculiar qualities. The Persian, Barbary, and Turkish horses are those which come nearest to the Arabian in conformation and qualities, and the Spanish horses long enjoyed a high character in Europe, probably from the breed being kept up by the intermixture of the horses of Barbary. In France are numerous varieties, and most of them very serviceable animals. The other European races it would be injpossible to enumerate here.

The Arabs divide their horses into two races. The first which they call Kochlani, or Kailhan, are those whose genealogy is known for two thousand years, and which has, they say, originated from the stud of Solomon. The other race, appropriated to servile uses, they name $K a$ dischi, or horses of an unknown race. And they are peculiarly careful, by certificates and other means, to preserve the principal races pure. The mares enjoy the exclusive privilege of transmitting the purity of the race to their descendants, and the genealogies are always reckoned from the mothers.

E. Hemionus, Desm. The Dzhiggtai. Fur light bay in summer, redder in winter; mane and dorsal line black; tail terminated by a black tuft. Size of the horse. Inhabits deserts of Mongolia.-Pall. Com. Petrop. xix. t. 7.

E. zebra, Lin. The Zebra. Fur white, with numerous symmetrical bands of brownish black. Size of a small horse. Inhabits Africa._Shaw, ii. pl. 217.

E. couagga, Desm. Gmel. The Quagga. Head and neck dark brown, with transverse grayish white stripes, the under part and legs, whitish ; tail tufted. Inhabits S. Africa._Shaw, ii. pl. 218.

E. montanus, Gray. The Dauw. Body covered with pure single black and white stripes down to the hoofs.-Gray, Zool. Journ.

E. asinus, Lin. The Ass. Fur gray, more or less reddish, with black dorsal line and a transverse band on the shoulders; ears very large; tail terminated by a tuft of hair.-Shaw, ii. pl. 216. The manners of the ass in domestication are well known. Patient and tempe- 
rate, the ass, but for the horse, would have been the most valuable of our domesticated beasts of burden. In eastern countries, however, the ass is still used for the saddle and as a beast of burden; and the qualities of its progeny, the mule, have secured attention to its production in many parts of the world. In a wild state the ass is still found in Kalmuc Tartary, in innumerable troops, which migrate from the north to the south, and back again according to the season. The ass varies much in size, and it has been observed to degenerate in this respect, according as it is removed from its original country. The ass couples with the horse and the zebra, but their progeny do not propagate.

\section{ORDER IX.-RUMINANTIA.}

No incisors in the upper jaw; in the lower usually eight; a vacant space between the incisors and molars, but in which in some genera are found one or two canines; molars twelve in each jaw, the crown marked with two double crescents of enamel, of which the convexity is outwards in the lower jaw, and inwards in the upper; no clavicles; extremities disposed for walking; two toes furnished with hoofs; metacarpal and metatarsal bones united; four stomachs ; intestines long; two or four inguinal mammæ; horns in the males and often in the females of most species.

This is one of the most natural groups of animals. The term Ruminantia indicates the singular faculty possessed by them of masticating their food twice; and their stomach for this purpose consists of four parts, of which the first three are disposed in such a manner that these animals can at will transmit their food from the one to the other. Their food is invariably vegetables, and they are widely distributed over both continents.

\section{* Without horns.-Camelide, Smith.}

Gen. 196. Camelus, Lin. Cuv. \&c.

Incisors $\frac{2}{6}$, canines $\frac{1}{1}-\frac{1}{1}$, false molars $\frac{1}{1}-\frac{1}{1}$, molars $\frac{5}{5}-\frac{5}{5}=36$. Inferior incisors in the form of cutting wedges; the superior lateral; canines conical, erect, and strong; false molars on each side in the interdentary space; toes united below ; head long; neck very long; upper lip cleft; nostrils slit obliquely; eyes projecting; ears small; back with fleshy hunches; callosities on the breast and flexures of the extremities; four ventral mammæ; hair woolly; tail of medium length.

C. Bactrianus, Lin. The Bactrian Camel. Two hunches on the back; colour generally brown. About 10 feet long. Inhabits Persia, Turkey, \&c.-Shaw, ii. pl. 167.

C. Dromedarius, Lin. The Arabian Camel. One hunch on the middle of the back; fur pale brown. Nearly eight feet long. Inhabits Arabia, Turkey, \&c.-Shaw, ii. pl. 166.

This valuable animal has been in domestication from the earliest times, and has for ages been the medium of commercial communication between the countries on either side of the great deserts of Arabia. For passing these extensive wastes the 
camel is provided with an internal apparatus, in which it can carry a supply of water for ten or twelve days; and when this essential article of life runs short in the passage through the desert, the camel is sometimes killed to procure a scanty supply. To enable him to move on a soft and sinking surface, the feet of the camel are like broad and spreading cushions; the nasal openings, closing at the will of the animal, are admirably adapted for excluding the minute particles of sand; ard his extreme temperance enables him to subsist for weeks on the thorny shrubs scattered over the desert, or a few dates or beans. The camel sees and hears well; and his sense of smell is so acute that it is said he can discover the presence of water at the distance of two miles. He is trained to lie down when he receives his load and to be unloaded; but when overloaded he refuses to rise and is obstinate. The general load is from three to four hundred weight, and with this weight he will travel for weeks in places where no other animal could subsist. Hence the camel, from transferring the productions of the neighbouring countries across these arid wastes, has been emphatically called the ship of the desert. To the wild Arab the camel is what the rein-deer is to the Laplander, invaluable. He feeds on the flesh and milk, makes clothes and tents of the hair, belts and sandals of the hide, and even the dung furnishes him with fuel.

Gen. 13\%. Auchenra, Illig.-Lama, Cuv.-Camelus, Lin.

Incisors $\frac{2}{6}$, canines $\frac{1}{0}-\frac{1}{0}$, false molars $\frac{1}{0}-\frac{1}{0}$, molars $\frac{5}{5}-\frac{5}{6}=32$. Teeth resembling those of the camel ; muzzle little protuberant; upper lip cleft; neck slender; eyes large ; ears long, pointed, and moveable; feet terminated by two toes furnished with little crooked nails, with a callous sole; callosities on the breast and knees; tail short; two mammæ.

A. glama, Desm. (Camelus glama, Lin.) Head long; forehead slightly protuberant, joining the face without sensible interruption ; fur brownish, or variegated with white spots, composed of long soft hair. Inhabits S. America.-Griff. iv. 57.

Before the conquest of Peru the Lama was the only beast of burden employed by the natives. It bears some external resemblance to the camel, but without the hunches. The lama is capable of carrying a weight of $150 \mathrm{lbs}$. and can travel with this weight from sixteen to twenty miles a-day.

The Guanaco of travellers, C. huanaca, Shaw, \&c. is perhaps a variety of this species. It differs little but in being larger and the fur of a uniform chestnut colour.

A. paco, Desm. The Paco. Face elevated above the forehead, and forming an angle with it ; fur clear chestnut or gray, composed of long, fine woolly hair. About the size of a stag, but lower on its legs. Inhabits Peru.-Mam. 426.

A. vicugna, Desm. (Camelus vicugna, Lin.) The Vicugna. Smaller than the preceding; forehead projecting ; fur woolly and fine, of medium length, of a clear brown fawn-colour above, and white below. S. America.-Griff. An. King. iv. 58.

$$
\text { ** Feet bisulcated._Cenvide, Smith. }
$$

\section{Gen. 138. Moschus, Lin. Cuv. Desm.}

Incisors $\frac{0}{8}$, canines $\frac{1}{0}-\frac{1}{0}$, molars $\frac{6}{6}-\frac{6}{6},=34$. Canines wanting altogether in the females; superior canines large in the males; ears long, pointed; body slender; feet with hoofs, separated and enveloping the last phalanges; tail very short; two inguinal mammæ.

v.or. I. 
M. moschiferus, Lin. The Thibetan Musk. Fur of a gray brown, hair coarse; a pouch before the prepuce of the male filled with an unctuous musky substance. Size of the roebuck. Inhabits Chinese Tartary and other parts of Asia.-Shaw, ii. pl. 171.

M. meminna, Gmel. Desm. Fur olivaceous ash-coloured above, white below; sides and back marked with white spots. About 16 inches long. Inhabits Ceylon.-Shaw, ii. pl. 173.

M. Javanicus, Desm. The Kantchil. Fur deep red brown on the back; three white streaks under the throat. Size of a rabbit.Inhabits Java.

M. Napu, Griff. The Napu. Fur ferruginous gray above, whitish on the sides; five white stripes under the throat divided by black ones. Size of the preceding. $-F$. Cuv. Mam.

M. pygmons, Lin. Desm. Fur reddish brown above, white below. About eight inches long.-Shaw, ii. pl. 172.

\section{1st Division.-Horns hollow and persisting-or bony and deciduous.}

1st Tribe.-Horns branched, deciduous, the new ones increasing in size each year, always in the males, and sometimes in the females.

\section{Gen. 139. Cervus, Lin. Cuv. Desm.}

Incisors $\frac{0}{8}$, canines $\frac{0}{0}-\frac{0}{0}$ or $\frac{1}{0}-\frac{1}{0}$, molars $\frac{6}{6}-\frac{6}{6}=32$ or 34 . Canines when they exist compressed and bent back; head long, terminated by a muzzle; eyes large, pupils elongated transversely; a lachrymal sinus in most; ears large and pointed; tongue soft; body slender; four inguinal mammæ; horns solid, deciduous, palmated, branched, or simple, in the males; females, with one exception, without horns.

C. alces, Lin. The Elk. Horns spreading into a broad palm, with numerous antlers upon its external border; muzzle tumid and cartilaginous; no canine teeth ; ears long; neck short; a tuft of hair under the throat; legs very long; fur ashy brown or whitish. Inhabits Northern parts of both continents.-Shaw, ii. pl. 174.

C. tarandus, Lin. The Rein-Deer, Horns large in both sexes, with a long compressed stem, and palmated and dentated antlers; no canines; tail short. About five feet and a-half long. Inhabits the arctic circle of both continents.-Shaw.

The Rein-Deer is the only animal of the genus which has been subjugated by man. The Laplanders possess numerous flocks, with which they travel according to the season to places where the food of the animal is most abundant. In the inhospitable wastes of Lapland the rein-deer is invaluable to the poor inhabitants, and supplies all their wants. Its flesh and blood is used for food, its skin forms their clothes, and its tendons are split and used as thread. The castrated males are trained to the sledge, and the females furnish their families with milk. The chief food of the rein-deer is the Lichen rangiferinus; and in winter they dig the snow with their feet to procure it. The rutting-season is in October, and the period of gestation is thirty-three weeks. Two young are generally produced. At birth the fawns have 
little knobs on their heads, and at fifteen days old the horns are about an inchlong. The adult males aud sterile females shed their horns in winter, the breeding females preserve theirs till the month of May. The castrated individuals often preserve their horns for a year longer than the others. The rein-deer is not now found in Europe beyond $60^{\circ}$. N. lat., although it appears that they have formerly existed in the Pyrenees. They are found wild in Siberia, the Uralian mountains, along the river Kema to Kurgus; and the Samoiedes and Koriacs possess flocks of rein-deer like the Laplanders.

C. major, Ord. Desm. The Wapiti. Horns very large, branching in serpentine curves, terminating in a fork; brow antler over the face ; muzzle broad; lachrymal sinuses ; tail very short ; a yellowish disc on the buttocks ; fur dun-brown in summer ; dark browngray in winter. Larger than thestag. N. America.-Griff. iv. 95.

Var. C. Canadensis. Somewhat smaller; antlers more bent up, and colour darker.

C. elaphus, Lin. The Stag. Horns with three anterior antlers, all curving upwards, the summit forming a crown of snags from a common centre ; lachrymal sinuses ; fur red brown in summer, brown-gray in winter; a pale disc on the buttocks. Inhabits Europe, Asia, and the north of Africa. B.-Shan, ii. pl. 177.

The stag sheds his horns in February, and has them renewed in July or August.

It can eat the leaves of the yew without injury.

Var. The Barbary and Corsican Stag. Legs shorter, and body thicker than the common stag.

C. Wallichii, Cuv. Horns rather short, with two small antlers at base, and another further up pointing forwards; large suborbital opening; fur yellowish brown gray, with a disc on the croup ; tail very short. Nepaul._Griff. Syn. 309.

C. hippelaphus, Desm. Horns trifurcated, basal antler on the burr; lachrymal sinuses; fur brown; margin of the lips and chin whitish ; hair coarse ; a mane on the neck ; tail long, terminated by a dark tuft. Size of the stag.-E. Indies.

C. unicolor, Smith. Horns long, slender; basal antler on the burr, curving upwards; another on the stem pointing inwards; fur entirely brown; throat covered with long bristly hair. Ceylon.Griff. Syn. 310.

C. Aristotelis, Cuv. The Samur. Horns short, pointed; a vertical antler on the burr, with a fork near the summit of the stem pointing obliquely backwards; fur blackish and dark brown; a large mane on the neck and throat. Bengal.-Griff. Syn. 310.

C. equinus, Cuv. The Malayan Rusa. Horns robust, pearled; basal antler on the burr; terminal bifurcation from the internal posterior side of the stem, with obtuse points; suborbital opening very large; orange-coloured disc on the buttocks, heavy mane; canines in both sexes. Java.-Griff. iv. 112.

C. axis, Lin. The Axis, Penn. Horns round, elongated, rather smooth ; anterior antler near the burr; summits converging; second antler on the internal side of the main branch turning backwards; lachrymal sinuses small; fur bright fulvous, spotted with white; tail long, brown above, bordered with white. E. Indies. -Shaw, ii. pl. 180. 
C. Mariannus, Desm. Horns round, with two antlers, the basal one nearly vertical, the second posterior and internal; lachrymal sinuses; fur grayish brown; tail short. Less than the fallow-deer. Marianna Islands.-Griff. iv. 115.

C. porcinus, Lin. The Porcine Deer, Penn. Horns slender, with two antlers very little developed, the second near the summit; head short; ears round at tip ; fur fawn-coloured, spotted with white.-Shan, ii. pl. 180.

C. dama, Lin. The Fallow-Deer. Horns in the male only, round, with two antlers; summits palmated, deeply dentated ; fur brown, with white spots, whitish below; tail long. Inhabits Europe and Western Asia. B.-Shaw, ii. pl. 178.

C. capreolus, Lin. The Roebuck. Horns rather small, cylindrical, a small antler on the middle of the stem pointing forward; a second higher up, directed backward; no lachrymal sinuses ; fur gray brown or fawn-coloured, buttocks white. About $3 \frac{1}{2}$ feet long. There is a black coloured variety. - Inhabits Europe. B.

C. pygargus, Desm. Horns cylindrical, rugous, denticulated ; first antler vertical, with processes at the base, the summit bilobed; posterior antlers horizontal; fur brown, paler below; a large white disc on the buttocks; tail rudimentary. Size of the stag. Russian Tartary.-Schreb. tab. 253.

C. muntjac, Desm. Horns extremely short, upon pedicles, bent inwards, with a little rudimentary antler at the base pointing forwards ; pedicles prolonged in the form of ribs down to the nose, two superior canines in the male; fur gray brown, paler below. Size of the roebuck. Inhabits India.-Griff. iv. 144 .

C. subcornutus, Blainville. Horns small, with regular burr, and small process in front; the point of the stem turned back; pedicles of the horns not much prolnnged on the forehead; no canines.

C. Virginianus, Desm. Virginian Deer, Penn. Horns much bent forwards, with an antler on the internal face of each stem directed inwards, and two or three others at the posterior face directed backwards; lachrymal sinuses; no canines ; fur cinnamon fawn in summer, gray in winter. Between five and six feet long. N. America.-Harlan, 238.

C. macrotis, Say. Horns slightly grooved and tuberculated at the base, similar in form to the C. Virginianus; ears very long, reaching to the bifurcation of the horns; fur reddish brown; tail compressed, almost naked beneath. United States.-Harlan's Faun. Amer. 243.

C. paludesus, Desm. Horns rather large, cylindrical, terminated by a fork, with a branch above the burr pointing forward and upwards, sometimes bifurcate; muzzle large ; lachrymal sinuses ; tail of medium length; fur red bay above, whitish below; a black triangle on the forehead. Size of the stag.-Griff. iv. 134.

C. campestris, F. Cuv. (C. leucogaster, Schreb.) Horns middle- 
sized, rather slender, more or less rugous ; stem sub-erect, with anterior antler pointing forwards and upwards ; one or two smaller behind, oblique ; lachrymal sinuses ; fur of reddish bay above, white below. About four feet long. Paraguay.-Griff. iv. 136.

C. nemoralis, Smith. Horns about eight inches long, sub-vertical, rugous at the base; small anterior antler about the middle of the stem; posterior second antler forming a fork with the summits of the horn, which flattens and turns inwards and forwards, making a hook; black spot on the nose and each side of the neck, and one on lower lip, all on a white ground; fur on the back brown gray. S. America._Griff. An. King. iv. 137.

C. rufus, Desm. Horns short, simple; canines in the upper jaw of the male; lachrymal sinuses ; tail pretty long; fur bright red above, white below. Four feet long. Paraguay.-Griff. iv. 104.

C. simplicornis, Smith. Horns small, simple, pointed; dark ring round the orbits, and spots about the corner of the upper lip; fur bright fulvous; tail short, with long hair of a red colour. Size of the roebuck. Inhabits Brazil.-Griff. iv. 141.

C. nemorivagus, Desm. Horns straight, about two inches long; lachrymal sinuses small; fur of a grayish brown above, white below. S. America.-Griff. iv. 142.

C. Hibernus, (fossil,) Desm. (C. giganteus, Cuv.) Horns of very great dimensions, forming a large palm, with antlers on both borders, fewer than in the elk; spread of the horns nine to twelve feet. The skeleton of a fine specimen of this animal from the Isle of Man is in the Edinburgh Museum.-Found fossil in Europe.

C. palceodama, Cuv. Horns resembling those of the fallow-deer, but with only one antler on the stem.-Found fossil in Sweden.

C. Somonensis, Desm. Horns resembling those of the fallow-deer, but larger, and rising immediately from the frontal bone.-Fossil in France and Germany.

C. Guetardi, Desm. Horns similar to the rein-deer, but smaller in dimensions, almost filiform, with two antlers at their base.-Fossil in France.

2d TRIBE.-Horns or prominences of the frontal bone enveloped in a hairy skin, in both sexes.-GIrafFIDE, Smith.

Gen 140. Camelopardalis, Lin. Cuv. Geoff. \&c.

Incisors $\frac{0}{8}$, canines $\frac{0}{0}-\frac{0}{0}$, molars $\frac{6}{6}-\frac{6}{6}=32$. Head very long, with a bony tubercle on the forehead, and two osseous peduncles covered with skin and hairy, terminated by a tuft of bristles ; upper lip entire ; no lachrymal sinuses ; ears point ed; tongue rough, with corneous papillæ; eyes large; neck extremely long; withers much elevated; legs slender; a callosity on the sternum; four mammæ. 
C. giraffa, Gmel. Desm. (C. Camelopardalis, Lin.) The Giraffe. Fur variegated with brown and ferruginous angular and numerous spots ; tail terminated by a tuft of dark long hairs. Height before about 15 feet. Inhabits Central Africa.-Shaw, ii. 182.

The Giraffe seems to have been unknown to the Greeks. In the year 708 of Rome, Julius Cæsar brought one to Europe, and the Roman Emperors afterwards exhibited them at Rome, either for the games in the circus, or in their triumphs over the African princes. Albertus Magnus, in his Treatise de Animalibus, is the first modern author who speaks of the giraffe. In 1486 ore of the Medici family possessed one at Florence, where it lived for a considerable time. In its native country the giraffe browses on the twigs of trees, preferring plants of the Mimosa genus ; but it appears that it can without inconvenience subsist on other vegetable food. The one kept at Florence fed on the fruits of the country, and chiefly on apples, which it begged from the inhabitants of the first storeys of the houses. The specimen in Paris, from its having been accustomed in early life to the food prepared by the Arabs for their camels, is fed on mixed grains bruised, such as maize, barley, \&c. and it is furnished with milk for drink morning and evening. It however willingly accepts fruits and the branches of the acacia, which are presented to it. It seizes the leaves with its long rugous and narrow tongue by rolling it about them, and seems annoyed when it is obliged to take any thing from the ground, which it seems to do with difficulty. To accomplish this it stretches first one, then the other of its long fore-legs asunder, and it is not till after repeated attempts that it is able to seize the objects with its lips and tongue. The pace of the giraffe is an amble, though when pursued it flies with extreme rapidity, but the small size of its lungs prevents it from supporting a lengthened chase. The giraffe defends itself against the lion, its principal enemy, with its fore-feet, with which it strikes with such force as often to repulse him. The name Camelo-pardalis (camel-leopard) was given by the Romans to this animal, from a fancied combination of the characters of the camel and leopard ; but its ancient denomination was Zurapha, from which the name Giraffe has been adopted.

3d TRIBE.-Prominences of the frontal bone covered with a horny case.-CAPRIDF, Smith.

Gen. 141. Antilope, Cuv. Geoff. Desm.-Capra, Moschus, Lin.

Incisors $\frac{0}{8}$, canines $\frac{0}{0}-\frac{0}{0}$, molars $\frac{6}{6}-\frac{6}{6}=32$. Horns in both sexes, or in the males only, covering a solid bony core, round, compressed, variously inflected, and often marked by transverse annulations, or a projecting spiral ridge, sometimes bifurcated ; muzzle partly naked in the greater number; often lachrymal sinuses; ears large; legs slender; two or four mammæ.

A. cervicapra, Pall. Desm. The Common Antelope. Horns black, round, with a triple bending, and annulated the greater part of their length; tufts on the knees ; fur fawn-coloured above, white below. About four feet long. India.-Pall. Spic. fas. i. t. 1, 2.

A. Saiga, Desm. Pall. (Capra Tatarica, Lin.) Horns of the male yellow, transparent, marked by 16 or 18 rings, smooth at the point, arched and lyre-shaped ; muzzle cartilaginous, gibbous ; nostrils very open; fur fulvous above, white below; tufts on the knees. Body four feet long. Inhabits sandy deserts near the Caspian Sea.-Pall. Spic. fas. xii. t. 1 and 3.

A. gutturosa, Pall. Desm. Horns of the male black, lyre-shaped, 
with transverse rings; larynx forming a remarkable projection before the neck; glandular bag near the prepuce; fur fawn-coloured in summer, grayish in winter. Inhabits deserts in Central Asia.-Pall. Spic. fas. xii. t. 2, 3, fig. 14-17.

Sub-Gen. 1. GazeLra, Blainville.-Horns with double flexure, lyreshaped, annulated, without ridges, in both sexes.

A. dorcas, Pall. Desm. Horns black in both sexes, lyre-shaped, annulated in the greater part of their length; fur fawn-coloured. above, white below, with a band of brown black upon each fiank; tail tufted with black; no projection of the larynx. Smaller than the roebuck. Inhabits Northern Africa, \&c.-Buff. xii. pl. 23. Major Smith describes three varieties of this species under the names of A. Kevella, Corinna, and Cora.

A. subgutturosa, Desm. Horns large, grayish black, lyre-shaped, annulated ; larynx projecting ; fur ash-coloured above, white below, a brown band on each tlank. Three feet and a-half long. Inhabits Persia, \&c.-Schreb. t. 170, B.

A. Euchore, Forster, Desm. The Springbok. Horns brown black, lyrate, annulated; a longitudinal fold of skin on the croup, with white hairs; fur fawn-coloured, white below, with a brown line on each flank. About four feet and a-half long. Inhabits plains of Southern Africa.-Shaw, ii. pl. 102.

A. pygarga, Desm. Pall. Horns black, round, lyrate, with eleven or twelve projecting rings ; fur hoary brown above, whitish below; head and neck of a red gray; a line of. white on the forehead; belly and buttocks white; no lachrymal sinuses. Upwards of five feet long. Inhabits Suuthern A frica.-Schreb. t. 273.

A. mytilopes, Smith. Horns one foot long, slender, round, sublyrate, black, with thirteen or fourteen obsolete rings, standing on a broad rufous spot; space between the eyes, mouth, under jaw, breast, belly, croup, and legs, white : a bar across the nose, neck, shoulders, and flanks fulvous; hoofs broad, flat, rounded. In habits Western Africa.-Griff. iv. 204.

A. melampus, Desm. The Pallah. Horns black, round, very long, lyrate, strongly annulated at their base ; fur ferruginous above, white below; a black line on the back and a transverse band of the same colour on the buttocks; a black spot above the spurious hoofs. Nearly five feet long. Cape of Good Hope.Daniell's Afr. Scen. No. 9.

A. Senegalensis, Desm. The Senegal Antelope, Penn. Horns black, a little flattened laterally, lyrate, very long, marked with from 12 to 17 rings, and their termination smooth; head and tail long. About 5 feet long. Inhabits Senegal._Penn. Quad.p. 38.

Sub-Gen. 2.-Cervicapra, Blainville. Horns simple, few or no annulations or ridges.

+ Horns bent forwards.

berkweres?

A. dama, Pall. Desm. Horns short, round, black, bent forwards 
and inwards, smooth at the extremity, with five or six broad illdefined rings at the base ; fur white, with the neck, back, and shoulders rufous; a fawn-coloured spot over each eye. Three feet and a half long. Inhabits Senegal.-Schreb. t. 265.

A. redunca, Pall. Desm. Horns short, round, black, sub-erect, a little bent forwards; fur entirely fawn-coloured. Four feet and a-half long. Inhabits Africa._Schreb. t. 265.

A. villosa, Burchell. Horns $8 \frac{1}{2}$ inches long, straight, vertical, slightly inclining forward, round, slender, with thirteen rings, sharppointed; black spot before the eyes ; suborbital sinus large beneath. Body slender, fur whitish gray, beneath white; hair soft and villous; tail tipped with white. Length four feet and a-half. Southern Africa.-Griff. Syn. 339.

A. tragulus, Desm. The Steenbock. Horns vertical, round, slender, and pointed, wrinkled at the base ; fur reddish above, white below; ears pointed; groin naked and black.-Inhabits Caffraria.

A. melanotis, Desm. (A. grisea, Cuv.) The Grysbock. Horns black, round, vertical, slightly bent forward; fur deep chestnut red, mixed with white hairs, whitish below; ears broad, open. -Inhabits Caffraria.

A. eleotragus, Schreb. Desm. The Rietbock. Horns 10 or 12 inches long, black, slightly curved, with the points forward, and oblique obsolete annulations on the first half; fur woolly, cine. reous above, white below; tail nine or ten inches long. Inhabits Caffraria.-Shan, ii. pl. 193.

A. acuticornus, Blainville. Horns three inches long, round, smooth, black and pointed, slightly bent outwards and forwards, the frontal crest passing behind them.-India.

\section{t+ Horns erect.}

A. oreotragus, Desm. The Klipspringer. Horns fire inches long, distant, round, vertical, slightly inclined forwards, obscurely wrinkled at the base and annulated in the middle; tips smooth and pointed ; fur olive-coloured, hard, and spirally twisted. Inhabits Caffraria._Shaw, ii. pl. 183.

A. pallida, Lichtenstein. Horns perfectly straight, inclining backwards, round, with an obsolete ridge in front, four inches long, very pointed; fur pale fawn-coloured above, white below ; a black naked ring round the eyes. Caffraria.-Griff. Syn. 342.

A. subulata, Smith. Horns $\frac{3}{8}$ of an inch in diameter, subvertical, round, smooth, $4 \frac{1}{\frac{1}{8}}$ inches long, slightly bent inwards. E. Indies. -Griff. Syn. 342.

A. Chickara, Hardwick. Superior horns black, subulate, round, without rings, erect, smooth, three inches long; spurious horns little more than an inch long, placed between the middle line of the orbits; fur bright gray, whitish beneath. India._Lin. Trans.

A. capreolus, Desm. Lichst. The Rehbock. Horns black, round, 
pointed, vertical, parallel, slightly annulated for half their length ; fur woolly, grayish-red above, white below; no lachrymal sinuses. About five feet long.-Cape of Good Hope.

A. Lalandia, Desm. Horns erect, slender, shorter than the head, parallel ; fur long, grayish-brown on the back, white on the belly. Cape of Good Hope.-Dict. Class. Hist. Nat. i. No. 14. pl. 1.

A. silvicultrix, Schreb. Desm. The Bush Antelope. Horns black, round, short, wrinkled at the base, rugous higher up, and smooth at the tip, slightly bent outwards ; fur shining-brown, with the lumbar and dorsal region covered with long fawn-coloured hair; lachrymal sinuses; no tufts on the knees; tail pendulous, tufted. Inhabits Sierra Leone.-Griff. iv. 258.

A. quadriscopa, Smith. Horns four inches long, reclining, straight, diverging, pointed, with six or seven small annuli at the base; ears longer than the horns; fur yellowish gray, white beneath; legs slender, with tufts on the knees and hind-legs. Size of the roebuck. Africa.-Griff. Syn. 345.

A. mergens, Blainville. The Deukerbok. Horns erect, annulated at the base, a half shorter than the head; fur dun, with the extremity of the feet brown and a line of the same colour on the anterior face of the fore-legs; a suborbitary furrow. Inhabits Cape of Good Hope.-Desm. Mam. 463.

A. grimmia, Desm. (Moschus grimmia, Lin.) Horns very short, stout, erect; fur fawn-coloured; face and line down the back dark; ears short and broad; legs gray ; tail black at the point ; a lengthened suborbital slit, but no lachrymal sinus. Two feet and a-half long. Inhabits Guinea.-Mam. 464.

A. ccerula, Smith. Horns very small, black, pointed, with five semiannuli nearly concealed in the hair of the forehead; fur slaty purplish-blue, white beneath. Upwards of two feet long. Caffraria._Griff. Syn. 348.

A. scoparia, Desm. Horns small, erect, with five annulations in the first half, points smooth, black; head and upper parts of the body pale fulvous ; lower parts white; tail short, blackish ; tufts on the knees. Inhabits Cape of Good Hope-Schreb. t. 261.

A. pygmaea, Pall. Desm. The Pigmy Antelope. Horns small, about an inch long, black, pointed; fur bright bay, whiter below; no tufts on the knees; a small lachrymal opening. Twenty inches long. Inhabits Central A frica.-Shan, ii. pl. 188.

\section{t+十 Horns bent backwards.}

A. Sumatrensis, Desm. Horns six inches long, round, bent back, with ten or twelve wrinkles at base ; fur brown black; neck and back with long white hairs; lachrymal sinuses with a small opening. Length $4 \frac{1}{2}$ feet. Sumatra.-Marsden's Sum. p. 93.

A. goral, Hardwick. Horns four and a-half inches long, black, subulate, bent back, with five or six annuli at the base. Fur grayish-brown, whitish under the throat. Nepaul._Lin. Trans. 
Sub-Gen. 3. A rcelaphus, Blainv.-Horns with double flexures, annulated, without ridges, in both sexes; lachrymal sinuses, but no inguinal pores.

A. bubalis, Pall. Desm. Head much elongated; horns black, of medium length, strongly annulated in a spiral form; point directed backwards; fur fawn-coloured; tail black at the end. Size of the stag. Inhabits Northern Africa.-Buff. xii. pl. 37, 38.

A. caama, Desm. Schreb. The Hartbeest. Head very long; horns thick, strongly annulated obliquely to the second bending; the points much prolonged backwards; fur bay fawn-colour, deeper on the back, with black or brown at the base of the horns, upon the forehead, and the anterior face of the legs. Upwards of six feet long. Southern Africa.-Schreb. t. 277.

Sub-Gen. 4. Tragelaphus, Blainville.-Horns more or less compressed, spiral, with ridges in both sexes, or in the males only; lachrymal sinuses sometimes wanting.

A. strepsiceros, Desm. Horns very long, diverging, describing three elongated spiral turns, smooth, compressed, with two ridges; a mane on the neck; fur brownish gray, with a dorsal line, and many transverse white bands on the flanks. Elever feet long. Interior Africa.-Daniell, Afr. Scen. No. 6.

A. sylvatica, Gmel. Desm. The Boshbock. Horns in the male only, ten inches long, with an obsolete ridge on both sides, spiral and sublyrate, black and closely annulated at base, smooth at the point; fur chestnut above, with white spots on the neck, croup, and thighs. Length $3 \frac{1}{2}$ feet. Caffraria.-Shaw, ii. pl. 193.

A. scripta, Pall. Desm. Horns seven inches long, reclining, straight, wavy, with two ridges twisting spirally round the axis; fur fulvous bay, with white transverse bands at the flanks, and spots on the thighs. Length $4 \frac{1}{2}$ feet. Senegal.-Shaw, ii. pl. 186.

Sub-Gen. 5. Oreas, Desm.-Horns straight, with a very strong spiral ridge, in both sexes; no lachrymal sinuses; four mammo; tail long and tufted.

A. oreas, Desm. Horns black, very thick, diverging, with a strong ridge, describing two spiral turns, towards their base, smooth at the point; a little mane upon the neck and back; a dewlap with long hairs, and a projection of the larynx below ; fur grayish fawn-coloured. Length eight feet.-Pall. Spic. fas. xii. p. 17.

Sub-Gen. 6. Boselaphus, Blainville.-Horns simple, not rugous, variously curved, without spiral ridge.

A. picta, Pall. Desm. The Nyl-ghau. Horns conical, black, smooth, with a triangular prolongation at their base; much separated, bending forwards and upwards; lachrymal sinuses; fur gray in the male, fawn-coloured in the female; a tuft of long dark hair on the throat; black and white rings on the pasterns; tail tufted. Inhabits India.-Shan, ii. pl. 189. 
A. gnu, Gmel. Desm. The Gnu. Horns in both sexes, strong, large, flattened at the base, arising from the occiput, bent forwards upon the eyes, and turning up into a pointed hook; a vertical mane on the neck, with a beard and dewlap; fur brown; tail long and lined with long white hair. Length five feet and ahalf. Inhabits Southern Africa.-Shaw, ii. pl. 196.

Sub-Gen. 7. Oryx, Desm.-Horns in both sexes, large, pointed, erect, or with a slight bend posteriorly, annulated, but with a ridge ; lachrymal sinuses; tail tufted.

A. oryx, Pall. Desm. The Caffrarian Oryx. Horns black, thin, round, very long, nearly straight ; fur gray above, white below, with a black dorsal line; head whitish, with a line over each eye and across the forehead of brown black; a chestnut spot on the shoulders and thighs. Five feet long. Southern Africa. - Schreb. t. 257.

A. leucoryx, Desm. Pall. The White Oryx. Horns very long, (three feet,) slender, horizontal, bent backwards, obliquely annulated, tips smooth ; fur white; black spot at the base of the horns passing down the face; a second through the eyes, towards the mouth; lower part of the thighs rufous ; short dark mane; tuft of the tail black. Size of a small horse. Arabia and Persia.Shaw, ii. pl. 184.

A. Addax, Smith. Horns upwards of two feet long, robust, black, round, divergent, with two and a-half spiral turns, and 32 to 35 annuli extending three-fourths of the length; no lachrymal sinus; dark coloured mane on the neck, and a tuft of hair on the throat; head and neck grayish, the rest of the body white; tail tufted. Inhabits Nubia.-Griff. iv. 193.

A. gazella, Pall. Desm. Horns black, round, slender, three feet long, bent back, with thirty-six annulations, not spiral; forehead narrow; head long ; body clumsy ; lachrymal sinuses; body and neck fulvous gray, with a reversed ridge of short white hair on the neck; head white; a dark spot at the root of the horns, passing down the face. Perhaps this, as well as the A. Tao of Major Smith, is but a variety of the preceding.-Interior of Senegal.

Sub-Gen. 8. Egocenus, Desm.-Horns very large and strong, pointed, simply bent back, annulated; a half muzzle, and no suborbilary sinus : tail prelty long.

A. leucophaca, Pall. Desm, The Blue Antelope. Horns slightly compressed, scimitar-shaped, about twenty inches long, closely annulated with from twenty to thirty rings ; ears long; fur silvery blue gray; short white mane turning towards the head; tail tufted at the end. Nearly six feet long. Southern Africa. -Shan, ii. pl. 195.

A. equina, Geoff. Desm. Horns very robust, about 24 inches long, strongly bent back, with from 17 to 27 prominent rings; fur 
coarse, undulating, grayish brown; a white spot round the eye, formed of long hairs. Inhabits Southern Africa.-Desm. 476.

Sub-Gen. 9. Rupicapra, Blainville.-Horns simple, vertical, round and striated, strongly bent backwards towards the point, in both sexes; no lachrymal sinuses nor inguinal pores; tail very short; two mamma.

A. rupicapra, Pall. (Capra rupicapra, Lin.) The Chamois. Horns seven or eight inches long, perpendicular to the head, hooked at the end; fur fawn-coloured in summer, and brown in winter; a dark line through each eye; tail short. Between three and four feet long. Switzerland.-Griff. iv. 281.

Var. A. The Yzard. Smaller, gray brown, cheeks and buttocks fawn-colour.-Inhabits the Pyrenees.

Var. B. The Persian Chamois. Horns bent back into a regular hook from their root; colour rufous yellow.

Sub-Gen. 10. Antilocapra, Blainville.-Horns compressed, bent into a hook posteriorly towards the point, and furnished with an anterior antler; general form of the antelope.

A. furcifer, Desm. Horns one foot long, compressed, flat on the inner side, striated, with a compressed antler to the front forking with the after part, which forms a hook backwards ; colour reddish brown above, white below; a red mane on the neck; tail very short. Larger than the roebuck. United States.-Griff.iv. 170.

\section{Gen. 142. Capra, Lin. Pall. Cuv. Desm. Geoff.}

Incisors $\frac{0}{8}$, canines $\frac{0}{0}-\frac{0}{0}$, molars $\frac{6}{6}-\frac{6}{6}=32$. Horns common to both sexes, directed upwards and backwards, striated transversely; no muzzle; interval between the nostrils naked; no lachrymal sinus, or inguinal pores ; ears pointed; legs robust; tail short; chin bearded.

C. Ibex, Lin. The Ibex. Horns flat, with two longitudinal ridges at the sides, crossed by numerous transverse knots, subvertical, curved backwards, about thirty inches long, dark-coloured; fur gray fawn-coloured, whitish below, with a dorsal line of blackish brown. Five feet long. Inhabits the Alps, Pyrenees, \&c. -Shaw, ii. pl. 198.

C. Jaela, Smith. Abyssinian Ibex. Horns three feet long, forming a semicircle backwards, subtriangular, with twenty-three variegated prominent knots; fur brownish fawn-coloured, with a dark dorsal line; long hair under the throat. Abyssinia.Griff. iv. 301.

Var. The Siberian Ibex of Pallas. Black line on the back and down the front of the legs.

C. Caucasia, Desm. Horns triangular, the anterior edge obtuse, irregularly marked with transverse knots and uniform wrinkles; fur dark brown above, white beneath the breast; line on the back dark. Caucausian Mountains.-Griff.iv. 302. 
C. agagrus, Desm. Pall. The Goat. Horns forming an acute angle to the front, rounded at the back, ribbed transversely; head black in front; beard brown; general colour brown and gray, varying with the seasons.-Mountains of Persia, \&c.

The domestic goat, $(\boldsymbol{C}$. Hircus $)$ the principal variety of the original breed, has the horns a little more vertical than the agagrus, and is a little smaller. It is known all over Europe. The Welsh breed is of a large description, with fine long hair. The Persian goat has long coarse ash-brown hair, and a large tuft of hair between the horns. The dwarf goat, originally from Guinea, now extremely multiplied in South America and the West Indies, is distinguished by close short hair more or less white with fawn colour, the males having the beard, tail, neck, and legs black, and without horns. The Cachemire breed have the hair long, silky, straight and white, the ears large and turned downwards; and the Thibet or Tartar half breed of the same has likewise very fine and white hair, but more subject to vary in the colour. The Angora breed has long soft hair, mostly white, with buff-coloured ears and yellowish horns; the Nepaul breed has long legs and the horns short and spiral, the hair long, loose, and blackish ; and the Syrian breed is blackish where the hair is long, with the head, ears, legs, and belly white mottled with black. In Egypt there are three varieties, one with long hair, a second with spiral horns and ears longer than the beard; and a third with very large ears and the horns small or none. But, like other domesticated animals, the goat runs into endless varieties.

C. Jemlachica, Smith. The Jemlah Goat. Horns placed obliquely on the frontal bone, high above the orbits, almost in contact, depressed, nearly flat, nine inches long, inclining outwards, then tapering and turning inwards ; anterior edge marked with seven small protuberances ; fur cinereous fawn-coloured, with abundant long hair; a dark line down the face and along the spine. Size of the Ibex. Himalayah Mountains.-Griff. iv. 308.

\section{Gen. 143. Ovis, Lin. Cuv. Geoff. Desm.}

Incisors $\frac{0}{8}$, canines $\frac{0}{0}-\frac{0}{0}$, molars $\frac{6}{6}-\frac{6}{6}=32$. Horns common to both sexes, sometimes wanting in the female, thick, angular, wrinkled transversely, pale coloured, turned laterally in a spiral form; ears small; legs slender; hair of two kinds; tail more or less short; two mammæ.

O. tragelaphus, Desm. The Bearded Sheep, Penn. Horns two feet long, wrinkled, angular, black, turned spirally backwards and downwards; a large beard from the cheeks and under jaw divided into two lobes; neck short, with a mane; knees covered with long hair; general colour rufous brown; tail short. Five feet nine inches long. Inhabits Barbary.-Shaw, ii. pl. 202.

O. montana, Geoff. American Argali. Horns very thick, of a spiral form, directed laterally; colour brown chestnut, formed of short dry hairs; a white disc on the rump; no mane. Inhabits Canada.-Griff. iv. 318.

O. Ammon, Desm. (Capra Ammon, Lin.) The Argali. Horns of the male very large and strong, sometimes four feet long, placed on the summit of the head, triangular, flattened before, striated across ; female with slender wrinkled horns ; colour fulvous gray above, white below, with white on the muzzle, and a whitish 
disc on the buttocks. Five feet long. Inhabits mountains and Steppes of Northern A sia.-Shaw, ii. pl. 201.

O. aries, Desm. (Capra Ammon, Lin.-Musmon, Plin.) The Sheep. Horns very strong, arched backwards, and curved downwards and towards the point; general colour fawn, more or less brown, white on the face and legs, and under the belly; a darker streak on the dorsal line, on the flanks, and often black about the neck. -Corsica, Sardinia, \&c.

Sheep live in families more or less numerous upon the most inaccessible mountains of Asia, Africa, Europe, and America. They are found in flocks of sometimes a hundred in number, conducted by an experienced leader. In the rutting-season these flocks divide into little bands formed by a single male and the females attached to him. When they meet at this season the males fight by butting with their heads, and sometimes kill one another. The domestic varieties are distinguished by differences in form, size, colour, and in horns. The long-legged sheep of Guinea has the body covered with hair, with a kind of mane on the neck. The Barbary and Egyptian broad-tailed sheep, (Ovis laticaudata of Ray) has the wool coarse, the tail long, and wider than the buttocks at its base, and many other breeds exist in Africa, distinguished by their horns, the nature of their wool, and the size of the tail. The Asiatic breeds have some of them the broad tail of the African sheep. The Astracan breed is distinguished by its fine spirally curled wool ; the Circassian race has the tail of such length as to trail on the ground; and other Asiatic families are distinguished by the number of their horns, which vary from four to six. India and China possess also particular breeds; but it is in Europe that, at the present day, the most useful varieties are found. The Merino sheep of Spain holds the first place among the European varieties, but in no country in Europe has the rearing of this valuable animal met with so much attention as in Great Britain. Wool was long a staple of her commerce, and was exported for centuries; and now, since circumstances have changed, and that the manufactures of the country create a demand for the wool raised, the annual value of wool shorn in England is not less than five millions Sterling. The varieties of the sheep in Britain are numerous, and adapted to all the different kinds of pasture and situation. The original breeds of the country still exist in Shetland and the northern counties of Scotland.

Gen. 144. Oviros, Blainville.-Bos, Lin. Cuv. Incisors $\frac{0}{8}$, canines $\frac{0}{0}-\frac{0}{0}$, molars $\frac{6}{6}-\frac{6}{6},=32$. Body thick, heavy ; legs short; face elevated; forehead long and bushy; horns very strong, directed laterally; no muzzle; ears short, eyes small; no furrow in the upper lip; tail very short.

O. moschatus, Desm. (Bos moschatus, Gmel.) The Musk Ox. Adult male size of a small cow; horns rising from the summit of the head, close together and wide at their base, then tapering, and bent down against the cheeks, with the point turned up ; fur brownish black, long and woolly. N. America._Shaw, ii. pl. 212.

The 0. Pallantis, (fossil, ) found on the coast of Siberia, is not ascertained to be a separate species.

Gen. 145 Bos, Lin. Cuv. Geoff. Desm. Lin.

Incisors $\frac{0}{8}$, canines $\frac{0}{0}-\frac{0}{6}$, molars $\frac{6}{6}-\frac{6}{6}=32$. Body large, membersstrong; headlarge; forehead straight; muzzle square; eyes large; ears generally funnel-shaped; a fold of the skin or dewlap on the under side of the neck ; four mammæ; tail long, tufted; horns simple, conical, round, with different inflections, but often directed laterally, and the points raised. 
B. Caffer, Desm. Gmel. The Cape Buffalo. Horns in contact at the base spreading horizontally, and turned up at the point; ears wide rather than pendant; dewlap large; fur deep brown. About nine feet long.-Interior of Africa.

B. pegasus, Smith. Horns lying across the summit of the head, the tips turned up; colour deep brown, with obscure transverse bands; neck with a dense mane ; ears long, pendulous; feet white. Inhabits Central Africa.-Griff. Syn. 371.

B. Arnee, Shaw. The Arnee. Horns triangular, rising obliquely, wrinkled, slightly hanging forwards, with the points turned inwards and backwards ; fur black, very hairy, tail tufted. Seven feet high at the shoulders. Inhabits India, and the domesticated varieties China and Indian Archipelago.-Shaw, ii.

B. Bubalus, Lin. Domestic Buffalo. Horns directed laterally, compressed, with a ridge in front, reclining towards the neck, and the tipsturned up; forehead convex; mammæ of the male placed in a transverse line ; colour darkish or black ; hair coarse ; tail tufted at the end.

B. Americanus, Gmel. Desm. The American Bison. Horns small, round, black, and very distant, turned laterally and upwards ; head short and thick; eyes full; head, shoulders, and upper part of the anterior extremities covered with long brownish woolly hair, tail tufted with black. Eight feet long. Inhabits interior of N. America.—Shaw, ii. pl. 206, 207.

B. grunniens, Lin. Desm. The Yak. Horns round, smooth, pointed, bending laterally forwards and upwards; forehead flat; lips tumid; muzzle small; occiput covered with frizzled hair; withers projecting; hair on the neck and back very woolly, whitish and black, that of the flanks long and pendant; tail with very long hair. Inhabits the Mountains of Central Asia._Shaw. ii.

B. urus, Desm. Pall. (Bos Taurus, var. urus, and Bos Bonasus, Lin.) The European Bison. Horns thick, round, lateral, curved upwards and forwards; forehead square; head and anterior part of the body covered with brown thick and coarse hair; below the throat to the breast a pendant beard, more than a foot long; mammæ disposed in a square form. Upwards of ten feet long. Forests in Europe.-Shaw, ii. pl. 205.

B. Gaurus, Smith. The Gaur. Adult male six feet high at the shoulders, twelve feet long; head resembling the common ox; forehead more arched; horns robust, not bent back; a spinous elevated process on the neck and shoulders; short tufts of dirty white coloured hairs on the forehead ; hair smooth, shining. Inhabits the district of Surjoogah in India.-Breton, in Trans. Med. Soc. Calcutta, ii. p. 247.

B. Gavceus, Smith. The Gayal. Head broad and flat; horns strong, short, distant, lateral, compressed, turned upwards and forwards; dewlap fringed with long hair; a ridge over the shoulders; ge- 
neral colour brown; tail tufted. Perhaps a variety of the preceding.-Inhabits forests east of the Burrampoohtra.

B. taurus, Plin. Desm. Horns round, lateral, arched, with the point turned outwards ; face flat, or a little concave ; occipital crest on the same line as the base of the horns; mamma disposed in a square form; hair fawn-coloured, brown or black, not sensibly longer at the anterior than the posterior parts. About seven feet long. -Griff. iv. 411.

The domestic varieties of the $0 x$ have been divided into two races, viz. those which have a hunch on their shoulders, and those which bave the back straight. Regarding their derivation from the existing wild races, from the Urus, the Bison, or the Yak, all is conjecture. The races with hunches are found in India, the eastern parts of Persia, Arabia, and the African Continent, from the Cape of Good Hope to Madagascar. The great Indian ox of Pennant, or Zebu, equals or surpasses the largest European breeds in size, and the hunch on the shoulders sometimes weighs fifty pounds. A smaller hunched variety has the shape and proportions of an ordinary ox, coloar whitish gray, and with the horns bent forwards. A third variety, scarcely larger than the hog, possesses the hunch, but has no horns; and a fourth, with two hunches, is found near Surat. Besides these varieties there is a race reared in Abyssinia, in the Galla country, and northern Central Africa, which is generally white, and provided with immerise horns. The straight-backed varieties vary much in form, size, and horns, and are spread over all Europe. In England the breeds of this valuable ani$\mathrm{mal}$ are much improved, both for the purposes of the dairy and the butcher. The white Urus, a wild variety, formerly inhabited the woods of Scotland and the north of England, and a few of the ancient race are still preserved. The ox is found fossil over nearly the whole of Europe.

\section{ORDER X.-CETACEA.}

Body pisciform, terminated by a caudal appendage, cartilaginous, and horizontal; two anterior extremities formed like fins, having the bones which form them flattened and very short; head joined to the body by a very short thick neck; two pectoral or abdominal mammæ; ears with very small external openings; brain large; pelvis and bones of the posterior extremities represented by two rudimentary bones lost in the flesh.

\section{Family I.-SIRENIA.-Herbivorous Cetacea.}

Two molars with flat crown; sometimes tusks in the upper jaw ; two pectoral mammæ; mustaches; nostrils, properly so called, placed at the end of the muzzle; nasal apertures on the upper part of the head; body very massive.

Gen. 146. Manatus, Lin.Cuv.Desm.-Trichecus, Lin. Shaw. Incisors $\frac{2}{0}$, canines $\frac{0}{0}-\frac{0}{0}$, molars $\frac{9}{9}-\frac{9}{9}=38$. The incisors exist only in the foetus, and the adults have but 32 teeth, four of the molars falling out in early age; molars with two transverse cushions on their crown; head not distinct from the body; eyes very small; tongue oval; vestiges of nails 
on the margin of the pectoral fins; six cervical vertebra; sixteen pairs of thick ribs; mustaches composed of a bundle of very strong hairs directed downwards, and forming on each side a kind of corn eous tusk.

The animals of this genus are gregarious, and feed on marine vegetables. The male and female demonstrate much attachment to one another, and tenderness for their young. The female, from the position of the breasts, may have given rise among mariners to the fable of the mermaid.

M. Americanus, Desm. Head bony, rather elongated; nasal foramina thrice as long as broad; inferior margin of the lower jaw straight; skin grayish, slightly shagreened, with isolated hairs. Body sometimes 20 feet long. Inhabits Rivers of S. America.Desm. Nouv. Dict. d'Hist. Nat. xviii. pl. G. 9.

M. Senegalensis, Desm. (Trichecus Australis, Shaw.) Head bony, short in proportion to its breadth; breadth of nasal foramina three-fourths of their length ; inferior margin of lower jaw curved; smaller than the preceding. About eight feet long. Inhabits the mouth of the Senegal.-Shan, i. pl. 69.

\section{Gen. 14\%. Halicork, Cuv.-Trichecus, Gmel.-Dugun- gus, Lacep.}

Incisors $\frac{2}{0}$, canines $\frac{0}{0}-\frac{0}{0}$, molars $\frac{3}{5}-\frac{5}{5},=14$. In early age, incisors $\frac{4}{8}$, canines $\frac{0}{0}-\frac{0}{6}$, molars $\frac{5}{5}-\frac{5}{5}=32$. Two of the upper incisors cylindrical and straight, forming tusks ; molars cylindrical, and only three on each side in the adults; body pisciform, terminated by a horizontal fin with two lobes; head not distinct from the body; muzzle truncated and moveable, with thick spiny hairs on the edges of the lips; tongue soft; fins short, without distinct fingers or nails; seven cervical vertebræ; eighteen pairs of ribs.

H. Indicus, Desm. The Dugong. Body pisciform; two short tusks in the upper jaw, straight and directed obliquely downwards; lips very thick, spinous; tail divided into two lobes; general colour bluish gray. 7 or 8 feet long.-Inhabits the Indian Seas.

\section{Gen. 148. Stellerus, Cuv.-Trichecus, Gmel.}

Incisors $\frac{0}{0}$, canines $\frac{0}{0}-\frac{0}{0}$, molars $\frac{1}{1}-\frac{1}{1}=4$. Teeth not implanted in the jaws, but attached to a molarplateby vessels and nerves; triturating surface hollowed into tortuous canals ; body enlarged in the centre, diminishing insensibly to the caudal fin; head obtuse, without distinct neck ; no external ears; lipś double; a cartilaginous crest to cover the eyes; anterior extremities in the form of palmated fins ; caudal fin very broad, crescent-shaped, with two points.

S. Borealis, Desm. (Trich. Borealis, Shaw.) Head round;-no tusks ; tail crescent-shaped ; skin naked, excessively thick, and of a fibrous nature, like horn. South Seas. Twenty-three feet long. 


\section{Family II. Certacea.}

Teeth pointed or obtuse, all of one kind, upon the borders of the jaws; or transverse corneous laminæ in the arch of the palate; two anal mammæ; spiracles on the top of the head.

\section{1st Division.-With small head.}

Gen. 149. Delphinus, Lin. Cuv. Geoff. Desm.-Delphinapterus, Lacep.

Teeth variable in number, of a canine form, sometimes compressed and dentated on their cutting margins, from 200 to none at all; jaws more or less advanced in form of a beak; spiracles with a crescent-shaped aperture; an adipose dorsal fin, or a longitudinal fold of the skin; tail flattened horizontally and bifurcated.

Sub-Gen. 1. Detphrnorhyncus, Blainville. Snout prolonged, with a long and slender beak; jaws almost linear, with numerous teeth on their margins.

D. Geoffroyi, Desm. Jaws straight, linear, very long; a longitudinal fold of the skin on the back in place of a fin; grayish above, white below. Four feet and a-half long. Coasts of Brazil.-Mam. 512.

D. coronatus, Desm. Jaws elongated into a very long and pointed beak, the lower surpassing the upper; 24 teeth on each side below, 15 above; a small dorsal fin; colour black. From 30 to 36 feet long. Frozen Ocean.-Mam. 512.

D. Gangeticus, Desm. (D. roslratus, Shaw.) Forehead gibbous; Q snout very long; upper jaw with 27 or 28 teeth, under one with 30; colour pearly gray. Length $6 \frac{1}{2}$ feet. Ganges.-Mam. 513 .

Sub-Gen. 2. Delphinus, Blainv. Snout prolonged into a beak, broad at its base and rounded at its extremity; jaws furnished with numerous teeth.

D. delphis, Desm. The Dolphin of the ancients. Jaws moderately elongated, and of equal length; 42 to 45 teeth in each jaw, pointed and bent; dorsal fin nearest to the tail; colour black above, fading insensibly to white below. Seas of Europe.-Shaw, ii. pl. 229, fig. 1.

The Dolphin is from eight to ten feet in length, preys on various species of the smaller fish, and sometimes even attacks the whale. According to Pliny this animal has an affection for man, and is fond of music; and he relates a very improbable story of one which carried a boy daily for many years across the arm of the sea from Baia to Puteoli to school. In modern times the appearance of the dolphin and the porpoise sporting on the water is held to portend an approaching storm.

D. tursio, Desm. Jaws moderately elongated, the lower one largest; 23 teeth on each side above, 21 below; back blackish; belly white. European Seas.-Mam. 514.

D. nesarnac, Desm. Snout compressed; teeth 20 to 23 on each side, strong, obtuse ; body very thick. Seas of Greenland.-Mam. 515. 
D. rostratus, Cuv. Desm. Snout long and slender, not depressed; teeth 22 to 26 on each side of the jaws, conical. Size of the common dolphin. Seas of Europe.-Mam. 515.

Sub-Gen. 4. Phoc艮a, Cuv. No beak; snout short and gibbous; numerous teeth in both jaws; a dorsal fin.

D. phocana, Lin. The Porpoise. Body and tail elongated; snout rounded; teeth compressed, from 22 to 25 in both jaws; dorsal fin near the middle of the body; colour blackish above, white below. Four to five feetlong. Inhabits all seas.-Shav, ii. pl. 229.

D. Peronii, Desm. Form and size of the poirpoise; back bluishblack, the rest of the body bright white.-Seas of Australasia.

D. Commersonii, Desm. Form and proportions of the porpoise; body entirely of a silvery white, with the exception of the extre. mity of the snout, the muzzle, tail, and fins, which are blackish. A little larger than the porpoise. Off Cape Horn.-Mam. 517.

D. gladiator, Lacep. Body and tail elongated; upper part of the head convex; snout rounded and very short; dorsal fin near the neck, and much elevated. Length 23 to 25 feet.-North Seas.

D. grampus, Desm. (D. orca, Lin.) The Grampus. Body and tail elongated; snout rounded and short; colour blackish above, white below. Length 25 feet. British Seas._Shaw, ii. pl. 232.

D. griseus, Cuv. Head like that of the porpoise ; dorsal fin elevated and pointed, near the middle of the body; colour gray above, fading into white below. Taken near Brest.-Mam. 518.

D. globiceps, Cuv. Top of the head very convex; snout rounded; dorsal fin not much elevated, sloping backwards, pectoral fins long and pointed; colour of the back shining black or gray. Eighteen to twenty-one feet long.-Mam. 519.

Sub-Gen. 5. Delphinopterus, Lacep. Head obtuse; snout short; no dorsal fin.

D. leucas, Desm. Beluga, Shaw. Head like that of the porpoise ; teeth short, blunt, nine on each side in both jaws; fin of the back replaced by a slight angular eminence; colour yellowish white. Twelve to eighteen feet long. Northern Seas._Shan, ii. pl. 232.

An individual of this species was taken in the Firth of Forth in 1815.

Sub-Gen. 6. Heterodon, Blainville. Teeth often one in each jaw, or none; lower jaw larger than the upper.

D. hyperoodon, Desm. Head convex, terminated by a rounded and flattened beak; no teeth; palate furnished with little points or false teeth ; orifice of the spiracles crescent-shaped; colour gray above, whitish below. Twenty-three feet long.-Mam. 521.

Gen. 150. Monodon, Lin.-Narwhalus, Lacep. Cuv.

One or two large tusks in the upper jaw ; general form analogous to the dolphins; orifice of the spiracles united on the top of the head; a longitudinal dorsal crest. 
M. monoceros, Lin. Body ovoid; head equal to a fourth of the length of the animal; left tusk only developed, furrowed in a spiral form, half the length of the body; colour grayish in the young, marbled or blackish in the old. Length 20 to 30 feet. Northern Ocean.-Shan, ii. pl. 225.

The Narwhal is of an ovoid form, and from twenty to thirty feet long. Its upper jaw, more advanced than the under, is covered by a thick lip, and from each side of this jaw projects a long narrow tusk terminating in a sharp point. This tusk, preserved in the cabinets of the curious, was long conceived to be the horn of the fabulous unicorn. It was afterwards conjectured to be placed upon the forehead of the Narwhal; till later and more correct observation discovered it to be one of two tusks proceeding from the upper jaw of the animal. This tusk or tooth is twisted spirally through its entire length, and is harder than irory. With this powerful instrument he attacks his prey, and often destroys the whale.

\section{2d Division. - Head very large.}

\section{Gen. 151. Physeter, Lin. Cuv.-Physalus, Lacep.}

Inferior teeth 18 to 23 on each side of the jaw; upper jaw broad, elevated, without teeth, or with these short and concealed in the gum; lower jaw elongated, narrow, corresponding to a furrow of the upper, and armed with thick and conical teeth, entering into corresponding cavities in the upper jaw; spiracular orifices united at the upper part of the snout; a dorsal fin in some species, a simple eminence in others; cartilaginous cavities in the superior region of the head filled with oily matter.

$$
\text { Sub-Gen. 1. Catodon, Lacep.-No dorsal fin. }
$$

P. macrocephalus, Desm. Great-headed Cachalot. Lower teeth 20 to 23 on each side, recurved and pointed at the extremity; small conical teeth concealed in the upper gums; tail narrow and conical; a longitudinal eminence on the back above the anus; upper part of the body blackish or slate-blue, a little spotted with white; belly whitish. Length 45 to 60 feet. Northern Seas-Shaw, ii. 228.

The usual length of the Macrocephalus is upwards of seventy feet, and its head is the largest of any known animal. It is more than a third the length of the body, truncated in front and almost cubical. The spermaceti, for which it is chicfly killed, is found in membranous cells.

\section{Sub-Gen. 2. Physeter, Lacep.-With a dorsal fin.}

P. microps, Lacep. Lower teeth 21 on each side, arched, the points directed backwards; dorsal fin large, erect, and pointed; pectoral fins large; eyes very small. Length 70 to 80 feet. Northeŕn Seas.-Mam. 525.

An individual of this species, fifty-four feet long, was stranded at Cramond Island, in the Firth of Forth, 22d December 1769.

P. sulcalus, Desm. Teeth of the lower jaw pointed and straight, with inclined furrows on each side of the jaw ; dorsal fin conical, situated above the pectorals. Seas of Japan.-Mam. 526.

Gen. 152. Balena, Lin. Cuv. Desm.-Balcenoptera, Lacep No teeth; upper jaw keel-formed, furnished on each side with 
whalebone or transverse horny laminæ, slender, serrated, and attenuated at the edges; orifices of the spiracles separated, and placed towards the middle of the upper part of the head; a dorsal fin in some species; nodosities on the back in others.

$$
\text { Sub-Gen. 1. BALAeNA, Lacep.-No dorsal fin. }
$$

B. nysticetus, Lin. The Common Whale. Body thick; tail short; no hunch on the back; upper jaw furnished with about 700 transverse horny laminæ. Length 80 to 100 feet. Inhabits the Atlantic Ocean and Polar Seas.-Shan, ii. pl. 226.

This is the largest of animals. It is found from 50 to 100 feet long, and is said often to have been taken greatly exceeding this length. The jaws being divested of teeth, their place is supplied in the upper one by corneous laminæ, the whalebone of commerce, and on each side of this jaw there are three or four hundred of these lamina fixed in the gum, and bristled at the point. The skin of the whale is black and thick, and between this and the flesh is the fat or blubber, from which oil is extracted. The spiracles are placed upon a rising on the top of the head, and they can eject water from these to the height of from twenty to thirty feet. The tail of the whale, terminated by a broad horizontal fin, is strong and flexible, and is the principal agent in the motion of the animal, and its principal arm of defence. The blows with its tail are dangerous to the boats and ships employed in its capture ; and some idea may be formed of its force from considering that a large specimen is equal in mass of body to nearly a hundred elephants. Regarding the growth or age of the whale little is known; but since their capture has become an object of commerce, the species seems gradually diminishing in number as well as in size. The female brings forth only one at a time, for which she shows great affection.

B. glacialis, Klein. Lower jaw rounded, high, and broad; tail elongated; no hunch on the back; general colour gray; a large oval space under the head of a shining white, with some blackish spots around and in the centre. Inhabits the North Atlautic Ocean.

B. nodosa, Desm. A hunch on the back, situated near the tail; pectoral fins white, long, and distant from the snout-Mam. 527.

B. gibbosa, Desm, Five or six hunches on the back, near the tail ; whalebones white.-Mam. 528.

Sub-Gen. 2. BaLmentera, Lacep.-With a dorsal fin.

B. gibbar, Desm. (B. physalus, Lin.) Jaws pointed and equal ; whalebones short, bluish; no folds under the throat or belly; body brown above, white below. Size of the common whale. Aretic Seas.-Mam. 528.

B. boops, Lin. Neck elevated and rounded; snout projecting, broad, and a little rounded; longitudinal folds under the throat and belly ; semispherical tuberosities before the spiracles; dorsal fin curved backwards. Fifty-fourfeet long. Inhabits Northern Seas. -Desm. Mam. 528.

M. Cuvier suspects that the B. rostrata of Hunter, and the B. musculus of Linnæus are only varieties of this species. 


\section{CLASS II.-BIRDS. (Aves.)}

Vertebrated animals, with red and warm blood, respiring by lungs, and the young of which are produced from eggs. Body covered with feathers, and general conformation organized for flying.

Aristotle and Pliny, the fathers of Natural History, are almost the only writers of antiquity who have attempted to detail the manners or distinguish the species of Birds; the former in his History of Animals, and the latter in the tenth book of his Natural History. After the revival of letters, Pierre Belon in 1553, and Conrad Gesner in 1555, each published a work on Birds. In Belon's work, a thin folio with wooden cuts, these animals are classed by their manners, or characterized by the places where they are found. Thus the Birds of Prey form the first class, the Waders the second, the Swimmers the third, and the birds which nestle in trees or on the ground the fourth. Gesner's Treatise on Birds forms the third volume of his History of Animals, and is also adorned with engravings on wood. Besides alphabetical tables of the names of birds in all the known languages, and descriptive characters, his work contains references to all the writers within the compass of his knowledge who had noticed this interesting class of animals.

Aldrovandus, a physician of Bologna, published a system of Ornithology in 1599, in which, following Belon, he classed the birds according to the places which they frequented, and the nature of their food, but added a great number of new descriptions. It is illustrated with wooden cuts, which, however, are in general inaccurate representations. Johnston followed in $165 \%$ with a condensed compilation of all that had been done before him. The figures, however, being engraved on copper, are many of them above mediocrity.

Francis Willoughby, an English gentleman, who had paid great attention to Natural History, and whose System of Ornithology was published under the superintendence of the celebrated Ray in 1678 , after its author's death, may be regarded as the first systematic writer on this subject. This excellent work is 


\section{BIRDS.}

divided into three books, the first of which treats of Birds in general; the second of Land Birds; and the third of Water Birds. The land birds are further arranged into groups which possess a crooked beak and talons, and those which have the bill and claws nearly straight. The water birds are separated into three families, viz. 1. Those that wade in the water, or frequent watery places; 2. Those that are of " a middle nature, between swimmers and waders, or rather that partake of both kinds, some whereof are cloven-footed, and yet swim; others whole-footed, but yet very long legged, like the waders ;" and 3. the palmated birds, or those "that swim in the water." The minor subdivisions are equally characterized by sound judgment and acute observation.

The Ornithology of Willoughby and his friend Ray had the same happy effect on the progress of the science, as Ray's $S y$ nopsis Animalium had on another great department of zoology; and it is no small praise to their sagacity that this work furnished the basis of the classification adopted half a century afterwards by Linnæus. Ray in his Synopsis Methodica Avium, a posthumous work published by Dr Derham in 1\%13, but entirely finished before the author's death, still farther improved the same system.

From the date of this publication till the appearance of the Systema Naturce of the great Linnæus, little progress was made in the science of ornithology. M. Barerre, a Frenchman, who published a system in 1741 , showed it was possible even to retrograde; nor were the attempts of Frisch, a German naturalist, who commenced a Natural History of Birds in 1734, much calculated, though his figures be exact, to forward its progress. Jacob Theodore Klein, who published a work on birds in 1750, and whose ambition was to be considered as the rival of Linnæeus, was still less successful in his confused attempt to improve the classification of birds.

In the Systema Naturce of Linnæus the Class of Birds is divided into six Orders, viz.

I. ACCIPITRES, Birds of Prey. Bill bent; upper mandible dilated on each side, or armed with a tooth; legs short, robust ; toes warty; claws crooked and pointed.

1I. PIC $\approx$. Bill convex or rounded above, edged on its lower part; legs short, robust ; toes smooth.

III. ANSERES. Bill smooth, covered with an epidermis and thickened 
at its point; feet for swimming; toes palmated, or uniter by a membrane.

IV. GRALL丑. Bill almost cylindrical ; legs formed for wading; thighs half naked.

V. GALLIN A. Bill convex, with the upper mandible arched over the uniler; feet formed for walking; toes rough below.

VI. PASSERES. Bill conical, pointed; legs formed for hopping, slender, and with the toes divided.

If in his arrangemenit of birds Linnæus deserves the acknowledgment of all the future students of ornithology, his determination of the genera, and his creation of terms to make his descriptions more certain, render his labours of double value. The terminology of Linnæus was extended by Forster in his Enchiridion, and improved by Illiger. The thirteenth edition of the Systema Naturce by J. F. Gmelin, including many new species', appeared in 1788.

Linnæus was followed as a systematic writer by Brisson in 1760. This able writer's System of Ornithology, still in estimation for its minute accuracy of description, is in six quarto volumes, containing 220 engravings. About 1300 species of birds are described, grouped into twenty-six orders and 113 genera, the characters of which are taken from the feet, bill, and feathers. J. Ch. Schæffer published in 1774 his Elementa Ornithologica, in which birds are divided into two families, Nudipedes and Plumipedes; and J. Ant. Scopoli, in his Introductio ad Historiam Naturalem, 17\%7, also arranges the birds in two great families, the first of which he terms Retipedes, or with the skin of the legs divided by small polygonal scales; and the second Scutipedes, or those which have the fore part of the legs covered with seginents or unequal rings terminated on each side in a longitudinal furrow. The first part of Buffon's work which treats of birds appeared in 17\%1, distinguished by the same want of arrangement which characterized his previous volumes, and the same enthusiastic eloquence. The work was completed in 1783.

Among the systematic writers who have followed Linnæus, our countryman, Latham, deserves a distinguished place. In 1781 he published a General Synopsis of Birds, followed by two supplements, the one in $178 \%$, and the other in 1801, and each genus is illustrated by at least one coloured figure. His Index Orni- 
thologicus, a convenient abridgement of his larger work, was published in two volumes quarto in $\mathbf{1 7 9 0 .}$

It would be impossible in the limits of a short notice to give a detailed account of the numerous works connected with ornithology which appeared previous and subsequent to the works of the systematical authors now mentioned. Hernandez and Marcgrave figured many of the birds of Mexico and Brazil; Sir Hans Sloane, in his History of Jamaica, has represented fortyfour species; and many of the birds of Carolina and Florida are excellently described by Catesby. The birds of Africa have been splendidly illustrated by Vaillant; and the Tanagers, Todiers, and Manakins by Desmarest; Wilson in his American Ornithology has done much to illustrate the feathered races in that vast continent ; and his able follower in that branch of science, Charles Bonaparte, promises to complete our knowledge of American birds. Edwards, in his Natural History of Birds, and in his Gleanings of Natural History, has given many excellent figures; and Dr Shaw in his General Zoology, continued by $\mathrm{Mr}$ Stephens, has made known to the English reader a great many interesting species. A number of other British writers have contributed to illustrate this interesting branch of natural history, such as Pennant in his British Zoology, Lewins in his work on British Birds, Bewick, Montague, Donovan, and very recently Mr P. J. Selby, in his splendid work entitled Illustra. tions of British Ornithology. A work on General Ornithology by the same gentleman and Sir William Jardine, Bart. may also be mentioned as now in progress. For other writers we must refer to the list of the principal works on ornithology at the end of this volume.

In the Encyclopedie Methodique the Abbé Bonnaterre divides Birds into twelve classes, after the structure of the feet, and 112 genera, characterized from the form of the bill and other minor distinctions.

Professor Blumenbach, in his Manual of Natural History, published in 180\%, arranges the Class of Birds into nine Orders, viz.
(A.) LaNd Birds.
I. ACCIPITRES, II. LEVIROSTRES, III. PICI, IV. CORACES, V. PASSERES, VI. GALLIN $A$, VII. STRUTHIONES. (B.) WATER Birds. VIII. GRALL $2 E$, IX. ANSERES. 
Baron Cuvier, in his Regne Animal, published in 181\%, preserved all the orders of Linnæus, with the exception of that of Pica, replacing it by his order Scansores for birds which have two toes before and behind, and classing the others among his Passeres. His arrangement in the Regne Animal stands thus :-

I. ACCIPITRES, divided into Diurnal and Nocturnal.

II. PASSERES, divided into Dentirostres, Fissirostres, Conirostres, Tenuirostres, and Syndactyli.

III. SCANSORES, or Climbers.

IV. GALLIN $\approx$, or birds resembling the domestic cock.

V. GRALLE, or Waders, divided into Brevipennes, Pressirostres, Cultirostres, and Macrodactyles.

VI. PALMIPEDES, divided into Brachypteri, Longipennes, 'Totipalmes, and Lamellirostres.

M. de Lacepede also published a method in 1799, dividing the birds into forty orders; and M. Constant Dumeril in 1806, in his Zoologie Analytique, comprises them in six. Meyer and Wolf, in their work on German Birds, $(1810$, ) make nine orders of this class; and Illiger in 1811 divides them into seven orders, forty-one families, and 147 genera.

M. Vieillot, a celebrated French ornithologist, and the author of the splendid work on the Birds in the French Museum, gave a methodical arrangement of birds in the 24th volume of the Nouveau Dictionnaire dHistoire Naturelle, in which the Class is arranged into five orders.

I. ACCIPITRES, divided into Diurnal and Nocturnal; and containing four families, viz. Vulturini, Gypaeti, Accipitrini, and AEgolii.

II. SYLVICOL $\mathbb{E}$, divided into two tribes, viz. ZYGODACTYLI and ANISODACTYLI, and thirty families. The families of the first tribe are Psittacini, Macroglossi, Aureoli, Pteroglossi, Barbati, Imberbi, and Frugivori; of the second, Granivori, Egithali, Pericalles, Textores, Leimonites, Carunculati, Paradisei, Coraces, Baccivori, Chelidones, Myiotheres, Colluriones, Canori, Aneropontes, Anthomyzi, Epopsides, Pelmatodes, Antriades, Prionoti, Lyriferi, Dysodes, Colum= bini, and Alectrides.

III. GALLIN \&, two families, viz. Nudipedes and Plumipedes.

IV. GRALLATORES, divided into two tribes, viz. DI-TrIDACTYLI and Tetradactyli, and fifteen families. To the first tribe belong the families Megisthanes, Pedionomi, Egialites; to the second, Helonomi, Falcirostres, Latirostres, Herodiones, Aerophoni, Coleoramphi, Uncirostres, Hylebates, Macronyches, Macrodactyli, Pinnatipedes, and Palmipedes. 
V. NATATORES, divided into three tribes, viz. TELeopodes, ATELEOPODEs, and PTILOPTERr. The first tribe includes the families Syndactyli, Urinatores, Dermorynchi, and Pelagii ; the second, Siphorini and Brachypteri ; the third Sphenisci.

Mr N. A. Vigors, in a paper in the 14 th volume of the Linnæn Transactions, founding upon a principle discovered by $\mathbf{M r}$ Macleay, the author of Horce Entomologica, proposed a new arrangement of birds, according to their natural affinities. "I I discovered (says he) as I advanced, that the larger or primary groups were connected by an uninterrupted chain of affinities; that this series or chain returned into itself ; and that the groups of which it was composed preserved in their regular succession an analogy to the corresponding groups or orders of the contiguous classes of zoology. I equally detected the existence of the same principle in most of the subordinate divisions, even down to the minutest, to a degree at least sufficiently extensive to afford grounds for asserting its general prevalence." P. 399.

This chain of affinities, $\mathrm{Mr}$ Vigors conceives, takes always a quincunx form; so that in the class of Birds, if the five orders into which he arranges them, viz. Raptores, Insessores, Rasores, Grallatores, and Natatores, were placed in connected circles, round a common centre, they would be found to be mutually connected together.

\section{INSESSORES.}

RAPTORES.

RASORES.

AVES.

Natatores. Grallatores.

'The same connection is found to take place between the minor subdivisions, when arranged in a similar form. For instance, in his second order Insessores, composed of five tribes, the arrangement stands thus :-

\section{Conirostres.}

Dentrirostres. Scansores.

\section{INSESSORES.}

Fissirostres.

Tenuirostres.

Each of these tribes again is further divided into five families, which, when placed in the same order, are found to be similarly connected.

As a further confirmation of Mr Vigors's theory, it may be 
remarked that Professor Blumenbach long since noticed the same principle as applicable to the arrangement of the feathers of birds on the skin, which he observed always to follow a quincun $x$ order.

This arrangement according to natural affinities is certainly curious, and affords room for hoping, should the principle be ascertained to pervade the families of animals very universally, that a more philosophical classification of the objects of nature may in time be perfected. But in the meantime we consider any such arrangement as merely theoretical, and that it would require all the species to be known, and the individuals examined, both with regard to their external appearance and internal structure, before such a method could be completed. The theory is however very ingenious, and deserves the consideration of naturalists.

Finally, M. C. J. Temminck, in his Manuel d'Ornithologie, the first edition of which was published in 1815, and the second in 1820, divides the class of Birds into sixteen orders, and numerous minor subdivisions. This gentleman, with opportunities beyond most others, in the possession of a splendid museum, of comparing birds, particularly the European species, at all ages, and in every stage of plumage, has rendered the knowledge of the class more precise, by referring to one species many individuals which had been characterized by preceding ornithologists as distinct, from having examined only young or imperfect specimens.

The arrangement of Birds into Orders has for its basis the conformation of the bill and feet, which are adopted to their different modes of living and food. Birds of Prey are characterized by a hooked bill, and feet armed with strong and crooked nails; Climbers are those the structure of whose feet is calculated for motion on an inclined or vertical surface; and web-footed birds are evidently adapted for swimming. Others again have the legs very long and naked for wading; and a large number, with the claws short and feeble, live chiefly on insects. But though it be thus easy to separate the more strongly marked groups into extended families, yet it has been found extremely difficult to distribute them in subordinate groups, so as to facilitate the knowledge of species in a class so widely extended. In adopting the 
arrangement of Temminck, therefore, though his Orders are more numerous than those proposed by Cuvier and Vieillot, yet the Families of the latter are in much greater number; and in an elementary work it has been judged proper to follow that system which involves the least change of the established nomenclature as likely to be most generally useful. Temminck divides the Class of Birds into sixteen orders, viz.

I. RAPACES. Birds of Prey. I\$!

II. OMNIVORES. Omnivorous Birds. 194

III. INSECTIVORES. Birds which feed on Insects. 210

IV. GRANIVORES. Birds which feed on Grains. 234

V. ZYGODACTYLI. Birds with two toes before and two behind.22y

VI. ANISODACTYLI. Birds which have the exterior toe joined to the middle one at the base. 238

VII. ALCYONES. Birds with three toes before, united, and one behind; the tarsi very short. 264

VIII. CHELIDONES. Birds with short legs, three toes before, divided, or only united at the base by a short membrane; the back toe often reversible. 266

IX. COLUMBE. Birds with three toes before, entirely divided, and one behind. 269

X. GALLIN A. Birds with three toes before, united by a membrane; the back toe joined to the tarsus above the joint of the other toes. 271

XI. ALECTORIDES. Biris with the tarsus long and slender; three toes before and none behind; the articulation of the posterior one higher than those before. 281

XII. CURSORES. Birds with long legs, naked above the knee, with two or three toes directed forwards. 283

XIIT. GRAILATORES. Birds with long and slender legs, more or less naked above the knee; three toes before and one behind, the posterior one jointed on the same level with the others or more elevated. $285^{\circ}$

XIV. PINNATIPEUES. Birds with feet of medium length ; tarsi slender or compressed ; three toes before and one behind, with a rudimentary membrane along the toes ; the posterior one joined interiorly on the tarsus. 304

XV. PALMIPEDES. Birds with short feet, more or less drawn up to the abdomen ; anterior toes partly or wholly connected by a membrane; the posterior toe articulated interiorly upon the tarsus, or totally wanting in some genera. $30 y$

XVI. INERTES. Birds with feet retracted into the abdomen; three toes divided, before; the posterior toe short, articulated interiorly. 32.5 ,

Birds support themselves and direct their flight in the air nearly in the same manner as fishes do in the water. But they 
are also calculated for motion on the ground; some families for motion on the surface of the water, or even to a certain degree through a mass of the same element; and their structure is varied to suit these different kinds of motion.

The part of the spine in birds which corresponds to the back is immoveable, and the only portions of the vertebral column capable of motion are the vertebræ of the neck and those of the tail. Their pectoral members or arms are elongated to wings proper only for flight. These members or wings, composed of one long finger and the vestiges of two others, are furnished with long, stiff, but elastic feathers, disposed like a fan, which follow the movement of the bone, and when extended occupy a large surface. The wings are attached by a double clavicle, and are supported by a broad sternum, carinated in front like the keel of a ship. This sternum is formed of five pieces, strongly joined together; and the greater or less ossification of these pieces is always relative to the powers of the bird for flight. The long feathers, attached to what may be termed the hand, generally to the number of ten, are termed primaries; the secondaries, variable in number, are those attached to the fore-arm; and scapulars are the smaller feathers which are attached to the humerus. In describing birds the term remiges is also used to denote the feathers of the wings which serve as oars ; and rectrices those of the tail, which have been considered to act as a rudder. The smaller feathers which cover the base of the wing and tail are termed tectrices.

The anterior extremities, destined to support them in flight, can neither be used for prehension nor support, and birds thus take objects from the ground by their mouth. The neck is elongated, and the body thrown forward, that the bill may easily reach the ground. The pelvis is lengthened to furnish an attachment for the muscles which support the trunk upon the thighs; and there is an arrangement of muscles going from the pelvis to the toes, in such manner that the weight of the animal bends the toes, and enables it to sleep perched upon one foot.

The bony part of the tail is short, but it carries a row of strong feathers which spreading contribute to support the bird. The number of these feathers is generally twelve, sometimes 
fourteen, and in the Gallinæ eighteen. The legs have a femur and a tibia, and the tarsus and metatarsus are represented by a single bone. The toes are attached to the tarsus, and are generally three before and a kind of thumb behind, which, however, is sometimes wanting. In the swallow it is directed forwards. In the climbers, on the contrary, the external toe and the thumb are directed backwards. The number of joints increases in each toe, counting from the thumb, which has two, to the external toe, which has five. Birds with the toes entirely free are adapted to walk or hop on a horizontal surface, such as the domestic fowl. Others with two toes behind and two before, such as the parrot, walk with difficulty, but climb with facility; and others again, such as ducks and swans, with the toes united by a membrane, are chiefly calculated for motion in water.

The bill in birds is covered with a corneous substance, and as these animals swallow their food without mastication, they are not furnished with teeth. The upper mandible is formed chiefly of the intermaxillary bones, prolonged behind into two arches, of which the internal is composed of the palate bones, and the external of the maxillary and jugal bones; and this mandible is united to the cranium by elastic laminæ. The bill is constructed less for bruising the food than for seizing and dividing it; and thus from the greater solidity and length of this organ the nature of the food may be inferred.

The bill or beak is sometimes furnished at its origin with a fleshy or membranous caruncle, which is called the cere; and sometimes the beak is prolonged upon the forehead into a kind of horn or helmet, as in the Calao. The two mandibles, moveable upon one another through the medium of an intermediate bone placed at the articulation, is a distinguishing anatomical character in the structure of the jaws of birds.

The quills and feathers are composed of a bearded or webbed stem hollowed at its base ; these webs or horizontal feathers are again themselves webbed by still smaller ones; and the texture, the strength, lustre, and general form of these feathers are infinitely varied. The feathers fall off twice a-year, and this change of plumage is termed moulting. In some species the winter plumage differs from that of summer, and in the 
greater number the female differs from the male in her colours being less bright. The young generally resemble the female.

- The brain of birds has the same general characters as that of the other oviparous vertebrated animals, but is distinguished by its proportionally greater volume, which often exceeds that of the Mammalia. But this apparent magnitude is caused by tubercles analogous to the corpora striata, and not by the hemispheres, which are very small and without circumvolutions. The cerebellum is of considerable size, without lateral lobes, and almost completely formed by the vermiform process.

The trrachea or windpipe in birds is formed of complete rings. At its bifurcation is a glottis provided with muscles, termed the inferior larynx. This is the organ which produces the voice of birds ; and it is afterwards modified by the length, breadth, and elasticity of the trachea and its orifice in the throat. The upper larynx is simple.

The cavity of the thorax is not in Birds separated by a fleshy partition from the abdomen. The lungs adhere to the spine, and communicate with many membranous sacs situate in the abdomen, under the axilla, and even in the cavities of the larger bones, the substance of the bill, and in the fistulous portions of the quills. The great quantity of air which birds respire appears to have effect upon all their motions. They respire, it may be said, as well by the branches of the aorta as by those of the pulmonary artery. It is believed that the temperature to which the bodies of birds is raised in hatching, and the great muscular force which they sometimes exert in almost continued flight for many days, depends upon the action of the air upon the blood.

Birds, like all the other vertebrated animals, possess five senses; but in this class that of touch is the least perfect. Their feathers prevent them from receiving by immediate contact the impressions of the objects which they touch; and their feet are enveloped in corneous laminæ or scales, which materially blunt sensation. All enjoy the orgar of sight; and by a particular mechanism in the structure of the eye they are enabled to perceive objects at a distance with the same facility as when near the body. Besides the two ordinary eyelids there is always a third semitransparent one placed at the internal angle of the 
eye, which, by the assistance of a remarkable muscularapparatus, may be drawn before the eye like a curtain. The cornea is very convex. Although birds have no external cartilaginous ear, all appear to enjoy the faculty of hearing. Some of the nocturnal birds have the auditory opening surrounded by feathers. The organs of smell are concealed in the base of the bill, and the breadth of the nasal openings determine their form. The sense of smell in the vulture and the raven has been said to be so very acute, that they can smell carrion at an immense distance; but this from recent observation seems doubtful. The tongue in birds is supported by a production of the hyoid bone. The taste is not very delicate.

Digestion in birds is in proportion to the activity of their life, and the quantity of their respiration. The stomach is composed, first of the crop, which is a dilatation of the oesophagus at the base of the neck. The food remains in this duct for some time, and there imbibes a fluid analogous to the saliva, which is secreted from the inside of the canal. When softened by the action of heat and moisture it passes by little and little into a strong muscular bag called the gizsard, where the food is triturated the more easily, that many species swallow little stones to increase the effect. This gizzard, it has been remarked, is strongest in birds which have slender bills, and which are of course unable to break down their food; in those which feed on flesh or fish the muscles are much weaker, and the stomach almost membranous. By the outlet of this stomach the food, reduced to. a species of chyme, flows through the remainder of the intestinal canal, where the nutritious parts are absorbed, and the remainder expelled by a cloaca, an orifice common to the urinary and genital organs.

Birds, such as the partridge and common fowl, whose young are able to walk and feed themselves on their departure from the egg, do not generally live in pairs. One male serves many females, and the young are entirely trusted to the maternal care. The greater part of birds, however, are blind and helpless at their birth, and their parents are therefore under the necessity of providing for their subsistence. Pigeons disgorge halfdigested grains to feed their young; and linnets bring themlarvac of insects or the soft parts of other animals. These live always 
in pairs, construct their nest with great care, and constantly in the same manner; and each species appropriates for this purpose certain materials. All possess a kind of instinct which leads them to choose the most convenient places for their nests, such as best afford concealment, or which render them inaccessible to their enemies.

In Birds the ova exist already formed in the mother before fecundation; and it is not a rare occurrence to see eggs laid without impregnation, similar in every respect to those which produce young. Fecundation in most of the species is accomplished by mere juxta-position. The eggs of birds differ much in the colour of their calcareous covering. They have generally the form of an elongated ball, and one of their extremities is thicker than the other. The fecundated eggs require a certain heat to be hatched; and the observation of this fact has led to the practice in Egypt and elsewhere, of hatching large broods of chickens by artificial heat.

The class of Birds, though not so apparently useful to man as the Mammalia, serve important purposes in the general economy of nature. Those whose food is chiefly insectivorous check the excessive reproduction of the insect races, and for this purpose migrate at certain seasons to places where their food abounds. The indiscriminate destruction of crows and sparrows in some districts has accordingly been found to give rise to an infinitely more prejudicial multiplication of creatures still more destructive. Some families of birds destroy field-mice, snakes, frogs, and lizards ; and others again are led by choice to feed on carrion, or dead animal matter. Birds are besides extensive agents in the spread of regetables and even animals. It is well ascertained that wild ducks in their emigrations carry impregnated spawn into remote ponds, and thus stock them with fish; and many by swallowing seeds whole, and subsequently expelling them, are the means of spreading vegetation over an extent of surface which scarcely any other means could accomplish. A great portion of the class and their eggs may be used as food, and the feathers of many form an object of commerce.

Nothing is more singular in the history of birds than their periodical migrations. That these are connected in some measure with the necessity of a supply of food and the impulse of repro- 
duction is almost demonstrable ; but the instinctive feeling which guides them without compass across seas and continents, and enables them to migrate at certain periods, corresponding with the production of their food in distant countries, can only be referred to one Great Source.

Who bade the stork, Columbus-like, explore Heavens not his own, and worlds unknown before?

Who calls the council, states the certain day?

Who forms the phalanx, and who points the way?

The flights of migratory birds have been noticed from the earliest periods; - "The stork in the Heaven knoweth her appointed times, and the turtle and the crane and the swallow observe the time of their coming." And, as if their passage through the air or the structure of their bodies made them sooner perceive the incipient changes of weather, the appearance and cries of birds have long been considered to afford presages of the coming storm or the cessation of the tempest. The institution of a College of Augurs at Rome may therefore be conceived to have reference to something better than mere superstition; and though the flight of particular species might, in the hands of interested individuals, be made to presage the wishedfor result of a battle, or direct a march already determined on, yet, in the absence of the barometer and thermometer, the appearance or disappearance and cries of birds were the signals for the husbandman to sow his fields or to secure his crop.

Jam veris prænuncia venit hirundo.-Ovid.

Now comes the swallow, harbinger of spring.

Tum cornix plena pluvium vocat improba voce - Virg.

The crow with clamorous cries the shower demands.-Dryd.

In this country the great migrations of birds take place in spring and autumn. Those which arrive in spring come from warmer climates, and after incubation leave us in autumn; and another host, chiefly Palmipedes, from the arctic regions, arrive in autumn, pass the winter on our lakes and shores, and depart again in the spring. Each species has a particular mode of flight in these annual journeys, and a certain period of arrival and departure. Assembled in large flocks the cranes cleave the air in the form of a long triangle; wild-geese fly in angular lines; and the smaller birds associate in less numerous families, and reach their destination by less continued flights. 
One of the most curious particulars connected with the annual migrations of birds is the circumstance of individuals returning for a series of years to the same nestling-places. Spallanzani having tied a thread of red silk round the leg of a swallow which built its nest in his window, saw for three seasons the same stranger with its progeny annually appear; Ekmark remarked a lame starling which occupied the same nest in the hole of an old alder for a period of eight years; and similar instances are on record concerning many other species of migratory birds. This wonderful direction of instinct, which divides the innumerable flocks of birds in their progress northward, and leads particular families to seek the protection of the same roof, or the same chimney-top which formerly sheltered them, affords a subject not the least worthy of contemplation, among the thousand instances of wisdom and beneficence which arrest the student of Nature at every step of his progress.

The flight of birds is very rapid. Birds of prey have been observed to fly at the rate of about twenty leagues in an hour. A falcon belonging to Henry II. of France escaping from Fontainebleau, was found next day at Malta, a distance of 1350 miles, and recognized from the ring on its leg. Sir Hans Sloane mentions that at Barbadoes the gulls came to feed and returned two hundred miles in the same day. And Mr Audubon relates of the migratory pigeons of America, that they have been killed in the neighbourhood of New York with rice in their crops, collected in the fields of Georgia and Carolina, the nearest points at which this supply could have been obtained. Reasoning from the fact that the food of pigeons is entirely digested in twelve hours, $\mathrm{Mr}$ Audubon concludes that they must have travelled between 300 and 400 miles in six hours.

Birds in general live long, considering how early they arrive at maturity. Swans are said to live for a hundred years; and the pelican arrives at a similar age. Carnivorous birds, particularly the eagle, live to a very great age, perhaps beyond a century; the raven for a still longer period; and parrots have been known to live from sixty to eighty years. The life of Gallinaceous birds, such as the domestic fowl, the pheasant and the partridge, seldom exceeds from twelve to twenty years. 


\section{ORDER I.-RAPACES.}

BiLL short, strong; upper mandible covered at its base by a membrane or cere, compressed on the sides, and hooked towards its extremity; nostrils open; legs strong, muscular, short, or of medium length, feathered to the knee or toes; toes three before and one behind, divided, or united at the base by a membrane, rough below, armed with powerful claws, sharp, retractile, and hooked.

The birds comprised in this order bear a relation in their mode of life to the Carnivora among the Mammalia. Almost all of them live on animal food. Some take their prey alive; others clear the ground of the noxious remains of dead animals; others feed on fishes and reptiles; and a few species live chiefly on insects. Those which pursue their prey by day have hence been termed diurnal birds; others flying only in the twilight, have been denominated nocturnal. The females are always larger than the males. The number of their eggs seldom exceeds four.

\section{Gen. 1. Vultur, Illiger, Tem.}

Bill thick and short, deeper than broad, its base covered by a cere; upper mandible straight, bent towards the point; under mandible straight, rounded, and inclined at the point; head naked, or covered with a short down; nostrils naked, lateral, opening diagonally towards the edge of the cere; legs strong, furnished with slightly bent claws; the middle toe longest, and united with the exterior one at the base.

These birds, feeding on carrion, are of service in removing dead animal remains. Their figure is as disgusting as their habits. The conformation of their toes and nails deprive them of the power of attacking or carrying off living prey. They fly slowly, and walk heavily, but their sight is acute; and, though some naturalists have asserted their sense of smell to be so acute as to guide them at great distances to their food, yet there is reason to think that this faculty has been much overrated.

V. cinereus, Lin. Posterior part of the head and neck naked, and of a bluish colour, the rest of the neck covered by a fawn-coloured down; cere bluish flesh-colour ; tarsus half feathered, its naked part round the toes of a pale blue; the claws black. About $3 \frac{1}{2}$ feet long. Inhabits the mountains and forests of Europe.-Tem. 4.

Vultur Bengalensis, Gmel. Lath.; Grand Vautour, Buff.; Le Vautour noir d'Egypte, Savigny.

V. fulvus, Lin. Head and neck furnished with a white down; lower part of the neck surrounded by rows of long slendér feathers of a reddish white colour; a spot on the middle of the breast, covered with a white down; body and wings fawn-coloured; flag and tail-feathers of a blackish brown; beak livid yellow; cere flesh-coloured; iris hazel-coloured; legs gray. About four feet long. Inhabits the mountainous parts of the north of Europe, Africa, and Asia._Shaw, vii. pl. 11.

V. leucocephalus, Meyer ; V. percnopterus, Daud.; V. trencalos, Bechst. ; Le Griffon, Buff.-The young, V. Kolbii, Lath.; Le Vautour chasse-fiente, Vaill.

V. monachus, Tem. Plumage dull brown; quill-feathers black; 
top of the head around the eyes and ears and the fore part of the neck naked and reddish ; occiput, hind part of the neck, and crop covered with short ashy down; tarsi feathered a little below the knee; feet yellowish. Two feet three inches long. Inhabits western coast of Africa.-Shaw, vii. pl. 7, 8, 9.

V. Ponticerianus, Lath. Bill short and much hooked, with its base covered by a naked skin; feet short and strong, the nails crooked; head and neck naked, or covered in part by short down; a thin naked red-coloured membrane on the neck; head, neck, and breast flesh-coloured; back, belly, wings, and tail black; iris red; bill black; feet yellowish. Inhabits India. Size of a large goose. -Shaw, vii. pl. 10.

V. Indicus, Lath. Back brownish-coloured, terminated by a band of a clearer colour; large feathers of the wing and tail black; head covered with a tuft resembling hair; neck with little tufts at small distances; feathers of the breast short, like hair ; iris red; feet and bill black. Inhabits India. Size of a goose.Shaw, vii. 26.

\section{Gen. 2. Cathantes, Illiger, Tem.-Vultur, Lin.}

Beak long, compressed, straight, bent towards the point; cere naked, covering more than half of the beak; upper mandible tumid towards the point; head oblong, naked, as well as the upper part of the neck; nostrils in the middle of the bill, near the ridge of the upper mandible, longitudinally cleft, broad, sometimes surmounted by fleshy appendages; legs with tarsus naked, more or less slender; middle toe long, and united to the exterior one at the base.

C. percnopterus, Tem. (Vultur percnoplerus, Lin.) The Egyptian Vulture. Head and fore part of the neck covered by a naked skin of a livid yellow colour; plumage white, except the large feathers of the wings, which are black; feathers of the occiput long and slender; the cere and bill orange ; iris yellow; feet of a livid yellow, claws black, tail raised. Young specimens of a deep brown variegated by yellowish brown spots; the cere and feet of a gray ash-colour. About two feet and a-half long. Inhabits the Pyrenees, Switzerland, and Africa.-Tem. 9.

V. leucocephalus, Lath.: Vautour blanc, Buff.; Rachamach, Bruce ; Vautour d'Egypte, Son. ; Percnopterus, Cuv.; the Ash-coloured and Alpine Vulture of Latham. The young, V. fuscus, Gmel. ; Le Vautour de Malte, Buff.; Maltese Vulture, Lath.

These birds feed chiefly on carrion and filth, and their use in removing these offensive objects and destroying reptiles occasions their being protected in some countries of the east, particularly in Egypt, where they were anciently held in such veneration, that any person who destroyed them was punished with death. At this day immense flocks of them are found in all the principal towns of Egypt, Syria, and Persia, mingling with other animals of similar propensitics. They feed witl the greatest familarity even in the streets of the most populous towns. At Cairo their skins are sold, and converted into dresses. 
C. gryphus, Tem. The Condor or Great Vulture of the Andes. Colour blackish; a spot on the wings, and ruff white; upper caruncle large, and without dentations; another under the bill like the cock ; female destitute of caruncles. Inhabits South A merica.Shaw, vii. pl. $2,3,4$.

This animal is the largest of the tribe. According to Humboldt it is about three feet three inches in length, and eight feet nine inches in spread of wings; though Marco Polo asserts that it can raise an elephant from the ground. The usual residence of these birds is in lofty rocks in the regions of the Andes, near the boundary of perpetual snow ; but they are capable of soaring beyond the reach of human vision. In Peru and Quito they are not unfrequently taken alive in the following manner: A cow or horse, which is of little value in those countries, is killed, and exposed; and in a short time the Condors are seen suddenly to emerge from quarters where their existence was not even suspected. They always begin with the eyes and tonguc, and then proceed to devour the entrails, \&c. When gorged they are too heavy and indolent to fly, and the Indians easily capture them in nooses. They make their nests in the most inaccessible rocks, and the female lays two white eggs, which are larger than those of the turkey-hen.

C. Papa, Lin. King of the Vultures. Of a whitish rufescent hue; head and neck naked; nostrils furnished with a loose orangecoloured caruncle, and the neck with a gray ruff.-Shaw, vii.pl.13.

This bird inhabits the plains in the warmer regions of South America, and it is also said of the West Indies. It lives on rats, lizards, snakes, carrion, and all sorts of excrementitious matters, exhaling a most offensive odour, which the stuffed skin has been known to retain for upwards of twenty years.

C. aura, Lin. American or Carrion Vulture. General colour blackish, with purple and green reflections; head and neck red, naked, papillous, and wrinkled. About two feet and a-half long. Inhabits America._Shaw, vii. 36.

C. vulturinus, Tem. (V. Californianus, Shaw.) Plumage black, with a whitish bill; head and neck naked and of a pale colour; feathers of the collar and breast lanceolate; legs and toes black. -Shaw, vii. 10.

\section{Gen. 3. Gypaetus, Storr.-Phène, Vieill.}

Bill long; upper mandible arched towards the point, and bent like a hook; nostrils oval, covered with stiff hairs directed forwards ; feet short ; four toes, the three anterior united by a short membrane, the middle one very long; nails slightly crooked; wings long.

The Gypaeti have more grace and activity in their motions than the vultures. Formidable by their strength and the impetuosity with which they dart on their prey, they seize the moment when a wild goat or its young separates from the flock on the borders of precipices, and kill it on the spoto Young and diseased animals are their common prey.

G. barbatus, Cuv. (Vultur barbatus, Lath.-Falco barbatus, Gm.) The Bearded Vulture. Head and neck of a dirty white; a black line extends from the base of the bill to above the eyes; another rising behind the eyes passes over the ears; lower part of the neck, breast, and belly of an orange-red; back and wing-coverts of a deep grayish brown, but on the centre of each feather is a white longitudinal line; wings and feathers of the tail of a gray 
ash-colour, the ribs white; tail long, much raised; bill and claws black; feet blue; iris orange; eyes surrounded by a red line. About four feet seren inches long.

V. barbatus and barbarus, Latl. and Gmel.; V. aureus, Briss.; Vautour doré, Buff.; Bearded and Golden Vulture, Lath.; the Nisser, Bruce. The young, V. niger, Lath.; G. melanocephalus, Meyer.

This species is a native of many of the wilder regions of Asia and Africa, and exists also, though more sparingly, in Europe, as in the Swiss Alps and Pyrenees, and in the mountains of Tyrol and Hungary. The German appellation of Laemmer Geyer, or Lamb Vulture, has been applied to it, as to other large birds of prey.

\section{Gen. 4. Gypogeranus, Illig.-Vultur, Lath.}

Bill shorter than the head; thick, strong, hooked, bent from its origin, furnished with a cere atits base, a little arched, compressed at the point; nostrils a little separated at the base, lateral, pierced in the cere, diagonal, oblong, open ; legs very long, slender ; tibia feathered, tarsus long, slenderer at its base than at its upper part; toes short, warty below, the anterior united at the base; thumb articulated on the tarsus; wings long, the first five wing-feathers longest and almost equal; wings armed with a blunt spur.

G. serpentarius, Tem. (Vultur serpentarius, Lin.) The Secretary. Colour cinereous; tail wedge-shaped, with the middle tailfeathers lengthened, and a crest of feathers on the occiput capable of erection. Inhabits Cape of Good Hope._Shaw, vii. pl. 14.

This species inhabits the dry plains in the lower parts of Africa and the Philippine Islands. Being almost always obliged to run in pursuit of its prey, it seldom avails itself of its power of flight; and it frequently kills, or at least wholly disables, a snake, by breaking the vertebræ with a single stroke of the wing. In its natural state it is very wild, and not easily approached, but when taken young, the snakeeater may be easily tamed, and kept with poultry in the farm-yard, where it is serviceable in destroying rats and other noxious animals. It may be fed with meat, either raw or dressed, and will readily eat fish; but if allowed to fast too long, it is apt to seize on small chickens and ducklings, which it swallows whole.

\section{Gen. 5. Falco, Lin.}

Head covered with feathers; bill hooked, generally bent from its origin; a coloured cere, more or less hairy at its base; mandibles sometimes notched; nostrils lateral, rounded or oval, pierced in the cere, open; legs with tarsi covered with feathers or scales; three toes before, one behind, the exterior generally united at its base to the middle toe; claws sharp, much hooked, retractile.

The Falcons are noble birds of prey. Their appearance and their motions indicate their manner of living to be very different from the preceding genera. Strength and cunning form the attributes of this family. They are provided with more powerful offensive arms, and their power of wing, of sight, and prehension are also very different. The size of their head is in proportion to their body, and both it and the neck, which is thick and short, are covered with feathers. They live in couples, and are not gregarious. Their food consists of living prey, which they seize and cirry in their talons. They rise in the air to a prodigious height, their flight is rapid and sustained, and their sight is very acute. The larger species feed on the smaller 
mammiferous animals and birds, others on fishes, and some attack reptiles. The greater number of the smaller species are insectivorous, and prey chictly on beetles. Their plumage at different ages is very various. The young are many years old before coming to their full and constant plumage, this not taking place till the third, fourth, and in some species till their sixth year. The young are always distinguished from old individuals by numerous and varied lines and spots, while the colour of the adult birds is gencrally in large masses; and when the colours and pluniage of the old birds are disposed in transverse lines or spots, the young of the same species have these bands and spots longitudinal. The males are always about a third smaller than the females.

\section{1.-FALCONS.}

Bill short, bent from its base; upper mandible with one and rarely two strong teeth, which lock into hollows in the lower mandible; legs robust; toes strong, long, armed with crooked and sharp claws; tarsi short; wings long, the first wing-feather and the third of equal length, the second longest.

The falcons prey habitually on living animals, and show much address in seizing and surprising their prey. They nestle in the crevices of rocks. The greater number of the species of this division may be employed with success in hawking. The name noble birds of prey, which has been applied to them, comes probably from the prerogative formerly attachel to falconry, of which the practice was only permitted to nobles. The species of this division are difficult to be distinguished from one another, the young of the first year and the smaller species resembling one another so much in colour and plumage. The comparative length of the wings and tail, and the colour of the feet, cerc, and eyelids, are the surest means of ascertaining the specific differences.

F. Islandicus, Lath. The Jerfalcon. Ground of the plumage white, with narrow brown bands on the upper parts, and on the tail; under parts marked by little brown spots in the form of tears, most numerous and largest on the flanks; bill yellowish; cere and round the eyes of a livid yellow; iris brown; feet of a fine yellow. Male about one foot nine inches long; the female two or three inches more. Inhabits Iceland, Denmark, and North of Germany, nestling in inaccessible rocks.-Selby, Illust. pl. 14.

F. rusticolus, Gmel.; Gerfaut de Norwege, Buff.; White Jerfalcon, Lath.; Collared Falcon, Penn.-The young, F. Gyrfalco and sacer, Gmel.; Buteo cinereus, Daud; Le Gerfaut, Le Sacre, Buff.; Brown Jerfalcon, Lath.

Next to the eagle, the Jerfalcon is reputed the most formidable and active, as well as the most prompt and intrepid of all our predaceous birds; and it is still the most esteemed for falconry. The female boldly attacks the largest of the feathered race, the stork, heron, and crane being its easy victims.

F. Lanarius, Lin. The Lanner. Wings ending two-thirds from the end of the tail; middle toe shorter than the tarsus; a very narrow mustache, which disappears with age ; feet bluish; the two first wing-feathers with truncated beards towards the end. Inhabits Europe.-Tem. 20.

F. peregrinus, Lin. The Peregrine Falcon. Wings extending to the extremity of the tail ; middle toe as long as the tarsus; a very large black mustache, which spreads with age; feet yellow; a single wing-feather with truncated web towards the end. Fourteen inches long.-Selby, Illust. pl. 15, 15.*

Le Lanier, and Faucon, Buff. ; F. abietinus, Bechst.; Blue Black Falcon, Pcnu. : Sparviere pellegrino, Storr.-The young, F. hornotinus, Briss.; Le faticon sors, Buff.; Y earling Falcon, Lath. 
Inhabits the mountrinous countries of Europe, and preys on grouse, pheasants, and partridges. Various instances are recorded of the rapidity of its flight. Thus, one that eloped from its master, in the county of Forfar, on the 24th of September 1772, with tour heavy bells at its feet, was killed on the morning of the 26 th of the same month at Mostyn, in Flintshire. Another, belonging to a Duke of Cleves, flew out of Westphalia into Prussia in one day; and in the county of Norfolk one was known to make a flight at a woodcock at the rate of nearly thirty miles in an hour. The female peregrine falcon is, in the terms of falconry, always called Falcon, while the male is denominated Tercel; and, when thoroughly bred, they are called Gentil or Gentle Hazoks.

F. subbuteo, Lath. The Hobby. Throat white, with a large black band extending on the white parts of the sides of the neck; upper part of the body bluish black; lower parts whitish, with longitudinal black spots; bill bluish; cere, eyelids, and feet yellow; iris brown; wings extending beyond the extremity of the tail. About 14 inches long.-Selby, Illust. pl. 16.

This is a migratory species, arriving in England in April for the purpose of incubation, and leaving the country in October for warmer latitudes. Its favourite prey is the lark. When falconry was in fashion the hobby was trained to the pursuit of young partridges, snipes, and larks.

F. asalon, Tem. (F. casius Meyer.) The Merlin or Stone Falcon. Cere and legs yellow; head ferruginous, body bluish-gray, with ferruginous spots and streaks above; yellowish-red, with oblong spots below; wings ending at two-thirds of the length of the tail. About 12 inches long.-Selby, Illust. pl. 18.

F. cæsius, Meyer; F. Iithofalco, Gmel.; Le Rochier, Buff,-The young, L'émérillon, Buff.; Sparviere smeriglio, Stor.

The Merlin is a migratory species, resorting to the north in spring, and returning to the south on the approach of winter. According to $\mathrm{Mr}$ Pennant it does not breed in England; but in Northumberland Colonel Montagu found three young ones about half-grown in the middle of a high clump of heath, in which they were so well concealed that they would not have been discovered but for a setting dog, which made a point at them.

F. tinnunculus, Lin. The Kestril. Wings ending at three-fourths of the length of the tail ; upper part of the plumage of the male variegated with numerous black spots; wing-feathers banded interiorly; claws constantly black. Fourteen inches long. Inhabits Europe. B.-Selby, Illust. pl. 17.

The young, F. bruneus, Bechsto; F. fasciatus, Retz.

The Kestril is by far the most elegant of the small British hawks. The eggs, which are four or five in number, are rather inferior in size to those of the sparrowhawk, and of a dirty white, blotched with rust-colour of various shades, and sometimes wholly covered with a deep rusty red. It is a common inhabitant of our rocky coasts, or in high or ruinous towers. Its prey is moles, field-mice, frogs, and small birds, on which it darts like an arrow. When taken young it is easily tamed.

F. tinnunculoides, Natterer. Wings ending at the extremity of the tail; upper part of the plumage and quill-feathers of the male without spots; claws pure white. Inhabits Europe-Tem. 31.

F. rufipes, Bechst. Principal colours of a more or less deep blu. ish ; cere and feet red; claws yellow. Common in Russia and Poland.-Lath. Ind. 46.

F. vespertinus, Gmel.; Le Kober, Son. ; Ingrian Falcon, Lath. 
F. punctatus, Cuv. Plumage rufous above, with the head and neck longitudinally striped with black; back and wings spotted with black; seven black bands on the tail ; body beneath white, spotted with black ; cere and legs yellowish ; bill bluish. Ten inches long. Inhabits Isle of France.-Tem. Pl. Col. 45.

F. femoralis, Tem. Plumage above ashy brown, red beneath, with a black band above and behind the eye ; thighs red ; bill blue; cere yellow. About a foot long. Brazil.-Tém. Pl. Col. 121.

F. severus, Horsfield. Plumage dusky brown above, with the quills black; chestnut coloured-beneath, with the throat pale. Ten inches and a half long. Inhabits Java._Lin. Trans. xiii. 135.

\section{2.-EAGLES.}

Bill strong, of considerable length, and hooked towards the extremity: legs strong, nervous, covered with feathers, or naked; toes robust, and armed with poverful and very crooked claws; wings long, the first, second, and third feathers shorter than the fourth and fifth.

F. imperialis, Tem. The Imperial Eagle. Crown of the head and occiput furnished with acuminate reddish feathers, edged with bright red; upper part of the body of a very dark glossy brown above, of a very dusky brown beneath, with the exception of the abdomen, which is yellowish red; some of the scapulars always pure white; wings the length of the tail, which is almost square; last joint of the middle toe with five scales.Shan, vii. pl. 15.

The Imperial Eagle is diffused over Hungary, Dalmatia, and Turkey, and is more common in the eastern and southern parts of the world than in any other quarter, abounding in Egypt and on the coast of Barbary; but it is rare in the centre of Europe. It inhabits the extensive forests of hilly countries, preying on stags, roebucks, foxes, and other mammiferous animals, and often on large birds. The female breeds in lofty trees or elevated rocks, and lays three or four eggs of a dirty white.

F. fulvus, Tem. (F. chrysaëtos, Lin.) Ring-tail or Golden Eagle. Crown of the head and neck with acuminate feathers of a bright rufous and golden tinge; all the other parts of the body of an obscure brown, more or less blackish, according to age; scapulars never white; three scales upon the last joint of all the toes. Male about three feet long; the female three feet and a-half; spread of the wings between seven and eight feet.-Selby, Illust. pl. 1 . and 2.

Aquila fulva, Meyer; F. fulvus and F. Canadensis, Gmel. ; F. chrysaëtos, Lin. ; l'Aigle Royal, Buff.; l'Aigle Commun, Cur.; Ring-tail and Golden Eagle, Lath.-Var. F. albus, Gmel.; F. cygneus, Lath.; l'Aigle Blanc, Briss.

The Golden Eagle inhabits the high mountain ranges of the north of Europe. It is frequently found in Scotland, and preys on fawns, lambs, hares, and large birds. It nestles on precipitous cliffs, and the female lays two eggs, rarely three, of a dirty white, spotted with reddish. It soars to a prodigious height, and from this elevation can discover its prey at an immense distance. It is extremely tenacious of life, whence probably originated the eastern notion, that eagles possessed the power of renewing their youth. Keysler alludes to an individual which lived a hundred and four years at Vienna, though in a state of confinement. Nor is it less remarkable for enduring abstinence, especially when deprived of exercise; 
for one taken from a fox-trap refused food for five weeks, when it was killed. Redi likewise informs us that he kept two alive, the one for twenty-eight, and the other for twenty-one days without food. In old age individuals of this species are said to become more or less hoary or white. Numerous stories are related of the strength of this bird, and of its carrying off children as its prey; but few of these are well authenticated. Ray, however, mentions, that in one of the Orkneys an infant of a year old was seized in the talons of an eagle, and conveyed about four miles to its eyrie; while the mother, knowing the spot, pursued the bird, found her child in the nest, and took it home unhurt.

F. navius, Lin., including his maculatus. (Aquila planga, Vieill.) The Spotted Eagle. Body, head, wings, and tail, of a glossy brown, of various degrees of intensity, according to age; bill black; cere and toes yellow. Nearly two feet long. Inhabits woods and mountains in Europe, Africa, and Asia._Shan, vii. 84. The young is F. maculatus, Gmel.; Rough-footed and Spotted Kagle, I.ath.; L'Aigle tacheté, Cuv.

F. armiger, Shaw. Plumage gray brown above, white below ; occiput crested ; smaller wing-feathers and tail crossed with whitish bands ; bill bluish with a black tip ; claws black, very strong and crooked. Size of the golden eagle. Inhabits Africa.Shaw, vii. 57.

F. pennatus, Lin. Feet feathered to the toes; a tuft of white feathers at the insertion of the wings ; tail brown above. Length 18 inches. Inhabits eastern parts of Europe-Tem. 44.

F. Malayensis, Tem. Plumage sooty brown, more or less dusky according to the age; irregular whitish bands at the base of the wing-feathers, and whitish lunules on the tail-feathers. Inhabits the Indian Archipelago.- Tem. Pl. Col. 117.

F. fucosus, Cuv. Plumage dusky brown, varied with yellowish red, throat and fore-part of the neck dusky brown; head and neck beautiful golden red; tail yellowish beneath, with indistinct bands; bill and legs yellow.-Tem. $\mathrm{Pl}$. Col. 32 .

F. brachydactylus, Wolf. Head very thick; a space above the eyes covered with white down; top of the head, cheeks, throat, breast, and belly white, but variegated with numerous spots of clear brown; coverts of the wings brown, with the origin of the feathers white; tail square, grayish brown, with bands of a deeper colour; bill black; cere bluish; iris yellow. Two feet long. Inhabits pine forests in the north of Europe, and feeds chiefly on lizards and snakes.-Shaw, vii. pl. 19.

Aquila brachydactyla, Meyer; F. Gallicus, Gmel.; F. leucopsis, Bechst.; Le Jean le blanc, Buff.; F. terzo d'2quila, Stor.

F. albescens, Daud. Whitish, variegated above with yellowish brown; tail black, barred with white; back of the head slightly crested. About a third smaller than the golden eagle, and of a more slender shape. Cape of Good Hope.-Shaw, vii. 93.

F. haliaetus, Lin. The Osprey Eagle. General colour brown above, white beneath, with whitish head, and blue cere and legs; iris yellow; bill black; wings extending beyond the extremity of the tail. About 21 inches long.-Selby, Illust. pl. 4. 
F. arundiaceus, Gmel. ; I.e balbuzard, Buff.; Osprey Eagle, Lath. ; Flus adler, Bechst.

This species makes its nest in the crevices of rocks, or on the tops of tall trees, and occasionally on the ground among reeds, laying from two to four white eggs, spotted with reddish, rather smaller than those of the domestic hen. It inhabits the banks of large rivers and lakes, and feeds principally on fish. It is found in most of the countries of Europe.

F. albicilla, Lath. Lin. (F. ossifragus, Gmel.) Sea Eagle or Osprey. Plumage of a clear brown, spotted with deeper colour; bill and iris almost black in youth; colour uniform ash-coloured, or brown in the adult; tail not reaching beyond the wings. Two feet four inches long. Inhabits the coasts of England, Holland, and France.-Selby, Illust. pl. 3, and 3.*

F. albicaudus, Gmel. ; Le grand Pygargue, Buff.; Fisch-adler, Bechst. ; Cinereous Eagle, Lath. - The young, F. ossifragus, melansetos, Gmel. ; L'orfraie, Buff.; Sea Eagle, Lath.; Golden Eagle, Penn.

The Greenlanders, who kill these birds with arrows, or catch them by snares laid on the snow, eat their flesh, make under garments or beds of their skins sewed together, and use the bill and claws as amulets in the treatment of various complaints. This species possesses astonishing capability of enduring the cravings of hunger; and Mr Selby mentions an instance where the bird was permitted, through the inattention of its keeper, to be without food for several weeks.

F. leucocephalus, Lin. White Headed Eagle. Plumage very irregularly spotted and variegated with light and deep brown; bill black; iris clear brown; in the young chocolate brown; bill, feet, and iris yellowish white in the adults; tail always extending beyond the wings. Inhabits Arctic regions.-Wilson, Ornith. iv. pl. 36.

L'Aigle à tête blanche, Cuv. ; L'Aigle Pygargue, Vieill. ; Bald Eagle, Lath.

F. vocifer, Shaw. Brown ferruginous, undulated with black; head, neck, breast, and tail, white. Size of the Osprey. Inhabits Southern Africa.-Shan, vii. 94.

F. maculosus, (Aquila maculosa, Vieill.) Head, neck, and back black; chin, throat, and breast white, each feather streaked with black; abdomen black, with round spots of white; vent and thighs rust-coloured; bill and cere blue; iris yellow; legs orange. Two feet long. Inhabits Guiana.-Vieill. Ois. de l'Amer. Sept.

F. Linnocetus, Horsf. Plumage of a reddish brown, slightly tinged with purple; tail beneath, except the tip, whitish ; cere yellow; bill black; feet bluish. Two feet long. Inhabits Java.-Lin. Trans. xiii. p. 138.

F. niveus, Tem. Plumage above fuscous, white beneath; base of the quill-feathers white; tail-feathers, with the exception of the two middle ones, whitish on the edges of their inner web, and bright brown on the other parts, and transversely banded with deeper brown; legs yellow. Two feet long. Java.-Tem. Pl. Col.127.

\section{3.- Hawks.}

Wings short, ending at two-thirds of the length of the tail; first ving-feather shorter than the second, the third nearly equal to the fourth; feet with long tarsi; toes long, the intermediate the longest; clans much bent and very sharp. 
F. palumbarius, Lin. The Goshawk. Upper parts bluish-cinereous ; a broad white stripe above the eyes ; the under parts white, with transverse bands, and longitudinal lines of dark brown; tail cinereous, with four or five blackish brown bars; bill bluish black; cere yellowish green; iris and feet yellow. Length of the female about two feet; size of the male about one-third less. Inhabits Europe, \&c.--Selby, Illust. pl. 12.

L'Autour, Buff.; Goshawk, Lath.; Hunerhabicht, Bechst. ; Sparvière da Colombi, Stor.-The young, F. gallinarius and gentilis, Gmel.; L'Autour sors, Buff.; Greater Buzzard, Lath.

This species breeds on the tops of high trees, the female laying two to four eggs of a bluish white, spotted with fulvous. It flies low, proves very destructive to game, pigeons, and poultry, and dashes through the woods with great impetuosity after its quarry; but if it cannot almost immediately catch the object of its pursuit, it desists, and perches on a bough, till some other opportunity occurs. In the days of falconry, it was held in higher estimation than any of the short-winged hawks, and was used for the larger sorts of game. According to Mr Low it is common in the Orkney Islands.

F. nisus, Lin. The Sparrowhawk. Bluish-cinereous above ; a white spot on the neck; white beneath, with brown undulations; tail ash-gray, with five bars of blackish-cinereous; cere yellowish green; feet and iris yellow. About 12 inches long. Inhabits Europe.-Selby, Illust. pl. 13.

L'Epervièr, Buff.; Die Sperber, Bechst; Accipiter fringillarius, Ray.

This species is well known for its depredations upon pigeons and small birds. In a nest containing five young ones, Mr Selby found a lapwing, two blackbirds, a thrush, and two green linnets, recently killed, and partly divested of their featlers. It likewise preys on mice, moles, lizards, and snails. It builds in lofty trees, old ruins, or high rocks, frequently occupying the old nest of a crow, and lays from four to six eggs, of a dirty white, and sometimes of a bluish tinge, blotched at the large, and sometimes, though rarely, at the narrow end, with reddish colour. It is easily tamed; though when the young are reared together, the female birds, being largest and strongest, will destroy and devour the males.

F. cachinnans, Lin. (Niacagua of Azara.) The Laughing Falcon. Cere and legs yellow ; eyelids white ; body variegated with brown and whitish; top of the head black, surrounded by a white ring. Inhabits Paraguay._Vieill. Gal. des Ois. pl. 19.

F. minullus, Shaw. Dwarf Sparrowhawk. Brown above, white beneath; breast marked with descending brown streaks, and the abdomen with descending brown bars. Size of the blackbird. Inhabits Southern Africa.-Shan, vii. 205.

F. musicus, Daud. Gray above, with brown undulations benenth, black wing-feathers, and brown wedge-shaped tail, barred with white. Inhabits Africa._Shaw, vii. 143.

In the breeding season the note of the male is much more musical than that of any bird of prey, and is heard at the dawn of day, or in the dusk of the evening, and not unfrequently during the greater part of the night.

F. hemidactylus, Tem. Plumage lead-coloured above, paler beneath; quills black, with a broad white band; tail with two broad black bands and two clear reddish ones. Fifteen inches long. Inhabits Brazil-Tem. Pl. Col. 3.

F. gracilis, Tem. Plumage cinereous lead-coloured above, whitish below, striped with ash-coloured bands; tail with very slight 
indications of transverse stripes. Eighteen inches long. Inhabits Brazil.-Tem. $\mathrm{Pl}$. Col. 91 .

F. nitidus, Tem. Plumage lead-coloured above, white below, transversely waved with ash-colour; tail black, with two narrow white bands; legs long and yellow. Thirteen inches long. Inhabits Guiana.-Tem. Pl. Col. 87.

F. xanthothorax, Tem. Plumage reddish brown above, white beneath; transversely striped with rufous; head, throat, and neck cinnamon red. Twelve inches long. Brazil.-Tem. Pl. Col.92.

F. brachypterus, Tem. Plumage dusky brown above, collar and abdomen white, transversely striped with black; tail wedge-shaped with three white bands. Eighteen inches long. Inhabits Brazil. -Tem. Pl. Col. 116, 141.

F. poliogaster, Natterer. Plumage slaty black, beneath ashy white; throat white; tail black, with three gray bands above and four below; male reddish, with the wings and back dusky. Sixteen inches long. Inhabits Brazil._Tem. Pl. Col. 164, 295.

\section{4.-Kites.}

Nostrils oblique, with a fold at their exterior margin; tarsi short, feathered a little below the knee; wings very long, the third and fourth feathers longest; tail forked.

F. milvus, Lin. The Kite or Glead. Upper parts of the body of a reddish brown, the feathers bordered with a brighter colour; lower parts ferruginous, with longitudinal dusky spots; feathers of the neck and head long and slender, whitish, striped longitudinally with brown; tail bright ferruginous, forked; bill hooked at the end ; cere, iris, and legs yellow. Two feet two inches long. Inhabits Europe. B.-Selby, Illust. pl. 5.

Le Milan Royal, Buff. ; Rother Milan, Bechst. The young, F. Austriacus, Gmel. and Lath.

The Kite is known by its flight, which resembles a sailing or gliding through the air, without apparent motion of its wings. It preys on young rabbits, hares, game of all kinds, poultry, and young birds incapable of flight. It will also destroy young lambs, and feed greedily on carrion; but, in default of these, it readily eats mice, worms, insects, and even snakes. It frequently resorts to the neighbourhood of towns to pick up offals, which it also sweeps from the surface of the water with great dexterity.

F. ater, Lin. Head and throat banded longitudinally with brown and whitish; upper parts of a deep grayish brown, lower parts reddish brown, with longitudinal spots on the middle of the feathers; thighs deep red; quill-feathers deep brown ; tail very little forked, with ten bands of a brighter colour; bill black. Length one foot ten inches. Inhabits Germany, \&c.-Lath. Syn. i. 62.

F. furcatus, Lin. Stwallow-tailed Kite. White; with the back, wings, and very long forked tail, purplish black. About two feet long. Inhabits Carolina, Louisiana, \&c._Shan, vii. 107.

F. melanopterus, Shaw. Plumage gray above, white beneath ; wing* coverts black ; tail subrufous, forked; bill black ; iris and legs yellowish. Size of the Kestril. Inhabits Africa._Leach, Zool. Mis. iii. pl. 122. 
F. Riocourii, Vieill. Plumage ashy blue above, the under parts, forehead, cheeks, and tip of secondary feathers white ; lower wingcoverts deep black : tail forked. Thirteen inches long. Inhabits Senegal.-Tem. $\mathrm{Pl}$. Col. 85 .

\section{5.-Buzzards.}

Bill small, bending immediately from the base; wings shorter than the tail, and the first four feathers notched near their tip; first quill-feathers very short, the fourth the longest; thigh-feathers long and pendant; tarsi short, and clans not much hooked.

F. buteo, Lin. Common Buzzard. Plumage brown and ferruginous above, white and ferruginous beneath; cere, iris, and legs yellow; tail banded with brown. About 21 inches long. Inhabits Europe.-Selby, Illust. pl. 6.

The Buzzard preys on small birds, young rabbits, and hares, moles, field-mice, lizards, frogs, toads, and likewise on worms and insects. The female makes her nest in the fork of a tree, with large sticks, and lines it with wool, hair, or other soft substance, and sometimes takes possession of a deserted crow's nest, which it enlarges, and accommodates to its purpose. It is a sluggish and inactive bird, and will sit for the greater part of a day on the same bough.

F. lagopus, Lin. Rough-legged Buzzard. Feet feathered to the toes, a large brown patch on the belly, and a considerable portion of the tail white from its origin. About two feet long. Inhabits Europe and N. America. B.-Selby, Illust. pl. 7.

This species feeds on partridges and small birds, nestles in large trees, and lays four or five eggs, marked with reddish undulations. It has sometimes been shot in England.

F. apivorus, Lin. The Honey Buzzard. Plumage brown above, with cinereous bands on the wings; under parts white, with triangular brown spots; space between the eye and the bill covered with close set feathers in the form of scales. About two feet long. Inhabits Europe. B.-Selby, Illust. pl. 8.

- This species feeds on small birds, mice, reptiles, and insects, particularly bees. It builds in trees, forming its nest of small twigs, lined with wool, and laying, for the most part, two eggs.

F. pterocles, Tem. Plumage slate-coloured above, beneath white, with the flanks and sides transversely waved with rufous; tail white, with a black band towards the tip. Sixteen inches long. Inhabits Brazil.-Tem. Pl. Col. 56, 139.

F. pocilonotus, Cuv. Plumage white; wings black, spotted with crescent-shaped spots of white; tail with a black band, its base and tip white; bill black; legs yellowish. Inhabits Guiana.1. Tem. Pl. Col. 9.

\section{6.-HARRIERS.}

Bill bending from its base; nostrils oviform; tail long and rounded; wings long, the first quill-feather very short, the third and fourth longest; tarsi long and slender.

F. rufus, Lin. Marsh Harrier. Plumage brown; head and breast white yellowish; bill black; cere and legs yellow. About twenty inches in length. Inhabits Europe. B.-Selby, Illust. pl. 9.

The Marsh Harrier is but sparingly dispersed over most of the countrics of Europe ; but Montagu remarks, that it is the most common of the falcon tribe about the sandy 
flats of the coast of Caermarthen, where he saw no fewer than nine of them regaling on the carcass of a sheep. It abounds in marshy districts both in England and Scotland.

F. cyaneus, Lin. The Hen-harrier. Head and upper part of the body bluish gray; wing-feathers white at their origin, the rest black; under part pure white ; iris and legs yellow; wings ending at three-fourths the length of the tail ; the third and fourth wing-feathers of equal length. Eighteen inches long. Europe. B.-Selby, Illust. pl. 10.

This species flies low, skimming along the surface in quest of prey; delights in marshy situations, and feeds on lizards, and other small reptiles and birds. It has its English appellation from its persecutions in the poultry-yard.

F. cinerarius, Mont. Wings terminating at the end of the tail; the third wing-feather the longest; body above blackish ash-coloured; two black transverse bands on the secondary feathers of the wings; belly, thighs, and flanks white, but striped longitudinally with red; iris and feet yellow. Seventeen inches long. Inhabits Hungary and Poland; rare in England.-Selby, Illust.pl. 11.

F. palustris, Tem. Plumage pale brown above, beneath pale yellowish red, with longitudinal brown stripes ; throat deep brown; quill-feathers and tail ashy-gray striped with brown; eyebrows white. Twenty inches long. Inhabits Brazil.-Tem. Pl. Col. 22.

F. rutilans, Lichten. Plumage bright golden red, varied on the head with small longitudinal striæ; back and wings spotted with ashy brown ; body beneath transversely lined with dusky stripes. Eighteen inches long. Inhabits S. America.-Tem. Pl. Col. 25.

\section{Caracara, Cuv.-Cheeks and throat naked.}

F. Braziliensis, Shaw. (V. Cheriway, Lath.) Cere rose-coloured; feet yellow; body ferruginous; head white; vertex crested with ferruginous; bill bluish ; head and neck yellowish ; tail-feathers blackish, with two intermediate white bands. Two feet and ahalf long. Inhabits S. America._Lath. Ind. 8.

F. formosus, Lath. (Ibycter aquilinus, Vieill.) Cere, orbits, and feet yellowish; throat purple; upper part of the body blackish red; abdomen flesh-coloured. Eighteen inches long. Inhabits S. America._Shaw, Nat. Mis. pl. 485.

F. aterrimus, Tem. (Daptrius ater, Vieill.) Plumage bluish black, shining; tail rounded, white at its base; bill and claws white ; legs yellow; cere blackish. 15 inches long. Brazil._Tem. Pl. Col. 37 .

8. Cymindi, Cuv.-Tarsi short; toes half webbed.

F. hamatus, Illig. Plumage lead-coloured or brown, spotted with red; quill-feathers black; base of the tail and under coverts whitish ; cere and legs reddish orange. Sixteen inches long. Inhabits Brazil.-Tem. Pl. Col. 61, 231.

F. uncinnatus, Illig. Plumage lead-coloured above, paler below ; quills banded with brown ash ; base of the tail white, its tip griseous; bill hooked. 15 inches long. Brazil.-Tem. Pl. Col. 103, 104. vol. $\mathrm{I}$. 
F. Cayanensis, Lath. Legs bluish; body blackish ash-coloured, white below; head and neck bluish white; tail banded with black and white; iris yellow; primaries black. Size of the peregrine falcon. Inhabits Cayenne.-Lath. Ind. 28.

\section{Gen. 6. Strix, Lin.}

Bill compressed, bent from its origin; base surrounded by a cere, covered wholly or in part by stiff hairs. Head large, much feathered; nostrils lateral, pierced in the anterior margin of the cere, rounded, open, concealed by hairs directed forwards; eyes very large, orbits surrounded by feathers; legs feathered, often to the claws; three toes before and one behind, separate, the exterior reversible; the first wing-feathers dentated on their exterior border, the third the longest.

The greater number of the species of this genus are nocturnal birds of prey, although some of them are capable of seeking their food by day. All have soft and downy feathers, which enable them to fly without noise. They seize their prey with their claws, and do not feed on dead animals but when pressed by hunger. The hair, the feathers, and the bones of the animals they feed upon are rejected after digestion in little balls. They moult once a year. Temminck names those which seek their prey by day Accipitrine owls, and distinguishes them by their large tail extending beyond the termination of the wings; and the nocturnal species by their tail being shorter and more rounded. But these divisions are not well marked, and it has therefore been thought better to arrange them by their having or wanting the auricular feathers. Although none of the nocturnal birds of prey are materially hurtful to mankind, and although they are instrumental in the destruction of vermin, yet in almost every age and country they have been regarded by the vulgar as creatures of evil omen, and the heralds of death.

\section{+ Horned Orls.}

S. bubo, Lin. Great-horned Owl. Body variegated and waved with black and ochre colour; inferior parts of this last colour with longitudinal black spots; throat white; two tufts of feathers on the forehead; legs covered to the toes with feathers of a reddish yellow; bill and claws horn-coloured; iris bright orange. Two feet long. Inhabits Europe. B.-Shaw, vii. pl. 28.

This species seldom perches on trees; but haunts mountainous, rocky, and desolate situations, as deserted towers, precipices, and lonely crags, and feeds on partridges, leverets, young rabbits, moles, mice, serpents, lizards, toads, frogs, and even bats. A variety of the present species was venerated by the Athenians as the sacred bird of Minerva, and the emblem of wisdom.

S. otus, Lin. Long-eared Owl. Plumage yellow ferruginous, with black and gray variegations; horns consisting of ten feathers, bordered with whitish yellow; lower parts of an ochre yellow, with oblong blackish brown spots; bill black; iris reddish. One foot 13 inches long. Inhabits both continents-Selby, Illust. pl. 20.

S. scops, Lin. Scops Eared Owl. Plumage gray brown, with blackish variegations above, and gray, speckled with black and reddish brown, beneath; horns formed of little feathers united in a tuft ; transverse bands, crossed by longitudinal ones on the centre of the feathers; bill black; iris yellow. Seven inches long. Europe.-Selby, Illust. pl. 22. 
S. brachyotos, Lath. Short-eared Owl. Head small, with two or three short feathers on the forehead, forming a kind of horns; around the eyes blackish; plumage above ferruginous, bordered with ochre yellow; tail of the same colour, with transverse brown bands ; bill black ; iris yellow ; legs and toes feathered. Twelve inches long. Inhabits Europe. B.-Selby, Illust. pl. 21.

S. atricapilla, Natterer. (Scops, Savigny.) Crown of the head black, with the body above, wings, and tail yellowish, varied with black and brown; white below, longitudinally spotted and striped with brown; feathers at the ears white, pencilled with black; a reddish collar on the nape of the neck. Ten inches long. Inhabits Brazil._-Shaw, xiii. pl. 39.

S. noctula, Reinwardt. Plumage black or brownish, marbled with reddish; beneath reddish white, transversely waved and spot. ted; a double collar on the neck, white above, with brown spots, black below, with reddish white spots. Eight inches long. Inhabits Java.-Tem. Pl. Col. 99.

S. Ceylonensis, Lath. (S. Ketupa, Horsf.) Auricular feathers short and pointed; body brownish black above, paler below; feathers round the face brown, banded with black; wing and tail-feathers with transverse lines of black and white; legs almost naked; claws and bill of a dark colour. Ceylon.-Tem. Pl. Col. 74.

S. lactea, Tem. Plumage white above, variegated with brown and striped with griseous and white ; beneath waved with brown; tail and quill-feathers banded with yellow; tarsi white; toes blue. Two feet long. Inhabits Senegal.-Tem. Pl. Col. 4.

S. ascalaphus, Savigny. (Otus ascalaphus, Cuv.) Plumage rusty red, spotted with brown; wings and back vermiculated and the belly transversely lineated with brown; ear-feathers short. Eighteen inches long. Inhabits Africa.-Tem. Pl. Col. 57.

\section{+十 Smooth-headed Owls.}

S. Lapponica, Retz. Head very large; face broad, covered with long feathers of a pure gray with brown bands, a broad circle of blackish feathers surrounding the face; upper part of the body and wings of a fine gray, marked with numerous zigzag spots of dirty brown; tail almost equal, much longer than the wings; tail and wing feathers banded with brown; feet feathered to the toes. About two feet long. Inbabits Lapland.-Tem. 82.

S. nyctea, Lin The Snowy Owl. Plumage snow-white, spotted with transverse brown bands; bead small; bill black; irides yellow. About two feet long. Inhabits Northern Europe and America. B.--Selby, Illust. pl. 23.

This species is not uncommon in Shetland; and a male and female were taken in Northumberland in January 1823, during a severe snow storm. It preys on grouse, hares, rabbits, carrion, \&c. nestles in craggy rocks or old pines, and lays two white round eggs, which, according to Vieillot, are spotted with black. Its cry has been compared to that of a man in deep distress. Among the Kalmuc Tartars it is deemed a crime to kill them, because they are considered to be the oracles of good or bad fortune, according as they fly to the right or to the left. 
S. Uralensis, Pallas. (Surnia, Dumeril.) Head very large, much feathered, of a grayish white, with some black hairs; a broad circle of white feathers spotted with black surrounding the face ; top of the head, neck, back, and coverts of the wings with large longitudinal spots; wings and tail banded with brown and white; bill yellow, entirely concealed in the long hairs of the face; claws long, yellowish; tail much longer than the wings. Ten inches long. Inhabits Northern Europe.-Shaw, vii. pl.35.

S. funerea, Lath. Forehead dotted with white and brown; a black band behind the eyes and surrounding the orifice of the ears; upper parts of the body with brown and white spots of various forms; lower parts white, banded transversely with brown ashcolour ; iris and bill yellow; feet feathered to the nails. Fourteen inches long. Inhabits the Arctic regions.-Tem. Man. 86.

S. nebulosa, Lin. (Ulula, Cuv.) Barred Owl. Transversely fasciated with brown and whitish above, with oblong ferruginous spots beneath ; extremity of the toes covered with scales; bill yellow ; iris brown. Length 20 inches. Arctic regions.-Shaw, vii. 245.

S. stridula, Gmel. (S. aluco, Meyer.) Common Brown Owl. Ferruginous, or gray brown; wing-coverts spotted with white; feathers of the wings and tail banded transversely with blackish and reddish ash-colour; iris glaucous; feet feathered to the toes. About 15 inches long.-Selby, Illust. pl. 25.

This species is a native of most of the countries of Europe, and is also found in Newfoundland and South America, frequenting large and dense forests, and concealing itself in the thickest recesses. It breeds in the hollows of trees, and sometimes in barns and granaries, in which it is welcomed by the farmer, on account of the numbers of mice which it destroys; but it is a far less acceptable visitor in pigeon houses, in which it commits serious devastations. It lays from two to four eggs, of a dull white, and of a roundish shape. The young are covered with a light-coloured down, and soon become tame, if fed from the hand. If put out of doors within hearing of the parent birds the mother visits them at night, and supplies them with ample provision. This is one of the most common of the British owls, and the only one of them which hoots, inflating its throat, at the same time to the size of a hen's egg.

S. flammea, Lin. Common Barn Owl. Sub-fulvous, variegated with gray and brown; black and white spots down the shafts of the feathers; breast and abdomen white; feet and toes covered with a short down; iris yellow. 13 inches long.-Selby, Illust. pl. 24.

This species is very widely diffused, and is found in most parts of the world. It usually haunts old churches, towers, barns, farm-houses, \&c. and preys on rats, mice, bats, and beetles. In fine weather it generally leaves its haunts about twilight, skimming along the ground, exploring the neighbouring woods for prey, and returning before sunrise, not hooting, but repeating a sort of blowing noise, like the snoring of a man who sleeps with his mouth open. Its sharper notes are of ten interpreted by the superstitious as the presage of approsching dissolution.

S. passerina, Tem. Passerine or Little Owl. Plumage grayishbrown, with irregular whitish spots above; whitish, with brown spots beneath; breast pure white; irides yellow; toes thinly covered with white hairs. About nine inches in length. Inhabits Europe. B.-Selby, Illust. pl. 26. 
S. Tengmalmi, Lin. (S. dasypus, Bechst.) Tail and wings longer in proportion than the preceding; upper parts of the body brown, shaded with blackish; top of the head and neck marked with small whitish rounded spots; bill and iris yellow; tarsus and toes downy. Eight inches long. Inhabits Europe-Tem. Man. 94.

S. acadica, Lin. (S. pygmaea, Bechst.) Upper parts of the body of a deep.gray brown, with whitish spots and points; inferior parts with longitudinal brown spots; large white spots on the throat and sides of the neck; tail with four narrow white bands ; feet feathered to the claws; bill lead-coloured, orange at the base, and yellowish at the point; iris yellow. Six inches long. Inhabits Northern Europe.-Tem. Man. 96.

S. ferruginea, Tem. Plumage above of a fine red, below whitish yellow, striped with rufous; scapulars spotted with whitish yellow; tail in the female banded with brown. Six inches and ahalf long. Inhabits Brazil.-Tem. Pl. Col. 199.

S. nudipes, Daud. Body above brownish fawn-coloured ; coverts of the wings spotted with white; under parts dirty white, with brownish spots; legs naked and brown; bill blackish. About seven inches long. Inhabits St Domingo._Shaw, vii. 269.

\section{ORDER II.-OMNIVOROUS BIRDS. (Omnivora.)}

Bill middle-sized, robust, sharp on the edges; the upper mandible more or less convex and notched at the point; feet with four toes, three before and one behind; wings of medium size, with the quill-feathers terminating in a point.

The birds which çompose this order are gregarious, and monogamous. They nestle on trees, in the holes of old ruins and towers, or in the clefts of trees or rocks. The male and female sit alternately. They live on insects, worms, offals, grains, fruits, \&c. and their flesh is generally hard, tough, and unsavoury.

\section{Gen. 1. OpIsтносомus, Illig.-Phasianus, Lath.}

Bill thick, short, convex, bent at its point ; base dilated laterally; lower mandible strong, terminated in an angle; nosstrils in the middle of the bill covered above by a membrane; legs robust ; tarsus shorter than the middle toe; toes bordered by rudimentary membranes; the first wing-feather short, the four following graduated, and the sixth the longest.

O. cristatus, Tem. (Hoatzin, Ray.) Plumage above brownish white, beneath black; a space round the eyes naked and rufous; head crested; wings with two pale bands ; tail cuneiform, tipped with yellow. One foot ten inches long. Guiana.-Shaw, xi.pl. 11.

Gen. 2. Buceros, Lin.

Bill long, convex, curved, sharp-edged, of large dimensions, 
serrated at the margin, with a horny protuberance near the base of the upper mandible rising into a crest ; nostrils behind the base of the bill, covered by a membrane; legs short, muscular; lateral toes equal, the external one united to the second joint; the first three wing-feathers graduated, the fourth or fifth longest.

B. rhinoceros, Lin. Rhinoceros Hornbill. Plumage black; tail tip* ped with white; casque red above ; bill about ten inches in length, yellowish, slightly curved, sharp-pointed, irregularly serrated on the edges. Size of the hen turkey, but more slender. Inhabits Java, \&c.-Shaw, viii. pl. 1.

The singular bill of this species is furnished at the base of the upper mandible with an extremely large process, continued, for a considerable space, in a parallel direction with the bill, and then turned upwards in a contrary direction in the style of a reverted horn. This appendage, which is eight inches long, and four in width at the base, is divided into two portions by a longitudinal black line. Though apparently a formidable weapon, this singular bill is by no means so in reality; for Levaillant assures us, that he often put his hand into it, without feeling the slightest pain, though the bird exerted all its endeavours to wound him. The young is destitute of the horn-like excrescence on the bill.

B. monoceros, Shaw. (B. Malabaricus, Lath.) Unicorn Hornbill. Plumage black above, with the abdomen and sides of the tailfeathers white; bill yellowish, with compressed casque, black above, and pointed in front. About the size of a raven. Inhabits India.-Shaw, viii. 8.

B. galeatus, Lath. Graleated Hornbill. Plumage black, with abdomen and tail white, the latter marked by a black bar; bill conical and yellowish, with squarish, convex red casque. Four feet long. Inhabits Papuan Islands.-Shaw, viii. 24.

B. violaceus, Shaw. Violaceous Hornbill. Violaceous black; sides of the wing and tail-feathers white; bill whitish ; casque compressed, obtuse in front, and marked by a black spot. Smaller than the monoceros. Inhabits Ceylon.-Shaw, viii. 19.

B. Abyssinicus, Lath. Abyssinian Hornbill. Black, with white primary quills; the secondaries ferruginous; bill black, and casque abruptly orbicular; neck with protuberances, as in the turkey. Inhabits Abyssinia.-Shan, viii. 21.

B. coronatus, Vaill. Crowned Hornbill. Black, with the abdomen, stripe on each side of the hind-head, and tip of the tail white; bill red, and slightly crested. Inhabits Africa.-Shaw, viii. 35.

\section{Gen. 3. Prionites, Illiger.-Momota, Shaw.}

Bill of medium size, strong, hard, convex above, bent towards its point, which is compressed; edges of the mandibles serrated; nostrils basal, lateral, oblique, open, but partly concealed by feathers; toes lateral, unequal; the internal very short, joined at its base; the external united to the second joint; wings short; the first three feathers graduated, the fourth and fifth longest. 
P. Braziliensis, Cuv. (Ramphastos momola, Liı.) Brazilian Sawbill. Green above, buff-coloured beneath ; crown blue, marked with a black spot; the two middle tail-feathers elongated; head large; bill black; legs black, and claws hooked. Size of the thrush. Inhabits Brazil._Shan, viii. pl. 3.

P. ruficapillus. (Baryphonus, Vieill.) Plumage of the wings and back green; primaries and tail blue; top of the head red; upper part of the breast reddish; a patch of black on the front of the neck; tail equal. Fourteen inches long. Inhabits Paraguay.Shaw, xiv. 84.

P. cyanogaster, (B. cyanogaster, Vieill.) Blue-bellied Momot. Green above; blue beneath; tail cuneated. Length fourteen inches and a-half.-Inhabits Paraguay.

\section{Gen. 4. Convus, Lin.}

Bill straight at its origin, thick, compressed on the sides, bent towards the point, and edged; nostrils covered by reflected bristly feathers; legs and feet plated; toes, three before and one behind, divided; tarsus longer than the middle toe; wings acuminated, the fourth feather longest.

$$
\text { 1.-Crows. }
$$

C. Corax, Lin. The Raver. Bill very strong; plumage glossy black, the upper parts with purple reflections; tail strongly rounded; iris with two circles, gray and brown. The young when hatched incline to whitish. Two feet long.-Selby, Illust.pl.27.

The Raven is found in every quarter of the globe, and under all climates. Its voracity is proverbial. In Greenland ravens usually haunt the neighbourhood of the sea, assembling in troops during winter around the huts of the natives, plundering the provisions, devouring the offals, or even from hunger pulling the leathern canoes to pieces. On the north-west coast of Hudson's Bay, in Kamtschatka, \& c they prey in concert with the white bear, the arctic fox, and the eagle, greedily seizing the eggs of other birds, shore-fish, and such testaceous and crustaceous animals as happen to be within their reach ; and they frequent woody places, in the neighbourhood of towns, for the sake of carrion and other refuse. They are also unsparing of ducklings and chickens, and destroy sickly sheep and lambs. Ravens build their nests in the crevices or in the holes of walls, on the top of deserted towers, or in the forks of large trees. The female lays generally five or six eggs, of a pale bluish green, marked with numerous spots and streaks of brown and ash.colour. Incubation lasts about twenty days, during which period the male assiduously waits on his mate, and not only provides her with abundance of food, but relieves her in turn, taking her place in the nest during part of the day. Ravens live to a great age, some well authenticated cases being on record of their having completed a century. When they croak three or four times, repeatedly extending their wings, and shaking the leaves of the trees on which they are perched, they are said to foretell serene weather. The Greenlanders observe tbat when they roan about in a restless manner, making a noise in the air, they presage a violent south wind and tempest.

C. corone, Lin. The Carrion Crow. Plumage deep black with violet reflections; tail rounded; bill and feet black; iris hazelcoloured. Eighteen inches long.-Selby, Illust. pl. 28.

This species is as widely diffused as the raven, being common in most parts of the world. They feed on flesh, eggs, worms, insects, and various sorts of grain; carrion, 
fish, fruits, and even shell-fish, which they contrive to break by dropping them on a hard surface from a height. They often destroy weakly lambs, and, when pressed with hunger, will even pursue birds on the wing. Their croaking in the morning is said to indicate fine weather. Like the raven and other congenerous birds the carrion crow may be domesticated, and taught to articulate several words. It has been also observed to manifest the same disposition to hoard provisions and glittering trinkets.

C. cornix, Lin. Hooded or Royston Crow. Plumage of the neck and body ash-coloured ; head, throat, wings, and tail black, with bronze reflections; bill and feet black; iris brown. Twenty-one inches long. Inhabits Europe, \&c.-Selby, Illust. pl. 29.

This species visits the south of England in October, or the beginning of winter, arriving and departing with the woodcock, and retiring north to breed in the beginning of April. In the Orkneys, Hebrides, and Shetland islands, it is the only genuine crow, the rook and carrion crow being there unknown. In these districts, and in some parts of Scotland, it is resident throughout the year. Where opportunities offer, it breeds in the pines and other large trees, in default of which it nestles in the cavities of rocks. The female, which is rather smaller than the male, and of less - lively hues, usually lays four, five, or six eggs, of a greenish-blue, marked with many spots of blackish-brown. The Royston crow is remarked for its double cry, of which one is hollow and well known, and the other shrill, and somewhat resembling the crowing of a cock. When other food is wanting, these crows eat crarberries and other mountain fruits. In open fertile countries they live much on grain, worms, and carrion; but they often resort to the sea-shores, and prey on the various animal matters thrown up by the tide. Mr Low, in his Natural History of Orkney, observes, that in that country they meet together in spring, as if to deliberate on the important concerns of summer, and, after flying about in this collected state for eight or ten days, separate into pairs, and betake themselves to the mountains.

C. frugilegus, Lin. The Rook. Base of the bill, nostrils, throat, and part of the head destitute of feathers; plumage of a fine black, with purple and violet reflections; bill straighter and more slender than in the preceding species; mandibles and feet black; iris of a grayish white. About eighteen inches long. Sometimes found white. Inhabits Europe. B.-Selby, Illust. pl. 30.

In England Rooks are stationary; but in France, Silesia, and many other countries, a great many migrate. In France they are the forerunners of winter, whereas in Siberia they announce the summer. Their flights are sometimes so dense as to darken the air, being frequently joined, not only by the common crow and the jackdaw; but also by troops of starlings. Every spring they resort to breed on the same trees, preferring the loftier branches, and building sometimes ten or twelve nests, rising one above another on the same tree. They feed chiefly on worms and insects; but in winter, particularly when the ground is covered with snow, they fly to the sea-shore to feed on small shell-fish, particularly the common periwinkle. These last they raise into the air, and drop them among stones to break the shell.

C. monedula, Lin. The Jackdaw. Top of the head of a black colour, changing to violet; occiput and upper part of the neck gray ash-coloured; the rest of the body above black, with a violet reflection; the under parts deep black; iris grayish white. About thirteen inches long. Inhabits Europe. B.-Selby, Illust. pl. 31. fig. 1 .

Jackdaws feed principally on worms and the larvæ of insects, and are very fond of cherries. Their voice is shriller than that of the rook or crow, and appears to be capable of different inflections. They are easily tamed, and seem so fond of domestication as seldom to attempt their escape. They may be fed on insects, fruit, grain, and even small pieces of meat. With no great difficulty they may be taught to articulate sevcral words; but they are mischievous and tricky, and will secrete not only portions of their fond, but pieces of money, jewels, \&c. 
C. Jamaicensis, Lath. Chattering Crow. Of a uniform deep black. Inhabits Jamaica._Lath. Ind. 154.

This scarcely differs in appearance from the European carrion crow, but utters a peculiar chattering note.

C. Dauricus, Lath. White-breasted Crow. Plumage black; neck and breast white. 12 inches long. Africa and Asia.-Lath. Ind. 154.

$$
\text { 2.-Pies. }
$$

C. pica, Lin. (Pica Europaea, Cuv.) The Magpie. Head, throat, neck, top of the breast and back black, with purple and green reflections ; the scapulars, breast, belly, and inside of the wingfeathers white ; tail lengthened and cuneated ; bill, iris, and feet black. 18inches long. Inhabits Europe-_Selby, Illust.pl.31.fig. 2.

The Magpie is generally diffused in most of the countries of Europe, and it also occurs in Asia. Being smaller than the rook, and with wings proportionally shorter, its flight is neither so lofty nor so well supported; neither does it undertake long journies, but only flies from tree to tree at moderate distances; yet it is seldom at rest for any length of time, but skips and hops about, and shakes its long tail almost incessantly. Though naturally shy and distrustful, yet it is seldom found remote from human habitations. Magpies generally continue in pairs throughout the year, and at times unite in flocks, when they are very clamorous. They reject hardly any species of animal food or fruits, and devour grain when nothing else is within their reach. They prey on birds, rats, field-mice, young poultry, leverets, feathered game, carrion, fish, insects, \&c. They are notorious pilferers and hoarders, and conceal provisions or any glittering objects with great address. In their wild state they proclaim aloud any apparent danger, by their chattering note, and thus the fowler is frequently deprived of his sport. In almost every country the appearance of the magpie is, in the minds of the vulgar, associated with superstitious prejudices.

C. Senegalensis, Lin. Plumage violet black; tail cuneated ; wing and tail-feathers subferruginous. Fourteen inches long. Inhabits Africa._Lath. Ind. 163.

C. rufiventris, (Pica rufiventris, Vieill.) Crown and nape of the neck grayish blue ; throat and primaries black ; breast, abdomen, back, and rump rufous; tail cuneiform. Size of the Magpie. Inhabits Eastern Asia.-Shan, xiii. 64.

C. Caledonicus, Lath. Plumage ash-coloured, except the tail, which is black; bill and legs black. Fifteen inches long. Inhabits New Caledonia._Lath. Ind. 154.

C. erythrorhyncos, Lin. Plumage brown violet, with very long tail; forehead, throat, and breast black ; occiput and tips of wings and tail white. Inhabits China.-Lath. Ind. 163.

$$
\text { 3.-Jays. }
$$

C. glandarius, Lin. (Garrulus glandarius, Cuv.) The Jay. Body of a reddish ash-colour; head white, with black streaks; wing-coverts with blue and black bars; bill and tail black ; iris blue ; legs dark brown. 13 inches long. Inhabits Europe.-Selby, Illust. pl. 32.

This bird is the most elegant of the tribe indigenous to Great Britain. Jays are great depredators of fruit and grain, and also frequently plunder the nests of smaller birds of their eggs and young. When full grown the jay is extremely shy; but if taken from the nest, it evinces great docility. Its common notes bespeak a wonderful flexibility of throat; for it naturally imitates the sounds with which it happens to be most familiar, as the bleating of a lamb, the mewing of a 
cat, the cry of a kite or buzzard, the hooting of an owl, the neighing of a horse, \&c. These imitations, Col. Montagu observes, are so exact, even in the wild state, that he has been often deceived by them.

C. infaustus, Lath. Head blackish; feathers around the nostrils and base of the bill white ; upper part of the body gray ash-coloured, lower parts reddish gray ; wing-coverts and internal part of the wings, rump, abdomen, and lateral feathers of the tail red; two middle feathers of the tail cinereous; bill black; feet brown. Eleven inches long. Inhabits Europe-Tem. Man. 115.

C. cristatus, Lath. (Garrulus, Cuv.) Blue Jay of Catesby. Crested blue above, sub-rosaceous beneath ; collar, back, wings, and cuneated tail barred with black. About eleven inches long. Inhabits North America._Catesby, i.t. 15.

C. Stelleri, Lath. Plumage purplish black ; abdomen bluish ; wings blue in the middle, banded with black ; tail blue, cuneated. Fifteen inches long. Inhabits N. America.-Lath. Ind. 158.

C. Canadensis, Lin. Plumage brown above, pale cinereous below ; forehead and throat yellowish; tail tipped with white. Nine inches long. Inhabits N. America.-Lath. Ind. 160.

C. pileatus, Illiger. Slightly crested ; head, front, and sides of the neck black; body above, wingsand tail azure blue; beneath and tip of the tail white or yellowish. Thirteen inches long. Inhabits South America.-Tem. Pl. Col. 58.

Gen. 5. Nucifraga, Briss.

Bill, long, straight, narrowed at the point; upper mandible rounded, longer than the under, both terminated in an obtuse and depressed point; nostrils basal, round, open, concealed by hairs directed forward; three toes before and one behind; tarsus longer than the middle toe; wings acuminated; fourth quill-feather the longest.

N. caryocatactes, Briss. (C. caryocatactes, Lin.) Nut-cracker. Plumage rusty brown, with triangular white spots; top of the head and wings blackish; tail fuscous, terminated with white; iris hazel-coloured; bill, feet, and claws black. Length thirteen inches. Inhabits Europe._Shan, vii. pl. 43.

This species, the only one of the genus, inhabits many parts of Europe, and is found even in Siberia and Kamtschatka, but is very rare in this island. Though not statedly birds of passage, they sometimes fly from the mountains to the plains; and flocks of them are frequently seen to accompany other birds into different parts of Germany, especially where there are pine forests. They feed on hazel-nuts, acorns, pine-seeds, \&tc.

\section{Gen. 6. Pyrrhocorax, Cuv.-Corvus, Lin.}

Bill of medium size, slender, compressed, bent, slightly notched or smooth; nostrils basal, lateral, ovoid, entirely concealed; legs strong; tarsus longer than the middle toe; toes almost wholly separated; claws strong and bent; wings cuneated, the fourth and fifth feathers longest. 
P. pyrrhocorax, Cuv. (The Alpine Crow, Lath.) Plumage of a brilliant black, with purple and green reflections; tail a little rounded; wings shorter than the tail; bill orange yellow; iris brown; feet vermilion red, soles of the feet black. About fourteen inches long. Inhabits mountains in Europe--Tem. Man. 121.

P. graculus, Tem. (Red-legged Crow, Lath.) Plumage black, with green, violet, and purple reflections; wings long; tail square; bill long, pointed, arched, and as well as the legs of a vermilion colour ; iris brown; tongue of a saffron yellow. Sixteen inches long. Inhabits mountains of Europe.-Selby, Illust. pl. 33.

In Britain this species seems to be principally limited to Devonshire, Cornwall, and Wales ; but it is also found in some parts of Scotland and the Hebrides. It appears in immense flocks in Egypt towards the end of the annual inundation of the Nile, when it feeds with the storks and falcons on the reptiles which then abound. With us they are stationary throughout the year. The Cornish peasantry often keep them tame in their small gardens.

\section{Gen. 7. Barita, Cuv.-Craticus, Vieill.}

Bill long, strong, convex above, notched at the point, without nasal furrow; nostrils lateral, pierced longitudinally in the bill, covered above and half shut by the corneous substance; legs robust; tarsus longer than the intermediate toe; the external toe united to the first joint, the internal free; back toe long, very strong; wings of medium size or long, the fourth or sixth quill-feathers longest.

B. varia, Tem. (Gracula, Shaw.) Plumage black above, variegated with white; white below ; lateral tail-feathers tipped with white ; bill bluish, apex curved ; legs plumbeous. . Thirteen inches long. Inhabits New Guinea.-Shaw, vii. 464.

B. strepera, Tem. (Coracias, Lath.) Plumage black, primaries white at the base; lower coverts of the wing and tail white; tail elongated, round, the feathers white at their base, apex black; wings reaching to the middle of the tail ; feet black. Nineteen inches long. Inhabits Norfolk Island.-Shaw, xiii. pl. 10.

\section{Gen. 8. Glaudopis, Forst.}

Bill of medium size, strong and thick; upper mandible convex, arched, curved towards the tip, covering the edges of the lower, at the base of which is a fleshy membrane or wattle; nostrils basal, lateral; legs robust; tarsus longer than the middle toe; thumb with a long and crooked nail;

G. cinerea, Lath. Body cinereous, nearly black; tail cuneiform, with twelve feathers; bill black, with wattles at the base of a reddish blue colour. Fifteen inches long. Inhabits New Zealand. -Shaw, vii. pl. 42.

Gen. 9. Gracula, Lin.

Bill of medium size, strong, much compressed, convex above, narrow at the point, which is notched in some individuals; 
nostrils lateral, open, partly concealed by the feathers. of the face; legs robust; tarsus the length of the middle toe ; the external toe joined at its base; the internal one free; back toe short; third wing-feather longest.

G. religiosa, Lin. Plumage violet black, with a white spot on the wings, and a naked yellow occipital band. $10 \frac{1}{2}$ inches long. Inhabits India._Shaw vii. pl. 54.-The only species of the genus.

Gen 10. Buphaga, Lin.

Bill strong, thick, obtuse ; inferior mandible stronger than the superior, both gibbous at the point ; nostrils basal, half shut by an arched membrane; tarsus longer than the middle toe; wings of medium size, first wing-feather very short, the second almost as long as the third.

B. Africana, Lin. African $\mathrm{Ox}$-pecker. Ferruginous-brown above, pale beneath ; tail feathers sub-acuminated. Size of a lark; Eight inches in length. Inhabits Africa._Shaw, viii. pl. 6 .

\section{Gen 11. Bombycivora, Tem.-Ampelis, Lin.}

Bill short, straight, elevated ; the upper mandible slightly curved towards the extremity, with a marked tooth; nostrils basal, ovoid, open, concealed by rough hairs directed forward; three toes before, and one behind, the exterior joined to that in the middle ; wings of moderate size, with the first and second quills the longest.

B. garrula, Tem. (Ampelis garrulus, Lin.) The Bohemian Chatterer. Back of the head crested; length nearly eight inches. Size about that of a starling. Inhabits Europe, Asia, and America. -Penn. Brit. Zool. i. pl. 48.

\section{Gen. 12. Ptilonorynchus, Kuhl.}

Bill short, strong, depresed at the base, bent, point notched; inferior mandible gibbous in the centre; nostrils basal, lateral, round, concealed by the feathers ; legs short, robust ; tarsus longer than the middle toe, which is united to the exterior one to the first joint; posterior claw strong, curved; the fourth and fifth wing-feathers longest.

This genus is formed from three exotic species, viz. $P$. violaceus, of a brilliant violet colour, the female olive; $\boldsymbol{P}$. viridis, body of a fine green; and $\boldsymbol{P}$. niger, glossy black colour.

\section{Gen 13. Coracias, Lin.}

Bill compressed, higher than broad, straight; the upper mandible bent towards the point; nostrils linear, lateral ; legs short, stout, and formed for walking; three toes before and one behind, entirely divided; wings long, with the first quill somewhat shorter than the second.

C. garrula, Lin. (Galgulus garrulus, Vieill.) Garrulous Roller. 
The plumage of the head and neck blue with green reflections; tail nearly even; wings varied with blue, sea-green, and black; back and scapulars fawn-coloured; wing-coverts and rump of a rich ultramarine blue; iris with a double circle of brown and gray ; feet yellowish; bill black, brownish at the base. Thirteen inches long. Inhabits Europe.-Shaw, vii. pl. 50.

This is the only one of the family known in Europe. It roams as far north as Sweden, and a few stragglers have been met with in England.

C. Bengalensis, Lath. Bengal Roller. Plumage sub-fulvous, bluish beneath; the under part of the neck striated with pale violet; tail entire. 12 inches long. Inhabits Bengal,-Lath. Ind. 168.

C. Senegalensis. Lath. Plumage reddish brown; the tail, wings, and upper parts bluish; face white; exterior tail-feathers longest. Eighteen inches long. Inhabits Africa._Lath. Ind. 169.

Gen. 14. Colaris. Cuv.

Bill short, strong, depressed, dilated on the sides, much broader than deep, ridge rounded, point a little crooked, with or without notch; inferior mandible in part concealed by the margin of the upper; nostrils basal, long, diagonally cleft, half shut by a membrane covered with feathers ; legs short; tarsus shorter than the intermediate toe; the anterior toes joined at their base ; wings long, the second feather longest.

C. orientalis. Tem. (Coracias orientalis, Lath.) Quill-feather varied with sea-green and blue; abdomen blue green; throat and base of the tail blue. 10incheslong. Inhabits India.-Briss. ii.t. 7.fig.2.

C. Madagascariensis, Tem. (Coracias, Lath.) Plumage above purple ferruginous, inclining to blossom colour beneath ; quill-feathers blue black; rump, vent, and tail blue green, tipped with purplish black. Ten inches long. Inhabits Madagascar.-Buff. Ois. Pl. Enl. 501.

C. afra Tem. (Coracias afra, Lath.) Plumage above rufous brown, lilac-coloured beneath; wings blue; tail sea-green, with blue black tip. 8 inches long. Inhabits Africa._Shaw. Nat. Mis. pl. 401.

Gen. 15. Oriouus, Tem.

Bill in the form of a lengthened cone, horizontally compresed at the base, and edged ; the upper mandible surmounted by a ridge, notched at the point ; nostrils basal, lateral, naked, and horizontally pierced in a large membrane ; tarsus shorter than, or of the same length as, the middle toe, which is joined to the exterior one; wings with the first quill very short, the third the longest.

O. galbula, Lin. Golden Oriole. Body and tip of the tail gold-yellow; wings, tail, and cere black; bill chestnut coloured; iris red; legs bluish gray. 10 inches long. Europe, \&c._Shaw, vii. pl. 53 
O. melanocephalus, Lin. Plumage purplish blue, head and neck black; beneath white; quill-feathers fuscous ; tail cuneiform, tip white. Inhabits China. Size of the jay.-Lath. Ind. 172.

O. paradisea, Tem. (Paradisea aurea, Lath.) Plumage brownish yellow, with the breast, wings, and tail-feathers black. Eight inches long. Inhabits India.-Edwards, t. 112.

\section{Gen. 16. Icterus, Tem.-Graculus Oriolus, Lin.}

Bill longer than the head, or as long, straight, like an elongated cone, pointed, sharp, a little compressed, without distinct ridge or notch, the base covered by feathers; margins of the mandibles more or less bent inwards; nostrils basal, lateral, and covered by a horny rudiment ; tarsus as long as or longer than the middle toe; wings long, third and fourth feathers longest.

I. cristatus, Tem. (Oriolus cristatus, Lath. Cassicus, Daud.) Crest black ; the lower part of the back, rump, and vent chestnut ; lateral tail-feathers yellow. Eighteen inches long. Inhabits S. America.-Buff. Ois. Pl. Enl. 344.

I. quisculus, Tem. (Gracula quiscula, Lin.) Plumage glossy purple, black; tail long, round; bill and legs black; iris silver-coloured. Nearly a foot long. Inhabits Mexico, \&c. Catesb. Car. i. pl.12.

I. baritus, Tem. (Gracula barita, Lin.) Plumage blackish, with a gloss of purple and green on the upper parts; bill blackish, base naked; tail rounded, concave above. Thirteen inches long. Inhabits N. America.-Sloane, Jam. t. 257. fig. 2.

I. Americanus, Tem. (Oriolus, Lath.) Plumage black, with deepred chin, throat, and breast; border of the wings red. Smaller than a blackbird. Inhabits Guiana.-Shaw, vii. 428.

Gen. 1\%. Sturnus, Lin.

Bill straight, in the form of an elongated cone, depressed, slightly obtuse; base of the upper mandible projecting on the forehead, the point much depressed, and without a notch; nostrils basal, lateral, half closed by an arched membrane; wings long, the first quill very short, the second and third longest; three toes before, and one behind, the exterior joined at its base to the middle one.

Starlings feed principally on insects, nestle in the holes of trees, under the tiles of roofs, and in the holes of walls. Like many of the omnivorous order, they consort and travel in large flocks. The males and females differ little in general aspect; but the young of the first year are very dissimilar to the mature birds. They are found in every quarter of the globe.

S. vulgaris, Lin. Common Starling or Stare. Body shining brassy black, spotted with little triangular spots of reddish white; lower coverts of the tail bordered with white; bill yellow; legs brown flesh-colour; eight inches long.-Inhabits Europe.

Stares occur abundantly in the old continent, from Norway to very southern lati- 
tudes. Their general food consists of insects and their larvæ, snails, earth-worms, grains, seeds, berries, \&ce. Fifty-seven individuals of this species were once killed at a single shot near Kirkwall in Orkney, where they are as common as sparrows elsewhere, and flocks of them perch on every wall and chimney top. The flight of stares is not undulatory, but smooth and even; and they walk very nearly in the manner of a wagtail ; but when they assemble in flocks their movements are noisy and tumultuous, describing a sort of vortex, combined with an advancing progress. They chatter much in the evening and morning, both when they assemble and when they disperse. On the approach of predaceous birds they rally in close array, and usually succeed in driving them off. The kings of Persia used to have starlings trained to hunt butterflies; but they are now principally tamed for their imitative talent, which enables them to whistle simple airs. They also articulate very distinctly, and may be taught to repeat words.

S. unicolor, Tem. Plumage of the body, the wings, and the tail, of a shining black, with light purple reflections; base of the bill blackish, point yellow; legs yellowish brown. Eight inches long. Inhabits Sardinia.-Tem. 33 .

S. Capensis, Lin. Cape Starling. Plumage blackish, with white spots on the wings and neck; sides of the head and belly white; bill yellowish at the base, the apex reddish. Inhabits Cape of Good Hope.-Buff. Ois. Pl. Enl. 280.

S. Ludovicianus, Lin. Plumage spotted with brown and gray; yellowish beneath; a white line on the head and eyes; throat black; bill whitish; four lateral tail-feathers white. Nine inches long. Inhabits America.-Buff. Pl. Enl. 256.

S. militaris, Lin. Plumage grayish; breast and throat reddish; a white spot behind and under the eyes : vent and tail black. Eight inches long. Inhabits S. America.-Buff. Pl. Enl. 113.

S. carunculatus, Gmel. Black, with the back and wing-coverts ferruginous; base of the under mandible with a yellowish wattle or caruncle. Ten inches long. New Zealand.-Lath. Syn. iii. t. 36.

Gen. 18. Pastor, Tem.-Turdus, Gracula, Gmel.

Bill in the form of an elongated cone, edged, much compressed, slightly arched, point feebly notched; nostrils basal, lateral, ovoid, half shut by a membrane furnished with small feathers; legs robust; three toes before and one behind, the exterior joined at the base to the middle one; wings with the first quillfeather very small, the second and third longest.

They fly like the starling in great flocks, and follow cattle, alighting on their backs for the insects.on their bodies. The greater number of the species have accessary appendages on their head, either crests or caruncles. The young always want these, their head being only covered with short and rounded feathers.

P. roseus, Tem. (Turdus roseus, Lath.) Head tufted; the neck and the top of the breast black with violet reflections; abdomen and back of a fine rose-colour; wings and tail brown-violet; coverts of the wings bordered with clear rose-colour; those of the tail and thighs black, banded with whitish; feet yellowish; iris deep brown. Eight inches long. Asia and Africa.-Shaw, x. pl.26. P. calvus, Tem. (Gracula calva, Lin.) Plumage cinereous, gray- 
ish below ; head naked on both sides ; breast, wing, and tail-feathers blackish brown. Ten inches long. Inhabits Philippine-Islands. -Shaw, vii. pl. 36.

P. tristis, Tem. (Paradisea tristis, Lin.) Plumage brown; head and neck blackish; a naked triangular red space behind each eye; a white spot at the tip of the wing and tail-feathers. Nine inches long. Inhabits Philippine Islands.-Buff. Pl. Enl. 219.

P. cristatellus, Tem. (Gracula cristatella, Lin.) Plumage black, with frontal crest ; base of the primaries and apex of the tail-feathers white; bill yellow. $8 \frac{1}{2}$ inches long. China.-Shaw, vii. pl. 55 .

P. gallinaceus, Tem. (Gracula carunculata, Gmel.) Plumage ashcoloured ; circle round the eyes naked; base of the inferior mandible with a double wattle; head with a yellow, erect bifid membranaceous crest. Six inches long. Inhabits Cape of Good Hope. -Lath. Ind. 324.

P. pagodarum, Tem. (Turdus pagodarum, Lath.) Crest grayish; body, wings, and tail black; belly streaked with white; vent white; feathers of the neck long; bill black; legs yellow. Inhabits India.-Lath. Ind. 332.

\section{Gen. 19. Paradisea, Lin.}

Bill of médium size, straight, quadrangular, pointed, a little convex above, compressed; ridge between the feathers of the forehead; nostrils basal, marginal, open, but entirely concealed by the feathers; legs short; tarsus longer than the middle toe; lateral toe unequal, the internal one united to the second joint; back toe longer than the others, robust ; wings with the five first feathers staged; the sixth or seventh longest.

P. apoda, Lin. (P. major, Shaw.) Great Bird of Paradise. Plumage cinnamon-coloured; throat golden green; head luteous; side feathers extremely long, floating, yellow, the two intermediate tail-feathers long, setaceous. Length from bill to tip of side feathers about two feet. Inhabits the Moluccas.-Shaw, vii. pl.58.

The name Apoda applied to this beautiful bird had its rise from the specimens procured by the early travellers having the feet cut off; and of course all the stories of these birds perpetually floating in the atmosphere, or suspending themselves, for a short time, by the naked shafts, and that they never descended to the earth till their death, are founded in fable. The great birds of paradise are found in the Molucca Islands, and in those surrounding New Guinea, particularly Papua and Aru, where they arrive with the westerly, or dry monsoon, and whence they return to New Guinea, on the setting in of the easterly, or wet monsoon. They are seen going and returning in flights of thirty or forty, conducted by a leader, which flies higher than the rest, and crying like starlings in their progress, preserving their light plumage by invariably moving against the wind. Their food is not known with certainty.

P. minor, Shaw. Plumage cinnamon-coloured, with luteous crown and back, and gold-green throat; side-feathers yellow, extremely long and floating. 18 inches in total length. New Guinea.

P. sanguinea, Shaw. Plumage cinnamon-coloured, with luteous occiput and back, gold-green front, and long floating sanguine- 
red side feathers, and two broad naked shafts. Body 9 inches long, to the tip of the flowing feathers 13 inches.-Shaw, vii. pl. 59.

P. magnifica, Shaw. Plumage orange-chestnut above, top of the head and back deeper than the rest, the head sometimes inclining to purple; tips of the wings and tail brown; throat blackish purple; breast, belly, and thighs of a deep changeable golden-green, inclining to blue down the middle of the breast; a double ruff of setaceous orange-coloured and yellow feathers on the neck, tipped with black; bill and legs yellowish brown. Inhabits New Guinea.-Shaw, vii. pl. 62.

P. regia, Lin. Royal Bird of Paradise. Plumage red chestnut, with a golden pectoral band; the two middle tail-feathers filiform, with lunated feathered tips. Five to seven inches long. Inhabits Indian Islands. - Shaw, vii. pl. 67.

This is the smallest of the tribe, not exceeding the size of a lark, and usually measuring five inches, or five inches and a-half, in length, without reckoning the two middle tail-feathers, which are about six inches long, in the form of naked shafts, divaricating as they extend, and each terminating in a moderately broad gold green web, rising from one side only of the shaft, and disposed into a flat spiral, of nearly two convolutions.

P. superba, Shaw. Bill black, with velvet-like black feathers rising into a bifid crest at its base; forehead shining golden-green; throat and sides of the neck glossy purple, with the feathers of a rounded form; lower part of the breast with a broad band of blue green feathers of a golden hue, diverging and lengthened like a forked wing; the rest of the plumage, with the wings, brownish black; wing-coverts broad, falciform feathers on the shoulders appearing like double wings; legs black. Inhabits New Guinea. -Shan, vii. pl. 63.

P. sexsetacea, Lath. (Parotia aurea, Vieill.) Golden-breasted Bird of Paradise. Plumage velvet-black; hind-head and breast gold'green; side feathers lengthened, and loose-webbed; head furnished on each side with three very long naked shafts, five or six inches in length, and terminating in broad oval webs; tail composed of twelve graduated feathers, of a rich velvety black colour, some of these feathers with long, separated, and floating webs ; bill black; iris yellow; feet blackish. From ten to eleven inches in length. Inhabits New Guinea._-Shaw, vii. pl. 66.

\section{Gen. 20. Lamprotornis, Tem.}

Bill of medium size, convex above, compressed at the point, which is notched; base depressed, and ridge between the feathers of the forehead; nostrils basal, lateral, ovoid, half shut by an arched membrane, often covered by feathers; legs long; tarsus longer than the intermediate toe; internal toe joined at its base, the external free; wings, the fourth and fifth quillfeathers longest.

All the species are of the Old Continent, the greater part from Africa. Their plumage is brilliant, shining with metallic lustre. In their habits they resemble the Stares.

VOL. I. 
L. gularis, Tem. (Paradisea gularis, Lath.) Plumage purplish-black; back and under parts blackish gold-green; the throat golden-copper-coloured, and the tail very long and cuneated. Size of a blackbird. Inhabits the Moluccas.-Shaw, vii. pl. 70 .

L. auratus, Tem. (Turdus auratus, Lath.) Plumage golden-green, with the head, neck, and body below violet; tail and bands of the wings blue; bill fuscous; iris yellow. Eighteen inches long. Inhabits Africa.-Buff. Pl. Enl.504.

L. nitens, Tem. (Turdus nitens, Lin.) Plumagegreen, with a bright violet-coloured spot on the coverts of the wings. Nine inches long. Inhabits Cape of Good Hope.-Edw. t. 320.

L. atratus, Tem. (Tanagra atratus, Lin.) Plumage glossy black; back subviolaceous; bill black. Size of the Thrush. Inhabits India._Lath. Ind. 430.

L. metallicus, Tem. Feathers of the head, nape, neck, in front and backelongated, and glossed with metallic purple,violet, and green; back and body beneath purple; wings and tail metallic green. Nine inches long. Inhabits Timor.-Tem. Pl. Col. 266.

L. erythrophrys, Tem. Orbits and ears black; vent yellow; wings green, the tips of the quills brown; tail olivaceous, the two middle feathers whitish-yellow towards the tip; feathers of the forehead stiff, shining, and of a vermilion colour. 9 inches long. Inhabits Java.-Tem. Pl. Col. 267.

ORDER III.-INSECTIVOROUS BIRDS. Insectivorce.

Bill middle sized or short, straight, rounded, slightly edged or awl-shaped; upper mandible curved and notched at the point, most frequently furnished at the base with some coarse hairs, pointing forwards; feet with three toes before and one behind, articulated on the same level, the exterior united at its base, or to the first joint of the middle toe.

The voice of these birds is distinguished by its harmony and cadence. Most of them chiefly subsist on insects, especially during the breeding season, but many of them have likewise recourse to berries. They have usually more than one brood in the year, and inhabit woods, bushes, or reeds, in which they build solitary nests.

\section{Gen. 1. Turuus, Lin.}

Bill middle-sized, sharp edged, tip compressed and recurved; upper mandible notched near the point; detached hairs at the opening of the mandibles; nostrils basal, ovoid, lateral, half concealed by a naked membrane ; tarsus longer than the middle toe, to which last the outer is united at the base.

This genus, numerous in species, is divided by Temminck into two sections, - those which inhabit woods and thickets in the lower grounds, and those which live solitary in rocky and mountainous situations. Many of the European species migrate in large flocks, whilst others are sedentary, especially in the south of Europe. Most 
of them have been remarked for their notes, and many of them are reckoned delicate eating.

T. viscivorus, Lin. Missel Thrush. Plumage gray-brown above, whitish yellow beneath, varied with dusky spots, the three outer tail-feathers tipped with white ; coverts of the wings bordered and terminated with white. Eleven inches long. Inhabits Europe. B. -Selby, Illust. pl. 44, fig. 1.

This is the largest of the European thrushes, and varies considerably in colour. It inhabits Kurope as far northward as Norway, and is common in Russia, but not found in Siberia. In most of the temperate parts of Europe it is partly migratory, and partly stationary. When disturbed or agitated, it utters a shrill grating scream, which is its usual note in autumn and winter. The male shares the duties of incubation, but ceases his song when the young are hatched.

T. pilaris, Lin. The Fieldfare. Head, neck, and lower part of the back ash-coloured; top of the back and wing-coverts chestnut; space between the eye and bill black, and a black line above the eyes ; throat and breast bright red, with black triangular spots; belly pure white; tail black. Ten inches long. Inhabits Europe, Scc.-Selby, Illust. pl. 45. fig 1.

The Fieldfare in this country is a migratory bird. It generally arrives in November in numerous flocks, and frequently remains till the beginning of April, though it often takes,its departure in March. This bird builds in the pine forests of Norway, Sweden, and Lapland, laying from three to five eggs of a pale bluish-green colour, spotted with reddish brown. Its flesh was highly prized by the ancient Romans, who fattened fieldfares for the table.

T. musicus, Lin. The Throstle or Thrush. Plumage gray-brown above, yellowish red beneath, varied with dusky spots; space between the eye and bill yellowish; belly and flanks white, with oval brown spots; legs gray brown. Nine inches long. Inhabits Europe.-Selby, Illust. pl. 45. fig. 2.

Var. From white to different shades of brown, reddish, or yellow.

T. iliacus, Lin. Red-wing Thrush. Plumage olive brown above; space between the eye and bill black and yellowish; a broad whitish band above the eyes; inferior wing-coverts and flanks of a bright red; sides of the neck, breast, and belly sprinkled with numerous longitudinal blackish spots; belly white. 8 inches long. Northern Europe. B.-Selby, 1llust. pl. 45, fig. 3.

T. rufus, Plumage ferruginous above, beneath paler and spotted; quills unspotted ; tail rufous, rounded. Eleven inches long. Inhabits N. America.-Shaw, x. 191.

T. torquatus, Lin. Ring-Ouzel. Plumage dusky, with a white collar; bill blackish; palate and opening yellow; iris hazel-coloured; legs blackish brown. Ten incheslong. Inhabits Europe. B. -Selby, Illust. pl. 44, fig. 2.

T. merula, Lin. The Blackbird. Plumage black; bill and feet tawny yellow; iris and legs black; a yellow circle around the eyes. 9 inches long. Inhabits Europe.-Selby, Illust.pl.43. fig. 2. The Blackbird inhabits the greatest portion of the temperate regions of Europe and Asia. The male begins his song in the first fine days of spring, and, except during the period of moulting, continues it till the commencement of winter. This 
species breeds twice or thrice in the year, placing its nest in thick bushes, at a moderate height from the ground, or on old trunks of pollards.

'T. atrogularis, Tem. Face, cheeks, top of the breast, and neck deep black, shading to cinereous ; lower part of the breast and middle of the belly whitish, shading to reddish; lower tail-coverts reddish, terminating in white; upper parts cinereous, deeper on the head; wing-coverts banded with yellowish; bill blackish brown; the lower mandible yellow at its base; iris and legs brown. Ten inches long. Inhabits Germany.-Tem. Man. 170.

T. Naumanni, Tem. Top of the head deep brown, the other superior parts cinereous red, shading to deeper red, which is the colour of the sides of the neck, the rump, and lateral feathers of the tail ; scapulars bordered with red, and spots of the same colour on the flanks and abdomen; middle of the belly and thighs white; bill and legs brown. Nine inches long. Inhabits Hungary, \&c.-Tem. Man. 170.

T. saxatilis, Lath. Head and top of the neck of a blue cinereous or lead colour; upper parts blackish brown, with a broad space on the middle of the back white; wings and middle feathers of the tail brown; the other tail-feathers and the lower parts of a lively red; inferior coverts of the tail terminated by white. 7 inches long. Inhabits mountains in Europe, \&c.-Shav, x. 266.

T. cyanus, Lin. Blue Thrush. All the upper parts, the wings and tail excepted, deep blue; lower parts paler blue ; the throat and neck without spots, but all the inferior parts with black narrow crescent-shaped lines towards the end of the feathers; wings and tail black, margined with gray; bill and feet black. 8 inches long. Inhabits Southern Europe.-Shaw, x. 224.

T. Orpheus, Lin. Mocking Thrush or Mocking Bird. Plumage gray-brown above, grayish-white beneath; lateral tail-feathers and spot on the wings white; bill blackish-brown; iris yellow, above the eyes white; rump gray-blue; legs black or cinereous. Size of the blackbird. Inhabits America. - Shan, x. pl. 20.

This species occurs in North America, especially in its more temperate regions, and in several parts of the West Indies. Its power of imitation has been often noticed. Thus, one of them confined in a cage has been heard to mimic the mewing of a cat, the chattering of a magpie, and the creaking of the hinges of a sign-post in high winds. On account of the diversified and imitative character of its notes, the Mexicans call it by a name which signifies the bird of a hundred tongues.

T. jocosus, Tem. (Lanius jocosus, Lin.) Head crested, black; throat white; body grayish; lower palpebra purple; vent bright red; the four lateral tail-feathers tipped with white. Seven inclies and a-half long. Inhabits China.-Buff. Pl. Enl. 508.

T. homorhausus, Tem. (Musicapa homorhausa, Lath.) Plumage fuscous, waved; crest and tail black; breast and abdomen white; vent red. $4 \frac{1}{2}$ inches long. Inhabits Ceylon.-Brown, Ill. t. 31.

T. Cayanensis, Tem. (Merops Cayanensis, Turdus punctalus and Manillensis, Lath.) Plumage brownish green; wings and tail 
red; base of the quill-feathers white, the rest black; bill black ; legs yellowish. Eight inches long. Inhabits Cayenne.-Buff. Pl. Enl. 454.

'T. migratorius, Lath. Plumage grayish; bill yellow, and blackish at its extremity; three white spots on the sides of the head; tail black, bordered with gray ; fore part of the neck, breast, and belly, of a bright red; lower part of the belly white. Nine inches long. Inhabits North America:-Buff. Pl. Enl. 556.

T. vociferans, Swainson. Body cinereous above, ferruginous below; with the ears and sides of the head black; tail rounded, its middle feathers black, and lateral ones ferruginous. $7 \frac{1}{2}$ inches long. Inhabits Southern Africa._Swains. Zool. Ill. iii pl. 80.

T. clamosus, Lath, Plumage olive green above, paler beneath, the quills edged with yellow. Seven inches long. Inhabits Africa. -Vaill. Ois. d'Afriq. iii. pl. 106, fig. 2.

\section{Gen. 2. Crnclus, Bechst.-Hydrobata, Vieill.}

Bill rather slender, slightly bent upwards, compressed at the sides; point of the upper mandible bent over the lower; nostrils basal, lateral, longitudinally cleft, and partly covered by a membrane; head small ; three toes before and one behind, the exterior joined at its base to the middle one; tarsus longer than the middle toe; wings short.

C. aquaticus, Bechst. European Dipper. Upper parts of the body of a deep brown, tinted with ash-colour; throat, front of the neck and breast pure white; belly red; bill blackish; iris pearl= coloured; feet horn-colour. 7 inches long. Inhabits Europe. B. -Selby, Illust. pl. 45.*

This singular bird feeds on aquatic insects, and in consequence is found al ways near the margins of clear streams. With the structure of a land-bird, and incapable of diving or swimming, it nevertheless advances into the water in pursuit of its prey, walking on the bottom and completely covered.

\section{Gen. 3. Menura, Shaw.}

Bill at its base broader than deep, straight, somewhat slender, inclined at the point, which is notched, and furnished at the base with setaceous plumes, pointing forwards; lower mandible shortest; nostrils oval, large, covered with a membrane, and situated in the middle of the bill; claws as long as the toes, broad, convex above, obtuse ; wings short, concave.

M. superba, Lath. Plumage above brown, inclining to rufous on the wings and neck, ashy-brown below; tail of sixteen loosewebbed feathers. Size of a hen pheasant. New South Wales. -Vieill. Ois. de Parad. pl. 14.

Gen. 4. Pitta, Vieill.

Bill of medium size, strong, hard, compressed through its whole length, slightly inclined from its base, bent at the point, 
slightly notched; ridge elevated at its base; nostrils basal, lateral, half shut by a naked membrane; legs long, slender; tarsus often double the length of the intermediate toe; the internal toe united to the first joint; wings short, rounded, the three first feathers equally graduated, the fourth and fifth longest ; tail short, equal, or rounded.

P. cyanura, Tem. (Turdus cyanurus, Lath.) Plumage chestnutcoloured; yellow, streaked with blue beneath; head banded with black; tail and transverse pectoral band blue. $8 \frac{1}{2}$ inches long. Inhabits Guiana. - Shaw, vii. pl. 47.

P. brachyura, Tem. (Corvus brachyurus, Lin.) Plumage green, yellowish beneath, with three black stripes on the head; shoulders and tail-coverts blue; vent red. 7 inches long. Inhabits Ceylon.-Shav, vii. pl. 48.

P. versicolor, Swainson. Plumage greenish above, fulvous below, with the rump and tail-feathers blue; vent red; crown rufous; nape, chin, and abdominal spot black. 9 inches long. Inhabits New Holland.-Zool. Journ. i. 468.

P. erythrogastra, Tem. Crown, occiput, and cheeks reddish brown; neck and throat dusky, with a rosy spot; back, scapulars, and pectoral fascia blue-green; wing-coverts, rump, and tail blue ; abdomen and vent red. $6 \frac{1}{2}$ inches long. Inhabits Philippine Islands. -Tem. Pl. Col. 212.

\section{Gen. 5. Myiother A, Illig.}

Bill long, straight, convex above, ridge a little arched, point bent suddenly, notched; lower mandible conical and a little turned up at the point; nostrils basal, lateral, half concealed by a membrare; legs long or of medium size, slender ; lateral toes nearly equal, the internal one united to the first joint; wings short, rounded; the fourth and fifth feathers longest; tail short and equal, or long and graduated.

M. grallarius, Tem. (Turdus grallarius, Lath. Grallaria, Vieill.) Plumage ferruginous brown above, paler beneath; occiput cinereous; legs long, bare a little above the knee, and of a reddish flesh-colour; tail extremely short. Size of the missel thrush. Inhabits Guiana._Shaw, vii. pl. 49.

M. tinniens, Tem. (Turdus tinniens, Lath. Grallaria, Vieill.) Plumage brown above, whitish beneath, the breast mottled with dusky ; tail moderately long; legs pale, plumbeous ; bill black above, white below. 7 inches long. Ceylon.-Shan, x. 306.

This species has its name from its shrill and loud tinkling cry, which has been compared to the alarum of a clock, and is continued for nearly the space of an hour during the mornings and evenings.

M. ferruginea, Tem. Plumage black, varied with white above; ferruginous below; throat variegated with red, white, and black; eyebrows, tip of the wing-coverts, and tail-feathers white. 5 inches long. Inhabits Brazil.-Tem. Pl. Col. 132, fig. 3. 
M. ncevia, Tem. (Pipra ncevia, Lath. Conophaga, Vieill.) Plumage brown above, fulvous beneath; throat and jugulum black; breast and upper part of the belly white, spotted with black; wings with two white bars; lower belly, thighs, and vent orange. 4 inches long. Inhabits Cayenne.-Buff. Pl. Enl. 823. fig. 2.

M. mentalis, Tem. (Formicivora, Swainson.) Plumage above ashy green, the wings and tail deeper, with a brown hue; clear yellow below; throat silvery gray, and a large black spot on the ear-feathers; the lesser coverts dusky, with white lunules. 4 inches long.-Shan, xiii. pl. 54.

Gen. 6. Tramnophrus, Vieill.-Lanius, Lath.

Bill short, strong, thick, a little gibbous, widened at the base, dilated on the sides, compressed towards the point, which is obtuse, much bent and notched; nostrils lateral, a little distant from the base, pierced in the horny bill, rounded or oval, open; legs long and slender; tarsus much longer than the intermediate toe; the external toe united to the first joint ; wings short, rounded, the fourth, fifth, and sixth quill-feathers equal and longest.

The Thamnophili are found in America, from Canada to Paraguay. They inhabit thick bushes, and feed chiefly on caterpillars and insects.

T. doliatus, Tem. Plumage transversely striped with black and white; tail rounded; feathers of the head long, tipped with black, capable of erection. 6 inches long. Inhabits Cayenne.-Lath. Ind. 80.

T. atricapillus, Tem. Plumage of the crown, neck, shoulders, and wings black; body above mouse-coloured; below bluish gray; - wings short; tail, except the two middle feathers, tipped with white, and cuneated. 5 inches long. Inhabits Surinam.-Lath. Ind. 73.

T. ncevius, Tem. Plumageblack above, cinereous below; back, wings, and tail spotted with white. 5 inches long. Inhabits Cayenne. -Lath. Ind. 81.

T. bicolor, Swainson. Head much crested ; plumage of the upper parts deep black; of the under parts pure white; tips of the wing-coverts, margins of the quills, and interrupted bands on the tail white; irides crimson. 8 inches long. Inhabits Brazil.Zool. Journ. iii. 86.

\section{Gen. 7. VANGA, Vieill.-Lanius, Lin.}

Bill long, hard, edged, bent at its point, which is crooked and sharp; nostrils lateral, a little distant from the base, in the horn of the bill, covered above by a cartilage; base of the bill with stiff hairs; tarsus as long or longer than the intermediate toe; the external toe united to the first joint; the third quill-feather longest. 
V. curvirostris, Tem. Back and wings black; coverts and smaller quill-feathers edged with white; tail black; the remainder of the body white; bill and legs black. 10 inches long. Inhabits Madagascar.-Buff. Pl. Enl. 228.

\section{Gen. 8, Lanios, Lin.}

Bill middle-sized, robust, straight from its origin, and much compressed; upper mandible strongly bent towards the tip, which is hooked, the base destitute of a cere, and furnished with rough hairs, pointing forwards; nostrils basal, lateral, almost round, half closed by an arched membrane, and often partly concealed by hairs ; tarsus longer than the middle toe; three toes before and one behind, separate; the third and fourth wing-feathers longest.

Butcher-Birds are so denominated from their singular habit of sticking their prey upon the thorns of bushes before feeding on it. After killing a bird, or large insect, they affix the body to some sharp thorn; for these birds want the strength of the hawk to retain their quarry in their claws, and pull it with their bill. They likewise spit the larger insects on thorns before devouring them, reserving them, according to some, or using them, according to others, as a decoy to the insectivorous. birds.

L. excubitor, Lin. Greater Butcher-Bird or Shrike. Plumage gray above, white beneath ; wings short, black; a broad black band below the eyes; origin of the primaries and the extremities of the secondary quills pure white ; the two exterior feathers of the tail white, the third black towards the centre, the fourth terminated by a large white space, and the two centre ones entirely black; bill and legs deep black. Nine inches long.-Shaw, vii. pl. 37.

L. meridionalis, Tem. Head, neck, and back of deep ash-colour; a broad black band under the eyes; throat whitish; lower parts of a reddish ash-colour; origin of the first quill-feathers and extremities of the secondaries pure white; four middle feathers of the tail black. Nine inches long. Europe-_Tem. Man. 143.

L. minor, Lin. The Gray Shrike. Plumage cinereous above; throat white; breast and flanks rose-coloured; forehead, region of the eyes and ears black; wings black; four middle feathers of the tail black. Nine inches long. Inhabits Europe-Tem. Man. 144.

L. rufus, Briss. Forehead, region of the eyes and ears black; occiput and nape of a bright red; top of the back and wings black; extremities and margins of the coverts white, as are the lower parts of the body; first feather of the tail white, with a black square spot on the interior web; the second with a larger spot on both webs, the others white at their origin, and towards the end; the two middle ones black; tail slightly rounded. Seven inches long. Inhabits Europe-Tem. Man. 146.

L. collurio, Lin. Red-backed Shrike. Back and wing-coverts reddish brown; back of the head and neck gray; throat and vent white ; breast, belly, and flanks rose-red; tail wedge-shaped, the middle feathers black, the rest with more or less white at the base, 
tipped with white ; legs and feet black. $7 \frac{1}{2}$ inches long. Inhabits Europe. B.-Selby, Illust. pl. 43, fig. 2, 3.

The Red-backed Shrike transfixes the larger insects, particularly the chafer, on a thorn, and tears off the body, leaving the wing-cases, wings, and head. Colonel Montagu kept a young brood of this species for some time; but though they lived in amity for about two months, they then became very pugnacious, and two out of

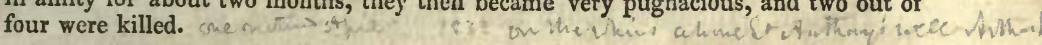

L. frontatus, Lath. (Falcunculus, Vieill.) Head and neck black, crested, with two lateral white bands ; wings and tail brown; body beneath yellow. About 7 inches long. Inhabits New Holland. 一Shan, xiii. pl. 50.

L. Antiguanus, Lin. Plumage reddish yellow; wing-feathers and cuneated tail black; bill large, with hooked tip. 7 inches long. Inhabits Philippine Islands. - Shaw, vii. 333.

L. collaris, Lin. Collared Shrike. Plumage black above, white beneath; white scapulars, and cuneated tail edged with white ; bill and legs black. 10 inches long. Inhabits A frica.

This species, according to Levaillant, when it sees a locust, a mantis, or a small bird, springs on it, and instantly carries it off, to impale it on a thorn, and with such dexterity that the spine always passes through the head of the victim; or, if a thorn cannot readily be found, it fixes, with great address, the head of the captured animal between a division of two small branches. Every creature which it seizes undergoes exactly the same process, and it thus continues to kill, and to store up its bloody acquisitions all day long, transfixing many more carcasses than it ultimately devours.

\section{Gen. 9. Psaris, Cuv. Tem.-Lanius, Lin.}

Bill thick, short, hard, conical, round, ridged, depressed at the base, compressed at the point, which is crooked and notched; no nasal furrow; nostrils distant from the base, lateral, round, open, in the corneous substance of the bill; legs strong; tarsus short, the length of the intermediate toe; the external toe united to the first joint, the internal at the base : wings of medium size, the third and fourth feathers longest.

P. Cayanus, Tem. Plumage bluish gray; head, borders of the wings, quill-feathers, and tail black; bill reddish, with black tip; legs black. 8 inches long. Inhabits Cayenne.-Buff. Pl. Enl. 377.

P. Cuvierii, Swainson. Plumage yellowish olive above; lower part of the neck, breast, sides, and inner wing-coverts yellow; abdomen white; crown of the head deep bluish black; bill bluish; tail short, slightly divaricated. $5 \frac{1}{2}$ inches long. Inhabits Brazil. Swainson, Zool. Illust. pl. 32.

Gen. 10. Sparactes, Illig.-Lanius, Lin.

Bill strong, thick, a little depressed at the base, much dilated on the sides, without projecting ridge, a little bent and compressed at the point, which is slightly notched; no distinct nasal furrow; lower mandible strong, broad, with obtuse point; nostrils basal, lateral, pierced in a furrow in the corneous mass; legs strong; tarsus longer than the middle toe. 
S. superbus, Illig. Plumage above fine black; throat with a scarlet spot, tinged at its extremity with yellow; a yellow band across the abdomen, with reddish streaks; quill-feathers slightly edged with white; rump greenish yellow; bill strong, gray, with an upright crest of long narrow feathers; legs black. Size of a Thrush. Inhabits South Sea Islands.-Shaw, vii. pl. 39.

Gen. 11. Ocypterus, Cuv. Tem.-(Leptopteryx, Horsfield.) Bill slightly depressed at the base, compressed and notched at the point; upper mandible convex above, bent at the point ; nostrils lateral, distant from the base, pierced in the corneous mass, concealed by the short hairs of the base; legs and toes short; wings long, the second and third feathers equal and longest.

O. viridis, Tem. (Lanius viridis, Lath.) Plumage dull green above, white beneath; with blackish wings and tail. 5 inches long. Inhabits Madagascar._Shaw, vii. 321.

O. leucorynchos, Tem. (Lanius, Lath.) Plumage blackish above; beneath and rump white. 7 inches long. Inhabits Philippine Islands.-Shaw, vii. 323.

\section{Gen. 12. Tricophorus, Tem.}

Bill short, strong, conical, compressed at its point, and widened a little at its base; upper mandible bent towards the point, which is slightly notched; base of the bill with strong and long bristles; legs short; tarsus shorter than the middle toe, the external toe united to the second joint; fourth, fifth, and sixth wing-feathers longest.

T. barbatus, Tem. Plumage above green, glossed on the back with ash ; tail tinged with reddish ; feathers of the throat long, forming a beard, clear yellow, with the shafts yellowish; under parts ashy-green; edges of the upper mandible with long bristles or hairs, and the occiput and upper part of the neck with eight or ten bristles. 8 inches long. Inhabits Africa._Shan, xiii. pl. 29.

\section{Gen. 13. Edourus, Cuv.-Dicrurus, Vieill.}

Bill strong, depressed at the base, compressed and notched at the end, upper mandible convex, bent, and a little crooked at the point ; the lower straight, turned up at the point; base furnished with long stiff hairs; nostrils basal, lateral, half covered with feathers and long hairs; legs slender, short; wings with the fourth, fifth, and sixth feathers longest; tail more or less forked.

E. forficatus, Tem. (Lanius forficatus, Lath.) Plumage greenishblack, with upright frontal crest and forked tail ; bill and legs black. Inhabits China, Miadagascar, \&c.-Buff. Pl. Enl. 169.

E. Malabaricus, Tem. (Lanius, Shaw.) Plumage deep black, with 
a gloss of blue on the upper parts and breast, where the feathers are lanceolate; a large crest rising from the base of the upper mandible; exterior tail feathers very long, with naked shaft and plumed tips. Size of the Thrush. India.-Shan, xiii. pl. 47.

E. mystaceus, Tem. Plumage black, glossed with green; wing-coverts, quills, and tail brown black; base of the bill with elongated bristles; tail slightly forked. Size of the Thrush. Inhabits Africa._V Vaill. Ois. d'Afriq. pl. 169.

\section{Gen. 14. Ceblepyris, Tem.}

Bill thick, short, strong, widened at the base, a little tumid, compressed at the point; upper mandible convex, bent and notched towards the point; lower mandible straight, almost equal to the upper; nostrils basal, lateral, ovoid, concealed by close-set hairs; legs short, weak; lateral toes unequal, united at the base; fourth and fifth wing-feathers the longest.

C. Papuensis, Tem.(Graculus, Cuv. Corvus, Lath.) Plumage brownish gray above, with white abdomen; quill-feathers blackish brown; eye-streak black. 11 inches long. Inhabits New Guinea. -Lath. Ind. 157.

C. canus, Tem. (Muscicapa, Lath.) Plumage ash-coloured above, darker beneath, with the tail-feathers black, the two exterior tipped with ash-colour, and the quill-feathers white on their inner webs. $8 \frac{1}{2}$ inches long. Madagascar.-Buff. Pl. Enl.541.

C. Vaillantii, Tem. (Echenilleur gris, Vaill.) Plumage above slatygray, beneath paler; before and behind the eyes and the breast dusky ; quill-feathers brownish, margined externally with white; tail doubly wedged. Size of a Lark. Inhabits Africa.-Vaill. Ois. d'Afriq. pl. 162, 163.

C. niger, Tem. Plumage above black, glossed with blue or green ; beneath, and with the quill-feathers within olive green. Size of the preceding. Inhabits Africa.-Vaill. Ois. d'Afriq. pl. 165.

Gen. 15. Cor acrna, Vieill.

Bill thick, strong, angular, convex above, straight, narrowed at its point, which is compressed, and feebly notched or smooth, with short hairs at the base; nostrils basal, rounded, open before, shut behind by a feathered membrane; legs strong; tarsus shorter than the middle toe; fourth and fifth wing feathers longest.

C. cephaloptera, Tem. (Cephalopterus ornatus, Geoff.) Plumage black; crest vertical, large, glossed with violet-colour, as are also the pendant breast feathers. Size of a Jay. Inhabits Brazil.Shaw, x. pl. 39.

C. calva, (Gymnocephalus, Geoff. Corvus, Lath.) Plumage ferruginous brown above, rufescent beneath; with the face naked beyond the eyes. 13 inches long. Inhabits Cayenne.-Shaw, vii. 352. 
C. rubricollis, Tem. (Querula, Vieill. Muscicapa, Lath.) Plumage black; chin and large spot on the throat purple. 12 inches long. Inhabits Cayenne.-Lath. Ind. 489.

C. nudicollis, (Gracula foetida, Shaw. Gymnoderes, Geoff.) Plumage bluish black, the feathers in front of the head and beneath the bill resembling velvet; wing-coverts and quill-feathers blue-gray; sides of the neck naked and red. Size of the Jackdaw. Inhabits South America.-Buff. Pl. Enl. 609.

\section{Gen. 16. Ampelis, Lin.}

Bill short, a little depressed, deeper than broad, trigonous at the base, notched and suddenly bent at the point; nostrils basal, lateral, rounded, half shut by a membrane; tarsus the length of or shorter than the middle toe ; the lateral toes united to the second joint; the second wing-feather longest.

A. Cotinga, Lin. Purple-breasted Chatterer. Plumage splendid blue above, purple beneath ; wings and tail black. $8 \frac{1}{2}$ inches long. Inhabits Brazil_-Edwards, pl. 340.

A. hypopyrra, Vieill. Plumage above deep gray, with a shade of green on the back and the exterior margin of the tail-feathers; lighter gray below ; a tuft of red orange feathers on the flanks ; wing-coverts reddish. 7 inches long.-Inhabits Guiana.

A. Pompadoura, Lin. Plumage purple, with the feathers of the greater wing-coverts elongated, narrow, and pointed. $7 \frac{x}{2}$ inches long. Inhabits Gúiana.-Edwards, pl. 341.

Gen. 17. Casmarhynchos, Tem.

Bill broad, much depressed, soft and flexible at the base, compressed, corneous, and notched at the point; nasal furrow large; the lower mandible thin and flexible; nostrils large, near the point of the bill, ovoid and open, furnished with small feathers; tarsus longer than the middle toe; third and fourth wing-feathers longest.

C. variegatus, Tem. (Ampelis, Lin.) Neck, breast, belly, back, and thighs ash-coloured; rump greenish; wing-coverts black, legs and quill-feathers dusky; fore part of the neck with a number of long black fleshy wattles. Inhabits Brazil.-Shaw, xiii. pl 62 .

C. carunculalus, Tem. (Ampelis, Lath.) Bill black, with a fleshy caruncle at its base, hanging over like that of the turkey ; plumage white, with the rump, quills, and tail-feathers inclining to yellowish; forehead naked; legs black. 12 inches long. Inhabits Brazil._Shan, x. pl. 37.

Gen. 18. Procnias, Illig.

Bill broader than the forehead, dilated on the sides, strong, depressed, but much compressed at the point, which is notched; ridge a little raised at the base; nostrils basal, tubular, bor- 
dered by a membranous circle ; tarsus longer than the middle toe; second and third wing-feathers longest.

P. ventralis, Tem. Blue Berry-eater. Plumage azure blue, with the forehead and jugulum black; body beneath white in the middle; sides with dusky transverse stripes; female greenish. 6 inches long. Inhabits Brazil.-Tem. Pl. Col. 5. fig. 1. 2.

P. cyanotropus, P. Max. Plumage above splendid azure or green, beneath white; wings and throat black. Inhabits Brazil.-Lath. Gen. Hist. v. 871.

\section{Gen. 19. Rupicola, Cuv.}

Bill of medium size, robust, slightly arched, bent at the point and notched; lower mandible straight, pointed; nostrils basal, lateral, ovoid, concealed by the semicircular feathers of the tuft ; legs robust; tarsus partly covered by feathers, and the length of the intermediate toe; the external toe united farther than the second joint; first wing-feather much elongated, filiform.

R. elegans, (Pipra rupicola, Lin.) Plumage saffron-orange; quills partly white, partly brown; coverts locse and fringed; crest erect, semicircular, with purplish margin; tail-coverts long, truncated. Size of a Pigeon. Inhabits S. America_-Briss. iv. t. 34, fig. 1.

R. Peruviana, Tem. (Pipra, Lin.) Body reddish saffron-coloured; greater wing-coverts ash-coloured; quills and tail black; tail-coverts not truncated; head crested. Rather larger than the preceding. Inhabits S. America.-Buff. Pl. Enl. 745.

R. viridis, Tem. (Calyptomena, Raffles.) Plumage shining green, with a spot on each side of the nape; three oblique stripes in the wings, and the quills, except the outer margias, dark-coloured. Inhabits Sumatra.-Tem. Pl. Col. 216.

\section{Gen. 20. Phibalura, Vieill.}

Bill very short, a little conical, convex above, dilated on the sides; upper mandible notched at the point, the lower straight; nasal furrow very small, and the nostrils covered by a membrane ; first and second wing-feathers longest ; tail long, slender, much forked.

P. flavirostris, Vieill. Plumage varied with black and rufous; crown, quills, and tail-feathers black; occiput and throat rufous; neck behind and breast black and white; abdomen spotted with black and white. 8 inches long. Inhabits Brazil.-Tem. Pl. Col. 118.

\section{Gen. 21. Pipra, Lin.}

Bill trigonal, short, widened at the base, compressed and notched; nostrils basal, lateral, open, half concealed by a feathered membrane; wings and tail short; two exterior toes united at about half their length; third and fourth wing-feathers longest. 
P. pareola, Lin. Blue-backed Manakin. Head with a crest of bright crimson feathers; back and lower wing-coverts blue ; body black. $4 \frac{1}{2}$ inches long. Inhabits S. America.-Desm. Man. pl. 50-53.

P. caudata, Lath. Long-tailed Manakin. Body blue ; crest crimson-coloured; wings black, with the two middle tail-feathers elongated and acuminate. Size of the preceding.-Shan, x. 15.

P. strigilata, Tem. Back and wings green; quills brown, edged with white on their inner webs; throat ashy green; body beneath yellowish-white, striated with brown; male with a red crest.Tem. Pl. Col. 54, fig. 1, 2.

P. Manacus, Lin. Plumage above black, beneath white, with a spot on the neck and wings white. Four inches long. Inhabits Brazil._Desm. Man. pl.58.

\section{Gen. 22. Pardalotus, Vieill.}

Bill very short, thick, dilated at the base, with distinct ridge; both mandibles equally strong, and of the same length, convex and a little obtuse, the upper one notched; nostrils basal, lateral, covered by a membrane; legs slender; tarsus longer than the middle toe.

P. punctatus, Tem. (Pipra, Lin.) Gray Manakin. Plumage gray, waved with brown; crown and wings black, spotted with white; tail-coverts red. Inhabits New Holland.-Shaw, Nat. Mis. 111.

P. striatus, Tem. Gray-brown Manakin. Plumage gray brown above, yellowish beneath; top of the head black, with white stripes; a deep yellow spot between the bill and the eye ; secondary quills yellow at the tips. $4 \frac{1}{2}$ inches long. Inhabits Van Dieman's Land.-Shaw, x. pl. 4.

P. superciliosus, Tem. Plumage chestnut red above, benerth yellowish; supercilia whitish above, margined with black; quills spotted with white. Inhabits New Holland.-Shav, x. 34 .

\section{Gen. 23. Todus, Lin.}

Bill long, formed of two thin plates, broader than deep, with a distinct ridge; point of the upper mandible straight, divided at the extremity, the lower obtuse and truncated; nostrils open and rounded; base of the mandibles with long hairs; toes lateral, unequal; the external united to the third joint, the internal to the second, wings short, with the fourth quill the longest.

T. viridis, Lin. Plumage green above, breast red, white below, throat red. $3 \frac{\mathrm{r}}{2}$ inches long. N. America._Shaw, viii. pl. 16.

\section{Gen. 24. Platyrhynchos, Desm.}

Bill broader than the face, dilated on the sides, much depressed, with the point bent and notched; nostrils round, open, closed above by a feathered membrane; tarsus longer than the mid- 
dle toe ; the exterior toe united to the middle one to the first joint ; nail of the hind toe hooked, strong; third and fourth wing-feathers longest.

P. Pitangua, Tem. (Tyrannus, Cuv.) Plumage ferruginous brown above; yellowish beneath, with a yellow band on each side of the head, and strong fulvous bill. Size of a blackbird. Inhabits Brazil.-Shan, vii. 300.

P. olivaceus, Tem. Plumage olive-green, with the throat, neck in front, and breast greenish ; abdomen ashy-yellow ; wings and tail brown, glossed with greenish. 5 inches long. Inhabits Brazil. -Tem. Pl. Col. 12. fig. 1 .

P. cancromus, Tem. With a yellow crest; forehead and eyebrows olive brown; a white spot on the lores; throat white; body above, breast, and middle of the abdomen, brown. $3 \frac{\pi}{2}$ inches long. Inhabits Brazil.-Tem. Pl. Col. 12. fig. 2.

\section{Gen. 25. Muscipeta, Cuv. Tem.}

Bill much depressed, broader than deep; upper mandible with a sharp ridge, hooked, and incurved on the lower, and generally notched; lower mandible much depressed, pointed, the base furnished with long hairs, which frequently project beyond the bill; nostrils basal and open; lateral toes unequal; the external one united to the second joint ; first three quillfeathers graduated, the fourth or fifth the longest.

M. plumbea, Tem. (Todus plumbeus, Lath.) Plumage above hoary lead-colour, inclining to black on the crown; beneath milk-white; wings and tail blackish. Size of the Wren. Inhabits Surinam. -Lath. Ind. 267.

M. regia, Tem. (Todus regius, Lath.) Plumage brown above, whitish, with brown undulations, beneath ; crest ferruginous, and tipped with black; chin and eyelids white; bill dusky-brown; legs flesh-coloured. 7 inches long. Cayenne.-Shaw, viii. pl. 14, 15.

M. paradisea, Tem. Crest on the head bluish-green, body white, tail wedge-shaped, with the two middle feathers very long in the male, but considerably shorter in the female. About six inches in length, and the tail fourteen. Inhabits Africa.-Edw. Glean. pl. 113.

M. Alavigastra, Tem. Plumage above ash-coloured, yellow beneath, with the quills and tail dusky black; legs dirty flesh-colour. Inhabits New South Wales.-Shaw, x. 343.

\section{Gen. 26. Muscrcapa, Lin.}

Bill strong, angular, depressed at the base, compressed towards the point, which is curved, and much notched ; base furnished with long and stiff hairs; nostrils basal, lateral, ovoid, partly covered by hairs; tarsus as long as the middle toe; lateral toes almost always equal.

This is a numerous genus and very widely dispersed, being found in almost all latitudes. 
M. grisola, Lin. Spotted Fly-catcher. Plumage brownish above, whitish beneath; neck longitudinally spotted; sides under the wings tinged with dull orange; legs short and black. About six inches long.-Selby, Illust. pl. 43, ${ }^{*}$ fig. 1 .

M. albicollis, Tem. (M.collaris, Bechst.) The Pied Fly-catcher. Top of the head, cheeks, back, small coverts of the wings, and all the tail-feathers deep black; forehead, a broad collar round the neck, and lower parts pure white; large coverts of the wings white, terminated by black on the interior webs. 5 inches long. Inhabits Europe.-Shaw, x. pl. 30.

M. luctuosa, Tem. (M. atricapilla, Gmel.) Upper parts of the body and the tail-feathers deep black; forehead and lower parts pure white; wings brownish black, the middle and greater coverts white. 5 inches long. Inhabits Europe. B.-Selby, Illust. pl. 43*, fig. 2, 3.

-M. parva, Bechst. Upper parts of the body reddish ash-coloured, which takes a slight bluish tint above the ears; feathers of the wings brown ash-coloured; four middle feathers of the tail and the extremities of the lateral ones blackish; throat and breast bright red, the lower parts whitish ; bill and legs brown; hairs at the base of the bill very long. $4 \frac{1}{2}$ inches long. Inhabits Europe.-Tem. Man. 158.

M. coesia, Tem. Plumage of the male bluish, with the quills ashybrown; tail-feather dusky ash ; female with the head, neck, and back yellowish brown; throat whitish; belly and vent red ; wings and tail brown. 6 inches Iong. Inhabits Brazil.-Tem. Pl. Col.17.

M. miniata, Tem. Top of the head and back of a fine polished steel black; lower part of the back, middle of the quills and lateral tail-feathers externally of a vermilion colour; the male with a black throat. 7 inches long. Inhabits Java.-Tem. Pl. Col. 155.

M. flammea, Lath. Plumage black, with the back, lesser wing-coverts, breast, vent, edges of the secondary quills, and tips of the tail-feathers orange-coloured. 6 inches long. Inhabits India.Tem. Pl. Col. 263, fig. 1, 2.

\section{Gen. 27. Marurus, Vieill.-Sylvia, Lath.}

Bill slender, deeper than broad; the upper mandible scarcely arched, base with small stiff hairs; nostrils basal, lateral; tarsi slender ; exterior toes united to the second joint; wings very short, rounded; tail very long, slender.

M. Africanus, Tem. Plumage above black, with the edges of the feathers red gray; beneath reddish white; crown of the head red, spotted with dusky; a longitudinal black stripe on each side of the throat; tail-feathers brown, edged with red. 7 inches long. Inhabits Cape of Good Hope.-Swainson, Zool. Illust. pl. 170.

N. marginalis, Tem. Plumage brown above, with the edges of the feathers paler or reddish; under parts, throat, and eyebrows white; 
breast and abdomen spotted with brown; tail very long and wedged. Inhabits Java.-Tem. $\mathrm{Pl}$. Col. 65, fig. 2.

M. longicaudus, Tem. Plumage olive, with the crown reddish; quills olive brown; tail-feathers long and narrow, the middle ones very long. Inhabits China.-Shaw, x. 756.

\section{Gen. 28. Sylvia, Lath. Temm.}

Bill straight, slender, awl-shaped, the base deeper than broad; point of the upper mandible frequently notched, the under one straight; nostrils basal, lateral, ovoid, partly covered by a membrane; tarsus longer than the middle toe; the exterior toe joined at its base to the middle one ; first quill-feather very short, or none; second scarcely exceeding the third; great wing-coverts much shorter than the quill-feathers.

This group comprises most of the small singing birds of Europe. The plumage of the species is plain and uniform in colour; and in general the males differ but slightly in this respect from the females. M. Temminck divides the genus into two sections, the first containing such as inhabit the margins of waters and marshes, and hence called Aquatic Warblers; the second those which in sumner visit our woods for the purpose of incubation, and which he terms Sylvan Warblers. Most of them possess much sweetness and variety of note. Except the Redbreast and Dartford Warbler, all are in Britain periodical visitants.

1. Aquatic WARBLERS.-Summit of the head depressed; wings shorl, much rounded; tail long, graduated, often conical.

S. turdoides, Meyer, Tem. (Turdus arundinaceus, Lin.) The Reed Warbler. Plumage ferruginous brown above, yellowish white beneath; a yellowish white line above the eyes; bill yellow at its base, brown towards the point; tail rounded. 8 inches long. Inhabits Europe.-Buff. Pl. Enl. 513.

S. galactoles, Tem. Plumage above of a bright red; lateral tailfeathers with a deep black spot towards the end, and the extremity pure white ; wings of a clear brown, bordered with reddish ; a brown band from the bill to the eye ; under parts white, shading

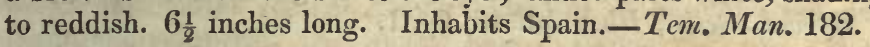

S. fluviatilis, Meyer. Danubian Warbler. Upper mandible and points of the bill brown; plumage olive-coloured above; throat white, with longitudinal spots of olive; abdomen white; legs fleshcoloured. 5 inches long. Inhabits Germany.-Tem. Man. 183.

S. locustella, Lath. Grasshopper Warbler. Bill awl-shaped; plumage above olive, shaded with brown and brownish-black spots; throat white, with under it a zone of oval brown spots ; tail long and graduated, the coverts reddish yellow, with brown spots; posterior claw shorter than the toe. 5 inches long. Inhabits Europe. B.-Selby, Illust. pl. 45,* fig. 1 .

S. certhiola, Tem. Bill strong; upper mandible black; plumage above olive, with brown spots; throat, neck before, and abdomen white ; tail-feathers with a large ash-coloured spot below; posterior claw bent, longer than the toe. 5 inches long. Inhabits Southern Russia,-Tem. Man. 186.

voI $\mathrm{I}$. 
S. aquatica, Lath. Bog-rush Warbler. Plumage above brown; with a band of yellowish white above the eyes, and another broader one from the base of the bill to the niddle of the head, the spaces between them brown black; scapulars and centre of the back gray, with longitudinal blackish spots ; tail-feathers acuminated, and the tail rounded. $4 \frac{1}{2}$ inches long. Inhabits Europe. -Tem. Man. 188.

S. phragmitis, Bechst. Sedge Warbler. Top of the head, back, and scapulars olive-gray; a broad band of yellowish white above the eyes; under parts of the body whitish yellow, tinted with reddish ; tail brown ash-coloured, slightly rounded. 4 inches long. Inhabits Europe. B.-Selby, Illust. pl. 45**, fig. 2.

S. arundinacea, Lath. Reed Warbler. Bill compressed at the base; plumage generally oil-green, tinged with reddish; throat, breast, and belly yellowish white ; tail cuneated, rather long; hind toe strong. 5 inches long. Inhabits Europe. B. - Selby, Illust. pl. $45^{* *}$, fig. 3 .

S. palustris, Bechst. Marsh Warbler. Bill broader than deep at the base; plumage above olive brown, the wings margined with cinereous; a narrow yellowish white stripe above the eyes ; under parts yellowish white. 5 inches long. Europe-Tem. Man. 192.

S. Cetti, Marmora. Plumage above deep brown, slightly shaded with red; feathers of the wings and tail blackish brown; between the bill and eyes an ash-coloured line ; throat white ; sides, flanks, and thighs brown; tail broad, with rounded feathers. 5 inches long. Inhabits Sardinia.-Tem. Man. 194.

2. Sylvan Warblers. - Tail square, or slightly forked at the end.

S. luscinia, Lath. Tem. (Motacilla luscinia, Lin.) The Nightingale. Plumage reddish brown above, cinereous white beneath; tail brownish-red; third and fifth wing-feathers of equal length. 6 inches long. Inhabits Europe, migrating in winter to Egypt and Syria.-Selby, Illust. pl. 46, fig. 1.

The Nightingale, so justly celebrated for the sweetriess and power of its song, arrives in Britain towards the end of April or beginning of May. The males precede the females by an interval of ten days or a fortnight. The nightingale excels nll birds in the softness and mellowness, as well as in the duration, of its song. Though heard to most advantage in the stillness of a fine evening, it also sings in the day-time, but its tones are then blended with those of other birds, and consequently not so readily distinguished. The Honourable Daines Barrington, who kept a very fine nightingale for three years, and bestowed particular attention on its musical faculties and exertions, ascertained that the sound of its song filled the circle of an English mile in diameter. The nightingale may be domesticated, though not without considerable pains and difficulty. For this purpose it must be treated with tenderness, and with favourite food, as the nymphæ of ants, meal-worms, and certain pastes, prepared by the dealers. In consequence of careful management, its warble is rendered much superior to that of the wild nightingale, and is continued all the year round, except during noulting.

S. philomela, Bechst. Plumage above grayish brown ; on the breast clear gray, shaded with deeper colour; throat whitish; second and third wing-feathers of nearly equal length. $6 \frac{1}{2}$ inches long. Inhabits Europe-Tem. Man. 196. 
S. sericea, Natterer. Plumage above gray brown, with the sides of the neck and breast ash-coloured, shaded on the flanks to gray brown; a line around the eyes, throat, and middle of the belly white; the fourth, fifth, and sixth wing-feathers longest. $5_{4}^{1}$ inches long. Inhabits Spain.-Tem. Man. 197.

S. Orpheu, Tem. Head and cheeks blackish; upper parts of the body ash-coloured; wings bordered with brownish; the exterior feathers on each side of the tail white, the others blackish, terminated with white; abdomen and lower tail-coverts red; upper mandible notched, the base of the under one yellowish. 6 inches long. Inhabits Europe.-Tem. Man. 198.

S. nisoria, Bechst. Head, neck, cheeks, and body above deep ashcoloured, with the feathers terminated by a brown and white line; sides waved with griseous; abdomen whitish; bill brown; iris yellow. $6 \frac{1}{2}$ inches long. Northern Europe.-Tem. Man. 200.

S. atricapilla. Lath. Black-cap Warbler. Orbits of the eyes covered with feathers; head of a deep black in the male, in the female red ; upper parts of the body ash-coloured; belly and throat whitish; bill and legs black. $5 \frac{1}{2}$ inches long. Inhabits Europe. B.-Selby, Illust. pl. 46, fig. 2 and 3.

S. melanocephala, Lath. Plumage gray above, wings and tail blackish; white below ; orbits naked ; male with the head black; female ash-coloured, blackish; bill thick and strong, the base of the lower mandible white. 5 inches long. Europe-Tem. Man. 203.

S. Sarda, Marmora. Plumage cinereous above, below whitish; orbits naked; male blackish ash-coloured on the throat; wings and tail blackish; bill short and slender. 5 inches long. Inhabits Sardinia.-Tem. Pl. Col. 24, fig. 2.

S. hortensis, Beehst. Garden Warbler. Plumage above gray brown, lightly tinted with olive, white around the eyes; throat whitish; breast and flanks reddish gray; belly white; base of the lower mandible yellowish. $5 \frac{1}{2}$ inches long. Inhabits Europe. B.Selby, Illust. pl. 46, fig. 4.

S. cinerea, Lath. The White-Throat. Plumage above yellowish brown, tinged with gray; throat and middle of the belly white; breast slightly tinged with rose-red; quills blackish brown; tail brown, the exterior feather having its end and anterior web white, and being shorter than the rest. $5 \frac{1}{2}$ inches long. Inhabits Europe. B. -Selby, Illust. pl. 46, fig. 6 .

S. curruca, Lath. Plumage above brown, whitish below, with the tail-feathers blackish; the exterior one with the outer web white. 5 inches long. Inhabits Europe-Tem. Man. 209.

S. conspicillala, Marmora. Top of the head and cheeks pure ashcolour; space between the bill and eye black; region of the eyes white, surrounded with black ; back rufous ; throat white ; wingcoverts bordered with red; tail rounded, blackish, the exterior feather almost white. 4 inches long. Inhabits Southern Europe. - Tem. $\mathrm{Pl}$. Col. 6, fig. 1 . 
S. provincialis, Gmel. Dartford Warbler. All the upper parts, with the exception of the tail, fine deep gray ; throat and flanks reddish purple or wine-coloured; belly white; wing-feathers black on their interior webs, very short. 5 inches long. Inhabits Europe. B.-Selby, Illust. pl. 46, fig. 6.

S. passerina, Lath. Top of the head, cheeks, and neck, clear ash-colour ; upper parts of the body olive, with the coverts fringed with reddish ; front of the neck, breast, and flanks red; throat and ceritre of belly white ; tail-feathers, except the middle four, tipped with white. $4 \frac{1}{2}$ inches long. South of Europe.-Tem. Man.213.

S. subalpini, Bonelli. Plumage above ash-coloured ; below vinousred, with the centre of the belly white ; tail nearly black, slightly rounded. $4 \frac{1}{2}$ inches long.-Tem. Man. 214.

S. rubecula, Lath. The Redbreast Warbler. Plumage above of a gray olive-brown; forehead, space between the eye and the bill, front of the neck and breast, lively red, margined with smoke gray; belly white. $5 \frac{1}{2}$ inches long. Inhabits Europe. B.-Selby, Illust. pl. 46 , fig. 2.

The Redbreast is a solitary bird, and is never found associating in numbers together, even during its partial migrations. It is widely diffused, being found through the greater part of Europe; and its general familiarity and confiding manners have attracted peculiar notice. In Britain the popular ballad of the Babes in the Wood has tended to protect the redbreast's nest; and its premature approach to houses in autumn is held the precursor of an early winter. The redbreast feeds on worms and insects, makes its nest in mossy banks or shady thickets, and lays from five to seven eggs, of a pale yellowish gray, with pale reddish-brown spots. The redbreast's notes are heard among the latest in the evening, and it commences its warble in the morning sooner than most other birds.

S. Suecica, Lath. Tem. (Molacilla Suecica, Lin.) Blue-throated Warbler. Plumage above rust-coloured; breast striped with blue; tail-feathers brown, and black towards the base. $5 \frac{1}{2}$ inches long. Inhabits Northern Europe.-Tem. Man. 217.

S. tithys, Scopoli. The Red-tail Warbler. Plumage above bluish ash-colour; space between the bill and eye, cheeks, throat, and breast deep black, shading to bluish-ash on the belly, and blue on the flanks; lower coverts of the tail, rump, and tail-feathers red; large coverts of the wings bordered with white. 5 inches long. Inhabits Northern Europe-Tem. Man. 218.

S. phonicurus, Lath. Tem. (Motacilla, Lin.) Red-start Warbler. Forehead and eyebrows pure white; a band at the base of the bill, space between that and the eye, throat, and neck black; under parts of the body orange-red. 5 inches long. Inhabits Europe. B.-Selby, Illust. pl. 46, fig. 3.

S. Hippolais, Lath. Lesser Petty-chaps. Plumage greenish-ash above, primrose yellow beneath; eyebrows white. Inhabits Europe. B.-Selby, Illust. pl. 47 , fig. 1.

S. sibilatrix, Bechst. Wood Wren. Top of the head and upper parts sulphur. yellow ; forehead and eye-streak yellowish ; under parts white; tail slightly forked, brownish. $4 \frac{1}{2}$ inches long. Inhabits Europe. B.-Selby, Illust. pl. 47, fig. 2. 
S. trochilus, Lath. The Yellow Wren. Upper parts of the body olive-green, tinged with gray; lesser wing-coverts and margins of quill-feathers pale yellow; lower parts of the body yellow, with centre of the belly white. $4 \frac{1}{2}$ inches long. Inhabits Europe.-Tem. Man. 224.

S. rufa, Lath. Top of the head and upper parts grayish brown, shaded with olive ; throat white, eye-streak yellowish, wings and tail brown; coverts of the wings yellow. $4 \frac{1}{2}$ inches long. Inhabits Europe.-Tem. Man. 226.

S. Nattereri, Tem. Top of the head and neck brown ash-coloured, shading to brown olive on the back and wing-coverts; eyebrows pure white; tail and wing-feathers blackish cinereous, with the margins greenish. 4 inches long. Inhabits Southern Europe. -Tem. Pl. Col. 24, fig. 3.

S. cisticola, Tem. Top of the head, neck, back, and coverts of the wings brownish ash-coloured; with the middle of the feathers blackish brown, producing large longitudinal spots ; extremity of the lateral feathers with a deep black spot; under parts reddish white ; tail short, graduated. 4 inches long. Inhabits Southern Europe.-Tem. Man. 228.

S. cyanocephala, Tem. Plumage above green, with the head and greater wing-coverts blue; throat hoary; quills brown, edged with green. 5 inches long. Inhabits Cayenne.-Shaw, x. 684.

S. Africana, Lath. African Warbler. Plumage above black, with the edges of the feathers red-gray; beneath reddish white; throat with a longitudinal black stripe on each side ; tail-feathers brown, edged with red. 7 inches long. Inhabits Africa-Shaw, x. 615.

S. coronata, Lath. Plumage varied with black and gray above, beneath white; crown, rump, and sides yellowish; a black stripe on the eyes ; wings and tail dusky. N. America.-Shaw, x. 636.

\section{Gen. 29. Regulus, Cuv.-Sylvia, Tem. Lath.}

Bill straight, slender, deeper than broad, compressed, the edges bending inwards; nostrils basal, with bristles directed forwards; wings with the first quill short, the second shorter than the third, which is the longest; tarsus longer than the middle toe.

R. auricapillus, Selby. (Motacilla regulus, Lin.) The Gold-crested Wren, Penn. Plumage above olive, tinted with yellowish ; crest of elongated silky feathers of a rich orange-colour; a black stripe on each side of the head; bill black, awl-shaped; lower parts yellowish gray. $3 \frac{\pi}{2}$ inches long. Inhabits Europe. B.-Selby, Illust. pl. 47, fig. 4.

R. ignicapillus, Tem. Plumage above olive-green, shading to yellowish : three longitudinal bands on the cheeks, two white and one black; crest of the male lively orange. $3 \frac{1}{2}$ inches long. Inhabits Europe.-Tem. Man. 231. 
R. calendulus, Vieill. (Motacilla, Lin.) Plumage brownish-green above, with a ruby-red stripe on the crown; body and wings beneath yellowish. $4 \frac{1}{2}$ inches long. Inhabits North America.Edw. Glean. pl. 254, fig. 2.

Gen. 30. Troglodytes, Cuv.-Sylvia, Lath.

Bill slender, slightly compressed, curved, emarginated; nostrils basal, half covered by a naked membrane; wings short and rounded; fourth and fifth feathers of equal length, and longest ; tail short, rounded, erect; tarsus the length of the middle toe.

The birds of this genus have the bill very slender and slightly bent. Their tail and wings are short, and they carry the former always erect. Their plumage is sombre, and they are of retired habits. The Common Wren is the only European species.

T. Europaus, Cuv. (Sylvia Troglodytes, Lath.) The Wren. Upper parts of the body pale chestnut-brown, with very narrow transverse stripes of a deeper colour; quill-feathers with alternate spots of black and reddish; throat and breast bluish-white; a narrow white band above the eye; under parts pale brown. $3 \frac{1}{2}$ inches long. Inhabits Europe. B.-Selby, Illust. pl. 47, fig. 5 .

T. fulvus, Vieill. (Sylvia fulva, Lath.) Plumage brown, inclining to yellowish below, and white on the middle of the belly; back, wings, and tail finely striped with black; feet yellowish. 4 inches long. Inhabits Surinam.-Shaw, x. 726.

Gen. 31. SAxicola, Bechst.-Sylvia, Lath.-Motacilla, Lin. Bill straight, slender, slightly carinated, and advancing upon the forehead; the top of the upper mandible a little bent and emarginated; nostrils basal, lateral, ovoid, partly concealed by a membrane; tarsus considerably longer than the middle toe; the outer toe joined at its base to the middle one; third and fourth quill-feathers longest.

The greater number of the individuals of this genus live in open and rocky situations. They are never found in large woods, and rarely in bushes. Their food is insects, which they seize on the ground, running with celerity. They are generally distinguished by the distribution of klack and white on their caudal feathers, in which the white occupies the greater part, the extremity and two middle feathers being black. Their tail is constantly in motion.

S. cachinnans, Tem. (Turdus leucurus, Gmel.) Plumage above deep black; rump, thighs, and tail from the base near to the tip white ; two middle tail-feathers black to near their origin. 7 inches long. Inhabits Southern Europe.-Shaw, x. pl. 22.

S. cenanthe, Bechst. (Sylvia, Lath.) The Wheat-ear. Plumage above bluish-gray ; a black band passes each eye and covers the orifices of the ears ; forehead, chin, eyebrows, rump, and belly white; tail white two thirds of its length. 6 inches long. Inhabits Europe. B.-Selby, Illust. pl. 48, fig. 1.

S. stapazina, Tem. Space between the eye and bill, round the eyes, all the throat, scapulars, and wings, deep black; top of the head, 
rump, and lower parts white; neck and back slightly tinted with reddish; tail white, tipped with black, except the exterior feathers, which are mostly black, and the two middle totally so. $5 \frac{1}{2}$ inches long. Inhabits Southern Europe.-Edw. pl. 31 .

S. aurita, Tem. Space between the eye and bill, region of the eyes and ears, and the wings deep black ; fore part of the neck, lower parts of the body, head, and rump white ; top of the back and neck tinged with reddish ; tail white three-fourths of its length, black at the end, except the exterior feathers, which are chiefly blackish, and the middle ones totally so. $5 \frac{1}{2}$ inches long. Inhabits Southern Europe.-Tem. Man. 241.

S. leucomela, Tem. (Motacilla, Pall.) Sides of the head, throat, and fore part of the neck deep black; occiput and nape white; back and wings brownish black; belly white; tail white twothirds of its length, the remainder and two middle feathers black. $5 \frac{1}{2}$ inches long. Inhabits Northern Europe-Tem. Man. 243.

S. rubetra, Bechst. The Whin-Chat. Top of the head and upper parts of the body blackish brown ; each feather bordered with reddish and yellow; a broad white band above the eyes; longitudinal stripe on each side of the neck white ; breast rose-coloured; a large spot of white on the wings and tail, the two middle feathers of which are dusky. $4 \frac{1}{2}$ inches long. Inhabits Europe. B.-Selby, Illust. pl. 48. fig. 2.

S. rubicola, Bechst. The Stone-Chat. Head and throat black; sides of the neck, upper parts of the wings, and rump white; breast orange brown; back black, the feathers edged with whitish red; lower parts of the body reddish white. $4 \frac{1}{2}$ inches long. Inhabits Europe. B.-Selby, Illust. pl. 48. fig. 3, 4.

S. sperata, Tem: Plumage above greenish brown; under parts and rump reddish gray; two middle tail-feathers dusky, the outer ones obliquely half brown and fulvous. 6 inches long. Inhabits Southern Africa._Shaw, x. 708.

S. melanura, Tem. Plumage above dull ash-colour, beneath paler ; wings brownish; tail rounded and black. $5 \frac{1}{2}$ inches long. Inhabits Arabia.-Tem. Pl. $\mathrm{Col} .257$, fig. 2.

Gen. 32. Accentor, Bechst.-Motacilla, Lin.

Bill strong, of medium length, straight, and drawn to a fine point; edges of the mandibles compressed, the upper one emarginated; nostrils basal, naked, pierced in a large membrane; legs strong, the exterior toe united at its base to the middle one ; the third quill-feather longest.

The birds of this genus inhabit the elevated regions of the Alps and other mountains, descending in winter to the plains and valleys. They feed on insects and seeds. The rest of the British species is frequently selected by the Cuckoo as the depository for its eggs.

A. alpinus, Bechst. Head, breast, neck, and back gray ash-colour, with large brown spots on the back; throat white, with brown 
scales; belly and flanks reddish, mixed with white and gray; wings and tail blackish brown; legs yellowish. $6 \frac{1}{2}$ inches long. Inhabits mountains in Europe.-Tem. Man. 248.

A. modularis, Cuv. Hedge Accentor. Top of the head ash-coloured, with brown spots; sides of the neck, throat, and breast with a bluish tinge; large reddish brown spots on the centre of the feathers of the back and wing-coverts; belly white ; lower coverts of the tail brown, with a white border. 5 inches long.Selby, Illust. pl. 43*, fig. 4.

A. montanellus, Tem. Plumage red brown, longitudinally striped with red; head and occiput black, with a black band below the eyes; two rows of little yellowish points forming a double band on the wings; lower parts yellow. 5 inches long. Inhabits Southern Europe.-Tem. Man. 251.

A. Calliope, Tem. Plumage above rusty brown, beneath yellowish white; throat vermilion, bordered with black and white; spot between the bill and eyes black; eyebrows white. 6 inches long. Inhabits Siberia.-Shaw, x. 644.

Gen. 33. Mot acilla, Lath.

Bill slender, straight, subulate, angular between the nostrils; edges of the lower mandible compressed; nostrils basal, lateral, oval, partly concealed by a naked membrane; tarsus considerably longer than the middle toe; exterior toe joined to the middle one at the base; hind claw strong and sometimes long; tail very long, equal, horizontal; one of the larger coverts as long as the wing-feathers.

The members of this well-marked genus haunt the banks of rivulets, the margins of rivers, and meadows in the neighbourhood of water. They run with great agility, and their food is insects taken both on the wing and on the ground, worms, larvæ, \&c. They are subject to a double moult. The lengthened tail of the bird of this genus is kept continually in motion. They are confined to the Old Continent.

M. lugubris, Pallas. Deep black on the upper parts of the body, and eight middle feathers of the tail ; forehead, around the eyes and ears, belly, and two lateral tail-feathers, white; flanks and wings ash-coloured, the coverts bordered with white. 7 inches long. Inlabits Southern Europe-Tem. Man. 253.

M. alba, Lin. The Pied Wagtail. Forehead, cheeks, sides of the neck, belly, and vent, white; crown of the head, nape of the neck, throat, breast, upper parts of the body, and middle tailfeathers black; coverts of the wings bordered with white; two outer tail-feathers white. 7 inches long. Inhabits Europe. B.Selby, Illust. pl. 49, fig. 1.

M. boarula, Lin. Gray Wagtail. Plumage above bluish gray ; rump sulphur yellow; a white streak above the eyes; throat black; under parts Igamboge-yellow; tail four inches long, with the exterior feather entirely white, the middle feathers black. 7 inches long. Inhabits Europe. B.-Selby, Illust. pl. 49, fig. 2. 
M. citreola, Pall. Yellow-headed Wagtail. Top of the head, cheeks, and lower parts citron yellow; a black crescent-shaped band on the occiput ; body above gray blue; wings and tail blackish, bordered with white, the lateral feathers white; posterior claw longer than the toe. 7 inches long. Siberia.-Tem. Man. 259.

11. flava, Lin. Yellow Wagtail. Head, nape of the neck, and earcoverts pale yellow, with the back, rump, and scapulars a shade darker; a yellow streak over the eyes ; wings and coverts blackish brown, margined with white; middle tail-feathers margined with yellow, the outer ones white. 6 inches long. Inhabits Southern Europe. B.-Selby, Illust. pl. 49, fig. 3.

\section{Gen. 34. Enicurus, Tem.}

Bill elongated, broad at the base; suddenly compressed towards the tip, attenuated; tip curved; nostrils in a groove with an elevated membrane; tarsi slender; hinder claw robust, short ; tail forked.

E. coronatus, Tem. (Motacilla speciosa, Horsf.) Plumage darkcoloured, with the pileus crested; the belly, rump, bar on the wings, outer tail-feathers entirely, and tips of the rest, snow white; tail very long. Body $4 \frac{1}{2}$ inches long; tail 6 inches. Inhabits Java.-Shaw, xiii. pl. 58.

E. velatus, Tem. Slaty black above, white beneath ; chin and neck in front black; a white frontal band; tail black, exterior feathers and tips of middle ones white. Java.-Tem. Pl. Col. 160.

Gen. 35. Anthus, Bechst. Tem. Vieill.

Bill straight, slender, cylindrical, subulate near the tip, edges inflected towards the middle; base of the upper mandible ridged, point slightly notched; nostrils basal, lateral, halfclosed by an arched membrane; hind claw generally longer than the toe; third and fourth quills the longest.

A. Richardi, Vieill. Plumage olive brown, varied with whitish and black above, whitish beneath; breast reddish, spotted with black; outer tail-feathers margined with white; legs and hinder claw very long. $6 \frac{1}{2}$ inches long. Europe.-Shan, xiii. pl. 59.

A. aquaticus, Bechst. Shore Pipit. Plumage above olive green; a white streak above the eye; lesser and greater wing-coverts dusky; inferior parts white, varied on the breast with longitudinal streaks ; two middle feathers of the tail brownish, the lateral black ; hind claw curved. $6 \frac{1}{2}$ inches long. Inhabits Europe. B. -Selby, Illust. pl. 49, fig. 6.

A. rufescens, Tem. Plumage above grayish yellow, with a slight tint of brown on the middle of each feather; a white band above the eyes; under parts whitish yellow; breast spotted with brown; tail blackish brown, the exterior feathers white; hind claw shorter than the toe. $6 \frac{1}{2}$ inches long. Europe.-Tem. Man.p. 267. 
A. pratensis, Bechst. Plumage above dark oil green, with the centre of the feathers brownish black; under parts yellowish white, with blackish brown upon the sides of the neck and breast; tail blackish brown, the outer feather with the exterior web and tip white; hind claw longer than the toe. $5 \frac{1}{2}$ inches long. Inhabits Europe. B.-Selby, Illust. pl. 49, fig. 4.

A. arboreus, Bechst. (Alauda, Lin.) Tree Pipit. Plumage greenish above, with the centre of the feathers brownish black; wingcoverts margined with yellowish white ; under parts whitish, spotted with brown; exterior tail-feathers white; hind claw short and curved. $5 \frac{1}{2}$ inches long. Europe. B.-Selby, Illust.pl.49, fig. 5.

A. Capensis, Tem. Plumage brown above; throat yellow, margined with black; eyebrows yellow; three lateral tail-feathers white at the tips. 8 inches long. Inhabits Africa._Shaw, x. 510.

\section{ORDER IV.-GRANIVOROUS BIRDS. Granivora.}

Bill more or less conical, short and strong ; ridge more or less flattened, advancing upon the forehead; mandibles generally without notches; three toes before and one behind, the anterior ones entirely divided; wings of medium length.

The food of this order consists chiefly of grain and other seeds, which the strength and form of their bill enables them to free from the exterior husk; but during the season of rearing their young, insects and larvæ form their chief support. They live in pairs, and are sedentary or migratory, according to the temperature of the countries they inhabit. In winter, or at the period of their migration, they congregate in numerous flocks. Most of the European species moult only once in the year. They are very easily tamed; and the males during the pairing season assume a brighter and more varied plumage.

\section{Gen. 1. Alauda, Lin.}

Bill subconic, short, with the mandibles of equal length and the upper one slightly convex; nostrils basal, lateral, partly concealed by reflected feathers; claw of the hind toe much produced, and nearly straight; wings with the first quill short or wanting, the third the longest; coronal feathers generally produced, and capable of erection.

This genus inhabits open fields or plains. They feed chiefly on seeds and grains, though they occasionally take worms and insects. They make their nests on the ground, and sing during their perpendicular ascent in the air.

A. Tarlarica, Pall. Head, neck, lower parts, and tail deep black; feathers of the neck below, rump. and flanks black in the middle, bordered and terminated by whitish; legs and claws black; the hind claw longer than the toe. $7 \frac{1}{2}$ inches long. Inhabits Asia.-Tem. Man. 275.

A. calandra, Lin. Plumage above reddish ash-coloured; throat and belly white; a black spot on each side of the neck; lanceolate 
brown spots on the breast; quills bordered and terminated with white ; middle tail-feathers terminated by a white spot; the lateral ones white. 7 inches long. Inhabits Europe, \&c. $-E d w .268$.

A. cristata, Lin. The Crested-Lark. Body above grayish, witk narrow brown spots ; wing-feathers bordered with reddish ; middle feathers of the tail reddish, the exterior ones red at their termination; lower parts yellowish white ; coronal tuft of elongated acuminated feathers black in the middle. $6 \frac{1}{2}$ inches long. Inhabits Southern Europe.-Tem. Man. 277.

A. alpestris, Lin. Plumage above reddish ash-coloured; line above the eyes and a band on the breast black; lateral feathers of the tail black, the exterior white on the outside; lower parts whitish fawn-colour. $6 \frac{1}{2}$ inches long. Inhabits Europe and America. -Catesby, Car. i. pl. 32.

A. arvensis, Lin. 'The Skylark. Upper parts reddish gray, each feather blackish in its middle; a whitish band above the eyes; throat white; neck, breast, and flanks tinted with reddish ; tail brown, the outer feather with the tip and exterior feather white ; coronal feathers capable of erection. $6 \frac{1}{2}$ inches long. Inhabits Europe. B.-Selby, Illust. pl. 50, fig. 1.

The Skylark is one of the most esteemed British song-birds. It is found throughout the whole of Europe, many parts of Asia and the north of Africa. Its song is begun early in spring and continued during the greater part of summer. It rises perpendicularly in a spiral direction, singing as it rises, till it frequently soars beyond the reach of vision. On the approach of winter larks begin to collect in immense flocks, quitting the more elevated parts of the country, and resorting to the coasts. At this period they are fat, and vast rumbers are taken for the table.

A. arborea, Lin. The Woodlark. Plumage above reddish ash-coloured, with a blackish brown spot on the middle of the feathers; a white band above the eyes and surrounding the occiput, and a triangular whitish spot on the cheeks; under parts yellowish white; wing-coverts terminated by white; feathers of the head longer, and tail shorter than the skylark. 6 inches long. Inhabits Europe. B.-Selby, Illust. pl. 50, fig. 2.

The Woodlark is chiefly confined in Britain to the southern and western parts of England. It surpasses the skylark in the richness, though not in the variety of its notes. Its song is generally poured forth when on the wing; but it differs from the skylark in describing widely extended circles in its fight.

A. brachydactyla, Tem. Plumage above reddish-yellow; throat and band above the eyes white ; breast and flanks red ; abdomen white; greater coverts of the wings as long as the quills; toes very short; exterior tail-feathers reddish. $5 \frac{1}{2}$ inches long. Inhabits Southern Europe.-Tem. Man. 284.

A. bilopha, Tem. Head double-crested; the crests, a band on the head, the feathers at the base of the upper mandible, a broad stripe through the eyes, and a crescent at the base, black ; body above varied with red, brown, and white; beneath whitish. $5 \frac{1}{g}$ inches long. Inhabits Arabia.-Tem. Pl. Col. 244, fig. 1.

A. isabellina, Tem. Plumage isabella-red above, paler below; throat 
whitish; wings and tail brown, the feathers edged with reddish. $5 \frac{1}{2}$ inches long. Inhabits Arabia.-Tem. Pl. Col. 244, fig. 2.

Gen. 2. Parus, Lin.

Bill short, straight, strong, conical, compressed, terminating in a point, base with small hairs; nostrils basal, rounded, concealed by projecting feathers; legs stout ; toes divided to their origin, nail of the hind one strongest and most bent ; wingfeathers, the first of medium length or almost deficient, the fourth and fifth the longest.

These are very small, but very lively and active birds, being constantly in motion, and possessing a great degree of strength and courage for their size. Their principal food consists of insects, though they likewise sometimes attack sickly birds. Temminck divides the genus into two sections, the first of which inhabits woods and bushes, nestling in the hollows of trees; the second nestles among reeds, rushes, and bushes near water. Their nests are constructed with peculiar ingenuity.

* First quill-feather of medium length.

P. major, Lin. The Great Titmouse or Ox-eye. Plumage olivegreen above, yellowish beneath ; head black; temples white; top of the neck yellowish; wing-coverts grayish-blue tipped with white; tail greenish-gray, edged with grayish-blue. $5 \frac{1}{2}$ inches long. Inhabits Europe. B.-Selby, Illust. pl. 51, fig. 1 .

P. ater, Lin. The Cole Titmouse. Top of the head and fore part of the neck black; a broad white band on the lateral part of the neck and a white spot on the occiput ; upper parts ash-coloured, and two white transverse bands on the wings; belly white; tail slightly forked. 4 inches long. Inhabits Europe. B.-Selby, Illust. pl. 51, fig. 3.

P. ccruleus, Lin. Blue Titmouse. Top of the head blue; forehead, band above the eyes, and cheeks white; streak before and behind the eyes black ; nape of the neck and collar azure-blue; back grayish-blue; wings and tail bluish, the greater coverts tipped with white; breast and sides sulphur yellow. $4 \frac{1}{2}$ inches long Inhabits Europe. B.-Selby, Illust. pl. 51, fig. 2.

P. cristatus, Lin. Crested Titmouse. Plumage reddish-gray above, white beneath; collar black; head furnished with a black crest, bordered with whitish. $4 \frac{1}{2}$ inches long. Inhabits Europe.-Selby, Illust. pl. 43, fig. 6.

P. palustris, Lin. Marsh Titmouse. Head black; back ash-colour ; temples white; the black on the head extending downwards on the nape; wings brown, bordered with ash-colour; under parts white, shaded with gray. $4 \frac{1}{2}$ inches long. Inhabits Europe. B.Selby, Illust. pl. 51. fig. 4.

P. lugubris, Natt. Top of the head black, terminating at the occiput; throat, a part before and the sides of the neck black; back and scapulars brown ash-coloured; temples and inferior parts white, shaded with gray-brown. 6 inches long. Inhabits Southern Europe.-Tem. Man. 293. 
P. Sibiricus, Gmel. Plumage gray-brown above, whitish beneath; abdomen reddish gray; throat and upper part of the breast deep black; temples and sides of the neck white; wing and tail-feathers bordered with reddish. 5 inches long. Inhabits Northern Europe.-Tem. Man. 294.

P. cyanus, Pall. Forehead, large spot on the neck, and all the under parts snowy white; top of the head shaded with blue; a band of deep blue from the bill over the eyes surrounding the head and spreading upon the neck ; back, rump, and top of the wings azureblue; wing-coverts blue, bordered with white. $5 \frac{1}{2}$ inches long. Inhabits Northern Europe-Tem. Man.295.

P. caudatus, Lin. Long-tailed Titmouse. Head, neck, throat, and breast pure white; top of the back, rump, and six middle feathers of the tail deep black; scapulars reddish; flanks and abdomen reddish white; quills black; lateral tail-feathers white on their exterior webs and at the ends; tail very long, cuneiform. $5 \frac{1}{2}$ inches long. Inhabits Europe. B.-Selby, Illust. pl. 51, fig. 5.

P. atricapillus, Lin. Body cinereous above, white beneath; crown and throat black; quills brown, with exterior margin grayish. $4 \frac{1}{2}$ inches long. Inhabits N. America._Wilson, Amer. Orn. pl.8. fig.4.

\section{** First quill-feather very short or wanting.}

P. biarmicus, Lin. (Calanophilus, Leach.) Bearded Titmouse. Head, neck, and breast bluish gray, the breast with a tinge of purple; a tuft of pendant feathers between the billand eyes; belly and flanks yellowish brown; under tail-coverts black; nape of the neck and back yellowish brown, tinged with orange; quills blackish-gray, the outer webs margined with white; tail long and wedge-shaped. 6 inches long. Inhabits Europe. B.-Selby, Illust. pl. 51, fig. 6.

P. pendulinus, Lin. Top of the head and neck ash-coloured; back and scapulars reddish gray ; throat white, the inferior parts whitish, with a rose tint; wings and tail blackish, bordered with reddish white ; tail-feathers terminated with white. $4 \frac{1}{2}$ inches long. Inhabits Europe.-Tem. Man. 300.

\section{Gen. 3. Emberiza, Lin.}

Bill strong, short, conical, compressed, sharp edged; the upper mandible narrower than the under, the edges of both bent inwards; nostrils basal, rounded, surmounted and partly covered by the feathers of the forehead; toes divided; the posterior with ashort and bent claw; tail forked, or slightly rounded.

The Buntings feed chiefly on farinaceous seeds, but also eat insects. Most of them live in woods and gardens, and nestle among bushes and thickets. Such of them as are furnished with a long hind toe haunt rocks and plains. The sexes are generally very different in their garb; and some of the foreign species moult twice in the year.

- Hind claw short and hooked.

E. melanocephala, Scopoli. Black-headed Bunting. Top of the 
head, region of the eyes and ears deep black; back rufous ; sides of the neck and inferior parts citron yellow; wings and tail brown, margined with whitish. $6 \frac{1}{2}$ inches long. Inhabits Southern Europe.-Tem. Man. 303.

E. citrinella, Lin. The Yellow Bunting. Head, neck, and upper part of the breast gamboge-yellow, varied with olive-green ; back and scapulars brownish, inclining to oil-green; wings and wingcoverts blackish brown; greater quills black, edged with yellow; two lateral tail-feathers with a white spot on the inner web. 6 inches long. Inhabits Europe. B._Selby, Illust. pl. 52, fig. 2, 3.

E. miliaria, Lin. Common Bunting. Upper parts yellowish brown, with the centre of the feathers darker; lower parts yellowish white, with numerous triangular black spots; middle of the belly white. $7 \frac{1}{2}$ inches long. Europe. B.-Selby, Illust.pl.52, fig. 1.

E. schoeniculus, Lin. Reed Bunting. Head black, with a white streak on the sides of the reck; under parts white; back and wings of a fine red, with longitudinal black spots on the flanks; tail blackish, with a conical brown spot on the exterior feathers. $5 \frac{1}{2}$ inches long. Inhabits Europe. B.-Selby, Illust. pl. 52, fig. 5, 6.

E. pithyornus, Pall. Pine Bunting. Head black, with an oval white spot on the summit ; throat and upper parts bright red ; varied with longitudinal black spots on the back; wings and tail brownish black, the two outer tail-feathers with a large conical spot of white. $6 \frac{1}{2}$ inches long. Inhabits Europe-Tem. Man. 310.

E. hortulana, Lin. The Ortolan. Plumage reddish gray above, paler below ; throat yellow; tail blackish; the two lateral feathers white at their inner web. $6 \frac{1}{2}$ inches long. Inhabits Europe.Tem. Man. 311.

This bird occurs in various parts of Europe, migrating in spring and autumn, when great quantities of them are caught, and fattened for the table, being proverbially celebrated for the delicacy of their flavour. That they may more speedily acquire the requisite degree of plumpness, they are shut up in a room, from which the external light is excluded, but in which are placed a few lanterns, to enable them to see to run about and pick up the millet and oats that are regularly strewed on the floor.

E. cirlus, Lin. Cirl Bunting. Throat and top of the neck black; breast and streak above and below the eye primrose yellow ; back blackish brown, edged with grayish white; scapulars reddish orange ; quills greenish gray ; belly and sides yellow ; lateral tailfeathers with their outer webs white. 6 inches long. Inhabits Europe.-Selby, Illust. pl. 52. fig. 4.

E. Cia, Lin. Foolish Bunting. Plumage reddish above, with longitudinal black spots; head ash-coloured, with blackish lines; superciliæ white ; flanks and abdomen red. 6 inches long. Inhabits Southern Europe-Tem. Man. 315.

E. Lesbia, Gmel. Plumage abore reddish ash-coloured, variegated with large blackish spots on the middle of the feathers; eyebrows and ears red; three little blackish brown bands on the sides of 
the neck; throat and parts beneath whitish, mixed with red on the breast and flanks; tail a little forked. $4 \frac{\pi}{2}$ inches long. Inhabits Southern Europe.-Tem. Man. pl. 317.

** Hind clan produced, slightly bent.

E. nivalis, Lin. The Snow Bunting. Head, neck, under parts, coverts of the wings, and the upper half of the quill-feathers, white; top of the back, the three secondaries, bastard wings, and lower half of the quills black; the three lateral feathers of the tail white, with a black streak; the others black, edged with white ; legs black. The winter plumage is more of an ash-colour or brownish. 6 inches long.-Selby, Illust. pl. 52. fig. 7.

$$
\text { E. glacialis, Lath.; E. mustelina, and montana, Gmel. }
$$

The colour of this species varies as it is in its winter or summer plumage, from white to brownish. In summer it inhabits the Arctic circle, but in winter it migrates to warmer regions. The northern parts of Scotland abound with them; and they have been traced in various districts of Northumberland and Yorkshire, but scarcely, we believe, farther south. Their arrival in the southern countries is supposed to betoken a severe winter or heavy falls of snow. These birds do not perch, but continue on the ground, and run about like larks, which they also resemble in size, and in the length of their hind claws.

E. calcarata, Tem. (Fringilla, Pall. Gmel.) Top of the head black, with little red spots ; throat whitish, with black streaks; a white stripe above the eyes and sides of the neck; under parts white; wings chestnut, with two transverse white bands ; neck, back, and scapulars reddish brown; quills bordered with red; tail slightly forked; hind claw very long. $6 \frac{1}{2}$ inches long. Inhabits Northern Europe.-Tem. Man. 322.

\section{Gen. 4. Tanagra, Lin.}

Bill short, strong, triangular at the base, carinated, much compressed at the point, which is bent; upper mandible longer than the under, and notched; edges of the mandibles bent inwards ; under mandible straight, and somewhat gibbous towards the middle; nostrils basal, lateral, rounded, partly concealed by projecting feathers ; tarsus the length of the middle toe; external toe joined at its base, the internal free; wings with the second and third quills longest.

The Tanagers have the habits of the sparrow tribes, and subsist on seeds, berries, and insects. Most of the species are conspicuous for the brilliancy of their plumage, and all are foreign.

T. Mississippiensis, Lath. (Pyranga, Vieill.) Plumage entirely red, with the wings and tail of a darker shade; legs reddish; bill horn-coloured. Inhabits N. America.-Lath. Ind. 421.

T. Alammiceps, Tem. (Pyranga, Vieill.) Plumage brick-red, with the forehead, cheeks, and occiput red-brown; wings brown, edged with reddish; crest of the male vermilion. 7 inches long. Inhabits Brazil.-Têm. Pl. Col. 177.

T. magna, Tem. (Saltator, Vieill.) Plumage above olive-brown, with the forehead and cheeks blue; stripe near the jaw black; 
throat and vent red; supercilixe and spot on the throat white. $8 \frac{1}{2}$ inches long. Inhabits Guiana.-Shan, x. 442.

'T. atra, Desm. (Saltator, Vieill.) Plumage cinereous, quills and tail darkest, with the head in front and whole of the lower part of the neck black. 7 inches long. Guiana._shaw, xiv. pl. 3.

T. archiepiscopus, Desm. Head, throat, and breast violet; lower belly and rump gray ; back olive ; upper lesser wing-coverts golden yellow, in the male; female gray-brown, beneath cinereous, tinged with violet, and a violet spot on the eyes; bill and legs black. 7 inches long. Inhabits S. America._Shaw, xiv. pl. 4.

T. speculifera, Tem. (Nemosia, Vieill.) Plumage above oliveblack; with the throat, neck in front, back, rump, and under tailcoverts yellow, and a white spot on the wings. 5 inches long. Inhabits Brazil.-Shaw, xiv. pl. 2.

T. diademata, Tem. (Nemosia, Vieill.) Cheeks, nape, lesser wingcoverts, tail-coverts, back, outer web of all the quills and tail, and nearly all the under parts, blue ; tail, throat, and forehead black; a red spot on the crown, and elongated white feathers on the occiput. Inhabits Brazil.-Tem. Pl. Col. 243.

T. viridis, Tem. Head and occiput yellowish green; throat and neck in front green, the latter with a coppery blue half collar; body above varied with blue and green; beneath yellow; wings green. Inhabits Brazil.-Tem. Pl. Col. 36. fig 3.

\section{Gen. 5. Ploceus, Cuv. Tem.-Loxia, Lin.}

Bill strong, conical, sharp, inflected, and compressed at the point, without a notch, edges of the mandibles bent inwards; nostrils basal, near the surface of the bill, ovoid, and open; tarsus of the same length as the middle toe; the three anterior toes united at the base; the fourth quill the longest.

P. Philippinus, Tem. (Loxia, Lin.) Philippine Weaver. Plumage brown above, whitish-yellow beneath; crown of the head and breast yellow; throat brown. The female has the upper parts brown, edged with rufous. $5_{4}^{1}$ inches long. Inhabits Philippine Islands. -Shan, ix. 315.

This bird forms a very curious nest, in the shape of a long cylinder, swelling out at the middle, composed of the fine fibres of leaves and grass, and fastened by the end to the branch of a ligh tree. This nest has two or three compartments, the eggs being deposited in that which is in the globose portion in the middle, the entrance being at the bottom of the long cylinder, and thus, in a great measure, concealed. The whole is generally suspended over water. The Philippine weaver may be rendered so very tame, as to come and perch on its master's hand, or to fetch and carry, like a dog, at command.

P. Abyssinicus, Tem. (Loxia, Gmel.) Abyssinian Weaver. Plumage yellow, with the crown, cheeks, throat, and breast black; wings antd ail brown. Size of the Hawfinch. Inhabits Abyssinia.-Shaw, ix. 294

This bird forms a nest of a pyramidal shape, which is suspended from the ends of branches. The opening is on one side, facing the east, being opposite to that 
from which the rain proceeds; the cavity is separated in the middle by a partition of half its height, up which the bird mounts perpendicularly, and then, descending on the other side, forms its nest in the further chamber.

P. pensilis, Tem. (Loxia, Lin.) Pensile Weaver. Plumage green above, gray beneath; vent rufous, with the head and lower parts of the neck yellow; quills and tail-feathers black. 5 inches long. Inhabits Madagascar._Shaw, ix. 275.

P. socius, Tem. (Loxia, Lath.) Sociable Weaver. Reddish brown above, yellowish beneath; capistrum black; tail short. $5 \frac{1}{2}$ inches long. Inhabits Cape of Good Hope.-Shaw, ix. 303.

These birds live in large societies, constructing their numerous connected nests on the branches of smooth barked trees, as a defence against serpents and monkeys.

P. Malimbicus, Tem. (Tanagra, Lath.) Plumage blue-black, with the crest, chin, and throat scarlet. 6 inches long. Inhabits Africa. -Shan, Nat. Mis. pl. 581.

P. aurifrons, Tem. Plumage yellow-green, with the back and scapulars spotted with brown; forehead and cheeks of the male golden yellow; of the female ashy-yellow; body beneath citron yellow. 6 inches long. Inhabits Southern Africa.-Tem. Pl. Col. 175, 176.

\section{Gen. 6. Loxia, Briss.-Crucirostra, Cuv.}

Bill rather long, strong, much compressed, the two mandibles equally convex and crossing each other at the points when at rest; nostrils round, basal, and lateral, concealed by reflected bristly feathers; the anterior toes entirely divided; wings with the first quill-feather longest; tail forked.

These birds inhabit the northern parts of Europe and America, and feed on the secds of trees and alpine plants. Their singular formed bill enables them to pick out the seeds from the cones of the pine and fir. Their period of reproduction is unusual, being in the winter months; and they emigrate in summer to the Arctic regions. Their change of plumage is one of the most singular pheriomena in their history. The bulfinches and grosbeaks, which were included under this generic title by the older naturalists, have been properly classed under another name.

L. pytiopsittacus, Bechst. Greater Cross-bill. Bill very strong, much bent, broad at its base, the crossing point of the lower mandible not surpassing the upper margin of the bill ; plumage olive-ashcoloured; cheeks, throat, and sides of the neck gray; rump, breast, and belly greenish-yellow; wings and tail brownish-black. 7 inches long. Inhabits N. Europe.-Selby, Illust. pl. 53**, fig. 1.

L. curvirostra. Lin. Cross-bill. Bill long, slightly curved, broad at the base, and the crossed point of the lower mandible projecting beyond the upper edge of the bill; body of a variable red; quills and tail-feathers brown; tail forked. The red of the male is varied with brown and green, and the female is olive-green, mixed with brown; but both sexes appear very different at different times of the year, and at different ages. 6 inches long. Inhabits Northern Europe. B.-Selby, Illust. pl. 53.

Gen. \%. Psitiriostra, Tem.-Loxia, Lath.

Bill short, much hooked, gibbous at its base; upper mandible VOL. I. 
bent at the point over the lower; lower broad, rounded, with obtuse point; nostrils basal, lateral, half covered by a feathered membrane ; tarsus longer than the middle toe; toes divided, the lateral ones equal; wings, first feather obsolete, second shorter than the third.

P. psittacea, Tem. Plumage olive-brown; head and neck yellow. Inhabits Sandwich Islands.-Shaw, ix. 268.

\section{Gen. 8. Pyrrhula, Briss.-Loxia, Lin.}

Bill short, thick, gibbous at the sides, compressed at the tip and towards the ridge; both mandibles convex, particularly the upper one, the tip of which overhangs the lower; nostrils basal, lateral, rounded, and most frequently concealed by feathers in front; tarsus shorter than the middle toe, the anterior toes divided to their origin; wings short, the fourth quill the longest; tail slightly rounded or square.

Most of the species belonging to this genus reside in the cold and temperate climates of the globe, subsist on hard grains and seeds, and undergo a double moulting.

P. enucleator, Tem. Pine Grosbeak. Head, neck, throat, breast, and rump bright crimson-red; back and scapulars black, the feathers deeply edged with red; wing-coverts tipped with crimson, forming two bars across the wings; quills and tail-feathers edged with pale crimson ; flanks, belly, and vent grayish-white, tinged with crimson; bill black. $7 \frac{1}{2}$ inches long. Inhabits Northern Europe, \&c. B. -Selby, Illust. pl. 53*, fig. 1, 2.

P. rosea, Tem. Throat and face covered with silvery feathers; head, neck, rump, and lower parts lively crimson; back and scapulars black, bordered with crimson; two bands of white rose-colour on the wings, and the abdomen and lower coverts of the same colour ; wings brown ash-coloured; bill brown. $5 \frac{1}{2}$ inches long. Inhabits Southern Europe.-Tem. Man. 333.

P. erythrina, Tem. (Loxia, Pall.) Smaller feathers on the nostrils and bill faint rose-coloured; head, neck, and upper part of the back bright crimson; base of all the feathers red-brown; rump, sides of the head, throat, neck, and breast, crimson or rose-coloured; belly white; coverts of the wings brown ash-colour; tail forked. $\quad \mathbf{5}_{\frac{1}{2}}$ inches long. Inhabits N. Europe-Tem. Man. 336.

P. vulgaris, Briss. (Loxia, Lin.) The Bulfinch. Head, throat, wings, and tail velvet black, tinged with violet purple; nape of the neck and back bluish gray ; cheeks, neck, breast, belly, and flanks red; rump and vent white; great wing-coverts tipped and margined with pinkish white, forming a transverse bar across the wing; bill and legs blackish-brown. 6 inches long. Inhabits Europe. B.-Selby, Illust. pl. 54, fig. 1, 2.

P. longicauda, Tem. A circle of red feathers around the bill ; feathers on the top of the head, throat, and fore part of the neck acuminated and rose-coloured; breast and belly crimson-red; 
feathers of the back and scapulars black in the centre, bordered with red; three lateral feathers of the tail white, with black spots. 6 inches long. Inhabits Siberia.-Tem. Man. 340.

P. lineola, Tem. (Loxia, Lin.) Bill gibbous and black, with a white spot on the base of the upper mandible, and a line of the same colour from the forehead to the crown; upper parts of the body glossy blue-black; under parts and base of the primaries white; tail black, slightly forked. Inhabits Africa.-Shaw, ix.326.

P. minuta, Tem. (Loxia, Lin.) Plumage above gray-brown; beneath and rump ferruginous, with the fourth, fifth, and sixth, quill-feathers white at the base. Size of the Wren._Shaw, ix. 334.

P. cinereola, Tem. Head, cheeks, back, and scapulars ashy-blue; under parts and spot on the wings white; wings and tail dusky; bill red; legs ash-coloured. $4 \frac{1}{\frac{1}{2}}$ inches long. Inhabits Brazil.Tem. Pl. Col. 11, fig. 1.

\section{Gen. 9. Fringilla, Illig. Tem.}

Bill short, stout, straight, and conical ; upper mandible gibbous, depressed above, a little inclined at the point ; nostrils basal, round, placed near the forehead, and partially concealed by the feathers in front; tarsus shorter than the middle toe, and the fore-toes entirely divided; wings short, the third and fourth quills the longest; tail of varied form.

The birds of this genus subsist on all sorts of seeds and grains, which they open with their bill, while they reject the husk, and they rarely partake of insect food. They are very generally scattered over the face of the earth, but are most numerous in the warm and hot latitudes. Many of them are subject to a twofold moulting, in which case the male takes in winter the plumage of the female.

* Bill thick, gibbous, more or less dilated.

F. coccothraustes, Tem. (Loxia, Lin.) The Hawfinch. Rump, head, and cheeks red brown; around the bill and throat deep black; neck ash-coloured ; a longitudinal white stripe on the wings; tailfeathers white interiorly, and blackish-brown on the exterior web; lower parts wine-red; legs and bill grayish. 7 inches long. Inhabits Southern Europe. B.-Selby, Illust. pl. 55, fig. 1.

F. Chloris, Tem. (Loxia, Lin.) Green Finch or Green Linnet. Plumage yellowish-green, with the primary quills in front, and the four lateral tail-feathers, yellow ; bill thick and whitish; head and back yellowish-green, edges of the feathers grayish; rump and breast yellow; tail slightly forked. The plumage of the female is less bright. $6 \frac{1}{2}$ inches long. Inhabits Europe. B.-Selby, Illust. pl. 54, fig. 3.

F. petronia, Lin. Foolish Sparrow. Plumage brown ash-coloured, mixed with whitish on the lower parts; eyebrows reddish white; feathers generally terminated with whitish; a rounded white spot on the interior web of the tail-feathers, and a large yellow spot on the fore part of the neck. $5 \frac{1}{2}$ inches long. Inhabits Furope. -Shaw; ix. 434. 
F. domestica, Lin. The Common Sparrow. Top of the head and occiput bluish ash-colour; a chestnut band above the eyes, spreading on the sides of the neck; space between the bill and eye, throat, and neck before of a deep black; black feathers of the breast margined with white ; feathers of the back and wings black, bordered with chestnut; a single white band across the wing. 5 inches long. Europe. B.-Selby, Illust. pl. 54, fig. 4, 5. This well known bird, constantly found near the dwellings of man, is often persecuted for its depredations; though, according to Bradley, it is of essential service in the general economy of nature as limiting the reproductive powers of insects. That observer ascertained that one pair carried to their nest forty caterpillars in the space of an hour; so that, on the supposition of their entering the nest only during twelve hours edch day, they would occasion a daily destruetion of 480 caterpillars, or 3360 in a week. The flight of sparrows is short and laborious. They have no native song, and, for the most part, only a disagreeable chirp; but they are capable, when in confinement, of acquiring the notes of the linnet and other birds.

F. Cisalpina, Tem. Top of the head, neck, and part of the back, chestnut-coloured, bright in summer; region of the cheeks white; otherwise resembling the preceding. Inhabits Southern Europe. -Tem. Man. 351.

F. Hispaniolensis, Tem. Top of the head and neck bright deep chestnut; back and coverts black, but all the feathers margined laterally with reddish-yellow; throat and neck black; long black spots on the flanks; cheeks and middle of belly white; bill strong. Inhabits Spain.-Tem. Man. 353.

F. montana, Lin. (Pyrgita, Cuv.) Mountain Finch. Top of the head and occiput copper-red; space between the bill and eye, band over the eyes, throat, and fore part of the neck deep black; wings and tail deep brown; two white bands on the wings; breast ash-coloured; belly whitish; bill black. 5 inches long. Inhabits Europe. B.-Selby, Illust. pl. 55, fig. 2.

F. serinus, Lin. (Carduelis, Cuv.) Forehead, around the eyes, and band above the eyes, yellowish-green; stripe on the sides of the neck olive; rump and breast yellow; two transverse bands on the wings, one yellowish-green, the other brownish; belly whitish yellow, with bluish spots; tail slightly forked. $4 \frac{1}{2}$ inches long. Inhabits Southern Europe.-Tem. Man. 356.

* Bill conical, more or less short, straight.

F. Coelebs, Lin. The Chaffinch. Forehead black; top of the head and neck blue ash-coloured; back and scapulars chestnut, with an olive tinge; rump green; all the lower parts reddish winecolour; abdomen white; wings and tail black; two transverse white bands on the wings, and a white spot on the lateral tailfeathers. 6 inches long. Inhabits Europe. B.-Selby, Illust. pl. 54 , fig. 6,7 .

The Chaffinch is widely disseminated, and found in almost all parts of Europe, being sedentary in the warmer provinces, but migratory in those situate to the northward. They begin their short and frequently-repeated carol early in spring, and continue it till the summer solstice, after which they only chirp. In confinement they are capable of acquiring the notes of the canary, nightingale, \&c. 
F. montifringilla, Lin. The Mountain Finch. Head, cheeks, nape, and top of the back black ; throat, front of the neck, breast, scapulars, and smaller coverts of the wings orange-red; a narrow orange transverse band on the wings; the three exterior quills black; rump and lower parts white; flanks reddish, with black spots; tail black. $6 \frac{1}{2}$ inches long. Bird of passage in Europe. B. -Selby, Illust. pl. 54, fig. 8, 9.

F. nivalis, Lin. The Snow Finch. Top of the head, cheeks, and neck bluish ash-coloured; scapulars and two of the secondary feathers of the wings brown; coverts of the wings, the other secondary feathers, and those of the tail white; lateral tail-feathers pointed with black; lower parts whitish. 7 inches long. Inhabits Mountains in Europe-Tem. Man. 362.

F. cannabina, Lin. Common or Brown Linnet. Bill strong, blackish, the breadth of the forehead; throat whitish, marked in the middle with some brown spots; top of the head and neck ash-coloured ; back, scapulars, and wing-coverts chestnut ; flanks reddishbrown; middle of the belly white; some of the quill-feathers black, bordered exteriorly with white ; tail forked, black. 5 inches long. Inhabits Europe. B.-Selby, Illust. pl. 55. fig. 3, 4.

The female Linnet is destitute of song. Linnets are very familiar, and easily tamed. When brought up under the nightingale, goldfinch, woodlark, \&c. they acquire the respective songs of those birds.

F. montium, Gmel. Mountain Linnet. Throat, fore part of the neck, broad eyebrows, and the region of the eyes bright red; feathers of the top of the head, neck, and back, black in the middle, bordered with red; two bands of whitish-red upon the wings; bill triangular; legs black. $4 \frac{1}{8}$ inches long. Inhabits Europe. B. -Selby, Illust. pl. 55, fig. 5 .

F. Canaria, Lin. Canary Bird or Canary Finch. Bill and body whitish-yellow; quills and tail-feathers greenish. $5 \frac{1}{8}$ inches long.

This bird in its wild state, as observed by Labillardière and others, exhibits a brown hue, mixed with various others, and its plumage is not so attractive as it becomes in confinement. In consequence of long domestication, it has, like the dog, assumed an almost endless series of varieties. The colours of the female are paler than those of the male. It principally occurs in the Canary Islands, frequenting damp places; and at Palma, Fayal, Cape Verd, and Madeira. From the Canary Islands they appear to have been brought into Europe about the beginning of the fourteenth century, and have been generally diffused over almost every civilized country, owing to the powerful attractions of their song, combined with the gracefulness and tenderness of their manners and their great docility. When imported from their native country they are often silent, or have but an indifferent song; and the fine warble to which our ears are so familiar, is usually modelled on that of the titlark or of the nightingale. Most of those from the Tyrol have been educated under parents, whose progenitors were instructed by a nightingale; but the Englishbred Canary birds have more of the titlark's notes.

*** Bill conical, long, straight, and compressed; point of the mandibles sharp.

F. citrinella, Lin. Throat, breast, and middle of the belly yellowish-green; occiput, sides of the neck, and flanks cinereous; back, scapulars, coverts, and transverse band on the wings deep yel- 
lowish-green; wings and tail black, bordered with greenish. $4 \frac{1}{2}$ inches long. Inhabits Southern Europe--Tem. Man. 370.

F. spinus, Lin. The Siskin. Top of the head and throat black; shaded with greenish on the neck; a broad yellow band behind the eyes; back and scapulars greenish, with a little black streak on each feather; two bands on the wings, one black, the other greenish-yellow; wings and the extremity of the tail black. $4 \frac{1}{2}$ inches long. Inhabits N. Europe. B.-Selby, 1llust. pl. 55, fig. 6, 7.

F. linaria, Lin. (Linaria, Vieill.) Red-headed Linnet. Top of the head, breast, lateral parts of the belly and rump, crimson-coloured; belly rose-coloured; upper parts reddish ash-coloured, with longitudinal black spots; wings, throat, and tail black. 5 inches long. Inhabits Europe. B.-Selby, Illust. pl. 54, fig. 10.

F. carduelis, Lin. (Carduelis, Cuv.) The Goldfinch. Forehead and throat crimson; occiput and neck black; fore part of the neck and lower parts of the body white; back, scapulars, and lateral parts of the breast brown; upper half of the wing-feathers pure yellow, the other black, with whitish spots towards the end; tail black, with whitish longitudinal spots; bill whitish, the tip black. $5 \frac{1}{8}$ inches long. Europe. B.-Selby, Illust. pl. 55, fig. 8, 9.

F. cucullata, (Carduelis, Swainson.) Plumage orange-coloured, with the head, throat, a band across the coverts, quills, and tail black; primary quills at the base obliquely banded with orange. 4 inches long. Inhabits South America.-Swainson, Zool. Ill. pl. 7.

F. melanotis, Tem. Plumage above olive-green, beneath whitishred, with a black spot on the eyes and ears; head and neck behind lead-coloured; rump and upper coverts vermilion-red. $3 \frac{1}{2}$ inches long. Inhabits Southern Africa.-Tem. Pl. Col.221, fig. 1 .

Gen. 10. Рнчтотомa, Gmel.

Bill short, strong, conical, edged, with the margins of the mandibles serrated and equal; nostrils basal, lateral, ovoid; four toes, three before, one behind.

P. rara, Gmel. Chili Plant-Cutter. Plumage dusky gray above, paler below; quills and tail-feathers spotted with black; tail rounded. Size of a quail. Inhabits Chili.-Shaw, ix. 336.

\section{Gen, 11. Hyreus, Stephens.}

Bill conical, thick, straight, somewhat serrated; nostrils ovate; feet with three toes, two before and one behind.

H. Abyssinicus, Steph. (Phytotoma tridactyla, Daud.) Plumage above black, with the head, throat, and jugulum red; wing-coverts brown, with white margins. Abyssinia.-Shan, ix. pl. 53.

\section{Gen. 12. Colius, Gmel.}

Bill short, thick, conical, somewhat compressed at the point; mandibles convex, the upper one covering the lower; nostrils 
basal, lateral, partly concealed by feathers; tail very long, conical; tarsus short, the hind toe reversible; the anterior toes divided; wings short; the third quill longest.

The birds of this genus are natives of Africa or India, climb somewhat in the manner of parrots, live in troops, build numerous nests on the same bushes, and sleep suspended on the branches, with their head downwards. They feed on fruits.

C. Capensis, Gmel. (Loxia, Lin.) Cape Coly. Outer edges of the exterior tail-feathers white; body cinereous above, whitish beneath. Size of the chaffinch. Cape of Good Hope.-Shaw, x. pl.1.

C. Senegalensis, Gmel. Head, neck, and breast tinged with purplish; the feathers on the top and hind parts of the head green, and formed into a crest; rest of the upper parts pale-gray; tail bluish, the middle feathers above eight inches in length. Inhabits Africa._Shaw, x. $\overline{\text {. }}$

\section{ORDER V.-ZYGODACTYLOUS BIRDS. Zygodactyli.}

Bill of various form, more or less curved, or much hooked; and often straight and angular; feet always with two toes before, and two behind, and the exterior hind toe frequently reversible.

The distirictive character of the birds of this order is chiefly the disposition of the toes in pairs. Many of them chiefly or exclusively live on caterpillars, worms, and insects, but others on soft or hard fruits, and most of them nestle in the holes of decayed trees.

FamiLY I.-Bill more or less curved; feet with two toes before and generally two behind, the exterior hind toe sometimes reversible.

\section{Gen. 1. Musophaga, Tem.-Opcethus, Vieill.}

Bill short, stout, broad, ridge arched and elevated, notched at the point, extremity of the lower mandible forming an angle; nostrils basal, and often concealed by feathers; legs stout, tarsus equal in length to the middle toe; the exterior reversible; lateral toes equal; the fourth and fifth quills the longest.

M. Africana, Tem. (Opcethus, Vieill. Cuculus, Lin.) African Touraco. Plumage bluish green, the feathers on the head lengthened into a crest, capable of erection; quill-feathers crimson, margined with black; tail bluish purple ; belly, thighs, and under tail-coverts blackish. Inhabits Africa.-Shan, ix. pl. 15.

M. Paulina, Tem. Plumage above glossy copper-coloured; belly and vent dull copper-green, glossed with bluish; a large white spot round the eye; crest and quill-feathers red; bill orange Inhabits Southern Africa.-Shaw, xiv. pl. 26.

M. violacea, Tem. Plumage deep violet, except on the lower part of the wings, where the quill-feathers are bright purple, or rather crimson, tipped with violet, and the crown of the head, which is 
also purple ; beneath the eyes a white stripe pointing backwards ; upper mandible vaulted over part of the forehead. 19 inches long. Inhabits Africa-Shaw, viii. pl. 4,5.

Gen. 2. Indicator, Vieill.

Bill short, depressed, dilated on the sides, a little bent and notched at the point; ridge distinct; nasal furrow large; nostrils basal, a little tubular; tarsus shorter than the external toe; the anterior toes united to the first joint; wings with the third feather the longest.

I. major, Stephens. Great Honey-guide. Upper part of the head, hinder part of the neck, wing-coverts, and back brownish olivegreen; rump and tail-coverts white; breast and under parts pale yellow, the middle of the neck with black spots. 10 inches long. Inhabits Africa.-Shaw, ix. pl. 27.

I. minor, Steph. Plumage olive gray, with the quills brownish, margined with yellow; belly and tail whitish, the latter with the middle feathers black; bill and legs brown. Inhabits Southern Africa._Shaw, ix. 140.

Gen. 3. Cuculus, Lin.

Bill as long as the head, compressed and slightly curved; nostrils basal, pierced in the margin of the mandible, and surrounded by a naked and prominent membrane; legs feathered below the knee; fore toes united at their base ; hind toes divided, the exterior reversible ; tail long, more or less graduated; the third quill-feather the longest.

The Cuckoos are a shy and solitary race of birds, whicn live chiefly on insects and caterpillars, and are remarkable for depositing their eggs in the nests of some of the smaller birds. Only one species is a native of Great Britain.

C. canorus, Lin. Common Cuckuo. Head, neck, breast, and upper parts deep bluish gray, darkest on the wing-coverts; belly, thighs, and under tail-coverts white, with transverse black bars; tail-feathers blackish, spotted with whitish, as are the exterior webs of the quills; membranous margin of the bill and around the eyes orange yellow. $10 \frac{1}{2}$ inches long. Europe. B.-Selby, Illust. pl. 37 and $45^{* * *}$, fig. 1 .

This well known species usually makes its appearance in Britain early in April, and begins to utter the cry from which it has derived its name, in almost every language, about the middle of the month. This, which is the note of the male, ceases about the close of June, and the birds soon after leave the country, the old ones in July, and the young in the beginning of September. The nest which the female cuckoo selects for the deposition of her egg is commonly that of the hedge sparrow, though sometimes that of the water-wagtail, yellow-wren, titlark, yellow-hammer, green-linnet, or some other small insectivorous bird. The female is somewhat smaller than the male, but has generally the same markings. The details of colouring, however, are so much subject to variation in this species, that scarcely two are marked alike.

C. clamosus, Lath. Plumage bluish black; wing-feathers fuscous ; feet yellowish; bill black. 10 inches long. Inhabits Southern Africa.-Shaw, ix. 108. 
C. cupreus, Lath. Head, neck, and upper parts of the body brilliant copper-colour, with a golden gloss ; belly and thighs yellow; tail wedge-shaped, with the exterior feathers marked with a triangular white spot at their tip ; legs black. Size of the Lark. Inhabits Africa.-Shav. ix. 129.

C. chalcites, Tem. Plumage metallic green, with the head red, glossed with bronze; tail red at the base, greenish in the middle, white at the tip ; belly white ; neck anteriorly and breast varied with brown. $5 \frac{1}{2}$ inches long. Australasia.-Tem. Pl. Col.103. fig.2.

C. Klasii, Vieill. Brilliant copper green on the head and upper parts ; eyebrows white ; wing-feathers bronze green above, black and spotted with white below; under parts pure white; lateral feathers of the tail white within, with blackish transverse lines; bill and legs black. 7 inches long. Inhabits Africa._Shaw, ix. 128.

Gen. 4. Coccyzus, Vieill.-Cuculus, Lin.

Bill strong, compressed in all its length, ridge distinct, slightly bent from its base; lower mandibles straight, inclined at the point ; nostrils basal, lateral, half shut by a naked membrane; legs slender; tarsus much longer than the exterior toe; wings short and rounded, the first five feathers graduated.

C. Cayanus, Tem. Plumage above purplish chestnut, paler beneath; tail wedge-shaped, all the feathers tipped with white. 16 inches long. Inhabits Cayenne.-Shaw, ix. 90.

C. novinu, Tem. Plumage above brownish ferruginous; beneath rufous white; hind part of the neck rufous gray, with deep brown down the shafts, back, and rump; quills grayish brown, with a rufous spot near the tips; tail tipped with reddish. $10 \frac{x}{2}$ inches long. Inhabits Guiana.-Shan, ix. 99.

P. Geoffroyii, Tem. Plumage above bronzed green with a golden gloss; forehead, cheeks, neck anteriorly, and breast brown, the tips of the featliers with a reddish white crescent; crest bluish; belly yellowish ; tail wedge-shaped. 19 inches long. Inhabits South America.-Tem. Pl. Col. 7 .

Gen. 5. Centropus, Illig.-Corydonyx, Vieill-_Polophilus, Leach.

Bill thick, strong, compressed, deeper than broad, carinated, arcuated towards the tip; nostrils basal, lateral, diagonally cleft; legs long, robust; tarsus longer than the exterior toe; the two anterior joined at the base; inner hind toe with a long subulate claw.

C. AEgyptius, Tem. (Cuculus, Lath.) Egyptian Coucal. Plumage dull green above, reddish white beneath; head, back of the neck, and tail of a beautiful green; wings red; tail wedge-shaped. 15 inches long. Inhabits Egypt.-Shaw, ix. 54.

C. rufinus, Cuv. Plumage above rufous, with the feathers streaked 
with light red or white; wings and tail reddish, the interior hinder claw long and straight. 11 inches long. Inhabits Africa. -Shaw, ix. pl. 8.

C. gigas, Cuv. Wing-coverts and back brownish red, the shafts pale red, and the feathers bordered with brownish black; under part of the body reddish, bordered with sooty black ; tail tipped with whitish. 30 inches long. Inhabits Africa.-Shaw, ix. 45.

C. phasianus, Tem. Back and wings varied with rufous yellow, brown and black ; bill, head, neck, and under parts blackish ; tail long, black, with transverse bands. 17 inches long. Inhabits New Holland._Shaw, ix. pl. 11.

Gen. 6. Phenicophaus, Vieill--Cuculus, Gmel.

Bill longer than the head, strong, thick, rounded, smooth, arcuated, the base with divergent bristles; nostrils lateral, linear, distant from the base ; orbits naked, papillated; tarsus longer than the external toe; wings short.

P. pyrrhocephalus, Tem. The Malkoha. Crown and part of the cheeks bright crimson, surrounded by a band of white ; hind part of the head and neck black, with white spots ; front of the neck, back, and wings black; tail very long, wedge-shaped, tip white; breast and belly white; legs pale blue. 16 inches long. Inhabits Ceylon.-Shan, ix. 59.

P. leucogaster, Steph. Plumage greenish-black, with the belly and tail-feathers margined with white; throat and neck dull green; head round the eyes orange. 9 inches long. Inhabits Africa.Shan, ix. pl. 14.

\section{Gen. \%. Leptosomus, Vieill-_Cuculus, Lin.}

Bill almost triangular, laterally compressed, with prominent ridge; upper mandible a little bent, the lower straight; nostrils in the middle of the bill, half shut by an elongation of the corneous matter; tarsus broad, depressed, covered with rough scales; wings long, the fourth quill longest; tail long, equal.

L. afer, Tem. Body beneath and forehead whitish, top of the head and neck behind black; wing-coverts green, with red margins; tail blue-black. 15 inches long. Inhabits Africa. The only species of the genus.-Shaw, ix. 25 .

\section{Gen. 8. Scythrops, Lath.}

Bill long, convex above, laterally compressed, curved at the tip, the upper mandible longitudinally grooved; nostrils basal, naked, rounded; orbits naked; tarsus shorter than the middle toe, the two exterior toes joined at the base; tail long, rounded.

S. Novae Hollandice, Tem. Plumage lead-coloured, with the tailfeathers barred black and white. 17 inches long; bill four in- 
ches. The only species of the genus. Inhabits New Holland.Shan, viii. pl. 50 .

Gen. 9. Pteroglossus, Illig.-Ramphastos, Lin.

Bill slender, longer than the head, convex above, externally serrated, and tip curved; nostrils vertical, orbicular, open; tarsus the length of the external toe; the two anterior toes united to the second joint; wings short, concave, the first four quills unequally graduated; tail long, graduated.

The Pteroglossi inhabit the southern regions of the globe. Their bill is somewhat smaller in proportion than the Toucans, and their plumage generally green or yellowish, with red or yellow on the throat and breast.

P. Aracari, Tem. Plumage blackish green, with yellow abdomen, red middle abdominal bar and rump, and cuneated tail ; upper mandible with a longitudinal black stripe. 17 inches long; bill four inches. Inhabits S. America.-Shaw, viii. pl. 49.

P. viridis, Tem. Head and neck deep black; back, wings, and tail blackish green ; breast, belly, and vent yellow ; rump red; upper mandible yellow at the top, reddish at the sides, with a line of black between. 14 inches long; bill near three inches. Inhabits Cayenne.-Shaw, viii. pl. 48.

P. sulcatus, Swainson. Plumage green, paler below ; jugulum whitish ; round the eyes blue; bill with two longitudinal grooves. 12 inches long; bill three.-Zool. Illust. i. pl. 44.

\section{Gen. 10. Ramphastos, Lin.}

Bill cellular, thin, transparent, broader than the head at the base, convex above, serrated at the edges, and a little incurved at the tip; nostrils vertical, concealed behind the corneous mass, surrounded by a membrane; tarsus as long as the external toe ; the two anterior toes united to the second joint; tail short.

R. toco, Lath. The Toco Toucan. Plumage black, with the fore part of the neck and rump white; vent red; bill reddish, with black tip. 17 inches long; bill eight inches. Inhabits Cayenne-Shaw, viii. pl. 46.

R. vitellinus, Illig. Throat golden yellow; sides and ears white; pectoral band and wing-coverts red; bill black, with a blue bar at the base, edges thickened._Swains. Zool. Illust. i. pl. 56.

\section{Gen. 11. Crotophaga, Lin.}

Bill short, thick, much compressed, carinated above, its edges angulated; legs long, slender; tarsus a little longer than the external toe ; wings short, tail of eight broad feathers, rounded.

C. ani, Lin. American Keel-bill. Plumage violet black, with a green tint ; tail wedge-shaped. Size of a blackbird.-Shaw, viii. pl. 51.

Gen. 12. Trogon, Lin.

Bill shorter than the head, thick, arcuated, broader than high, 
bent at the point, dentated on the margin, with long bristles at the base ; nostrils basal, open ; legs short ; tarsus shorter than the external toe, partly covered by feathers; the exterior toe reversible; the fifth quill-feather longest.

T. viridis, Lin. The Green Curucui. Upper part of the head violet, with a mixture of golden green; sides of the head and throat black; upper parts of the body golden green, with a band of the same colour on the breast ; beneath orange yellow ; the thighs nearly black; three lateral tail-feathers obliquely dentated with white. $11 \frac{1}{2}$ inches long. Inhabits Cayenne--Shaw, ix. pl. 4.

T. rufus, Lath. General colour rufous, the belly, thighs, and vent yellow ; wing-coverts striated with black and gray ; three lateral tail-feathers striated with black and white, and white tips. 9 inches long. Inhabits Cayenne.-Shaw, ix. pl. 3, 3*.

T. sulphureus, Spix. Plumage glossy greenish above; forehead, throat, and thighs black; wing-coverts black, crenulated with white; abdomen sulphureous ; tail glossy copper-coloured, beneath black, with the three outer feathers banded with black and white; female blackish. 8 inches long. Brazil._Spix, Avium, pl.38. fig. I, 2.

T. Reinwardtii, Tem. Head, cheeks, sides of the neck and band on the breast green, tinged with olive; throat, belly, and under tail-coverts yellow; wing-coverts striped with green and yellow; orange spots on the body. 11 inches long. Java.-Tem. Pl. Col. 124.

Gen. 13. Capito, Vieill.-Tamatia, Cuv.-Bucco, Lath.

Bill long, straight at the base, broader than deep, point compressed; upper mandible bent at the point and surpassing the under one; nostrils basal, lateral, in the corneous substance, entirely concealed by stiff hairs; tarsus the length of the exterior toe; the two anterior toes united to the second joint; wings short.

C. macrorhynchos, Tem. Plumage black, with the forehead, throat, front of the neck, abdomen, and tip of the tail white; bill very large, hooked, and black. Cayenne.-Swainson, Zool.Ill. ii. pl.99.

C. collaris, Tem. Plumage above rufous, with a band on the shoulders fulvous, on the breast black ; throat and belly whitish ; tail transversely striated with black. $7 \frac{1}{2}$ inches long. Inhabits Guiana. -Shan, ix. pl. 7.

C. melanotis, Tem. Throat, neck, under parts of the body and wingcoverts white; sides more or less dotted or striped with black; top of the head, back, and wings red, waved with black lines; region of the ears and part of the neck black. 8 inches long.Tem. Pl. Col. 94.

Gen. 14. Bucco, Lin.

Bill strong, pointed, laterally compressed, covered with strong bristles at the base; uppermandible emarginated andincurved; 
nostrils basal, lateral; tarsus shorter than the exterior toe; the anterior toes united to the second joint; wings short.

B. grandis, Tem. The Great Barbet. Plumage above fine green, with the quill-feathers variegated with black; head and neck blue ; vent red ; bill whitish, with the tip black. 11 inches long. Inhabits China.-Shaw, ix. 40.

B. Javensis, Horsfield. Plumage emerald green above, below paler; the top of the head orange; a double black stripe on the sides of the head, the one superciliary, the other uniting on the nape; throat and transverse band on the back of the neck crimson. 11 inches long. Inhabits Java.-Lin. Trans. xiii. 181.

B. versiculor, Tem. Plumage green, paler below; crown red; a band on the sides of the head above blue, below black, and behind the eyes a rufous spot. $10 \frac{1}{2}$ inches long. Inhabits Sumatra.-Tem. Pl. Col. 309.

B. gularis, Reinwardt. Plumage dark green above, beneath paler; forehead and throat turquoise blue; a spot on the latter black or dusky, and edged with yellow; a citron-coloured stripe at the gape.-Tem. Pl. Col. 89. fig. 2.

\section{Gen. 15. Pogonias, Illig.-Bucco, Lath.}

Bill short, strong, with a prominent arched ridge ; cutting edge of the upper mandible with one or two strong teeth, and furrowed or smooth; lower mandible less deep than the upper; nostrils basal, lateral, with rigid bristles at the base; tarsus the length of the exterior toe; the two anterior united to the second joint.

All the species of this genus are natives of Africa.

P. sulcirostris, Tem. Upper parts of the body, wings, and tail black, with a white spot on the back; throat, neck, belly, and an obscure stripe on the wings scarlet; sides yellowish; quills dark brown; upper mandible with one longitudinal, the under with many transverse grooves. 9 inches long. Africa.-Shan, ix. pl. 1.

P. niger, Tem. Throat, jugulum, breast, and nape black; forehead red; neck on both sides with two strix and with the abdomen whitish; wings and tail yellow, varied with black. $6 \frac{1}{2}$ inches long. Cape of Good Hope-Leach, Zool. Mis. ii. pl. 116.

P. personatus, Tem. Plumage ashy-green, with the crown, throat, and neck entirely vermilion red; nape and breast deep black; wings and tail brown, edged with yellow; belly greenish white. 7 inches long. Inhabits Africa.-Tem. Pl. Col. 201.

\section{Gen. 16. Psittacus, Lin.}

Bill short, thick, gibbous, very strong, convex above and below, much bent and hooked at the point; lower mandible short, obtuse; base of the bill with a cere; head large ; nostrils orbicular, pierced in the cere, open; legs short, robust ; 
tarsus shorter than the external toe; the interior toes united at their base ; tail of varied form.

This large genus is at once to be distinguished by the peculiar structure of the bill. Their food is chiefly fruits ; they have in general a brilliant plumage; and inhabit the Southern hemisphere of the globe. In climbing they are greatly assisted by their bill. The genus may be divided into four sections.

\section{* No crest on the head.}

P. melanocephalus, Lin. White-breasted Parrot. Plumage green above, beneath luteous; breast whitish; quill-feathers tipped with blue; bill and legs dusky. Size of a Pigeon. Inhabits Mexico. $-E d w$. pl. 169.

P. mitratus, Tem. Head deep green, with the sinciput of a scarlet blood-colour; face, occiput, and throat, varied with green and scarlet; outer webs of the quills blue, margined with green and yellow; tail beneath green blue, above green, the tip obscure blue. Inhabits Brazil.-Tem. Pl. Col. 207.

P. cyanotis, Tem. (P. Braziliensis, Lin.) Plumage grass-green, rather paler beneath, the feathers edged with purplish brown; round the base of the bill bright red; cheeks deep-blue, and top of the head yellow; edge of the wings red, the wing-coverts and secondaries edged with yellow, the primaries dusky blue; outer tail-feathers blue, the next red, and the others green, tipped with yellow. Inhabits Brazil.-Shan, viii. pl. 77.

P. accipitrinus, Lin. Plumage green, with ferruginous head and neck, waved with blue; quill and tail-feathers edged with blue. Size of a small Pigeon. Inhabits Guiana.-Edw. pl. 165.

P. erythacus, Lin. Gray Parrot. Plumage ash-gray, deeper on the upper parts, and more inclining to white below; orbits naked and white ; tail crimson; bill black. About 12 inches long. Inhabits Africa.

This well known species is remarkable for its docility, the distinctness of its articulation, and its loquacity. It readily imitates every sound within its hearing. The gray Parrot is extremely long-lived; and $\mathbf{M}$. Vaillant mentions one as having lived at Amsterdam in domesticity for seventy-three years after its arrival in Europe. It moulted regularly every year till the age of sixty-five, after which its moulting was irregular, and the red feathers of the tail were replaced by yellow ones.

\section{*** With a pendulous or falling crest.}

P. cristatus, Lin. Broad-crested Cockatoo, Plumage white, with a tinge of rose-colour on the head and breast; crest on the head large, arching over the whole head, white above, scarlet beneath; capable of erection or depression; orbits of the eyes naked; tail short; bill black. Size of a common fowl. Inhabits Moluccas. -Shaw, viii. pl. 72.

P. sulphureus, Lath. Sulphur-crested Cockatoo. Plumage white, with a shade of pale yellow on the breast, sides, and wing-coverts; a large yellow spot beneath each eye; crest lengthened and pointed, slightly reversed at the tip; bill black. 15 inches long. Inhabits Moluccas._Shaw, viii. pl. 73. 
P. Cookii, Tem. Crimson-tailed Cockatoo. Plumage black, more or less spotted with yellowish ; crest small ; tail bright crimson, the base and tip black. 20 inches long. New Holland.-Shaw, xiv. pl. 14.

P. Eos, Tem. Head, neck, all the under parts, and inner surface of the wings rose-coloured; the rest of the plumage gray, deeper on the wings and tail ; bill yellowish. 12 inches long.-Tem. $\mathrm{Pl}$. Col. 81.

*** Face naked, or striped with feathered lines; tail long, wedged, acute.-Macrocercus, Vieill.

P. macao, Lin. Scarlet Maccaw. Head, neck, breast, belly, and thighs, upper part of the back, and lesser coverts of the wings bright red or scarlet-colour; wings blue above, faint red below, coverts yellow; tail-coverts blue : tail with the middle feathers red, the lateral ones partly blue; cheeks wrinkled and naked. Inhabits S. America.-Edn.pl. 158.

P. Aracanga, Lin. Plumage scarlet, with the greater wing-coverts yellow, tipped with green and blue; quills above blue, beneath rufous; cheeks naked. 2 feet 10 inches long. Inhabits Guiana. -Vaill. Per. pl. 2.

P. ambiguus, Bechst. Plumage brown-green, with the forehead scarlet, quills and rump blue ; tail rufous above, back yellow, the tip blue ; cheeks naked, with plumose lines. About 2 feet long. Inhabits South America._Vaill. Per. pl. 6.

\section{**** Tail long, graduated.}

P. pulchellus, Tem. Plumage green, yellow beneath; wings and frontlet blue; two middle tail-feathers green, the lateral ones yellow, with a black streak near the shaft. $6 \frac{1}{2}$ inches long. Inhabits New Holland.-Shan, viii. 470.

P. eximius, Shaw. Head, neck, and breast scarlet ; wings and tail blue; back black, undulated with green; abdomen yellowish; bill horn-coloured. New Holland.-Shaw, viii. pl. 57,58.

P. scapulatus, Bechst. (P. Tabuensis, Shaw.) Back, wings, and tail deep grass-green; with a paler band across the smaller wingcoverts ; head, neck, and whole under parts bright scarlet. 16 inches long. Inhabits New South Wales._Shar, viii. pl. 55.

P. setarius, Tem. Forehead, cheeks, neck, and all the under parts of the body fine green ; bluish on the forehead, a red spot between the bill and eyes, and an orange band between the neck and back; two middle tail-feathers elongated, with part of the shafts naked. 11 inches long. Inhabits Indian Archipelago._Shaw, xiv. pl. 16.

P. formosus, Lath. The Ground Parrot. Plumage green on the back, spotted with black and yellow; forehead as far as the eyes red; tail strongly cuneated, and consisting of sharp-pointed feathers of the finest yellow, crossed by numerous arrow-shaped black bars. Size of the Pigeon. Inhabits New Holland. -Shaw, viii, pl. 66. 
FamiLy II.-Bill straight and angular.

Gen. 1\%. Prcus, Lin.

Bill long, or medium-sized, straight, angular, wedge-shaped at the tip; nostrils basal, open, covered by setaceous feathers; tongue round, vermiform; legs strong; two toes before and two behind, rarely one behind; anterior toes joined at their base, the posterior divided; tail of twelve feathers, the lateral very short.

The birds of this genus live in forests, and feed chiefly on insects and their larvæ. Their strong hooked claws enable them, by the assistance of their tail, to clincb the trunks of trees in search of their food, and strike or perforate the bark with their bill; and their long tongue, armed with reflected bristles, serves them for procuring it in the crevices and holes of the bark.

P. martius, Lin. Great Black Woodpecker. Black, with the crown red; part of the tarsus covered with feathers; bill dark ashcoloured, whitish on the sides. 17 inches long. Inhabits Europe. -Shaw, ix. pl. 29.

P. viridis, Lin. Green Woodpecker. Plumage above green, with a scarlet crown, and rump yellow; below yellowish gray. $12 \frac{1}{2}$ inches long. Inhabits Europe. B.-Selby, Illust. pl.38, fig. 1.

P. canus, Gmel. Forehead crimson red, line between the eye and bill blackish; two black bands on the sides of the neck; occiput, cheeks, and neck clear ash-coloured; back bright green, rump yellowish; wings olive green, with white spots on the exterior webs of the quills, ash-coloured below; joint fof the thee fea thered. $11 \frac{1}{2}$ inches long. Northern Europe.-Tem. 'Man.'393.

P. major, Lin. Greater Spotted Woodpeeker. Plumage varied with black and white; back of the head and vent red; female without red on the occiput; bill dusky, irides reddish-brown. 9 inches long. Inhabits Europe. B.-Selby, Illust. pl. 38, fig. 2.

P. leuconotus, Bechst. Band of the forehead whitish yellow; top of the head and occiput bright red ; cheeks, sides, fore;part of the neck, middle of the belly, back, and rump white ; abdomen and inferior coverts of the tail crimson; two middle tail-feathers black. $10 \frac{1}{2}$ inches long. Inhabits Northern Europe.-Tem. Man. 396.

P. medius, Lin. Back and wings black; middle coverts of the wings, scapulars, and spots on the webs of the wing-feathers white; abdomen and lower coverts of the tail crimson; coronal and occipital feathers red, slender, and elongated; bill short, compressed and pointed. 8 inches long. Inhabits Europe.-Tem. Man. 398.

P. minor, Lin. The Lesser Spotted Woodpecker. Forehead, region of the eyes, sides of the neck, and lower parts dirty white; upper part of the back and lesser wing-coverts glossy black; rest of the upper parts with black and white bands; quills black, spotted with white; lateral tail-feathers black, banded with white. $5 \frac{1}{8}$ inches long. Inhabits Europe. B.-Selby, Illust. pl. 38, fig. 3. 
P. principalis, Lin. White-billed Woodpecker. Plumage black, with a line on both sides of the neck and secondary quills white; tail black; bill channeled and white. 16 inches long. Inhabits America._Shaw, ix. pl. 30.

P. galeatus, Tem. Crested Woodpecker. Crest, head, and whiskers vermilion red; region of the ears striped with black and whitish; body above reddish; below transversely striped with black and red. 11 inches long. Inhabits Brazil.-Tem. Pl. Col. 171.

P.aurulentus, Tem. Plumage above green; beneath striped with whitish and green ; top of the head and occiput red; cheeks with two golden and one greenish stripe; throat pale yellow. $8 \frac{1}{2}$ inches long. Inhabits Brazil.-Tem. Pl. Col. 59, fig. 1.

P. tridactylus, Lin. (P. hirsutus, Vieill.) Top of the head golden yellow; occiput and cheeks shining black; forehead varied with white and black; a white band above and below the eyes; fore part of neck and breast white ; top of the back, sides of the breast, flanks, and abdomen striped black and white; two toes before and one behind. 9 inches long. Europe, \&c.-Shaw, ix. pl. 38.

\section{Gen. 18. Galbula, Briss.}

Bill long, straight, or slightly bent at the point, quadrangular, pointed; nostrils basal, oval, covered in part by a naked membrane; legs short; tarsus shorter than the external toe; the fore toes united to the third joint.

This genus inhabits the warmer regions of America.

G. grandis, Lath. Great Jacmar. Upper parts of the body golden copper-coloured; beneath ferruginous ; throat with a white band; primary quills brown; tail long, wedge-shaped. 12 inches long. Shaw, ix. pl. 40.

G. viridis, Lath. (Alcedo galbula, Lin.) Body of a golden green above; throat white; belly and vent rufous; tail long, wedgeshaped, of ten feathers; irides blue. Size of the lark. Inhabits Brazil.-Shaw, ix. pl. 39.

\section{Gen. 19. YuNx, Lin.-Wryneck.}

Bill short, straight, in the form of a depressed cone ; ridge rounded; slender at the tip; nostrils basal, naked, partly closed by a membrane; the two fore toes united at their origin, the hind ones divided; tongue long, lumbriciform, armed at the point with a horny substance; tail with ten soft flexible feathers.

The Wrynecks have many of the habits of woodpeckers, but are not so capable of climbing trees, and chiefly fix on the bark to extract insects from the crevices. They also frequent ants' nests, preying on the ants and their larvæ. . There are only two foreign species of this genus mentioned by authors, the $\boldsymbol{Y}$. minutus, (Picus minu* tus, Lath.) and a new species from South America.

voL 1 . 


\section{ORDER VI.-ANISODACTYLI.}

Bill more or less arched, often straight, always subulate, and slender ; feet with three toes before and one behind, the exterior united at the base to that in the middle, the hinder one generally long, and all provided with long and bent claws.

The birds of this division have more or less the manners and habits of those of the preceding order ; for almost all of them are climbers, and insectivorous. Their tongue is more or less extensible. The character of the order, as implied in the name, is having the toes of unequal length.

\section{Gen 1. Oxyrhynchus, Tem.}

Bill short, straight, triangular at its base, attenuated and awlshaped at the point; nostrils basal, lateral, naked, and partly covered by a membrane; tarsus short, nearly the length of the middle toe; three toes before, the lateral equal, the external joined at the base, the internal divided; fourth and fifth quill-feathers longest.

O. flammiceps, Tem. Plumage of back and wings fine olive green; beneath yellowish white, with dusky spots; head with crimson incumbent crest, its sides with three transverse yellowish lines. 7 inches long. Inhabits Brazil._Shav, xiv. pl. 24. The only species of the genus.

\section{Gen. 2. Sitta, Lin.}

Bill straight, cylindrical, slightly compressed, tip acuminated; nostrils basal, rounded, partly concealed by reflected bristles; tongue short, horny; three toes before, the exterior joined at its base to the middle one; hind toe very long, with a long hooked claw; tail composed of twelve feathers.

The species of this genus are climbers, and differ from the woodpeckers in being able to ascend or descend the trunks of trees with equal facility. They feed chiefly on insects and their larvæ; sometimes on nuts and seeds.

S. Europaea, Lin. Nuthatch. Plumage plumbeous above, sub-ferruginous beneath; a black streak across the eyes ; lateral tail feathers black, whitish near the tips; breast and belly buff orange. $5 \frac{1}{2}$ inches long. Inhabits Europe--Selby, Illust. pl. 39, fig. 1.

S. Caroliniensis, Lath. Black-headed Nuthatch. Plumage cinereous above, whitish beneath, with the lower part of the abdomen inclining to rufous; head and upper part of the neck black, and the tail-feathers varied with black and white. Inhabits America. -Wilson's Amer. Orn. i. pl. 2, fig. 4.

\section{Gen. 3. Orthonyx, Lin. Tem.}

Bill very short, compressed, almost straight, point notched; nostrils in the middle of the bill, open, surmounted by bristles; tarsus longer than the middle toe; claws longer than the toes, furrowed laterally; wings very short; tail long, pointed. 
O. maculatus, Tem. Plumage dull brown above, spotted with black; male with a red throat, edged with black; throat of the female white. Inhabits Australasia.-Tem. Man. Ixxxi.

\section{Gen. 4. Dendrocolaptes, Herman.}

Bill depressed and trigonous at the base, straight or slightly bent, acute; nostrils basal, lateral, pierced in the bill; tongue short, cartilaginous; tail conical, the feathers stiff and acuminated; external toe united to the intermediate to the second joint, the internal very short; claws hooked and furrowed.

All the species of this genus inhabit South America. They resemble each other greatly in the plumage, but differ widely in the length and form of the bill. A Monograph of the genus by Lichtenstein appeared in the Berlin Transactions for 1820.

D. procurvus, Tem. Head, neck, and scapulars olive-brown, striped with white; wings and tail rufous; body beneath olive-brown, with whitish stripes; bill reddish, curved. Inhabits Brazil.Tem. Pl. Col. 28.

D. longirostris, Illig. Bill elongated, slightly bent, stout, compressed, white ; throat white. Brazil.-Berl. Trans, 1820, 200.

D. falcirostris, Spix. Plumage cinnamon-coloured above, beneath and vent olive-brown, striped with white; head and neck striped with white; bill greatly compressed, ash-coloured. $10 \frac{1}{2}$ inches long. Inhabits Brazil.-Spix, Avium Nov. Sp. pl. 88.

D. miniatus, Illig. Bill slightly bent, compressed, black; mandible white; tail and edges of the quills vermilion red.-Berl. Trans. 1820, 202.

\section{Gen. 5. Xexops, Illig.}

Bill short, slender, much compressed, subulate, acute; tips of the mandibles recurved; nostrils basal, lateral, covered by a naked membrane; lateral toes equal; external toe united to the second joint; claws strong, compressed, bent, tail wedged.

X. genibarbis, Tem. Plumage reddish-brown above, gray-brown below ; chin, eyebrows, and spots on the throat and breast whitish, a snowy spot beneath the ears; lesser quills blackish, with rufous margins. $4 \frac{1}{4}$ inches long. Brazil.-Shaw, xiv. pl. 22.

X. anatoboides, Tem. Red-brown, with the throat, collar on the nape of the neck, and line behind the eyes to the occiput white ; tail red. 7 inches long. Brazil.-Tem. Pl. Col. 150, fig. 2.

X. rutilans, Tem. Back and wings olive, quills golden yellow at the base, black in the middle, with red tips; throat and lines on the neck white. $4 \frac{1}{2}$ incheslong. Brazil.-Tem.Pl.Col.pl. 72, fig. 2.

\section{Gen. 6. Anabates, Tem.}

Bill straight, shorter than, or the length of the head, compressed, deeper at the base than broad, a little bent at the tip, entire; nostrils basal, lateral, oval, partly covered by a plumose 
membrane; tarsus longer than the middle toe; the exterior toe united to the second joint, the interior at the base; wings short; tail with weak shafts.

A. Guianensis, Tem. Plumage gray above; wings and tail rufous; under parts white; tail very long. $6 \frac{\pi}{2}$ inches long. Inhabits Guiana.-Shaw, x. 678.

A. striolatus, Tem. Plumage above brown, with longitudinal redbrown stripes ; chin and tail red; cheeks, sides of the neck, and body below olive-brown, longitudinally striped with white. 7 inches long. Inhabits Brazil.-Tem. Pl. Col.238, fig. 1.

\section{Gen. \%. Opetiorhynehos, Tem.}

Bill longer than the head, slender, subulate, depressed at the base, compressed at the point ; tongue short, cartilaginous; nostrils lateral, a little from the base, half shut by a naked membrane; tarsus twice longer than the middle toe; lateral toes equal, the exterior united at the base; wings short, the first three feathers graduated, the third and fourth longest ; tail short, slightly graduated.

O. rufus, Tem. (Merops, Lath.) Plumage rufous, deepest on the upper parts, and inclining to paler yellow beneath ; large quillfeathers brownish; tail slightly rounded at the end. $8 \frac{1}{2}$ inches long. Inhabits S. America.-Shan, viii. 182.

\section{Gen. 8. Certhia, Lin.}

Bill long, or of mean length, more or less curved, triangular, compressed, slender; nostrils basal, naked, pierced horizontally, and half closed by a membrane; three toes before, the outer united at its base to the intermediate one; claws much hooked, that on the hind toe longest; tail graduated, with stiff-pointed shafts ; fourth quill-feather longest.

The birds of this genus climb trees like the Woodpeckers, supporting themselves by the stiff-pointed feathers of the tail. They nestle in the chinks and holes of trees, and feed principally on small insects and seeds. Only one species is indigenous to Europe.

C. familiaris, Lin. Common Creeper. Plumage above yellowishbrown, intermixed with black brown and grayish white; rump reddish; a white streak above the eyes; throat, breast, and belly white; tail yellowish-gray, tinged with brown, the feathers stiff, long, and acuminated. $5 \frac{1}{4}$ inches long. Inhabits Europe. B.Selby, Illust. pl. 39, fig. 2.

C. cinnamomea, Lath. Cinnamon-coloured above, tips of the quillfeathers blackish ; white beneath, with subcuneated tail, the feathers pointed. 5 inches long.-Shaw, viii. 224.

Gen. 9. Careba, Briss.-Certhia, Lin.

Bill slightly arcuated, thick at the base; edges of the mandibles 
bent inwards, points sharp; upper mandibles finely notched at the point; tongue long, not extensible, bifid, flamentous ; tarsus longer than the middle toe; lateral toes equal; tail of medium size.

C. cyanea, Tem. Plumage ultra-marine blue; crown of the head pale green; tail and outer sides of the wings black, with oblique blue band on the wings; insides of the wings yellow. $4 \frac{1}{2}$ inches long. Inhabits Brazil-Shan, viii. pl. 32 .

C. spiza, Tem. Plumage green, with the under parts, wings, and tail tinged with blue; crown and cheeks black. 5 inches long. Intabits S. America-Edw. pl. 25.

\section{Gen. 10. Trochinus, Lin.}

Bill long, straight or arcuated, tubular, very slender, base depressed, acuminated; upper mandible almost concealing the lower; tongue long, extensible, bifid, and tubular; nostrils open before, covered by a broad membrane; legs very short; tarsus shorter than the middle toe; the three anterior toes nearly divided; wings graduated, the first feather longest.

The birds of this family are of very small dimensions, and, with a very few exceptions, inhabit the southern regions of America. They fly very rapidly, take their food on the wing, and suck the honied juice of flowers. They construct an elegant hemispherical nest of the down of a species of Thapsus, and suspend it over branches of trees, where it is concealed by the leaves, the female laying two white eggs of the size of peas. The male assists in incubation. The unrivalled brilliancy of their colours has been aptly compared to the richest metallic hues, or to the changeable reflections of gems, and in sunshine they glow with peculiar splendour. This numerous genus has been divided by some naturalists into those with curved, and those with straight bills; and by others as their tail is more or less forked, square, or rounded.

T. pella, Lin. Topaz-throated Humming-Bird. Plumage purplered, with black head, topaz-coloured throat, and the two middle tail-feathers very long. Body equal in size to that of a wren, but including the middle tail-feathers 8 to 10 inches long. Inhabits S. America._Shan, viii. pl. 37

T. sparganurus, Shaw. Bar-tailed Humming Bird. Plumage golden green, with emerald-coloured throat, black forked tail, and a crimson gold bar across the feathers. $3 \frac{1}{8}$ inches long; two long tail-feathers $4 \frac{1}{2}$ inches. Peru.-Shan, viii. pl. 39*.

T. enicurus, Tem. Jugulum, lower part of the breast at the side and chin golden green; neck in front at the base, breast above, and belly in the middle white; throat lilac; six tail-feathers, the two middle golden green, the others black.-Shaw, xiv. pl. 28.

T. jugularis, Lin. Red-breasted Humming-Bird. Plumage above deep golden green ; throat and breast blood-red ; abdomen blackish, and short tail. $4 \frac{1}{2}$ inches long. S. America.-Edv. pl. 266.

T. squalidus, Natterer. Plumage obscure brownish, sides of the head with two reddish white bands; a brown stripe through the eyes; back with a metallic tinge; breast reddish ash-coloured; vent red; quills white at the tip. Brazil.-Tem.Pl. Col.120, ifg. 1. 
Gen. 11. Nectarinia, Illig.-Certhia, Lin.-Cinnyris, Cuv. Bill long, slender, subulate, more or less bent, widened and depressed at the base; mandibles equal; edges of the under mandible bent inwards, and in part concealed by the upper; tongue long, extensible, tubular, bifid ; nostrils near the base, lateral, shut above by a naked membrane; tarsus longer or as long as the intermediate toe, the lateral toes united at the base; wings, first feather none or very short, the third and fourth the longest.

All the known species of this genus belong to the warmer parts of the Old Continent. They do not climb, but hop from flower to flower, exploring the nectary for food.

N. chalybea, Tem. Head, neck, breast, smaller wing-coverts, and back golden green; wings and tail dusky brown; breast red, banded above by a steel-blue bar. $4 \frac{\pi}{2}$ inches long. Inhabits Southern Africa._Shan, viii. pl. 28.

N. Javanica, Tem. Head above, nape, and back deep olive green; shoulders and rump glossy violet; wings and cheeks olive brown; throat and jugulum rust-coloured; breast and abdomen saffron colour; tail black. $4 \frac{1}{2}$ inches long. Java.-Lin. Trans. xiii. 167.

N. longirostra, Tem. Plumage blackish olive; crown and nape pale green ; throat and breast white; abdomen yellowish. 5 inches long; bill $1 \frac{1}{2}$ inch long. Bengal.-Tem. Pl. Col. 84, fig. 1 .

N. pectoralis, Tem. (N.eximia, Horsf.) Top of the head and tail deep glossy emerald green; two middle tail-feathers elongated ; rump yellow; throat and breast scarlet; a band of purple on the throat; belly olive brown. $4 \frac{1}{2}$ inches long. Inhabits Java.Tem. Pl. Col. 138, fig. 3.

\section{Gen. 12. Cumacteris, Tem.}

Bill short, much compressed, awl-shaped; mandibles equal, pointed; nostrils covered by a naked membrane; tarsus the length of the middle toe, which, with the thumb, is very long; claws large and hooked, furrowed on the sides; exterior toe united to the second joint, the anterior to the first; third and fourth wing-feathers longest.

C. scandens, Tem. Plumage above deep brown; rump and two middle tail-feathers lead-coloured; throat and neck in front white; breast and belly cream yellow; sides and under tail-coverts varied with brown and white; wings brown, with two transverse bands. $5_{4}^{\frac{5}{3}}$ inches long. New Holland.-Tem. Pl. Col. 281, fig. 2.

C. picumnus, Tem. Plumage brown above; throat and cheeks whitish ; breast, top of the head, and neck gray ; wings brown, with a transverse yellowish band. $6 \frac{1}{9}$ inches long. Inhabits New Holland, \&c.-Tem. Pl. Col. 281, fig. 1.

Gen. 13. Tichodroma, Illig.-Certhia, Lin.

Bill very long, slightly arched, slender, cylindrical, angular 
at the base, tip depressed; nostrils basal, naked, half shut by an arched membrane ; the exterior toe joined at its base to the middle one; claw on the hind toe very long; tail rounded, with weak shafts.

There is only one species of this genus, which climbs the vertical faces of rocks as the common creeper does the surface of the trunks of trees. It nestles in the clefts of rocks and feeds on insects.

T. phønicoptera, Tem. (Certhia muraria, Lin.) The Wall-Creeper. Top of the head deep ash-colour; back and scapulars lighter ; throat and fore part of the neck black ; wing-coverts and upper part of the exterior webs of the quills red; tail black, terminated with white and ash-colour. $6 \frac{1}{2}$ inches long. Inhabits Southern Europe.-Shaw, viii. pl. 25.

\section{Gen. 14. UPUPA, Lin.}

Bill very long, slightly arched, slender, triangular, compressed; nostrils basal, lateral, ovoid, open, and surmounted with feathers in front; three toes before, the exterior united to the middle one to the first joint; one behind; tail square, of ten feathers.

U. epops, Lin. The Hoopoe. Head with two rows of reddish feathers terminated with black, forming an arched tuft ; body ferruginous; wings black, with five white bands; tail black, with a lunated white band. 11 inches long. Inhabits Europe.-Selby, 1llust. pl. 40. fig. 2.

This beautiful bird inhabits Europe, Asia, and Africa, in the last of which many of them are stationary. Some of the migrating detachments visit Britain occasionally in autumn, but they seldom breed in this country. In France they arrive late in spring, and depart towards the close of summer,

U. Madagascariensis, Shaw. Plumage above dusky brown, deepest on the wings and tail ; crest and under parts white. 10 inches long. Inhabits Madagascar.-Shan, viii. 140.

\section{Gen. 15. Epimachus, Cuv.}

Bill much longer than the head, slender; more or less arcuated, compressed; mandibles pointed, the upper one slightly notched at the point, and longer than the lower; gape extending to under the eyes; tongue short, cartilaginous; nostrils basal, lateral, open before, half shut by a feathered membrane; legs short; tarsus longer than the middle toe; the external toe united to the first joint; fourth and fifth wingfeathers longest.

E. superbus, Tem. (Promerops, Shaw.) Plumage black, with a violet and green gloss; scapulars falciform, purplish black on the inner web, brilliant golden green on the edges and tip; on each side below the wings loose-webbed, pendant brownish feathers; tail very long. 4 feet long. Inhabits New Guinea.Shan, viii. 145 . 
E. erythrorhynchos, Tem. (Upupa, Lath.) Plumage black, with a green and purple gloss; bill and legs red; tail very long, all the feathers, except the two middle ones, marked near the tip by an oval white spot on each side of the web. 15 inches long. Inhabits Africa.-Shan, viii. pl. 18.

\section{Gen. 16. Drepanis, Tem. -Certhia, Lath.}

Bill very long, rounded above, thick and triangular at the base, subulate at the point; upper mandible longer than the under; tongue short, cartilaginous; nostrils half closed above; tarsus twice as long as the middle toe; the lateral toes equal; wings with the third, fourth, and fifth feathers longest.

D. Pacifica, Tem. General colour black, with rump, lower part of the belly, and thighs bright yellow; spurious wing yellowish white; bill greatly curved, brownish black. 8 inclies long. Inhabits South Sea Islands.-Shaw, viii. 227.

D. vestiaria, Tem. General colour bright scarlet, with the wings and tail black; tail-feathers slightly pointed at their extremities ; bill stout, considerably curved; pale yellow. 6 inches long. Inhabits Sandwich Islands.-Shan, viii. pl. 33.

Gen. 17. Meliphaga, Lewin.-Philedon, Vieill.

Bill of the length of or shorter than the head, compressed, rather arcuated, emarginate towards the tip, acute; nostrils lateral, ovoid, covered by an arched membrane ; tongue long, extensible, terminated by cartilaginous filaments; toes, the external united to the second joint, the internal to the first; back toe very strong, long.

This genus is very numerous in species.

M.cyanops, Tem. (Merops, Lath.) Blue-faced Honey-Sucker. Plumage brown above, white beneath; crown and throat black; eyes surrounded by a blue patch; bill black; legs blue. 16 inches long. Inhabits New Holland.-L,ewin's New Holl. Birds, pl. 25.

M. Phrygia, Tem. (Merops, Lath.) Plumage black, elegantly variegated with bright and pale yellow; a granulated naked yellow skin round the eyes; back and breast undulated by numerous pale or whitish yellow crescents. Size of a thrush. Inhabits New Holland.-Shaw, viii. pl. 20.

\section{ORDER VII.-ALCYONES.}

Bill middle sized or long, pointed, almost quadrangular, and either slightly arched or straight; tarsus very short; three toes before, united, and one behind.

The birds of this order, instituted by Temminck, fly with grcat celerity. Their movements are quick and abrupt, and they neither walk nor climb. They seize 
their food on the wing, and often from the surface of water, and nestle in holes on the banks of rivers. They moult only once a-year; and the females and young are not very dissimilar from the males and mature birds.

\section{Gen. 1. Merops, Lin.}

Bill sharp-edged, pointed, slightly curved; nostrils basal, lateral, ovoid, concealed by hairs directed forwards ; tarsus short ; three front toes united, the exterior to the second joint, the interior to the first joint of the middle toe; hind toe broad at its base ; the second wing-feather the longest.

This genus feeds chiefly on bees and wasps, which they seize on the wing. They nestle in holes on the banks of rivers. Many of the exotic species have their nostrils entirely naked, and the third wing-feather the longest.

M. apiaster, Lin. Common Bee-eater. Forehead greenish white ; occiput, nape, and top of the back chestnut ; rest of the body reddish yellow ; middle of the wing deep red ; wing and tail-feathers olive-green; eye-stripe black; throat golden yellow, with a black semicollar; two middle tail-feathers elongated and acuminated. Inhabits Europe. B.-Selby, Illust. pl. 41.

M. Savignii; Swainson. Green Bee-eater. Plumage green, beneath whitish ; rump and tail blue ; crown of the head, eye-stripe, and broad band across the neck black; chin and eyebrows white. $8 \frac{1}{9}$ inches long. Inhabits Africa. -Zool. Illust. pl. 76.

M. gularis, Shaw. Red-throated Bee-eater. Plumage black; forehead and rump blue; abdomen spotted with blue; throat red; tail even at the end. Inhabits Africa.-Shan, viii. pl. 23.

\section{Gen. 2. Alcedo. Lin.}

Bill long, straight, quadrangular, pointed, edged, and very rarely depressed; noștrils basal, lateral, pierced obliquely, almost wholly closed by a naked membrane; legs short, naked above the knee ; exterior toe united to second joint, and the interior to the first joint of the middle toe.

The birds of this genus are dispersed over the whole world, although only one species is found in Europe. They are more remarkable for brilliancy of plumage than elegalice of shape. Their prevailing colours are blue, green, and orange. Their flight is horizontal, and, notwithstanding the shortness of their wings, remarkably strong and rapid. Most of them frequent rivers, and the vicinity of waters, and live on fish, which they catch with singular art and dexterity, sometimes hovering over the stream, when a shoal of small fishes is seen playing near the surface, at other times waiting with attention on some low branch the approach of a single one, which may happen to move in that direction, and in either case darting with rapidity on their prey. The Kingfishers may be divided into two sections, as the tail is short or elongated.

A. ispida, Lin. The Kingfisher. Upper parts bluish green, marked on the head and coverts of the wings with little spots of azure blue; back and rump blue; a red patch of orange brown, con. cealed by a white one, behind each eye ; a streak of azure blue from the bill to the wings; throat and neck white; lower parts. reddish. 7 inches long. Europe. B.-Selby, Illust. pl. 40, fig. 1. This species is the Halcyon of the ancients, which the poets feigned as occupying a floating nest, and calming adverse winds and stormy seas. 
A. biru, Tem. Plumage above azure-blue ; wings externally brown ; throat, jugulum, abdomen, and vent white; bill and legs black. $5 \frac{1}{2}$ inches long. Inhabits Java.-Tem. $\mathrm{Pl}$. Col. 239, fig. 1 .

A. corulocephala, Lin. Plumage above blue, rufous beneath; the crown undulated with black; breast white; bill and legs red. 4 inches long. Inhabits Madagascar.-Shaw, viii. pl. 9.

A. cristata, Lin. Crown of the head with long blue green feathers, varied with black lines; back, rump, wings, and tail ultra-marine blue; fulvous beneath, with whitish throat and vent. $5 \frac{1}{8}$ inches long. Inhabits Africa._Shaw, viii. pl. 12.

\section{Gen. 3. Dacelo, Leach.-Alcedo, Lin.}

Bill thick, strong, four-sided conical ; mouth gaping to the eyes ; upper mandible longest, broadly notched towards its point on each side; nostrils oblong, half shut by a feathered membrane; tarsus shorter than the middle toe; the external toe united to the third joint, the internal to the second; wings of medium size.

D. gigantea, Tem. Plumage brownish above; feathers of the head elongated; whitish beneath, with black undulations; wing-coverts and rump pale sea-green, and the tail crossed by numerous black bars. 18 inches long. New Holland._Shaw, xiii. pl. 43.

D. pulchella, Horsfield. Sea green, fasciated with white and dusky above ; head chestnut brown, the vertex azure ; throat and jugulum whitish; abdomen dilute ferruginous. 8 inches long. Inhabits Java.-Tem. Pl. Col. 277.

\section{ORDER VIII.-CHELIDONES.}

Bill very short, much depressed, and very wide at the base; the upper mandible curved at the point; legs short; three toes before, either entirely divided, or connected at the base by a short membrane, the hinder often reversible; claws much hooked ; wings long.

The flight of these birds is rapid and abrupt, their sight piercing, neck short, throat wide, bill broad, and often gaping for the reception of insects, which constitute their only food.

Gen. 1. Hirundo, Lin.

Bill short, triangular, broad at the base, depressed, cleft near to the eyes; upper mandible slightly hooked at the tip; nostrils basal, oblong, partly closed by a membrane, surmounted by feathers in front; legs short, with slender toes and claws; three toes before, the exterior united to the first joint of the middle one; one behind; wings long, the firstquill the longest; tail of twelve feathers, mostly forked.

The Swallow tribes manifest a predilection to the neighbourhood of water, and 
those situations in which insects most abound. These last they seize with great promptitude in their long sustained and very rapid flights. They catch their food, drink, and bathe, as they glide smoothly and nimbly along the surface of the water. Their motions are easy, swift, and graceful ; and, when not occupied with breeding or sleep, they are alihost incessantly on the wing. Their nests are hard and rough on the outside, but furnished with soft materials within. Their migrations are no longer matter of doubt ; and the observations of $M$. Natterer of Vienna have established the important fact that they moult in February, which is a fresh argument against their alleged torpor in winter.

H. rustica, Lin. Chimney Swallow. Forehead and throat brown chestnut ; sides of the neck and a broad band on the breast black, with violet reflections; a large white spot on the interior web of the tail-feathers, with the exception of the middle ones ; exterior wing-feather on each side longer than the others ; belly and abdomen dirty white or reddish. $66_{\frac{1}{2}}$ inches long. Inhabits Europe. B.-Selby, 1llust. pl. 42. fig. 1 .

This well known species occurs almost everywhere in the old continent. It visits us earlier in the season than any of its congeners, usually, if the weather be mild, about the beginning of A pril, or a week before the House Martin, and it retires about the end of September, or beginning of October. Previous to their departure, the chimney swallows congregate in flocks of three or four hundred, on houses or trees, and usually steal off in the night, to avoid the birds of prey, which seldom fail to harass them in their route. On such occasions their progress is always in a southerly direction, availing themselves as much as possible of favourable winds; and when no obstacles interfere, they usually arrive in Africa in the first week of October.

H. urbica, Lin. The Martin. Head, neck, and top of the back black, with violet reflections; wings, tail, and larger coverts black; tail forked; lower parts and rump white, tarsi and toes covered with downy feathers. 5 inches long. Inhabits Europe-B. Selby, Illust. pl. 42. fig. 2.

Their first annual appearance in this island is about the 16th of April, and they leave us the latest of their tribe, in general about the beginning of October, although some have been known to remain till the 6 th of Noveniber. According to Mr White, many more leave this country than return to it in spring; but such as revisit their native seats, find their way back again to their own nests, as has been ascertained by tying coloured threads or brass wires to their legs.

H. riparia, Lin. Sand Martin. Upper parts, cheeks, and pectoral band dark brown; wings olive brown, inclining to blackish; throat, belly, and upper tail-coverts white; tail forked; tarsi and toes naked, except a few small feathers at the insertion of the hind toe. 5 inches long. Europe. B.-Selby, Illust.pl. 42 fig. 33.

H. rupestris, Lin. Upper parts clear brown, the wings a little deeper; lower parts dirty white, tinged with reddish on the sides; tarsi furnished with a grayish down; tail with feathers of equal length, the two middle feathers without spots, the others with a large oval white spot. 5 inches long. Inhabits Southern Europe. -Tem. Man. 430.

H. leucoptera, Lath. White-winged Swallow. Crown and upper parts of the body cinereous, with blue and green reflections; greater coverts and secondary quills variegated with white; primary quills and tail brown; rump and under parts white. 5 inches long. Inhabits Guiana.-Shaw, x. pl. 13 . 
H. Senegalensis, Lin. Plumage black, shining with blue; beneath and rump rufous; quills and tail-feathers black. $8 \frac{1}{2}$ inches long. Inhabits Senegal.-Shaw, x. 93.

Gen. 2. Cypselus, Illig.-Hirundo, Lin.

Bill very short, triangular, broad at the base, inconspicuous, depressed; gape as far as under the eyes; upper mandible hooked at the tip; nostrils cleft longitudinally, at the upper part of the bill, open, and the raised margins furnished with small feathers; legs very short, with the four toes directed forwards, and quite divided; the toes and claws short and thick; wings very long; tail with ten feathers.

The birds of this genus present many analogies with the preceding. They are even more active and unwearied in their movements, and their flight seems to be continuous, and with but little motion of their wings. They are rarely seen to rest even upon elevated places, and never on the ground.

C. alpinus, Tem. (Hirundo Melba, Lin.) White-bellied Swift. Grayish brown above, with the throat and belly white; legs covered with brown feathers. $8 \frac{1}{2}$ inches long. Europe.-Shaw, x. 74.

C. murarius, Tem. (Hirundo apus, Lin.) The Swift. Throat of a white ash-colour; rest of the plumage blackish brown; tarsi covered with small feathers; bill black. $7 \frac{1}{2}$ inches long. Inhabits Europe. B.-Selby, Illust. pl. 42, fig. 4.

C. comatus, Tem. Plumage of a copper-green, with the wing-coverts, quills, and tail-feathers green; a line above and beneath the eyes, and tip of the greater wing-coverts white. 6 inches long. Inhabits Sumatra.-Tem. Pl. Col. 268.

C. longipennis, Tem. Green black above; with the quills and tail obscure; back grayish on the lower parts ; body beneath ashcoloured. $8 \frac{1}{2}$ inches long. Inhabits Java.-Tem. Pl. Col. 83. fig. 1. Gen. 3. Caprimulgus, Lin.

Bill slightly curved, very small, and depressed at the base; mouth extremely wide; nostrils basal, wide, closed by a membrane surmounted by feathers; tail round or forked, of ten feathers; legs short, the anterior toes united to the first joint; middle claw long, and serrated on the edge, but smooth in some of the foreign species; hind toe reversible.

This genus has its name from the ancient but erroneous notion of the species sucking the teats of the she-goat. They are shy and solitary, come forth chiefly in the evening, prey on nocturnal moths and insects, and lay their eggs on the ground. Their eyes and ears are large, like those of the owl.

C. Europoeus, Lin. European or Nocturnal Goatsucker. Upper parts varied with black, cinereous, brown, rust-colour, and white, under parts reddish-white, with brown bands; legs short, scaly, and feathery below the knee. The male is distinguished by a large, oval, white spot, near the end of the first three quill-feathers, and another on the outer tail-feathers 10 inches long. Inhabits Europe. B. Selby, Illust. pl 42* 
In Britain the Goatsucker is only a summer visitant, arriving about the end of May, and departing in September. Its winter retreat is supposed to be Africa and Asia.

C. ruficollis, Tem. Head, back, and wings clear gray, varied with black points and zigzag lines; a large red collar round the nape, shading into whitebefore ; two lateral feathers of the tail terminated by a white spot. 12 inches long. Inhabits Europe-Tem. Man. 438.

C. grandis, Lath. (Nyctibius, Vieill.) Plumage variegated with dusky white, and yellow above, black and white beneath; space round the eyes yellowish; feet white ; bill covered with hairs. 2 feet long. Inhabits South America._Shaw, x. 142.

\section{Gen. 4. Podargus, Illig.-Caprimulgus, Lath.}

Bill broader than the head, abruptly acuminate at the tip, deflexed; upper mandible spatuliform, carinated; nostrils linear; wings shorter than the tail; toes separate; claws nearly equal.

P. cornutus, Tem. Head with a tuft of long decomposed feathers, a little above and behind the eyes ; bill surrounded with bristles; back and wings red, sprinkled with black; scapulars spotted with white ; throat white; tail wedged, red, with undulated lines. 9 inches long. Inhabits Java. -Shaw, xiii. pl. 41.

\section{ORDER IX.-COLUMBA.}

Bill of moderate dimensions, compressed; base of the upper mandible covered with a soft skin, in which the nostrils are perforated, the tip more or less curved; feet with three toes in front, quite divided, and one behind.

This order contains but one genus, but is numerous in species, and these very widely dispersed over the world. Pigeons are generally of an elegant form, of beautiful varying plumage, and gentle manners. They are strictly monogamous, and the female lays but two eggs, which are incubated alternately by both sexes. The young are fed by the parent birds with food from their crop which has undergone maceration. The food of pigeons consists of grain and seeds, rarely fruits. They drink with a continued draught.

Gen. 1. Columba, Lin.

Bill of medium size, straight, compressed, arched, tip curved; base of the upper mandible covered with a soft skin, more or less inflated; nostrils in the middle of the membrane; legs generally red; three toes before, entirely divided, one behind, articulated on the heel; wings with the second quill-feather longest.

C. palumbus, Lin. Ring-Dove or Cushat. Head, cheeks, neck, and lower parts of the back bluish gray ; upper parts of the back and wing-coverts deeper; a patch of white on the neck; breast and belly brownish-purple; quills blackish-gray, margined with white; 
iris yellowish white. $17 \frac{1}{2}$ inches long. Inhabits Europe. B.Selby, Illust. pl. 56, fig. 1 .

This species breeds twice or thrice a-year, and is stationary in Britain. Its note is louder and more plaintive than that of the common pigeon, but uttered only in pairing time, or during fine weather. Various attempts to domesticate the RingDove have been made, but without success.

C. anas, Lin. Stock Dove. Head, throat, wings, and under parts bluish ash-coloured; sides of the neck of a changeable green; breast lavender purple; top of the back brown ash-coloured; a black spot on the last two secondary feathers and some of the coverts of the wings; wings and tail bluish ash-coloured; tail terminated with black; iris brownish red; legs and toes bright red. 13 inches long. Europe. B.-Selby, Illust.pl. 56*, fig. 1.

C. livia, Briss. The Rock Dove. Upper parts bluish ash-coloured; sides of the neck changeable green ; rump white; two black transverse bands on the wings; wing and tail-feathers terminated with black; lateral tail-feathers margined with white; iris reddishyellow. 12 inches long. Inhabits Europe. B.-Selby, Illust. pl. $56^{*}$, fig. 2.

From this species all the domestic varieties are supposed to be derived.

C. turtur, Lin. The Turtle-Dove. Head, neck, breast, and back light wood-brown, tinged with pearl-gray ; a patch of black feathers, margined with white, on each side of the neck; scapulars and wing-coverts black, shading into bluish-gray, and deeply edged with buff-orange; belly and under tail-coverts white; two middle tail-feathers brown, the rest with their tips white. 11 inches long. Inhabits Europe. B.-Selby, Illust. pl. 56, fig. 2.

This delicate bird is only a periodical visitant in Britain, arriving in the beginning of May, and departing after incubation at the commencement of September. It is only found in the southern counties.

C. lacernulata, Tem. Plumage reddish-brown; head blue ash-coloured; middle of the belly purple; under tail-coverts red; shoulders and wings dusky, shining with bronzed-green; tail dusky at the base. 15 inches long. Inhabits Java.-Tem. Pl. Col. 164.

C. scripta, Tem. Plumage above ashy-brown, the wing-coverts sprinkled with opaline green spots; throat white, edged with black; breast and middle of the belly ashy-blue ; lateral tail-feathers brown at the base, deep black at the tip. $9 \frac{x}{q}$ inches long. Inhabits New Holland.-Tem. Pl. Col. 187.

C. lophotes, Tem. Plumage brownish ash-coloured; head with an elongated crest; back and lesser wing-coverts with a transverse black bar towards the tips; the greater coverts with green tips; quills with a purple spot on the outer web ; tail-feathers elongated, with white tips. 12 inches long. Inhabits New Holland. Shaw, xiv. pl. 34 .

C. magnifica, Tem. Plumage above fine golden green; wing-coverts spotted with yellow; head, cheeks, and nape ash-coloured; secondary feathers and quills deep changeable green; throat, ante- 
riorly, and upper part of the breast violet-purple; abdomen, thighs, and under tail-coverts ochraceous. 16 inches long. New Holland.-Tem. Pl. Col. 163.

C. migratoria, Lin. Migratory Pigeon. Tail cinereous; neck greengolden purple; wings with ovate spots in the middle; breast rufous, and abdomen white. 14 inches long. Inhabits N. America. -Shaw, xi. 93.

The Migratory Pigeon of North America exists in immense flocks, which in their excursions sometimes cover a space of two miles in length, and a quarter of a mile in breadth. They travel in the morning and evening, and repose about mid-day in the forests, especially in those which abound in oaks, of the acorns of which they are very fond. Although they always shape their course in the same general direction, they seldom observe the same line of march for two seasons in succession, proceeding sometimes by the maritime, and sometimes by the more inland regions. Their passage, whether in spring or autumn, lasts from fifteen to twenty days, after which they are met with in the centre of the United States. When in the southern districts, they keep always in flocks, but when in the north, they pair, disperse, and nestle in the vast forests of Nova Scotia, Canada, \&c. where they commit serious havock on the newly-sown fields. Large quantities are annually killed. An individual of this species was shot in Fife in 1826.

C. coronata, (Lophyrus, Vieill.) Great Crowned Pigeon. Bodybluish, shoulders ferruginous, with a white band on the wings; orbits black ; crest composed of long feathers of a loose texture, erect. Size of a turkey. Inhabits India.-Shaw, xiv. pl. 19.

\section{ORDER X.-GALLINA.}

Bill short, convex, in some genera covered by a cere; upper mandible bending from its base or only at the point; nostrils lateral, covered by a membrane, naked or feathered; tarsus long; three toes before, united at their base by a membrane, hind toe articulated on the tarsus above the junction of the anterior toes.

The birds which form this order are of a bulky and heavy form. The greater number have short wings, which renders them incapable of distant or long continued flight. Their principal food consists of grain and seeds, though some add to those roots, herbs, and the buds of trees, and most of them devour insects. Their nest is in most cases placed on the ground amung bushes or herbage, without much art. Some members of the order are polygamous; others pair every season. Their eggs are numerous, and the young when first excluded are covered with soft down, and are immediately able to follow their parent and feed themselves. They scratch the ground with their feet in search of food, and have the peculiar habit of rolling themselves in the dust. The chief part of our domestic poultry is derived from the birds of this order.

\section{Gen. 1. Pavo, Lin.}

Bill naked at the base, convex above, thickened, bent down towards the tip; nostrils open; cheeks partially denuded ; tailcoverts very long; tail of eighteen feathers, elongated, broad, capable of being expanded like a fan, and ocellated; tarsus longer than the middle toe, with a conical spur; head crested. 
P. cristatus, Lin. Crested or Common Peacock. Crest compressed, body of the male golden green, glossed with brassy reflections above; wing-coverts green gold, with blue and brassy reflexions, under parts of the body dusky, varied with green gold; head with two white stripes on each side ; upper tail-coverts very long, with various colourings, and auriferous eyes or arches. 4 feet long. Inhabits India._Shaw.

- The Peacock is one of the most beautiful of birds. It is a native of India, but has been domesticated in Europe for many ages. It is a proud and quarrelsome bird, and utters a discordant scream. The female lays from five to six eggs, which are hatched in from twenty-seven to thirty days. The young acquire their perfect plumage in the third year. The food of the peacock is similar to that of the gallinaceous birds. Aged females sometimes acquire the plumage of the male. The brains of peacocks formed a dish in high estimation at the tables of the Roman epicures.

P. muticus, Lin. The Japan Peacock. Body above green blue, with a brassy gloss; beneath ash-coloured, with black spots and white stripes; breast rich blue, glossed with green and gold; upper tail-coverts ocellated; head with an erect spicated crest. Size of the commen peacock. Inhabits Japan.-Shaw, xi. 148.

Gen. 2. Gallus, Briss. Tem.-Phasianus, Lin.

Bill of medium size, strong, base naked ; upper mandible arched, convex, bent towards the point; head surmounted by a crest or plume ; ears naked; three toes before, united to the first joint; the hind toe raised from the ground; tarsus with a long and bent spur; middle feathers of the tail arched; wings short.

G. Sonneratii, Tem. (P.gallus, Gmel.) The Jungle Cock. Comb toothed, throat wattled beneath, feathers of the neck elongated, spotted with white, black, and fulvous, with membranaceous tips; throat, breast, abdomen, and back, gray, striped with white; wingcoverts reddish-chestnut; quill and tail-feathers deep black. Inhabits India._Shan, xi. pl. 12.

G. domesticus, Tem. (P. gallus, Lin.) Domestic Cock. Comb dentated; throat wattled; feathers of the neck linear and elongated; body variegated with beautiful colours; tail compressed and ascending; comb and wattles of the female less than those of the male. -Shan, xi. 203.

This is the origin of all the domestic varieties of this useful bird, and is supposed to have come originally from Asia. It is spread over the whole world, and the vast varieties in point of colour, comb, feet, feathers, \&c. are an exemplification of the power of domestication, food, and climate, in producing and continuing particular breeds or races. The hen lays eggs for nearly the whole year, if properly fed, and kept in a certain temperature. The young are hatched in about three weeks. In domestication few of the race are allowed to live long; but an instance is related of a hen in Cumberland living for thirty years. For the seven previous years, however, she had given over laying eggs. The female in old age sometimes assumes the plumage of the male.

G. furcalus, Tem. The Fork-tailed Cock. Comb entire ; throat with a wattle in the middle; feathers of the neck short and rounded; body above green-gold, beneath black; wing-coverts orange and brown; female with comb or wattle. Java.-Shaw, xi. 215. 
Gen. 3. Phastanus, Lin.

Bill short, thickened, naked at the base, bent towards the tip; nostrils basal and lateral ; cheeks naked, warty ; cars covered; three toes before, united to the first joint, and one behind; tarsi furnished with spurs in the males; tail elongated, cuneiform, and cornposed of eighteen feathers; wings short.

The beautiful and elegant birds coniprised under this genus are all natives of Asia, frequenting woody situations, and subsisting on seeds and insects. The females produce many young at a brood, which they foster for some times like the domestic hen. Their nests, which are rudely constructed, are formed on the ground. The young, when first hatched, are clothel with a soft down.

P. Colchicus, Lin. Common Pheasant. The male rufous, with the head and neck blue, shining with green and gold, and variegated with black and white; cheeks furnished with red papillæ; breast, belly, and flanks purple-chestnut ; tail very long, with transverse black bands. 2 feet 11 inches long. The female is smaller, and brown-gray, varied with reddish and dusky.-Selby, Illust. pl.57.

The Pheasant is supposed to have been originally introduced from Asia; but it is at present diffused over most of the southern and temperate regions of the old continent, and has been met with even as far north as Bofhnia and Siberia.

P. pictus, Lin. Painted or Golden Pheasant. Crest yellow; feathers of the occiput brown, varied with black lines; body golden yellow above, scarlèt beneath, secondary quills blue; tail cuneated. 2 feet 9 inches long. Inhabits China.-Edw. pl. 68, 69.

Gen. 4. LophorHoris, Tem.-Phasianus, Lath.

Bill long, thick, much bent, broad at its base; upper mandible arched, very long, extending much beyond the under one, edged at its extremity ; ridge elevated ; nostrils basal, lateral, half shut by a thinly feathered membrane; tarsus cóvered with feathers on its upper part; a long and sharp spur; three fore toes united by membranes, hind toe elevated; tail short, rounded; head crested.

L. refulgens, Tem. Body above with splendid purple feathers, the margins brass-coloured ; beneath black, with a brassy tinge; tail cinnamon-coloured, rounded. 2 feet long. Inhabits India.Shaw, xi. pl. 15.

L: Cuvieri, Tem. Plumage black, with a violet gloss, the feathers marked with grayish zigzag lines; rump and tail-coverts tipped with a broad white zone; crest composed of long decomposed feathers, with short webs ; cheeks naked. 18 inches long.-Shaw, xiv. pl. 36.

Gen. 5. Polyplectron, Tem.-Diplectron, Vieill. Pavo, Lin.

Bill middle-sized, slender, straight, compressed ; upper mandible bent down towards the tip; nostrils lateral, in the middle of the bill, half covered by a naked membrane; orbits and cheeks naked; legs slender, fore toes united by membranes; vol. I. 
back-toe elevated; the tarsi long, and, in the male, furnished with two or more spurs; tail long, rounded.

P. chinquis, Tem. (Pavo bicalcaratus, Tibetanus, Lin.) Argus Polyplectron. Cinereous, striated with dusky, and spotted with white above; wing-coverts sprinkled with brilliant orbicular cærulean spots, or eyes; under parts of the body gray, undulated with dusky lines ; secondary quills with shining blue spots, and tailcoverts with two shining green spots. 23 inches long. Inhabits China.-Shaw, xi. pl. 7 .

\section{Gen. 6. Meleagris, Lin.}

Bill short and thick, base covered with a naked skin; head and upper part of the neck invested with a naked, tuberculated skin; a loose caruncle on the upper part of the bill; throat with a longitudinal, pendulous, and carunculated wattle; tarsi of the male with an obtuse and weak spur; wings short; tail of eighteen feathers, spreading into a circle.

M. gallopavo, Lin. Common Turkey. Body black above and beneath, and glossed with violet and gold; head and upper part of the neck with a blue papillated and hairy skin; feathers of the tail brown, varied with black. The female has smaller wattles, and is incapable of erecting the feathers of the tail. $3 \frac{1}{2}$ feet long. Inhabits N. America.-Shaw, xi. pl. 8.

In its wild state the Turkey associates in flocks, feeding on wild berries, acorns, or insect food, and roosts on the highest trees. This valuable bird is said to have been originally introduced from America to Spain, and brought to England in 1524.

M. ocellata, Cuv. Head and neck naked; back, rump, and breast golden-green, banded with glossy violet; primaries white, spotted with black; secondaries white; tail-feathers wedge-shaped, griseous, spotted with black, the tip green, shining with violet and gold; bill horny. $3 \frac{1}{2}$ feet long. Honduras. - Shaw, xiv. pl. 35.

\section{Gen. 7. Argus, Tem.}

Bill as long as the head, compressed, straight, with the base naked; upper mandible arched, and bent towards the tip; nostrils lateral, placed in the middle of the bill, and halfclosed by a membrane; head, cheeks, and neck, naked; legs slender; tarsi smooth; fore toes united by membranes, hind toe jointed on the tarsus; tail ascending, compressed, with twelve feathers, of which the two middle are much elongated.

This genus is distinguished from Phasianus by having the secondary wing feathers much larger than the primaries.

A. giganteus, Tem. (Phasianus Argus, Lin.) Argus Pheasant. Lower parts of the neck and under parts of the body red brown, striped with black; back and tail-coverts yellowish, marked with rounded brown spots ; secondary feathers with many ocelli; webs of the quills blue; tail brown-black, spotted with white. The female is brown-black, spotted with yellow and brown, with the 
webs of the quills blue-black, and the two long feathers without spots. 5 feet 3 inches long. Inhabits Surinam.-Shan, xi. pl. 14.

Gen. 8. Numida, Lin.

Bill short, thick, arched, the base covered with a warted membrane, and a carunculated wattle hanging from the under mandible; nostrils situated in the cere, divided by a cartilage; head naked or feathered, the crown with a callous horn or crest ; tarsus smooth; the three fore toes united by membrancs; hind toe jointed on the tarsus ; tail short, bent down.

The species belonging to this genus are originally natives of Africa and the neigh. bouring islands, have the manners of domestic poultry, except that they are less assiduous than some of the other tribes in rearing their young, and have been multiplied for the use of the table in various places.

N. meleagris, Lin. The Pintado or Guinea Fowl. Body grayblue, sprinkled with small white spots; head and upper part of the neck naked; a conical tubercle with its tip reflected on the crown, and a broad geminated membrane near the gape. 22 inches long. Inhabits Africa.-Shan, xi. pl. 17.

This species is now domesticated over all Europe. The two other species of the genus are the $N$. mitrata and cristata, both from Africa.

\section{Gen. 9. Pauxi, Tem.-Crax, Lin.-Ourax, Cuv.}

Bill short, strong, compressed, arched, convex ; base of the upper mandible dilated into a hard and elevated corneous substance; nostrils basal, lateral, open below; tarsus long, smooth, the three fore toes united by membranes; hind toe jointed on the tarsus, but partly leaning on the ground; wings short.

P. galatea, Tem. Galeated Curassow. Body dark-coloured; glossed with green; abdomen and tip of the tail white; base of the bill with a horny blue pear-shaped tubercle. $2 \frac{1}{2}$ feet long. Inhabits South America.-Shaw, xi. 173.

P. mitu, Tem. Body black, glossed with purple and violet; abdomen chestnut; tip of the tail white; ridge of the bill horny, sharp and red; forehead with a dark crest. Brazil._Shaw, xi. 175.

\section{Gen. 10. Crax, Lin.}

Bill long, thick, compressed at the sides, incurved towards the tip, the base covered with a cere, nostrils lateral, placed in the cere, half covered, open in front; top of the head ornamented with revoluted feathers; four toes, of which the three anterior are connected at the base ; tail broad, pendant.

The birds of this genus are easily tamed, and will live with domestic poultry. They feed on fruits and seeds, and nestle on trees.

C. globicera, Lin. Globe-bearing Curassow. Body black; abdomen beneath white ; feathers of the crown contracted and dark coloured; a broad rounded tubercle at the base of the bill about the size of a cherry; cere yellow, and tip of the tail white. Inhabits South America._Shaw, xi. 166. 
C. rubra, Lin. Red Curassow. Body above reddish chestnut-coloured, paler below ; nape and upper parts of the neck with alternate lines of white and black; cere black; tail with nine whitish yellow bands, edged with black ; crest with curled feathers tipped with black. 2 feet 6 inches long. S. America.-Shaw, xi. pl.9.

Gen. 11. Penelope, Lin.

Bill middle-sized, broader than deep, the tip compressed and arched; nostrils lateral, ovate, half-covered, but open in front; cheeks naked; the throat with a longitudinal wattle, carunculated in the middle; tarsi reticulated; fore toes united by membranes, hind toe jointed on the same level; wings short.

P. pipile, Tem. The Yacou Guan. Body dusky violet; neck and breast spotted with white, and a white crest on the head; wingcoverts sprinkled with white spots; temples naked and whitish; wattle blue and downy ; quill-feathers truncated at their tips. 28 inches long. Inhabits Brazil.-Shan, xi.pl. 10.

P. obscura, Tem. Crown and upper part of the neck black; under part of the neck, back, and wings dusky, spotted with white; rump, belly, and abdomen chestnut; tail and quill-feathers black; no crest. 29 inches long. Inhabits S. America.-Shan, xi. 185.

\section{Gen. 12. Tetrao, Lin.}

Bill short and thick, arched above, convex, bent down towards the tip, base naked; nostrils basal, half closed with an arched scale above, and concealed by small feathers; eyebrows naked, with scarlet warts; tarsi feathered; three toes before and one behind, united to the first joint; one toe behind, margined with asperities.

Grous are polygamous birds, the females only taking charge of incubation and rearing the young. They make their nests on the ground, in a very artless manner, of a few small branches of pines, heath-tops, \&c. They produce many eggs, usually breed only once in the year, and the young run about as soon as hatched. Their food consists of seeds, berries, a few insects, the tops of heath, and evergreens. They inhabit the colder and more temperate Jatitudes.

T. urogallus, Lin. Wood Grous, Cock of the Wood, Capercailzie of the Scots. Neck and upper parts of the body dusky, transversely waved with cinereous; feathers of the throat black, elongated, dusky, varied with white spots beneath, axillæ white; breast with green reflections ; tail black, rounded, and its feathers marked with two white spots towards the tip; bill white. 2 feet 10 inches long. Inhabits Northern Europe. B.-Shan, xi. pl. 18.

This species inhabits the wooded and mountainous regions of Europe and northern Asia, occurring abundantly in the pine forests of Russia, Siberia, Norway, Sweden, \&c. It was formerly not uncommon in Ireland and Scotland, but may now be said to be extirpated from both.

T. medius, Meyer. Head and breast black, with bronze reflections; feathers of the throat a little elongated; back and rump shining black; wings blackish, with little zigzag ash-coloured and brown 
spots; base of the secondary feathers white; tail slightly forked; bill black; asperities of the toe very long. 2 feet 3 inches long. Inhabits Northern Europe.-Tem. Man. 459.

T. tetrix, Lin. Black Grous, Black Cock. No long feathers under the throat; the general plumage black, with violet reflections; tail much forked, with the two outer feathers convoluted, and the inferior tail-coverts white. 1 foot 10 inches long. Inhabits Europe. B.-Selby, Illust. pl. 58.

T. Bonasia, Lin. Hazel Grous. Plumage above varied with red, black, and white spots; below, the feathers black, reddish in the middle, and bordered with white; feathers of the head a little elongated; a black band towards the extremity of the lateral tailfeathers ; lower part of the tarsus and toes naked. 13 inches long. Inhabits France and Germany.-Tem. Man. 463.

T. Scoticus, Lath. Red Grous. Plumage of a red chestnut; eyebrows dentated, and very elevated, tarsi and toes covered with gray hairs ; sixteen feathers in the tail, the lateral ones blackish, and terminated with chestnut brown; caruncle above the eyebrows scarlet and lunated. 16 inches long. Inhabits Britain.-Selby, Illust. pl. 59, fig. 1.

T. lagopus, Lin. Ptarmigan or White Grous. Plumage varied with cinereous and white; in summer, quills white, tail-feathers black, with white tips, and the two middle ones entirely white; a black spot between the bill and eyes in the male; eighteen feathers in the tail; legs and toes covered with hairy feathers ; claws crooked, subulate, and black. Europe. B.-Selby, Illust. pl. 59. fig. 2. Ptarmigans haunt the mountainous countries of northern Europe, descending within the range of vegetation to feed on the buds of trees, the young shoots of pines, and heath, mountain berries, rhododendron, \&c. They fly heavily, but run swiftly.

T. saliceti, Tem. (T. albus, Laponicus, Gmel.) Plumage pure white; lateral feathers of the tail black, terminated with white; bill thick, short, depressed towards the point, obtuse; claws long, white, slightly bent. 16 inches long. Plumage in summer chestnut. Inhabits Northern Europe-Tem. Man. 471.

T. phasianellus, Lin. Long-tailed Grous. Body above brownish, varied with dusky; breast chestnut brown, with white spots; sides of the neck and wing-coverts with rounded white spots ; tail wedgeshaped, the two middle feathers elongated, with ocellated spots. 17 inches long. Inhabits Hudson's Bay.-Shaw, xi. 284.

Gen. 13. Ptenocles, Tem.-Tetrao, Lath. Lin.

Bill of medium size, compressed, slender in some species ; upper mandible straight, bent towards the point ; nostrils basal, half shut by a membrane; toes short; hind toe very small, and jointed high on the tarsus; three fore toes united to the first joint ; fore part of the tarsus feathered, the rest naked; tail conical, in some species the two middle feathers elongated and filiform; wings long, acuminated, the first feather longest. 
P. arenarius, Tem. Plumage gray yellow above, black below; a triangular black spot on the throat ; base of the mandible and region of the ears reddish chestnut; a black band from the base of the breast across the wings; tail banded with gray, red, and yellow. 12 inches long. Southern Europe-Tem. Mun. 476.

P. setarius, Tem. Throat black; sides of the head and fore part of the neck yellowish ash-colour; a broad reddish orange band on the breast ; liead, neck, rump, and coverts of the tail banded with black and yellow; lower parts white; two middle tail-feathers long and filiform, three inches beyond the others. $10 \frac{1}{2}$ inches long. Inhabits Southern Europe.-Tem. Man. 478.

\section{Gen. 14. Syrrhaptes, Illig.-Tetrao, Lath.}

Bill short, slender, conical; upper mandible slightly bent, with a groove or furrow along the ridge; nostrils basal, lateral, covered by feathers before; feet with only three toes, directed forwards, and united to the claws; tarsus and toes covered with woolly feathers; tail conical, the two middle feathers elongated and filiform, as are also the first and second wing-feathers.

S. Pallasii, Tem. ( $T$. paradoxus, Pall.) Head and neck as far as the throat hoary; chin yellowish; back undulated with gray and black; abdomen black, with pale spots; sides of the neck with a fulvous spot. Inhabits Southern Tartary.-Shaw, xiv. pl. 37.

\section{Gen. 15. Perdix, Lath.-Tetrao, Lin.}

Bill short, compressed, stout, base naked ; upper mandible arched, convex, strongly curved towards the tip; nostrils basal, lateral, half closed by an arched and naked membrane; the three anterior toes united by membranes to the first joint; - tail composed of eighteen or of fourteen feathers, short, rounded, and slanting downwards; wings short.

These birds, which are stationary in some countries, and migratory in others, are greatly multiplied in the warm and temperate regions of the globe, living in pairs, and steady in their family attuchments. The greater number frequent fields and open tracts of country, but some prefer the outskirts of woods in the neighbourhood of water. They feed on grain, seeds, bulbous plants, insects, and worms. They run more frequently than fly, get up from the ground with an effort, and make a whirring noise when on the wing. 'They generally have numerous broods, and the young run about as soon as hatched.

* Males with one or two spurs.

P. francolinus, Lath. Feathers of the head and nape black, bordered with reddish yellow; a white band below the eyes ; a chestnut collar around the neck; throat and lower parts black; wings brown; back and rump banded with black and white; legs reddish, spurs brown. 12 or 13 inches long. Inhabits Southern Europe.-Willough. pl. 31.

** Tarsus furnished with a callosity, or entirely smooth.

P. saxatilis, Meyer. Plumage above and breast bluish ash-coloured; 
cheeks, throat, and fore part of the neck white, with a black band; a narrow black band on the flanks; bill, around the eyes, and legs red. 13 inches long. Southern Europe.-Tem. Man. 484.

P. rubra, Briss. Throat and cheeks white, surrounded by a black band, which spreads on the sides of the neck into a number of spots and stripes of the same colour; a broad white band above the eyes; upper parts of the body reddish gray; belly red ; eighteen feathers in the tail. 12 inches long. Inhabits Southern Europe._Lewin's Brit. Birds, iii. pl. 137.

P. petrosa, Lath. Forehead, top of the head, and nape, deep chestnut, spreading on the sides of the neck into a broad collar; throat, temples, and a broad band above the eyes bluish ash-colour; upper parts of the body reddish-gray; wings with from 8 to 10 spots of turquoise blue, bordered with orange ; tail of 18 feathers. 12 inches long. Inhabits rocky Mountains of Europe.-Tem. Man.487.

P. cinerea, Lath. Common Partridge. Plumage gray, varied with red and black above; yellowish-white beneath, varied with black lines and rufous spots; a broad chestnut spot of a horse-shoe form on the top of the belly, tail-feathers 18, the seven outer ones on each side tipped with cinereous. 12 inches long. Inhabits Europe. B.-Selby, Illust. pl. 61.

\section{***. Bill deeper than broad; orbits naked; tail short.}

P. Virginiana, Lath. Body above brown-chestnut, varied with rufous and black; white beneath, transversely waved with dusky; eyebrows and throat white; jugulum with a black lunule; lateral tail-feathers gray.-Wils. Amer. Orn. vi. pl. 47, fig. 2.

**** Tail very short, concealed by the feathers of the rump; first quill-feather the longest.

P. colurnix, Lath. (Tetrao, Lin.) Common Quail. Body rusty gray, varied with black spots; shafts of the feathers yellowish; eyebrows and a longitudinal stripe on the crown white; throat rufous. Female paler, with the throat white, and two blackish brown bands. 7 inches long. Europe. B.-Selby, Illust. pl. 62. Quails are very generally distributed over the world. They arrive in Britain in spring for incubation, and leave this country in August. With wind and weather in their favour, they have been krown to perform a flight of fifty leagues, across the Black Sea, in the course of a night. Clouds of them also alight in spring along the shores of Provence, where they are sometimes found so exhausted, that for a few days at first they may sometimes be caught with the hand. The males fight fiercely for the females; and from their pugnacious disposition, they were exhibited in regular combats both by the Athenians and Romans. The practice of quail.fighting is still cherished in China, Sumatra, and some districts of Italy. Quails are killed in great numbers for the table.

Gen. 16. Cryptonyx, Tem.-Perdix, Lath. Liponyx, Vieill. Bill short, thick, compressed; mandibles of equal length, the upper one straight and a little bent at the point; nostrils lateral, longitudinally cleft, towards the middle of the bill, covered above by a broad naked membrane; tarsus long; three toes 
before, united at their base; hind toe not touching the ground, and without claw; wings short.

C. coronatus, Tem. Chestnut crest on the occiput ; six long bristles at the base of the bill; crown with a white streak; body dark violet; back and feathers of the rump dark green ; temples naked. 10 inches long. Inhabits Sumatra. - Shan, xi.pl. 16. - The only species of the genus.

\section{Gen. 1\%. Tinanus, Lath.-Tetrao, Gmel.}

Bill slender, straight, depressed; broader than deep, tip rounded, ridge distinct, forming a large nasal furrow ; nostrils lateral, pierced in the furrow, ovate; tarsus lorig, frequently with asperities behind; toes short, entirely divided; hinder one very short; tail wanting, or very short; wings short.

The birds of this genus are all natives of South America, where they live on fruits, wild berries, and insects. They fly heavily, and run quickly, seldom perching, except to pass the night, and then only on the lowest branches of trees.

T. rufescens, Tem. Rufescent Tinamoo. Grayish-red, transversely striped with black and white above; margin of the wings rufous red; region of the ears black; sides and abdomen grayish. $15 \frac{x}{2}$ inches long. Inhabits Paraguay.-Shaw, xi. 403.

T. Brasiliensis, Lath. (Tetrao major, Gmel.) Brazilian or Great Tinamoo. Olive brown, slightly striated across with black above ; grayish-red beneath; crown rufous; the secondary quills transversely striated with rufous and black. 18 inches long. Inhabits Brazil._Shaw, xi. 406.

Gen. 18. Hemipodius, Tem.-Tetrao, Lin.-Perdix, Lath.

Bill slender, straight, much compressed, with an elevated ridge, and bent towards the point; nostrils lateral, linear, partly shut by a naked membrane; tarsus long; three toes before; no posterior toe; tail with slender feathers, concealed by the upper coverts ; first wing-feather the longest.

The birds of this genus, the smallest of the gallinaceous order, inhabit the barren countries on the confines of great deserts. They run rather than fly, and with a surprising speed. They are solitary birds, never unite in flocks, and their principal food is insects.

H. tachydromus, Tem. Top of the head blackish brown, with three reddish yellow longitudinal bands; throat white; breast red, bordered with yellowish feathers, which have a black spot at some distance from their point; belly white; back black, with zigzag black and red stripes. 6 inches long. Inhabits Southern Europe. -Shaw, ix. pl. 25.

H. lunatus, Tem. Back brown, transversely banded with black; wing-coverts red, bordered with white; a black spot, surrounded with white, in the middle of each feather; throat black; tail-feathers bordered with white and striped with black and whitish; legs and bill yellow. 6 inches long. Inhabits Southern Europe.

-Tem. Man. 495. 


\section{ORDER XI.-ALECTORIDES.}

Bill shorter than the head, or of the same length; strong, robust; upper mandible convex, and often hooked at the point; tarsus long and slender; three toes before and one behind, the hind toe articulated higher up than those before.

This order, established by Temminck, is composed, with the exception of one, of exotic species. This author arranges the genera which compose it into those which frequent the open country and those which inhabit the banks of streams. The former inhabit deserts, where they are continually in pursuit of reptiles and lizards ; and the latter feed chiefly on insects and worms.

\section{Gen. 1. Psophra, Lin.}

Bill short, conical, curved, much bent at the tip ; upper mandible longer than the under; the nasal furrow wide and extended; nostrils near the middle of the bill, wide, diagonal, closed behind by a naked membrane; legs long and slender, the middle and external toe united, the internal separated; hind toe articulated interiorly, and on a level with the others; wings short and concave; tail very short.

P. crepitans, Lin. Golden-breasted Agami or Trumpeter. General plumage black ; back gray ; breast blue, with a green gloss ; orbits naked and red ; feathers of the head and neck short and downy, those of the lower part of the neck squamiform, of the shoulders ferruginous, lax, pendulous, and silky ; scapulars long and pendant. 22 inches long. S. America.-Shaw, xiv. 318.

Gen. 2. DichoLophus, Illig._Lophorhynchus, Vieill._Palamedea, Lath.

Bill longer than the head, thick, arched, cleft to under the eyes, depressed at the base, compressed at the tip, which is a little hooked; nasal furrow large; nostrils small, covered with a membrane; legs long and slender; toes very short and thick, the anterior ones united at the base by a membrane, the hind toe articulated to the tarsus, and not touching the ground; claws short and strong; wings spineless.

D. cristatus, Illig. (Palamedea cristata, Lath.) Crested Dicholophus. Feathers of the body and of the upper part of the head white ; those of the neck, throat, and breast whitish-brown, long, with very feeble shafts, and lax webs. Brazil._Shaw, xii. pl.34. This bird, the only one of the genus, frequents the outskirts of dry and elevated forests, and particularly stony hills, feeding chiefly on terrestrial reptiles and insects.

Gen. 3. Glareola, Briss.

Bill short, convex, compressed towards the tip; upper mandible curved from the half of its length ; nostrils basal, lateral, and obliquely cleft; legs feathered to the knee; tarsi long and slender, the middle toe united to the outer by a short mem- 
brane, and the inner separate; hind toe jointed on the tarsus ; claws long and subulate; wings very long.

The birds of this genus inhabit the warm and temperate regions of the old continent, affecting the banks of fresh and limpid waters; and very rarely appearing on the sea-shore. Their principal food is worms and very small insects. They run with great agility, and are capable of long and rapid flights.

G. torquata, Meyer. Collared Pratincole. Top of the head, nape, back, scapulars, and coverts of the wings brown gray; throat and fore part of the neck reddish white, bordered by a narrow black band, which rises to the corners of the bill; space between the eyes and bill black; coverts of the tail and origin of the feathers white; tail blackish towards the end; naked circle round the eyes red. $9 \frac{1}{2}$ inches long. Europe.-Selby, Illust. pl. 63.

G. grallaria, Tem. Tail almost square, longer than the wings by three inches; tibia in a great part naked; tarsus very long; plumage above and breast bright red; throat, abdomen, and tailcoverts white; belly chestnut; quills black. Inhabits Australasia.-Tem. Man. 503.

G. lactea, Tem. Tail slightly forked; upper parts of the body and wings grayish white; quills and interior of the wings black; under parts white; tail-feathers, the exterior excepted, with a black spot, their union forming a large angular space. $5 \frac{1}{2}$ inches long. Inhabits India.-Tem. Man. 503.

Gen. 4. Palamedea, Lin.

Bill short, conico-convex, much curved at the point, compressed throughout its length; nasal furrow large; head small, covered with down, and armed with a slender and flexible horn; nostrils remote from the base of the bill, lateral, oval, open ; legs short, thick; toes very long, the lateral connected with the intermediate by a short membrane; wings ample, and spurs on the winglets.

P. cornuta, Lath. Kamichi or Horned Screamer. Body blackish above, white beneath; under side of the wings reddish; bill and legs black; irides golden; horn three or four inches long, and two or three lines thick at the base, which is inclosed in a sheath; two strong triangular spurs on each winglet. 2 feet 4 inches long. Inhabits S. America.-Shan, xii, pl. 35.

\section{Gen. 5. Chauna, Illig.-Parra, Lin.}

Bill shorter than the head, conico-convex, slightly arched, curved at the tip; base furnished with small feathers; lores. naked; nostrils oblong; legs long, slender; toes long, united by membranes; wings armed with two spurs.

C. Chavaria, Tem. Body above brown; neck and abdomen black; temples and throat white; occiput with pendant blackish feathers. Size of the domestic cock. S. America.-Shaw, xii. 272. 


\section{ORDER XII.-CURSORES.}

Bill middle-sized, or short; legs long, naked above the knee; and with only two or three toes, directed forwards.

The birds which compose this order live always in the fields, and most frequently in desert places, remote from woods. They are polygamous, and feed on herbs, seeds, and insects. Some few of the species are incapable of flight, and others fly little and near the ground. They run, however, with great celerity, not only when pursued, but habitually, and differ, in this respect, from the greater number of the waders, which walk by measured steps. All of them capable of rising from the ground stretch their legs backwards in flight.

\section{Gen. 1. Strutrhio, Lin.}

Bill obtuse, straight, depressed at the tip, which is rounded and unguiculated; mandibles equal and flexible; nostrils near the middle of the bill ; legs very long, robust, and muscular, with only two strong toes directed forwards, but the inner much shorter than the outer; the former provided with a large and blunt claw, the latter clawless; tibia very fleshy to the knee; wings unfit for flight, being composed of long, soft, and flexible feathers, and armed with a double spur.

S. camelus, Lin. The Ostrich. Body black, the feathers varied with white and gray; primary quills and tail-feathers white; the female brown or ash gray, where the male is black. Inhabits Africa and Asia.-Shaw, xi. pl. 27.

This is the largest species of the feathered tribe, weighing about eighty pounds, and often measuring upwards of eight feet in height, and as many in length, from the tip of the bill to the end of the tail ; but, from the ground to the top of the back it seldom exceeds four feet, the rest of its height being made up by its extremely long neck, the greater part of which is flesh-coloured, with a few scattered hairs. The feathers on the body are lax and waving, the webs on both sides being equal, and incapable of locking into a compact whole. There are two alar spurs, namely, one on the end of the wing, and another on the spurious wing. These birds run with great rapidity. The natural aliment of the ostrich is entirely of a vegetable description, as grass, fruits, grain, \&c. and they may frequently be seen pasturing with the zebra and quagga. Yet so keen is their voracity that they will often swallow hard, and even noxious matters, as wood, plaster, glass, stones, lead; copper, \&c. "I saw one at Oran," says Dr Shaw, " that swallowed, without any seeming uneasiness or inconvenience, several leaden bullets, as they were thrown upon the floor, scorching hot from the mould." According to Adanson, the ostrich is able to run with a full grown man on its back.

\section{Gen. 2. Rhea, Briss.-Struthio, Lin.}

Bill straight, short, soft, depressed at the base, a little compressed at the tip, which is obtuse; lower mandible much depressed, flexible, and rounded at the tip; nostrils on the lateral surface of the bill, large, longitudinally cleft, and open; legs long, with three toes before, and a callosity behind; wings short, with feathers more or less long, and terminating in a spur.

B. Americana, Tem. American Ostrich. Body white, wings and 
back obscurely gray. About 6 feet in height. Inlabits S. America. -Shaw, xi. pl. 28.

This bird is somewhat less than the ostrich, being about six feet in height, of which the neck is two feet eight inches. The wings stretch from tip to tip no less than eight feet ; but, on account of the webs being disunited, they are useless in flight, hanging over, and hiding the tail, which is composed of short feathers of equal length.

Gen. 3. Dromiceus, Vieill.-Casuarius, Lath.

Bill straight, the edges greatly depressed, tip rounded; head feathered ; throat naked ; feet three-toed, the toes placed before ; wings very short.

D. Nove Hollandia. The Emu. Body hairy, colour brown and gray mixed, paler on the under parts; head and neck feathered; tibiæ serrated behind; wing quills feathered. Nearly seven feet long. Inhabits New Holland.-Shaw, xiv. pl. 39.

\section{Gen. 4. Casuarius, Briss.-Struthio, Lin.}

Bill straight, short ; compressed, rounded towards the point; ridge keeled, and a bony rounded protuberance at the base ; inferior mandible soft, flexible, and angular near the extremity; nostrils round, in the lateral part of the point of the bill; legs muscular, with three toes placed forwards, the inner short, and armed with a very long and strong claw; tibix almost entirely covered with feathers; wings not adapted for flight.

E. galeatus, Steph. Galeated Cassowary. Body black, crowngaleated; body hairy ; head and part of the neck naked and bluish ; crest or horny protuberance on the head reaching from the base of the bill to the middle of the crown; a pendant caruncle on each side of the neck. $5 \frac{1}{2}$ feet long. Inhabits India.-Shaw, xi. pl. 29.

\section{Gen. 5. Oris, Lin.}

Bill straight, conical, compressed; tip of the upper mandible slightly arched; nostrils open, oval, approximated, but remote at the base; legs long, naked above the knee; three toes before, short, united at their base and bordered by a membrane; wings of medium length, third quill-feather longest.

These are heavy birds, which fly little, and are extremely shy. When fatigued in the course, or on the point of being captured, they graze along the ground with a rapid and well sustained flight. They inhabit corn-fields or bushy plains, and feed on herbs, grains, seeds, and insects. One male is attended by several females.

\section{* Mandibles compressed at the base.}

O. tarda, Lin. The Great Bustard. Head, neck, breast, and margin of the wings bluish-gray; a black streak along the crown of the head; upper parts of the body reddish yellow, striped with black; under parts white; tail white at its base, brownish orange in the middle, and crossed by two black bars; a tuft of long wiry-feam thers, with the webs disunited, at the base of the under mandible. 3 feet 3 inches long. Europe. B.-Selby, Illust. pl. 64 . 
O. tetrax, Lin. The Little Bustard. Variegated with black, rufous and white, with black zigzag markings above; white beneath; neck black, with a double white ring. Collar of the female of the same colour as the back, and the breast rufous-white, streaked with dusky. 18 inches long. Europe. B.-Selby, Illust. pl. 65.

** Mandibles depressed at the base.

O. houbara, Lin. Bill long, depressed at the base; a large tuft of slender feathers on the head; similar feathers on the sides of the neck; body above yellow, spotted with brown; beneath white; tail ochreous, with black fasciæ, and white tips. 2 feet long. Inhabits Barbary and Arabia; sometimes found in the South of Europe.-Tem. Man. 509.

\section{Gen. 6. Cursorius, Lath.-Charadrius, Gmel.}

Bill shorter than the head, depressed at the base, curved towards the end and pointed; nostrils oval, surmounted by a small protuberance; legs long and slender; toes, three before, very short, and entirely divided, the interior one shortest; claws very small, second wing-feather the longest.

The species belonging to this genus hitherto discovered are few, and these natives of the warmer parts of Africa and Asia. In Europe one species only is an accidental visitor.

C. Isabellinus, Meyer. Swiftfoot. General plumage buff-orange or senna-yellow, palest upon the belly and wing-coverts; a double black band behind the eye, going to the occiput; quills black; lateral feathers of the tail black toward the tip. 9 inches long. Inhabits Europe. B:-Lewin's Brit. Birds, i. pl. 187.

C. Asiaticus, Lath. Crown of the head red ; breast and neck chestnut ; nape, wings, and tail brown ; rump, coverts, and extremity of the tail-feathers white; bill black. 8 inches long. Inhabits India.-Tem. Man. 514.

C. bicinctus, Tem. Top of the head brown, varied with reddish; cheeks and neck yellow, with longitudinal brown stripes; a double nuchal collar, the lower black, as are the quills, the upper white. 8 inches long. Inhabits Africa.-Tem. Man. 515.

\section{ORDER XIII.-GRALLATORES.}

Bill of various forms, but most frequently straight, in the form of an elongated cone, and compressed, more rarely depressed, or flat; legs slender, long, more or less naked above the knee, three toes before and one behind, the posterior one jointed at the level of those before, or more elevated.

The birds included in this order are almost all semi-nocturnal, stalking along the margin of the sea, lakes, or rivers, and feeding on fish or their fry, reptiles, worms, or insects. Those which have a hard bill feed on fishes and reptiles; those with a 
soft or flexible bill on worms and insects. All are furnished with long wings, suited to the extensive migrations which they undertake at stated seasons, and for which purpose they associate in numerous bands, the young and the old travelling separately. They extend their legs behind when they fly, and their walk is slow, and as it were by measured steps. They are divided into two sections; those which have three toes only forming the first, and the others with a hind toe forming the second. Many of them enter into the water without swimming, but they are capable of the latter, and even of diving when occasion requires.

\section{FamrLY I.-With three toes only.}

Gen. 1. Edicnemus, Tem.-Otis, Lath.-Charadrius, Lin.

Bill longer than the head, straight, strong, compressed at the tip, the ridge carinated; lower mandible forming an angle with the upper; nostrils placed in the middle of the bill, longitudinally cleft, and open in front; legs long and slender, with three toes before, united to the second joint by a membrane, which extends along the toes; tail distinctly wedge-shaped.

CE. crepitans, Tem. Thick-kneed. Bustard. Gray-brown, with dusky longitudinal lines above, the two primary quills white in the middle; a longitudinal white band on the wings ; belly and thighs white; knees thick, as if gouty. 18 inches long. Inhabits Europe. B.-Shaw, xi. pl. 33.

E. magnirostris, Tem. Body above bluish, striated with black; beneath grayish ; quills with a white spot; feet blue. Inhabits New South Wales.-Shan, xi. 462.

E. longipes, Vieill. Crown, back, and wings blue-gray, marked with black streaks, largest on the back and crown; beneath the eyes on the ears a large patch of brown. Inhabits New South Wales.-Shaw, xii. 184.

Gen. 2. CAlivRIs, Illig.-Tringa, Lin. Charadrius, Lath. Bill middle-sized, slender, straight, soft, flexible in its whole length, compressed from the base, depressed towards the tip, flattened and obtuse; nostrils lateral, and longitudinally cleft; legs slender, with three toes before, almost entirely divided; wings middle-sized, the first quill-feather longest.

C. arenaria, Illig. (Tringa, Lin.) The Sanderling. Upper parts and sides whitish ash-coloured, with a deeper line on the centre of each feather; throat, face, and lower parts white; border of the wings black; tail ash-coloured, margined with white. 7 inches long.-Shan, xi. pl. 35.

The Sanderling, the only species of the genus, is found in Europe and the north of Asia and America, frequenting the sea-shores, especially in spring and autumn, and feeding on minute marine insects and worms.

Gen. 3. Falcineruus, Cuv.-Numenius, Lath.

Bill arched, soft, compressed in its whole length, depressed at the point; nasal furrow elongated; nostrils basal, lateral, linear; tarsus longer than the middle toe; only three tocs, directed anteriorly. 
F. pygmaeus, Pigmy Curlew, Penn. Head and occiput dusky brown, divided by two longitudinal rufous bands; back and scapulars black, edged with rufous; quills and outer tail-feathers margined with white; body beneath and rump white. $6 \frac{1}{2}$ inches long. Inhabits Europe. B.-Shan, xii. pl. 6. The only species of the genus.

\section{Gen. 4. Himantopus, Briss.-Charadrize, Lin.}

Bill long, slender, cylindrical, flattened at the base, compressed at the point; mandibles laterally channelled to the half of their length; nostrils lateral, linear, long; legs very long and slender, with three toes before, of which the intermediate is united to the outer by a broad membrane, and to the inner by a rudimentary one; claws very small and flat; wings very long, the first much longer than the others.

H. melanopterus, Meyer. Black-winged Long-Shanks. Face, neck, breast, and lower parts white, with a slight rose tint on the breast and belly; occiput and nape blackish, with white spots ; back and wings black, with greenish reflections; tail ash-coloured; legs very long. 14 inches long. Inhabits Europe. B.-Shan, xii. pl.23. This is the longest legged bird in proportion of any known species, its limbs being, in fact, thrice as long as its body, and extremely slender. Though generally spread over the world, it is scarce in many countries. In Britain it is very rare.

H. nigricollis, Vieill. (Recurvirostra himantopus, Wils.) Body black above; forehead and lower parts white ; tail ash-coloured; bill black; legs red. N. America.-Wilson's Amer. Orn. pl. 58.

\section{Gen. 5. Hamatopus, Lin.}

Bill long, stout, compressed, tip much compressed and cuneated; nostrils lateral, longitudinally cleft in the channel of the bill; legs strong and muscular, with three toes before, the middle one united to the first joint, and the inner margined by a rudimentary membrane; wings middle-sized, the first quill longest.

H. ostralegus, Lin. The Oyster-Catcher. Head, neck, top of the breast, back, wings, and tail, deep black ; collar, under the throat, rump, origin of the quill and tail-feathers, and all the lower parts white; bill and naked circle round the eyes orange. $15 \frac{1}{2}$ inches long. Inhabits coasts of Europe, B.-Shaw, xi. pl. 36.

This species feeds on marine insects, shell-fish, and mollusca, and derives its name from insinuating its bill into the open shells of oysters.

H. palliatus, Tem. Differs from the preceding in the brown ashcolour of the back, scapulars, and wings, and larger bill.-Inhabits South America-Tem. Man. 532.

H. niger, Cuv. Plumage totally black; bill and legs coral red. A little larger than the common oyster-catcher. Inhabits Africa. -Tem. Man. 533.

Gen. 6. Charadrius, Lin.

Bill shorter than the head, slender, straight, compressed; man- 
dibles gibbous towards the tip; nostrils longitudinally cleft in the large membrane which covers the nasal furrow; legs slender, with three toes before, the outer connected to the middle one by a short membrane, and the inner divided; tail slightly rounded or even; wings middle-sized, the second quill-feather longest.

Plovers frequent watery situations, the marshy banks of rivers, or the sea-shore, and feed on small worms and aquatic insects. The greater part of them live in little bands, and migrate in flocks more or less numerous, the old preceding the young in these annual journeys. Some foreign species have spurs on the wings, and many have fleshy excrescences on the head or mandibles.

C. pluvialis, Lin. Golden or Green Plover. Upper parts of the body, wings, and tail sooty black, marked with spots of golden yellow on the margins of the webs. $10 \frac{1}{2}$ inches long. Inhabits Europe, B.-Shaw, xi. pl. 34.

C. morinellus, Lin. The Dottrel. Top of the head and occiput blackish ash-colour; eye-brows reddish white, uniting on the occiput; upper parts blackish ash-colour, tinged with greenish; breast and flanks with a reddish tinge; a line on the breast, and the middle of the belly white; tail terminated with white. Inhabits Europe, B.-Penn. Brit. Zool. ii. pl. 73.

C. hiaticula, Lin. (C. torquatus, Leach.) Ringed Plover. Graybrown above, white beneath; breast black ; forehead dusky, with a white stripe; crown of the head brown; bill three-fourths orange red, tip black; legs orange. 7 inches long. Inhabits Europe-Lenin's Brit. Birds, v. pl. 184.

C. minor, Meyer. Occiput and upper parts gray brown, under parts white; frontal band, and a line on the breast black; bill entirely black; legs yellow. Inhabits Europe--Tem. Man. 542.

C. Cantianus, Lath. The Kentish Plover. Head and neck of a bright red; upper parts brown gray ; two large black or brown spaces on the sides of the breast ; quill-feathers with white shafts ; bill and feet black. $6 \frac{1}{2}$ inches long. Inhabits Europe, B.Lewin's Brit. Birds, pl. 185.

C. nigrifrons, Tem. Reddish brown, longitudinally striped with white ; beneath white; with the forehead, a stripe on the crown, and another behind the eyes, and a band on the breast black. 6 inches long. Inhabits New Holland.-Tem. Pl. Col. 47, fig. 1.

FaMILY II.-With four toes.

Gen. \%. Vaneluus, Briss.-Tringa, Lin.-Squatarola, Cuv.

Bill short, slender, straight, compressed, tip gibbous; nostrils lateral, longitudinally cleft; legs slender, with three toes before and one behind, the middle toe connected with the outer by a short membrane, and the.hinder one almost obliterated, or very short, not touching the ground; wings elongated.

In some of the forcign species the base of the wing is armed with a long and sharp spur, and a few have wattles or a crest. The two indigenous species undergo 
a double moult, and, like other vermivorous birds in this country, are migrants. The plumage of both sexes is the same.

\section{* With the first quill-feather longest.}

V. melanogaster, Bechst. Forehead, throat, and middle of the belly, thighs, abdomen, and upper coverts of the tail white; fore part of the neck, eyebrows, sides of the breast and flanks varied with brownish spots; upper parts brownish black, with yellowish green spots; tail white, but reddish towards the end, banded with brown. 10 inches long.-Shaw, xi. 505.

\section{** With the three exterior quill-feathers graduated, the fourth and fifth the longest.}

V. cristatus, Meyer. (Tringa vanellus, Lin.) The Lapwing. Top of the head, crest, fore part of the neck, and breast black ; upper parts deep glossy green ; sides of the neck, belly, and base of the tail, white ; tail-feathers terminated with a large black space, except the exterior feather; occipital feathers long, slender, and turned upwards. $12 \frac{1}{2}$ inches long. Europe, B.-Shan, xi. pl. 38.

In France, and some other countries, the great body of Lapwings is migratory; but in Britain most of them seem to remain the whole year, congregating in large flocks in autumn. On dry ground, though usually near some marsh, the female prepares a little bed of grass, on which she lays four olive-coloured eggs, spotted with black, with their narrow ends in contact, so as to occupy little space. On these she sits about twenty days; and the young are able to run within two or three days after they are hatched, though they are incapable of flying till they are nearly full grown. The parent shows them the greatest attachment, and practises her wiles to allure boys and dogs from their retreat. When as near them as she can venture with safety, she rises from the ground with a loud screaming voice, as if just flushed from hatching, though possibly not within a hundred yards of her nest. She now flies with great clamour and apparent anxiety, whirring and screaming, striking at her disturbers with her wings, and sometimes fluttering as if wounded. To complete the deception, she becomes still more clamorous as she recedes from the nest. If very near it, she appears to be altogether unconcerned; and her cries subside in proportion as her fears increase. The food of the lapwing consists chiefly of worms, which it draws from their holes, beating the ground around the worm casts to make them rise.

Gen. 8. Strepsilas, Illig.-Tringa, Lin.

Bill middle-sized, hard at the point, strong, straight, slightly bent upwards, ridge flattened, tip truncated; nostrils basal, lateral, half closed by a membrane; a short naked space above the knee; the three anterior toes connected at the base by a very short membrane, and the hinder one articulated to the tarsus; wings acuminated.

S. collaris, Tem. The Turnstone. Plumage varied with black, white, and ferruginous above; abdomen white; under parts of the cheeks and neck black; base and tip of the tail white, the middle black. 8 inches long. - Inhabits Europe. B.-Shaw, xi. pl. 39.

The Turnstone, the only species of the genus, inhabits both the old and new continent, but is more common in the northern than in the southern regions. Though not known to breed in Britain, it visits some of our shores in August, and departs in spring. It las its vernacular name from its habit of turning up stones, to get at worms and marine insects. It is found only on the coast.

vol $I$. 


\section{Gen. 9. Grus, Pallas.-Ardea, Lin.}

Bill as long as, or longer than the head, strong, straight, compressed, obtuse towards the tip; lateral base of the mandible deeply sulcated, ridge elevated; nostrils in the middle of the bill closed behind by a membrane; region of the eyes and base of the bill naked and papillous, or covered with feathers; legs long, with a large naked space above the knees, the middle fore toe united to the outer by a rudimentary membrane, the inner divided; hind toe articulated higher on the tarsus.

Cranes are periodical migrants, frequenting marshy places, and rarely the scashore, subsisting on herbs, seeds, worms, frogs, slugs, \&c. There are several species, but only one-indigenous to Europe. In most the trachea of the male is of a particular construction, having several convolutions.

G. cinerea, Bechst. (Ardea grus, Lin.) Common Crane. Body cinereous ; throat, fore part of the neck, and occiput dusky; forehead and space between the eye and bill with black hairs; top of the head red and naked; some of the secondary quills arched, long, and with divided webs. 3 feet 8 or 10 inches long. Inhabits Europe and Asia._Shaw, xi. pl. 40.

These birds inhabit Europe and Asia, and in autumn regularly migrate in flocks to the southern parts of Asia and Africa. They were formerly not uncommon in the fenny districts of England. In France they make their appearance from September to Novembcr, but only as passengers southward; and they return in March and April, on their way to the north, which is their breeding station. In winter they resort in crowds to Egypt, and the warmer parts of India. In their migratory expeditions they fly very high, and arrange themselves in a triangular form, the better to cleave the air. Whon the wind freshens, and threatens to break their array, they collect their forces into a circle; and they adopt the same disposition when menaced by the eagle. They travel chiefly in the night, and betray their course by their loud screams. During their nocturnal voyages, the leader frequently calls to rally his troops, and to point out the track, and the signal is repeated by the flock, each individual answering, as if to give notice that it follows, and keeps its rank. Their cries during the day are conceived to forebode rain, and their noisy tumultuous screams to announce a storm. The flesh of the Crane was prized by the Romans as a delicacy; and it was also formerly used at table in England.

G. pavonina, Tem. (Ardea pavonina, Lin. Anthropoides, Vieill.) Balearic Crane. Bluish, with the head black, adorned with an erect hairy yellowish crest; wings white; tail black. 2 feet 9 inches long. Inhabits Africa.-Edw. pl. 192.

G. virgo, Tem. (Ardea virgo, Lin.) Numidian Crane. Body bluegray, the head and tip of the primary quills black; behind the eyes, on each side, a recurved, elongated, and feathery white crest; feathers of the breast long and pendant. 3 feet 3 inches long. Inhabits Asia and Africa.-Edw. pl. 134.

\section{Gen. 10. Aramus, Vieill.-Grus, Cuv.}

Bill longer than the head, straight, hard, inclined at the point, which is gibbous; lower mandible tumid towards the middle, angular, pointed; nostrils lateral, distant from the base of the bill; legs long; toes entirely divided, the hind one articulated posteriorly; third wing-feather longest. 
A. scolopacea. (Ardea, Lath.) Plumage coppery brown, with the neck and breast striped with white; throat black. 25 inches long. Inhabits Cayenne. Shaw, xi. 540.-The only species of the genus.

\section{Gen. 11. Ardea, Lin. Tem.}

Bill as long as or longer than the head, strong, straight, compressed, pointed; upper mandible slightly sulcated, ridge rounded; nostrils lateral, placed almost at the base of the bill, longitudinally cleft in a groove, and half closed by a membrane; orbits and lores naked; legs long and slender, with a naked space above the knee; the middle toe connected with the outer by a short membrane ; claws long, compressed, that of the middle toe dentated interiorly.

The birds of this genus reside on the banks of lakes or rivers, or in marshy situam tions, subsisting on fish and their spawn, testacea, field-mice, frogs, insects, snails, worms, \&c. Many of them nestle together. In flight their neck is contracted and bent over the back, while their legs are stretched out behind. -They migrate periodically in large flocks, and moult once in the year. The sexes resemble each other; but the young differ much in appearance from the adults.

* Bill much longer than the head; upper mandible nearly straight; a great portion of the tibia naked.

A. cinerea, Lath. Common Heron. Plumage of a bluish ash-colour; a long tuft of pendulous black feathers on the occiput, and a similar one of silvery white ones hang from the base of the neck; scapulars elongated, silvery; forehead, neck, middle of the belly, margins of the wings, and thighs, white; sides of the breast and flanks deep black; on the fore part of the neck large longitudinal black and ash-coloured spots; middle toe and claw much shorter than the tarsus. 3 feet long. Inhabits Europe. B. -Penn. Brit. Zool. ii. pl. 3.

The Common Heron is dispersed over most of the countries of the world. In some latitudes it is migratory, and in others stationary, though it frequently clianges its residence without "varying the climate. It chiefly haunts woods in the neighbourhood of lakes, rivers, or swamps. Having waded as far as it can into the water, it patiently awaits the approach of its prey, and seizes it with undeviating aim. The heron has a demure and melancholy air, and is extremely shy, and impatient of confinement; but the young are capable of being tamed. They fly very high in the air, especially before rain. In the day time they are often inactive, or indulge in repose. Although in general shy and solitary in their habits, herons are gregarious during the breeding season, and many of them build their nests in the same place, which is called a heronry. The eggs are usually four; but sometimes five or six, of the size of those of a duck, and of a greenish-blue cast. When the female incubates, the male fishes for her, and fetches a portion of his captures.

A. purpurea, Lin. The Purple Heron. Plumage of a bright red, or reddish ash-colour; tuft of slender blackish green feathers on the occiput, and purplish white at the base of the neck ; scapulars elongated, and purple red; top of the head and occiput black, with green reflections; throat white; lateral parts of the neck red, with three narrow black bands; fore part of the neck with longitudinal, red, black, and purple spots ; flanks and breast purple. 2 feet 9 inches long. Inhabits Europe. B.-Lewin's Brit. Birds, iv. pl. 151. 
A. egretla, Lin. Great Egret. Plumage pure white; a pendant crest on the head; some long feathers on the back, with strong shafts and loose slender webs; legs long, slender; a large naked space above the knee; claws very long. 3 feet 2 inches long. Inhabits Europe. B.-Lewin's Brit. Birds, iv. pl. 150.

A. garzetta, Lin. Little Egret. All the plumage pure white; occiput with a pendant crest of two or three long and narrow feathers; a large tuft of similar feathers at the base of the neck; feathers of the upper part of the back elongated and silky; bill bluish. 2 feet long. Inhabits S. Europe. B.-Shaw, xi. pl. 41. ** Bill as long as, or a little longer than the head, much compressed; upper mandible slightly bent.

A. nycticorax, Lin. Night Heron. Head, occiput, back, and scapulars, black, with blue and greenish reflections; three long white feathers on the nape ; lower part of the back, wings, and tail ash-coloured ; forehead, space between the eyes, throat, and lower parts white; bill black; iris red. 1 foot 8 inches long. Inhabits Europe. B.-Shaw, xi. pl. 47.

A. stellaris, Lin. Common Bittern. Top of the head and moustaches black ; ground colour of the plumage yellowish red, marked on the sides of the neck with zigzag brown lines, and upon the fore part of the neck with brown and red spots; on the lower parts large black longitudinal stripes; quills banded alternately with red and gray. 2 feet 4 inches long. Inhabits Europe. B. -Shan, xi. pl. 45.

A. ralloides, Scopoli. The Squacco Heron. Crested, with the forehead and crown yellow, marked with longitudinal black spots; upper parts of the body rufous ; under parts, throat, rump, and tail, white. 16 inches long. Asia and Africa.-Shan, xi. 573.

A. minuta, Lin. Little Heron. Top of the head, occiput, back, scapulars, secondary wing-feathers, and tail, of a fine black, with greenish reflections; sides of the head, neck, wings-coverts, and lower parts reddish yellow ; quills black ash-coloured; the young with longitudinal brown spots on the breast. 13 inches long. Inhabits Europe. B.-Shaw, xi. pl. 44.

\section{Gen. 12. Ciconia, Tem.-Ardea, Lin.}

Bill long, straight, stout, cylindrical, in the form of an elongated pointed cone; ridge rounded, of equal height with the head; under mandible slightly bent upwards ; nostrils longitudinally cleft in a groove of the horny substance ; eyes surrounded with a naked space; legs long; the three anterior toes united to the first joint, the hind toe jointed on the same level as the others; wings of moderate size.

Storks live in marshy situations, and feed principally on reptiles, frogs, and their spawn, as well as on fish, small mammiferous animals, and birds. In many countries they are a privileged race, being cherished and protected on account of the noxious animals which they destroy. They moult in autumn, migrate in large bo- 
dies, and are easily tamed. The young of the first year do not very materially differ in appearance from the full-grown birds.

C. alba, Bellon. (A. ciconia, Lin.) Common Stork. Body white ; scapulars and wings black; bill and feet red, the bill perfectly straight; naked skin round the eyes black; iris brown. 3 feet 6 inches long. Inhabits Europe.-Shaw, xi. pl. 48.

The White Stork, from its use in destroying reptiles, and the familiarity of its dispo. sition, has long enjoyed the protection of man, and is a privileged bird in most countries of the world. In Holland, boxes are sometimes placed on the roofs of the houses for the reception of its nest. It rarely visits England. The stork sleeps upon one leg, and, before its migration, makes a singular snapping noise with its bill. Previous also to this migration storks assemble in numerous flocks; and some idea of the number which thus change their residence may be conceived from Dr Shaw mentioning that he saw three flights of them leaving Egypt, and passing over Mount Carmel, each half a mile in breadth, and which took three hours in passing.

C. nigra, Bellon. Black Stork. Plumage above of a shining brown; the wings and tail blackish, with purple and green reflections; lower part of the breast and belly white; naked skin of the eyes and throat crimson-red; bill straight, red; iris brown. 3 feet long. Inhabits Europe.-Shan, xi. 620.

C. Magzari, Tem. American Stork. Head, neck, back, tail, and lower parts pure white; feathers at the back of the neck long and pendant; wings and upper tail-coverts blackish, with green reflections; a large naked space below the throat; this, with the space round the eyes, crimson; bill slightly bent upwards. 3 feet long. Inhabits America.-Tem. Man. 563.

\section{Gen. 13. Anastomus, Illig.}

Bill thick, much compressed, gaping towards the middle; upper mandible denticulated on the margins, furrowed at the base; nostrils linear; legs long, slender; the three exterior toes united by a short membrane; hind toe jointed on the same level as the others.

A. Coromandelianus, Tem. Head, rump, belly, and wing-coverts white; face, upper part of the back, quills, and tail black ; sides of the bill serrated; tip dentated; wings short. $14 \frac{1}{2}$ inches long. $x$ Inhabits India. Shaw, xi. 633.-The only species of the genus.

Gen. 14. Scopus, Briss.

Bill compressed, soft, bent at the point; upper mandible surmounted in all its length by a projecting ridge, accompanied by a groove; nostrils oblique ; feet with four toes, the middle one shorter than the tarsus, the outer toes connected by a membrane to the first joint; hind toe leaning on the ground.

S. umbretta, Lath. Body of an uniform umber colour, the under parts paler; a dense crest of loose feathers on the occiput; tail with three or four bands of deeper brown. 20 inches long. Southern Africa. Shaw, xi. pl. 50.-The only species of the genus.

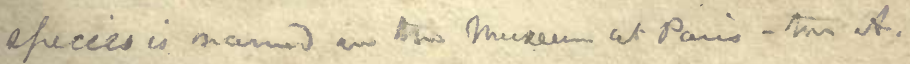


Gen. 15. Phønicopteris, Lin.

Bill thick, strong, deeper than broad, dentated, naked at the base, upper mandible bent over the under at the tip; the under broader than the upper; nostrils longitudinal, in the middle of the bill, covered by a membrane; legs very long, with three toes before, and a very short one articulated high on the tarsus behind, the fore-toes connected to the claws; wings middle-sized.

P. ruber, Lin. Red Flamingo. Head, neck, and lower parts rosecoloured; wings bright red; back and scapulars rose-coloured; quills deep black; the long red secondary feathers of the wings considerably exceeding the quills in length; bill blood-red at the base, black towards the tip. 4 feet 4 inches long. Inhabits the warmer parts of Europe, Africa, and Asia.-Shaw, xii. pl. 24.

Flamingos inhabit the warmer latitudes of both continents, and are not often met with higher than the 40 th degree, north or south. Their food consists of small fishes and their spawn, testacea, and aquatic insects. When flying in bands, they form an angle, like geese. These beautiful birds were held in high estimation by the ancient Romans, who often used them in their entertainments. Pliny, Martial, and other writers, celebrate the tongue as the most delicate of eatables.

Gen. 16. Recurvirostra, Lin.

Bill very long, slender, feeble, depressed throughout its length, flexible and turned up at the point, the upper mandible channelled on its surface, the under laterally; nostrils linear and long; legs long and slender, the three fore-toes united as far as the second joint by a membrane, the hind toe placed high up, and very short; wings acuminate, the first quill longest.

These birds, of which only one species inhabits Europe, frequent salt marshes, or the banks of rivers, where the water is shallow. They migrate and live in pairs; their flight is rapid and sustained; and their food is minute insects. They do not habitually swim, although provided with palmated toes.

R. avocetta, Lin. Common Avoset. Plumage white, with the exception of the top of the head; posterior part of the neck, scapulars, coverts of the wings, and quills deep black; feet bluish. 18 inches long. Inhabits Europe, \&c. B.-Shan, xii. pl. 22.

R. Americana, Lath. Head, neck, top of the back and breast reddish-yellow ; face whitish; middle of the back and front of the scapulars black; tail grayish. 18 inches long. Inhabits North America.-Wils. Amer. Orn. vii. pl. 63, fig. 2.

Gen. 1\%. Cancroma, Lin.

Bill longer than the head, much depressed; broader than deep, dilated towards the middle; ridge prominent, with a groove on each side ; upper mandible in the form of a reversed boat; the lower pointed; nostrils oblique, in the nasal groove; the three anterior toes united at their base; hind toe on a level with the others. 
C. cochlearia, Lin. The Boat-bill. Plumage above cinereous; belly rufous; a long black pendant crest on the occiput; a black spot on the base of the neck; bill dusky. 22 inches long, bill 4 inches. Inhabits South America. Shan, xi. pl. 51.-The only species of the genus.

Gen. 18. Platalea, Lin.

Bill very long, much flattened, dilated towards the extremity, and rounded like a spoon or spatula; upper mandible channelled, and transversely sulcated at the base; nostrils approximated, oblong, open, bordered with a membrane; face and head wholly or partially naked; legs long; the three anterior toes connected to the second joint by deeply cut membranes; the hinder one long, and bearing on the ground. Spoonbills live in suciety, subsisting on small fish and their spawn, on frogs, and other small reptiles, fluviatile testacea, and aquatic insects. They undergo one regular moulting in the year, and are migratory. They are but thinly dispersed over various parts of the world.

P. leucorodia, Lin. (P. nivea, Cuv.) White Spoonbill. Plumage pure white, with the exception of the breast, on which is a large patch of reddish-yellow; naked space round the eyes and throat, pale yellow; a crest on the occiput of long subulate yellowishwhite feathers. $2 \frac{1}{2}$ feet long, bill $8 \frac{1}{2}$ inches. Inhabits Europe. B. -Shaw, xi. pl. 52 .

The other known species of this genus are the Pl. tenuirostris and azaza.

Gen. 19. Tantalus, Lin. Tem.

Bill very long, straight, without a nasal furrow, ciliated at the tip, which is curved; upper mandible arched, the base broad, sides dilated, tip compressed and cylindrical; edges of both mandibles much inflected and sharp; face naked; nostrils longitudinally cleft in the corneous substance; legs very long, tarsus double the length of the middle toe; lateral toes united by a broad scalloped membrane.

T. loculator, Lin. Wood Tantalus. Plumage white; quills and tail black; thighs and legs dusky; skin of the fore part of the head and round the eyes black; that of the neck dusky-brown, rough and warty. 3 feet long, bill nine inches. Inhabits South America.-Shaw, xii. pl. 1.

The other described species of this genus are T. leucocephalus and ilis, Lath.

Gen. 20. IвIs, Lacep.-Tantalus, Lin.

Bill long, slender, arched, broad at the base, tip depressed, obtuse, and rounded; upper mandible deeply furrowed in its whole length; nostrils near the base, at the upper part of the bill, oblong, straight, and perforated in the membrane which covers the furrow; the face, and frequently a part of the head and neck, naked; legs naked above the knee; the fore-toes united as far as the first joint, the hind toe long, and reaching the ground. 
The birds of this genus frequent the margins of streams and lakes, and feed on insects, worms, shell-fish, and sometimes vegetables. Their destroying reptiles and serpents is a popular fable. They migrate periodically. The $I$. falcinellus, as well as the $I$. religiosa, were held sacred by the Egyptians; and both species are found in great numbers in the vast catacombs of the ancient Memphis.

I. falcinellus, Tem. Glossy Ibis. Head, neck, front of the body, and top of the back, of a beautiful chestnut hue ; rump, back, wings, and tail, blackish-green, with bronze and purple reflections ; bill greenish-black, and the tip brown ; irides brown; and legs greenish-brown. 22 inches long. Inhabits Europe and Asia. B. - Shaw, xii. pl. 2.

I. religiosa, Cuv. (T. Ethiopicus, Lath.) Sacred Ibis. Plumage white, with the head and upper part of the neck brown; back behind and quills black. Inhabits Egypt.-Shaw, xii. 10.

I. rubra, Vieill. Scarlet Ibis. Face, bill, and legs red ; body scarlet; wings tipped with black ; in the female the bill is yellowish-gray; a mixture of white and gray prevails in different parts of the plumage, and the tips of the two first quills are of a deep azure. 22 inches long. S. America.-Shaw, xii. pl. 3.

1. plumbea, Tem. Plumage leaden-blue, with the feathers of the occiput and nape whitish in the middle; forehead with a white band. 27 inches long. South America.-Tem. Pl. Col. 235.

Gen. 21. Numexius, Briss.-Scolopax, Lin.

Bill long, slender, arched, compressed, point hard, and slightly obtuse; upper mandible projecting beyond the lower, rounded at the end, and channelled through three-fourths of its length; nostrils lateral, linear, and pierced in the furrow ; face feathered; legs slender, naked above the knee; the three fore-toes united by a membrane to the first joint; the hinder articulated to the tarsus, and touching the ground.

The birds of this genus frequent the neighbourhood of waters and marshes. Their food principally consists of earthworms, insects, slugs, and testacea. Their flight is lofty and well sustained. They migrate in large flocks, but live in an insulated state during the breeding season.

N. arquata, Lath. Tem. Common Curlew. General plumage bright cinereous, with brown longitudinal spots on the neck and breast ; belly white, with longitudinal spots ; feathers of the back and scapulars black in the middle, and edged with rufous; tail whitish-cinereous, striped with transverse brown bands; upper mandible black-brown, the under flesh-coloured; iris brown; legs deep cinereous. 2 feet long. Europe, B.-Shaw, xii. pl. 4.

The bill of this species is generally from five to six inches long. This instrument is admirably fitted for picking worms, small crabs, \&c. out of the sand, and is, at the same time, successfully used as a weapon of defence aganst the shieldrake and gull.

N. phocopus, Lath. (Phceopus, Cuv.) The Whimbrel. Plumage bright cinereous, with brown longitudinal spots on the neck and breast; a longitudinal band of yellowish-white on the middle of 
the head, with a broad brown one on each side; belly white; feet lead-coloured. 16 inches long. Europe.-Shaw, xii. pl. 5.

Gen. 22. Tringa, Briss. Tem.

Bill middle-sized, or long, very slightly arched, curved or straight at the tip, soft and flexible through its whole length, compressed at the base, depressed, dilated, and obtuse at the point ; both mandibles channelled to near their extremities; nostrils lateral, conical, in the membrane which covers the nasal furrow; legs slender, naked above the knee; the three fore-toes quite divided; but in a few species the middle and outer toe are connected by a membrane; the hinder articulated to the tarsus.

These birds frequent marshy soils near rivers, lakes, and seas, and search the ooze, mud, shifting sands, or heaps of sea weed, thrown on the beach, in quest of coleopterous insects, larvæ, worms, mollusca, the contents of small bivalve shells, \&c. The young, before their first moulting, are very unlike their parents, and the female is, for the most part, somewhat larger than the male.

\section{- Anterior toes entirely divided.}

T. subarquata, Tem. (Scolopax Africana, Gmel.) Red Sandpiper, Penn. Back, scapulars, and wing-coverts brownish cinereous; face, throat, and under parts white; a brown stripe between the bill and eye; bill arched, much longer than the head; the two middle tail-feathers longer than the lateral ones; tarsus fourteen lines long. $7 \frac{1}{2}$ inches long. Europe, \&c.-Tem. Man. 609.

T. variabilis, Meyer. (T. ruficollis and Scolopax pusilla, Gmel.) The Purre, Penn. Plumage brown cinereous above, white below; bill almost straight, black, slightly sloping at the tip, and a little longer than the head; the two middle tail-feathers longer than the lateral ones, and terminating in a point ; length of thetarsus nearly twelve lines. 7 incheslong. Europe. B. - Shaw, xii.pl.15.

In its winter plumage, Cinclus, and Cinclus minor, of Brisson; and in its sum. mer dress, T. alpina, Gmel. I.ath. Wils. and Numenius variabilis, Bechst. At the time of its two periodical moultings, it is the Cinclus torquatus, and Gallinago An. glicana, of Brisson.

T. platyrhyncha, Tem. Bill slightly bent at the point, longer than the head, much depressed at the base; lateral feathers of the tail equal, the two middle ones longer; tarsus ten or eleven lines long. $6 \frac{1}{2}$ inches long. Europe-Tem. Man. 616.

T. maritima, Brunn. (T.nigricans, Mont.) PurpleSandpiper, Shaw. Bill slightly inclined at the point, longer than the head; almost no naked space above the knee; feet and base of the bill reddishyellow; tarsus ten lines long. $7 \frac{1}{2}$ inches long. Europe.-Ten. Man. 619.

T. Temminckii, Leisler. Temminck's Sandpiper. Bill slightly inclined at the point, shorter than the head; lateral feathers of the tail graduated, the exterior pure white; tarsus eight lines long. $5 \frac{1}{2}$ inches long. Inhabits Europe-Tem. Man. 622. 
T. minuta, Leisler. Bill straight, shorter than the head; tail doubly forked, lateral feathers brown cinereous, margined with white; length of the tarsus ten lines. $5 \frac{1}{2}$ inches long. Inhabits Europe.-Tem. Man. 624.

T. cinerea, Lin. (Calidris, Cuv. T. grisea, Canutus, Islandica, noevia, and Australis, Gmel. T. ferruginea, Meyer, and 'T. rufa, Wils.) The Red Knot. Bill straight, a little longer than the head, turgid and dilated towards the tip; all the tail-feathers of equal length. $9 \frac{1}{2}$ inches long. Europe.-Shav, xii. pl. 14.

** Middle and exterior toe united to the first joint. Machetes, Cuv.

T. pugnax, Lin. (T.littorea, Gmel. T. Grenovicensis and equestris, Lath. Totanus cinereus, Briss.) The Ruff. Bill very slightly inclined, and gibbous towards the tip; legs long; tail rounded, the two middle tail-feathers striped, the three lateral always of a uniform colour. $11 \frac{1}{2}$ inches long. Europe. B.Shaw, xii. pl. 16.

The details of the markings in this species are so variable, that two individuals are seldom found identical in this respect. The male is distinguished by a ruff, or large tuft of feathers, which he does not acquire till the second year, and which falls off in moulting, leaving him more like his mate till spring, when he not only resumes the ruff, but certain red tubercles on the face. These birds are particularly abundant in Holland, haunting moist and marshy meadows, and sometimes visiting the sea-shore in spring. At that season they arrive in this island; and, with a very few exceptions, which seem to be accidental, they leave it in autumn. The males - are of a very pugnacious disposition, and fight keen battles for the females.

Gen. 23. Totanus, Bechst.-Scolopax and Tringa, Lin.

Bill of moderate length, straight, compressed, rarely recurved, soft at the base, hard, sharp at the tip, which is pointed; mandibles furrowed at the base, the extremity of the upper slightly bent down on the under; nostrils linear, longitudinally cleft in the furrow; legs long, slender, naked above the knee, the middle toe united to the outer by a membrane, which sometimes extends to the second joint.

These birds, which travel in small troops, live indiscriminately on the banks of lakes and rivers, and in meadows adjacent to fresh-waters, and also at times frequent "sea-shores, and the muddy and oozy margins of large rivers. With the hard. point of their bill they pick up worms, testaceous animals, and sometimes fish.

\section{* Mandibles straight.}

T. semipalmatus, Tem. Semipalmated Snipe, Lath. Plumage above uniform brown; breast ash-coloured, with brown striæ; throat and belly white; quills black, with a white spot; bill thick, very strong; toes semipalmated. Inhabits North America. 15 inches long.-Wils. Amer. Orn. vii. pl. 56. fig. 3.

T. fuscus, Leisler. Plumage above gray ash-coloured, with black stripes; under parts and rump white ; upper coverts of the wings striped with white and blackish; base of the lower mandible red. 11 inches long... Inhabits Europe. B.-Bèvick's Birds, ii. pl. 88.

T. calidris, Bechst. Red-shanked Sandpiper. Plumage above 
brown ash-coloured; rump and belly white; the half of both mandibles red; the rudiment of a membrane uniting the inner to the middle toe; secondary wing-quills white the half of their length. 10 inches long. Europe. B.-Penn. Bril.Zool.ii. pl.10.

T. stagnalilis, Bechst. Bill very long, slender, and subulate, the exterior webs of the tail-feathers with two zigzag longitudinal brown bands; legs very long, greenish. 9 inches long. Inhabits Northern Europe.-Tem. Man. 647.

T. Bartramia, Wilson. Top of the head and back blackish-brown, the feathers margined with yellow ; flanks banded with fine zigzag lines; belly white; tail very long, surpassing the extremity of the wings, graduated and rounded; bill short. $9 \frac{1}{2}$ inches long. Inhabits North America.=Wilson's Amer. Orn. vii. pl. 59, fig. 2.

T. ochropus, Tem. Back brown-green; base of all the tail-feathers white for two-thirds of their length; two or three of the exterior quills white, or having a spot at their end. $8 \frac{1}{2}$ inches long. Inhabits Europe. B.-Shaw, xii. pl. 17.

T. glareola, Tem. Wood Sandpiper. All the feathers of the tail banded transversely with white and brown. $7 \frac{1}{2}$ inches long. Inhabits Europe-Tem. Man. 655.

T. macularia, Tem. Spotted Sandpiper. Upper parts of the body brown ash-coloured, slightly shaded with olive; lower parts naked, with large rounded spots. 8 inches long. Inhabits Europe--Shaw, xii. 19.

T. hypoleucos, Tem. Common Sandpiper. Upper parts brownolive, with reflections; a black stripe along the shafts; feathers of the wings and back striped transversely with zigzag bands of white and blackish; under parts white, without spots. 7 inches long. Inhabits Europe. B.-Lewin's Brit. Birds, v. pl. 172.

** Mandibles a little recurved, straight at the point.

T. glottis, Bechst. Greenshank. Plumage gray-brown, with dusky spots ; under covirts of the wings striped with brown ; legs greenish ; bill strong, compressed at the base. $12 \frac{1}{2}$ inches long. Inhabits Europe.-Shaw, xii. pl. 13.

Gen. 24. Limosa, Briss.-Limicula, Veill.-Scolopax, Lin.

Bill very long, more or less recurved, soft and flexible, depressed, flattened towards the tip; both mandibles channelled longitudinally; tip dilated and obtuse ; nostrils lateral, longitudinally cleft in the sulcus; legs long and slender; a large naked space above the knee; the middle toe united to the outer by a membrane to the first joint, hind toe articulated on the tarsus.

These are tall birds, with long bills, destined to live in marshes, and on the swampy shores of rivers, their soft and flexible bill being unfit for picking food from the surface of a hard or gravelly soil, and only adapted to perforate slime or moist sand. Hence they live in marshy meadows, and habitually resort to the mouths of 
rivers, where the mud is deep, and supplies them with worms, the larvæ of insects, \&c. Their period of migration coincides with that of the snipes. They moult twice a-year, and the females later than the males.

L. melanura, Leisler. Black-tailed Godwit. Upper parts brown uniform ash-colour ; throat, breast, and flanks clear gray; a white spot on the quills; tail uniform black; pure white at the base; claw of the middle toe long and dentated. 16 inches long. Inhabits Europe. B.-Shaw, xii. pl. 11.

L. rufa, Briss. Red Godwit. Bill turned upwards; all the feathers of the tail on both webs with eight or nine blackish bands; claws of the middle toe short, without dentations. $13 \frac{1}{\mathrm{~g}}$ inches long. Inhabits Europe. B.-Shaw, xii. pl. 12.

\section{Gen. 25. Scolopax, Lin.-Rusticola, Vieill.}

Bill long, straight, compressed, slender, soft, with the tip tumid; both mandibles channelled the half of their length, the tip of the upper projecting beyond that of the under, and the tumid portion being hooked; nostrils lateral, basal, longitudinally cleft near the edges of the mandible, and covered by a membrane; legs slender, with a very small naked space above the knee; the three fore toes quite divided, or rarely the outer and middle united.

The species which compose this genus live in woods or marshes, and subsist on small slugs or worms. In some countries they are stationary, but in most migratory. They abound more in the northern than in the southern regions, and they moult twice a-year, but without inducing those remarkable changes of plumage observable in some of the preceding families. Cuvier remarks that the peculiar character in these birds, of having the head much compressed, and large eyes, placed much behind, giving them a stupid appeurance, is not contradicted by their manners.

\section{- With the tibia feathered to the knee.}

S. rusticola, Lin. (Rusticola vulgaris, Vieill.) The Woodcock. Upper parts varied with reddish-yellow and ash-colour, and marked with large black spots; occiput banded transversely; under parts reddish-yellow, with zigzag brown lines; quills banded with red and black upon the exterior webs. 13 inches long. Inhabits Northern Europe. B.-Shaw, xii. pl. 7.

This well-known species inhabits the northern regions of Europe, Asia, and Africa, migrating on the approach of winter to more temperate latitudes. In this island it seldom appears in numbers till about the middle of November. They generally come with northerly or easterly winds; and, if intense cold suddenly overtakes them, they sometimes arrive on the coasts in large flocks, and after remaining for a day to recruit their strength, disperse over the interior of the country.

\section{* Inferior part of the tibia naked.}

S. major, Lin. Great Snipe. Upper parts varied with black and bright red, the red dispersed longitudinally; lower parts whitishred; tail of sixteen feathers ; shaft of the first quill-feather whitish. 10 inches long. Northern Europe. B.-Shaw, xii. pl. 8.

S. gallinago, Lin. Common Snipe. Tail composed of fourteen feathers; all the shafts of the quills brown. 10 inches long. Inhabits Europe. B.-Bewick, ii. 68. 
The Snipe is met with in marshy situations in almost every part of the world, and is very plentiful in Britain. In very wet seasons it resorts to the hills; but it more generally frequents the marshes in plains, where it can penetrate the soil with its long bill in quest of worms. Some few remain with us the whole year, and breed in the extensive wet moors and mountainous bogs. The nest is formed of coarse grass, or heath, lined with feathers, and placed in a dry spot, contiguous to a pool or swamp. The eggs, which are usually four or five, are whitish, spotted with cinereous and brown, and, like those of the Lapwing, much pointed, and invariably ranged with their small ends inwards.

S. gallinula, Lin. The Jack Snipe. The tail composed of twelve feathers; a broad longitudinal black band, spotted with rufous, running from the forehead to the nape. $7 \frac{1}{2}$ inches long. Inhabits Europe. B.-Lewin's Brit. Birds, iv. pl. 159.

*** Exterior and middle toe united by a very short membrane.

S. grisea, Gmel. Red-breasted Snipe. Top of the head, breast, and coverts of the wings ashy-brown, without spot; eyebrows, throat, and thighs white; tail-feathers twelve, with numerous black and white bands. 10 inches long. Inhabits Europe and America. B.-Shan, xii. pl. 9.

Gen. 26. Rynchøa, Cuv.-Scolopax, Lin.-Rostratula, Vieill.

Bill longer than the head, gibbous towards the point, much compressed, inflected towards the end; upper mandible furrowed in its whole length, the under only at the point ; nasal furrow prolonged to the middle of the bill; tongue as long as the bill, pointed; nostrils linear; tarsus longer than the intermediate toe; the anterior toes wholly divided; hind toe articulated on the tarsus.

R. Capensis, Tem. Cape Snipe. Plumage reddish-brown; bill, and a line on the vertex, reddish; a black band on the breast, and a white line on each side of the back. 10 inches long. Inhabits Cape of Good Hope.-Shaw, xii. pl. 10.

Gen. 27. Eurypyga, Illig. Ardea, Lin.

Bill long, straigit, hard, compressed, with the point a little tumid; nasal furrow very deep ; sides of the lower mandible sulcated; point of the bill notched; nostrils basal, linear, long; legs long, slender ; tarsus longer than the middle toe; the external toe united by a membrane, the internal divided, but all with membranous borders; hind toe on a level with the others; tail very long.

E. Helias, Tem. Body banded with black, fulvous, and white ; abdomen and stripes on the head white; neck rufous, with transverse black lines; tail clouded, with a black bar. 15 inches long. Inhabits Guiana.-Shav, xiv. 323. The only species of the genus.

Gen. 28. Rallus, Lin.

Bill longer than the head, slender, slightly arched, or straight, compressed at the base, cylindrical at the tip; upper mandi- 
ble channelled; nostrils lateral, longitudinally cleft in the furrow, half-closed by a membrane; legs long and stout, with a small naked space above the knees, the three anterior toes divided, the posterior articulated on the tarsus ; wings rounded, the third and fourth feathers longest.

The body of these birds is much compressed and loaded with fat, and they run more than they fly. Their chief residence is in the immediate neighbourhood of fresh waters, overgrown with herbage and shrubs; and their food principally consists of worms, insects that have no wing-cases, slugs, vegetables, and seeds.

R. aquaticus, Lin. Water Rail. Throat whitish; sides of the head, neck, breast, and belly lead-coloured; flanks of a deep black, transversely banded with white; feathers of the upper parts reddish-brown, and black in their middle; bill reddish. $9 \frac{1}{2}$ inches long. Inhabits Europe. B.-Shaw, xii. pl. 25.

The Water Rail flies slowly, with its legs hanging down, and generally alights at no great distance from the spot from whence it first arose. When running, it flirts up its tail and exposes the white of the under tail-coverts. It wades in the water, swims, occasionally dives, and forms its nest among aquatic plants.

R. Australis, Tem. Plumage ashy rust-coloured; wings and tail dark-brown, the feathers banded with black. 17 inches long. Inhabits New Zealand.-Shaw, xii. 206.

Gen. 29. Galitinula, Briss.-Rallus, Lin.

Bill shorter than the head, compressed, conical, deeper than broad at the base; the ridge advancing on the forehead, and, in some species, dilated into a naked plate; tips of both mandibles compressed, and of equal length, the upper slightly curved, the lower forming an angle; nostrils lateral, in the middle of the bill, longitudinally cleft, half-closed by a membrane, which covers the large nasal furrow; legs long, naked above the knee; fore-toes long, divided, and furnished with a narrow edging.

The birds of this genus, like the Rails, have their body much compressed. They swim with ease, dive with facility, run with speed on land, and often on the leaves of aquatic plants on the surface of the water. Their food consists of insects and vegetables. The males are only distinguished from the females in their colours being brighter; and the young do not acquire their mature plumage till the second year. These birds composed part of the genera Rallus and Fulica of Linnæus; but were properly brought together by Latham under the present generic term.

* Ridge of the upper mandible between the feathers of the forehead, but not dilated into a plate.

G. crex, Lath. Land-Rail or Corn-Crake. Plumage gray above, rufescent white beneath; wings reddish-rusty; bill and legs brownash ; feathers of the body reddish-brown, the upper ones blackish in the middle; a large ash-coloured eyebrow prolonged on the sides of the head; chin very pale; irides hazel. $9 \frac{1}{2}$ inches long. Inhabits Europe. B.-Shaw, xii. pl. 26.

The Land-Rail is a migratory species, appearing in Britain about the latter end of April, and departing about the middle or close of September. In Ireland it is supposed to remain throughout the year. On its first appearance, and until the fe- 
male begins to sit, the male is frequently heard to make a singular kind of noise, much resembling that of a comb when the finger is drawn along its teeth. The nest is loosely formed of moss or dry grass, generally in some hollow place among thick grass, and the female lays from seven to sixteen eggs, of a reddish-cinereous white, marked with rusty and ash-coloured spots and blotches. The young run about as soon as hatched.

G. porzana, Lath. Spotted Water-Hen or Spotted Rail. Plumage olive-brown, variegated with spots and dashes of black and white above; ash-coloured, with white markings beneath; bill greenishyellow, but red at the base; legs greenish-yellow; iris brown. $7 \frac{1}{2}$ inches long. Furope. B.-Donov. Brit..Birds, v. pl. 122.

G. pusilla, Bechst. Dwarf Rail. Plumage above olive-gray; wings ending at the extremity of the tail; bill and legs bright green; feathers of the middle of the back marked with little white but not numerous lines. The female differs much from the male. 7 inches long. Inhabits Europe. B.-Shaw, xii. pl. 28.

G. Baillonii, Vieill. Plumage olive-red; wings ending at half the length of the tail; bill deep green; legs flesh-coloured; a great number of white spots on the back and wings. $6 \frac{1}{2}$ inches long. Inhabits Europe.-Shaw, xii. pl. 27.

* * Ridge of the upper mandible dilating on the forehead into a naked plate.

G. chloropus, Lath. (Fulica, Lin.) The Water-Hen. Head, throat, and lower parts of a slaty-blue; upper parts olive-brown; the exterior margin of the wings, longitudinal spots on the flanks, and the lower tail-coverts white; base of the bill and frontal plate bright red, point of the bill yellow; legs greenish; a red naked circle on the tibia. 12 to 14 inches long. Inhabits Europe. B.-Shaw, xii. pl. 30 .

G. Cayanensis, Tem. Plumage olive-brown; crown and under parts red; cheeks dusky; quills black. 7 inches long. Inhabits Cayenne.-Shaw, xii. 220.

\section{Gen. 3C. Parra, Lin.-Jacana, Briss.}

Bill as long as the head, straight, slender, compressed, somewhat inflated towards the tip, the depressed base dilated in front into a naked plate or elevated crest; mandibles unequal; nostrils lateral, placed near the middle of the bill, oval, legs very long, slender; nudity of the tibia very long; toes very long, slender, entirely divided; wings ample.

The birds of this family are natives of Asia, Africa, and south America. In their natural habits and dispositions, the shortened form of their body, the figure of their bill, and the smallness of their head, they resemble the Gallinula; but they have spines or spurs on their wings, and most of them have caruncles on the forehead ; their toes are completely separated, and their claws are extremely long, straight, and slender. They haunt the marshes of hot countries; walk on the broad' and floating leaves of plants on the surface of the water with great nimbleness; and fly more frequently and more vigorously than the Gallinulæ. They are monogamous, nestle on the ground among the aquatic herbage, and lay four or five eggs. The young as soon as hatched follow their parents. 
P. Jacana, Lath. Chestnut Jacana. Hind claws very long, legs greenish, bill of a deep yellow, carunculated at its base; the throat, reck, and under parts black, tinted with purple; back, upper wing-coverts, and scapulars of a rich chestnut hue. 10 inches long. Inhabits S. America.-Shaw, xii. pl. 32.

P. anea, Cuv. Bronzed Jacana. Plumage black, glossed with blue and violet; head and neck glossy green; rump and tail-feathers blood-red; a white spot behind the eyes; bill with the base naked. Inhabits Brazil.-Shaw, xii. pl. 33.

\section{Gen. 31. Ponphyrio, Briss.}

Bill strung, hard, thick, conical, nearly as deep as long, and shorter than the head; the upper mandible dilated and depressed as it approaches the cranium; nostrils lateral, pierced in the corneous mass of the bill, nearly round and pervious; legs long and stout; toes very long in some species, the anterior quite divided, and edged with a very narrow membrane.

This genus of birds, like the Gallinulæ, reside in or near fresh waters, haunt the extensive rice-fields of the south, and prefer grain to aquatic herbs, their formidable bill being well adapted to remove the husks, and break the straws, while their legs, and very long retractile toes, are equally suited to lay hold of the stalks of the plant, and to carry the ears to their mouth.

P. hyacinthinus, Tem. (Gallinula porphyrio, Lath. Fulica porphyrio, Lin.) Purple Water Hen. Ridge of the upper mandible almost identified with the skull; the middle toe clawless, and longer than the tarsus; all the plumage blue; the frontal plate terminating behind the eyes. 18 inches long. Europe-_Edw. pl. 87. The Greeks and Romans tamed and fostered this bird, and introduced it into their palaces and temples. According to Sonnini, it abounds in Lower Egypt, appearing in the rice-fields in May, and the following months, and breeding in the desert. P. smaragnotus, Tem. Ridge of the upper mandible suddenly inflected, less elevated than the cranium; frontal plate not surpassing the posterior margin of the eye ; middle toe clawless, and nearly the length of the tarsus. $14 \frac{1}{2}$ inches long. Inhabits Southern Africa.-Tem. Man. 700.

P. melanotus, Tem. Ridge of the upper mandible on a level with the frontal plate, which passes beyond the posterior margin of the eye ; middle toe clawless, shorter than the tarsus. Inhabits New Holland.-Tem. Man. 701.

\section{ORDER XIV.-PINNATIPEDES.}

Bill middle-sized and straight; upper mandible slightly curved at the tip ; legs of medium size ; tarsi slender or compressed; three toes before and one behind, with rudiments of webs along the toes; hind toe articulated interiorly on the tarsus. 
The birds included in this order are monogamous, but unite in large bands for their periodical voyages, which they perform by flight or swimming. They swim and dive with equal facility, and stretch their legs backwards in flight. In gene. ral, there is no very marked difference between the male and the female. Their food consists of insects, worms, fisn, and their spawn, and occasionally of vegetables. Their body is covered with an abundant down; and their plumage is close and glossy.

\section{Gen. 1. Furica, Lin.}

Bill midle-sized, strong, conical, straight, compressed, much. deeper than broad at the base; the ridge projecting in front, and dilated into a naked plate; both mandibles of the same length, the upper slightly curved, and widened at the base, the lower forming an angle; nostrils lateral, in the middle of the bill, longitudinally cleft, half closed by a membrane; legs long, slender, naked above the knee; all the toes very long, connected at their base, and furnished along their sides with scalloped membranes.

The Coots are more decided residents in the water than even the Gallinulæ, being rarely seen on land, and swirnming and diving with equal facility. They inhabit fresh waters. gulfs, and bays, but venture not into the deep and open seas. The sexes are scarcely distinguishable, and the young differ very little in appearance from the adults. Their food chiefly consists of insects and aquatic vegetables.

F. atra, Lin. Common Coot. Head and neck deep black; upper parts slaty gray; under parts bluish ash-coloured ; frontal plate very broad, white; bill white, tinged with rose colour. 15 to 16 inches long. Inhabits Europe. B.-Shaw, xii. pl. 29.

F. cristata, Lath. Body dusky blue, with a red, green, and yellow ring above the knee; caruncle red, bifid, erect. 18 inches long. Inhabits Madagascar._Shaw, xii. 239.

Gen. 2. PodoA, Illig.-Plotus, Lath.-Heliornis, Vieill.

Bill as long as the head, cylindrical, straight, pointed; point notched, ridge distinct; nasal furrow large; nostrils lateral, towards the middle of the bill; legs short, placed very far back; tarsus rounded; the three anterior toes united by a lobed membrane; hind toe smooth; tail very broad.

P. Surinamensis, Tem. Body above brown, white beneath; crown and neck behind black; throat, jugulum, and stripe near the eye white; sides of the neck banded with black and white. 13 inches long. Inhabits Surinam-Shav, xiii. 22.

P. Senegalensis, Tem. Body brown above, white beneath; sides of the neck and back spotted with black; tail wedge-shaped, rigid and narrow; bill and legs red. Senegal._Shaw, xiii. 21.

Gen. 3. Phalanopus, Briss.-Tringa, Lin.

Bill long, slender, feeble, straight, depressed at the base, both mandibles channelled to the tip; the extremity of the upper bent down on the lower, and obtuse; point of the lower man-

VOL. I. 
dible subulate; nostrils basal, lateral, oval, prominent, surrounded by a membrane; legs middle-sized, slender, tarsi compressed; the anterior toes connected to the first articulation, and the rest of their length furnished with scalloped and serrated membranes; the hind toe without a membrane.

The few species which belong to this genus are among the smallest of swimming birds, and flit over the waves with much grace and nimbleness. On land they run beavily. They are often observed at a great distance from the shore; and they principally subsist on small insects and marine worms, which they pick up on the surface or margin of the water. Like the sea-fowls, they have their body furnished with down, and their plumage thick-set and glossy.

* Bill slender, depressed at the base, subulate at the point.

P. hyperboreus, Lath. Red Phalarope. Top of the head, nape, sides of the breast, space between the eye and bill deep cinereous; lateral parts and front of the neck bright red; throat, middle of the breast, and lower parts white; flanks with ash-coloured spots; back, scapulars, wing-coverts, and two middle feathers of the tail black. 7 inches long. Inhabits Europe. B.-Shaw, xii. pl.21.

This is the type of Cuvier's genus Lobipes.

* Bill depressed through its whole length, compressed at the point.

P. platyrhynchus, Tem. (P. lobatus, glacialis, Lath. P. rufus, Bechst. Tringa hyperborea, glacialis, Gmel.) Gray Phalarope. Plumage cinereous above, with a black band on the nape; a transverse white band on the wings; bill broad, depressed, flattened at the base; tail long, and much rounded. 8 inches long. Inhabits Europe. B.-Shaw, xii. pl. 20.

Cuvier forms of this species his genus Phalaropus.

Gen. 4. Podiceps, Lath.-Colymbus, Gmel.

Bill middle-sized, straight, hard, compressed, in the form of an elongated and pointed cone; tip of the upper mandible slightly inclined; nostrils lateral, concave, oblong, closed behind by a membrane, open in front, and pervious; legs long, placed far backwards; tarsi much compressed; fore toes much depressed, connected at their base, and furnished with a simple lobe; hind toe compressed and scalloped; claws broad, much depressed; no tail; wings short.

All the Grebes have the under parts of their body, and especially the breast, covered with a very compact and glossy down. They dive, swim rapidly even under water, and pursue fish to a considerable depth. On land their motions are awkward, owing to the conformation of their legs. They alike frequent the sea and the fresh waters; and fishermen sometimes catch them in their nets even at the depth of twenty feet. The males and females seldom exhibit any very marked differences of appearance.

P. cristatus, Lath. Crested Grebe. Top of the head, flat occipital tuft, and ruff on the cheeks black, shading to red on the sides of the head; under parts silvery white; bill longer than the head, reddish, the point white; distance from the anterior margin of the nostrils to the point of the bill 17 or 18 lines. 18 inches long. Inhabits Europe. B.-Penn. Brit. Zool. ii. 130. 
P. rubricollis, Lath. Tem. Red-necked Grebe. Bill black, the length of the head, yellow at the base; occipital crest very short; no ruff; distance from the anterior margin of the nostrils to the point of the bill eleven lines; chin, cheeks, and region of the ears cinereous, under part of the neck and breast rusty red; belly and secondary quill-feathers white. 15 to 17 inches long. Inhabits Europe. B.-Penn. Brit. Zool. ii. 139.

P. cornutus, Tem. (P.obscurus and Caspicus, Lath.) Dusky Grebe. Bill strong, shorter than the head, compressed throughout its length, black, but red at the tip; iris double; distance from the anterior margin of the nostrils to the tip of the bill six or seven lines; crown of the head, and very broad ruff of a deep and glossy black; two large tufts of rufous feathers placed above and behind the eyes; neck and breast of a bright shining rufous; under parts pure white; nape and upper parts blackish. 12 to 13 inches long. Inhabits Europe. B.-Shaw, xiii. pl. 1.

P. auritus, Lath. Top of the head, face, short occipital tuft, and ruff, deep black; a pencil of long, slender, yellow feathers behind the eyes; upper parts, throat, neck, and sides of the breast black ; flanks and thighs deep-red chestnut, lower parts white ; bill shorter than the head, black, base depressed, point recurved; distance of the nostrils from the tip of the bill 6 or 7 lines. $11 \frac{1}{2}$ or 12 inches long. Inhabits Europe-Penn. Brit. Zool. ii. pl. 24.

P. minor, Tem. (P. Hebridicus, Lath. Hebridicus and minor, Gmel.) Black Chin Grebe. Bill very short, strong, compressed; neither crest nor ruff; distance from the anterior margin of the nostrils to the tip of the bill five lines; tarsi posteriorly furnished with long asperities. 9 to 10 inches long. Inhabits Europe. B.Sham, xiii. pl. 2.

\section{ORDER XV.-PALMIPEDES.}

Bill of various forms ; legs short, placed more or less backwards ; the anterior toes partially or wholly connected by webs, and, in some families, all the four toes united by one membrane; the hinder toe interiorly articulated to the tarsus, or in some genera wanting.

Most of the species belonging to this numerous order may be termed sea.birds. Their plumage is thicker, closer, and better furnished with down, than that of other birds. Some of the order both swim and dive, others only swim or skim over the surface of the sea, but never plunge under water, while a few are almost habitually resident in the ocean, repairing to the shore only to breed. They subsist on fish and their fry, testaceous animals, and marine insects ; and a few, as geese, swans, and some species of ducks, also feed on vegetables. They breed in holes, among rocks, or sometimes on the stony beach. Most of them moult twice a-year; the female, in some instances, moulting later than the male. The young, during the first year, and, in some cases, during several years, differ much in appearance from the full grown birds. For the most part they are polygamous and prolific. The flesh of most of the species is eatable, and that of some is highly prized. 
Gen. 1. Cereopsis, Lath.

Bill very short, strong, almost as deep at the base as long, covered by a cere prolonged towards the point, which is arched and truncated; nostrils very large, in the middle of the bill, open; tarsus longer than the middle toe; hind toe long, jointed on the posterior part of the tarsus; toes palmated, with deeply notched membranes; claws thick and strong; wing-coverts almost as long as the wings.

C. Novce Hollandice, Tem. Plumage ashy-gray; brownish above, with some of the wing-coverts spotted with black. 39 inches long. Inhabits New Holland.-Shaw, xii. pl. 44.

Gen. 2. Chionis, Forst.-Vaginalis, Lath.

Bill strong, hard, conico-convex, compressed, inclined towards the point; base of the upper mandible half covered by a moveable corneous sheath, with longitudinal furrows; nostrils marginal, in the middle of the bill, on the border of the corneous substance; naked part of the tibiæ small; toes with a rudimentary border; the middle and exterior ones semipalmated, the anterior united only at the base; wings tuberculated.

C. Forsteri, Tem. Sheath-bill. Plumage snowy white; knob at the head of the wings blackish; bill black at the base, the appendage or sheath yellowish; papillæ on the face orange. 15 to 18 inches long. Inhabits New Zealand._Shaw, xii. 281.

Gen. 3. RHYnchops, Lin.

Bill long, straight, flattened into a blade, truncated at the apex ; upper mandible much shorter than the under; nostrils lateral, marginal, remote from the base; legs slender; tarsus longer than the middle toe; the fore toes united by a membrane ; hind toe jointed on the tarsus ; tail forked, and shorter than the wings.

R. nigra, Lin. Black Skimmer or Cut-water. Blackish above; white beneath; wings with a transverse white band; legs red. 18 to 20 inches long. Asia and America.-Sham, xiii. pl. 16.

This bird is ever on the wing, sweeping the surface of the water, and dipping in its bill, or at least the under mandible, to scoop out the smaller fishes on which it feeds. In stormy weather it frequents the shores, and subsists on shell-fish.

R. flavirostris, Vieill. Body above ashy brown, beneath white; bill yellow; legs brown. Inhabits Senegal.-Shaw, xiii. 138.

Gen. 4. Sterna, Lin.

Bill as long as, or longer than the head, almost straight, compressed, slender, edged, and pointed; mandibles of equal length, the upper slightly sloping towards the tip; nostrils in the middle of the bill, longitudinally cleft, and pervious; 
legs small, naked above the knee ; tarsus very short, the three anterior toes connected by a membrane, the hinder detached; tail more or less forked; wings very long and pointed.

The Terns are almost constantly on the wing. In the course of their wheeling flights, they graze the surface of the sea, or pounce down abruptly in pursuit of small fish or insects. Their cry is incessant, shrill, and piercing. They nestle in numerous flocks in the same places.

S. Caspia, Pallas. The Caspian Tern. Forehead and part of the demeritit crown white; occiput black and white; nape, back, scapulars, and coverts of the wings bluish cinereous; quills brown cinereous; lower parts white; bill thick, strong, bright red; height of the tarsus 1 inch 8 lines ; tail short, forked. 20 to 21 inches long. Inhabits coasts of the Baltic Sea, \&c.-Shan, xiii. 145.

S. Cantiaca, Gmel. (S. Boysii, Lath.) Sandwich Tern. Back scapulars, and wing-coverts bluish cinereous; nape, top of the back, and lower parts white; bill long, black, yellowish at the tip; feet short and black; height of the tarsus one inch; tail long, much forked, shorter than the wings. 15 to 16 inches long. Inhabits Europe, B.-Don. Brit. Birds, v. pl. 120.

S. Dougallii, Montagu. Roseate Tern. Top of the head and nape deep black ; back, scapulars, and wings, cinereous; lower parts white ; bill entirely black ; legs orange-coloured; tarsus 9 lines long; the middle toe, including the claw, shorter than the tarsus; tail much longer than the wings. 15 inches long. Inhabits coasts of Europe.-Shaw, xiii. 153.

S. hirundo, Lin. Common Tern or Sea Swallow. Top of the head and long feathers of the occiput black; back and wings bluish cinereous; white below; bill middle-sized, red, with the tip black; legs red; length of the tarsus 10 lines; tail much forked, of the same length as the wings, or even shorter. 14 inches long. Inhabits Europe. B.-Shaw, xiii. pl. 18.

S. Arctica, Tem. Arctic Tern. Top of the head and long feathers of the occiput deep black ; back and wing-coverts bluish cinereous; a small part of the abdomen, inferior coverts of the tail, and a band below the eyes, white ; bill slender, red, without black at the tip; length of the tarsus six lines; tail much forked, and sometimes rather exceeding the wings in length. 13 to 14 inches long. Inhabits Northern Europe. B.-Shaw, xiii.152.

S. Anglica, Mont. Marsh Tern. Top of the head, neck, and lower parts, white ; upper parts bluish cinereous ; bill very short, thick, and quite black; legs long and black; length of the tarsus $I$ inch and 3 or 4 lines; tail slightly forked, the wings extending 3 inches beyond its extremity; hinder toe straight. Inhabits Europe. B.-Tem. Man. 744 .

S. leucopareia, Natterer. Bill and legs lake red; middle toe with the claw much longer than the tarsus, which is 10 lines long; tail slightly forked, the wings extending $1 \frac{1}{2}$ inch beyond its extremity. 11 inches long. Inhabits Southern Europe.-Tem. Man. 746. 
S. leucoptera, Tem. Bill brown; legs coral red; membranes of the toes much gashed; the internal rudimentary; length of the tarsus 9 lines; tail slightly forked; wings extending 2 inches 4 lines beyond its extremity. $9 \frac{1}{2}$ inches long. Inhabits coasts of Southern Europe-Tem. Man. 747.

S. nigra, Lin. Black Tern. Bill black; legs purple brown, webs gashed to the half of their length; height of the tarsus 7 or 8 lines; tail slightly forked, and the wings extending an inch and a half beyond its extremity. 9 inches long. Inhabits marshes, \&c. in Northern Europe. B.-Shaw, xiii. pl. 19.

S. minuta, Lin. Minute or Lesser Tern. Bill orange-coloured, but black at the tip; legs orange; length of the tarsus 7 lines; tail much forked; forehead white. $8 \frac{1}{2}$ inches long. Inhabits Shores of Europe.-Don. Brit. Birds, iv. pl. 96.

S. stolida, Lath. Foolish Tern or Noddy. Body black; forehead whitish ; eye-brows, bill, and legs, black; ucciput cinereous. 15 inches long. Inhabits Brazil, \&r._Shan, xiii. pl. 17.

Gen. 5. Larus, Lin.

Bill long, or middle-sized, strong, hard, compressed, edged, bent towards the tip; lower mandible angulated near the point; nostrils lateral, in the middle of the bill, longitudinally cleft, straight, and pervious; legs slender, naked above the knee; tarsus long; three fore-toes quite webbed, the hinder free, short, placed high on the tarsus; tail-feathers of equal length; wings long.

The birds of this genus are diffused over every coast. Flocks of them haunt the sea-shore in pursuit of living or dead fish; and such is their voracity, that hardly any thing comes amiss, for they greedily feed on putrid carcasses of whales, and the refuse of the tide. Like other predacious birds, they throw up pellets of feathers, and other indigestible matters. Like most ravenous animals, they are also capable of enduring protracted abstinence. The young do not attain their full plumage till the second or third year. Gulls breed among the rocks or downs, and some of the smaller species in meadows adjacent to the coast. When they floek in numbers to the land, and are clamorous along the coast, or when at sea they alight on ships, they are said to portend a storm.

L. glaucus, Brun. Glaucous Gull. The Burgomaster of the Dutch. Back, shoulders, and wing-coverts, bluish cinereous; legs livid; length of the tarsus within a line or two of three inches; quillfeathers terminated by a large white space; shafts white; bill of a beautiful yellow, with the angle of the lower mandible bright red; orbits red; iris yellow. 2 feet 2 inches long. Inhabits Europe. B.-Lenin's Brit. Birds, vi. pl. 7.

L. marinus, Lin. Great Black-Backed Gull. Shoulders slateblack; legs white; length of the tarsus nearly 3 inches; folded wings stretching a very little beyond the tail : quill-feathers black towards the end, but tipt with white; bill whitish yellow, the angle of the lower mandible bright red. 26 to $27^{\circ}$ inches long. Inhabits Europe. B.-Tem. Man. 760. 
L. argentatus, Brun. Silvery Gull or Herring-Gull of Latham. Mantle bluish-cinereous; legs livid; length of the tarsus two inches and a half; wings very little exceeding the tail ; quill feathers black, near the extremity, but tipt with white, and their shafts blackish. 21 to 22 inches long. Inhabits Europe. B.Lewin's Brit. Birds, vi. pl. 7.

L. fuscus, Lin. Lesser Black-Backed Gull. Mantle slate-black; legs yellow; length of the tarsus two inches and one or two lines; the wings stretching about two inches beyond the extremity of the tail ; the bill proportionally shorter and more slender than in the preceding. 18 or 19 inches long. Europe. B.-Shaw, xiii. 194.

L. eburneus, Lin. Ivory Gull. Body quite white; legs black; a very small naked spot on the tibia; length of the tarsus one inch five lines. 19 inches long. Inhabits Greenland.-Tem. Man. 769.

L. canus, Lin. Common Gull or Sea Mew. Head, occiput, nape, and sides of the neck white; spotted with blackish brown; all the lower parts white ; back, scapulars, and wings bluish cinereous; quills towards the tip deep black; length of the tarsus two inches ; wings reaching beyond the tail ; shafts of the two outer quill-feathers black; bill small. $16 \frac{1}{2}$ inches long. Inhabits Europe. B.-Don. Brit. Birds, vi. pl. 79.

L. tridactylus, Lath. Tarrock or Kittiwake Gull. Top of the head, occiput, nape, and part of the sides of the neck, bluish ash-coloured; fine black lines before the eyes; region of the eyes, lower parts, rump, and tail, white ; back and wings bluish ashcoloured, the exterior quill-feather bordered with black; bill greenish yellow; iris brown; length of the tarsus one inch four lines; a clawless tubercle in place of a hind-toe. 15 inches long. Inhabits European Seas. B.-Shaw, xiii. pl. 21.

L. melanocephalus, Natterer. Adriatic Gull. Bill thick and strong; shoulders and back pure ash-coloured; all the feathers of the wings terminated by a large white space; length of tarsus 2 inches. 15 inches long. Coasts of the Adriatic Sea.-Tem. Man. 777.

L. atricilla, Lin. Bill and legs deep lake red; shoulders and back deep bluish cinereous; quill-feathers black, extending two inches beyond the tail; length of the tarsus 1 inch 9 lines. Nearly 14 inches long. Inhabits Europe and America.-Tem. Man. 779.

L. ridibundus, Leisler. (L. cinerarius, Gmel.; the young, Sterna obscura, Lath. and after moulting $L$. erythropus.) Red-legged Gull. Head, neck, and tail white, with the exception of a black spot before the eyes, and another on the surface of the ears; breast, belly, and abdomen, whitish, slightly tinted with rose-colour; back, scapulars, and coverts of the wings bluish ash-coloured; exterior margin of the wings white; length of the tarsus 1 inch and 8 or 9 lines; bill and legs vermilion. 14 inches long. Inhabits Europe. B.-Shaw, xiii. pl. 22.

L. capistratus, Tem. Brown Masked Gull. A clear brown mask, 
which terminates at the occiput; length of the tarsus one inch and a half; outer quill-feathers with white shafts. $13 \frac{1}{2}$ inches long. Inhabits Europe. B.-Tem. Man. 785.

L. minutus, Pallas. Pigmy Gull. Length of the tarsus 11 lines; shafts of the primary quills brown; wing-feathers tipt with pure white; legs, when extended, reaching only to three-fourths of the length of the tail ; hind toe very small, with an inconspicuous claw. 10 inches long. Inhabits Europe.-Tem. Man. 787.

L. Sabini, Tem. (Xema, Leach.) Sabine's Gull. The thigh feathered to within three-eighths of an inch of the knee; length of the tarsus 1 inch and a half; the hinder toe small, and placed high. 12 to 14 inches long. Inhabits Greenland.-Shan, xiii. pl. 20.

Gen. 6. Lesters, Illig.-Stercorarius, Briss.-Larus, Lin.

Bill middle-sized, hard, strong, cylindrical, sharp-edged, compressed, and hooked at the tip; upper mandible covered with a cere, the lower angulated; nostrils near the apex of the bill, diagonal, straight, closed behind; legs slender, naked above the knees; tarsi long; the three anterior toes completely webbed, the hind one nearly obliterated, and on a level with those before; claws large and much hooked; tail slightly rounded, with the two middle feathers elongated.

The birds which compose this genus are much bolder and intrepid than the gulls, which they persecute, and, compelling them to disgorge their food, catch it with great dexterity as it falls in the air. They likewise fasten on the carcasses of whales, and sometimes eat shell-fish. Their principal abode is in the northern regions; and they may be distinguished at a considerable distance by their jerking and leaping mode of flight. There is no very marked distinction between the sexes, but age imprints on their plumage very different shades of colouring, of which bistre-brown and white are the prevailing. The young are very unlike the full grown individuals.

L. catarractes, Tem. (Larus catarractes, Lin.) Brown or Skua Gull. Head and region of the eyes deep brown; neck and lower parts reddish gray, shaded with brown; back and scapulars dull red; quill-feathers white the half of their length, the other half deep brown; tail white; shape and dimensions of the bill similar to those of the same part in the herring gull; the projecting tail-feathers broad to the end; inconspicuous asperities on the hinder part of the tarsus, which is about two inches and a half in length. 20 to 21 inches long. Inhabits Northern Enrope. B.-Lewin's Brit. Birds, vi. pl. 211.

L. pomarinus, Tem. Pomarine Skua. Size and form of the bill as in the Larus eburneus; the two long feathers of the tail broad to the end, where they are rounded; marked asperities on the posterior part of the tarsus, which measures 1 inch 11 lines. 15 or 16 inches long. Inhabits Northern Europe.-Shaw, xiii. pl. 24.

L. parasiticus, Tem. Parasitic Gull. Face, top of the head, occiput, back, wings, and tail, uniform deep brown; feathers of the neck long, subulate, and of a golden yellow colour; throat, fore part of the neck, belly, and abdomen, white; a broad collar on the 
breast formed of brown spots ; bill of the shape and size of that of the Larus canus; the two middle tail-feathers much elongated, slender, and pointed at the extremities; a few warts on the hinder part of the tarsus, which measures 1 inch 7 lines. 14 or 15 inches long; the long tail-feathers 3 to 5 more. Inhabits Northern Europe.-Shaw, xiii. pl. 23.

\section{Gen. 7. Procellania, Lin.}

Bill as long as, or longer than the head, very hard, edged, depressed, and dilated at the base; the tip compressed and arched; both mandibles channelled, and abruptly inflected towards the extremity; nostrils prominent, at the surface of the bill, united and concealed in a tube, which either forms a single opening, or exhibits two distinct openings; legs middle-sized, often long, slender, the tarsi compressed; the three front toes entirely webbed and long, and the hinder represented by a pointed claw; wings long.

This genus is composed of a number of species, of which many are but little known to naturalists. All the species are semi-nocturnal, or seek their food in the morning or evening twilight, and conceal themselves in fissures of rocks, caverns, or holes during the day. They chiefly frequent those portions of the ocean that are the abodes of cetaceous animals, and are seldom seen along the shores, or at a distance from the sea, unless driven by violent gales from their ordinary stations. They feed on the flesh of the morse and whale, and on such mollusca, insects, and worms, as float on the surface of the ocean. They breed in the crevices of rocky cliffs, or the deserted burrows of quadrupeds, discharging a sort of oily liquid from their nostrils on those who attack them or their young. The female is rather smaller than the male, but not otherwise distinguishable; and the young are not so unlike the mature birds as in the two preceding genera. Temminck divides the genus into three sections, according to the structure of the nasal tube.

1. Petrels.-Bill thick, hooked, gibbous towards the point; nostrils united in a tube or furrow on the surface of the bill; tail rounded or conical.

P. glacialis, Lin. Fulmar Petrel. Plumage whitish; back hoary; bill and feet yellowish; nostrils composed of two tubes, lodged in a common sheath. 16 inches long. Inhabits Arctic Circle. B. -Shaw, xiii. pl. 27.

2. Puffin Petrels.-Bill generally longer than the head, slender, much compressed at the point; nostrils opening in two tubes approaching the surface of the bill.

P. puffinus, Lin. (P. cinerea, Gmel.) Puffin or Cinereous Petrel. Bill depressed at the base, channelled above, compressed and turgid at the tip ; nostrils consisting of two openings under a common sheath; bill two inches long; tarsi 1 inch 10 lines; tail conical. 18 inches long. Inhabits all seas.-Tem. Man. 805.

P. Anglorum, Tem. Manks Petrel. Bill very slender, 1 inch and 7 or 8 lines in length; tail rounded, the wings projecting a little beyond its extremity; length of the tarsus 1 inch 9 lines. 13 inches long. Inhabits Isle of Man, \&c.-Shaw, xiii. pl. 26. 
P. obscura, Gmel. Dusky Petrel. Bill very slender, 1 inch 1 line long; tail rounded, wings ending at its extremity; length of the tarsus 1 inch 6 lines; plumage dusky above, white beneath. 10 inches long. Southern Seas.-Tem. Man. 808.

3. Swallow Petrels.-Bill shorter than the head, much compressed at the point; nostrils in a single tube with two distinct orifices; tail square or slightly forked.

P. pelagica, Lin. Stormy Petrel, Mother Carey's Chicken. Tail square, extremity of the wings a very little exceeding its tip ; length of the tarsus 10 lines; head, back, wings, and tail, dull black; under parts sooty; a broad transverse and pure white band on the rump; scapulars and secondary wing-quills tipped with white; bill and legs black; iris brown. $5 \frac{1}{2}$ inches long. Inhabits Europe, \&c.-_Pen. Brit. Zool. ii. pl. 36.

P. Leachii, Tem. Head and body dull black; sides of the belly and upper tail coverts white, with the shafts brown; quills and tail black; tail forked, extremity of the wings not surpassing it; length of tarsus 11 lines. $7 \frac{1}{4}$ inches long. Inhabits St Kilda.Shan, xiii. pl. 25.

P. gigantea, Lath. Giant or Osprey Petrel. Plumage brownish, spotted with white above, white beneath ; shoulders, wings, and tail, brown; bill and legs yellow; a naked, wrinkled, yellow membrane at the corners of the mouth. $3 \frac{1}{2}$ feet long. Inhabits Southern Seas.-Shaw, xiii. 237.

Gen. 8. Pachy ptila, Illig.-Procellaria, Lath.

Bill thick, strong, much depressed, very broad; upper mandible gibbous on the sides, interior margin with cartilaginous plates ; ridge distinct, terminated by a compressed hook ; nostrils basal, opening by two apertures in a short tube; three toes before, with deeply cut membranes ; a short claw in place of the hind toe.

P. Forsteri. ( $P$. vittata, Lath.) Plumage above bluish ash, beneath white; quills, tail-feathers at the tip, and band on the expanded wings brown black. 12 inches long. Inhabits Southern Hemisphere.-Shan, xiii. 251.

Gen. 9. Haladroma, Illig.-Procellaria, Lath.

Bill short, straight, compressed, edged, furrowed longitudinally, tip hooked; lower mandible with a small dilatable and naked pouch; nostrils distinct, the base concealed under a tube; legs short; only three toes, directed forwards, palmated; wings short.

H. urinatrix. Diving Haladrome. Plumage dark brown above; chin black; white below. $8 \frac{1}{4}$ inches long. Inhabits New Zealand-Shaw, xiii. 257. 
Gen. 10. Dromedea, Lin.

Bill very long, stout, edged, compressed, straight, suddenly curved; upper mandible channelled on the sides, and much hooked at the point, the under smooth and truncated at the extremity; nostrils lateral, remote from the base, tubular, covered on the sides, and open in front; legs short, with only three very long toes, entirely webbed; the lateral one margined; wings very long and narrow, with the primary quills short, and the secondaries long.

D. exulans, Lin. Wandering Albatross, or Man of War Bird. Plumage above brown red, striped and spotted with dusky; white beneath ; the upper part and sides of the neck transversely striped with brown ; greater quills black; the lesser and tail dusky leadcoloured; bill yellowish ; feet reddish brown. $3 \frac{1}{2}$ to 4 feet long. Inhabits between the Tropics._Shaw, xiii. pl. 30 .

These birds are extremely voracious, preying on shoals of salnion in the mouths of rivers, and on the flying or other fishes, which they swallow whole, and in such quantities, as to be occasionally prevented by their weight from rising. They chiefly occur between the tropics. Towards the end of June they migrate in thousands to the coasts of Kamtschatka, the Sea of Ochotsk, \&c. The Kamtschadales catch these birds with rude hooks, baited with fish, chiefly for the sake of the bones of the wings, which they convert to various domestic uses.

D. fuliginosa, Lath. Sooty Albatross or Quaker Bird. General plumage brown ; head, bill, tail, quill-feathers, and claws, sooty brown; area of the eyes white. 3 feet long. Inhabits Southern Ocean.-Shaw, xiii. 263.

\section{Gen. 11. ANas, Lin.}

Bill middle sized, robust, straight, more or less depressed, covered by a thin skin, often deeper than broad at the base, which is furnished with a fleshy tubercle, or smooth; always depressed towards the tip, which is obtuse, and furnished with a nail ; edges of both mandibles divided into conical or flat lamellated teeth; nostrils almost at the surface of the bill, at some distance from the base, ovoid, half closed by the flat membrane that covers the nasal furrow; legs short, feathered to the knee, and placed near the abdomen; the three fore toes webbed, the hinder detached, and either destitute of a web, or having only a rudimentary one.

The birds which compose this numerous family swim with ease and gracefulness, feeding on fish, testacea, insects, vegetables, and grains. Some make use of their long necks to catch, with their submersed bill, the food most suited to their taste, and others dive, and remain a considerable time under water; a practice to which most of them have recourse when closely pursued. Many of the species are found on fresh, and others on salt water, or on the sea-shore. Their gait is awkward and hobbling. Most of them moult twice a-year, namely, in June and in November, the male only changing the colour of his plumage; assuming in June a part of that more appropriate to the female, and in November his bridal attire, which he retains till hatching time. The females moult'later than the males. When journeying in Iapland, in 1732, Linnæus observed the river Calix quite covered with birds 
of this genus for eight days successively, migrating to the sea in scarch of a warmer latitude. Their numbers, he tells us, exceeded those of the army of Xerxes. The larvæ of the common gnat, an insect which swarms in countless myriads in the moist and woody districts, during the short summer of these northern regions, supply whole legions of web-footed fowls with a favourite food.

1. GEESE.-Bill shorter than the head, a little conical, with conical dentations on the margins: neck of medium length.

A. hyperborea, Gmel. Blue-winged Goose. Forehead much elevated, yellowish; head, neck, and body white; quills white the half of their length, the rest black ; upper mandible red; lateral portion of the bill cut on each side by longitudinal channels and serratures. 2 feet 5 or 6 inches long. Arctic Regions.-Edw. Glean. pl. 152.

A. anser, Lath. The Wild Goose. Plumage cinereous above; pale beneath; the folded wings do not reach to the extremity of the tail; bill robust, thick, and of an uniform orange-yellow. 2 feet 8 or 10 inches long. Inhabits the eastern and central parts of Europe. B.-Shan, xii. pl. 41.

At the time of their migrations in Autumn, flocks of this species, consisting of from fifty to a hundred individuals, are often seen flying at very great heights, and their cry may be frequently heard when they are too elevated to be visible. On the ground they always arrange themselves in a line; and they seem to descend rather for rest than refreshment. Their flight is conducted with great regularity, for they always proceed either in a line abreast, or in two lines, joining in an angle at the middle, like the letter $\mathrm{V}$. In this order they generally take the lead by turns, the foremost falling back in the rear, when tired with cleaving the air, and the next in succession occupying its place. In these lofty flights they are seldom within reach of a fowling piece; and, even when they move in a lower track, they file so equally, that one discharge rarely kills more than a single bird. Their food consists of aquatic vegetables and all kinds of grain. Domesticated breeds of this species are reared in most countries; and in Britain great numbers are kept in the fens of Lincolnshire, several persons there having as many as a thousand breeders. They are stripped once a-year for their quilis, and no fewer than five times for the feathers. The first plucking for both commences about Lady.day, and the other four are between that and Michaelmas. It is alleged that, in general, the birds do not materially suffer from these operations, except cold weather happens to set in, when numbers of them die. The old ones submit quietly to be plucked, but the young ones are very noisy and unruly. These geese breed in general only once a-year, but, if well kept, sometimes twice. During their sitting, each bas a space allotted to it, in rows of wicker pens placed one above another. The goose lives to a great age, to eighty years it is said, or even to a hundred.

A. segetum, Gmel. The Bean Goose. Plumage ashy-brown above, whitish beneath ; scapulars and wing-coverts margined with whitish ; folded wings extending beyond the extremity of the tail; bill long, depressed, and of a dusky orange hue. $2 \frac{1}{2}$ feet long. Inhabits Arctic Regions. B.-Lewin's Brit. Birds, vi. pl. 239.

A. albifrons, Lin. White-Fronted Goose. Plumage above brown ash-coloured; quills black; secondaries tipped with white; breast and belly whitish, varied with black feathers; a large white spot on the forehead. 27 inches long. Inhabits Arctic Regions. $B$. -Don. Brit. Birds, v. pl. 102.

A. leucopsis, Tem. (Anas erythropus, Lin.) Bernacle Goose. Plumage cinereous, with black and white undulations above; neck, top of the breast, tail, and quills black ; face and belly white, bill, 
and legs black. 26 inches long. Inhabits Aretic Regions. B. -Levin's Brit. Birds, vii. pl. 242.

A. bernicla, Lin. Brent Goose. Head, neck, and top of the breast blackish; on the lateral part of the neck a space formed of blackish feathers, tipped with white; back, scapulars, and wing-coverts deep gray, terminated with brown; middle of the belly, crown, abdomen and tail-coverts white; secondaries and tail-feathers black; bill and legs black. 22 or 23 inches long. Inhabits Arctic Regions. B.-Bervick's Birds, ii. 311.

This species was long conceived to have been produced in the shell of the Lepas anatifera of Linnæus, growing on old timber; and even Gerard the botanist strongly asserts the improbable circumstance.

A. ruficollis, Lin. Red-breasted Goose. A white space between the eye and the bill, and white behind the eyes, and on the sides of the neck; a girdle of the same colour surrounds the lower part of the breast, and rises to the back ; top of the head, throat, belly, tail and all the upper parts deep black; abdomen, lower coverts of the tail, and rump, white. 20 to 21 inches long. Inhabits Arctic Regions.-Shaw, xii. pl 43.

2. Swans. - Nostrils pierced in the middle of the bill; neck very long.

A. cygnus, Lin. Wild, or Whistling Swan. Bill semicylindrical and black; cere yellow; body white; head and nape very slightly tinted with yellowish; iris brown; legs and feet black. 4 feet 5 to 4 feet 9 inches long. Arctic Regions.-Shaw, xii. pl. 37.

The Whistling Swan inhabits Europe, Asia, and America, affecting chiefly the northern regions of the globe, and appearing in small flocks of eight or ten on the coasts of England and France in hard winters : but on the approach of spring they quit their southern stations, and again retire northward, to breed. A few, howcver, remain in the Hebrides, the Shetland and Orkney islands. In the two latter, and in the Faroe islands, large flocks of them annually arrive in October, and pass the winter about the numerous fresh water lakes. Early in spring they take their departure for the Arctic Regions. Great bodies of them occur on the large rivers and lakes near Hudson's Bay, and those of Kamtschatka, Lapland, and Iceland. They are said to resort to the last mentioned island in flocks, of about a hundred at a time, in spring, and also to pour in on it from the north, in nearly the same manner, on their way south, toward the close of autumn, flying very high in the air, and in such compact array, that the bill of the one seems to touch the tail of the other. In their flight they emit a note, which has been expressed by whoogh, rohoogh, and which is very loud, hoarse, and shrill, but not disagreeable when heard at a distance and modulated by the breeze. The Icelanders compare it to the sound of the violin; and, when heard at the end of their long and dreary winter announcing the approach of genial weather, it will no doubt be associated in their minds with all that is agreeable. But the musical notes of the swan, and its dying strains, so often alluded to by the ancient writers, have no further support than the lively imagination of the poet.

A. olor, Lin. Tame or Mute Swan. Bill red; fleshy tubercle at the base and edges of the mandibles black; the body white. $4 \frac{1}{2}$ feet long,-Shaw, xii. pl. 38.

Nothing can exceed the graceful and elegant appearance of these birds, when glid. ing along the surface of the water. Multitudes of this species are found in Russia and Siberia, as well as farther south, in an unreclaimed state. They likewise occur without any owner, on the Trent, on the inlet of the sea near Abbotsbury in Dorsetshire, and on some rivers and lakes in different parts of the British isles. Those on the Thames have been for ages protected as royal property; and it is still reckoned 
felony to steal their eggs. In former times, great numbers were reared for the table ; but they are now reckoned by most a coarse sort of food. A fattened cygnet, however, is still accounted a delicacy. It is generally believed that the swan lives to a great age. The young do not acquire their full plumage till the second year.

3. Ducks. - Bill much depressed, broad towards the extremity, and the serratures long and flat; the hind toe detached and unwebbed, or with the rudiment of a free membrane.

* Hind toe without a membrane.

A. rutila, Pallas. Ruddy Shieldrake. Plumage reddish-brown; head and upper half of the body mouse gray; collar and quill-feathers black; rump and tail greenish black; middle wing-coverts tipped with white ; bill black. 20 inches long. Inhabits Eastern Europe, \&c.-Tem. Man. 832.

A. tadorna, Lin. Sheldrake or Shieldrake. Head and neck dusky green ; lower part of the neck, wing-coverts, back, flanks, rump, and base of the tail white; scapulars, a broad band at the middle of the belly, abdomen, quills, and extremity of the tail-feathers black; a red band on the breast; bill, and fleshy protuberance on the forehead blood red; legs Hesh-coloured. Inhabits Europe. B. -Shan, xii. pl. 45.

A. boschas, Lin. Wild Duck or Mallard. Head and neck deepgreen ; upper parts striped with very fine zigzag cinereous and whitish lines; speculum of the wing violet green ; four middle tail-feathers recurved into a semicircle; bill yellowish green; legs orange. 1 foot 9 or 10 inches long. Inhabits Northern Europe and America.-Don. Brit, Birds, v. pl. 124.

This species, the origin of the domestic varieties, inhabits the northern countries of the globe, and migrates southward in large bodies in autumn, when they spread themselves over the lakes and humid wastes of the more temperate latitudes. Considerable numbers return northward in the spring; but many remain in Britain throughout the year. They breed only once in the year, the pairing time commencing about the end of February or the beginning of March. The incubation lasts thirty days, and in three months the young are able to fly. The reclaimed breeds of this species assume very various markings, but the male, or Drake, even in confinement, retains the curling of the tail-feathers. The Chinese hatch numbers by means of artificial heat. Great quantities of the wild species are annually taken in the fens of Lincolnshire by means of ingeniously contrived decoys.

A. strepera, Lin. Gadwall Duck. Head and neck marked with brown points, on a gray ground; under part of the neck, the back, and breast, with black crescents; the scapulars and flanks with blackish and white rigzag lines; middle wing-coverts rufouschestnut; great coverts, rump, and under tail-coverts, deep black; bill black; tarsi and toes orange; webs blackish. 18 or 19 inches long. Northern Europe. B.-Lewin's Brit. Birds, vii. pl.258.

A. acuta, Lin. Pintail Duck. Top of the head varied with brown and blackish; cheeks, throat, and top of the neck brown, with violet and purple reflections; a black band on the nape, bordered with two white ones; under part of the body white; back and flanks with rigzag black ash-coloured lines; two middle feathers of the tail elongated, greenish black. 23 or 24 inches long. Northern Europe and America. B.-Lenin's Brit. Birds, vii. pl. 261. 
A. Penelope, Lin. The Widgeon. Head and neck red chestnut; forehead whitish yellow; throat black; breast wine-coloured; wingcoverts and lower parts whitish; speculum of the wing of three bands, the middle one green, the lateral deep black; scapulars black, edged with white; back and flanks with zigzag black and white lines; bill blue, black at the tip. 18 inches long. Inhabits Northern Europe. B.-Lewin's Brit. Birds, vii. pl. 251.

A. clypeata, Lin. Shoveler Duck. Head and neck deep green, with reflections; belly and flanks red chestnut; wing-coverts blue; scapulars white, with blackish points and spots; bill broad, rounded like a spoon, brownish black, yellowish beneatl. 18 inches long. Inhabits Europe--Shan, xii. pl. 48.

A. querquedula, Lin. The Garganey Teal. A white band on the sides of the head; small wing-spot cinereous green; throat deep black; head and neck reddish brown, with small white points; a white band on the middle of the scapulars; wing-coverts bluish; belly whitish yellow; zigzag black lines on the flanks; bill blackish. 16 inches long. Inhabits Europe. B.-Shaw, xii. pl. 51.

A. crecca, Lin. The Common Teal. Head, cheeks, and back chestnut red; a broad green band extends from the eyes to the nape; lower part of the neck, back, scapulars, and flanks striped with black and white zigzag lines; breast reddish, with round spots ; belly yellowish white; speculum of the wings half white and half black, edged with two white bands; bill blackish. 14 inches long. Northern Europe. B.-Lewin's Brit. Birds, vii. pl. 260.

The flesh of this species was much prized by the Roman epicures, and is still in request for the table.

\section{** Hind toe with a loose membrane.}

A. mollissima, Lin. Eider or St Cuthbert's Duck. On each side and above the eyes a broad band of black violet; cheeks, a band on the top of the head and occiput greenish white; back, scapulars, and smaller coverts white; breast reddish white; belly and rump deep black; base of the bill laterally prolonged into two flattened plates on the forehead; bill and legs greenish-ash. 21 to 22 inches long.-Shaw, xii. pl. 60.

This species inhabits the high and icy latitudes of Europe, Asia, and A merica, and feeds chiefly on testaccous animals and fish. They are very abundant during summer in all the islands situated in the Greenland sea. Their appearance in great numbers is an indication of the proximity of land. They are capable of protracted flights in the day time, but generally return to their stations at night. They are rarely, if ever, seen in the south of England, but they breed in the Orkneys and the Hebrides in June and July. The nest is composed of marine plants, and lined with down of exquisite fineness, which the female plucks from her own body. The eggs are usually four, of a pale olive green, and rather larger than those of a common duck. About Iceland the eider ducks generally build their nests on small islands not far from the shore. When the collectors come to the nest, they carefully remove the female, and take away the superfluous down and eggs. They then replace the mother, and she begins to lay afresh, covering the eggs with new down; and this is repeated several times. When the young ones leave the nest, it is once more plundered. The best down and most eggs are got during the first three weeks of her laying; and it has been generally observed, that they lay the greatest number of eggs 
in rainy weather. One female, during the time of laying, usually yields half a pound of down, which, however, is reluced one-half after it is cleaned. It is extremely soft and warm, and so light and elastic, that two handfuls squeezed together are sufficient to fill a quilt five feet square. A large quantity is procured every year from Iceland by the merchants of Copenhagen.

A. spectabilis, Lin. King Duck or Gray-headed Duck. Top of the head, occiput, and neck of a fine bluish gray ; cheeks shining sea green; upper part of the back, wing-coverts, and two large spots on each side of the rump white; breast reddish white; lower part of the back, wings, tail, and under part of the body deep black; base of the bill laterally prolonged on the forehead into two processes, which rise in the form of crests; bill and legs of a fine vermilion hue. 22 to 24 inchès long. Inhabits the Frozen Ocean. -Levin's Brit. Birds, vii. pl. 245.

A. perspicillata, Lin. Black Duck. Plumage black, with the crown and nape white; two long protuberances on the lateral part of the bill; no speculum on the wings. 20 inches long. Inhabits North America.-Edw. Glean. pl. 155.

A. fusca, Lin. Velvet or Great Black Duck. No protuberance at the base of the bill; wing-spot small and white; tarsi and toes red; almost the whole plumage of a deep velvet black; a white crescent under the eyes; webs black. 20 to 21 inches long. Inhabits N. Europe, \&c. B.-Penn. Brit. Zool. ii. pl. 41.

A. nigra, Lin. Black Diver. Plumage wholly black; no wingspot; a spherical protuberance on the base of the bill; nostrils and a longitudinal band on the bill orange; naked circle of the eyes yellow ; tail very conical ; toes brown, membrane black. 16 inches long. Inhabits Arctic Regions.-Shaw, xii. pl. 59.

A. leucocephala, Lath. Ural Duck. Top of the head deep black; forehead, cheeks, and throat white; lower parts of the neck and nape black ; breast, upper parts of the body, and flanks fine deep red, with zigzag lines of brownish-black; bill very broad, blue; wings very short ; tail long, conical. 15 to 16 inches long. Inhabits salt lakes in Eastern Europe.-Tem. Man. 859.

A. glacialis, Lin. Long-tailed Duck. Plumage white, with a large brown-chestnut spot on the sides of the neck ; breast, back, rump, and part of the wings black; bill very short, black, with a transverse red band; two middle tail-feathers very long, sooty brown. 21 inches long. Inhabits Arctic Seas. B.-Shaw, xii. pl. 58.

A. rufina, Pallas. Red-Crested Duck. Back and wings brown; head and neck reddish-brown ; breast, belly, and abdomen deep black; a tuft of long silky feathers on the head; bill long, depressed towards the point. 20 inches long. Inhabits Northern Europe.-Tem. Man. 864.

A. Marila, Lin. Scaup or White-faced Duck. Head and upper part of the neck black, with green reflections; lower part of the breast and rump deep black; top of the back and scapulars whitish, with distant fine zigzag lines; wing-coverts marbled black 
and white; bill broad; wing band white. 17 to 18 inches long. Inhabits Arctic Regions. B.-Lewin's Brit. Birds, vii. pl. 250.

A. ferina, Lin. Red-Headed Widgeon. Head and neck bright red; upper part of the back, breast, and rump black ; back, scapulars, coverts of the wings, flanks, thighs, and abdomen pale cinereous, with numerous zigzag lines; bill long, with a blue transverse band on the upper mandible. 16 inches long. Inhabits Northern Europe.-Pen. Brit. Zool. ii. 271.

A. clangula, Lin. Golden Eye. Bill very short; base broader than the tip ; nostrils situated near the latter; tarsi and toes yellowish; back, rump, and part of the scapulars deep black; coverts of the wings and under parts white; tail cinereous; iris brilliant yellow. 17 inches long. Inhabits Arctic Regions. B.-Shan, xii. pl. 56.

A. fuligula, Lin. Tufted Duck. Body black; abdomen and speculum of the wing white; point of the bill broader than the base; nostrils near the base; tarsus, bill, and toes bluish, membranes black. 15 to 16 inches long. Arctic Regions.-Shaw, xii. pl. 54.

A. leucophthalmos, Bechst. Ferruginous Duck. Plumage dark olivaceous, with the head, neck, and breast chestnut; bill long : iris white; speculum of the wing white, terminated by black; a white spot under the bill. 15 inches long. Inhabits Eastern Europe. B.-Shaw, xii. pl. 55.

A. histrionica, Lin. Harlequin Duck. Head and neck blackish violet; a large white space between the bill and eye; a spot behind the eyes, longitudinal band on the sides of the neck, collar, a half crescent on the sides of the breast, and part of the scapulars pure white ; lower part of the neck and breast blue cinereous ; flanks reddish ; belly brown; back, wings, and rump black, with green and blue reflections; bill short, compressed; nostrils approaching. 16 inches long. Inhabits Arctic Regions. B.Shan, xii. pl. 57.

\section{Gen. 12. Mergus, Lin.}

Bill middle-sized or long, slender, in the form of an elongated cone, and almost cylindrical, base broad; tip of the upper mandible much hooked, and furnished with a nail; edges of both mandibles serrated in a backward direction; nostrils lateral, towards the middle of the bill; legs short, placed backwards on the abdomen, the three fore toes completely webbed, the hind toe articulated on the tarsus.

The birds of this tribe are nearly allied to the ducks, residing on the water, and usually swimming with the body submerged, the head only appearing above the surface. They dive frequently, and with great facility; while, by means of their wings, they can advance quickly under water. They are capable, too, of sustaining a protracted and rapid flight. They feed principally on fish and amphibious reptiles. Their appropriate and breeding stations are in the cold latitudes, and they appear in the temperate regions only in winter. The males moult in the spring, and the females and the young in autumn.

M. merganser, Lin. Goosander. Head and upper part of the neck vol. I. 
black, with green reflections; lower part of the neck, breast, belly, abdomen, and coverts of the wings white, shaded with rose-yellow ; top of the back and scapulars next to the body deep black; wing speculum white, without transverse bands; male with a thick and short tufted crest. 26 to 28 inches long. Inhabits Arctic Regions. B.-Shaw, xii. pl. 53.

M. serrator, Lin. Red-breasted Merganser. Wing-spot white, crossed by two black bars in the male, and by one in the female; the mature male with a long and filamentous crest; head, tuft, and upper part of the neck black, with green reflections; a white collar round the neck; five or six large white spots, bordered with black at the insertion of the wings; belly white; bill and iris red. 20 inches long. Northern Europe. B.-Don. Brit. Birds, ii. pl. 38.

M. albellus, Lin. Smew or White Nun. Crest pendant; occiput greenish-black; body white; back and temples green-black; wings variegated with white, ash-coloured and black; tail ash-coloured; flanks and thighs varied with ash-coloured zigzag stripes; bill, tarsi, and toes bluish ash-coloured. 15 to 16 inches long. Inhabits Europe. B.-Shaw, xii. pl. 52.

Gen. 13. Pelecanus, Lin.

Bill long, straight, broad, much depressed; upper mandible flattened, terminated by a nail, or very strong hook; the lower formed by two bony branches, which are depressed, flexible, and united at the tip; from these branches is suspended a naked skin, in form of a pouch; face and throat naked; nostrils basal, in the form of a narrow longitudinal slit; legs short and stout; all the four toes connected by a web.

The Pelicans are large birds, residing on rivers, lakes, or along the sea-coasts. Though excellent swimmers, they also occasionally perch on trees. They are gregarious, very fond of fish, and when harassed or pursued readily reject the contents of their stomach, like the gull tribe. They store up their prey in their gular pouch, from which it is gradually transferred into the œsophagus, as the process of digestion goes on. Though remarkable for their voracity, some of the species have been trained to fish for mankind. In external appearance the two sexes very nearly resemble each other.

P. onocrotalus, Lin. White or Common Pelican. Plumage white, faintly tinged with flesh colour, except the quills, which are black; upper part of the bill bluish, yellowish in the middle, and the margins reddish; face naked; pouch bright yellow. 5 to 6 feet long. Inhabits Eastern Europe.-Shaw, xiii. pl. 12.

This bird has its specific name from its cry, which is loudest during flight, and which the ancients compared to the braying of an ass. During the summer months many of them take up their abode on the borders of the Black Sea and the shores of Greece. They are rare in France, and unknown in Great Britain. In fishing, they do not immediately swallow their prey, but fill their bag, and return to the shore to consume at leisure the fruits of their industry. The female feeds her young with fish from her pouch.

P. Australis, Lath. Plumage white, with the upper part of the back, quills, and tail black. 5 feet long. Inhabits New Holland.-Shan, xiii. 113. 
Gen. 14. Савво, Meyer--Pelecanus, Lin.-Phalacrocorax, Cur.-Hydrocorax, Vieill.

Bill middle-sized, or long, straight, compressed; upper mandible much bent at the tip, the lower compressed; base of the bill involved in a membrane which extends to the throat; face and throat naked; nostrils basal, linear, and concealed; legs strong, short, situated far behind; all the toes included in a web, and the middle claw serrated.

The birds which compose this genus are very expert divers, and swim with ease under water. They feed much on river fish, especially eels, and they are more addicted than the pelicans to perch on trees. Their moulting is partially double.

C. cormoranus, Meyer. (P. Carbo, Lin.) The Cormorant or Corvorant. Top of the head, neck, breast, lower parts, and rump, blackish green, with reflections; small whitish stripes on the neck; feathers of the back and wings brown cinereous or bronze in the middle, bordered with blackish green; quills and tail black; tail of 14 feathers; guttural pouch small, yellowish ; iris green; legs black; bill 2 inches 3 lines longer than the head. 27 to 29 inches long. Inhabits Northern Europe. B.-Shaw, xiii. pl. 10.

The Cormorant is not uncommon on many of our own shores, building its nest of sticks, seaware, and grass, on the highest parts of cliffs that impend over the sea, and laying three or more green eggs about the size of those of a goose. Cormorants were formerly occasionally trained in this country to catching fish for the table. For this purpose they were kept with great care in the house, and when taken out for fishing, they had a leathern thong tied round their neck, to prevent them from swallowing their prey. Mr Patrick Neill, a zealous and able naturalist, has long preserved tame specimens in his collection at Canonmills.

C. graculus, Meyer. The Shag or Green Cormorant. Head, throat, neck, and lower parts greenish-black; feathers of the back and wings cinereous in the middle, bordered with black; tail very long, graduated, conical, composed of twelve feathers; bill 1 inch 10 lines longer than the head. 23 to 24 inches long. Inhabits Europe, \&c. B.-Lewin's Brit. Birds, vii. pl. 264.

C. cristatus, Tem. Crested Cormorant. Body glossy green, obscure beneath; head crested; bill very long, slender, 2 inches 4 lines longer than the head; tail very short, composed of 12 feathers. 2 feet 1 or 2 inches long. N. Europe. B.-Pen. Brit. Zool. ii. pl. 47.

C. pygmaus, Tem. Dwarf Cormorant. Plumage above blackish cinereous, each feather bordered with a black band; bill 1 inch 2 lines shorter than the head; tail long, graduated, of 12 feathers; scapulars and coverts of the wings long; breast greenish; legs cinereous. 21 inches long. Eastern Europe-Tem. Man.901.

Gen. 15. Tachypexes, Vieill,-Pelecanus, Lin.

Bill long, stout, edged, depressed at the base, flattened at the sides, with a suture above; tips of both mandibles strongly curved, and the upper terminated by a very pointed hook; nostrils more or less concealed, and linear; legs placed far back, very short; tarsus shorter than the toes, and half-fea 
thered ; the three fore-toes long, and half-webbed; wings very long and straight; tail much forked.

T. aquilus, Vieill. (Pelecanus aquilus, Lath.) Frigate Bird. Body and orbits black, glossed with green; bill red; belly of the female white. The old male has a bright red fleshy membrane under the throat. 3 feet long. Southern Seas. - Shaw; xiii. pl. 13.

This species has its English name from its lengthened form, rapid movement, and the spirited manner in which it attacks the birds which it compels to disgorge.

\section{Gen. 16. Sula, Briss.-Pelecanus, Lin.}

Bill long, stout, in the form of an elongated cone, very thick at the base, compressed towards the tip, which is obliquely curved; cleft beyond the eyes; edges of both mandibles serrated ; face and throat naked; nostrils basal, linear, concealed ; legs short, stout, placed far behind, all the toes connected by a web; claw of the middle toe serrated; wings long; tail conical, and composed of twelve feathers.

S. alba, Meyer. (P. Bassanus, Lin.) The Gannet or Soland Goose. Top of the head and occiput ochre-yellow; the rest of the plumage milk-white, except the quills of the bastard wing, which are black; bill bluish, cinereous at the base, white at the point ; naked membrane surrounding the eyes blue; the membrane which forms the prolongation of the opening of the bill, and that extending on the middle of the throat blackish-blue; iris yellow ; claws white; tail conical. 2 feet 7 or 8 inches long. Inhabits Northern Europe, \&c. B.-Shan, xiii. pl. 11.

This species chiefly haunts the northern regions of the two continents. They breed abundantly on the Bass Island in the Firth of Forth, on Ailsa, off the coast of Ayrshire, the Skellig Isles, on the coast of Kerry in Ireland, the Islands of St Kilda, Orkney, Shetland, Faroe, \&c. The Gannet arrives in the districts which we have just meutioned in March, and continues till September; and a few seem to stay about their breeding stations all winter. The female lays one egg, or more frequently two, which are white, of a rough surface, a long shape, and remarkably small for the size of the bird, being scarcely larger than those of a duck. The male and female incubate, and go a-fishing by turns. The young begin to be taken in August, and are sold every season in numbers in the markets of Edinburgh.

S. candida, Briss. (P. piscator, Lin.) The White Gannet. Body white; face red; quills black. 2 feet 7 inches long. Inhabits China and New Holland.-Shaw, xiri. 103.

Gen. 17. Plotus, Lin.

Bill long, perfectly straight, slender, spindle-shaped, sharppointed; edges of the upper mandible dilated at the base, but compressed and inflected in the other portions; both mandibles finely serrated; nostrils linear, and hid in a shallow groove; legs short, thick, and strong, tarsus much shorter than the middle and outer toe; all the toes connected by a web ; wings long; tail very long.

P. melanogaster, Lath. The Black-bellied Darter. Back, scapu- 
lars, and wing-coverts brownish ; lower part of the neck, sides, and wing-coverts with oval white spots; scapulars streaked longitudinally with white; a dull rufous bar across the breast; belly, quills, and tail black; bill dusky yellow, covered at the base with a skin of the same coluur. 3 feet 3 inches long.Shaw, xiii. pl. 15.

P. anhinga, Lin. The White-bellied Darter. Head small, and neck long and slender; throat and fore part of the neck gray; upper part of the back and seapulars dusky-black; lower part of the back, rump, and upper tail-coverts black; under parts pure silvery-white ; tail of twelve broad glossy black feathers. 2 feet 10 inches long. Inhabits Brazil.-Shaw, xiii. 132.

\section{Gen. 18. Phaeton, Lin.}

Bill as long as the head, thick, stout, hard, sharp-edged, much compressed, pointed, slightly sloped from the base; edges of the mandibles widened at the base, compressed and serrated in the rest of their length; nostrils basal, lateral, covered above and near the base by a naked membrane, and pervious ; legs very short, placed far back, all the toes connected by a web; wings long; tail short, but the two filamentous middle feathers very long.

P. phoenicurus, Lin. Common Tropic Bird. Plumage of a roseate flesh-colour; bill, and two middle tail-feathers red; superciliary band and the legs black; two middle tail-feathers very long. 2 feet 10 inches long, including tail-feathers. Inhabits South Seas. -Shan, xiii. pl. 14.

These birds are well known to navigators, and generally announce their approach to the tropics. They are capable of supporting long flights, and of reposing on the water, feeding on the flying and other fishes that approach the surface. They rarely alight on the ground, and walk awkwardly; but they glide through the air or along the water with grace and agility. They brced in desert or unfrequented islands.

\section{Gen. 19. Colymbus, Lath.}

Bill of medium size, straight, very pointed, compressed; nostrils basal, lateral, concave, oblong, half closed by a membrane; legs placed far behind; tarsi compressed; the three fore toes very long, and webbed; the hinder short, with a loose rudimentary web; wings short; tail very short and rounded.

The species of this genus reside chiefly in the water, and are almost habitual divers. On the land, which they scarcely ever visit but in the breeding season, they walk with difficulty. They nestle on small islands or headlands, generally lay two eggs, and devour quantities of fish and their fry, marine insects, and even vegetable productions. The plumage of the young is very different from that of the adult birds.

C. glacialis, Lin. Great Northern Diver. Head, throat, and neck greenish black, with bluish reflections ; back, wings, flanks, and rump deep black; feathers of the back and scapulars with two white square spots at the extremity ; breast and lower parts white; upper mandible almost straight, the under bent upwards, broad 
in the middle, and channelled beneath ; length of the bill 4 inches, and from 1 to 4 lines, according to the age. 27 to 29 inches long. Inhabits Arctic Regions. B.-Shaw, xii. pl. 61.

C. arcticus, Lin. Black-throated Diver. Head and nape brown cinereous; throat black, with violet reflections; back, rump, and flanks black, without spots; scapulars banded transversely with 12 or 13 white bands; apper mandible slightly bent upwards; the middle of the lower mandible of the same breadth with the base, without grooves below; length of the bill 3 inches 3 to 6 lines. 24 to 26 inches long. Aretic Regions. B.-Penn. Brit.Zool. ii. pl.30.

C. septentrionalis, Lin. Red-throated Diver. Sides of the head, throat, and sides of the neck, mouse-coloured; top of the head with black spots; occiput, posterior and inferior part of the neck with longitudinal black and white bands; on the fore part of the neck a long band of bright chestnut; breast and lower parts white; flanks and upper parts blackish brown; bill straight, slightly bent upwards; edges of both mandibles bent inwards; length of the bill 2 inches 10 lines or 3 inches. 21 to 24 inches long. Inhabits Arctic Regions.-Penn. Brit. Zool. ii. pl. 30.

Gen. 20. Uria, Briss. Tem.-Colymbus and Alca, Lin. Bill middle-sized, or short, stout, straight, pointed, compressed ; upper mandible slightly bent towards the point, the lower forming an angle more or less open; nostrils basal, lateral, concave, longitudinally cleft, half-closed by a broad membrane covered with feathers, and pervious; legs short, placed far behind; tarsi slender; only three toes before, entirely webbed; wings short.

The Guillemots, like the Divers, inhabit the northern seas, are little fitted for moving on land, and seldom venture on shore except in breeding time, or when impelled by tempests. During the rigour of their native clinuates, they migrate southwards, along the coasts of some of the countries of Europe. They dive with great facility, and swim nimbly under water. They breed in company, in the holes of rocks, each female laying only one large egg. They moult twice a-year, and the complete winter plumage of the sexes is the same; nor do the young materially differ in their markings from the mature birds.

\section{* Bill longer than the head.}

U. troile, Lath. (Colymbus troile, and Colymbus minor, Gmel.) Foolish or Lesser Guillemot. Upper parts velvety-black, slightly cinereous; lower parts white; bill much compressed in its whole length, longer than the head; wings of an uniform colour, but the secondaries tipped with white; legs dusky. 15 to 17 inches long. Northern Europe. B.-Shan, xii. pl. 62, fig. 1.

U. Brunnichii, Sabine. Body fuliginous; breast and abdomen snow white; secondary quills white on the tip; bill dilated, broad at the base, as long as the head; wings with the secondary feathers tipped with white; legs greenish. 18 inches long. Inhabits. Northern Ocean_-Shan, xii. pl. 62, fig. 2. 
U. grylle, Lath. (Colymbus grylle, Lin.) Black or Spotted Guillemot. Black above, white beneath, and on the cheeks; a large white patch on the middle of the wings; legs red; iris brown. 14 inches long. Inhabits Northern Ocean. B.-Shav, xii. pl. 64.

* Bill shorter than the head.

U. alle, Tem. (Alca alle, Lin. Mergulus, Vieill.) Little Auk, or Small Black and White Diver. Plumage above black; under parts and tips of posterior quills white; bill very short, about half as long as the head, and very little arched. $8 \frac{1}{2}$ inches long. Inhabits the Polar Regions.-Shan, xiii. pl. 3.

These birds inhabit the northern seas, at least as high as latitude $76^{\circ}$, where they abound among the channels between the floes of ice. During storms or intense cold some of them are impelled into more southerly climates. They feed much on a small species of crab, and breed in the holes and crevices of craggy rocks, the female laying one bluish-green egg, generally without spots, but sometimes minutely sprinkled with dusky.

\section{Gen. 21. Phaleris, Tem.-Alca, Lath.}

Bill shorter than the head, depressed, dilated on the sides, nearly quadrangular, notched at the tip, the lower mandible forming a salient angle; nostrils marginal, in the middle of the bill, linear, half-concealed, and pervious; legs short, placed far behind; tarsus slender; three toes before; claws much bent ; wings middle-sized, the first quill longest.

P. cristatella, Tem. (Alca cristatella, Lath.) Tufted Stariki or Tufted Auk. Body dusky; back with rusty spots; a tuft on the forehead, composed of several short feathers, from the middle of which rise six long filamentous and silky ones, which bend forward on the bill; bill red. 12 inches long. Inhabits Islands between Asia and America.-Shaw, xiii. pl. 5.

P. Psittacula, Tem. Body dusky, abdomen white; face produced and straightened towards the base of the bill ; bill red ; legs dirtyyellow; membrane brown. Size of a blackbird. Inhabits Kamtschatka.-Shaw, xiii. 44.

Gen. 22. Mormon, Illig.-Alca, Lin.-Fratercula, Vieill.

Bill shorter than the head, deeper than long, and much compressed; both mandibles arched, transversely furrowed, and notched towards the tip; ridge of the upper mandible elevated above the level of the skull; nostrils lateral, marginal, linear, naked, almost wholly concealed by a large naked membrane; legs short, placed far behind, furnished with only three toes, all directed forwards and webbed; claws much hooked; wings short.

The birds of this genus are nearly allied to the Guillemots and the Penguins, with the last of which they have been generally classed. They fly less than the former, and are seldom found on land except during the breeding season.

M. fratercula, Tem. (Alca arctica, Lin.) The Puffin. Top of the 
head, all the upper part, and a large collar surrounding the neck of a deep lustrous black; quills slackish-brown; a broad band above the eyes, and the throat clear gray; breast and belly white; bill compressed, cinereous at the base, yellow in the middle, and red at the point; upper mandible with three grooves, the under with two; naked margins of the eyes red; legs orange. $12 \frac{1}{2}$ inches long. Northern Europe. B.-Shan, xiii. pl. 4 .

M. glacialis, Tem. Northern Puffin. Body black; cheeks slatywhite ; breast and abdomen white ; bill pale, with the base black. Inhabits Northern Regions.-Shan', xiii. 40.

M. cirrhata, Tem. Tufted Puftin. Body dusky; forehead, sides of the head and throat white; eyebrows white, with an elongated crest rising over each eye. 19 inches long. Inhabits Kamtschatka.-Shaw, xiii. 40.

\section{Gen. 23. Alca, lin.}

Bill straight, broad, compressed, much bent towards the tip, both mandibles half covered with feathers, and grooved near the point, the upper hooked, the lower forming a salient angle; nostrils lateral, marginal, linear, situated near the middle of the bill, almost entirely closed by a membrane, and covered with feathers; legs short, placed far behind, with three toes directed forwards and palmated; wings short.

The Auks have nearly the same habits as the other marine arctic birds, seldom being seen on land, except for the purpose of breeding, and resembling the Guillemots, in particular, in their mode of life, and in laying one large egg.

A. torda, Lin. Razor-billed Auk. Body black, beneath from the middle of the throat white; a white line on each side from the bill to the eyes; wings ending at the rump ; tail in the form of an elongated cone, $14 \frac{1}{2}$ inches long. Inhabits Arctic Regions. B.-Don. Brit. Birds, iii. pl. 64.

A. impennis, Lin. Great Auk or Penguin. Body black; under parts from the middle of the throat, the tips of the secondary quills, and an ovate spot before the eyes, white; wings destitute of feathers capable of flight; tail short. 2 feet 1 or 2 inches long. Inhabits Northern Regions. - Shan, xiii. pl. 6.

Gen. 24. Spheniscus, Briss.-Aptenodytes, Lath.-Eudyptes, Vieill.

Bill shorter than the head, compressed, very thick, strong, straight, hooked at the tip, obliquely grooved; edges of both mandibles bent inwards, the under covered with feathers at the base, and truncated, or obtuse at the tip; nostrils small, lateral, placed near the middle of the bill, and cleft in the furrow; legs very short, thick, placed very far behind; four toes directed forwards, of which three are webbed, and the fourth is little more than a tubercle; wings incapable of flight. 
The birds of this genus inhabit the South Seas, from the equator to the antarctic circle, and are analogous to those of the preceding in food and habits. They are fortified against cold by an abundance of fat; they swim very swiftly; and on land they cackle like geese, but in a hoarser tone.

S. demersus, Tem. Cape Penguin. Bill and legs black; eyebrows white ; pectoral band black; plumage black above, white beneath. 21 inches long. Cape of Good Hope, \&c.-Shan, xiii. pl. 9.

S. minor, Tem. Little Penguin. Bill of the same conformation as the preceding, with the upper mandibles blackish, and the in-ner blue at the base; plumage above ash-blue, and dusky-brown at the origin of the feathers; the under parts white. 14 inches long. Inhabits New Zealand.-Shaw, xiii. 61.

S. chrysocome, Tem. Crested Penguin. Bill red, brown, three inches long; upper mandible curved at the end, the lower obtuse ; an erect, frontal, and reflexed auricular crest of a sulphur colour; head, neck, back, sides, and wings black; legs yellowish. 2 feet long. Inhabits Falkland Islands.-Shaw, xiii. pl. 8.

\section{Gen. 25. Aptenodytes, Forster.}

Bill longer than the head, slender, straight, inflected at the tip; upper mandible furrowed throughout its length, the under wider at the base, and covered with a naked and smooth skin; nostrils in the upper part of the bill, concealed by the feathers of the forehead; legs very short, thick, placed very far behind; four toes directed forwards, three of which are webbed, and the fourth very short; wings incapable of flight.

A. Patachonica, Lath. (Eudyptes, Vieill.) Patagonian Penguin. Bill and legs black; ears with a golden spot; lower mandible tawny at the base ; irides hazel; head and hind part of the neck brown; back dark-blue ; breast, belly, and vent white. 4 feet 3 inches long. Inhabits South Sea Islands.-Shaw, xiii. pl. 7 .

The A. Chiloensis, is the only other known species.

\section{ORDER XVI.-INERTES.}

Bill of different forms; body probably thick, covered with down and feathers with distant webs; legs placed much behind; tarsus short; three toes before, divided to the base; hind toe short, articulated exteriorly; claws thick and sharp; wings improper for flight.

Temminck places in this order two genera of little known birds, which are connected in some respects with the Sphenisci and Aptenodytes, though their divided toes approach them to the Cursores.

Gen. 1. Apteryx, Shaw.

Bill very long, straight, subulate, soft, furrowed in all its length, inflected and gibbous at the point; base covered by a cere 
furnished with hair; nostrils opening near the point of the mandible, at the end of a tubular furrow; legs short, feathered to the knees; wings rudimentary, terminated by a spur.

A. Australis, Shaw. Southern Apteryx. Ferruginous-gray, with yellowish-brown bill and legs. $2 \frac{1}{2}$ feet long. Inhabits New Zealand.-Shaw, Nat. Mis. xxiv. pl. 1057, 1058.

\section{Gen. 2. Didus, Lin.}

Bill long, stout, broad, compressed; upper mandible bent at the point, transversely furrowed; lower mandible straight, gibbous and bent upwards at the point; nostrils in the middle of the bill, placed obliquely in a furrow; tarsus short; three toes before, divided, the hind toe short, claws short, bent ; wings incapable of flight.

D. ineptus, Lin. The Dodo. Plumage cinereous, soft; belly and thighs whitish; head large; wings and tail yellowish ash-colour. Nearly 3 feet long. Inhabits the Mauritius.-Shan, xiv. pl. 40.

Fossil remains of birds are known under the name of Ornitholites. They are more rare than the fossil remains of quadrupeds, either from their being more recent productions of the animal kingdom, or because the bones of birds are more susceptible of decomposition. Such remains as are found are also less easily referred to known genera; for the parts which in birds serve to characterize the different families, as the corneous mandibles and the claws, have in most instances lost their form, from the compression and rupture to which they have been subjected.

The principal and best authenticated fossil remains of birds have been found in the gypsum quarries in the neighbourhood of Paris, where fragments referable to six or seven genera have been discovered. 


\section{CLASS III.-REP'TILES. (Reptilia.)}

Vertebrated animals with cold red blood, respiring by lungs ; body naked, or covered with scales.

ManY of the animals of this class were well known to the ancients ; and Pliny in his Natural History has embodied all the information known to bis time respecting the different species. The earliest of the modern writers on the same subject, such as Gesner, Aldrovandus, and Johnston, though they added somewhat to the general stock of information, yet, from the prejudices of their age, or the want of accurate observation, proceeded but little way in separating fact from fable, and reducing the fictions of poets and the representations of travellers to the capability of ordinary belief. This class of animals, most of them forbidding in their appearance, and many of them dangerous in their nature, seems particularly to have become the subject of exaggeration; and many are the fables which have been related of their magnitude and power, from the African serpent of 120 feet in length which stopped the army of Attilius Regulus, to the basilisk which killed its observer by a glance.

The celebrated John Ray, the precursor of Linnæus in methodical arrangement, was the first to introduce a system upon intelligible principles. In his Synopsis Methodica Animalium Quadrupedum et Serpentini generis, published in 1693, he arranges reptiles into 1. Oviparous Animals with red blood, respiring by lungs, and having a heart with one ventricle; $2 . \mathrm{Li}$ zards ; and, 3. Serpents. The first of these divisions includes the frogs, divided into aquatic and terrestrial, the toads, and the tortoises. The second division includes the Saurian reptiles of Cuvier; and the third the Ophidian reptiles of the same author.

Ray was followed as a systematic writer by Linnæus, who, in his Systema Naturce, arranged this tribe of animals, under the title of Ampнibia, into three orders, viz. Reptilia, Serpentes, and Nantes. This last order, which included the cartilaginous fishes, was removed to its proper piace in the class of fishes by 
Gmelin, in his edition of the Systema Natura published in 1788.

Klein, in his Tentamen Erpetologice 1755, arranged the serpents into two classes, 1 . those which have the head distinct from the body, and the tail elongated; 2. those which have the head not distinct from the body, and the tail obtuse. Laurenti, in 1768, in his Synopsis of Reptiles, divides them into three orders, viz. Leapers, as the frogs ; Walkers, as the lizards; and Serpents. By a strange oversight, however, it has been observed that he forgot to place the Tortoises in his arrangement. Scopoli and Gmelin followed in proposing methodical arrangements ; but as these were but slight modifications of that of Linnæus, it is not necessary to notice them further.

Lacepede's arrangement, the next to be noticed, appeared in his excellent work on Oviparous Quadrupeds and Serpents, published in 1790, as a continuation of Buffon's great work. It differs not materially from that of Linnæus, but is valuable for the accuracy of the details and the precision of the characters, besides the introduction of many new genera.

The arrangement of reptiles which has been generally adopted is that of Alexander Brogniart, who in 1799 proposed a classification, of which the highest praise is, that it has been followed by Cuvier in his Règne Animal. This naturalist derived his orders from the differences of organization in the principal organs, such as those of respiration and generation; and with these characters combined others which appear next in importance to the exercise of the animal functions; for instance, the organs of touch, of digestion, and of locomotion. The result of this comparison was the division of the class into four Orders, viz.

I. CHELONIANS. Body covered with a shield or plate.

II. SAURIANS. Body covered with scales.

III. OPHIUIANS. Destitute of feet.

IV. BATRACHIANS. Body covered with a naked skin.

Latreille, in his Histoire Naturelle des Reptiles, making part of Deterville's edition of Buffon, and in his Familles Naturelles du Règne Animal, (1825,) has made some slight changes in the arrangement of Brogniart; but the general principle of the 
division has been preserved both by this author, by Dumeril in his Elémens des Sciences Naturelles, and by Daudin in his Natural History of Reptiles, written for Sonnini's edition of Buffon.

Besides the systematic writers, there are many others from whose works much information may be derived in the details of the structure, history, and habits of this class of animals. A list of the chief of these will be given at the end of this volume. The third volume of Shaw's General Zoology may be mentioned, as containing good figures of the principal species described, and as easily accessible.

This department of Natural History is frequently treated of under the general title of Herpetology, the term being derived

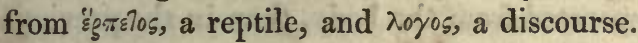

In Reptiles the heart is so disposed, that at each contraction only a portion of the blood which it receives is conveyed to the lungs; and from this it results that the action of oxygen on the blood is much less than in the mammiferous animals and birds, where all the blood is exposed to the action of the air. As respiration gives the blood its heat, and muscular fibre its susceptibility for nervous irritation, the temperature of reptiles is comparatively lower, and their muscular strength weaker than that of quadrupeds, and much less than that of birds. Their motions are chiefly confined to crawling and swimming; and though many at times leap and run very quickly, yet their general habits are sluggish, their sensations obtuse, their digestion slow, and in cold or temperate countries they pass almost the whole winter in a state of torpidity.

The heart is composed in Frogs of an auricle and a ventricle; in Serpents of two auricles, and a ventricle of two compartments; and in the Tortoises and Lizards of two auricles and a ventricle of communicating cavities.

The general resemblance in point of form which characterizes the two preceding classes, is not applicable to the present class; for while some, as the Serpents, have no members at all, others have two short legs; and the Lizards, Tortoises, and Frogs have four, adapted in the two last to progression in the water and on the land. Neither is there a common external cover- 
ing for the class, as fur for the quadrupeds, or feathers for the birds. Their low temperature, not differing much from the medium in which they live, renders such a covering to retain the heat unnecessary. The skin is naked in Frogs, scaly in Lizards and Serpents, and covered with a shelly plate in the 'Tortoises.

The brain in Reptiles is small, their nerves are very solid, and the relation of their sensations to a common centre seems less necessary to their animal and vital functions than in the higher classes. They continue to live and possess voluntary motion for a considerable time after the brain has been removed, and even when their head is cut off. The connection of the nervous system with the muscular fibre is also less necessary to its contraction; and their muscles preserve their irritability longer after being separated from the body, than in the previous classes. Even in some species the heart beats many hours after it has been taken from the body, and the body itself to move for a still longer period, after the removal of this essential organ.

Reptiles possess five senses, but none of them in great perfection. Thus their sense of touch is obtuse, from the scales, plates, or shells of some species; and even when the skin is naked it is not adherent to the body, but envelopes it like a bag, as is seen in the frog. Sometimes, as in the serpents, their eyes have no eyelids, are often immoveable, and covered with a corneous substance; in some three eyelids are to be distinguished; while some again appear to be destitute of sight. They have no cochlea, and but a small bone under the tympanum. Their nostrils are small, and their sense of smell appears weak. Their taste is not delicate, for the greater number swallow their prey whole, and in those which have the tongue soft and flexible, this organ serves chiefly for the seizure of their food.

Many species of Reptiles have no ribs, as the Frogs; among others, as the Serpents, these ribs are free and without a sternum; in the Tortoises they are all fixed together; and in the. Lizard family the ribs are disposed nearly as in birds. The lungs are always included in the same cavity as the intestines. The smallness of the pulmonary vessels permits reptiles to suspend their respiration without stopping the circulation of the blood; and thus they can remain for a long time under water with ease. The cells of their lungs are few in number, 
and generally large, and this organ has sometimes the form of simple sacs, scarcely cellular. They are provided with a tracheal artery and larynx, although all have not the faculty of uttering sounds.

No species of reptile is possessed of true fleshy lips. Some, as the Tortoises, have a horny bill like the parrot; others have teeth of various forms, not serving, however, in general for the maceration of food, but for retaining their prey; while others, as certain serpents, have hollow fangs, which are erected when the animal opens its mouth to bite, and which insert an active poison into the wound made by these teeth. Reptiles have but one opening for rejected solid and fluid matters, and for the organs of generation.

The females have a double ovary and two oviducts, and, though oviparous, none of the species hatch their eggs. Those which couple deposit eggs covered with a hard envelope; and the eggs of those species which do not are soft and glairy. The greater part abandon their eggs after having deposited them in a convenient place; though some species carry them about with them. 'The young on quitting the ova appear sometimes in the form which they preserve through life; but in other cases they are at this period of their existence organized like fishes, are not fully developed till after a certain period, and undergo a complete metamorphosis. Such are the tadpoles of the frog.

Many species of this class are used as articles of food in different countries. The use of others in the economy of nature is apparent, in limiting the excessive reproduction of insects and worms; while they themselves, on the other hand, form the principal food of some families of birds. The poisonous species are not very numerous, and their range is daily diminishing as cultivation and population increase.

According to the arrangement of Reptiles by M. Brogniart, and followed by M. Cuvier, founded upon their organization, and which is adopted in the following summary, they are divided, as noticed above, into four orders, viz. Chelonian REPtiles or Tortoises; Saurian Reptiles or Lizards; OpHIdian Reptiles or Serpents; and Batrachian Reptiles or Frogs. 


\section{ORDER I.-CHELONIA.}

Heart with two auricles; body enveloped in two plates or shields, formed of the ribs and sternum; four feet.

In the Chelonian reptiles (so named from $\chi \notin \lambda \operatorname{corn}_{n}$, a tortoise, ) the heart consists of two auricles, and a ventricle with two unequal chambers which communicate together.

- The bluod of the body enters the right auricle, that of the lungs into the left, but both kinds of blood are partially mixed in passing through the ventricle. These animals are distinguished externally by the double shield in which all their body is inclosed, cxcept their head, neck, tail, and feet. The upper shield or plate is formed by their ribs, consisting of eight pairs, widened and united together, and at the annular portion of the dorsal vertebræ by dentated sutures, in such a manner that all these parts are deprived of mobility. The lower shield, or breast-plate, is formed of pieces which are a substitute for the sternum, and which are generally to the number of nine. A circle of bony pieces, which appear analogous to the cartilaginous part of the ribs in the mammalia, generally surrounds the upper shell, uniting all the ribs which comprise it. The vertebræ of the neck and tail are alone inoveable.

These two bony cases being covered by the skin or by scales, the scapula, and all the muscles of the arm and neck, in place of being attached to the ribs and spine, are below, whifh has made the tortoise be termed in this respect a retroverted animal. The vertebral extremity of the scapula is articulated with the shield, and the opposite extremity of the clavicle with the breast-plate, in such a manner that the shoulders form a ring for the passage of the trachea and œesophagus. A third bone, larger than the other two, and directed backwards and downwards, represents, as in birds, the coracoid apophysis.

The lungs are extensive, and in the same cavity with the other viscera. The thorax being immoveable in the greater number, it is by the action of the mouth that the tortoise respires. Keeping the jaw shut, it alternately lowers and raises the hyoid bone. The first movement allows the air to enter by the nostrils, and the tongue afterwards closing the interior opening, the second movement forces the air to penetrate into the lungs.

Tortoises have no teeth; their jaws are covered with horn, as the mandibles of birds, except in the Chelides, where they are simply covered with skin. Their chest and palatine arch are fixed to the cranium, and immoveable. Their tongue is short, and rough with fleshy threads; their stomach simple and strong; and their intestines of medium length, and deprived of coecum.

Tortoises lay numerous eggs, covered with a hard shell. These eggs, deposited in the warm sand, under a southern sun, and in summer, are hatched without the parents' care by the influence of the atmosphere. The under shell or breast-plate of the male is concave, that of the female convex.

Tortoises are very tenacious of life, and they have been known to move without the head for many weeks. They subsist on little food, and they are able to pass months and even years without eating.

\section{* Land Tortoises.}

\section{Gen. 1. Testudo, Brogniart.}

Upper shell gibbous, supported by a solid bony frame, and joined through the greater portion of its sides to the under shell; feet with short toes, united nearly to the nails, and capable, as well as the head, of being withdrawn within the shell; fore feet with five nails, these behind with four, all thick and conical.

T. Gracca, Lin. The Common Tortoise. Shell hemispherical, marbled with black and yellow, gibbous behind; disc composed of 13 convex pieces, of an oblong square form, and 25 marginal ones; under shell pale yellow, of twelve pieces, with a broad blackish 
band down each side; legs short, covered with ovate scales; tail short, conical, terminating in a horny tip. Shell 6 to 8 inches long. Inhabits Greece, Italy, \&c.-Shaw, iii. pl. 1.

This species, one of the most common of the land tortoises, digs its winter retreat about the end of autumn, and reappears about the middle of A pril. It lives to a great age ; and there is a well ascertained fact of one, introduced into the archiepiscopal garden at Lambeth, in the time of Archbishop Laud, about the year 1633, which survived till the year 1753 , and was then supposed to have perished rather from accis dental neglect than old age.

T. Indica, Vosm. Indian Tortoise. Shell convex, deep brown, with the anterior margin reflected; a tubercle on the three upper scutella ; tail terminating in a horny tip. Shell 3 feet long. Inhabits Coromandel.-Shan, iii. pl. 3.

T. geometrica, Lin. The Geometrical Tortoise. Shell black, ovate, with the scutella regularly ornamented with yellow lines in rays arising from a disc of the same colour; dise with 13 or 14 pieces; marginal pieces 24 to 26 . Shell nearly a foot long. Inhabits Africa.-Shaw, iii. pl. 2.

T. radiata, Shaw. Radiated Tortoise. Shell black, ovate, smooth, with flattish scutella, radiated with yellow. Shell a foot or upwards in length. Inhabits Madagascar.-Shaw, iii. pl. 2.

T. tabulata, Schœep. Tabular Tortoise. Shell oblong, gibbous, brown, with the scutella of the disc rectangular and furrowed, and yellowish centres. Shell 5 or 6 inches long.-Shan, iii pl.8.

\section{** Fresh vater Torloises.}

\section{Gen. 2. Emys, Brong.}

Upper shell gibbous, divided into compartments by large scales : feet with distinct toes, terminated by crooked nails; toes more or less palmated; five toes before and four behind.

This genus has the shell generally more flattened than in the land tortoises. They feed on insects and small fishes.

E. Europaea, Cuv. The European Tortoise. Shell oval, slightly convex, smooth, blackish, strewed with yellowish points disposed in rays; disc composed of 13 , and the margin of 25 pieces ; under shell whitish yellow, tinged with brown at the joints. Inhabits Europe._Shaw, iii. pl. 5.

E. picta, Cuv. The Painted Tortoise. Shell oblong, slightly convex, smooth, brown, and each of the scutella bordered with yellow, broadest on the anterior margin; disc composed of 13 and the margin of 25 pieces. Shell 4 to 6 inches long. Inhabits North America.-Shan, iii. pl. 10.

E. scripta, Cuv. The Lettered Tortoise. Shell orbicular, depressed, whitish, tinged with yellow, marked with variously formed black narrow lines and undulations; marginal pieces spotted beneath. Shell $1 \frac{1}{2}$ inch long.-Shan, iii. pl. 12 .

E. serrata, Cuv. The Serrated Tortoise. Shell brown, fasciated with yellow, with the posterior marginal pieces tridentated, and voL. I. 
five brown spots in one row upon the lower edge of the marginal plates. Shell about a foot long. Carolina.-Shaw, iii. pl.9.

Gen. 3. Cistuda, Fleming.-Tortues à boite, Cuv.

Back plate emarginate in front, with two notches behind; under shell with one or two moveable divisions; lips corneous.

C. Amboinensis, Cuv. Shell convex, brown, with yellow border ; head spotted with yellow ; breast-plate moveable before and behind. Inhabits Amboyna.-Daud. ii. 309.

C. tricarinata, Cuv. Shell ovate, blackish, slightly convex, with the margin entire, and all the scutella of the disc carinated; tail short, conical, scaly, pointed; breast-plate moveable before and behind. Size of a large walnut.-Shan, iii. pl. 11.

C. Pennsylvanica, Cuv. Pennsylvanian Tortoise. Shell brown, smooth, elliptic, with flattish back; the middle row of scutella subrhomboid and subimbricated, the first subtriangular; breastplate moveable before and behind. Shell 3 or 4 inches long. Inhabits N. America.-Shan, iii. pl. 14.

C. clausa, Cuv. Close or Box Tortoise. Shell brownish-black, irregularly spotted with yellow; scutella striated parallel to their sides, yellowish in the middle, and the dorsal ones carinated; anterior part of the under shell moveable. Shell 4 or 5 inches long. Inhabits N. America._Shaw, iii. pl. 7 .

This species has its name from the manner in which the under part of the shell is applied to the upper, after the animal withdraws its head and legs within the shell.

Gen. 4. Chelonura, Fleming.

Extremities incapable of being withdrawn within the shell; tail about as long as the shield; upper shell carinated, with sharp processes behind.

C. serpentina, Fleming. Snake Tortoise. Shell ovate, depressed, triply carinated, rounded, and acutely serrated at the posterior margin; tail as long as the body, very thick at its base, covered with scaly tubercles, of which those above project and form a crest. Shell 4 feet long. Inhabits N. America.-Shav, iii. pl. 19.

\section{*** Sea Tortoises.}

Gen. 5. Chelonia, Brongniart.

Feet flattened into scaly fins; toes unequal, elongated, scaly, and united by a membrane, with very small nails upon their exterior border, terminated by scaly laminæ.

C. mydas, Cuv. Green Turtle. Shell brown, heart-shaped, of 13 dorsal segments, surrounded by 25 marginal pieces; the brown variegated with deeper undulations. 5 to 6 feet long. Inlabits Seas in the Torrid Zone.-Shan, iii. pl. 22.

This is the species now imported regularly, and so much esteemed as an article of food. It lays a great number of eggs, about a thousand annually, which it deposits 
in the sand. When turned on its back on shore it cannot recover itself. Turtles feed in great numbers on the algæ at the bottom of the sea; and various modes of taking them are practised when in this situation, swimming on the surface of the water, or on shore.

C. imbricata, Cuv. Imbricated or Hawksbill Turtle. Shell heartshaped, with thirteen imbricated semitransparent and variegated scales on the disc ; marginal pieces twenty-five; head small; neck long; beak narrow and sharp. 3 to 5 feet long. Inhabits seas of the Torrid Zone.-Shun, iii. pl. 26.

This is the species which affords the tortoise shell of commerce. Fire is applied below the shell, to separate the plates from their bony support. Tortoise shell was extensively used to ornament furniture by the ancient Romans.

C. Caouana, Cuv. Shell oval or heart-shaped, dentated on the margin, more or less brown or reddish, with fifteen scales on the disc, the intermediate ones ridged posteriorly; point of the upper mandible hooked ; fore feet long and narrow. Inhabits the Mediterranean Sea.-Cuv. Reg. An. ii. 13.

C. coriacea, Cuv. Coriaceous Turtle. Body without scales, but covered with a brown skin resembling leather; upper part oval, and pointed behind, with longitudinal prominent ridges. 7 to 8 feet long. Inhabits Mediterranean Sea-Shaw, iii. pl. 21.

This species grows to a large size, and has sometimes been taken on the coast of England.

\section{Gen. 6. Chelys, Dumeril.}

Shell too small to receive the members; mouth cleft across; lips fleshy, with the nose prolonged into a small trunk; toes webbed.

C. fimbriata, Cuv. Shell oval, subconvex, brown, rough with pyramidal eminences; neck with fimbriated membranaceous appendages; snout cylindrical, truncated ; disc of 13 semicircular pieces ; marginal pieces 25, almost square. 2 feet 3 inches long; shell 15 inches. Inhabits Guiana.-Shaw, iii. pl. 18.

\section{Gen. 7. Trionyx, Geoff.}

Lips fleshy; nostrils prólonged into a cylindrical tube; backplate destitute of scales, but covered with a coriaceous skin, studded near each extremity with hard knobs; only three of the five toes with nails.

T. Egyptiacus, Geoff. Soft Tortoise of the Nile. Back slightly convex, of a green colour, spotted with white. Inhabits the Nile, and devours the young crocodiles when newly hatched.-Ann. du Mus. xiv. 1.

T. ferox, Cuv. Soft Tortoise of America. Shell brownish, ovate, osseous in the middle, cartilaginous on the margin, obscurely marked with five or six transverse bands, and granulated with small warts, of larger size near the margin; head small, trigonal ; snout much lengthened; nostrils tubular, prominent. 18 inches long. Inhabits N. America._Shan, iii. pl. 17. 
This species inhabits the rivers of Carolina and Georgia ; lies in ambush among the reeds, \&c. and preys on birds, the smaller reptiles, and young alligators. Its flesh is caten.

\section{ORDER II.-SAURIA.}

Body elongated, covered with scales, generally with four feet ; toes with claws, at least in part ; tail more or less long; mouth armed with teeth.

The Saurian family (so named from raig $\dot{s}_{s}$ a lizard) have the heart composed, as in the preceding order, of two auricles, and a ventricle sometimes divided by inperfect partitions. Their ribs are moveable, partly attached to the sternum, and capable of being elevated and depressed by respiration. Their lung extends more or less towards the hinder part of the body ; it penetrates often before into the lower belly, and the transverse muscles of the abdomen glide under the ribs and even towards the neck to embrace it. Those species which have the lung very large possess the singular faculty of changing the colours of their skin as they are intluenced by their wants or passions.

The mouth in Saurian reptiles is always armed with teeth; their toes have nails, at least in part; and their skin is covered with scales more or less impacted. All have a tail more or less long, and almost always thick at the base. The greater number have four legs; but some have only two. Their food is chiefly animal. They also deposit their eggs in places convenient for their being hatched without the care of the parent ; and the animal when produced has the form which it afterwards preserves.

The Saurian reptiles are distinguished from the Chelonian by the want of a shield and by the presence of teeth; from the Ophidians because they have eyelids and the branches of the jaws united, asternum and two lungs; and from the Batrachians by their having ribs, nails, a scaly skin, and in not undergoing a metamorphosis.

\section{Family I.-Crocodilide.}

Body elongated, covered with square scales, of which the upper and under are the largest, and those above raised into a ridge in the middle ; four feet, with five toes before, and four behind, the three interior with nails, and all more or less united by membranes; a single row of pointed teeth in each jaw ; tongue fleshy, flat, and attached almost entirely to the lower jaw; tail flattened on the sides, with a strongly dentated crest.

Croccdiles are reptiles of large size, with the body covered by square scales, of which those above form projecting lines, raised into a double crest on the tail. Their head is long and heavy, and their jaws are articulated behind the cranium. Their nostrils form a long canal which has its origin in the throat, and terminates at the point of the muzzle, where the crescent-shaped orifice opens and shuts at will. Their eyes have three eyelids; the exterior ear can be shut at pleasure by two fleshy coverings; and under the throat are two small holes, the orifices of glands which secrete a musky substance. Crocodiles are the only Saurian animals which are destitute of clavicular bones; but their coracoid apophysis is attached to the sternum, as in all the others. The eggs of crocodiles are hard and as large as those of a goose. The females watch the eggs, and when they are hatched rake charge of the young for some months.

Gen. 1. Gaviala, Cuv.

Muzzle narrow, cylindrical, and much elongated; teeth nearly. 
equal; hind legs dentated on the external margin, and palmated to the claws.

G. Gangetica, Cuv. The Gangetic Crocodile. Muzzle narrow, as long as the head; upper jaw with 28 teeth on each side; lower jaw with 25 ; two carinated plates upon the neck; eyes very large, with a large hole in the cranium behind them, which may be felt through the skin. 12 to 18 feet long. India._Shaw, iii.pl.60.

G. tenuirostris, Cuv. Muzzle double the length of the head; both jaws furnished with 27 teeth on each side; four carinated plates disposed in a square upon the neck. $2 \frac{1}{2}$ feet long. Inhabits India. Reg. An. ii. 20.

\section{Gen. 2. Crocodruss, Cuv.-Lacerta, Lin.}

Muzzle oblong and depressed; teeth unequal; legs dentated, and feet palmated; the fourth tooth in the lower jaw on each side lying along a groove in the upper.

C. vulgaris, Cuv. (L. crocodilus, Lin.) The Common Crocodile. Blackish brown above, yellowish white beneath; upper parts of the legs and sides varied with deep yellow, and in some parts tinged with green; fourth tooth on each side of the lower jaw passing into a groove in the edge of the upper jaw; six rows of square carinated plates, nearly equal, along the back; plates of the neck six ; tail with two lateral crested processes. 20 to 30 feet long. Inhabits rivers of Africa.-An. Mus. x. 82.

The Common Crocodile, the largest of the Saurian family of reptiles, has been known from the earliest times. It has the general form of the lizard, with an elongated and flattened head rounded at the extremity. The number of teeth is about 36 in the upper jaw and 30 in the under one, in one single row, but the number is not constant. These teeth are strong, conical, striated, and of unequal length. It was long believed that the upper jaw of the crocodile was alone moveable, but modern investigation has proved that the lower jaw, as in other animals, is possessed of motion. The error, however, was natural ; for the centre of motion being in this tribe behind the cranium, their head appeared to be raised by the opening of the mouth. With the exception of the top of the head, the whole body is covered with scaly plates. The eggs of the crocodile are deposited in the sandy shores of the Nile, to be hatched by the heat of the sun. The young on their departure from the egg take to the water; but numbers of the eggs and young are destroyed by the ichneumon and other animals. The age to which the crocodile arrives is not ascertained; but as their growth is slow, it is supposed to be great. This animal is considered to be the Leviathan of the Sacred Writings. Among the ancient Romans, crocodiles were sometimes exhibited in the public spectacles; and Scaurus during his adileship displayed no fewer than five of these animals in a temporary lake for the gratification of the populace.

C. Suchus, Geoff. The Sacred Crocodile. Body green, with black spots ; plates of the neck longer than broad; cranium smooth, elongated. 5 feet long.-An. Mus. x. 84.

This animal is the Sacred Crocodile of the Egyptians, and was first distinguished as a species by M. Geoffroy-St-Hilaire, from the inspection of many crocodiles brought by him from Thebes. The weakness of its jaws prove that it was not a very dangerous animal ; and Herodotus mentions that the priests tamed this species, which was held in veneration, and adorned it with ear-rings and bracelets.

C. biporcatus, Cuv. With eight rows of oval plates along the back,

$$
\text { hetween tho equecis } 2
$$


1 is and two projecting ridges on the top of the muzzle; plates of the neck six. Inhabits India._Cuv. Reg. An. ii. 20.

(1) C. acutus, Cuv. Muzzle elongated, gibbous at the base; plates of the back ranged in four rows, the exterior ones placed irregularly and with the ridges more projecting; plates of the neck six. Inhabits West India Islands.-Cuv. Reg. An. ii. 21.

C. rhombifer, Cuv. Muzzle subconvex, with two converging ridges; plates of the neck six; scales of the back in sixes, square; those of the limbs thick and carinated.-Ann. Mus. x. 65 .

C. galeatus, Cuv. Top of the head with a bidentate elevated crest; plates of the neck six. Inhabits India.-Ann. Mus. x. 65.

C. biscutatus, Cuv. Intermediate scales of the back square; outer ones irregular, both in form and situation; plates of the neck two. -An. Mus. x, 65.

\section{Gen. 3. Alligator, Cuv.}

Muzzle broad, obtuse, teeth unequal; the fourth tooth on each side of the lower jaw entering a cavity in the upper; feet semipalmated, and with dentations.

A. sclerops, Cuv. (Lacerta alligator, Lin.) The Alligator. Grcenish brown above, with irregular marblings of greenish ; pale yellow below; muzzle flat, a little narrower than the head, with a transverse ridge uniting before the projecting margin of its orbits; jaws with nineteen teeth on each side; neck with four rows of strong plates. 18 to 20 feet long. Inhabits Guiana and Brazil.-An. du Mus. x. 31.

The Alligator or American Crocodile abounds in the rivers and lakes of Carolina and Florida. They pass the winter in holes or burrows in the marshes. In the spring at the period of their coupling, they make a loud bellowing; and at other times, make a noise by opening and shutting their jaws forcibly. They swim with facility, but their movement on land is slow. The young feed chiefly on insects.

A. Lucius, Cuv. Muzzle parabolic, depressed, with four large plates on the neck, and eighteen transverse rows of carinated plates on the back. 11 to 14 feet long. N. America.-An. du Mus. x. 29.

A. palpebrosus, Cuv. With bony palpebræ; neck furnished with four bony carinated bands; 21 teeth on each side in the lower jaw, 19 above.-Ann. du Mus. x. 35.

A. trigonatus, Cuv. With bony palpebræ, and the neck furnished with irregular triangular carinated scales.-Seba, i. pl. 105, fig. 3.

\section{Famtly II.-Lacertinide.}

This family is distinguished by a slender and extensible tongue, terminating in two long filaments, as anıong the vipers. Their body is elongated and their motions quick. All their feet have five toes, armed with nails, separate and unequal, especially those of the hind feet. Their scales are disposed under the belly and around the tail in transverse and parallel bands. Their tympanum is on a level with the head; a production of the skin, longitudinally cleft, and which shuts by a sphincter, protects the eye; under the anterior angle is the vestige of a third eyelid. Their false ribs do not form a complete circle. The male organ of generation is double, and the anus is a transverse cleft. 
Gen. 4. Monitor, Cuv.-Tupinambis, Lacepede.

Scales on the head, belly, and tail, small and imbricated; tail compressed laterally; teeth in both jaws, but none on the palate.

According to Cuvier, Marcgrave, speaking of a lizard of America, says that it was named teyu-guacu, and among the Tupinambous, temapara. Seba has taken the first word for the name of the animal, and the later naturalists have copied him in making it a generic term.

\section{* Tail compressed and carinated.}

M. clegans, Cuv. Elegant Monitor. Body brownish black, with white concentric lines above the head and neck; nine transverse bands of round white spots upon the back; belly white. Inhabits Indian Archipelago.-Reg. An. ii. 24.

M. variegatus, Cuv. (L.varia, Shaw.) VariegatedMonitor. Blackish above, variegated with double transverse rows of rounded yellow spots and lines; tail twice as long as the body. Inhabits New Holland.-Shaw, Nat. Mis. pl. 83.

M. maculatus, Cuv. Spotted Monitor. Black above, irregularly marked with transverse bands, and seven longitudinal rows of greenish spots on the upper parts ; neck plaited below ; tail half the length of the body.-Seba, i. pl. 110. fig. 4.

\section{** Tail almost rounded, with a dentated ridge above.}

M. Niloticus, Cuv. (Lacerta Nilotica, Lin.) The Monitor of the Nile or Ouaran. Back brown, with whitish spots, forming small, oval, and irregular compartments ; tail almost triangular; 24 to 30 teeth in each jaw. 3 feet long. Egypt._Cuv. Reg. An. ii. 25.

M. ornatus, Cuv. Body black; throat white, with transverse black bands; seven transverse rows of round white spots on the back, and from 12 to 18 whitish rings round the tail; 24 to 30 teeth in each jaw. 5 to 6 feet long. Africa.-Cuv. Reg. An. ii. 25.

M. albigularis, Cuv. White Throated Monitor. Lower part and sides of the head and neck whitish, spotted with brown; two whitish lines running from the eyes to the neck; tail long. Daud.ii. pl. 32 .

\section{*** Tail almost round, not carinated.}

M. terrestris, Cuv. Back uniform brown or yellowish green. Inhabits Egypt.-Cuv. Reg. An. ii. 25.

The jugglers of Cairo train this animal to play tricks, after having extracted its teeth.

\section{Gen. 5. Draceena, Cuv.}

With angular plates on the head; large carinated scales on the back, and forming crests on the tail; scales under the neck small; those of the belly and around the tail rectangular; teeth conical ; tail rounded at the base, and compressed towards the end. 
D. Guianensis, Cuv. Body reddish brown, shaded with green. 4 to 6 feet long, of which the tail forms one-half. Inhabits Guiana.Shaw, iii. pl. 67.

It frequents savannahs and marshy plains. Its flesh is eaten.

Gen. 6. Tkius, Merrem.-Les Sauvegardes, Cuv.

With all the scales of the back small and smooth; a row of indistinct pores under the thighs; teeth notched; tail more or less compressed, carinated or smooth; scales of the belly longer than broad.

\section{* Tail carinated.}

T. bicarinatus, (Lacerta, Lin.) Body reddish brown, more or less tinged with greenish; two rows of carinated scales on the back, confluent on the tail, and forming a serrated crest. 2 feet 5 inches long. Inhabits South America.-Shaw, iii. 212.

** Tail smooth, compressed towards the point.

T. Teguixin, (Lacerta, Lin.) Body black, spotted with blue above, bluish below; tail banded with blue and black. Nearly six feet long. Inhabits Brazil._Shaw, iii. pl. 73.

This species runs rapidly, takes the water when pursued, and dives freely. It feeds on insects, reptiles, sci. Its flesh is eaten.

Gen. \%. Amerva, Cuv.-Lacerta, Lin.

Tail entirely cylindrical, covered, as well as the belly, with transverse rows of square scales; those of the belly broader than long; scales of the throat small; head pyramidal.

A. vulgaris, (L. ameiva, Gmel.) The Common Ameiva. Body grayish-blue above, paler below; with four longitudinal rows of round whitish spots on each side; neck transversely plaited below. 12 inches long. South America, \&c.-Shaw, iii. pl. 75.

A. litterata, Cuv. Body bluish green, variegated above with oblong black spots and transverse black bands, dotted with white, on each side; neck transversely plaited below._-Seba, i. pl. 83.

A. carulocephala, Cuv. Blue-headed Ameiva. Head blue, with a white longitudinal line along the middle of the back; two yellow parallel lines on each side; thighs dotted with white; tail twice the length of the body.-Seba, i. pl. 91, fig. 3 .

A. lemniscata, Cuv. (Lacerta, Gmel.) Striped Ameiva. With nine white longitudinal lines upon the back and sides; tail long, blue on the upper part; thighs spotted with white; dorsal line forked at the head. Inhabits Africa.-Shaw, iii. pl. 75.

Gen. 8. Lacerta, Cuv.

Palate armed with two rows of teeth; a collar on the under side of the neck formed by a transverse row of large scales, separated from those of the belly by very small ones; bone of the cranium projected on the temples and orbits. 
L. ocellata, Daud. Eyed Lizard. Body black above, with lines and rings, or eye-like spots of a light green; below pale yellow, without spots. 12 inches long. Inhabits South of France, Spain, Italy, \&c.-Daudin, iii. pl. 33.

L. viridis, Daud. The Green Lizard. Body bright green, marked above with numerous black or brown points; pale green below, without spots.-Daudin, iii. pl. 34.

L. bilineata, Daud. Two-lined Lizard. Back with two longitudinal white lines, margined above with brown; a longitudinal row of brown spots and white points on the sides; tail long.-Daudin, iii. pl. 35, fig. 1 .

L. agilis, Cuv. Ash-coloured above, whitish below; back marked with a longitudinal dotted brown line, and a subreticulated brown longitudinal line edged with paler colour on the sides. Inhabits Europe. B.-Daudin, iii. pl. 38, fig. 1.

L. arenicola, Cuv. Body brownish-gray, with a row of brown spots on the back, and a double series of brown ocellated spots, dotted with white, and a single row of white dots on each side; pale below, and without spots. Europe-Daud. iii. pl. 38, fig. 2.

\section{Gen. 9. Takydromus, Cuv.}

Body and tail excessively elongated; rows of square scales on the back; pores on the thighs; two vesicles on the sides of the anus.

T. quadrilineatus, Cuv. Brown above, whitish below, with two longitudinal white lines on each side.-Daudin, iii. 252.

T. sexlineatus, Cuv. Bright shining blue, with three longitudinal black lines on each side.-Daudin, iii. pl. 39.

\section{Family III.-Igroanide.}

General form of the Lizard; but with the tongue thick and fleshy, not extensile, and notched at the point.

\section{Gen. 10. Corvylus, Cuv.}

Belly and back covered with large scales in transverse rows, forming spinous circles on the tail; line of large pores on the thighs; head simple; no palatine teeth.

C. Capensis, (L. cordylus, Lin.) Body livid bluish or sometimes blackish-brown. About the size of the common green lizard. Inhabits Cape of Good Hope.-Seba, i. pl. 84, fig. 3, 4.

\section{Gen. 11. Steiclo, Daud.}

Body covered with pointed scales; spines of the tail of medium size; head inflated behind; ears surrounded with spines; thighs destitute of pores ; tail long and pointed; no palatine teeth.

$$
\text { H. Truent }
$$


S. vulgaris, (L. stellio, Lin.) Common Stellio. Body olive-coloured, shaded with blackish, with a few transverse bands of larger scales on the back and thighs. 12 inches long. Egypt.-Cuv.Reg.An.ii.32.

The Mahometans kill this species, because they say it lowers its head as mocking their attitudes in prayer.

Gen. 12. Mastigura, Fleming.

Scales of the body smooth and uniform, those of the tail larger and more spinous than the preceding; pores under the thighs; no palatine teeth.

M. spinipes, Daud. Body inflated, meadow-green, covered with minute scales, spinous on the tail above, and on the thighs. 2 or 3 feet long. Inhabits Egypt.-Geoff. Rept. Egypt, pl. 2, fig. 2.

M. quetz-paleo, Daud. Scales edged and carinated; tail spinous above and below ; body gray, with two black spots forming a semicollar on the nape.-Cuv. Reg. An. ii. 33.

\section{Gen. 13. Agama, Daudin.-Lacerta, Lin.}

Body oblong, more or less thick, entirely covered with small carinated scales, raised into rough points in different parts of the body, and chiefly above the region of the ears; head tumid; skin of the throat loose, plicated transversely, and capable of inflation.

A. vulgaris, (L.agama, Gmel.) Common Agama. Body brownish, with a row of small spines on the nape, and some groups round the ears. Inhabits Guiana.-Cuv. Reg. An. ii. 34 .

A. muricata, Cuv. Body grayish; rows of large spinous scales in transverse bands upon the back and tail ; throat capable of inflation, and furnished with scales elongated into points, which form a sort of beard; similar scales on the flanks and behind the ears; tail twice as long as the body. Upwards of a foot long. Inhabits New South Wales.-Shaw, iii. pl. 65.

A. orbicularis. Cuv. Body orbicular and rough, depressed and variegated above with brown; head like that of a toad; tail short. 6 inches long. Inhabits South America._Shaw, iii. pl. 71.

Gen. 14. Trapelus, Cuv.

Body oblong; head tumid; scales small, smooth, and without spines.

This genus is founded by M. Cuvier on a small animal discovered by M. Geoffroy, which is even more remarkable for the change of its colours than the chameleon.

T. Egyptiacus, Cuv.-Geoff. Rept. Egypt, pl. 5, fig 3, 4.

Gen. 15. Calotes, Cuv.

Body covered with imbricated scales, edged on their margin, those on the middle of the back forming a crest. 
C. vulgaris. Body fine blue, with transverse white bands; two rows of spines behind the ears ; tail very long. 18 inches long. Inhabits India._Shan, iii. pl. 64.

\section{Gen. 16. Lophyrus, Dumeril.-Lacerta, Lin.}

Body shagreened; dorsal crest prolonged upon the tail; tail compressed vertically.

L. scutatus, (L. scutata, Lin.) Dorsal crest high on the neck, formed of many rows of vertical scales; two bony ridges continued from the muzzle, terminating in a point at the eye. 12 to 16 inches long. Inhabits Ceylon.-Shaw, iii. pl. 68.

L. superciliosus. Body pitchy black; back and tail crested above ; a slight appearance of a ridge over the eyes; occiput callous and spinous; scales of the body rhomboid. 12 to 16 inches long. Inhabits S. America._Shaw, iii. pl. 68.

Gen. 1\%. Basiliscus, Daud.-Lacerta, Lin.

Crests edged, supported by long spiny apophyses of the vertebræ, extending on the back and at least part of the tail; crests scaly, as the rest of the body; scales of the belly and tail small, of a square form ; teeth strong, compressed, without notches; no palatine teeth; a row of pores on the thighs; skin of the throat loose, without forming a pouch.

The Basilisks of modern naturalists have nothing of the deadly properties attributed by the ancients to their fabulous animal of this name. Though rather repulsive in their appearance, they are harmless animals, inhabiting woods, feeding on insects, and leaping from branch to branch by the assistance of their crested back and tail.

B. mitratus, Cuv. (L. basiliscus, Lin.) Mitred Basilisk. With a crest on the back, another on the first half of the tail, and a third on the occiput; tail long and pointed. 2 to 3 feet long. Inhabits Brazil.-Shaw, iii. pl. 63.

B. Amboinensis, Cuv. Head quadrangular, with a convex scale on the middle ; crest on the origin of the tail, and dorsal crest pectinated; tail long. 4 feet long. Amboyna.-Shaw, iii. pl. 62.

Gen. 18. Draco, Lin.

Six false ribs, extending in a right line and supporting an extension of skin, which forms a kind of wing; body covered with imbricated scales, those of the tail and legs carinated; a long pointed gular pouch under the throat; tail long; no femoral pores; a small dentation on the nape; four incisors in each jaw, a long and pointed canine, and twelve triangular molar teeth.

This genus possesses the scales and gular pouch of the Iguanas, with the head and teeth of the Stellios. They are of small size, seldom exceeding ten inches in length.

D. lineatus, (D. volans, Lin.) The flying Dragon. Body variegated with blue and gray above; wings brown, longitudinally stri- 
ated with white. 9 or 10 inches long. Inhabits Asia and Africa. —Shan, iii. pl. 54.

Notwithstanding the terror of its name, as celebrated by poets and historians, the flying dragon of modern naturalists is a very innocent animal, inhabiting trees and feeding on insects, which it seizes in leaping from branch to branch. The lateral expansions or wings are merely aids to it in leaping, and quite incapable of supporting it in continued flight. These wings are triangular, and their upper surface is furnished with small scales. They are strengthened by six bony rays, unequal in length, and extend from the fore to the hind feet. This species walks with difficulty on the ground.

D. viridis. Body green, rather scaly; wings gray, transverse, marked with four brown bands, and connected with the thighs.Daud. iii. pl. 41.

D. fuscus. Body brown above, paler beneath, scarcely scaly ; wings brown.-Daud. iii. 307.

Gen. 19. Iguana, Cuv.-Lacerta, Lin.

Body and tail covered with small imbricated scales; a row of spines or impressed and pointed scales along the back ; throat with a pendant and inflated skin, compressed laterally; femoral pores; head plated; a row of compressed triangular and serrated teeth around the jaws; and two little rows on the posterior margin of the palate.

I. vulgaris, (L. Iguana, Lin.) The Common Iguana. Body blue above, changing to green and violet, paler below; dorsal spines large; a large round plate under the tympanum, at the angle of the jaws ; sides of the neck furnished with pyramidal scales scattered among the others ; anterior margin of the gular pouch dentated. 4 to 5 feet long. Inhabits S. America.-Shaw, iii. pl. 61 . Tlis animal lives generally among trees, goes sometimes to the water, and feeds on fruits, grains, and leaves. Its flesh is much esteemed.

I. nudicollis, Cuv. (I. delicatissima, Laur.) Head with gibbous plates; no tubercles on the sides of the neck; gular pouch without dentations. Inhabits India.-Cur. Reg. An. ii. 40.

Gen. 20. Polychrus, Cuv.-Lacerta, Lin.

No dorsal crest; toes not dilated; head covered with plates; body and tail with small scales; throat extensible and capable of inflation; femoral pores; maxillary teeth edged and dentated, and small ones on the palate.

This genus has the faculty, like the Chameleon, of changing colour. Their lungs are large, filing a great part of the body and dividing into many branches; and their false ribs, like the same genus, surround the abdomen, uniting to form complete circles.

P. marnoratus, Cuv. Reddish gray, marbled with irregular transverse bands of red brown; tail very long. Inhabits Guiana.Cuv. Reg. An. ii. 41.

Gen. 21. Avolius, Cuv.-Lacerta, Lin.

Skin of the toes extended in the antepenult joint into an oval 
disc, striated across below ; claws much hooked ; tail uniformly shagreened with small scales; a gular pouch in the greater number; teeth edged and dentated as in the preceding genus, and small ones on the palate.

This genus has the faculty of changing colour almost equal to the Chameleon; and their false ribs form circles as in the preceding. The skin of the tail forms slight folds, of which each comprehends circular rows of scales.

\section{* Tail crested.}

A. principalis, Cuv. Body bluish-black, with a crest on the half of the tail supported by five rays composed of the spinous apophyses of the vertebræ; gular pouch extending under the belly. A foot long. Inhabits Jamaica.-Cuv. Reg. An. ii. 42.

A. bimaculatus, Cuv. Body greenish; spotted with brown towards the snout and upon the sides, and a black spot upon each shoulder. 6 inches long. Inhabits S. America.-Cuv.Reg. An. ii. 43.

\section{** Tail rounded.}

A. bullaris, Cuv. Body greenish; muzzle short, spotted with brown; eyelids projecting. Inhabits S. America.-Cuv. Reg. An. ii. 43. This is a small animal, and when enraged its gular pouch becomes as red as a cherry. It changes colours too with great facility.

\section{Family IV.-Geckotide.}

\section{Gen. 22. Gecko, Daud.-Ascalabotes, Cuv.}

Body flattened, particularly the head; eyes large; tongue flcshy and not extensible; jaws furnished with a row of very small and close-set teeth; skin shagreened above with small scales, and often tubercles, below with smaller, flat, and imbricated ones; tail with circular folds; toes widened in all their length, or at the extremity, with the skin folded or scaly.

The species of this numerous genus are found in the warmer parts of both continents. They are dull and heavy-looking animas, and the structure of their feet enables them to walk on perpendicular surfaces and even ceilings. Sir Everard Home, in the Philosophical Transactions for 1816, has demonstrated the peculiar mechanism by which this is effected. The claws vary according to the species, and are entirely wanting in some. Cuvier divides this genus into five sections or subgenera.

\section{Platydactyli.-Toes widened thronghout, and furnished be-} lon with transverse scales.

Some of the species of this section want nails, and their thumb is very small; and others want the femoral pores.

G. inunguis, Cuv. Body violet above, white below; with a black line upon the sides.-Cuv. Reg. An. ii. 46.

G. ocellatus, Oppel. Body gray, covered with ocellated spots, white in the middle.-Cuv. Reg. An. ii. 46.

G. Cepediensis, Peron. Body black-coloured, marbled with blue, and a white line along each side; femoral pores distinct. Inhabits Isle of France.-Cuv. Reg. An. ii. 46.

G. fascicularis, Daud. (L. Mauritanica, Lin.) Common Gecko. 
Body deep gray; upper part of the body tuberculated, each tubercle formed of three or four smaller ones; scales below the tail similar to those of the belly ; no nails on the thumbs or on the second and fifth toes; no femoral pores. Inhabits Southern Europe and Asia._Cuv. Reg. An. ii. 46.

G. guttatus, Daud. (Stellio Gecko, Schneid.) Body reddish, with rounded tubercles above, and numerous round white spots; under part of the tail with square and imbricated scales; no nails on the thumbs; a row of pores before the anus. Inhabits Indian Islands. - Lacep. i. pl. 29.

G. vittatus, Cuv. Body brown, with a white band on the back, bifurcated on the head and on the base of the tail, with white rings around the tail; no nails on the thumbs. India.-Daud.iv. pl. 50.

2. Hemidactyli.-Base of the toes furnished with an oval disc, formed below by a double row of scales; from this disc rises the second phalange, which is slender and supports the nail joint; nails on all the toes, and a row of pores on both sides of the anus; scales under the lail large.

G. tuberculosus, Daud. The Tokay. Body marbled with bluish and reddish; the body and tail rough with conical tubercles. About a foot long. Inhabits Indian Islands.-Cuv. Reg. An. ii. 47.

3. TheCaDACTYLI. - Toes widened throughout their whole length and furnished with transverse scales, the scales divided by a longitudinal furrow; no nails on the thumbs; tail covered above and below with small scales; no femoral pores.

G. loevis, Daud. Body gray, marbled with brown and granular above; tail long and plicated. Inhabits Surinam.-Daud. iv. pl. 51.

4. Pryodactyur. - Toes dilated only at the tip, and striated below; the nails crooked, placed in a fissure.

G. lobatus, Geoff. The House Gecko. (Stellio Hasselquistii, Schn.) Body smooth, reddish-gray, spotted with brown; scales and tubercles very small; toes free; tail round. Inhabits Egypt.-Geoff. Rept. Egypt. iii. pl. 5.

This species frequents houses. Its voice resembles the croaking of a frog.

G. fimbriatus, Cuv. The Fimbriated Gecko. Head, body, and legs flattened at the sides, and bordered with a fringed membrane; feet semipalmated. $8 \frac{1}{2}$ inches long. Inhabits Madagascar.Shaw, iii. pl. 78.

G. caudiverbera. Body blackish; no fringe on the body but only on the tail, on which there is also a membranous vertical crest. About a foot long. Inhabits S. America._Shaw, iii. pl. 78.

5. Phyluuri.-Similar in form to the Geckos, but without the toes widened; tail flattened, cordiform.

G. phyllurus, (Stellio phyllurus, Schn. L. platura, White.) Body gray, marbled with brown above, and rough with pointed tuber- 
cles; tail smooth and flattened longitudinally, like a cordiform leaf. 4 to 6 inches long. New Holland.-Shav, iii. 247.

\section{Family V.-Chameleonide.}

Gen. 23. Chameleon, Cuv.

Body shagreened with small scaly granules, compressed, and the back edged ; tail round and prehensile; five toes on all the feet, but divided into two sets; the one of three toes, the other of two, each united by a membrane to the nails; tongue fleshy, cylindrical, and extremely extensible; teeth trilobed; eyes large, but almost covered by skin, and with separate movements; no external ear ; occiput pyramidal; lungs very large.

The Chameleons have long been known for their property of changing colour. The great size of their lungs is, according to Cuvier, the cause of this property; not as was formerly believed according to the body upon which they were placed, but according to their wants and passions. When the lungs are inflated their body seens transparent, which occasioncd the ancients to fancy that they fed on air. Chameleons inhabit trees, and feed on insects, which they take with the glutinous extremity of their tongue. They are very sluggish and inactive animals. The species of this genus have been accurately described by Mr Gray in the Philosophical Magazine, Vol. ii. p. 209.

C. vulgaris, Daud. Common Chameleon. Head keeled over the eyes; occiput crested; crest reaching to the middle space between the eyes; scales small, uniform; dorsal and medial ventral line from the chin to the vent larger, naked; ventral line white. 22 inches long. Africa and India._Phil. Mag. ii. 209.

C. pumilus, Laur. Eyebrows crested; occiput keeled; scales square, with scattered ovate shields on each side of the back; head tubercular, with two oval smooth places on each side; back part of the tail and chin denticulated. 5 inches long. Inhabits Cape of Good Hope.-Phil. Mag. ii. 211.

C. Senegalensis, Daud. Eyebrows crested, denticulated; occiput flat, rather convex behind, not denticulated, bony ; scales small, uniform, granular, those of the head rather larger and ovate; back of the neck, throat, and belly denticulated. 8 inches long. Phil. Mag. ii. 212.

C. bifurcus, Brong. Eyebrows arched; occiput lunate, obliquely crested; face between the front of the eyes and tip of the nose extended into two lanceolate lobes; scales flat, quadrangular, those of the head larger, hexangular; occipital crest and back of the neck denticulated. 10 inches long.-Phil. Mag. ii. 212.

C. Parsonii, Cuv. Eyebrows arched; occiput obliquely expanded over the back of the neck; front of the head over the nostrils expanded into two short, compressed, serrated lobes; scales of the head large and hexangular, those of the body small and quadrangular, separated into ovate groups. 12 inches long. Phil. Mag.ii.213.

C. tigris, Cuv. MS. Body slender, dull reddish, sprinkled with 
black spots; head small ; two tubercular lines behind the eyes, running into one elevated median line.-Phil. Mag. ii. 213.

C. Seychellensis, Peron. MS. Body reddish; no dorsal or abdominal crest ; crest of the head with four bony tubercles ; orbits surrounded with a tuberculous bony margin. Seychell's Islands. $i b$.

\section{Family VI. SCINCIde.}

Legs short; tongue not extensible; body covered with equal imbricated scales.

\section{Gen. 24. Scincus, Daud.-Lacerta, Lin.}

Body long, covered with elliptical or rounded imbricated shining scales; tongue fleshy, little extensible, and slightly cleft; jaws with small close-set teeth, and two little rows on the palate; feet with five toes, free and unguiculated.

S. officinalis, Schn. (L. scincus, Lin.) Officinal Scink. Body silvery gray, with transverse blackish bands ; muzzle pointed and a little recurved; tail shorter than the body, silvery yellowish. 6 to 8 inches long. Inhabits Arabia, \&c.-Shaw, iii. pl. 79.

The Officinal Scink has held a high place in eastern countries from time immemorial as a restorative. In Arabia it is said to cure cutaneous diseases, and even elephantiasis ; and Pliny reports that it was considered a specific against poisoned arrows. According to Bruce it burrows in the sand, and performs this operation so quickly that it is out of sight in an instant, and appears rather to have found a hole than made one.

S. occiduus, (L. occidua, Shaw.) The Galley Wasp. Body reddish, with irregular whitish transverse bands; molar teeth rounded; two little lobes before the tympanum; tail scarcely the fourth of the total length. 12 to 18 inches long. Inhabits Jamaica.Shaw, iii. pl. 81 .

S. Schneiderii, Daud. Scales smooth, of a greenish yellow colour; a pale line on each side, and a triple elevation before the ears; tail longer than the body. Inhabits the Levant.-Cuv. Reg. An. ii. 54.

S. ocellatus, Daud. Body greenish gray above, with little brown spots circled with white; tail short and slender. 2 inches long. Inhabits Western Europe and Asia.-Daud. iv. pl. 56.

\section{Gen. 25. SePs, Daud.}

Body, neck, and tail very long, cylindrical, covered with imbricated scales of a rounded or elliptical form; tongue short, slightly cleft at the tip; feet small, the two pairs widely. separated; toes four or five.

S. pentadactylus, (Lacerta serpens, Lin.) Five-toed Eft. Body bay or ash-coloured above, with numerous longitudinal brown streaks ; whitish below ; feet with five toes, furnished with claws. $5 \frac{1}{2}$ inches long. Inhabits Java.-Shaw, iii. 307.

S. tridactylus. Three-toed Eft. Feet with three very short toes 
without nails; body ash-coloured above, with four longitudinal brown streaks, paler below.-Daud. iv. pl. 57.

S. monodactylus. (Lacerta anguina, Lin.) One-toed Eft. Feet extremely thin and short, composed of one toe, without a claw ; tail three times as long as the body. 15 inches long. Inhabits Cape of Good Hope.-Shaw, iii. pl. 85.

\section{Gen. 26. Bipes, Lacep.}

No fore feet, the scapulars and clavicles being concealed under the skin; feet slightly divided, or without divisions.

B. apus. (Lacerta apus, Gmel.) Head and body without distinct separation; tail long and round; scales small, imbricated; two feet near the anus, with slight divisions. Inhabits shores of the Volga._Cuv. Reg. An. ii. 56.

B. Gronovii. (Anguis bipes, Lin.) Dorsal scales dotted with brown; tail shorter than the body; two feet, round, and without divisions.-Cuv. Reg. An. ii. 56.

Gen. 2\%. Chalcides, Daudin.

Body excessively elongated; feet four, short and distant, toes varying according to the species; scales not imbricated, but forming transverse bands or rings.

C. tridactylus, Three-toed Chalcides. Feet three-toed, short, and without claws; tail a little longer than the body.-Daud. iv. pl. 58 , fig. 3.

C. monodactylus, (L. anguina, Lin.) One-toed Chalcides. Feet short and very slender, with one toe; tail longer than the body, cylindrical.-Daud. iv. 370.

\section{Gen. 28. Chirotes, Cuv.}

Hind feet wanting. In other respects resembling the preceding.

C. lumbricoides. (Bipède cannelé, Lacep.) Hind feet wanting; fore feet with five toes, of which four are clawed and one naked; sides of the body longitudinally furrowed. 8 or 10 inches long. Inhabits Mexico.-Lacep. i. pl. 41.

\section{ORDER III.-OPHIDIA.}

Heart with two auricles; body much elongated, cylindrical, destitute of feet, generally covered with scales.

The Ophidian reptiles, (so named from ö $\phi$ cs, a serpent) have no feet; and in consequence that division to which the name of Reptiles is more properly applied. They are readily known from this character : from their cylindrical form and elongated body ; by the wonderful flexibility of their dorsal spine; and by their crawling with the assistance of the large scaly plates on their belly.

Cuvier divides the order into three families. In the first, or Anguines, the teeth and

vor. I. 
tongue are similar to those of the genus Seps of the preceding order; and the eye is furnished with three eyelids. Latreille places them indeed at the end of the Saurian reptiles. The second family, or the True Serpents, comprehends the genera without sternum or vestiges of shoulder bones, in which the ribs surround a great part of the circumference of the trunk, and in which the vertebra are articulated to one another by a convex and concave surface. They want the third eyelid and tympanum. Although their head be large, the cranium forms but a small part of it. Their eyes are fixed, and they have no external ear. Their nostrils are short, not much developed, and generally situate at the extremity or sides of the muzzle. The tongue varies much; but although soft, moist, long, and forked, it appears rather destined to assist in seizing their food than as an organ of taste. Their sense of touch is blunted by the scaly epidermis which covers their body, and which they change at least once in the year. The third family comprehends the Naked Serperits, or those singular animals which form the genus Cacilia.

All serpents are furnished with conical and curved teeth, calculated rather for securing their prey than for breaking down their food. Some of the genera have pervious teeth or fangs in the upper jaw, which, pressing a gland or sac, forces the included poison into the wounds they inflict. The jaws are often not united in the middle, in consequence of which they are enabled to dilate the mouth very consider. ably. The digestion of serpents is very slow, and when they have taken food, they fall into a state of languor or lethargy. The organs of generation and the cloaca terminate in a common opening.

The circulation in serpents is slow. They possess a heart with two auricles and one ventricle divided into two compartments, and a single lung. Their voice is feeble, and they emit only a hissing noise. The ova liave in general a slightly calcareous covering, and they are commonly united together in a chaplet form. Sometimes these ova are developed in the body of the female, and the young are pro. duced alive. The females take care of the young for some time.

\section{Family I. Anguines.}

Teeth small and of nearly equal size; tongue notched in a lunated form; ribs more or less united, to supply the place of a sternum; eye furnished with three eyelids.

\section{Gen. 1. Ophisaurus, Daud.-Anguis, Lin.}

Tympanum externally visible; maxillary teeth conical, and two small groups of teeth on the palate.

O. ventralis, Cuv. Body yellowish green, spotted with black above; under parts pale yellow; a line on each side furnished with smaller scales, and a deep longitudinal furrow ; tail longer than the body. 18 to 24 inches long. N. America.-Catesby, Car. ii. pl. 59.

This animal is said to be so very brittle as to be denominated in Carolina the Glass-snake.

\section{Gen. 2. Avguis, Cuv.}

Tympanum concealed under the skin; maxillary teeth compressed and hooked; no palatine teeth.

A. fragilis, Lin. Blind-Worm, Penn. Body silvery yellow above, blackish below ; scales smooth and shining; three black longitudinal dorsal streaks, changing with age into a series of points, and finally disappearing; tail longer than the body. 10 to 12 inches long. Inhabits Europe. B.-Penn. Brit. Zool. iii. pl. 5.

The excessive fragility of this animal has been greatly overrated. Dr R. E. Grant has had living species in his possession for months, which sustained no injury by a fall from a table. This animal feeds on lumbrici and insects, and is viviparous. 
Gen. 8. Acontias, Cuv.-Anguis, Lin.

No vestige of a sternum or pelvis; teeth conical ; second lobe of the lungs rudimentary.

A. meleagris, Cuv. Tail obtuse, and much shorter than the preceding; eight rows of longitudinal brown spots on the back. Inhabits Guiana._Seba, ii. pl. 21, fig. 1.

\section{Family II.-Serpentes.}

This numerous family includes those genera which are destitute of a sternum and scapular bones, and want the third eyelid and tympanum. Cuvier divides them into two tribes, the first of which has the lower jaw supported, as in all the preceding genera of reptiles, by a tympanal bone articulated to the cranium; the two branches of this jaw fixed before, and those of the upper jaw to the cranium and to an intermaxillary bone, which prevents them from dilating, as in the second tribe. The eyes are small; the body cylindrical and covered with scales; the tongue short; the trachea long; the heart very much behind; and they have only a single lung.

\section{JAWS NOT DILATABLE.}

Gen. 4. Amphisbena, Lin.

Body surrounded with circular rows of quadrangular scales; a row of pores before the anus; teeth not numerous, conical, in the jaws only; oviparous.

A. alba, Lacep. Body white, without spots; head covered with six large scales; eight small tubercles around the anus. Inhabits S. America. 18 inches long.-Shaw, iii. pl. 134.

A. fuliginosa, Lin. Body black, variegated with white; head with six large scales in three rows; tongue broad, rough above, forked and free ; eyes small, and covered by a membrane ; anus surrounded by eight tubercles. 2 feet long. Inhabits Ceylon.Shaw, iii. pl. 135.

\section{Gen. 5. Trphlops, Schn.-Anguis, Lin.}

Body covered with small imbricated scales; snout depressed, furnished with plates; tongue long and forked; eyes scarcely visible through the skin; anus almost at the extremity of the body.

T. lumbricalis, Cuv. (A. lumbricalis, Lacep.) Extremity of the body thicker than the anterior part; colour livid white. About 8 inches long. Inhabits S. America.-Lacep. ii. pl. 20, fig. 1.

T. nasutus. (A. nasutus, Gmel.) Muzzle elongated, with a yellow spot; body greenish brown, with a yellow spot and lines on the tail; abdominal scales 218, subcaudal 12.12 inches long. Inhabits Surinam.-Shaw, iii. 587.

\section{II.-JAWS DIIATABLE.}

The second tribe have the tympanal bone or pedicle of the lower jaw moveable, and almost always suspended to a bone analogous to the mastoid, attached to the cranium by muscles and ligaments, which lcave it considerable motion. The branch. 
es of this jaw are also not united; and those of the upper jaw are united to the intermaxillary only by ligaments. From this structure these animals have the faculty of dilating their jaws, so as to swallow bodies thicker than themselves. Their palatine arches participate in this mobility, and are armed with sharp teeth curved backwards, - one of the most constant characters of the tribe.

These serpents are naturally divided into those which are poisonous and those which are not; and these again may be subdivided into poisonous serpents with many maxillary teeth, and poisonous serpents with isolated fangs. In those not poisonous, the jaws and the palatine branches have fixed and solid teeth ; four rows of these teeth, nearly equal, being in the upper part of the mouth, and two rows below.

\section{Body cylindrical; tongue short.}

\section{Gen. 6. Tortrix, Oppel.-Anguis, Lin.}

Scales of the belly and under the tail larger than the others; tongue thick and short; tail extremely short.

T. scytale, Oppel. Body fulvous, with irregular black and white rings. From 1 to 2 feet long. S. America.-Shaw, iii. 581.

T. corallinus, Cuv. - Body pale red, with broad alternate bands and variegations of deep coral-red. 18 inches long. Inhabits South America.-_Shaw, iii. pl. 131.

T. ater, Cuv. Bndy white, with black bands. Inhabits S. America.-Shaw, iii. pl. 132.

T. maculatus, Cuv. Body yellowish or orange-coloured, with an alternately fasciated black dorsal band. 18 to 20 inches long. Inhabits South America.-Shan, iii. 585.

\section{Occiput more or less gibbous; tongue forked and exten- sible.}

Gen. \%. BoA, Lin.

Anus with a hook on each side; body compressed, thickest in the middle; tail prehensile; scales small, at least upon the posterior part of the head.

The largest of serpents, some species reaching thirty or forty feet in length, and swallowing dogs, deer, and even oxen, according to some travellers. This genus formerly comprehended all serpents, poisonous and not poisonous, of which the body and tail were furnished with transverse scaly bands, and which had neither spur nor rattle at the end of their tail.

B. constrictor, Lin. With a long chain-like line, formed alternately by large blackish spots, irregularly hexagonal, and pale oval spots, hollowed at their ends, running along the back. 20 to 35 feet long. India, Africa, and S. America--Shaw, iii. pl. 92, 93.

B. cenchris, Lin. The Ringed Boa. Body fawn-coloured, with a chain of large brown rings along the back, and variable spots on the sides. 265 abdominal plates, 57 subcaudal. 20 feet long. Inhabits Surinam.-Shaw, iii. pl. 94.

B. scytale, (and murina, Lin. The Anaconda. Body brightbrown; a double row of deep brown round spots along the back; 
ocellated spots on the sides. 20 feet long. Inhabits S. America.-Shaw, iii. 343.

B. hortulana, Lin. Back variegated with deep brown, purplish, and whitish; sides with angular spots; abdomen yellowish, with dusky spots. The arrangement of colours on the head resembles lace. 2 feet 2 inches long. S. America._Shaw, iii. pl. 98.

B. phrygia, Shaw. Body white, with a grayish cast on the back, elegantly marked with black lace-like variegations. 4 feet long. Inhabits India._Shaw, iii. pl. 97 .

B. canina, Lin. Head large ; body green, with transverse undulated white dorsal bands. 4 feet long. Inhabits S. America.Shaw, iii. pl. 95.

Gen. 8. Errx, Daud.-Anguis, Lin.

A longitudinal row of scales, larger than the others, under the body and tail ; nine large plates on the head; teeth small and pointed.

E. Clivica. Body variegated with gray and brown. Inhabits Duchy of Cleves.-Shan, iii. 589.

\section{Gen. 9. Er peton, Lacep.}

Two soft prominences, covered with scales, at the extremity of the muzzle; head furnished with large plates; those of the belly a little smaller, and those under the tail slightly different from the other scales.

E. tentaculatus, Lacep. About four inches long, of which the tail forms a third._Lacep. An. Mus. ii. pl. 50.

3. Shields under the tail ranged in pairs.-CoLUBER, Lin.

Gen. 10. Рүтном, Daud-Coluber, Lin

Anus with lateral hooks; ventral plates narrow; plates of the head large and numerous.

P. Javanicus, Cuv. The Oular-Sawa. Body gray, striped with blue, and crossed by blue stripes with yellowish edges ; abdominal scales 312, subcaudal 93. 20 to 30 feet long.-Shaw, iii. 441.

P. ordinatus, Cuv. Body bluish-green, with whitish dorsal line, and sides spotted with brown. 2 to 3 feet long. Inhabits N. America.-Catesby, ii. pl. 51.

P. rhombeatus, Cuv. Body gray or brownish, with three alternating longitudinal rows of ovate but somewhat rhomboid dusky spots, with bluish centres. 2 or 3 feet long. S. America._Shan, iii. 437.

Gen. 11. Hurnia, Daud.-Coluber, Lin.

With a double row of longitudinal plates under the extremity of the tail; the rest of the body below witk one row only.

This genus was instituted by Daudin for the reception of some species of Indian 
serpents figured by Russell; but Cuvier expresses a doubt of the necessity for this minute subdivision.

\section{Gen. 12. Dipsas, Laurenti.-Coluber, Lin.}

Body compressed, less broad than the head; scales on the ridge of the back larger than the others.

D. Indica, (C. bucephalus, Shaw.) Bull-headed Snake. Body narrower than the head, brownish, with broad transverse whitish bars; large, cordated, depressed head, compressed body, and very long slender tail. $4 \frac{1}{2}$ feet long. Ceylon.-Shan, iii. pl. 109.

\section{Gen. 13. Coluber, Cuv.}

With transverse plates on the belly, divided into two under the tail, or forming a double row ; head flattened, with nine larger plates; teeth almost equal; no poison fangs.

C. natrix, Lin. Ringed Snake. Body ash-coloured, with black spots along the sides, and three white spots forming a collar on the neck; scales carinated. It feeds on insects, frogs, \&c. and its flesh is eaten. 4 feet long. Europe. B.-Penn. Brit. Zool. iii. pl.5.

C. atro-virens, Lacep. Body spotted with black and yellow above, yellowish-green below, with a row of black spots down each side; scales smooth. Size of the preceding. Common in France.-Shaw, iii. 449.

C. Austriacus, Gmel. Body reddish-brown, marbled with steel-colour below; two rows of small blackish spots along the back; scales smooth, brown towards the point. 4 feet long. Common in France. -Shaw, iii. 515.

C. viperinus, Latr. Body gray-brown; a row of zigzag black spots along the back; and another of smaller ocellated spots along the sides; belly spotted with black and grayish ; scales carinated. 3 feet long. Inhabits France.-Cuv. Reg. An. ii. 70.

C. Girondicus, Daud. Body gray, with numerous bands, bordered with black; scales smooth, and the spots on the back smaller and more separated than the preceding. Inhabits South of France and Italy.-Cuv. Reg. An. ii. 70.

C. Elaphis, Shaw. Body fawn-coloured, with four brown or black lines upon the back; abdomen white. France, \&c.-Shan, iii. 450.

This is the largest of the European serpents, sometimes exceeding six feet in length. It is supposed to be the Boa of Pliny.

C. Asculapii, Shaw. Esculapian Snake. Body brown above, strawyellow on the belly and sides; scales of the back oval and carinated, those on the sides smooth. 4 feet long, and thicker than the preceding. Inhabits Southern Europeand Asia._Shaw, iii. 452.

This is supposed to be the animal which the ancients represented in their statues of Esculapius. Linnæus was mistaken when he applied this specific name to an American species. It iq common in Italy, where it is often tamed, and taught to play tricks. 
C. viridissimus, Lin. (C. janthinus, Merrem.) Body bright bluegreen, with a tinge of purple on the back; abdomen whitish, with the scales dilated towards the middle. 3 feet long. Inhabits Surinam.-Shaw, iii. 471.

C. lineatus, Lin. (C. jaculatrix and atratus, Seb.-terlineatus, Lacep.) . Body bluish-green above, with three or five brown longitudinal stripes, of which the middle one is broadest. 2 to 3 feet long. Inhabits India._Shaw, iii. 529.

The other foreign species of this genus are very numerous. Some are remarkable for the vivacity of their colouring; others by the regularity of its distribution ; and others by their extremely slender forms. Few of them are of any large size.

Gen. 14. Acrochordus, Hornsted.

Body and tail covered with small uniform tuberculous scales; two rows of teeth; body much thicker than the tail.

A. Javensis, Lacep. (Anguis granulatus, Schn.) Body black above, whitish below; sides gray, spotted with black; scales raised, each into three small ridges, and sometimes resembling isolated tubercles. 8 feet long; tail less than one-fourth of the total length. Inhabits Java.-Shaw, iii. pl. 128.

\section{With poison fangs.}

The jaws of this section are organized and armed nearly as the preceding; but the number of teeth in the exterior row is smaller, and the first of these teeth, larger than the others, is hollow, and conducts the poison into the wound.

Gen. 15. Pseudoвoa, Oppel.-Boa, Schn.

Plates of the belly and under the tail single, head short, covered with large plates; occiput a little prominent; back carinated, with a longitudinal row of broader scales.

P. fasciata, Cuv. Body subtriangular, yellowish, with numerous dusky blue transverse longitudinal bands. 5 feet long. Inhabits India.-Shaw, iii. pl. 99.

P. lineala, Cuv. (Boa lineata, Shaw.) Body blackish-blue, with white dotted transverse arcuated lines and whitish abdomen. Inhabits India._Shaw, iii. 356.

\section{Gen. 16. Trimeresurus, Lacep.}

Plates under the tail, near the vent, single, and double plates towards the extremity; head with large plates.

T. leptocephalus, Lacep. With nine large plates on the head; scales of the upper part of the back striated, the others smooth; head very small.-An. Mus. iv. pl. 56, fig. 1.

Gen. 17. Hydrophis, Cuv.-Hydrus, Shaw, Schn.

A row of scales on the belly a little larger than the others; head small, not tumid, covered with large plates; tail compressed vertically. 
H. lavis, Cuv. (Aipysurus, Lacep.) With 151 large plates under the body; twenty-eight small scales under the tail; neck very broad; thirteen plates on the head. Inhabits New Holland.-An. Mus. iv. pl. 56, fig. 3.

H. curtus, Cuv. Body compressed ; head flattish ; colour pale yellow, with a series of decurrent dusky bands, somewhat confluent above. About a foot long. Inhabits India.-Shaw, iii. 562.

H. spiralis, Cuv. Body much compressed, the back rising into a ridge ; colour yellow, barred from head to tail with deep chestnut fasciæ, widening on the abdomen; body alternately flatter on one side than the other. 2 feet long.-Shaw, iii. pl. 125.

\section{Gen. 18. Pelamis, Cuv.}

Belly and head with larger plates; occiput tumid on account of - the length of the pedicles of the inferior jaw, which is very dilatable; all the scales of the body small and equal; tail compressed vertically

P. bicolor, (Anguis platurus, Lin.) Head and upper parts deep black; lower parts pale yellow; tail spotted; back carinated; scales of the sides small, and brighter yellow. $2 \frac{1}{2}$ feet long. Inhabits Sea at Otaheite.-Shaw, iii. pl. 126.

This species, although poisonous, is eaten at Otaheite.

\section{Gen. 19. Chersydrus, Cuv.}

Head and body equally covered by small scales; posterior part of the body and tail compressed vertically.

C. fasciatus, Cuv. (Acrochordus fasciatus, Shaw.) Body dusky brown, with carinated abdomen, and whitish ascending lateral bands. 18 inches long. Rivers of Java._Shaw, iii. pl. 130.

\section{With isolated poison fangs.}

The poisonous serpents with isolated fangs have a particular structure in their organs of manducation. The superior maxillary bones are very small, supported on a long pedicle, and very moveable. Into these is fixed a sharp pervious tooth, through which issues, when pressure is applied, a fluid secreted by a gland situated under the eye. It is this fluid which, injected into the wound by the tooth, produces effects more or less serious, according to the species which inflicts the wound. The tooth is concealed in a fold of the gum when the animal does not use it; and behind are many germs of new fangs, destined to replace the original one, should it be broken by any accident or left in a wound. Naturalists have named these teeth moveable fangs; but it is properly the maxillary bone which moves. In these serpents there are only two rows of palatine teeth in the upper part of the mouth. All poisonous species of which the history is known are viviparous, which has occasioned them to have received the name of vipers, an abbreviation of the term viviparous. The poisonous serpents present exterior characters nearly the same as the preceding genera. But the greater number have the jaws very dilatable, and the tongue extensible. Their head, being broad behind, gives them a ferocious aspect, which in some measure announces their nature. They may be divided into two groups, the Rattlesnakes and Vipers.

Gen. 20. Crotalus, Lin.

Head broad, triangular, and flattened; scales carinated; tongue 
forked; a hollow behind the nostrils; upper maxillary bones with isolated fangs; plates or transverse bands under the body and tail ; extremity of the tail with a rattle formed of hollow, moveable, and sonorous plates.

This group is celebrated for the active nature of the poison they communicate. They have, as the Boas, simple transverse plates under the body and tail; but what distinguishes them chiefly is the hollow moveable scales at the termination of the tail. This rattle, as it is called, is formed of horny plates, which sound when the animal crawls or moves its tail. The number of these plates augment with age, and they acquire an additional one at each shedding. All the species of which the country is known come from America. Rattlesnakes creep slowly, and never bite unless provoked, or to kill their prey. Although they rarely climb trees, their principal food is birds, squirrels, \&c. It has long been supposed that they had the power of fascinating small animals, or overpowering them by their breath. The agitation and terror of the birds, lowever, and anxiety to lead the snake from their young brood or nests, by provoking his attention, are sufficient to account for the observed fact, without the necessity of having recourse to a particular and mysterious power of fascination.

* Scales of the head and back similar.

C. horridus, Lin. The Rattlesnake. Body brown, with transverse irregular blackish bands; extremity of the tail black. 4 to 6 feet long. Inhabits America.-Shaw, iii. pl. 88.

C. durissus, Lacep. The Striped Rattlesnake. Body brown, with lozenge-formed spots bordered with black, and four black lines along the top of the neck. 5 feet long. Inhabits Guiana.Shan, iii. pl. $89,90$.

Both these species are equally dangerous, and their bite causes death in a few minutes. The poisonous fangs, even when withdrawn from the animal, have been known to retain the power of inflicting fatal wounds for years.

\section{** Head furnished with large plates.}

C. miliaris, Lin. Body gray brown, with a red line along the back, interrupted by a series of black spots, bordered with white; sides and under parts with smaller spots. 2 feet long. Inhabits Carolina._Catesby, Car. ii. pl. 42.

\section{Gen. 21. Scytalus, Latr.}

Body and tail below with a row of transverse plates; poisonous fangs in the upper jaw; no hollows behind the nostrils; tail destitute of rattles.

S. ziczac, Daud. (Boa horatta, Shaw.) Body dark brown, with a waving yellow band on each side, and a row of yellowish dorsal spots, edged with black; head with four dark spots. 15 inches long. Inhabits India.-Shan, iii. 359.

\section{Gen. 22. Acantulophis, Daud.}

With double plates under the tip of the tail, which is terminated by a pointed spur; large plates on the anterior part of the head; no hollows behind the nostrils; poisonous fangs in the upper jaw; hind part of the head tumid, and with scales similar to those of the back. 
A. palpebrosus, Cuv. (Boa palpebrosa, Shaw.) Body pale gray, with black transverse bands on the back, and two rows of black points below. 15 inches long.-Shaw, iii. 362.

A. Brownii, Leach. Body blackish, with the lower lip white; a transverse groove before the nostrils ; tail short and flattened laterally. 8 inches long. New Holland._Leach, Zool. Mis. pl. 3.

Gen. 23. Langaha, Brug.

Body covered anteriorly with small scales above; plates behind the anus surrounding the tail; tail towards the end furnished with small scales; muzzle long and pointed; poisonous fangs in the upper jaw.

L. nasuta, Shaw. Head with seven large scales; muzzle with a tendinous prolongation, covered with small scales; body covered with reddish and violet and yellow points; scales rhomboidal. 2 feet 8 inches long. Inhabits Madagascar.-Shan, iii. pl. 127.

6.-With transverse plates under the belly, divided into two under the tail.-Vipera, Daud.

Gen. 24. Trigonocephalus, Oppel.

Head widened behind, in some covered with scales similar to those of the back, in others granulated; depressions behind the nostrils; poison fangs in the upper jaw ; tail often terminated by a small horny. spur.

T. lanceolatus, Cuv. (Coluber Megcera, Shaw.) Body brown, with yellow variegations; head flat, cordate; a large orifice on each side between the eyes and nostrils. 5 to 6 feet long. Inhabits Martinico.-Shan, iii. 406.

T. Alecto. (Coluber Alecto, Shaw.) Body whitish, with rectangular rhomboidal brown spots along the back, and cordated ferruginous head; a black lateral stripe. $5 \frac{1}{2}$ feet long. Inhabits Ceylon.-Shaw, iii. 405.

T. atrox. (Coluber atrox, Lin.) Body gray brown, with transverse linear whitish stripes; abdomen dusky, with white transverse variegations. 18 inches long. Ceylon.-Shaw, iii. 429.

T. viridis, Cuv. (Trimeresurus, Lacep.) Body green, with three large plates and two smaller under the tail ; top of the head covered with scales similar to those of the back. Inhabits New Holland.-An. Mus. iv. pl. 56, fig. 2.

Gen. 25. Platurus, Latr.

Tail compressed; with two rows of plates, and terminated with two large ones; head covered with larger plates; poison fangs in the upper jaw.

P. laticaudatus, Cuv. (Hydrus Colubrinus, Schn.) Body cinereous, banded transversely with white and blackish stripes; scales rhomboidal. 2 feet long. Inhabits Indian Seas, -Shaw, iii. pl. 123. 
Gen. 26. NAIA, Laurenti.

Plates larger on the body near the head; head covered with large plates, and hind head furnished with a hood; poisonous fangs in the upper jaw.

N. vulgaris, (Coluber naja, Lin.) The Cobra de Capello. Body ferruginous yellow; rieck capable of inflation, and marked above by white marks, with black edges, in the form of spectacles. 3 to 4 feet long. Inhabits India.-Shaw, iii. pl. 107.

N. haje, (Coluber haje, Lin.) Neck widened as in the preceding; body greenish, bordered with brown. 5 to 6 feet long. Inhabits Egypt.-Geoff. Rept. Eg. pl. 7 .

This species is conceived by Cuvier to be the aspic of the ancients. The jugglers of Egypt, by pressing on the nape of the neck with the finger, throw the animal into a kind of catalepsy, which renders it stiff and immoveable. The habit which this species has of raising itself up when approached, induced the ancient Egyptians to believe that it guarded the fields where it was found; and it is sculptured on the gates of their temples as an emblem of the protecting divinity of the world.

\section{Gen. 2\%. Elaps, Schn.-Coluber, Lin.}

Large plates on the head; jaws with poison fangs, but not capable of much dilatation; head behind same breadth as the neck.

E. lemniscatus, Cuv. (C. lemniscatus, Lin.) Body yellowish or white, with triple ferruginous or blackish bands; point of the muzzle black. Inhabits Asia.-Shav, iii. 485.

E. lacteus, Cuv. Body white, the back marked by double black spots; head black, with a longitudinal white line. 18 inches long. Inhabits India and South America.-Shaw, iii. 427.

E. lubricus, Cur. Body white, with equidistant black bands; head. marked with a black band across the muzzle, and on the top by two oblique stripes nearly meeting at an angle in front. 18 inches long. Inhabits Africa.-Shan, iii. 487.

Gen. 28. Conra, Laurenti.

Scales on the head carinated; head from the eyes to the mouth subtriangular; poisonous fangs in the upper jaw.

C. Atropos, Cuv. (Coluber, Lin.) Body whitish, with four rows of red round spots, white in their centre; four black spots on the head. 15 inches long. Inhabits S. America.-Shaw, iii. 404.

C. Lachesis, Cuv. Body yellowish-gray, variegated with brown, with loose carinated scales; head indistinct, and short tail. 4 to 5 feet long. Inhabits Ceylon.-Shan, iii. pl. 105.

C. Clotho, Cuv. Body grayish-orange, with numerous transverse undulated black bands; beneath ash-coloured, with black variegations. 6 feet long. Inhabits Ceylon.-Shan, iii. 401.

Gen. 29. Vipera, Cuv.-Coluber, Lin.

Scales on the head rough or granulated; plates under the belly divided in two under the tail; poisonous fangs in the upper jaw. 
V. Berus, Cuv. The Common Viper. Brown, with a black zigzag line along the back, and a row of black spots on each side; belly slate-coloured. 2 to 3 feet long. Europe. B.-Shan, iii. pl.101. The Viper or Adder, as it is called in Scotland, is pretty generally diffused over all the old continent. It is plentiful in some counties of England, and abounds in several of the Hebrides. The viper grows to the length of two feet, and sometimes more. The ground colour of the body is a dirty yellow, and along the back runs a chain of irregular black spots joined at the points. This is the only poisonous British species; but olive oil is said to be a certain remedy for the bite, if speedily applied. Viper's flesh is still used medicinally in some countries.

V. ammodytes, Cuv. (Col. aspis, Gmel.) Body glaucous brown, with dentated black dorsal band, and upright nasal wart. Inhabits Southern Europe.-Shan, iii. 379.

V. cerastes, Cuv. Body pale yellowish or grayish, with distant subovate transverse brown spots; a pointed and solid horn on each eyelid. 1 to 2 feet long. Inhabits Egypt._Shan, iii. pl. 103.

V. Chersaa, (Col. Chersaa, Lin.-C. berus, Daudin.) Body subferruginous, with black flexuous dorsal band; three larger plates on the middle of the head. About a foot long. Inhabits Northern Europe.-Shaw, iii. 382.

The variety of a black colour has been named the Black Viper. (Col. prester, Lin.)

V. hamachates, Cuv. (Col. hicmachates, Gmel.) Body brownishred, marbled with white; abdomen yellowish-white; head covered with plates. 2 feet long. Inhabits Persia and India.Shaw, iii. 425.

\section{Family III.-Naked Serpents.}

This division comprehends but one very singular genus, which many naturalists seem inclined to refer to the Batrachians.

\section{Gen. 30. CeCILIA, Lin.}

Body cylindrical; skin naked, with longitudinal folds; eyes extremely small.

This genus is thus named, because its eyes are excessively small, and nearly concealed under the skin. Smooth, viscid, and naked as the eels, when the skin is dried the vestiges of scales are scarcely perceived; but transverse folds are seen on the sides. The head is depressed, and the anus round and near the extremity of the body. The articulation of the vertebræ is accomplished by the faces of a hollow cone filled by a gelatinous cartilage, as in the fishes; and the cranium is united to the first vertebra by two tubercles, as in the Batrachian reptiles. The maxillary bones cover the orbit, which is pierced with a very small hole, and those of the temples cover the temporal depressior, in such a manner that the head presents above a continuous bony shield. The maxillary and palate teeth, pointed and curved backwards, resemble those of the serpents, properly so called; but their lower jaw has no moveable pedicle. They deposit their eggs, with a semi-membranous skin, united in long strings.

C. glutinosa, Lin. Brown, with a white line on each side; wrinkles very close and numerous. About a foot long. Inhabits S. America.-Shaw, iii. pl. 137.

C. tentaculata, Lin. Body above bluish brown, abdomen paler; two tentacula on the upper lip. A foot long. Inlabits S. America. -Shan, iii. pl. 136. 


\section{ORDER IV.-BATRACHIA.}

Heart with one auricle; body covered with a naked skin; lungs two when mature, but with branchiæ like fishes in their early stage.

Batrachia, (from $\beta \dot{\alpha} \tau \rho \tilde{a} \chi \circ$ os, a frog.) The animals of this order have a heart with a single auricle and ventricle. They have all two lungs, to which are added, in the first stage of their existence, branchice or gills, more or less analogous to those of fishes. The greater part lose these branchiæ on arriving at their perfect state. In two genera only, Sirena and Proteus, they are preserved during life. While the branchiæ subsist, the aorta in going from the heart is divided into as many branches on each side as there are gills. The blood of the branchiæ returns by veins, which unite towards the back into a single arterial trunk; and it is from this trunk, or from the veins which form it, that the arteries arise which nourish the body, and even those which conduct the blood to the lung. In the species which lose their branchiæ, the branches which lead to them become obliterated except two, which, uniting in a dorsal artery, give off each a little branch to the lung. It is, as Cuvier observes, the circulation of a fish changed into that of a reptile.

Batrachian reptiles have neither scales, nor shield, nor nails on their toes, - a naked skin covering the whole body. The envelope of their ova is membranous. In some species the male assists in their extrusion, and impregnates them as they are extruded; in others the ova are deposited. The young differ not only from the adult by the presence of gills ; their feet are developed only by degrees; and many species possess in their first stage a snout and a tail, which they afterwards lose.

\section{Gen. 1. RaNa, Lin.}

Body slender; hind-feet very long, muscular, and completely palmated; skin smooth; upper jaw furnished with a row of small teeth, and an interrupted transverse one in the middle of the palate; males with a thin membrane under the ear, which is inflated with air when they cry.

In their perfect state frogs have four legs and no tail. Their head is flat, their snout rounded, and the opening of their jaws large. Their tongue is soft, not attached to the gullet, but to the edge of the jaw, and folds inwards. They have four toes on the fore feet; the hind feet have five, and sometimes the rudiment of a sixth. The skeleton of this family is entirely destitute of ribs; and a cartilaginous plate on the head supplies the place of a tympanum. The cye has two fleshy eyelids, and a third, transparent and horizontal, concealed under the inferior one. Inspiration in these animals is effected by the muscles of the throat, which in dilatation receive the air by the nostrils, and, contracting while the nostrils are shut by the tongue, force the air to penetrate into the lungs. Expiration, on the contrary, is performed by the muscles of the lower belly. The embraces of the male are long continued. His thumbs are furnished with a spongy inflation, which is increased in the coupling season, and which assists in attaching him to the female. The ova are impregnated at the moment of expulsion. The tadpole is at first provided with a long fleshy tail, and a horny beak, and has no other apparent members but little fringes at the sides of the neck. These disappear at the end of a few days, and are replaced by branchiæ or gills. These gills, by which they respire at this period, are formed of numerous small tufts attached to four cartilaginous arches placed on each side of the neck, adhering to the hyoid bone, and enveloped in a membranous tunic covered by the general skin. The water which enters by the mouth passes in the intervals of the cartilaginous arches, and is extruded sometimes by two openings, sometimes by one, in the middle or left side of the exterior skin, according to the species. The hind feet of the tadpole are developed by degrees, the fore feet being developed under the skin, which they afterwards pierce; the tail is gradually absorbed; the beak falls off, and discovers the true jaws, which 
were at first soft and concealed by the skin. The branchiæ or gills also disappear, and leave the lungs to exercise the function of respiration, as in other reptiles. At last the eye, seen through a transparent skin in the tadpole, appears with its three eyelids. The intestines, at first long, sletider, and convoluted spirally, are now shortened, and take the necessary form of the stomach and colon, to accommodate the changed animal to its new food. The period of this change varies according to the species. In cold and temperate countries the perfect animal buries itself in the mud or under ground during winter, and passes that season in torpidity. The members of the tadpole are regenerated as those of the salamanders.

R. esculenta, Lin. Green Frog. Body green, spotted with black; three yellowish dorsal lines; abdomen whitish.-Shaw, iii. pl.31.

This is the largest of the European frogs, and is found plentifully in France, Germany, and many other parts of Europe. The croaking of these animals in the breeding season is excessively annoying to those in their neighbourhood. They, however, furnish a wholesome and agreeable food.

R. temporaria, Lin. Common Frog. Body yellowish brown, spotted with black, with an elongated brown patch extending from the eye over the ear. Inhabits Europe. B.-Shan, iii. pl. 29.

This species appears early in spring ; goes oftener on land than the preceding, and croaks much less.

R. paradoxa, Lin. Paradoxical Frog. Body greenish, spotted with brown ; irregular brown lines along the thighs and legs. 16 inches long. Inhabits Guiana.-Shaw, iii. pl. 36.

Of all the species this has its tadpole the largest before its metamorphosis. Its very large tail and singular form led the early observers to suppose that it became a fish ; or that the full grown frog, contrary to the usual rule, took again the tadpole form.

R. taurina, Cuv. (R. pipiens, Daud.) The Bull Frog. Body olive green, spotted with black; a yellow line along the back. 12 to 18 inches long. North America._Shaw, iii. pl. 33.

Gen. 2. HyLA, Cuv.-Rana, Lin.

Body slightly compressed, elongated, smooth; tongue short and thick; the two fore feet furnished with four toes, the hinder with five, all without claws, but terminated by lenticular tubercles; male with a gular pouch capable of inflation.

H. arborea, Lin. Tree-Frog. Body bright green above, whitish below, with a yellow and blackish lateral line on each side of the body; abdomen granulated; feet not webbed. Inhabits Europe.-Shan, iii. pl. 38.

In the beauty of its colours, elegance of its form, and agility of its movements, the arborca exceeds every other European species. It is plentiful on the continent of Europe, but has not been found in Britain. It suspends itself by its feet to the twigs of trees for the purpose of catching its prey.

H. tinctoria, Cuv. Stained Tree-Frog. Body smooth, with two longitudinal lines and one transverse yellowish one upon the back. Inhabits South America._Shaw, iii. 135.

\section{Gen. 3. Buro, Cuv.}

Body thick, short, and broad, covered above with warts or papillæ, which exude a fetid fluid; a thick projection behind the ears; no teeth; eyes large and protuberant; fore feet with four toes, separate; hind feet short, with five toes, generally palmated. 
B. vulgaris, (R. bufo, Lin.) The Common Toad. Body reddish or brownish gray, sometimes olive-coloured or blackish, the back covered with rounded tubercles, those on the belly smaller and closer together; hind feet semipalmated. Inhabits Europe. B.

This well-known animal is found in gardens, woods, and fields, and often makes its way into cellars and other obscure places. It passes the winter in holes in a state of torpidity. The female produces small eggs in very great numbers, united by a transparent jelly in two strings, often twenty or thirty feet in length. The tadpole is blackish, and its branchial opening is on the left. The toad lives about fifteen years, and produces at four. The warts on its back exude an acrid fluid.

B. calamila, Cuv. (R. mephitica, Shaw.) Body olive above, with dark spots and reddish pustules; a longitudinal yellow line along the middle of the back. Inhabits Europe.-Shan, iii. pl. 43.

This animal diffuses a mephitic odour, resembling the smoke of gunpowder. It does nut leap, but runs very quickly ; climbs walls to creep into crevices; and for this purpose its fore-feet are furnished with two small osseous tubercles. It is not found in water but in the breeding season. The male has a gular pouch.

B. fuscus. Laurenti. (R. alliacca, Shaw.) Body clear brown, marbled with deep brown or blackish; tubercles on the back not numerous, the size of lentils ; belly smooth ; hind feet with lengthened and palmated toes. Germany, \&c.-Shaw, iii. pl. 41.

The eggs of this species are attached by a single string. The tadpole has but one branchial opening, on the left side. It has a strong garlic smell when irritated.

B. bombinus, Cuv. (R.bombina, Gmel.) The Natter-jack. Body grayish brown above; blackish blue with orange yellow spots below ; feet completely palmated, and almost as long as those of the frog. Inhabits Europe. B.-Penn. Brit. Zool. iii. pl. 2.

B. obsletricans, Laur. Body gray ; the tubercles on the back blackish ; whitish on the sides. Common in the neighbourhood of Paris.-Daud. pl. 32, fig. i.

The male of this species assists the female to expel the eggs, which are attached in clusters to the thighs by means of a glutinous matter. When about to be hatched, the animal seeks some stagnant water in which to deposit them. They soon afterwards open, and the tadpole swims out.

B. variabilis. (R. variabilis, $\mathrm{Gm}$.) Body whitish, spotted with green; remarkable for the changes of colour of its skin, according to the light it is in, or as it wakes or sleeps. Found near Paris.-Daud. pl. 28. fig. 2.

B. marinus. (R. marina, Gmel.) Body ash gray, irregularly spotted with brownish; warts large; parotid glands large and gibbous. 8 or 10 inches long, without including the legs. Inhabits Guiana. -Shaw, iii. pl. 44.

B. cornutus. (R. cornuta, Gmel.) The Horned Toad. Head and jaws very large; a conical tubercle above each eye. Inlabits South America.-Shaw, iii. pl. 48, 49.

B. margaritiferus. ( $R$. margaritifera, Gmel.) With an erect stiff rounded lobe behind each eye, and numerous warts on the body, bearing some resemblance to pearls; hind feet semipalmated.Daud. pl. 33. 


\section{Gen. 4. Pipa, Laurenti.}

Body flattened horizontally; head large and triangular; tongue wanting; tympanum concealed under the skin; eyes small, towards the margin of the upper jaw ; toes of the fore feet cleft into four small points ; larynx of themale very long, triangular.

P. Surinamensis. (Rana pipa, Lin.) Body broad, flattened, olivecoloured, with red spots; head short, with a crenulated coriaceous appendage at the angles of the mouth. 5 inches long. Inhabits Surinam.-Shan, iii. pl. 50, 51.

Gen. 5. Salamandra, Brongniart.-Lacerta, Lin. Body elongated; tail long, cylindrical or flattened; head depressed; ears concealed, and with a small cartilaginous plate upon the opening; jaws furnished with numerous small teeth, and two longitudinal rows of similar teeth on the palate; tongue short, thick, and fixed in the lower jaw ; no third eyelid; feet four, with four toes before and five behind.

This genus has the general form of the lizards. In the adult state they respire in the saine manner as the frog and tortoise. The tadpoles respire at first by three tufted branchiæ on each side of the neck, which are afterwards obliterated. These tufts are not covered. The fore feet are developed before the hind feet, and the toes appear in succession.

\section{* Terrestrial.-Tail rounded when adult.}

S. terrestris. (Lacerta Salamandra, Lin.) Black, with large spots of bright yellow; rows of tubercles upon the sides, which exude a milky liquor, which acts as a poison on small animals. 7 or 8 inches long. Inhabits Europe.-Shaw, iii. pl. 82.

It is perhaps owing to this milky exudation that the fable of the salamander's being able to resist fire has arisen. They inhabit moist places, retire into holes, feed on lumbrici, insects, \&c. Their young are deposited in marshy situations, and at first have their tail flattened vertically, but in their adult state it is rounded.

** Aquatic.-Tail compressed vertically.-Triton, Laurenti.

The experiments of Spallanzani on the astonishing power of reproduction in these animals are well known. Another faculty no less singular is that of being able to survive after being a long time frozen in ice. The ova are expelled in long chaplets; the young are hatched fifteen days after, and preserve their gills for a longer or shorter period, according to the species.

S. marmorata, Latr. Skin shagreened, pale green above, with large irregular brown spots; brown, dotted with white below; a crest on the back of the male; tail much compressed. Inhabits Europe.-Cuv. Reg. An. ii. 100.

S. punctata, Latr. Skin smooth, clear brown above, paler below or reddish, with black and round spots; black streaks on the head; crest of the male festooned. Inhabits Europe-Cuv. Reg. An. 100.

S. palmata, Latr. (L.aquatica, Lin.) Back brown; top of the head waved with brown and blackish; sides paler, with round blackish spots; belly whitish, without spots ; male with three small crests on the back ; toes dilated and united by membranes; tail terminating in a small filament. Europe. B.-Shaw, iii. pl. 83. 
S. gigantea, Barton. Body bluish black. 15 to 18 inches long. Inhabits lakes and rivers in North America.-Cuv. Reg. An. ii. 101.

The Axolotl of Mexico, the Siren pisciformis of Shaw, which was long considered as the larva of a large species of Salamander, has persistent branchiæ; four feet, with four toes before and five behind; and the organs of generation have been found in a developed state by Sir Everard Home, in specimens brought from Mexico by Mr Bullock.

\section{Gen. 6. Proteus, Laurenti.}

Body elongated,cylindrical; tail compressed; tongue short, thick, and free only before; eyes excessively small, and concealed by the skin; fore feet with three toes; hind feet with two, all without claws; interior lungs and persistent branchiæ.

P. anguinus, Laur. (Siren anguina, Schn.) Body smooth and whitish ; tail compressed vertically; branchiæ bright red or carmine coloured. About a foot long.-Shan, iii. pl. 139.

This species, the only one of the genus, is found in the subterranean streams by which some lakes in Carniola communicate together. Besides lungs it has, like the salamanders, three tufted branchiæ on each side, which it appears to preserve through life. The skeleton somewhat resembles that of the salamander, but the vertebræ are more numerous, and the general conformstion of the head decidedly different.

Gen. 7. Siren, Lin.

Body elongated, cylindrical, and terminated by a compressed tail ; tongue short, thick and adherent; only two feet, placed forwards on the body, with each four toes; interior lungs and persistent branchiæ.

S. lacertina, Lin. The Siren. Body blackish, resembling that of an eel. 2 to 3 feet long. Inhabits marshes of South Carolina. -Shan, iii. pl. 138.

This species, the only one of the genus, retains during life, as the Proteus, three free branchial tufts on each side of the neck, at the same time with interior lungs. The vertebræ are much more numcrous than those of the salamanders, and of a different form. The eyes are very small; the ears concealed; the inferior jaw armed with teeth all around, and many rows on both sides of the palate. By a curious mistake, Cuvier describes the feet as having five toes; and Mr Gray in the Annals of Philosophy, Vol. X. asserts the same. But in a live specimen which we have seen there are only four, as mentioned by the older naturalists. It inhabits the marshes of Carolina, and chiefly those formed for the culture of rice, feeds on insects, worms, \&c.

Dr Garden of Charleston, South Carolina, first sent specimens of what he justly regarded as a very curious reptile, preserved in spirits, to $\mathrm{Mr}$ Ellis of J.ondon. The Doctor remarked, that he had seen the reptile of all sizes, but all possessing gills, and having only fore-feet; and that there was no lizard in South Carolina of which it could be regarded as the larva. Mr Ellis communicated one of the specimens to Linnæus, and that illustrious naturalist did not hesitate to pronounce it a perfect animal, of the most truly amphibious character, and to create for it a new order, Meantes, in his class Amphibia, giving it the generic name of Siren. A number of distinguished naturalists, however, have disputed this opinion, as Camper, Pallas, and Lacepede; and have insisted that the Siren is only a larva. Within these few years past, Configliachi and Rusconi in Italy, and Dr Fleming in our own country, have published opinions to the same purpose. But Baron G. Cuvier, after dissecting the animal, has given his verdict in favour of the opinion of Garden, Ellis, and Linnæus, that it is a perfect animal, destined through life to breathe either by external branchiæe or internal lungs, according to the situation it may for the time occupy in its native marshes.

VOI. I. 
The habits of the Siren are still but little known. It seems indeed to be a rare animal even in America; for M. Bosc sought it in vain during eighteen months of his residence at Charleston. The latest account of it, which is contained in Silliman's Journal for October 1826, is far from satisfactory. It may here be mientioned, that, in May 1825, a living specimen was received from Charleston by Dr Monro of Edinburgh. The professor fortunately confided the charge of this interesting animal to Patrick Neill, Esq. a gentleman fully qualified to observe and record its peculiar characters and habits, in whose collection at Canonmills it still remains. This excellent naturalist lately communicated the result of his observations for a period of upwards of two years to the Wernerian Society. The Siren is kept in a box among watér, but where it has the choice of leaving the water, and reposing among moss or hypnum, if so inclined. It is fed with earth-worms, which it takes at intervals of some days. It is quite lively, particularly in the summer months. It begins to croak like a frog in April, but has no vox cantillans, or at least no change of note. The water box in which it is kept is placed on a trellis shelf in a hot-house, about three feet from the ground. On one occasion it had made its way over the margin of the box and had fallen to the ground; but it was not hurt, and is not therefore a fragile animal, as was long supposed. It may be added, that on this particular occasion it lived for many hours out of water, when it must have breathed solely by its internal lungs. On the other hand, it has often been observed to lie quiet at the bottom of the water for many huurs, breathing of course wholly by means of the air separated from the water by its external branchiæ. Upon the whole, the observations made on this living specimen decidedly tend to confirm the opinion of Linnæus and Cuvier, that the Siren is a perfect animal.

\section{FOSSIL REPTILES.}

Fossil Reptiles are met with in different parts of Europe. Of the Chelonian Order, fossil marine tortoises have been found in the coarse marine limestone at the village of Melsbroeck in the neighbourhood of Brussels, in the coarse chalk of the hill of St Peter near Maestricht; and in the limestone slate of Glaris. The gypsum quarries near Paris have afforded specimens of fresh water tortoises. In England, fossil remains of tortoises have been found in the Isle of Sheppey; in the iron-sand beds of Tilgate Forest, in the argillaceous limestones called Purbeck beds; and in the Stonesfield slate and lias; and impressions of the feet of an animal considered to be of this order have been found in the red sandstone of Corncockle Quarry in Dumfries-shire.

Of Saurian Reptiles, fossil crocodiles have been found in the bluish-gray compact limestone at the bottom of the cliffs of Honfleur and Havre; at Altorf near Nuremberg, in coarse gray marble; and in England, near Whitby, in pyritical slate ; at Brentford, in Lancashire silt, in the clay of Sheppey, the-iron-sand of Tilgate Forest, and near Oxford. Fossil remains of Monitors have becn found on the Continent ; in the quarries of Maestricht, one gigantic species twenty-four feet long; at Thuringia, near Manheim, and in the quarries of Aichstedt. In Britain, in the calcareous slate of Stonesfield, near Woodstock, the remains of the Megalosaurus, a gigantic animal, intermediate between the Crocodile and Monitor, and supposed to have been forty feet long. The Iguanodon, another gigantic species supposed to have been upwards of sixty feet long, occurred in the iron-sand of Tilgate Forest. The fossil genus Ichthyosaurus, from the lias limestone of England, furnishes several remarkable remains, partaking of the characters of the Dolphin, Crocodile and Lizard, with the vertebræ of a fish. And the species of Mr Conybeare's genus Plesiosaurus occur in lias at Lyne and in the Kimmeridge clay.

Of the Ophidian order remains of vertebræ occur in the red calcareous breccia in the environs of Cette, mixed with bones of other animals.

Fossil remains of Batrachian reptiles have been found on the Continent in the fetid calcareous schistus of CEningen, among remains of fishes. The Proteus of CEningen, first described and figured by Scheuchzer as the remains of an antediluvian human being, was afterwards ascertained by Cuvier to be an extinct species of Salamander. A fossil toad has been found in the same strata.

None of the fossil species of reptiles hitherto discovered are identical with the existing species. 


\section{CLASS IV.-FISHES. (Pisces.)}

Vertebrated animals with cold red blood, respiring by gills or branchice, and moving in the water by the aid of fins.

Thougu fishes have been known and used as food from the earliest ages, Aristotle is regarded as the first writer who has considered them in a general view as forming a particular class of animals. After him the work of Pliny, as in the other branches of Natural History, may be considered as the great receptacle of all the facts known to his time in regard to the history, characters, and manners of fishes. Among the comparatively modern writers on this subject, Belon, a French physician, who in 1551 published a work entitled Histoire des Poissons, is the first who attempted to arrange the class in anything like connected families. In one of his groups he placed Cartilaginous flat fishes; in another flat fishes not cartilaginous; and in a third and fourth, were separated the sharks and eels or elongated fishes, as marked by prominent and distinguishing characters.

Some years after (1554) William Rondelet, professor of medicine at Montpellier, published a work on fishes in one volume folio, illustrated by figures from wood. Though this writer cannot be said to have very much improved the scientific arrangement of the class, yet his work is valuable for accurate specific descriptions. The figures, too, are in most cases capable of being referred to their prototypes. In the same year, Hippolyto Salviani, a physician at Rome, published a work entitled Aquatilium Animalium Historia, with good figures of many fishes.

From this period a taste for the study of Ichthyology, as this branch of Natural History has been termed, (from ‘ $\chi$ bus a fish, and $\lambda_{0}$ yos a discourse) seems to have been disseminated. But passing over the intervening authors, we only notice that part of the work of Aldrovandus, published in the beginning of the following century, which treats of fishes, and where they are arranged according to their habitats, such as Littoral fishes, - those which are found among Rocks, - and Pelagian or deep-sea fishes. 
The work of Willughby, entitled De Historia Piscium libri quatuor, published in 1686 by his celebrated countryman and coadjutor John Ray, may be considered the earliest modern work in which the classification of fishes is fuunded on a scientific basis. Willughby's volume was followed, in 1713 , by the Synopsis Methodica Piscium of Ray, a posthumous work, published along with his Synopsis of Birds, by his friend Dr Derham, after the death of their author. This work of Ray contains nearly the same arrangement as he had adopted in the previous one of Willughby ; and it continued to be the standard and model for ichthyological inquiries till the publication of the Systema Naturce of Linnæus. Ray in his synopsis distinctly marked the leading division of this class of animals into Cartilaginous and Osseous ; distinguished the families with soft or spinous fins; and was the first to direct attention to the characters which the position and the number of the fins and their rays afford as the foundation of family distinctions. Though he included the Cetacea among his fishes, yet he was perfectly aware of their anomalous character; for he observes (p. 4.) that, excepting in the external figure, naked skin, and in their progressive motion by swimming, they had nothing in common with fishes, but were otherwise allied to the viviparous quadrupeds. And even Artedi, the friend and coadjutor of Linnæus, who, it may benoticed, adopted Ray's principles of classification and most of his leading characters in the arrangement of this portion of the animal kingdom, included the Cetaceous Mammalia among the fishes.

The work of Artedi, who died before its completion, was published by Linnæus, in 1738, under the title of Ichthyologia. The method of Artedi it is not necessary here todetail. It wasadopted by Linnæus in the first edition of his great work, was modified considerably in the second, and in the tweltth edition, the last which this eminent man lived to publish, the fishes were included in four orders, according to the position of the fins, viz. 1. Arodes, or fishes destitute of ventral fins. 2. Jugulares, those which have the ventral fins placed before the pectoral ones. 3. Thor Acici, those which have the ventral fins placed under the pectoral. And 4. Aвdominales, or those which have the ventral fins placed behind the pectoral ones. Linnæus removed the 
Cetacea from the class of fishes to place them as mammiferous animals in his first class ; and the cartilaginous fishes of Ray were placed in his order Nantes, in the class Amphibra. Gmelin, however, in his edition of the Systema Natura, transferred the cartilaginous fishes to their proper place. Linnæus, relying on imperfect observation, had placed them among the Amphibia.

It is not necessary to detail all the subsequent attempts at the classification of fishes by Groonvius, Klein, Schœffer, Brunnich, Scopoli, Bonaterre, and others, since either in themselves, or as modifications of the systems proposed by Ray, Artedi, and Linnæus, they had little effect on the subsequent progress of ichthyology, Among those who contributed to that progress, however, by accurate representations of the animals, Mark Eliazar Bloch, a Jewish physician at Berlin, deserves to be noticed. His Ichthyologie, ou Histoire Naturelle des Poissons, in six volumes folio, was published in 1785-95, with 452 coloured plates, the greater part of which are accurately drawn and described from nature, and the facts connected with the history, specific differences, and uses of fishes, detailed with equal accuracy, have furnished most subsequent writers with a storehouse of information on the subject of the European species. The original edition being difficult to be procured, a small copy in ten volumes 18 mo was published at Paris in 1801.

The next systematic writer in this department of Zoology to be noticed, is the Count de Lacepede. His Natural History of Fishes, a continuation of the work of Buffon, appeared in five volumes quarto from 1798 to 1803 . The arrangement adopted in this work, the most extensive which had hitherto appeared, is partly adopted from Ray and Linnæus, and partly his own. He divides the fishes into two subclassesthe Cartilaginous and Osseous,-and each of these subclasses is formed of four divisions, taken from the structure or absence of the operculum and the branchial membrane Thus the first division of the Cartilaginous Fishes is formed of those which have neither operculum nor branchial membrane; the second of those which have the operculum; the third of those which have a branchial operculum and no membrane; and the fourth of those which have both an operculum and branchialmembrane. The Osseous Fishes follow an inverse order, - that is, the 
first division includes fishes which have both appendages; the second those which have a branchial operculum and no membrane; the third those which have simply a membrane; and the fourth those which have neither operculum nor branchial membrane. Each of these groups is further divided into four orders, viz. Apodes, Jugulares, Thoracici and Abdominales, borrowed from the Linnæan arrangement, making in the whole thirty-two orders, of which, as Dr Fleming remarks, fifteen have no examples in nature.

Lacepede has preserved all the generic terms used by Linnæus, and has formed many others to characterize the new groups which he had found it necessary to establish. But these generic terms are not always happily applied; and he has been blamed even by his own countrymen for want of precision in this respect. The work of Lacepede, however, will always retain its place as an extensive collection of useful and varied information on a very important and interesting class of animals.

Blainville, in his Prodromus of a new distribution of the animal kingdom, arranges the Fishes into two subclasses, the Cartilaginous and Osseous, the first of which includes four orders, and the second two tribes, three orders, and four sub-orders.

The classification, however, now most generally adopted is that given by Baron Cuvier in his Règre Animal; and as this is the arrangement meant to be followed in the following pages it is necessary to give it in detail. The Class of Fishes, he observes, present many difficulties when an attempt is made to divide them into orders established on fixed and precise characters ; but the two great divisions, founded on the character of their bones, as being Cartilaginous or Osseous, are natural and well marked. The First Series or Chondropterygii have, as a general character, the palatine bones arranged so as to supply the place of those of the upper jaws. These he divides into three orders, viz.

I. Cyclostomi. Jaws fixed in an immoveable ring, and the branchial openings numerous.

II. SElachir. With the branchiæ as in the preceding order, but not their jaws. *

* In his Introductory observations on the characters of the class, Cuvier indicates these two divisions as orders; but in the after details he arranges them as two fami- 
III. Sturiones. Branchiæ opening as usual in a cleft protected by an operculum.

The Second Series consists of the Osseous Fishes, or fishes with fibrous and hard bones, and these are subdivided into orders as follows:

IV. Prectognathi. Maxillary bone and palatine arch fixed to the cranium.

V. Lophobranchir. Fishes with complete jaws, but with the branchiæ in small tufts.

For the subdivision of the remainder of this numerous class M. Cuvier, after much investigation, found no characters better suited than those employed by Ray and Artedi, derived from the nature of the rays of the dorsal and anal fins. This great portion of the class he therefore divides into two groups, viz. 1. MaLACOPTERYGII, in which all the rays are soft, except sometimes the first of the dorsal or pectoral fins; and 2. Acanthorterygir, which have always the first portion of the dorsal fin, or the first dorsal fin itself where there are two, supported by rigid or spinous rays, and where also the anal fin possesses some rays of the same nature, and the ventrals at least one each. To make these two groups orders would naturally occur as the most proper division; but both include so many genera, and such a multitude of otherwise disjoined species, that Cuvier subdivides the first, or the Malacopterygii, into three orders, according to the position of their ventral fins. The necessity of a double term for these orders cannot in this view be avoided.

VI. Malacopterygit Abdominales. Ventral fins on the hinder part of the abdomen.

VII. Malacopteryeir Subrachiati. Ventral fins under the pectorals, on the throat.

ViII. Malacopterygit Apodes. Destitute of ventral fins. This method of subdivision M. Cuvier having found impracticable with the numerous group of Acanthopterygious fishes, he divides them into natural families, to which the characters of the subordinate groups afford considerable facilities;

lies of his Chondropterygii with fixed branchiæ. We have preferred, with Latreille, the arrargement which makes them separate orders. But in any view they are natural families with strongly marked characters. 
and though in his arrangement they of course form but one order, yet these families are so well distinguished that no inconvenience can arise from this circumstance.

IX. Acanthopterygir. First portion of the dorsal fin, or first dorsal fin where there are two, with spinous rays. This very numerous order is divided into seven families, 1. Tcenioides ; 2. Gobioides ; 3. Labroides ; 4. Percoides ; 5. Scomberoides; 6. Squamipennes; \%. Fistularida.-The arrangement in a tabular form will stand thus :

\section{SUB-CLASS I.-CARTILAGINOUS FISHES. \\ ORDER I. CYCLOSTOMI, \\ II. PLAGiostomi, (Selachir, Cuv.) \\ III. STURIONES. \\ SUB-CLASS II.-OSSEOUS FISHES. \\ Order IV. PLECTOGNATHI, \\ V. LOPHOBRANCHII, \\ VI. MALACOPTERYGII ABDOMINALES, \\ VII. MALACOPTERYGII SUBRACHIATI, \\ VIII. MALACOPTERYGII APODES, \\ IX. ACANTHOPTERYGII.}

In addition to the systematic writers on Ichthyology now mentioned, many others might be noticed, whose labours in delineating and describing portions of this important class of animals have been useful to science. A list of the chief of these will be found at the end of this volume. Pennant in his British Zoology, Montague and Donovan, the last of whom particularly in his extensive works on British Zoology, have done much towards the investigation of indigenous species; and Baron Cuvier's extensive and important work on fishes, now in progress, which is intended to include the whole discovered species, will, it is probable, leave little to be desired regarding our knowledge of this class. The portion of Dr Shaw's General Zoology on fishes may be referred to for good figures of many species, though most of them are copied from previous writers.

The form of fishes seems as admirably adapted for motion in water as that of birds for flight in the air. Suspended in a liquid of nearly the same specific gravity as their own bodies, 
they do not require extended members for their support. Their general form is elongated, but thicker in the middle than at the extremities; and the tail, the principal instrument in their progressive motion, is always long, and terminated by a vertical fin, capable of expansion and contraction like a fan. The organs of locomotion assume in this class the form of fins, of which those named thoracic or pectoral, from their situation on the body, have been considered as analogous to the fore-feet of quadrupeds; and those placed further backwards, called $a b$ dominal or ventral fins, have been conceived to represent the hind feet of the first class of vertebrated animals. The vertical fins on the back are termed dorsal fins, and those on the under surface of the body analfins; the fin by which the tail is terminated being termed the caudal fin. The membranes of these fins are supported by rays or bands more or less numerous; and those of the pectoral and ventral fins, according to the supposed analogy between the organs of fishes and quadrupeds, have been supposed to represent the toes of the feet. Other rays, placed at the extremity of the spinous processes, support the vertical fins of the back, those under the tail, and at its extremity. These radii or rays are of two kinds; those of a solid, bony, and pointed form, sometimes flexible and elastic, are called spinous rays; and those composed of a number of small joints, generally divided into branches at their extremity, are called soft or articulated rays.

In the number of the members as many varieties are observed among the fishes as among the reptiles; for though generally speaking the fishes have four, yet in some families there are but two, and others want them altogether.

The greater part of fishes make their progressive motion in the water by means of their expanded tail, which, striking the water alternately from right to left, impels them forward; and they change their direction by striking more rapidly, or with greater force on one side than another. The fins which are in pairs appear to be intended, besides aiding in progression, to maintain their equilibrium in the water, and to regulate the direction of their course. Some families, however, as the Rays, swim chiefly by means of these fins; but the particular form of the body must naturally influence their medium of locomotion. 
The greater part of Fishes, besides having their bodies admirably constructed for the liquid in which they move, have in addition a singular apparatus, for rendering them specifically lighter or heavier than water. This consists in a membranous sac containing air, called the air-vessel or swimming-bladder, which is placed under the spine, and by compressing or dilating which they are supposed to rise or sink in the water. This vessel forms two compartments in the carp, and often communicates with the intestines in fishes which inhabit lakes or rivers.

One of the chief differences in structure which characterizes the present class of animals is their respiratory apparatus. Living in a fluid element, their respiration is necessarily adapted to the nature of that fluid. This is accomplished by means of an apparatus named gills or branchice, placed on the sides of the neck or head. These branchiæ consist of numerous laminæ, suspended on arches attached to the hyoid bone, each composed of a great number of separate laminx, covered with a tissue of innumerable blood-vessels. The water which they swallow passes between these laminx, and escapes by the branchial openings. In its passage, the blood which is sent from the heart to the gills is acted upon by the air contained in the water. After undergoing this change, it is collected in an arterial trunk situate under the spine, which, though resembling in anatomical situation the aorta of animals with double heart, performs the functions of a left ventricle, and distributes it by numerous ramifications through the body, from which it returns to the heart by the veins. The branchial openings are covered either by an osseous moveable plate, which is termed the gillcover or operculum, or by a simple membrane, with one or more openings.

The whole of the blood in fishes is sent by the heart to the branchial vessels, and is then venous or dark blood; but when it has been exposed to the air in the water, it assumes the arterial or red colour, and passes into other vessels, which unite in the great arterial trunk under the spine. Thus the heart has but a single auricle, a single ventricle, and a single artery; and it is believed, that the little portion of heat developed in this mode of respiration is owing to the small quantity of air to which the blood is at one time exposed in passing through the branchix. 
The vertebræ of fishes are united together by concave surfaces, filled with cartilage. In the greater number these vertebræ have long spinous processes which keep the body in a vertical position. The ribs are often joined to transverse processes.

Though the head in fishes varies more in point of form than in any other class of animals, it always consists of the same number of bones. The frontal bone is composed of six pieces; the parietal of three; the occipital of five; the spherioidal bone of five, and each temporal bone of two pieces. The cranium forms but a small portion of the head. The brain is enveloped by a gelatinous matter, and forms many ganglions or consecutive knots, as in the reptiles; and there are ganglions or knots, besides, at the base of the olfactory nerve. A superficial nerve also runs along the body, almost immediately under what is called the lateral line, from the head to the tail. Sensation appears to be weak in almost all the class, although many, as the eel, possess irritability after being cut into small portions.

The nostrils in fishes are simple cavities or hollows at the point of the snout, in the interior of which are disposed laminix in a radiated form. These cavities are often divided into two compartments, and sometimes, as in the lamprey, the two nostrils are united into one. The eye is possessed of a very flat cornea, with but little aqueous humour, but the crystalline lens is almost globular and very hard. In general the eyes of fishes are large in proportion to their size, and they are destitute of eyelids. The pupil, or the opening by which light penetrates into the eye, varies much in form. In the greater part of the species of which the eyes are vertical, anatomists remark a singular disposition of the pupillary orifice, which presents the fringes of the iris arranged in such a manner as to dilate or contract, in order to weaken or augment the quantity of light which enters the eye. In the Pleuronectes both eyes are on the same side of the mesial line.

The ear consists of a sac which represents the vestibule, in which are suspended bones of a stony hardness, and of three semicircular membranous can,ls, situate rather in the cavity of the cranium than in the substance of its walls, except among the Chondropterygii. There is neither Eustachian tube nor tympanal bones; and the order Selachii have only an oval plate on a 
level with their head. It is probable that the vibrations of the water may communicate a sensation analogous to that of sound.

The sense of tasie in fishes cannot be delicate, as their tongue is often osseous and furnished with teeth or other hard covering; they are destitute of salivary glands; and the greater part swallow their food without maceration. Neither is the sense of touch very acute, as in most the body is covered with scales, and in all the organs of prehension are wanting. The cirri or filamentous fleshy processes of some families may perhaps supply the imperfections of their organs of touch.

In the greater number of fishes the intermaxillary bone forms the margin of the upper jaw, having behind it the maxillary or labial bone. The palatine arch, composed of the palate bones, the two pterygoid processes, the zygomatic process, the tympanum, and the squamous portion, forms, as in birds and serpents, a kind of interior jaw, and furnishes behind an articulation for the lower jaw, which has two bones on each side; but these pieces are reduced to the smallest number in the Chondropterygii. The teeth of fishes present many varieties. Some have none at all, and in others the jaws are so hard that they form a kind of solid beak; in some these teeth are pointed, edged, crenated, or flat; and in others they are placed on the lips, the jaws, the palate, the tongue, the gullet, or in all these parts at the same time. The stomach is almost always simple, and the intestinal canal short, as in carnivorous animals; the liver is very large; and there is but one opening for rejected matters, the milt of the male and the ova of the female.

The sexes in fishes are in the greater portion in separate individuals. The ova are generally irnpregnated by the male after extrusion, and the young are developed without the care of the parent. The male is known, besides other distinctions, by the presence of the testes or milt, and the females by the ovary or roe, which both occupy the same relative place in the body of the animals. Those are said to be viviparous in which the ova are matured, and the young developed before extrusion. In the developement of the embryo, the heart first appears, afterwards the spine, eyes, and tail. Of the organs of motion the pectoral fins first appear, followed in succession by the caudal, dorsal, and anal fins. 
Among the oviparous fishes, hermaphroditism was long considered as a rare and accidental circumstance. Baster noticed this occurrence in the Whiting, Duhamel in the Carp; Haller gave his testimony to facts of the same nature; and Pallas believed that the genus Syngnathus had no males. Lastly, Sir Everard Home, in the Philosophical Transactions for 1815, states the same fact regarding the Lampern or Pride, and the Gastrobranchus coecus of Bloch.

The amazing reproductive powers of fishes are well-known. In the ovary of the Cod in December were found $3,686,760$ ova; in the Flounder in March, 1,35\%,400; in the Herring in October, 36,960; and in the Tench 383,252.* And Bloch relates, as the result of an experiment regarding the reproductive power of the Carp, that, in a pond of seven acres, in which were placed four males and three females, the increase was 110,000 young carp, - a number far too great for the size of the pond, and the necessary supply of food. But this astonishing capability of increase is modified by a thousand circumstances which regulate the number produced to the supply of their food. Myriads of these ova form the food of different species; and myriads more of the young may be supposed to be destroyed in an element where almost all are destined to become the prey. of one another. Notwithstanding these deductions, however, the importance of this class as an object of commerce, and as a supply of food, hold out an inexhaustible field for the enterprize of nations whose territories approach the sea.

Of the migrations of fishes, and the causes which prompt these annual influxes of certain fishes on certain coasts, little is with certainty known. Probably they are regulated by the same causes which influence the migrations of birds, - to find food and proper places for reproduction; and the same instinctive impulse which induces the salmon at certain seasons to ascend rivers, may bring myriads of fishes to the shores for a similar purpose.

Little is known with regard to the comparative age of fishes. The carp has been known to reach 200 years, and the pike to 260 ; and if whales be found of less size now than in former ages, when their fishery was but little attended to, it may be conjectured, that their age is still more considerable.

- See a paper by Thomas Harmer in Phil. Trans. Vol. Ixvii. 280. 


\section{SUB-CLASS I.-CARTILAGINOUS FISHES}

\section{(Chondropterygii, Cuv.)}

THE bones of this division are essentially cartilaginous, and in general are never formed of bony fibres. The calcareous matter being deposited in minute grains, and not in fibres or filaments, it necessarily follows that no sutures occur in the cranium, which is always in a single piece. The parts analogous to those in the crania of other fishes may however be distinguished by projections, hollows, and openings. Even the moveable articulations of the other division are not found in this; for in some of the rays a part, and in the lampreys the whole, of the vertebral column is united, and the divisions not distinguished but by annular marks. In the greater number of the genera also, some of the articulated portions of the bones of the face are wanting. In other respects however, as for instance in the nervous system, and in the organs connected with nutrition, the arrangement of parts is as complete as in the other fishes; and many genera have besides the organs of reproduction in a form equally perfect with those of the Reptiles.

The most general character common to the Cartilaginous Fishes, and sufficient to distinguish them from all others, is that of wanting entirely, or having only in a rudimentary form, the maxillary and intermaxillary bones, the place of which is supplied by bones analogous to the palatine ones, and even sometimes by the vomer.

This sub-class Cuvier divides into three Orders., viz. those which have the branchiæ fixed, which includes the Cyclostomi and Plagiostomi ; and those in which the branchiæ are free, which comprises the Sturiones.

\section{ORDER I.-CYCLOSTOMI.}

\section{Jaws fixed in an immoveable ring; branchiæ fixed, and the openings numerous.}

- The branchiæ in this order, in place of being free at their external margin, and all the intervals opening into a common receptacle, as is generally the case, are on the contrary attached to the skin; and the water escapes by as many openings in this skin as there are intervals between them. Another peculiarity in these fishes consists in having small cartilaginous arches or ribs suspended in the flesh at the exterior margin of the branchiæ.

The fishes of this order are with regard to their skeleton the most imperfect of vertebrated animals. Destitute of pectoral and ventral fins, their elongated body is terminated before by a circular fleshy lip, supported by a cartilaginous ring. The vertebræ are united in a tendinous cord, filled interiorly with a nucilaginous substance, and covered exteriorly with indistinct cartilaginous rings, more or less solid. The ordinary ribs are wanting, but the branchial ribs or supports, scarcely visible in the sharks and rays, are much developed, and united to one another. The branchiæ in place of being pectinated, as in all the other fishes, have the appearance of purses, from the junction of their faces to the opposite faces of the neighbouring ones. The labyrinth of the ear is inclosed in the crasium; the nostrils open by one orifice, before which is a blind cavity, which some writers bave improperly named a spiracle; and the intestinal canal is short.

Gen. 1. Petromyzon, Dum. Lin.

Maxillary ring armed with strong teeth; lips formed for suction; tongue with two rows of small teeth; a dorsal fin before and another behind the anus.

P. marinus, Lin. The greater, or Sea Lamprey. Body yellowish, marbled with brown; silvery below; the first dorsal fin distinct from the second; two large approximated teeth at the top of the 
maxillary ring. 2 or 3 feet long. Inhabits European Seas. B. -Shan, v. pl. 133.

This species ascends in spring into the mouths of rivers.

P. fluviatilis, Lin. The Lesser Lamprey. Silver-coloured, blackish, or olive-coloured on the back; the first dorsal fin distinct from the second; two large teeth at the top of the maxillary ring. 12 to 18 inches long. Rivers. B.-Pen. Brit. Zool. iii. pl. 10 .

P. Planeri, Bloch. Body olive-coloured above, paler below; two large teeth in the upper part of the maxillary ring; dorsal fins contiguous or united. Inhabits fresh waters in Germany.-Cuv. Reg. An. ii. 119.

\section{Gen. 2. Ammocøtes, Dum.-Petromyzon, Lin.}

Body soft and membranous; branchial openings nearly the same as in the lampreys ; lip semicircular, and covering only the upper part of the mouth; no teeth; dorsal fins united to the caudal one, forming a low and sinuous ridge.

A. branchialis, Cuv. The Common Pride. Body marked with transverse lines; tail lanceolate. 6 to 8 inches long. Inhabits Rivers. B.-Pen. Brit. Zool. iii. pl. 10.

Gen. 3. Gastrobranchus, Bloch.-Myxine, Lin.

Maxillary ring membranous, with only one tooth above; lateral dentations of the tongue strong, and in two rows on each side; two spiracles under the abdomen.

Linnæus placed the animal which forms the type of this genus in his class Vermes, though its organization is analogous to that of the lamprey, except in regard to the branchial openings, which in this genus, in place of an outward aperture, open into a common canal on each side, and these two canals terminate in two apertures situate under the belly. The mouth is circular, surrounded with eight cirri, and at its superior margin is an opening which leads into the interior. The body is cylindrical, and furnished with a fin on the hinder part, which surrounds the tail. It has no eyes. Through the lateral pores of this singular animal a mucous fluid exudes in great abundance.

G. coecus, Bloch. (M. glutinosa, Lin.) Glutinous Hag. Body whitish, reddish towards the head and tail; a double row of lateral pores. 4 to 6 inches long. European seas. B.-Shaw, v. pl. 134.

G. Dombeyi, Lacep. Head rounded, broader than the body. Inhabits South American Seas.-Shaw, v. 267.

\section{ORDER II._PLAGIOSTOMI, Dumeril.-Selachii, Cuv.}

Branchiæ pectinated, the openings numerous, without operculi or membranes; palatine and postmandibulary bones armed with teeth in place of jaws.

The ordinary bones of the jaws in this family are merely rudimentary. One single bone connects these jaws to the cranium, and supplies the place of the tympa- 
nal, jugal, and temporal bones. The hyoid bone, attached to this pedicle, supports rays as in the ordinary fishes, and is accompanied with branchial arches. These fishes have pectoral and ventral fins, the last placed backwards on the abdomen. Some species of this order are viviparous, and others oviparous, the ovum in this case being inclosed in a quadrangular coriaceous shell. The males have appendages at the internal margin of the ventral fins, of which the use is not known.

\section{Family I.-Sevalides.}

Body elongated; tail thick and fleshy; pectoral fins pretty large; branchial openings on the side of the neck; eyes lateral; snout supported by three cartilaginous branches, which supply the place of the anterior portion of the cranium.

\section{Gen. 1. Scyllium, Cuv.-Squalus, Lin.}

Snout short and obtuse; nostrils near the mouth, continued in a furrow; spiracular openings; teeth notched; dorsal fins placed much behind; branchial openings in part above the pectoral fins; caudal fin truncated at the end.

S. canicula, Cuv. Body narrow and elongated, reddish above with numerous brown spots; anal fin below the space between the dorsal ones. Inhabits European Seas. 3 to 4 feet long.-Pen. Brit. Zool. iii. pl. 19.

S. catulus, Cuv. (S. catulus and stellaris, Lin.) Body cinereous, streaked in some parts with red; spots larger and less numerous than in the preceding; ventral fins united. About 2 feet long. Inhabits European Seas-Pen. Brit. Zool. iii. pl. 19.

S. Africanus, Cuv. Body gray, with seven longitudinal blackish bands; anal fin placed behind the second dorsal fin. $2 \frac{1}{2}$ feet long. Inhabits African Seas.-Shaw, v. 345.

S. denticulatus, Cuv. (S.tuberculatus, Schn.) Body gray or ashbrown, with large unequal rufous spots above; a row of tubercles running from between the eyes to the first dorsal fin. $-L a-$ cep. i. pl. 11. fig. 1 .

In other foreign species of this genus, the anal fin is placed behind the second dorsal; the spiracles are excessively small; the fifth branchial opening is often concealed in the fourth; and the lobules of the nostrils are generally prolonged into cirri.

Gen. 2. Carcharias, Cuv.-Squalus, Lin.

Snout prominent, conical and depressed; nostrils under its middle; teeth in many rows, edged, pointed, and often dentated on their margin; no spiracles; first dorsal fin before the ventrals, and the second nearly opposite the anal fin; last openings of the branchiæe extending over the pectoral fins.

C. vulgaris, Cuv. (Sq. carcharias, Lin.) The White Shark. Body pale cinereous, darker on the upper parts; tail trilobed; teeth in the form of an isoceles triangle, with rectilineal and dentated sides. 20 to 25 or 30 feet long. Inhabits all seas.-Shan, v. pl. 148. 
This animal, the terror of mariners, is one of the most voracious of fishes. But how. ever large and dangerous the existing race may be, yet, from the magnitude of the fossil teeth found at Malta and elsewhere, some of them measuring $4 \frac{1}{2}$ inches from the point to the base, and 6 inches from the point to the angle, the animal to which they belonged must have much exceeded the present species in size.

C. vulpes, Cuv. The Fox Shark. Body lead-coloured, whitish beneath; head short and conical ; upper lobe of the tail as long as the body. 13 feet long. Inhabits Mediterranean and other seas. -Sham, v. 333.

C. glaucus, Cuv. The Blue Shark. Body slender, slate-blue coloured above, whitish beneath; snout long and pointed; tail deeply bilobed, the lower lobe longer than the upper. 10 to 14 feet long. Inhabits all seas. B.-Shaw, v. pl. 151.

\section{Gen. 3. Lamsa, Cuv.-Squalus, Gmel.}

Snout pyramidal, with the nostrils at the base; teeth numerous, in rows; branchial openings before the pectoral fins.

L. Cornubiensis, Cuv. Porbeagle Shark. Body above blackish-blue, white or silvery beneath, with a projecting keel on each side of the tail, and the caudal lobes almost equal; teeth slender, with two processes at their base; tail semilunar. 4 to 8 feet long. Inhabits European seas. B.-Lin. Trans. iii. pl. 153.

The $L$. Monensis does not seem to differ from the present species.

Gen. 4. Zygena, Cuv.-Squalus, Lin.

Head flattened horizontally, truncated before, and its sides prolonged transversely into branches, like the head of a hammer; eyes at the extremity of the branches, and the nostrils at their anterior margin.

Z. vulgaris, Cuv. The Hammer-headed Shark. Body elongated, brown above, whitish beneath ; first dorsal fin falcate, towards the upper part of the back; second small and near the tail. 5 to 15 feet long. Mediterranean and Indian seas.-Shaw, v. pl. 154.

Z. Blochii, Cuv. Nostrils placed nearer the middle, and the second dorsal fin closer to the caudal one than in the preceding.-Cuv. Reg. An. ii. 127.

Z. Tiburo, Cuv. Head flattened, cordiform; body grayish, belly white, and skin covered with small tubercles. Inhabits European and American Seas.-Shaw, v. pl. 154.

\section{With spiracles and anal fin.}

Gen. 5. Galeus, Cuv.-Squalus, Lin.

Body elongated; snout produced, pointed; with temporal orifices; teeth dentated on their exterior side ; first dorsal fin nearly above the pectorals.

G. vulgaris, Cuv. The Common Tope. Body above light cinereous, white below; fins small and blackish. 5 feet long. Inhabits European seas.-Penn. Brit. Zool. iii. pl. 18.

voL. I. 
Gen. 6. Mustelus, Cuv.-Squalus, Lin.

Body elongated; snout blunt; with temporal orifices; teeth blunt and crowded; dorsal fins unarmed.

M. vulgaris, Cuv. (Sq. mustelus, Lin.) Body brownish above, whitish beneath; pectoral fins short; first dorsal fin large, and placed nearly in the middle of the back, the second nearly opposite the anal fin. 2 feet long. European seas.-Shaw, v. pl. 153.

Gen. 7. Notidanus, Cuv.-Squalus, Lin.

Head small, depressed, and obtuse, with temporal orifices; teeth compressed and serrated; dorsal fin single.

N. griseus, Cuv. Body pale brown, with small carinated scales; six branchial openings on each side ; teeth triangular above, serrated below. $2 \frac{1}{2}$ feet long. Mediterranean sea.-Shaw, v. 346 .

Gen. 8. Selache, Cuv.-Squalus, Lin.

Body elongated; head small, with temporal orifices; branchial openings embracing nearly the circle of the neck; teeth small, conical, and without dentations ; first dorsal fin nearly between the pectorals and ventrals.

S. maximus, Cuv. The Basking Shark, Penn. Body deep leadcolour above; belly white ; first dorsal fin very large ; teeth small, conical, very numerous. About 30 feet long. Inhabits European seas.-Penn. Brit. Zool. iii. pl. 16.

This species has nothing of the ferocity of the C. vulgaris, though it surpasses it in size. It is common in some seasons on the western coasts of Britain. In swimming the dorsal fin is often above the surface of the water.

Gen. 9. Cestracion, Cuv.-Squalus, Schn.

Jaws pointed, as long as the snout, armed with small pointed teeth, and towards the angles with larger rhomboidal ones; a spine before each dorsal fin.

C. Philippi, Cuv. Body brown above, white beneath; mouth wide, with ten or eleven rows of teeth; a lengthened lobe on each side of the head. 2 feet long. Inhabits seas of New Holland.Shaw, v. 341 .

2. With spiracles, but destitute of anal fins.

Gen. 10. Spinax, Cuv.-Squalus, Lin.

Snout elongated, blunt at the end ; teeth small, edged, in many rows; a strong spine before each dorsal fin; no anal fin.

S. acanthias, Cuv. Picked Dog-Fish. Body brown above, whitish below; nose blunt. The young are spotted with white. 2 to 3 feet long. Common on the British Coasts. This species is ovoviviparous._Shaw, v. 338.

s. fuscus, Will. Body dusky above, abdomen nearly black. Inhabits European seas.-Shaw, v. 339. 
Gen. 11. Centrina, Cuv.-Squalus, Lin.

Skin very rough; teeth of the lower jaw edged, and in one or two rows, those of the upper slender, pointed, and in many rows; second dorsal fin placed above the ventrals; no anal fin; tail short.

C. vulgaris, Cuv. (Sq. centrina, Lin.) Body subtrigonal, brown coloured above, white below; head small and flattened; spiracles behind the eyes. 3 to 4 feet long. Inhabits European seas.Shaw, v. pl. 153. *

C. squamosa, Cuv. Snout oblong, depressed ; eyes oblong; body covered with ovate carinated scales. 3 feet long.-Shaw, v. 348 .

Gell. 12. Scymnus, Cuv.-Squalus, Risso. Lin.

Snout short, obtuse; teeth in the lower jaw edged, in one or two rows, in the upper pointed, and in many rows; no spines before the dorsal fins.

S. borealis, Fleming. Greenland Shark. Body gray ; first dorsal fin larger than the second, more advanced than the ventrals; pectoral fins large; ventrals elongated, the two sides nearly parallel. About fourteen feet long. Inhabits Northern Seas. B.British Auimals, 166.

S. Nicensis, (Sq. Americanus, Gmel.) Scales small and angular; snout short and obtuse; second dorsal fin largest; ventral fins near the tail. 3 feet long. European seas.-Shan, v. 347.

\section{Gen. 13. Seuatina, Dumeril.-S'qualus, Lin.}

Body broad, and flattened horizontally; head round; mouth terminal ; temporal orifices; pectoral fins very large and extended forwards, separated from the neck by a cleft, in which are the branchial openings; the dorsal fins behind the ventrals; no anal fin.

S. laevis, Cuv. (Sq. squatina, Lin.) The Angel Fish. Body gray above, and covered with tubercles, white beneath ; head circular, broader than the body. 6 to 8 feet long. Inhabits European seas. B.-Shan, v. pl. 155.

The Romans used the rough skin of this species for polishing wood and ivory, and it still furnishes the finest shagreen.

\section{Gen. 14. Pristis, Latham.-Squalus, Lin.}

Body flattened anteriorly, with four or five branchial openings below on each side; two spiracles behind the eyes; no anal fin; head prolonged into a depressed bony beak, with strong pointed spines on each side; teeth crowded, flattened.

P. antiquorum, Lath. (Sq. pristis, Lin.) The Saw-Fish. Beak armed with twenty-four large teeth on each side; body graybrown above, paler below; jaws with several rows of small blunt 
teeth. 15 feet long; beak nearly a third of the total length. Inhabits European seas._Shaw, v. 357.

P. pectinatus, Lath. Beak armed with thirty-four sharp teeth on each side; tail longer than the preceding. Inhabits European seas.-Lin. Trans. ii. pl. 26. fig. 2.

P. cuspidatus, Lath. Beak armed with twenty-eight teeth on each side, of nearly equal breadth throughout. Inhabits European seas. -Lin. Trans. ii. pl. 26. fig. 3.

\section{Family II.-Platysom.}

Body much flattened, discoidal, with the eyes and spiracles on the back; nostrils, mouth, and branchial openings below; sides bordered by large pectorals.

The body in this family is much flattened horizontally and resembles a disc, from its union with the extreinely large and fleshy pectoral fins. These fins, which are joined to one another before or to the snout, extend backwards on both sides of the abdomen to the base of the ventral fins. The scapulæ of the pectoral fins are articulated with the spine behind the branchiæ. The dorsal fins are almost always on the tail. The ova of this family are brown, coriaceous, and square, with pointed angles.

\section{Gen. 15. Rhinobatus, Schn.-Raia, Lin.}

Five branchial openings on each side below; snout angular; body flat; tail long and very thick at the base; dorsal and caudal fins distinct; teeth serrated, and in quincunx order.

R. vulgaris, Cuv. Body elongated, brown above, paler below, with one row of dorsal spines ; first dorsal fin behind the ventral ones. 4 feet long. Inhabits European seas.-Shaw, v. pl. 147.

R. Djiddensis, Forsk. Body pale cinereous, with three rows of spines on the anterior part of the back; first dorsal fin above the ventral ones. Inhabits the Red Sea.-Shaw, v. 319.

The genus RHINA of Schneider differs not from the present, otherwise than in the type of it, $R$. ancyclostomus, having the snout short, broad, and rounded.

\section{Gen. 16. Tor PEDo, Dum.-Raia, Lin.}

Body smooth, depressed, obtuse before, and nearly circular ; anterior border formed by productions of the snout, which extend along the sides to meet the pectoral fins; five branchial openings on each side, beneath; electrical organs on the sides; teeth sinall and pointed; tail short and fleshy.

This singular tribe of fishes, and their electrical powers, was well known to the ancients. Oppian relates, that when taken by a hook and line they benumb the astonished fisherman; and Pliny affirms, that, when touched by a spear or stick, the paralyzing effect is communicated in a high degree. The observations of Redi and others in the 17th century tended in some degree to make known the peculiar action and anatomy of the Torpedo; and later investigations have elucidated the singular faculty it possesses. The electrical apparatus, contained in the space between the pectoral ins and the head and branchiæ, is forned of small united membranous tubes, subdivided by horizontal diaphragms and minute cells filled with a mucous substance. These are abundantly provided with nerves, which come from the eighth pair. In this apparatus resides the electric power which has rendered the fishes of this genus so celebrated, and which perhaps is given them for the purpose of stunning their prey. 
T. vulgaris, Cuv. The Torpedo. Body circular ; cinereous above, marked by five large circular dusky spots, paler in the centre; under surface whitish. 2 to 4 feet long. Inhabits European seas.-Shaw, v. pl. 146.

The other European species of this genus, the T. unimaculata, marmorata, and Galvanii of Risso, have been confounded with this species by most naturalists.

\section{Gen. 17. Rara, Cuv.}

Disc rhomboidal ; five branchial openings on each side beneath ; mouth below ; tail slender, with two small dorsal fins near its extremity; teeth small, crowded, and in quincunxorder; males with hooked spines on the pectorals.

R. clavata, Lin. The Thornback. Snout subacute; body cinereous, rough with bony tubercles, each furnished with a hooked spine, the dorsal row longest; tail longer than the body, with three rows of spines. 2 to 4 feet long. Inhabits European Seas. B.-Pen. Brit. Zool. iii. pl. 13, 14.

R. radiata, Donov. Starry Ray. Snout slightly prominent, front obtuse; base of the spines enlarged, radiated. Inhabits British seas.-Donov. Brit. Fishes, pl. 114.

R. oxyrhynchus, Lin. Sharp-nosed Ray. Body much depressed, cinereous, with several pale or whitish spots and dusky streaks above; white beneath, with dusky spots ; snout prolonged, subacute; the row of dorsal spines extending along the tail, which is short. 4 to 6 feet long. Inhabits British seas.-Shaw, v. pl. 138.

R. rubus, Lin. The Rough Ray. Body yellowish gray, variegated with dusky or brownish spots, and rough with minute spines; spines around the eyes and on the snout, and three rows of larger ones on the tail. Upwards of three feet long. Inhabits British seas. -Donov. pl. 20.

R. microcellata, Mont. Small-eyed Ray. Body above brown, with scattered spots and lines, and rough with minute spines; snout obtuse; one row of small hooked spines on the tail, running along the dorsal ridge to the head; eyes very small. 20 inches long.Wern. Mem. ii. 430.

R. Batis, Lin. The Skate. Body brown or cinereous above, grayish below; skin rough, but without spines, except a row on the tail. Inhabits European Seas. - Shaw, v. pl. 136.

This species attains large dimensions, some individuals weighing upwards of 200 lbs. It is spotted when young, but assumes in age a more uniform tint of colour.

R. undulata, Lacep. Undulated Ray. Body pale gray brown above, with numerous undulated dusky transverse streaks, whitish below. Inhabits European Seas. - Shaw, v. pl. 140.

Gen. 18. TrYgon, Adans.-Raia, Lin.

Head joining with the pectorals to form an obtuse angle; teeth slender, united in a quincunx form; tail armed with a dentated or serrated spinous point; no fins on the tail. 
T. pastinaca, Cuv. The Sting Ray. Body subrhomboidal, approaching to ovate, yellowish olive, smooth; snout pointed; tail slender, with a long serrated bone towards the base. 2 to 3 feet long. Inhabits European seas.-Pen. Brit. Zool. iii. 125.

T. tuberculata, Cuv. With subobtuse distant depressed glossy spines down the back and tail; tail long and slender, with a serrated spine, and without a fin. Inhabits American seas.-Shan, v. 290.

T. Lymna, Cuv. Body reddish brown above, with numerous oval blue spots of different sizes; tail longer than the body, marked half its length with two longitudinal blue stripes; tail pinnated, with one or two spines. Inhabits the Red Sea.-Shaw, v. 237.

T. sephen, Cuv. Body cinereous brown above, with tubercles on the back and anterior part of the tail reddish; white beneath; the three central tubercles largest. 11 feet long. Red Sea.-Shan, v. 288.

Gen. 19. Mүцго в атіs, Dumeril.-Raia, Lin.

Head projecting beyond the pectoral fins, which are broader transversely than in the other rays, and pointed; jaws with large flat teeth, in different proportions ; tail extremely long and slender, terminating in a point and armed with a bony spine, serrated on both sides, with a small dorsal fin near its base.

M. aquila, Cuv. The Sea Eagle. Snout projecting and parabolic; teeth in the middle of the jaws broader than long, and in one row; the lateral ones of a hexagonal form, and in three rows. Of large size. Inhabits Mediterranean Sea.-Cuv. Reg. An. ii. 137.

Gen. 20. Cephaloptera, Dumeril.-Raia, Schn.

Body depressed; head truncated before; teeth slender and finely dentated; five or six branchial openings on each side, below; pectoral fins large, projecting before the head; tail slender, conical, narrower than the body.

C. Giorna, Cuv. Body blackish above, bordered with violet, white beneath; horns or appendages blackish, longitudinally striated, with eight rows of tubercles; pectoral fins triangular; tail very long. 4 feet broad. Inhabits Mediterranean sea._Shaw, v. pl. 145.

C. Massena, Risso. Margins of the fins bent back; horns or appendages black at the extremity; tail with three rows of asperities. Grows to a large size. Mediterranean sea.-Risso, 15.

\section{Family III.-Chimere, Lin.}

With one branchial opening on each side.

This group resembles the Sharks in general form ; but all their branchiæ open outwards by a single aperture on each side, which communicates, however, with five others at the bottom of the general cavity. The bones of the upper jaw are represented by the vomer, and hard bony plates in place of teeth occupy the lower jaw. The elongated snout is marked by lines of pores ; and the first dorsal fin, armed with a strong spine, is over the pectorals. The males are recognized as among the Squali by spinous plates at the base of the ventral fins, and a fleshy spinous appendage between the eyes. 
Gen. 21. Chrmera, Cuv.

Body elongated, compressed; snout conical ; one branchial opening on each side of the neck ; tail terminated by a long filament; second dorsal fin commencing immediately behind the first.

C. monstrosa, Lin. Northern Chimæra. Body compressed laterally, silvery white, marbled with brown; head large, two broad incisors in each jaw. 3 to 4 feet long. Inhabits Northern Seas. B.Shan, v. pl. 157.

Gen. 22. Callorynchus, Gronov.-Chimara, Lin.

Snout terminated by a fleshy protuberance resembling a hoe; second dorsal fin commencing over the ventrals, and ending opposite the beginning of the fin under the tail.

C. Australis, Cuv. Body silvery, tinged with yellowish brown above; fins pale brown. 3 to 4 feet long. Inhabits South Seas.-Shaw, pl. 158, 158*.

\section{ORDER III.-STURIONES.}

Branchial openings much cleft, furnished with an operculum, but without rays in the membrane; branchiæ free.

Gen. 1. Acipenser, Lin.

Body elongated, and furnished, as well as the head, with rows of bony prominences; mouth placed under the snout, cylindrical, retractile, and without teeth; four cirri beneath the snout.

The fishes of this genus have the general form of the sharks; but their body is more or less covered with bony prominences in longitudinal rows. Their eyes and nostrils are on the sides of the head, the dorsal fin behind the ventrals, and the anal under it. Sturgeons ascend the rivers in the northern seas at certain seasons in vast numbers, and in these rivers their fishery is of great importance. Their flesh is an agreeable fond; caviar is prepared from the roe; and the large swimming-bladder affords the isinglass of commerce.

A. Sturio, Lin. The Sturgeon. Body long, pentagonal, cinereous, with dusky variegations, and covered with five rows of large bony. tubercles, one on the back and two on each side ; belly flat, whitish; pectoral fins oval; dorsal fin near the tail ; tail bifurcated, the upper lobe much longer than the under. 10 to 18 feet long. Inhabits European seas.-Shan, v. pl. 159.

A. Ruthenus, Lin. The Little Sturgeon. Body elongated, brownish, the sides spotted with pale red; three rows of bony plates above ; the lateral ones carinated and numerous, and those of the belly flat. 3 feet long. Inhabits the Danube and other rivers which run into the Black and Caspian Sea._Shan, v. pl. 160.

A. huso, Lin. The Great Sturgeon. Body black above, white be- 
low, the sides bluish ; fins small, grayish; lateral plates smaller, and snout and cirri shorter than in the common sturgeon ; skin also smoother. 15 to 25 feet long. Inhabits Caspian and Black Sea. -Shaw, v. pl. 159.

It is from the sounds of this species that the best isinglass is made.

Gen. 2. Spatularia, Shaw.

Snout very much prolonged, in the form of a spatula ; branchial openings one on each side of the neck, with very large operculi; mouth beneath, with sharp serrated teeth.

S. reticulata, Shaw, Body subcylindric, tapering to the tail ; head and snout nearly as long as the rest of the body, the snout reticulated with prominent lines; lateral line strongly marked; dorsal fin near the tail ; tail lunated. 12 inches long, young specimens.-Shaw, v. pl. 156.

\section{SUB-CLASS II.-OSSEOUS FISHES.}

This division includes the fishes with free branchiæ, and of which the bones, though varying in hardness, are always fibrous. The cranium is divided by sutures.

\section{ORDER IV.-PLECTOGNATHI.}

Bones fibrous; upper jaw formed by the intermaxillary bone, which is immoveably fixed upon the side of the maxillary; palatine arch fixed to the cranium ; branchial cleft simple.

This order approaches the cartilaginous fishes by the imperfection of the jaws and the softness of the bones. The bones, however, are fibrous, and the skeleton has all the structure of the ordinary fishes. The principal distinctive character consists in the maxillary bone being firmly attached to the side of the intermaxillary, which alone forms the jaw; and the palatine arch, being connected by a suture with the cranium, has in consequence no motion. The operculi and rays are concealed under a thick skin, and nothing is seen externally but a small branchial cleft. Of true ribs but slight vestiges are found, and they are destitute of proper ventral fins; the intestinal canal is ample, but without cœcums; and almost all have a swinmmingbladder of considerable size. This order comprises two natural families, characterized by their teeth.

\section{Family I.-Gymnodontes.}

This family, in place of apparent teeth, have the jaws furnished with a substance like ivory, divided interiorly into laminæ, which are in fact true teeth united. Their operculi are small, with five rass on each side but both imperfectly seen. They feed on crustacea and fuci. Their flesh is not much esteemed, and that of some species seems poisonous at certain seasons.

\section{Gen. 1. Diodon, Lin.}

Jaws undivided, formed of one piece above and another below, with a rounded portion furrowed across behind the cutting 
edge of each; nostrils with double fleshy tentaculi; skin armed in every part with thick pointed spines; body capable of inflation like a globe.

D. atinga, Lin. Body elongated, spines close together; caudal fin rounded; back broad, round, and blackish; belly white, spotted with black, and edged with brown; dorsal and anal fins opposite. 15 to 18 inches long. Inhabits Indian Seas._Bloch, pl. 125.

Gen. 2. Tetraodon, Lin.

Jaws divided in the middle by a suture in such a manner as to present the appearance of four teeth, two above and two below ; skin furnished with small spines; body capable of in. flation.

T. lineatus, ( $T$. physa, Geoff.) Back and sides striped longitudinally with brown and blackish; spines small, numerous. 10 to 12 inches long: Inhabits the Nile.-Cuv. Reg. An. ii. 147.

At the period of the inundation of the Nile many of this species are thrown upon land, and serve for sport to the children.

T. stellatus, Donov. ( $T$. lagocephalus, Penn.) Globe Tetraodon. Body oblong, rich blue on the back; tail and fins brown; sides and belly white, shagreened or wrinkled, with numerous small sharp spines attached at the base by four rays. 19 inches long. European and American seas. B.-Penn.Brit. Zool. iii. pl. 23.

T. testudineus, Bloch. Body ferruginous brown, with blue spots above; bluish, with longitudinal brown bands beneath. 2 feet long. Inhabits Indian seas.-Bloch, pl. 139.

T. electricus, Paterson. Body brown above, yellow on the sides, sea-green beneath, and varied with red, green, and white spots. 7 or 8 inches long. Inhabits Indian and American seas.-Phil. Trans. Ixxvi. pl. 13.

Gen. 3. Cephalus, Shaw.-Orthagoriscus, Schn.

Jaws undivided ; body short, compressed, terminating abruptly, and without spines, not capable of inflation; tail short, and very high vertically; dorsal and anal fins high and pointed, uniting with the caudal fin; no swimming-bladder.

This genus is distinguished from all others by the singular shortness of the body, which seems as if it were cut off abruptly, the posterior parts wanting, and rather resembling the head of a large fish than a complete animal.

C. brevis, Shaw. (T. mola, Lin.) Short Sun Fish. Body brown, with a silvery tinge on the sides and abdomen; skin rough; pectoral fins small, rounded, and placed horizontally. 8 to 10 feet long. Inhabits European seas. B.-Shan, v. pl. 175.

C. oblongus, Shaw. Oblong Sun Fish. Back dusky, with some variegations; abdomen silvery; a few dusky streaks pointing downwards between the eyes and pectoral fins. Inhabits European Seas. B.-Shan, v. pl. 176. 


\section{Family II.-Sclerodermi, Cuv.}

This family is distinguished by their conical or pyramidal snout, prolonged from the eyes, and terminated by a small mouth, with distinct teeth in each jaw. The skin is generally rough, or covered with hard scales. Two dorsal fins, the first spirous, the second soft; no ventral fins; swimming bladder oval, large.

Gen. 4. Balistes, Lin.

Body compressed, covered with hard rhomboidal scales; eight teeth in a single row in each jaw ; first dorsal fin with three spines, the first the largest, the third much smaller and separate; extremity of the pelvis projecting and prickly.

The fishes of this genus abound in the tropical seas near rocks on a level with the water, and are remarked for the brilliancy of their colours. Their flesh is not much prized, and is said to be dangerous at certain seasons.

\section{Tail unarmed.}

B. capriscus, Lin. Mediterranean File-Fish. Body ovate, brownish gray, spotted with blue or green ; tail unarmed ; scales behind the branchial opening not larger than the others. 1 to 2 feet long. Inhabits Mediterranean sea.-Shaw, v. 411.

B. stellaris, Schn. Body gray above, with small white spots; sides and abdomen whitish; first dorsal fin with four spines, the first longest; second dorsal and anal fins speckled with white bars; tail unarmed. Inhabits Indian seas.-Shaw, v. 417.

B. forcipatus, Lin. Skin marked into scale-like areæ; first dorsal fin three-spined, the first extremely thick and strong; second dorsal and anal fin with numerous small round spots; tail unarmed, forked. 16 inches long. Inhabits Indian seas.-Shaw, v. 416.

B. vetula, Bloch. Body broad and thin, rough, the scales divided into small trapezoidal figures, yellowish olive above, paler beneath; three spines in the first dorsal fin, the first largest; tail unarmed, forked, with blue bands. 1 to 2 feet long. Inhabits Indian and American seas.-Bloch, pl. 150.

\section{Tail armed with two rows of spines.}

B. lineatus, Schn. Tail with two rows of spines; scales behind the branchial openings larger than the others.-Schn. 87.

3. Tail with three rows of spines.

B. cinereus, Lacep. (B. arcuatus, Schn.) Body cinereous, marked on each side by a black thoracic band, and three lunated blue spots near the tail; tail slightly lunated, with three rows of spines. Inhabits Indian Seas.-Shaw, v. 410.

B. aculeatus, Lin. Body ferruginous, with the top of the head and sides of the thorax streaked with blue; skin rough and reticulated; tail rounded, with three rows of recumbent spines. 12 inches long. Inhabits Indian, American, and Red Seas.-Shaw, v. pl. 169. 


\section{Tail armed with four ron's of spines.}

B. fasciatus, Shaw. (B. rectangulus, Schn.) Body rhombic-ovate, slightly lengthened ; upper parts pale yellow, the head deep yellow; an oblique black band on each side; lower parts red brown; tail armed with four longitudinal rows of small spines. Inhabits Indian Seas._-Shaw, v. 409.

\section{Tail armed with six or seven rows of spines.}

B. ringens, Bloch. Body entirely black, strongly marked by cross lines into rhombic divisions; a streak of blue along the base of each of the pectoral fins, and across the tail ; tail slightly lunated. 10 or 12 inches long. Inhabits Indian and American seas.Bloch, pl. 152, fig. 2.

\section{Tail with from twelve to fifteen rons of spines.}

B. Sonneratii, Shaw. (Le Baliste bourse, Lacep.) Body ovate, gray brown above, bluish white beneath; on each side of the head a black crescent, passing downwards as far as the base of the pectoral fins. 6 to 10 inches long. Indian seas.-Shaw, v. 406.

Gen. 5. Monocanthus, Cuv.

Scales very small, rough with scabrosities; extremity of the pelvis projecting and spinous; first dorsal fin with one large serrated spine; eight teeth in a single row in each jaw.

M. Chinensis, Bloch. Pelvis moveable and attached to the abdomen by an extensible membrane; body broad, rough, compressed on the sides, pale gray, and marked with small yellow spots; a double row of teeth on the dorsal spine. A few inches long. Inhabits Indian Seas.-Bloch, pl. 152. fig. 1.

M. tomentosus, Bloch. Body compressed on the sides, yellowish brown; abdomen ventricose, yellow, with semilunar, rough, black spots; dorsal spine strong, serrated behind; tail rounded, the sides with stiff hairs. A few inches long. Inhabits Indian seas. -Shaw, v. pl. 169.

\section{Gen. 6. Aluteres, Cuv.-Balistes, Lin.}

Body elongated, covered with crowded, scarcely perceptible granules; a single spine at the first dorsal fin; pelvis not projecting; eight teeth in each jaw, in a single row.

A. monoceros, Cuv. Body cinereous, spotted irregularly with brown. 1 foot long. Inhabits Asiatic and American seas.-Bosc. Nouv. Dict. iii. 208.

A. lavis, Cuv. Body elongated, pale yellowish brown, marked on the fore part with four or five longitudinal blue stripes reaching to the middle of the body, and behind by transverse bands of the same colour. 12 inches long. Indian seas.-Bloch, pl. 414.

Gen. 7. Triacanthos, Cuv.-Balistes, Bloch.

Ventral fins composed of a single large spinous ray ; first dor- 
sal fin with one large spine and three or four smaller ones; skin covered with small crowded scales; eight teeth in each jaw; tail elongated.

T. biaculeatus, Cuv. Body elongated, dusky on the upper parts, whitish on the sides and abdomen; snout elongated; first ray of the first dorsal fin much longer than the others; ventral spines long and pointed; tail forked. 6 to 8 inches long. Inhabits Indian seas.-Shaw, v. pl. 169.

\section{Gen. 8. Ostracion, Lin.}

Head and body covered with osseous plates; jaws armed with ten or twelve conical teeth; destitute of the bones of the pelvis and ventral fins; branchial openings with a cutaneous lobe, but having within an operculum with six rays; one dorsal and one anal fin.

The fishes of this genus have the bony plates by which they are covered fixed into an inflexible shield, in such a manner that the tail, fins, mouth, and the lobes of the branchiæ are alone moveable. The greater number of the vertebræ are also fixed. Cuvier proposes the division of the genus according to the form of the body and the spines; but the differences in this respect, which may be only sexual, have not been well ascertained.

\section{Body triangular, without spines.}

O. triqueter, Bloch. Triangular Trunk-Fish. Body reddish-brown, with a white spot in the centre of each hexagonal space; sides sloping obliquely from the ridge of the back; abdomen flat; fins yellowish; tail rounded. 12 inches long. Inhabits Indian and American seas.-Bloch, pl. 130.

O. concatenatus, Bloch. Plates of the body of various shapes, but in a reticulated order; colour brown, the dividing lines pale rosecoloured ; sides violet or grayish ; belly white ; tail fins reddishbrown. Inhabits American seas.-Bloch, pl. 131.

\section{Body triangular, with spines behind the abdomen.}

O. bicaudalis, Bloch. Body marbled with gray and pale yellow, with numerous small round black spots ; two spines near the anus. Inhabits Indian seas.-Shaw, v. pl. 170.

O. trigonus, Bloch. Back very convex; head thick and truncated; opening of the mouth small; plates hexagonal, with numerous small tubercles; colour brownish-yellow ; fins yellow, with a bluish border; two subcaudal striated spines. I foot long. Inhabits South American seas.-Bloch, pl. 135.

3. Body triangular, with two frontal and two subcaudal spines.

O. quadricornis, Bloch. Body subtrigonal, very convex above; plates of the body in large hexagons, and marked with numerous and very small tubercles; two strong spines on the top of the head pointing forwards, and two before the anal fin pointing backwards; colour deep brown, with elongated spots; tail and fins 
yellow, the tail with black spots. 12 inches long. Inhabits Indian seas.-Bloch, pl. 134.

\section{Body triangular, with spines on the ridges.}

O. bicuspis, Blumen. (O. stellifer, Schn.) With two dorsal spines. Inhabits coasts of China and America.-Abbild. Nat. Hist. Gegenst. pl. 58.

\section{Body quadrangular, without spines.}

O. cubicus, Bloch. Body quadrangular; plates hexagonal, with a brown circle and white central spot, and covered with tubercles; sides gray; head yellowish; tail and fins reddish-brown. One foot long. Inhabits Indian seas.-Bloch, pl. 137.

O. meleagris, Shaw. (O. punctatus and lentiginosus, Schn.) Body quadrangular, the plates hexagonal and of a deep blackish chestnut-colour, the whole marked with numerous small white spots ; fins and tail whitish, with chestnut-coloured rays.-Shaw, v. pl. 172.

O. nasus, Bloch. Head convex, sloping downwards, and rounded off in front into an obtuse snout, beneath which the mouth is situate; plates forming by their borders hexagonal stars, with a round red spot in the centre of small tubercles; general colour grayish ; tail and fins reddish brown. Inhabits Indian and American seas. - Shaw, v. pl. 171.

6. Body quadrangular, with frontal and subcaudal spines.

O. cornutus, Bloch. Body quadrangular, yellowish-brown, deeper below ; head short and truncated ; two long stout spines projecting forward from the head ; and two circular ones pointing backwards on each side of the anal fin. 8 or 10 inches long. Inhabits Indian Seas.-Shav, v. pl. 170.

\section{Body quadrangular with spines on the ridges.}

O. turritus, Bloch. Body subquadrangular, the back rising into a pyramidal hunch, terminated by a very strong, short, and striated spine, curving slightly backwards; abdomen with three to five spines on each side curved slightly backwards ; plates with lines and elevated borders of a triangular shape, forming various figures; colour yellowish-brown, with irregular brown spots. 10 to 12 inches long. Inhabits Indian seas.-Shuw, v. pl. 171.

8. Body compressed; abdomen carinated, with scattered spines.

O. auritus, Shaw. Body thick, broad, and short, with the back very convex; above each eye a very strong, thick, sharp pointed spine, curving backwards; on each side of the dorsal ridge two others; two spines on each side of the abdomen, and one shorter on each side of the body; colour deep brown, except the fins and spines, which are paler. $4 \frac{1}{2}$ inches long. Inhabits Indian seas. -Shan, v. pl. 173 . 


\section{ORDER V.-LOPHOBRANCHII, Cuv.}

Jaws complete; branchiæ in the form of small round tufts, disposed in pairs along the branchial arches.

This order is distinguished from all the other fishes by the character of their branchiæ, which, in place of being pectinated, are disposed in tufted pairs along the branchial arches. These are covered by a large operculum attached on every side, but in which is a small opening for the exit of the water. The fishes of this order are besides distinguished by their body being armed with bony cushions, which render its appearance angular. They are generally of small size.

\section{Gen. 1. Syngnathus, Lin.}

Body long and slender; snout tubular, much produced, of nearly equal thickness; mouth at the extremity, cylindrical, subvertical; branchial opening toward the neck; no ventral fins.

The ova of this genus are hatched in a pouch, formed by an expansion of the skin, which in some is placed under the belly, and in others at the base of the tail, and which opens to allow the young to get out.

* With two pectoral fins, and one dorsal, caudal, and anal fin.

S. typhle, Lin. Smaller Pipe-Fish. Body hexagonal, marbled with yellow and black ; fins grayish ; beak slender, a little compressed on the sides; eighteen plates on the body and thirty-six on the tail, forming as many articulations; tail square. 12 to 15 inches long. Inhabits Northern Seas.-Shaw, v. pl. 179.

S. acus, Lin. The great Pipe-Fish. General form of the preceding; trunk with twenty plates, and the tail, which is hexagonal, of forty-three, with broad alternate bands of a yellowish-white and brown; the plates slightly radiated. 1 to 2 feet long. Inhabits European seas.-Shaw, v. pl. 179.

\section{** Wanting the anal fin.}

S. pelagicus, Risso. Body heptagonal, yellowish brown, variegated with narrow transverse deep brown bars placed at intervals along the body. 12 inches long. European seas.-Shaw, v. 454.

\section{*** Wanting anal and pectoral fins.}

S. aquoreus, Lin. Body rather compressed and angular, with an acute dorsal and abdominal ridge, which, together with three slight angles on each side, give it an octangular appearance; thirty plates from the gills to the vent, and about sixty-six from the vent to the point of the tail, which is long and slender; colour yellowish, with transverse pale lines and dark margins. Inhabits British seas.-Mont. Wern. Trans. i. pl. 4.

\section{**** Wanting all but the dorsal fin.}

S. ophidion, Lin. Body rounded, greenish, without fins, except a dorsal one. 1 to 2 feet long. Inhabits Northern seas.-Bloch, pl. 91 , tig. 3. 
Gen. 2. Hippocampus, Cuv.-Syngnathus, Lin.

Snout tubular; trunk of the body compressed laterally, and more elevated than the tail; joinings of the scales raised into ridges, and the projecting angles spinous; no ventral fins; branchial openings on the neck.

H. vulgaris, (S. hippocampus, Lin.) The sea Horse. Body heptagonal, and furnished with seven rows of tubercles; belly projecting, with dentated edge; tail square, terminating in a finless point; head large, with a cartilaginous excrescence above the nose, and four above the eyes, terminating in cirri ; colour gray on the back and sides, with a number of black and white spots and streaks; belly brown. 8 to 12 inches long. Inhabits European Seas-Shaw, v. pl. 179.

This species has its name from its head in the dried state, having some resemblance to that of a horse; when recent, however, the head, as in other fishes, is in a straight line with the body.

H. foliatus, Cuv. (S. foliatus, Shaw.) Foliated Hippocampus. General form of the preceding, but larger in proportion, with leaflike appendages on the head, back, tail, and abdomen; colour dusky or blackish-olive, thickly sprinkled on all parts, except on the appendages, with small whitish round specks; fins soft and transparent. 10 inches long. Inhabits Coasts of New Holland. -Shaw, v. pl. 180.

This singular animal was described and figured by Dr Shaw from specimens in the possession of the late Sir Joseph Banks. The leaf-like appendages are placed on strong, rough, square spines; and, were it not for perfect regularity of their pro. portions, might be mistaken for the leaves of some species of fucus adhering to the spines.

Gen. 3. Solenostomus, Lacep.

Jaws narrow, elongated, and tubular; opening of the mouth at the extremity of the snout; large ventral fins behind the pectoral ones, united together with the body into a kind of apron; first dorsal fin elevated, near the nape; the second at the origin of the tail ; caudal fin large, pointed; branchial openings near the throat.

S. paradoxus, Lacep. (Fistularia paradoxa, Pall.) Body covered with slightly elevated scales; five rays on the first dorsal fin, eighteen on the second ; tail lanceolate. 18 inches long. Inhabits Indian seas.-Pall. Spic. Zool. viii. pl. 4, fig. 6.

$$
\text { Gen. 4. Pegasus, - Lin. }
$$

Snout much elongated, depressed, with the mouth under its base; body broad, depressed, covered with plates; branchial openings on the side; two distinct ventral fins behind the pectoral ones, which are very large; dorsal and anal fins opposite.

P. Draco, Lin. Dragon Pegasus. Thorax subquadrangular, with several radiated shields or bony plates above and below; a length- 
ened cirrus on each side of the abdomen; tail long and narrow, in a case of eight or nine scaly rings; pectoral fins very large, round, with a scalloped margin. 3 or 4 inches long. Inhabits Indian seas.-Shaw, v. pl. 182.

P. natans, Bloch. Swimming Pegasus. Snout slender, slightly dilated and rounded at the tip, and marked above and below by a central furrow; pectoral fins rounded, and of moderate size; dorsal fin on the middle of the back; ventral cirri slender and flexible; abdominal segments eleven or twelve in number; tail small, slightly rounded. 3 or 4 inches long. Inhabits Indian seas.-Shaw, v. pl. 182.

P. volans, Lin. Flying Pegasus. Snout much elongated, flattened, slightly dilated at the tip, with a longitudinal furrow, and crenated on the edges; a rhomboidal depression on the head, and two deep subpentagonal cavities behind it. 3 inches long. Inhabits Indian seas.-Shaw, v. 462.

\section{ORDER VI.-MALACOPTERYGII ABDOMINALES.}

Skeleton osseous; jaws complete; branchix pectinated; all the rays of the fins soft, except sometimes the first ray of the dorsal or pectoral fins; ventral fins behind the abdomen.

This order, which includes the greater portion of fresh water fishes, is divided by Cuvier in to five natural families.

\section{Family I.-Salmonides.}

Body scaly, with two dorsal fins, the second adipose, and without rays.

This family comprehends in the system of Linnæus one great genus, characterized by the first dorsal fin with soft rays, followed by a second smaller one, formed of an adipose extension of the skin, not supported by rays. They are provided with numerous cœcums and a swimming-bladder.

\section{Gen. 1. Salmo, Cuv.}

The greater part of the upper jaw formed by the maxillary bones ; mouth large, and furnished with teeth; ventral fins opposite the middle of the first dorsal, and the adipose fin opposite the anal; branchial membrane with more than eight rays.

S. Salar, Lin. The Salmon. Upper jaw longest; lower jaw turned up in the niale; back bluish black, silvery gray on the sides, and white below, more or less marked above the lateral line with irregular brown spots; teeth on the vomer; flesh red. 2 to 5 feet long. Inhabits European seas. B.-Shaw, v. pl. 102.

The Salmon Fisheries in many parts of this country have long been an object of national importance, and numerous Parliamentary regulations have been issued regarding the proper time and modes of fishing. Salmon annually ascend the rivers in great numbers in summer for the purpose of spawning; and when this is accomplished 
they return again to the sea. The fry when of sufficient size likewise leave the fresh waters for the sea; and it is for the protection of the fisl when on their instinctive journeyings, and the preservation of the samlets, that legislative enactments have become necessary.

S. trutla, Lin. The Salmon Trout. Body marked with brown spots, of which those on the upper part are surrounded by a brighter circle; beneath silvery ; flesh red. 18 inches long. Inhabits European Seas. B.-Bloch, pl. 21.

\section{This species ascends rivers like the salmon.}

S. fario, Lin. The Common Trout. Body with brown spots upon the back, red upon the sides, each surrounded by a paler circle; a large spot on the operculi ; the adipose fin yellow, with a brown border; under jaw rather longer than the upper; flesh white. 12 to 17 inche:s long. Inhabits Rivers and Lakes in Europe. B.-Penn. Brit. Zool. iii. pl. 70.

S. Hucho, Lin. Body sub-elongated, silvery gray, with numerous round brown spots ; back dusky ; fins, except the ventral, which is yellowish, pale purple, thickly spotted with brown; tail forked. 2 to 5 feet long. Inhabits fresh waters of Europe.-Bloch, pl. 100.

S. alpinus, Lin. Alpine Trout. Body marked with numerous spots and points, black, red, and silvery, mixed with yellow, and without a circle; back tinged with olive-green; the belly white ; all the fins, except those of the back, are reddish, and the adipose one is red on its edge. About a foot long. Inhabits Alpine Lakes and Rivers. B.-Shan, v. pl. 103.

S. Umbla, Lin. Body silvery, without spots; back tinged with olive-brown; fins pale olive; tail forked; scales very small. About a pound or a pound and half in weight. Inhabits the Lake of Geneva.-Bloch, pl. 101.

Gen. 2. Osmenus, Artedi.-Salmo, Lin.

Mouth at the extremity of the snout; head compressed; scales scarcely visible; two dorsal fins, the second adipose, and without rays; the first more distant from the head than the ventral fins; two rows of scattered teeth on each palatine bone; branchial membrane with eight rays.

O. eperlanus, Cuv. The Smelt or Sparling. Head semitransparent ; back whitish, with a shade of green; sides variegated with blue; abdomen silvery. 3 to 6 inches long. Inhabits European Seas. B.-Penn. Brit. Zool. iii. pl. 72.

This species is found on the British coasts through the whole year, and rarely goes to any distance from the shores, except when it ascends rivers about the spawning season. It has a peculiar odour, which has been compared to that of a cucumber or violet.

Gen. 3. Conegonus, Artedi.-Salmo, Lin.

Mouth at the extremity of the snout, very little cleft; head compressed; scales large ; two dorsal fins, of which the sevor. I. 
cond is adipose and without rays ; branchial membrane with seven or eight rays; teeth small, scarcely perceptible, and often wanting on the palate, tongue, and lower jaw.

C. thymallus, Cuv. The Grayling. Body elongated, gray, with longitudinal dusky blue lines crossing each row of scales; central lateral row of scales with black points; back rounded, greenishblack; belly white ; first dorsal fin long and high, violet-coloured, barred with brown; pectoral fins white, ventral and caudal ones reddish. 18 inches long. Inhabits mountainous Rivers in Europe. B.-Shan, v. pl. 105.

C. marcenula, Cuv. (S. albula, Bloch.) Body sub-elongated, silvery white, with a tinge of blue on the back; head somewhat taper; under jaw longer than the upper; scales large; fins pale-yellow ; tail forked and bluish towards the tip. 6 inches long. Inhabits European Lakes._Bloch, pl. 28, fig. 3.

C. lavaretus, Cuv. The Gwiniad. Head small and very taper in front; upper lip produced very considerably beyond the lower in the form of a blackish soft snout; mouth small, without teeth; scales broad; back bluish-gray ; sides bluish ; belly silvery. 10 to 12 inches long. Inhabits Alpine Lakes of Europe. B.-Penn. Brit. Zool. iii. pl. 73.

C. rostratus. (S. rostratus, Shaw.) Broad Gwiniad. Body dusky bluish, with longitudinal dusky lines on the sides; scales rounded; mouth large; snout as in the preceding. Inhabits Rivers of Germany and Sweden, \&c.-Bloch, pl. 26.

\section{Gen. 4. Argentina, Lin.}

Mouth small, depressed horizontally; tongue armed with hooked teeth, and a transverse row of small ones on the vomer; six rays in the branchial membrane.

A. sphyrana, Lin. Inhabits the Mediterranean sea.-Cuv. Mém. du Mus. i. pl. 11.

The swimming-bladder of this species abounds in the silvery substance so remarkable in fishes, and employed to form imitation pearls. Its stomach is singular from its black colour.

Gen. 5. Curimata, Cuv.-Salmo, Lin.-Characinus, Artedi. Mouth at the extremity of the snout, small; head depressed; scales distinct; first dorsal fin above the ventral fins; the second adipose and without rays; teeth various; four rays in the branchial membrane.

C. edentula, Cuv. Toothless Salmon. Body silvery, with a slight greenish tinge; back olive-brown; head yellowish, ssinking in above the eyes; snout obtuse; mouth small and toothless. 12 inches long. Inhabits Surinam.-Bloch, pl. 380.

C. unimacilata, Cuv. Body brownish above; back and belly almost round; belly silvery; fins gray; a black round spot on the 
lateral line; the upper row of teeth small and denticulated; tail deeply forked. 18 inches long. Inhabits Lakes of South America. -Bloch, pl. 381, fig. 3.

C. fasciata, Cuv. Body pale-yellow, deepening on the back into dull brownish orange, with transverse brown bands; a row of teeth in each jaw, directed obliquely forwards, the anterior ones largest; dorsal fin and tail crossed by an obscure black band. 1 foot long. Inhabits Surinam.-Bloch, pl. 379.

Gen. 6. Anastomus, Cuv.-Salmo, Lin.

Mouth terminal, small; head compressed; one row of small teeth above and below; the lower jaw turned up before the upper one; branchial membrane with four rays.

A. Gronovii. (S. anastomus, Lin.) Inhabits Indian Seas.-Gronov. Mus. pl. 7, tig. 2.

\section{Gen. \%. Serrasalmus, Lacep.-Salmo, Lin.}

Body compressed, high vertically; belly carinated and serrated; teeth triangular, edged, dentated, and disposed in one row on the intermaxillaries and lower jaw; branchial membrane with four rays.

S. rhombeus, Cuv. Body dusky red above, marked with a few scattered dusky spots ; sides and abdomen silvery ; abdomen strongly carinated and serrated; tail lunated and terminated with a black border; a trifid spine before the dorsal fin. Inhabits Rivers of Surinam.-Bloch, pl. 383.

This species grows to a considerable size, pursues ducks, and even tears with its sharp teeth the skin of those who attempt to bathe.

\section{Gen. 8. Prabucus, Cuv.-Salmo, Bloch.}

Body elongated, compressed; head small, and mouth little cleft; teeth pointed and dentated as in the preceding; belly carinated; anal fin very long; first dorsal fin opposite the anal one; branchial membrane with four rays.

P. argentinus, Cuv. Body greenish above, silvery below, with a bright silvery longitudinal line running from head to tail, at some distance above the lateral line; fins pale or white; tail forked. 6 to 8 inches long. S. American Rivers. -Bloch, pl.382, fig. 1.

Gen. 9. Tetragonopterus, Artedi.

Body compressed, high vertically; two rows of triangular and dentated teeth in the upper jaw; mouth small; belly not carinated; anal fin long.

T. argenteus, Artedi. Rivers of South America.-Seba, iii. pl. 34.

Gen. 10. Mreetes, Cuv.-Cyprinus, Lin.

Teeth triangular, short, rounded on the edges, the upper sur- 
face hollowed; mouth small, with two rows of teeth in the intermaxillaries, one row in the lower jaw, and two isolated teeth behind; tongue and palate smooth.

M. dentex, Cuv. (Cyprinus dentex, Lin.-S. Niloticus, Forsk.) Body elongated, silvery, lineated above with brown and whitish; fins white, and lower half of the tail red ; first dorsal fin above the interval between the ventral and anal fins. Inhabits the Nile.Shaw, v. 71.

\section{Gen. 11. Hydrocynus, Cuv.-Salmo, Lin.}

Body compressed; point of the snout formed by the intermaxillary bones ; maxillaries commencing near or before the eyes; tongue and vomer smooth; teeth conical in both jaws.

\section{* With one row of small teeth in the jaws and palate.}

H. falcatus, Cuv. Body silvery, with a bluish tinge on the sides, brownish on the back; scales thin and easily detached; two black spots, one near the head, the other near the base of the tail, on both sides; anal fin falcated, the first dorsal fin over the space between the anal and ventral ones; tail forked. 12 or 14 inches long. Inhabits Surinam.-Bloch, pl. 385.

H. odoe, Cuv. Head compressed, broad above, narrow and without scales before; back and fins blackish-brown; tail forked; the first dorsal fin opposite the space between the anal and ventral ones. 2 to 3 feet long. Inhabits African Seas.-Bloch, pl. 386.

** With a double row of teeth on the intermaxillary bones.

H. Braziliensis, Cuv. Body striped longitudinally with blackish ; a double row of teeth on the intermaxillaries and under jaw, a single row on the maxillary bones, and the palate smooth; first dorsal fin above the ventral fins.-Cuv. Reg. An. pl. 10.

Cuvier further divides this genus into, 1 . those which have a single row of teeth on the maxillaries and lower jaw, the teeth alternately very short and long, as the H. scomberoides. 2. Those which have the snout projecting, the maxillaries short, and furnished, as well as the lower jaw, with a single row of crowded teeth, and the body covered with strong scales; H. lucius, Cuv. 3. Those with teeth only in the intermaxillaries and lower jaw; the Roschal of Forskal.

\section{Gen. 12. Citharinus, Cuv.}

Mouth depressed, cleft across the point of the snout; upper margin formed by the intermaxillary bones; maxillaries small and without teeth; tongue and palate smooth; adipose fin covered with scales, as well as the greater portion of the caudal fin.

C. Niloticus. Body compressed, high vertically; teeth in the upper jaw only; belly smooth, not carinated. Inhabits the Nile. -Geoff. Poiss. d'Eg. pl. 5, fig. 2, 3.

C. AEgytius. (S. AEgyptius, Gmel.-S. Niloticus, Hasselq.) The Nefasch of the Egyptians. Body elongated, greenish on the 
back ; slender forked teeth in both jaws in many rows. Inhabits the Nile.-Geoff. Poiss. d'Eg. pl. 5, fig. 1.

Gen. 13. Saurus, Cuv.-Salmo, Bloch.

Snout short; jaws cleft to behind the eyes; margin of the upper jaw formed entirely of the intermaxillaries; many pointed teeth along both jaws, the palate, and the tongue, but none on the vomer; eight or nine, and often twelve or fifteen rays in the branchial membrane; the first dorsal fin a little behind the ventral ones; scales large.

S. vulgaris. (S.saurus, Bloch.) The Sea Lizard. Body oblong; back blackish-green; belly white, variegated with blue, brown, and greenish spots. 12 inches long. Inhabits Mediterranean, American, and Red Seas._Bloch, pl. 384, fig. 1.

S. foclenis, Cuv. Head compressed, truncated, and half covered with scales; back blackish ; flanks and belly silvery ; fins reddishbrown. 1 foot long. American Seas.-Bloch, pl. 384, fig. 2.

S. Tumbil, Cuv. Head and body covered with large scales; teeth of the first row large, the others small ; sides of the body yellowish; belly silvery, with semidecurrent transverse red bands; fins yellow towards their base, and blue towards the margin. 12 inches long. Inhabits Indian Seas.-Bloch, pl. 400.

Gen. 14. Scopelus, Cuv.-Serpes, Risso.

Mouth and branchial openings widely cleft; jaws furnished with very small teeth; margin of the upper jaw formed by the intermaxillaries; tongue and palate smooth; nine or ten rays in the branchial membrane; second dorsal fin very small.

S. Humboldtii, Risso. With brilliant silvery points disposed along the belly and tail.-Risso, pl. 10, fig. 38 .

Gen. 15. Auropus, Cuv.-Salmo, Bloch.

Jaws much cleft ; intermaxillaries forming the upper margin, and furnished, as well as the palate and lower jaw, with a band of crowded teeth ; maxillaries without teeth ; ventral fins under the pectoral ones, and their external rays thick and forked; twelve rays in the branchial membrane; scales ciliated.

A. filamentosus, Cuv. Inhabits Mediterranean Sea.-Cuv. Reg. An. ii. 170.

Gen. 16. Gasteropelecus, Bloch.-Serpes, Lacep.

Belly compressed and projecting; ventral fins small and much behind ; first dorsal fin over the anal, which is long; mouth directed upwards, with conical teeth in the upper jaw, and edged and dentated ones in the lower.

G. slernicla, Bloch. Head and body compressed laterally, silvery, 
with a steel blue shade; from the throat to the anus extends a bone as thin as paper, covered with scales; three rays on the branchial membrane. American Seas. -Bloch, pl. 97, fig. 3.

\section{Gen. 17. Sternoptix, Herm.}

Body compressed, very high vertically, without scales; abdomen carinated and bent up before, so that the mouth is directed upwards; no ventral fins, but a festooned membrane on each side of the abdominal ridge under the pectoral fins; dorsal fins small and in the middle of the back, with a strong spine in front.

S. diaphana, Herm. Body silvery, semitransparent in the lower part, without lateral line; pectoral fins yellow; tail forked. 2 inches long. Inhabits South America.-Cuv. Reg. An. ii. 171.

\section{Family II.-Clupee.}

This family is distinguished by their having no adipose fin; the upper jaw formed in the middle by intermaxillaries without pedicles, and on the sides by the maxillaries. Their body is scaly; all have a swimming-bladder; and the greater part coecums. The genus Clupea of Linnæus, which forms the type of this family, are distinguished by their narrow and short intermaxillary bones. The maxillaries, in three pieces, form the sides of the upper jaw in such a manner that these sides are alone protractile. The branchial arches are furnished on the side next the mouth with long pectinated teeth; and the scales on the lower part of the body, which is compressed vertically, form a serrated ridge.

\section{Gen. 18. Clupea, Cuv.}

Intermaxillary bones narrow, arched before, and divided longitudinally into many pieces; mouth not entirely furnished with teeth, and often edentate; belly compressed, carinated, the scales forming a serrature on the ridge; one dorsal fin, above the ventral ones.

C. Harengus, Lin. The Common Herring. Body silvery, with dusky back, and deciduous scales; lower jaw longer than the upper; a few small teeth in the front of both jaws; 16 to 17 rays on the anal fin. 10 to 12 inches long. Inhabits Northern Seas. B.Shaw, v. pl. 119.

The Herring, which forms an object so important in the fisheries and commerce of Europe, was long supposed, from its appearing and disappearing on the coasts at certain seasons, to have migrated on these occasions, in countless numbers, from the Polar Seas, and, after carrying wealth along the northern shores, retiring again to the arctic deeps. Pennant describes in glowing language the march of these finny columns of fishes, five or six miles in length, and three or four in breadth; but the assumption of their returning to or coming from the Polar Seas is entirely hypothetical. It is more in consonance with the habits of other fishes which approach the shore to spawn, to suppose that the herring approaches our coasts for the same purpose, and that they retire when this is effected to the deep sea.

C. Pilchardus, Bloch. The Pilchard. Body silvery, with dusky back, and large adherent scales; teeth imperceptible; dorsal fin a little farther forward on the body than in the preceding species, and anal fin with one or two more rays. 8 inches long. Inhabits western coasts of England.-Shaw, v. pl. 119. 
C. Sprattus, Lin. The Sprat. Body narrow, silvery; back bluish ; scales easily detached; under jaw longer than the upper; anal fin with nineteen rays; tail forked. 5 inches long. Inhabits European Seas. B.-Bloch, pl. 29, fig. 2.

This is probably, notwithstanding the statements to the contrary, the young of the common Herring or Pilchard.

C. Alosa, Lin. The Shad. Upper jaw cleft at its extremity; body bright silvery, shading to dusky on the back; a black spot near the gills, accompanied when young by four or five others. 18 to 20 inches long. Inhabits Mediterranean and Northern Seas, and ascends the rivers at particular seasons. B.-Shliaw, v. pl. 120.

C. Africana, Cuv. Head small, compressed, without scales; lower jaw longer than the upper; back and belly carinated, the back steel-coloured, the belly silvery; fins grayish, that of the tail very long and forked. Inhabits Coasts of Africa.-Bloch, pl. 407.

C. Chinensis, Cuv. Body slender, head tapering; lower jaw longer than the upper; no teeth in either; body silvery; fins yellowish, those of the back and tail with a deeper border. 10 inches long. Inhabits Indian Seas. - Bloch, pl. 405.

\section{Gen. 19. MEGalors, Lacepede-Clupea, Bloch.}

Eyes very large; twenty-four rays or more on the branchial membrane; last ray of the dorsal fin terminating in a long filament.

M. filamentosus, Lacep. (C. cyprinoides, Bloch.) Body compressed, and covered with large scales; head, sides, and belly silvery; back and fins bluish; last ray of the dorsal fin long, extending backwards in the form of a long filament. 10 to 12 feet long. Inhabits Indian and American Seas.-Bloch, pl. 403.

M. Thrissa, Cuv. Head small, compressed, and without scales; the lower jaw bent upwards, and terminating in a point which fills the notch in the upper; body bluish silvery, dusky on the back; pectoral fins bluish; last ray of the dorsal fin much elongated. 10 or 12 inches long. American Seas.-Bloch, pl. 404.

M. nasus, Cuv. Back blue; belly and tlanks silvery; snout long, projecting beyond the jaws; dorsal fin with the last ray long and slender. 7 or 8 inches long. Indian Seas.-Bloch, pl. 429 .

\section{Gen. 20. Engraulis, Cuv.-Clupea, Lin.}

Ethmoid and nasal bones forming a projecting point, below which the very small intermaxillaries are fixed; maxillary bones straight and very long; jaws much cleft, and both furnished with teeth; branchial openings large.

E. encrasicolus, Cuv. The Anchovy. Upper jaw longer than the under; back brown; sides and belly silvery; fins short; dorsal fin opposite the ventrals, transparent, that of the tail forked. 3 inches long. Inhabits European Seas.-Shaw, v. pl. 120. 
E. atherinoides, Cuv. Body brownish, with a broad silvery longitudinal band on each side. 10 inches long. Inhabits Indian Seas.-Bloch, pl. 408, fig. 1 .

E. Malabaricus, Cuv. Lower jaw bent upwards, and anal fin very long; body silvery. 12 inches long. Inhabits Indian Seas.Bloch, pl. 432.

Gen. 21. Thrissa, Cuv.-Mystus, Lacep.-Clupea, Iin.

Maxillary bones with teeth, and prolonged into free points beyond the lower jaw; anal fin long and united to that of the tail.

T. Mystus, Cuv. Body compressed, whitish, like the blade of a sword; belly carinated. Indian Seas.-Lin. Amcen. Ac. iv. pl. 3.

T. setirostris, Cuv. Body lanceolate, silvery, tinged with blue above ; upper jaw terminating in a setaceous process. Inhabits Indian Seas.-Brouss. i. pl. 10.

Gen. 22. Gnatновоцus, Schn.-Odontognathus, Lacep.

Maxillary bones prolonged and moveable, with the points forward; dorsal fin very small, and much behind; no ventral fins.

G. spinosus, Cuv. Body much compressed, carinated and armed with twenty-eight spines, disposed in two rows below; anal fin very long; tail forked. Indian Seas.-Lacep. ii. pl. 7, fig. 2.

Gen. 23. Pristigaster, Cuv.

Body much compressed, without ventral fins; belly projecting, strongly dentated; jaws as in the herring.

P. triangularis. Body nearly triangular, silvery; eyes very large; anal fin extending to nearly opposite the dorsal fin; tail forked; belly and space before the dorsal fin dentated. Inhabits American Seas.-Cuv. Reg. An. pl. 10, fig. 3.

Gen. 24. Notopterus, Lacepede-Gymnotus, Pall.

Operculi and cheeks scaly; two ridges on the lower jaw; belly carinated and dentated; both jaws and palate with fine teeth; tongue with hooked teeth; ventrals very small; anal very long, uniting with the caudal fin; a soft dorsal fin opposite the middle of the anal one.

N. Kapirat, Lacep. (Gymnotus notopterus, Pall.) Dorsal fin very short; snout short and rounded; a small opening above the eyes; scales variegated with gold and silver colour. About a foot long. Inhabits Amboyna.-Pall. Spic. vi. pl. 6, fig. 2.

Gen. 25. Elops, Lin.

Thirty or more rays in the branchial membrane; belly neither edged nor dentated; caudal fin with a flat spine above and below; edge of the jaws and palate with crowded small teeth. 
E. saurus, Bloch. Head compressed, without scales, long, and a little flattened above; the under jaw longer than the upper; tail forked, with a spinous ray on each side. 14 inches long. Inhabits American Seas.-Bloch, pl. 393.

Gen. 26. Chirocentrus, Cuv.

Jaws with a row of strong conical teeth, those in the middle above, and all those below very long; tongue and branchial arches rough with small teeth; a long pointed scale above each pectoral fin, and the pectoral rays very hard.

C. Dorab, (Clupea Dorab, Gmel.) Body elongated, compressed, silvery, dusky blue on the back, carinated below ; ventral fins extremely small, and the dorsal shorter than the anal fin, opposite to which it is placed. Indian Seas.-Lacep. v. pl. 8, fig. 1.

Gen. 2\%. Erythrinus, Gronov.

A row of conical teeth in each jaw, with some larger in front than the others; five rays in the branchial membrane; head round, furnished with osseous plates, and without scales; body covered with large scales; dorsal fin above the ventral ones.

E. Malabaricus, Cuv. (Esox, Bloch.) Head flat, compressed on the sides; colour yellowish, dusky on the back; fins grayish, with brown transverse bands; tail forked. 12 inches long. Inhabits rivers of Malabar.-Bloch, pl. 392.

\section{Gen. 28. Amia, Lin.}

Head covered with osseous plates; scales large ; twelve flat rays in the branchial membrane ; two cirri near the nostrils; teeth conical before, with flat ones behind.

A. calva, Lin. Body slender; an osseous shield on the throat; dorsal fin long and sloping; tail rounded, with a black spot at the upper part of the base. Rivers of Carolina._Shaw, v. 9.

\section{Gen. 29. Sudis, Cuv.}

Head with osseous plates and without scales; five rays in the branchial membrane ; teeth conical ; dorsal and anal fins opposite.

S. giganteus, Cuv. Body elongated, covered with large osseous scales; snout oblong, and head singularly rude; tail very short. Inhabits rivers of Brazil.-Cuv. Reg. An. pl. 10, fig. 4.

Gen. 30. Lepisosteus, Lacep.

Body covered with osseous scales; file-like teeth interiorly in both jaws, and a row of long pointed ones on their margin; branchiæ united under the throat by a common membrane, with three rays on each side. 
L. osseus, Cuv. Head flat ; snout long, without scales; nine rays in the dorsal and anal fin; the first ray of each fin, and the last of the caudal strong, furnished with scales, and appearing as if dentated; scales very large, square, osseous, disposed in oblique rows along the sides; colour greenish above; abdomen rose-coloured. 5 to 6 feet long. Inhabits rivers and lakes of America.-Bloch, pl. 390 .

\section{Gen. 31. Polypterus, Geoff.}

Margin of the upper jaw immoveable; a row of conical teeth in both jaws, and behind these rasp-like smaller ones; body elongated, and covered with strong scales; a large plate on the cheeks; one Hat ray on the branchial membrane; a number of small dorsal fins, each supported by a strong spine; caudal fin surrounding the tail.

P. Bichir, Geoff. Body sea green, with some black spots; belly whitish. Inhabits the Nile.-Shaw, v. pl. 112.

\section{Family III.-Esoces.}

This family want the adipose fin, and the upper jaw is formed by the intermaxillary bone, or, when it is not, the maxillary is without teeth, and concealed in the thickness of the lips. Their intestinal canal is short, without coecums, and all have a swimming-vessel. They are very voracious fishes, and many ascend rivers.

Gen. 32. Esox, Cuv.

Snout long, obtuse, broad and depressed; long pointed teeth on the sides of lower jaw ; the intermaxillaries, vomer, palate, and tongue furnished with small and crowded teeth; one dorsal fin opposite the anal one.

E. Lucius, Lin. The Common Pike. Body pale olive gray, deepest on the back, and marked on the sides by several yellowish spots or patches; abdomen white, slightly spotted with black. 4 to 8 feet long. Lakes and rivers in Europe.-Shan, v. pl. 108.

The Pike is one of the most voracious of fresh water fishes. Mr Pennant mentions an instance of one choked by attempting to swallow another of its own species that proved too large. It is common in most of the lakes of Europe, feeds on fish, frogs, \&c., and will even devour the water-rat or young ducks. It is, according to Bloch, of all fishes that which increases most rapidly in size. The first year it grows to the length of 8 or 10 inches; in the second to 12 or 14 ; and the third to 18 or 20. It sometimes grows to the length of six feet. The pike appears to survive to an advanced age. Rzaczynski mentions one that was ninety years old ; and Gesner relates that in 1497 a pike was taken near Hailbrun in Suabia, with a brazen ring attached to it, hearing that it had been put into the lake in October 1230. This ring is preserved at Manheim. Pikes spawn in March or April, according to the weather. Their flesh is much esteemed.

\section{Gen. 33. Galaxias, Cuv.}

Body without apparent scales; teeth pointed, and medium sized on the palate and both jaws; upper jaw formed almost entirely by the intermaxillary bone; some strong hooked teeth on the tongue; pores on the sides of the head. 
G. truttaceus, Cuv. A new species.-Cuv. Reg. An. ii. 184.

Gen. 34. Microstoma, Cuv.

Snout very short; lower jaw projecting, furnished, as well as the intermaxillaries, with very fine teeth; three broad and flat rays in the branchial membrane; lateral line formed by a row of strong scales. Risso.

This genus was instituted by Cuvier. The type of it is the Serpe microstome of

\section{Gen. 35. Stomias, Cuv.-Esox, Risso.}

Snout extremely short; mouth much cleft; teeth long and hooked; those on the tongue smaller; operculi thin and membranous; body elongated; dursal opposite to the anal fin.

S. boa, Cuv. Body black, with many rows of silvery spots along the belly. Inhabits the Mediterranean sea.-Risso, pl. 10, fig. 34.

Gen. 36. Chauliodus, Schn.

Two teeth in each jaw, crossing over the opposite jaw when the mouth is shut; dorsal fin opposite the interval between the pectoral and ventral fins; first ray of the dorsal fin elongated and filamentous.

C. Sloani, Schn. (Esox stomias, Shaw.) Body obscure greenish brown. 15 to 18 inches long. Inhabits Mediterranean sea.Shaw, vi. pl. 111.

\section{Gen. 3\%. Salanx, Cuv.}

Head depressed; operculi folding downwards ; four flat rays on the branchial membrane; jaws pointed, furnished with a row of crooked teeth; palate smooth.

This genus is founded by Cuvier on a species not yet described.

Gen. 38. Belone, Cuv.

Snout long, formed by the intermaxillaries and lower jaw ; jaws furnished with small teeth; body elongated, with a row of large carinated scales on each side of the body.

B. vulgaris, (Esox belone, Lin.) The Gar-Fish. Body blue green above, silvery below; jaws long and taper. 2 feet long. Inhabits European seas. B.-Penn. Brit. Zool. iii. pl. 74.

This fish is in esteem as food, notwithstanding the prejudice inspired by the green colour which the bones assume when dressed.

Gen. 39. Scomberesox, Lacep.

Body and tail much elongated; jaws very long, slender, and narrow ; dorsal opposite the anal fin; last rays of the dorsal and anal fins detached, forming spurious fins.

S. saurus, (Esox saurus, Schn.) The Saury Pike. Body eelshaped, dusky above, silvery beneath; pectoral and anal fins very 
small; tail much forked. 11 to 18 inches long. Inhabits British seas.-Penn. Brit. Zool. iii. pl. 75.

The Saury Pike is gregarious, and is frequently found in autumn in the shallows of the Frith of Forth, upon the recess of the tide, with its long nose imoedded in the mud.

\section{Gen. 40. Hemiramphus, Cuv.-Esox, Bloch.}

Both jaws furnished with small teeth; symphysis of the lower jaw prolonged into a long point without teeth.

H. Braziliensis, Cuv. Body long, subcylindrical, pale green, with five or six broad semidecurrent brown bands across the back; abdomen silvery; tail sharply forked. 12 to 15 inches long. Inhabits Indian and American seas.-Bloch, pl. 391.

\section{Gen. 41. Exocetus, Lin.}

Head covered with scales; ten rays in the branchial membrane; eyes large; jaws furnished with small pointed teeth, and the pharyngeal bones with flat ones; pectoral fins as long as the body.

This genus is remarkable for the extreme length and size of their pectoral fins, by which they are enabled to support a kind of flight in the air for two or three hundred feet. The general height to which they rise above the water is three feet. In thus endeavouring to escape from their aquatic enemies, however, they often form the prey of sea-birds.

E. exiliens, Bloch. Mediterranean Flying-Fish. Head compressed, broad above, narrow below, and covered with large scales; body silvery, with brownish back; ventral fins long, and behind the middle of the abdomen. 12 to 15 inches long. Inhabits Mediterranean sea.-Shaw, v. pl. 116 .

E. evolans, Bloch. Common Flying-Fish. Body silvery, with brownish back; ventral fins small, of a slightly lunated form, near the pectoral ones. American and Indian seas.-Shaw, v. pl. 117.

E. mesogaster, Bloch. Body bright silvery, with a dusky tinge on the back; fins bluish; ventral fins in the middle of the abdomen. Inhabits Atlantic Ocean._Shaw, v. pl. 116.

\section{Gen. 42. Mormyrus, Lin.}

Body compressed, oblong, scaly; head covered by a naked and thick skin, covering the operculi and branchial rays; mouth small; teeth slender and notched in the intermaxillaries and lower jaw, and a long band of crowded teeth on the tongue and vomer.

M. Hasselquistii, Geoff. Snout cylindrical; dorsal fin long; tail forked. Inhabits the Nile.-Geoff. Pois. du Nil, pl. 6, fig. 2.

M. anguilloides, Geoff. Snout cylindrical ; dorsal fin short. Inhabits the Nile.-Geoff. pl. 7, fig. 2.

M. labiatus, Geoff. Snout short, rounded; dorsal fin short. Inhabits the Nile.-Geoff. pl. 7, fig. 1. 
M. cyprinoides, Lin. Forehead with a gibbous projection; snout obtuse ; tail forked. Inhabits the Nile.-Geoff. pl. 8, fig. 2.

\section{Family IV.-Cyprinide.}

This family is characterized by the want of an adipose fin; by their small mouth and weak jaws, generally without teeth. The pharyngeal bones, however, are strongly dentated. The margin of the upper jaw is formed by the intermaxillarics; the branchial rays are few in number; the body is scaly ; the intestinal canal short, and without cœcums; and they are the least rapacious of fishes. They are found in fresh waters, and their swimming.bladder is generally divided into two parts by a strangulation.

\section{Gen. 43. Cyprinus, Cuv. Lin.}

Three flat rays in the branchial membrane; tongue and palate smooth; dorsal fin long; second ray of the dorsal and anal fin spinous and dentated.

\section{* Cirri at the angles of the upper jaw.}

C. carpio, Lin. The Common Carp. Body greenish olive, deeper on the back; scales large ; fins violet; lateral line with black spots. 12 to 16 inches long. Inhabits lakes and rivers in Southern Europe. B.-Shaw, v. pl. 121.

This species is said to have been introduced into England previous to the year 1496 from Germany. They are very long lived, and grow to a great size. They are also extremely tenacious of life. Pennant relates an experiment of placing a carp in a net, well wrapped up in wet moss, the mouth only reinaining out, and being fed in this manner in a cellar for a fortnight with bread and milk. Though so cunning in general as to be styled the River Fox, yet at spawning time they suffer themselves to be tickled and caught without attempting to escape. The carp is fed in ponds in some parts of the Continent.

$$
\text { * Without cirri at the upper jaw. }
$$

C. auratus, Lin. The Golden Carp. Body of a splendid metallic golden hue, with a shade of scarlet on the upper parts; silvery below; fins carmine red; tail frequently trifid, and anal fin double. 4 to 6 inches long. Inhabits lakes in Southern China. -Shaw, v. pl. 126, 127.

This beautiful fish is a native of China, but now domesticated all over Europe in rivers and ponds. It is said to have been introduced into England in 1691. It is extremely subject to variations in the domesticated state, not only in colour but even in the number of the fins, the tail frequently assuming a trifid form, and the anal fins becoming double.

Gen. 44. Barbus, Cuv.-Cyprinus, Lin.

Dorsal and anal fins short; a strong spine for the second or third ray of the dorsal fin; four cirri, of which two are at the point and two at the angles of the upper jaw.

B. vulgaris, (C. barbus, Lin.) The Barbel. Head oblong; snout reddish; body elongated, silvery gray, with a darker shade on the upper parts; scales rounded; second ray of the dorsal fin strong and serrated; ventral fins pale brown, tipped with yellow; tail dull purple and forked. 3 to 10 feet long. Inhabits rivers in Southern Europe.-Shan, v. pl. 132. 
The Barbel frequents the still and deep parts of rivers, rooting like swine with its nose in the soft banks. They are so tame as to suffer themselves to be taken by the hand. Their flesh is coarse, and the roe is considered noxious.

B. Capoëta, Cuv. (C. capoëta, Gmel.) Body silvery, with a dusky shade above ; white below ; scales with brown points ; fins brown with dusky specks; pectoral fins acuminated; third ray of the dorsal fin very long, serrated downwards. 12 inches long. Caspian Sea.-Guldenst. Nov. Com. Petrop. xvii. pl. 18. fig. 1, 2.

B. Mursa, Cuv. Body golden olive, dusky above; skin mucous ; anal and ventral fins white, spotted with brown on the upper part, the other fins brown; third ray of the dorsal fin very long and thick, and serrated beyond the middle; tail forked. 12 inches long. Inhabits Caspian Sea.-Shaw, v. 235.

\section{Gen. 45 Goвro. Cuv.-Cyprinus, Lin.}

Dorsal and anal fins short, without spines; two cirri at the upper jaw, which is longer than the under one.

G. Aluviatilis, Rondel. (C.gobio, Lin.) The Gudgeon. Body elongated, subcylindrical, pale olive brown above, spotted with black; belly white ; scales middle sized; dorsal fin short, spotted with black spots ; tail forked. 4 to 6 inches long. Inhabits lakes and rivers in Europe. B.-Bloch, pl. 8. fig. 2.

This fish is generally found in gentle streams, and is of small size. It is a very prolific species, and is extrernely plentiful in the lakes of some parts of Germany.

\section{Gen. 46. Tinca, Cuv.-Cyprinus, Lin.}

Dorsal and anal fins short, without spines; minute cirri on the jaws; scales very small.

T. vulgaris. (C. tinca, Lin.) The Tench. Body thick and short, brownish yellow; abdomen paler; skin slimy; tail nearly even. 12 to 14 inches long. Inhabits lakes and marshes. B.-Bloch, pl. 14.

The Tencn is like the carp, remarkably tenacious of life, and is sometimes found of unusual size and weight. In the clearing out of an old pond in Yorkshire in I801, where rubbish had been thrown for years, and where no fish were expected, two hundred of Tench and as many Perch were found; and in a hole among roots was found a large fish, 2 feet 9 inches long, and 2 feet 3 inches in circumference, which appeared to have been stationary for years, and which in growth had accommodated its body to the form of the hole.

Gen. 41. Cirnhinus, Cuv.-Cyprinus, Bloch.

Dorsal fin large; cirri on the middle of the upper lip.

C. Malabaricus, (C.cirrhosus, Bloch.) Body compressed, silvery, with a violet brown shade on the upper parts ; fins of a pale or whitish colour. 18 inches long. Inhabits rivers and lakes in India.-Bloch, pl. 411 .

Gen. 48. Abramis, Cuv.-Cyprinus, Lin.

Dorsal fin short, placed behind the ventral fins; anal fin very long; destitute of spines and cirri. 
A. vulgaris, Cuv. (C. brama, Lin.) The Bream. Head truncated; upper jaw a little projecting; forehead bluish black; cheeks yellowish ; body olive, paler below ; fins obscure ; an oblong conical process at the base of the ventral fins, 29 rays in the anal fin. 2 to $2 \frac{1}{2}$ feet long. Inhabits lakes and rivers of Europe. B. -Shan, v. pl. 124.

A. Blicca, Cuv. Body silvery olive, with brownish back; pectoral and ventral fins reddish; 24 rays on the anal fin. 10 inches long. Inhabits lakes and still rivers of Europe-Bloch, pl. 10.

A. Ballerus, Cuv. Body slender, sides silvery white; belly reddish; lateral line with brown points; back blackish; 41 rays in the anal fin. 10 to 15 inches long. Inlabits lakes and rivers in Germany.-Bloch, pl. 9.

A. Vimba, Cuv. (C. Serta, Shaw.) Body bluish olive above, silvery or whitish below; head small and cuneiform; upper jaw projecting; twenty-four rays in the anal fin. 12 to 18 inches long. Inhabits rivers in Northern Europe.-Bloch, pl. 4.

\section{Gen 49. Labeo, Cuv.}

Dorsal fin long; lips fleshy and very thick; destitute of spines and cirri.

L. Niloticus, Cuv. (C. Niloticus, Geoff.) With seven rays in the anal fin, and eighteen in the dorsal fin. Inhabits the Nile.-Geoff. Pois. du Nil, pl. 9. fig. 2.

L. fimbriatus, Cuv. (Cyprinus, Bloch.) Body above violet brown, with numerous red spots; below silvery or white; lips broad, thick, and fringed; fins violet; anal fin with nine rays. 12 inches long. Inhabits fresh waters in India.-Bloch, pl. 409.

Gen. 50. Levciscus, Klein.-Cyprinus, Lin.

Dorsal and anal fins short, and destitute of spines and cirri.

L. Dobula, Cuv. Head broad; snout round; body silvery, dusky blue above, pectoral and ventral fins red. 10 or 12 inches long. Inhabits lakes and rivers in Germany.--Bloch, pl. 5.

L. rutilus, Cuv. The Roach. Body compressed, silvery; scales large; all the fins red; dorsal fin opposite the ventral ones; tail slightly forked. Weighs a pound or a pound and a half. Inhabits rivers of Europe. B.-Bloch, pl. 2.

L. vulgaris, Cuv. The Dace. Body narrow, silvery, with yellowish olive back ; fins pale ; snout slightly prominent; eleven rays in the anal and ten in the dorsal fin. 10 inches long. Inhabits rivers of Europe. B.-Bloch, pl. 97. fig. 1.

L. alburnus, Cuv. The Bleak. Body narrow, compressed, bright silvery, with the back olive green; fins pale; the lower jaw a little longer than the upper; 21 rays in the anal fin. 5 or 6 inches long. Inhabits rivers of Europe. B.-Penn. Brit. Zool. iii. pl. 84. 
The scales of this species along with those of the Dace are used in the manufacture of artificial pearls. They are beat into a fine powder, prepared with isinglass, and introduced into a thin gluss globule, which is afterwards filled with wax.

L. phoxinus, Cuv. The Minow. Body blackish green, with blue and yellow variegations; abdomen silvery; scales small; ten rays in the ventral, anal, and dorsal fins; tail forked and marked near the base with a dusky spot. 3 inches long. Inhabits rivulets in Europe. B.-Shan, v. pl. 132.

This beautiful and well-known species is frequent in clear gravelly streams and rivulets in many parts of Europe. In Britain it is observed to appear in March, and is seldom seen after October. The Minow is gregarious; spawns in June, and is indeed found in roe during the greater part of the summer. The Minow is easily tamed, and in captivity may be taught to pick flies or filaments of beef from the hand. We have kept individuals in domestication for two years and a half.

L. erythropthalmus, Cuv. The Rud. Body broad and short, pale golden olive, deeper on the back; abdomen reddish ; fins vermilion red; fourteen rays in the anal fin. 8 to 10 inches long. Lakes and rivers of Europe. B.-Penn. Brit. Zool. iii. pl. 83.

L. nasus, Cuv. The Nase. Body bluish silvery, with small head and prominent snout; scales large; pectoral, ventral, and anal fins red; dorsal and caudal blackish; fifteen rays in the anal fin. 12 to 15 inches long. Inhabits lakes and rivers of Northern Europe.-Bloch, pl. 3 .

This species is remarkable for the black colour of the peritonæum or investing membrane of the intestines, which has occasioned a prejudice against its being used as food.

L. cephalus, Penn. (C. Jeses, Donov.) The Chub. Body robust, silvery, with a bluish olive tinge above; head thick, and snout rounded; scales large, angular; fins ferruginous, the anal one with fourteen rays; tail dull bluish. 14 to 18 inches long. Clear and rapid rivers of Europe. B.-Penn. Brit. Zool. iii. pl. 84.

L. Idus, Cuv. Body thick, silvery, with a dusky tinge on the upper parts; head truncated; pectoral fins yellowish; ventral red in the middle and white at the sides; anal with the base white, the rest red, and with thirteen rays. 18 to 24 inches long. Inhabits lakes and rivers in Northern Europe.-Bloch, pl. 36.

L. Pomeranicus, (C. Buggenhagii, Bloch.) Body silvery, with a bluish or dusky tinge on the upper parts and fins; nineteen rays in the anal fin; tail forked. 12 to 15 inches long. Inhabits lakes and rivers of Germany.-Bloch, pl. 95.

L. aspius, Cuv. Body silvery gray; back brownish; sixteen rays on the anal fin; lower jaw incurved larger than the upper. Inhabits rivers of Germany.-Bloch, pl. 7 .

L. bipunctatus, Cuv. Body yellowish olive; scales spotted with black; and a double row of black points on the lateral line, which is red; sixteen rays in the anal tin. 3 or 4 inches long. Inhabits rivers and brooks of Germany.-Bloch, pl. 8. fig. 1.

L. amarus, Cuv. Body broad, yellowish olive, with a shade of silvery; seven rays in the pectoral and ventral fins, and eleven 
rays in the anal one. 2 inches long. Inhabits lakes and rivers of Germany.-Bloch, pl. 8, fig. 3.

L. Aphya, Cuv. Body pale brown above, and whitish or reddish beneath; nine rays in the dorsal and anal fin. 2 or 3 inches long. Inhabits coasts of the Baltic.-Bloch, pl. 97, fig. 2.

L. Chalcoides, Cuv. Nineteen rays in the anal and eight in the dorsal fin. 10 to 12 inches long. Inhabits the Caspian sea.Guldenstaedt, Nov. Com. Petrop. 1772, pl. 16.

L. cultratus, Cuv. Body bluish silvery, compressed ; abdomen carinated; anal fin with thirty rays, and opposite the dorsal. 18 to 24 inches long. Rivers of Northern Europe-_Bloch, pl. 37.

L. Americanus, Cuv. Lateral line much bent towards the abdomen ; 13 rays in the anal fin. American seas.-Lacep. v. pl. 15, fig. 3.

L. falcatus, Cuv. Head small, without scales, and compressed ; upper jaw longest; body silvery, shading to brown above; dorsal and anal fin sickle-shaped, the last with eight rays. 12 inches long. Inhabits fresh waters in India.-Bloch, pl. 412.

Gen. 51. Gonorhynchus, Gronov.-Cyprinus, Gmel.

Snout projecting; mouth small, without teeth or cirri; three rays in the branchial membrane; body covered with small scales.

G. Capensis, (C.gonorhynchus, Gmel.) Body cylindrical ; ventral fins opposite the small dorsal one. 9 inches long. Inhabits sea at the Cape of Good Hope-Gronov. Zooph. pl. 10, fig. 2.

\section{Gen. 52. Cовітіs, Lin.}

Body elongated, covered with small scales and slimy; head small ; mouth terminal, bearded, without teeth, but with lips fitted to act as a sucker; three rays in thebranchial membrane ; air-vessel in a bony sheath.

C. barbatula, Lin. The Common or Bearded Loche. Body shaded and dotted with brown upon a yellowish ground; mouth with six cirri. 3 to 5 inches long. Inhabits rivulets in Europe. B.-Penn. Brit. Zool. iii. pl. 69.

C. fossilis, Lin. The Great Loche. Body blackish, with longitudinal brown and yellow stripes; six cirri on the upper lip and four on the lower. 10 to 12 inches long. Inhabits lakes and marshes in Germany.-Shaw, v. pl. 93.

This species is very tenacious of life. When its native marshes are dried up or covered with ice, it buries itself in the mud, on which account it was supposed by the older authors to originate in the ground and to be carried to rivers by inundations,-and hence its specific name. It has also been remarked, that before stormy weather this fish comes to the surface and seems restless and uneasy; and Bloch suggests, that in a vessel with water and mud at the bottom it might serve the purpose of a barometer.

C. Iania, Lin. The Spiny Loche. Body compressed, orange coloured, marked with a series of black spots; a forked and moveable vor. $I$. 
spine beneath each eye; mouth with six short cirri. 3 inches long. Rivers of Europe, under stones. B.-Shaw, v. pl. 93.

\section{Gen. 53. Anableps, Bloch.-Cobitis, Lin.}

Body cylindrical ; covered with strong scales; snout truncated; mouth with small teeth in both jaws; eyes projecting and iris divided into two portions by transverse bands; ovoviviparous. A. tetrophthalmus, Bloch. Body yellowish gray, with longitudinal black lines on each side; pectoral fins rounded, scaly; dorsal fin small, near the tail. 8 to 10 inches long. Inhabits rivers in Guiana. -Shaw, v. pl. 94.

\section{Gen. 54. Pecilia, Schn.}

Jaws flattened horizontally, not much cleft, and furnished with a row of very small teeth; head flat; operculi large; three rays in the branchial membrane.

P. heteroclita, (Cobitis heteroclita, Lin.) Body brown, yellowish beneath, with large scales; dorsal and anal fins opposite ; tail rounded, spotted with white and banded with black. 4 inches long. Inhabits Carolina._Shaw, v. 5.

\section{Gen. 55. Lebras, Cuv.}

Jaws flattened horizontally, with a row of dentated teeth ; branchial membrane with five rays.

This genus is formed by Cuvier for the reception of two species, of which the country is unknown.-Reg. $A n$. ii. 199.

\section{Gen. 56. Cyprinodon, Lacep.}

Teeth crowded, and in both jaws, the anterior row hooked; four rays in the branchial membrane.

This genus was instituted for the reception of a new species from the Bay of Charleston, described and figured by M. Bose, the C. variegatus, Lacep. v. pl. 15, fig. 1 .

\section{Family. V.-Siluride.}

This family is distinguished from all the preceding by the want of scales, the body being covered with a naked slimy skin or large osseous plates. The intermaxillary bones suspended under the ethmoid form the margin of the upper jaw, and the maxillaries are rudimentary, cr elongated into cirri. The intestinal canal is ample, but without coecums; the swimming-bladder large, and attached to a particular bony ap. paratus; the dorsal and pectoral fins have almost always a strong spine for the first ray; and in some species they have an adipose dorsal fin like the salmon. These fishes abound in the rivers of warm countries.

\section{Gen. 57. Silurus, Artedi, Gronov.}

Head depressed; mouth terminal ; teeth crowded, in both jaws; fleshy cirri at the jaws; skin covered with a mucous secretion ; one very short dorsal fin without perceptible spine; anal fin long.

S. glanis, Lin. Back round, greenish black; belly whitish yellow ; the body covered with blackish spots, and slimy; fins margined with violet ; six cirri at the mouth; of which the two on the upper 
lip are very long and filamentous. 3 to 4 feet long, but sometimes reaching to the length of $\mathbf{1 5}$ feet. Inhabits large rivers in Europe, \&c.-Shaw, v. pl. 95 .

This is the largest fresh water fish of Europe. It is a sluggish animal, being rarely observed in motion, and often found watching its prey beneath hollow banks, or half imbedded in the soft mud under the projecting roots of trees. Its long tentacula moving about gently in the mud, are conceived to be an attraction to the smaller fishes. S. fossilis, Bloch. Body blackish brown above, gray beneath; head covered with bony plates ; cirri eight, in four pairs ; anal fin very long; tail small, rounded. 8 inches long. Inhabits lakes in India. -Bloch, pl. 370, fig. 2.

S. bimaculatus, Bloch. Body compressed; olivaceous above, silvery beneath; head small ; upper lip with a long cirrus on each side ; lower jaw projecting; dorsal fin very small; anal long; tail deeply lunated, with black tips. 12 inches long. Inhabits Indian rivers.-Bloch, pl. 364.

\section{Gen. 58. Schilbe, Cuv.}

Body compressed vertically ; head small, depressed ; eyes placed very low; a strong and dentated spine on the dorsal fin; cirri eight.

S. Niloticus, (Silurus mystus, Lin.) Dorsal fin with eight rays ; tail forked. Inhabits the Nile._Geoff. Poiss. d'Egyp. pl.2, fig.3 and 4.

The only other species of this genus is the $S$. auritus, also from the Nile.

\section{Gen. 59. Synodontrs, Cuv.}

Snout narrow ; lower jaw with flattened teeth, laterally hooked and on a flexible pedicle; bone of the head forming a rough helmet prolonged to the first dorsal fin ; spines of the dorsal and pectoral fins very strong; cirri pinnated.

S. scheilan, Cuv. (Sil.clarias, Hasselquist.) According to Hasselquist, the wounds made by the spines of the pectoral tins are dangerous.-Hasselq. Voyages, 225.

Gen. 60. Prmelodus, Cuv.-Silurus, Bloch.

Head depressed; crowded teeth in both jaws; upper jaw with one intermaxillary band; two dorsal fins, the second adipose.

P. clarias, Cuv. With six cirri, of which two are on the upper lip and four on the chin, those above longer than the body; first ray of the pectoral fins strong and serrated. 12 to 15 inches long. Inhabits rivers of S. America.-Bloch, pl. 35, fig. 1 and 2.

P. nodosus, Cuv. Head flat, rounded; six cirri, the two upper ones longest ; first ray of the dorsal fin longer than the others, serrated on its inner margin, with the base knotty. 1 foot long. Inhabits rivers of India.-Bloch, pl. 368, fig. 1.

P. Herzbergii, Cuv. Body rounded; back brownish; fins yellow; sides and belly silvery ; first ray of the dorsal fin longest, serrated on its exterior margin; thirteen rays in the anal fin. 12 to 18 inches long. Inhabits rivers of S. America.-Bloch, pl. 367. 
P. quadrimaculatus, Cuv. Body brown, shading to violet; thorax with four black spots on each side; belly silvery; fins yellow ; cirri six, the two upper very long; nine rays in the anal fin. 6 inches long. Inhabits rivers of S. America._Bloch, pl. 368.

P. galeatus, Cuv. Head short, broad, enveloped in a plate with angular figures; back bluish; sides and belly gray; fins brownish ; twenty-four rays in the anal fin. 8 or 10 inches long. Inhabits S. American rivers.-Bloch, pl. 369.

\section{Gen. 61. Bagrus, Cuv.}

Teeth of the upper jaw disposed in two transverse and parallel bands, one intermaxillary, the other on the vomer; cranium smooth; nuchal plate small; two dorsal fins, the second adipose.

B. Docmac, Cuv. (Silurus, Lin.) Body gray above, whitish beneath ; mouth with eight cirri, the exterior ones of the upper lip half the length of the body ; first ray of dorsal and anal fins long and serrated; ten rays in the anal fin. 3 feet long. Inhabits the Nile.-Shaw, v. 26.

B. Bajad, Cuv. (Silurus, Lin.) Head obtuse, depressed, with a depression on each side before the eyes ; cirri eight, the exterior ones on the upper lip very long; twelve rays in the anal fin. I foot long. Inhabits the Nile.-Shaw, v. 27.

B. vulgaris, (Silurus Bagre, Lin.) Head flat, rounded before, with an oblong hollow above ; body compressed, greenish, with silvery abdomen; four cirri, those of the upper lip flat and long, the lower short and white; first ray of the dorsal and pectoral fins long and filamentous. 12 to 18 inches long. Inhabits Indian rivers.Bloch, pl. 365.

\section{* Snout long and flattened.}

B. fasciatus, Cuv. (Silurus, Bloch.) Head very long, broad, and rounded at the extremity; body banded with numerous transverse dusky stripes; cirri six, two on the upper lip, four below, all longer than the head. 12 to 15 inches long. Inhabits S. American rivers.-Bloch, pl. 366.

Gen. 62. Ageneionus, Lacepede.-Silurus, Bloch.

Head depressed, covered with large hard plates or a viscid skin; mouth terminal and without cirri; two dorsal fins, the second adipose.

A. militaris, Cuv. Body olive-coloured; head large, flat, with two serrated bony spines near the nostrils; eyes large, the iris red; first ray of the dorsal fin very large, strong, and sharply serrated; lateral line flexuous; tail slightly bilobate. 12 to 18 inches long. Inhabits Indian rivers. - Bloch, pl. 362.

A. inermis, Cuv. Head smooth and without horns; body greenish, with brownish spots; dorsal, pectoral, and ventral fins brown, the 
others grayish. 1 foot long. Inhabits rivers of S. America.Bloch, pl. 363.

\section{Gen. 63. Doras, Lacepede.-Silurus, Lin.}

Head depressed, and covered with large and hard plates, or a viscid skin; cirri at the jaws; two dorsal fins, the second adipose; dorsal and pectoral spines strongly dentated; sides covered with carinated or spinous plates.

D. costatus, Cuv. (Cataphractus, Bloch.) Body yellowish brown, deeper on the head and back; mailed on the sides with broad bony plates with a curved spine in the centre; plate of the head extending to half the dorsal fin ; cirri six, the two above longest ; first ray of the dorsal and pectoral fins serrated; tail sharply forked. Inhabits S. American seas.-Shan, v. pl. 100.

D. carinatus, Cuv. Body compressed : cirri six, slightly pinnated below ; lateral plates carinated and spinous ; first ray of the dorsal and pectoral fins strong and serrated. Inhabits S. America. -Shan, v. 26.

Gen. 64. Macropteronotus, Lacep.-Heterobranchus, Geoff. Head broad, depressed, and covered with large and hard plates; mouth terminal; jaws with eight cirri ; skin slimy; only one extended dorsal fin.

M. anguillaris, Lacep. (Silurus, Lin.) The Sharmuth or Black Fish. With ten rays in the branchial membrane, and seventy rays in the dorsal fin. Inhabits the Nile.-Shaw, v. 23.

M. batrachus, Cuv. (Silurus, Lin.) Head mailed by bony pieces, ending in a point behind; dorsal fin extending from the neck to near the tail ; anal fin very long; cirri eight; branchial membrane with seven rays. 8 to 10 inches long. Inhabits rivers of Asia and Africa.-Bloch, pl. 370, fig. 1.

\section{Gen. 65. Plotosus, Lacepede.}

Head depressed, and covered with large hard plates; lips fleshy and pendant; cirri on the jaws; two dorsal fins, of which the second or adipose one, and the anal, are united to the caudal fin; tail pointed; branchial membrane with nine or ten rays.

P. anguillaris, Cuv. (Platystacus, Bloch.) Body eel-shaped, brown, with longitudinal white stripes ; cirri eight ; teeth conical, those on the palate globular; spines of the dorsal and pectoral fins dentated. 12 to 15 inches long. Indian seas.-Shan, v. pl.99.

Gen. 66. Callichtys, Lin.-Cataphractus, Lacep.

Body mailed on the sides by four rows of scaly plates; head covered with plates; snout and under part of the body naked; two dorsal fins, the second with one ray; cirri four; teeth almost imperceptible.

C. vulgaris, (Loricaria Callichthys, Shaw.) Body dusky brown, 
with a tinge of reddish on the fins; head short, flat, rounded, with a blunt spine on each side; tail small, rounded, with several black spots. 10 to 12 inches long. Inhabits S. A merican rivers. -Bloch, pl. 377, fig. 1 .

This fish, it is said, is capable of crawling like an eel upon land.

Gen. 67. Malapteruius, Lacep.-Silurus, Lin.

Head depressed and covered with smooth skin; mouth terminal; six cirri at the jaws; skin slimy; one adipose dorsal fin, near the tail.

M. electricus, Cuv. Body cinereous, spotted with black; two cirri on the upper jaw, four below; teeth small and arranged in a crescent form. 20 inches long. Inhabits African rivers.-Geoff. Poiss. d'Egyp. pl. 12, fig. 1.

This animal possesses the faculty of giving electrical shocks like the Torpedo and Gymnotus. The seat of this faculty is in a particular tissue between the skin and muscles, which presents the appearance of fat cellular tissue abundantly provided with nerves.

Gen. 68. Platystacus, Bloch.-Aspredo, Lin.

Head flattened ; cirri six or eight; bones of the operculum immoveable, and fixed to the chest; first ray of the pectoral fins large and strongly serrated; one dorsal fin, with the first ray weak; anal fin very long, running under the whole tail; tail long and compressed.

P. cotylephorus, Bloch. With six cirri, and numerous small acetabular processes or suckers on the under surface of the body; anal fin very long, with fifty-six rays; dorsal fin with the first ray simple, the four others dichotomous. 1 foot long. Inhabits Indian seas and rivers.-Shaw, v. pl. 98.

P. lavis, Bloch. With eight cirri, the four of the lower jaw in pairs, the one behind the other; under surface of the body smooth. Inhabits Indian seas.-Shaw, v. 29.

P. verrucosus, Bloch. Body brown, marked above by longitudinal warted lines; anal fin short; tail short and rounded. Inhabits South American seas.-Bloch, pl. 373, fig. 3.

Gen. 69. Hypostomus, Lacepede-Loricaria, Lin.

Body and tail covered with bony plates; mouth below; lips extensible, with a small cirrus on each side; two dorsal fins, the second small, with a single ray; no plates under the belly; branchial membrane with four rays.

H. flavus. (L. flava, Shaw.) Body orange-yellow, spotted with brown; tail much forked, barred with several stripes of the same colour; head large, rough, with minute points; first dorsal fin large, with eight rays, the second with one. 10 inches long. Inhabits Indian seas.-Shaw, v. pl. 101.

Gen. 70. Loricaria, Lacepede.

Body and tail covered entirely with hard angular plates; mouth 
below, with many small cirri, and sometimes rough with villosities; lips extensible ; one dorsal fin ; first ray of the dorsal and pectoral fins with spines; branchial membrane with four rays.

L. cataphracta, Lin. Body yellowish-brown; snout pointed, with numerous small filaments, and mouth furnished with teeth. Inhabits Indian seas.-Bloch, pl. 375, fig. 3, 4 .

L. maculata, Bloch. Body yellowish-brown, with a few distinct bands of deeper brown spots; surface roughened with small points; head large, rounded before ; mouth without teeth. 12 to 15 inches long. Indian seas.-Bloch, pl. 375, fig. 1, 2.

\section{ORDER VII. MALACOPTERYGII SUBRACHIATI.}

Jaws complete ; branchiæ pectinated; ventral fins placed either before the pectorals, between them, or a little behind.

Family I.-Gadites.-Gadus, Lin.

The ventral fins in this family are attached under the throat and pointed; the body is elongated and covered with soft scales; the head without scales; and all the fins are soft. The jaws and the fore part of the vomer are armed with pointed unequal teeth, in many rows, similar to those of a card or rasp ; the branchial openings large, with seven rays. Almost all have two or three dorsal fins, one or two behind the anus, and a distinct caudal fin. The stomach in this family is large, their coecums numerous, and their air-vessel large and often dentated on the sides. The greater part of the group form important objects in the national fisheries.

\section{Gen. 1. Morrhua, Cuv.-Gadus, Lin.}

Head compressed; eyes distant, on the sides of the head; body elongated, slightly compressed; three dorsal fins; two anal; ventral fins pointed; and a cirrus at the point of the lower jaw.

M. vulgaris. (G. morrhua, Lin.) The Cod. Head, back, and sides grayish, with yellowish spots ; belly whitish ; scales somewhat larger than the other species of the genus. 2 to 3 feet long, but sometimes upwards of five feet. Inhabits Northern ocean. B.-Shaw, iv. pl. 22.

The cod-fishery has for ages formed an important object of national industry. Before the great cod-fisheries of Newfoundland attracted mercantile enterprize, the chief fisheries of this valuable animal were on the coasts of Iceland and the northern coasts of Great Britain.

M. Aglefinus, Lin. The Haddock. Body above dusky or brown, beneath silvery; lateral line black; head cuneiform, the upper jaw longest; a large black spot on each side near the pectoral fins; tail forked. 18 to 24 inches long. Irhabits Northern seas. B. -Bloch, pl. 62.

M. callarias, Lin. 'The Dorse. Body gray, with brown spots in summer, and black in winter; lateral line broad and spotted; upper jaw much longer than the under. Inhabits Northern seas. -Bloch, pl. 63. 
M. barbatus, Bloch. Whiting-pout. Body very deep, whitish, darker on the back, which is arched and carinated; six or seven small openings on each side of the lower jaw. 12 inches long. Inhabits Northern seas. B.-Bloch, pl. 166.

M. minutus, Bloch. Body brownish above, silvery below, with dusky spots on the sides ; lateral line straight; upper jaw longest ; vent in the middle of the body. 6 or 7 inches long. Inhabits Northern seas. B. - Bloch, pl. 67, fig. 1.

\section{Gen. 2. Merlangus, Cuv.-Gadus, Lin.}

With three dorsal and two anal fins; no cirrus at the lower jaw.

M. vulgaris, Cuv. The Whiting. Head and back pale brown, silvery beneath, upper jaw longest; lateral line white, slightly bent; a black spot at the base of the pectoral fins. 10 to 12 inches long. Inhabits Northern seas. B.-Bloch, pl. 65.

The Whiting is esteemed one of the most delicate fishes of this family, and great quantities are caught in the spring and summer months.

M. carbonarius, Cuv. The Coal-fish. Head, dorsal fins, tail, and upper part of the body black, shading into silvery below; under jaw longest; lateral line straight and white. 6 to 30 inches long. Inhabits Northern seas. B.-Shav, iv. pl. 22.

The Coal-fish is known under various names on different parts of the coast, according to its age. In Scotland it is named Podley, Sillock, Cuddy, Cooth, Pitlock, Sethe, Sey, and Gray lord. It varies also much in colour; but the lateral line is always white.

M. pollachius, Cuv. The Pollack. Body dusky above; sides with yellowish streaks; belly white; under jaw longest; lateral line curved upwards towards the middle. 18 inches long. Inhabits Northern seas. B.-Bloch, pl. 68.

M. virens, Cuv. Body greenish or olive above, shading to silvery below; jaws of equal length; lateral line straight ; tail forked. Inhabits Northern seas. B.-Shaw, iv. 149.

\section{Gen. 3. Merluccius, Cuv.}

Two dorsal fins and one anal fin; no cirri.

M. vulgaris, Cuv. The Common Hake. Head long, broad above, and compressed on the sides; mouth wide; body pale ash-coloured above, whitish below ; first dorsal fin small, pointed; tail nearly even. 1 to 2 feet long. Inhabits Northern seas. B.Bloch, pl. 164.

Great quantities of this species are annually taken and cured in the Mediterranean and northern seas. When salted and dried, it is named Stock-fish; but this name is employed indifferently for others of the family cured in the same manner.

\section{Gen. 4. Lот A, Cuv.-Gadus, Lin}

Two dorsal fins, one anal fin, and cirri more or less numerous; second dorsal and anal fins long.

L. Molva, Cuv. The Ling. Body elongated, olive-coloured above, silvery below; the two dorsal fins of equal height; under jaw a 
little shorter than the upper, with a single cirrus; tail rounded, with a black band. 3 to 4 feet long. Inhabits Northern seas. B.-Shan, iv. pl. 23.

This fish, as abundant as the cod, is fished extensively on many coasts, and cured in great quantities for exportation.

L. fluviatilis. (G. Lota, Lin.) The Burbot. Body almost cylindrical, yellowish, marbled with brown; head depressed; a single cirrus on the chin; jaws equal ; tail ovate. 1 to 3 feet long. Inhabits rivers in Europe. B. -Shan, iv. pl. 23.

\section{Gen. 5. Mustela, Cuv.-Gadus, Lin.}

With the first dorsal fin little elevated, and scarcely perceptible.

M. tricirratus. (G. mustela, Lin.) Body and head reddish-yellow, marked above the lateral line with black spots; two cirri on the upper jaw, one on the under. 19 inches long. Inhabits Northern seas. B.-Bloch, pl. 165.

The M. argenteolus, Mont. (Wern. Mem. ii. 449.) with body bluish-green above; sides and belly silvery; two cirri on the apper jaw, and one on the lower, and two inches long, is probably the young of this species.

M. quinquecirratus, Penn. Body deep olive-brown above, whitish below ; cirri on the upper jaw four, two at the end of the nose, two a little above them, and a single one at the point of the lower jaw. 19 inches long. British seas.-Penn. Brit. Zool. iii. 268.

\section{Gen. 6. Brosmus, Cuv.}

With one long dorsal fin extending nearly to the tail; a furrow on the nape, extending to the fin; ventral fins thick, fleshy, terminating in four soft rays or cirri.

B. vulgaris. (Gadus Brosme, Gmel.) The Torsk. Head small, dusky, with a cirrus on the chin ; back and sides yellowish, shading to white below; dorsal and anal fins extending almost to the tail ; tail rounded; edges of dorsal, anal, and caudal fins white. 2 to 3 feet long. Inhabits Northern seas. B.-Pern. Brit. Zool. iii. pl. 37.

\section{Gen. 7. Phycis, Artedi, Cuv.-Blennius, Lin.}

Ventral fins of one ray, often forked; two dorsal fins, of which the second is longest; head thick, and a cirrus on the chin.

P. Mediterraneus, Laroche. (B. phycis, Lin.) First dorsal fin round and more elevated than the second; ventral fins nearly the length of the head, with one setaceous ray. 18 to 20 inches long. Inhabits Mediterranean sea.-Ann. Mus. xiii. 333.

P. furcatus. (B. gadoides, Risso.) The Forked Hake, Penn. Body cinereous brown; first dorsal fin elevated; the first ray long and slender; ventral fins twice as long as the head. 11 to 18 inches long.-Shaw, iv. 172.

\section{Gen. 8. Raniceps, Cuv.}

Head depressed and very broad; first dorsal fin very small, 
and almost lost in the thickness of the skin; two first rays of the ventral fins elongated.

R. trifurcatus, Cuv. (Blennius trifurcatus, Shaw.) Body brown, compressed; lips white; second dorsal fin reaching almost to the tail ; ventral fins slender and trifurcate ; lateral line tuberculated above the pectoral fins. 8 to 12 inches long. Inhabits British seas.-Penn. Brit. Zool. iii. pl. 38.

R. blennioides. (Batrachoides blennioides, Lacep.) Head depressed and broader than the body; mouth turned up, and white within; second dorsal and anal fins equal; two first rays of the ventral fins long and filiform.-Shaw, iv. 183.

\section{Gen. 9. Lepidoleprus, Risso.}

Body and head covered with rough carinated scales; two dorsal fins, the first short and elevated, the second very long, and uniting, as well as the anal fin, into a point at the tail ; teeth short, very small.

L. trachyrhynchus, Risso. Body elongated and compressed behind like the blade of a sword, and covered with rough osseous scales, forming crests at many points; snout prolonged and triangular at the point; first dorsal fin blackish, with eleven rays; the second gray, and not far from the first; dorsal and anal fins arising from a furrow, with a row of spines on each side. Inhabits Mediterranean sea.-Risso, pl. 7, fig. 21.

L. calorhynchus, Risso. Snout depressed, advancing above the mouth. Body grayish, shaded with violet red. 5 inches long. Inhabits Mediterranean sea._Risso, pl. 7. fig. 22.

\section{Gen. 10 Macrourus, Bloch.}

Scales carinated and rough; teeth small and in many rows; two dorsal fins, the first strong and elevated, the second long, and forming a point with the anal fin at the tail; a cirrus on the lower jaw.

M. rupestris, Bloch. Head large and thick, the upper jaw projecting above and obtuse; body silvery gray, deepest on the upper parts, and gradually tapering into a long, slender, and pointed tail. 3 feet long. Inhabits Northern seas,-Shaw, iv. pl. 33.

\section{Family II.-Pleuronectes.}

This family is characterized by the singular circumstance of the eyes being both on the same side, which also remains uppermost when the animal swims. The side on which the eyes are placed is also always coloured, while the opposite side is whitish. The other parts of their body partake somewhat of this want of symmetry. The two sides of the mouth are not equal, and it is rare that the pectoral fins are so. The body is compressed vertically; the dorsal fin runs along the whole back; the anal fin occupies the under part, and the ventrals have almost the appearance of continuity before, from their being often united together. There are five rays in the branchial membrane. The abdominal cavity is small, but is prolonged in a sinus in the thickness of the sides of the tail. They have no swimming vessel, as they rarely quit the bottom. The cranium has a particular arrangement from the two orbits being placed on the same side. The bones, however, are 
nearly the same as in other fishes, but of unequal proportions. Sometimes irdividuals are found which have the eyes reversed or on the opposite side, and others are met with which have both sides of the body equally coloured. The Pleuronectes are found on almost every coast, and furnish an agreeable and wholesome food. This large family was included by Linnæus in one genus, which Cuvier has subdivided into many sub-genera.

Gen. 11. Platessa, Cuv.-Pleuronectes, Lin.

Body rhomboidal ; a row of obtuse cutting teeth in each jaw, and crowded teeth on the pharyngeal bones; dorsal fin advanced to above the upper eye ; an interval between the anal fin and the tail; eyes on the right side.

P. vulgaris, Cuv. The Plaise. Body smooth, palish brown above, marked, as well as the fins, with numerous rather distant orangecoloured spots; white below; six or seven tubercles forming a line on the right side of the head, between the eyes; a spine at the commencement of the anal fin; tail rounded. About a foot long. Inhabits Northern seas. B.-Shan, iv. pl. 43.

P. Flesus, Cuv. The Flounder. Body smooth, brown above, with paler spots, with rough lateral line, and a series of spines at the base of the fins; white below; tail slightly rounded; a spine at the commencement of the anal fin. About 10 inches long. Inhabits Northern seas. B.-Bloch, pl. 44. This species is sometimes found with the eyes on the left side.

P. Limanda, Cuv. The Dab. Body yellowish brown above, with obscure spots, white beneath; eyes large; scales rough, with ciliated margins ; lateral line curved over the pectoral fins. 6 to 8 inches long. Inhabits Northern seas. B.-Bloch, pl. 46.

\section{Gen. 12. Hippoglossus, Cuv.-Pleuronectes, Lin.}

Body oblong, compressed; the jaws and pharynx armed with slender pointed teeth, an interval between the dorsal and anal fins and tail.

H. vulgaris. Common Holibut. Body elongated, smooth, deep brown above, white beneath; eyes on the right side ; lateral line forming an arch at the breast; a spine at the commencement of the anal fin; tail cuneated. 3 to 6 feet long. Inhabits Northern seas. B.-Bloch, $\mathrm{pl} .47$.

This is the largest species of the family, being sometimes taken of the weight of from two to three hundred pounds.

H. macrolepidotus, Cuv. Body elongated, brownish yellow above, white beneath; scales large, each marked at the base by a dusky spot; eyes on the left side; tail rounded. 2 feet long. Inhabits South American seas.-Bloch, pl. 190.

H. Boscii, Cuv. Body grayish; eyes large ; under jaw longest; dorsal and anal fins with large black spots. 10 inches long. Inhabits Mediterranean sea.-Risso, pl. 7, fig. 33.

H. limanoides, Cuv. Body elongated, rough; brownish yellow above, white beneath; lateral line broad, straight; tail rounded. Inhabits Northern seas.-Bloch, pl. 186. 
Gen. 13. Ruом вus, Cuv.-Pleuroncetes, Lin.

Jaws and pharynx with numerous slender pointed teeth; dorsal fin rising from the margin of the upper jaw, and running, as well as the anal, almost to the tail; eyes in the greater number sinistral.

R. maximus, Cuv. The Turbot. Body rhomboidal, almost as broad as long, dark brown above, marbled with blackish spots, white beneath; skin wrinkled, with numerous pointed tubercles or abrupt spines; lateral line arched over the pectoral fins; eyes approaching. 2 feet and upwards long. Inhabits Northern and Mediterranean seas. B.-Shaw, iv. pl. 45.

R. lavis, Rond. (P. nudus, Risso.) The Brill; in Scotland the Bonnet Fluke. Body broad, glabrous, without tubercles; pale brown, spotted with rufous and yellow, white beneath ; under jaw longest; eyes approaching ; lateral line arched over the pectoral fins. Smaller than the turbot. Inhabits Northern and Mediterranean seas. B.-Penn. Brit. Zool. iii. 321.

R. megastoma, (P. megastoma, Donov.) Body oblong, brown above, clouded with dusky shades, below reddish white; mouth large ; the under jaw longest; lateral line tuberculated, arched near its origin; dorsal and anal fins broadest in the middle. 18 inches long. Inhabits British seas.-Donov. Brit. Fishes, pl. 51.

R. punctatus, Cuv. Body broad, black above, with black spots and smaller interspersed red ones; scales small, rough, denticulated; dorsal and anal fins broadest posteriorly; jaws nearly equal. 5 inches long. British seas._Fleming, Phil. Zool. pl. 3, fig. 2.

R. podas, Cuv. ( $\boldsymbol{P}$. podas, Laroche.) Body oval, brown above, white below, without spines, marked by whitish ocellated spots; pectoral fins short, equal. 8 inches long, Inhabits Mediterranean sea.-An. Mus. xiii. pl. 24, fig. 14.

R. Argus, Cuv. Body yellowish white above, with numerous ocellated spots, yellow in the centre, and margined with blue; eyes distant; tail rounded. S. American seas.-Catesby, Car. pl.27.

Gen. 14. Solea, Cuv.-Pleuronectes, Lin.

Mouth twisted to the side opposite to the eyes; jaws destitute of teeth on the eye side; body oblong; dorsal fin commencing at the mouth and running, as well as the anal fin, to the tail; lateral line straight.

S. vulgaris, Cuv. The Sole. Body brown above, white beneath with rough scales, and upper jaw longest; pectoral fins tipped with black. 1 to 2 feet long. European seas. B.-Bloch, pl. 45 .

S. lingula, Hanmer. Body oblong, light brown, tinged with red above; scales ciliated, rough ; dorsal, anal, and caudal fins marked with brown or blackish spots; lateral fine straight. $6 \frac{1}{2}$ inches long. Common near Plymouth.-Pen. Brit. Zool. iii. pl. 48.

S. ocellata, (P. Rondeletii, Shaw.) Body brownish above, with large 
distant blackish spots, pale in the centre. Size of the common Sole. Inhabits Mediterranean sea.-Shaw, iv. 307.

S. zebra, Cuv. Zebra Sole. Body elongated, pale brownish above, and marked from head to tail by numerous double deep brown transverse bands passing across the fins; scales rough and dentated. Inhabits Indian seas.-Shaw, iv. pl. 44.

S. plagiusa, Cuv. Body grayish brown, with the dorsal, caudal, and anal fins united; scales rough. American seas._Shaw, iv. 306.

Gen. 15. Monochinus, Cuv.-Pleuronectes, Lin.

One very small pectoral fin on the eye side, that on the opposite side imperceptible.

M. microchirus, Cuv. (P. microchirus, Laroche.) Pody oblong, pale brown; mouth wide; tongue round and long. Inhabits Mediterranean sea.-An. Mus. xiii. 356.

Gen. 16. Achinus, Lacepede--Pleuronectes, Lin.

Head, body, and tail much compressed; eyes on the same side of the head; no pectoral fins.

A. marmoratus, Cuv. Body brown, variegated or marbled with milk white spots and marks; fins marbled with gray and blue, with black points; a row of pores along the base of the dorsal and anal fins. Inhabits Indian seas.-Shaw, iv. 310.

A. bilineatus, Cuv. Body thin and elongated, pale brown above, rufous white beneath ; scales small, round, and denticulated ; dorsal and anal fins united to the caudal; two lateral lines on each side, one along the middle, the other near the back. Inhabits Chinese seas.-Bloch, pl, 188.

\section{Family. III.-Discoboli, Cuv.}

This family are so named on account of their ventral fins being united at the base by a membrane into a disk-like form.

Gen. 17. Lepadogaster, Gouan.-Cyclopterus, Shaw, Pectoral fins double, and the under united in the form of a disc urider the throat by a transverse membrane; head broad and depressed; snout projecting and extensible; body smooth and without scales; one soft dorsal fin.

The species of this and the following genus are generally small. Their pectoral fins are large and united under the throat by a transverse membrane directed forwards; another transverse membrane directed backwards, fixed to the pelvis, and prolonged on the sides, supplies the place of ventral fins. Their body is smooth and without scales; their head broad and depressed; they have but one soft dorsal fin opposite the anal; and they are destitute of a swimming-bladder.

L. Cornubiensis, The Cornish Sucker. Body taper, reddish, with dusky spots ; snout depressed, elongated, and rounded ; two ocellated purple marks behind the eyes, with a blue point in the centre ; dorsal fin with eleven rays. 4 inches long. Inhabits British seas.-Shaw, v. 397.

L. bimaculatus. Head flat and tumid ; snout conical ; body slender, 
pink-coloured, with white spots, and a purple spot on each side behind the pectoral fin, surrounded with a white ring. $1 \frac{1}{2}$ inch long. Inhabits British seas._Shaw, v. 398.

\section{Gen. 18. Goblesox, Lacep.}

Two pectoral fins not united; one very short dorsal fin placed above the extremity of the tail ; anal fins short; head thick, broader than the body.

G. dentex, (Lepadogaster, Schn.) Body rounded, red; head large, broader than the body; mouth as wide as the head; tail rounded. Inhabits American seas.-Shaw, v. 392.

G. bimaculatus, Cuv. (Cyclopterus, Penn.) Head flat and tumid, body taper, pink-coloured, with minute white spots, a black spot on each side of the abdomen. 2 inches long. Inhabits European seas. B.-Pen. Brit. Zool, iii. pl. 25.

\section{Gen. 19. Cyclopterus, Lin.}

Mouth large, with very small pointed teeth in both jaws; pectoral fins large; ventral fins united in the form of an oval and concave disc; branchial membrane with six rays; skin viscid and without scales.

The most marked character in this genus is the structure of the ventral fins, the rays of which surrounding the pelvis, and connected by a membrane, form an oval and concave sucker, by which the fishes are enabled to adhere to rocks. Their skin is viscid and without scales.

C. lumpus, Lin. Lump-sucker. Skin rough, with small tubercles ; back elevated, ridged, dusky ; belly flat, red; three rows of large conical tubercles on each side. 19 inches long. Inhabits Northern seas. B.-Shaw, v. pl. 166.

This fish by means of its sucker is able to adhere with great force to objects. Pennant says, that, on throwing an individual of this species into a pail of water, it adhered so firmly to the bottom, that on taking the fish by the tail the whole pail was lifted, though it held some gallons.

C. minutus, Pall. Small Sucker. Body compressed, whitish, with two white unequal bony tubercles on each side; snout marked above the mouth by three tubercles. Inhabits Atlantic Ocean. -Shaw, v. 396.

C. ventricosus, Pall. Head thick, blunt, flattish on the top; dorsal fin whitish yellow, with black rays ; tail suddenly attenuated beyond the vent; sucker oval, yellow. 1 foot long. Inhabits American seas.-Shaw, v. 394.

Gen. 20. Liparis, Artedi.

Body elongated, compressed, smooth; dorsal and anal fins long.

L. barbatus. Unctuous sucker. Body pale brown with darker stripes, semitransparent; pectoral fins extending to the throat and resembling a beard; sucker circular. 5 inches long. Inhabits Northern seas.-Penn. Brit. Zool. iii. pl. 24.

L. Montagui, Cuv. Body rounded to the rent, purplish brown; 
under parts paler; sucker ovate; dorsal, anal, and caudal fins separate. 2 inches long. Inhabits British coasts.-Wern. Trans.i. pl. 5. fig. 1.

L. gelatinosus, Cuv. Body slender, oblong, compressed, with a rosy tinge; skin smooth, flesh very smooth, trembling like jelly when touched; dorsal and anal fins dark violet. 18 inches long. Inhabits coasts of Kamtschatka._Shaw, v. 393.

\section{Gen. 21. Echeneis, Lin.}

Head flattened or truncated before, the flattened disc on the top composed of transverse plates obliquely directed backwards, and dentated or spinous on their posterior border ; body elongated, covered with small scales; one soft dorsal fin.

E. Remora, Lin. The Remora. Body brown; head flat above, with eighteen plates on the disc; under jaw rather longer than the upper ; tail crescent-shaped. 18 inches long. Inhabits Mediterranean sea._Shaw, iv. pl. 31 .

This fish was believed among the ancients to possess the power of stopping a ship in the middle of its course, by attaching itself to the rudder; and the fate of the battle of Actium is said to have been decided in favour of Augustus, from the circumstance of a Remora having stopped Anthony's ship. The Remora is of an elongated form, and its body is covered with a viscid fluid.- The flattened disc on the top of the head is composed of a number of transverse plates obliquely directed backwards, dentated or spinous at their posterior extremity, and moveable in such a manner that the fish is able, by producing a vacuum, to adhere by this process to rocks, fishes, or other bodies. The smallness of the fins of the Remora prevents it from swimming rapidly ; but this is compensated by the faculty which it possesses of adhering to other fishes, such as the shark; and instances are related of sharks being taken with the Remora attached, which it required considerable force to remove.

E. naucrates, Lin. Indian Remora. Body olive green, elongated, whitish beneath ; fins deep yellow, with a violet border ; twentytwo to twenty-four plates on the disc; tail ovate. 2 to 3 feet long. Inhabits Indian and American seas.-Shaw, iv. pl. 31.

E. lineala, Schn. Body long; subulate, smooth, dark brown, dotted all over with minute darker spots, and two longitudinal white lines on each side ; ten plates on the disc ; tail cuneated. 5 inches long. Inhabits Pacific Ocean.-Shaw, iv. 211.

\section{Gen. 22. Ophice phalus, Bloch.}

Body and head covered with large scales, those of the vertex irregular; some larger hooked ones on the sides; head depressed, obtuse, and short before; one dorsal fin; teeth in a rasp-like form, with five rays in the branchial membrane.

O. punctatus, Bloch. Body dusky, paler beneath, with numerous black points; dorsal fin long. 10 inches long. Inhabits rivers and lakes in India._-Shaw, iv. pl. 75.

O. striatus, Bloch. Body elongated, dusky ; abdomen whitish ; part of the body obliquely striped with yellow and brown bands. 12 inches long. Inhabits lakes of India.-Bloch, pl. 359. 


\section{ORDER VIII.-MALACOPTERYGII APODES.}

Body elongated, with thick skin, and destitute of ventral fins.

This order may be considered as forming a natural family, distinguished at once by their anguilliform body, their thick skin, and almost imperceptible scales. They are destitute of cœcums, but almost all have swimming-bladders, and often of singular forms.

Gen. 1. Anguilla, Cuv.-Murcera, Lin.

Body rounded, elongated, smooth; branchial openings lateral, placed under the pectoral fins; pectoral fins large; dorsal and anal fins united, and forming a pointed caudal fin.

A. vulgaris, Cuv. (M. anguilla, Lin.) The Common Eel. Body olive-brown, silvery beneath; the under jaw longer than the upper. 2 to 3 feet long. Waters of Europe. B.-Shaw, iv. pl. 1.

This species varies frequently in its colours, according, it is believed, to the nature of the water it inhabits. The vertebræ, to the amount of about 116, are compressed and small; the ribs very short and but slightly attached; and this structure gives the body a wonderful flexibility. The eel, from being enabled to close the branchial apcrtures, often leaves the watex during the night to search for worms and insects in the neighbouring meadows; and it has been ascertained that it can live for six or eight days in a humid and not too warm a situation. During the day it generally lies hid in the mud; and is able in summer droughts to support existence in places where the water is almost completely evaporated. The eel is viviparous.

Gen. 2. Conger, Cuv.-Murcena, Lin.

Dorsal fin commencing near the pectoral fins or over them ; upper jaw longer than the under.

C. vulgaris, Cuv. (M. conger, Lin.) The Conger Eel. Body dusky above, silvery below ; dorsal and anal fins edged with black ; lateral line dotted with white. 5 or 6 feet long. Inhabits Northern Seas. B.-Shaw, iv. pl. 1.

The Conger grows to a large size, and some have been taken weighing $100 \mathrm{lbs}$. It is extremely voracious.

C. Myrus, Cuv. Body similar to the preceding, with some spots on the snout, a band across the occiput, and two rows of points on the nape of a whitish colour. Smaller than the preceding. Inhabits the Mediterranean sea.-Shaw, iv. 24.

C. Balearica, Cuv. (Murcena, Laroche.) Body brilliant yellowish green, with the margins of the dorsal, anal, and candal fins black; dorsal fin commencing above the branchial openings ; upper jaw longer than the under. 16 inches long. Inhabits Mediterranean sea.-An. Mus. xiii. pl. 20, fig. 3

Gen. 3. Ophisurus, Lacepede.-Murcena, Lin.

Body and tail cylindrical, and much elongated; no caudal fin ; head small; nostrils tubular; anal and dorsal fins long.

O. serpens, Cuv. Snake Eel. Body brown above, silvery below; snout slender and pointed; twenty rays in the branchial membrane. 5 to 6 feet long. Mediterranean sea.-Shan, iv. 23.

O. ophis, Lacep. Body silvery, long, and slimy; both jaws equal; 
back with brown spots of an indeterminate form; lateral line com- . posed of white points and round brown spots. 3 feet long. Inhabits Indian seas.-Shaw, iv. pl. 2.

O. colubrinus, Cuv. Body long and slender, pale or yellowish white, with alternate yellow and black bands; pectoral fins very small. 2 feet long. Inhabits Indian seas._Shan, iv. 33.

Gen. 4. Murena, Thunb.-Gymnothorax, Bloch. Murcenophis, Lacep.

Pectoral fins wanting; nostrils tubular; branchiæ opening by small lateral holes; branchial rays scarcely perceptible.

II. Helena, Lin. Body elongated, dusky greenish brown, with dull yellow irregular marks or patches; mouth large, with sharp teeth; dorsal and anal fins shallow, and united at the tail. Upwards of 3 feet long. Inhabits Mediterranean sea.-Shan, iv. pl. 2.

These fishes were held in high estimation by the ancient Romans; and ponds were formed on the coast for the purpose of feeding them. In these receptacles they became so tame as to come at the call of their masters; and history records, that a noble Roman went into mourning for the death of a favourite Muræna. Vedius Pollio made the slaves who offended him be thrown into the ponds as food for his Murænæ.

M. reticulata, Shaw. Body whitish, with a tinge of yellow, and marked throughout by transverse brown bands; sides reticulated with brown, and dorsal fin as long as the body. Inhabits Indian seas. -Bloch, pl. 416.

M. Africana, Shaw. (G.afer, Bloch.) Body brown, compressed, marbled with whitish variegations; dorsal fin as long as the body; mouth wide and armed with sharp teeth bent backwards, those before largest. Inhabits African seas. - Bloch, pl. 417.

M. Meleagris, Shaw. Body deep brown, very thickly marked with small round white spots, confluent on the head ; teeth sharp. 2 feet long. Inhabits Southern ocean.-Shan, iv. 32.

M. catenata, Shaw. Body brown, crossed by chain-like white bands, and marked by numerous brown spots and freckles; teeth obtuse. Size of a small eel. Inhabits Surinam.-Shaw, iv. pl. 3.

M. unicolor, Cuv. Body deep reddish brown; back elevated ; fins bordered with yellow ; teeth obtuse. 24 to 30 inches long. Inhabits Mediterranean sea.-An. Mus. xiii. pl. 25, fig. 15.

M. zebra, Shaw. Body blackish brown, with transverse linear distant white bands, meeting irregularly beneath; no perceptible dorsal or anal fins. 2 to 3 feet long. Inhabits American Seas. -Shaw, Nat. Mis. pl. 322.

M. Iacepede names Gymnomurena the species with obtuse teeth, and without perceptible fins; and one of them which exudes much mucous matter he places in a genus termed Muræenoblenna.

Gen. 5. Sphagebranchus, Bloch.

Head terminating in a point; branchial openings approaching, and under the throat. 
S. rostratus, Bloch. Body cylindrical, slender, pale brown; no pectoral fins, and the vertical ones appearing only towards the tail. 9 inches long. Inhabits Indian seas.-Shaw, iv. pl. 5.

S. imberbis, Laroche: Body slender, elongated, almost cylindrical, violet gray, with brownish specks; belly white; head small, snout pointed and without cirri; pectoral fins very small. 12 inches long. Inhabits Mediterranean sea.-An. Mus. xiii. pl. 25, fig. 18.

Gen. 6. Apterichthus, Dumeril.-Sphagebranchus, Bloch.

Body extremely elongated, very slender, almost cylindrical, slightly flattened below; destitute of fins and scales; head with rounded pores ; eyes not perceptible ; snout pointed and flattened; mouth small; teeth subulate, pointed, bent back; anterior teeth of the upper jaw largest; branchial openings on the neck below.

A. coecus, Dum. Body uniform brown colour, with some blackish spots on the head; lateral line scarcely visible. 18 inches long. Inhabits Mediterranean sea.-Au. Mus. xiii. pl. 21, fig. 6.

\section{Gen. \%. Synbranchus, Bloch.}

Branchiæ with a single opening under the throat; no pectoral fins, and the vertical ones almost entirely adipose; head large; snout rounded; teeth obtuse; six branchial rays.

S. marmoratus, Bloch. Back deep olive, with dusky spots; belly and sides yellowish, with spots of a violet tinge; dorsal fin extremely remote from the head. $2 \frac{1}{2}$ feet long. Inhabits fresh waters in Surinam.-Shaw, iv. pl. 4.

S. immaculatus, Bloch. Similar to the preceding in form, but smaller, of a brown colour, and without spots. Inhabits Surinam.-Bloch; pl. 419 .

\section{Gen. 8. Alabes, Cuv.}

A common opening in the throat for the branchiæ; a small concave disc between the pectoral fins; branchial operculum with three rays; teeth pointed.

Only one species known, from the Indian seas.

Gen. 9. Grmnotus, Lir.

Branchial openings in part closed by a membrane opening before the pectoral fins; anus placed much forwards, the anal fin running along the greater part of the body; no dorsal fin; skin without perceptible scales.

G. electricus, Lin. The Electrical Gymnotus. Body long, nearly of similar thickness throughout, brownish black; head and tail obtuse. 3 to 6 feet long. Inhabits rivers in South America.Shaw, iv. pl. 6.

This singular animal was first made known to the philosophers of Europe about the year 1671 by $M$. Richer, and its qualities more fully detailed afterwards by Condamine, Dr Bancroft, Mr Williamson, Dr Garden, and still later by John 
Hunter and Humboldt. It is able to give shocks so violent as to stun men and even horses, and seems to have the power of directing these shocks at will. The organ which produces such sirgular effects runs along the under part of the tail, of which it occupies nearly half the thickness; is dividied into four longitudinal bundles, two larger above and two smaller below. Each bundle is composed of a great num. ber of membranous parallel laminæ nearly horizontal, united to one another by an infinite number of vertical laminæ directed transversely. The small cells or prismatic transverse canals intercepted by these laminæ are filled with a gelatinous matter, and the whole apparatus is abundantly provided with nerves. The electrical shock given by the Gymnotus is readily communicated through a circle formed by eight or ten persons; and its use to the animal seems to be to procure its prey, by stunning the fishes, which it is said to do through the medium of the water at some distance.

\section{Gen. 10. Carapus, Cuv.-Gymnotus, Bloch.}

Body compressed, scaly, the tail tapering suddenly behind.

C. brachiurus, Cuv. Head small and compressed; under jaw longer than the upper, and both furnished with small teeth; body yellowish, with brown undulations; tail short; pointed. Inhabits rivers of Brazil._Bloch, pl. 157, fig. 1 .

C. macrourus, Cuv. Head compressed, upper jaw projecting beyond the lower; body brown, with a few irregular spots of a deeper colour; tail long, slender. 2 to 3 feet long. Inhabits rivers of Brazil.-Bloch, pl. 157, fig. 2.

C. rostratus, Cuv. Snout elongated, the opening at the point; anal fin extending to the extremity of the tail. Inhabits S. American rivers.-Shan, iv. 63.

\section{Gen. 11. Sternarchus, Schn.-Gymnotus, Gmel.}

Anal fin terminating before arriving at the point of the tail; caudal fin distinct; head oblong, depressed, naked; a soft fleshy filament on the middle of the back retained in a furrow; body scaly.

S. albifrons, Cuv. Snout obtuse; head naked, with numerous apertures from which a viscid fluid exudes; body white above, blackish on the sides and belly ; tail compressed. 1 foot long. Inhabits fresh waters in Surinam.-Shan, iv. 64.

The curious structure on the back of this fish, Cuvier conjectures, may be an accidental separation of some of the muscles of the tail, from the weakness of the skin on this part.

\section{Gen. 12. Leptocephalus, Penn.}

Head small; body laterally compressed like a riband; dorsal, caudal, and anal fins united; branchial aperture small, transverse.

L. Morrisii, Gmel. Body semipellucid, pale; margin of the back and belly with minute black spots; lateral line nearly in the middle, and straight; pectoral fins extremely small. 6 inches long. Inhabits coasts of England -Wern. Mem. ii. pl. 22, fig. 1.

Gen. 13. Ophidium, Lin.

Dorsal, anal, and caudal fins united; tail pointed; body elon- 
gated compressed, and covered with small irregular scales; branchiæ with a large operculum and a membrane with short rays; two small bifid cirri under the throat.

O. barbatum, Bloch. Bearded Ophidium. Head small and naked; body silvery; dusky above and reddish beneath, spotted all over with small oblong dusky spots; vertical fins margined with black. 8 to 10 inches long. Inhabits European seas. B.-Shaw, iv. pl. 7.

Gen. 14. Fierasfer, Cuv.-Ophidium, Lin.

Body oblong and slender; head short, flattened; no cirri; dorsal fin so small as to resemble a fold of the skin.

F. imberbe, Lin. Body purplish brown, gradually decreasing in thickness to the tail; head thick and rounded at the snout; no cirri, and dorsal fin very small. 3 inches long. Inhabits European seas.-Wern. Mem. i. pl. 4, fig. 2.

Gen. 15. Ammodytes, Lin.

Body slender and elongated; dorsal, anal, and caudal fins separate; snout pointed, the upper jaw susceptible of extension, and the lower in repose longer than the other; no swimming-vessel.

A. Tobianus, Lin. The Sand-Launce. Body above bluish green; sides and belly silvery; lateral line dusky, with another line near the back and a third near the belly. 3 to 8 inches long. Inhabits sandy shores of Northern seas.-Shaw, iv. pl. 9.

The Sand-launce is found on most of our sandy shores during the summer months, and is dug or drawn out by means of blunt hooks at the recess of tide.

\section{ORDER IX.-ACANTHOPTERYGII.}

First rays of the dorsal, ventral, and anal fins supported by simple spinous rays.

This order includes the greatest portion of the ordinary fishes. They are distinguished by the spines which form the first rays of the dorsal fin, or which support or alone form the first dorsal fin where there are two. The first rays of the anal fin are also spinous, and there are generally one spine at each ventral fin. The differences of character, however, are otherwise so various, that Cuvier divides them into eight natural families.

\section{FAMILY I.-Tenioides.}

Body extremely long and flattened, with a dorsal fin the length of the body.

This family is divided into two tribes by Cuvier, according to the form of the jaws. The first of these has the snout short and the maxillaries distinct; the second is characterized by a pointed snout, and the gape wide.

\section{Snout short.}

Gen. 1. Cepola, Lin.

Body elongated and compressed; dorsal, anal, and caudal fins 
distinct; upper jaw short, and the lower turned up; teeth strong and sharp.

C. rubescens, Lin. Red Band-Fish. Body smooth, pale red-coloured, tapering from the head to the tail, with waved silvery bands on the sides; jaws with one row of distant subulate teeth. 10 to 15 inches long. Inhabits the Mediterranean sea. B.-Lin. Trans. vii. pl. 17.

C. Toenia, Lin. Band Fish. Body bright silvery, with a dusky tinge above, and marked along the sides by a few obscure distant reddish spots; a single row of teeth in the upper jaw, and a double one in the lower; tongue broad and rough. 3 to 4 feet long. Inhabits the Mediterranean sea.-Shaw, iv. pl. 26.

\section{Gen. 2. Lophotes, Giorna.}

Head short, surmounted by an elevated osseous crest, on the top of which is articulated a long and strong spinous ray, bordered behind by a membrane; a low fin with almost simple rays runs along the back; caudal fin distinct, and anal very short; a spinous ray before each of the pectoral fins; ventral fins very small; six rays in the branchial membrane.

L. Cepedianus, Giorna. Body elongated, and pointed behind; mouth directed upwards ; eyes very large; abdominal cavity occupying almost the whole length of the body. 4 feet long. Inhabits the Mediterranean sea.-Cuv. Reg. An. ii. 243.

\section{Gen. 3. Regalecus, Ascanius.}

Pectoral fins small; first dorsal fin small, with simple rays, the second running nearly along the whole body; no anal or caudal fins; and the ventral thoracic ones reduced to very long filaments.

R. Glesne, Ascan. (Gymnetrus remipes, Schn.) Body much elongated, silvery, with a bluish tinge on the back; first dorsal fin slightly elevated; and the long ventral filaments terminated by a membranous disc. 10 to 18 feet long. Inhabits Northern seas. -Shaw, iv. pl. 27.

This fish is said to be generally seen either preceding or accompanying the shoals of herrings in the northern seas, from which it has acquired the popular name of $K i n g$ of the Herrings.

R. Russelii, Shaw. Body extremely elongated, bright silvery; fins pale brown; first dorsal fin much elevated and terminating in a very long filament ; ventral processes of great length, terminating in simple filaments; tail lanceolate, with a terminating filament. 3 feet long." Inhabits Indian seas.-Shan, iv. pl. 28.

\section{Gen. 4. Grmnetrus, Bloch.}

No anal fin, one dorsal fin, and a distinct caudal one; pectoral fins small; upper jaw very extensible, and teeth very small.

G. Cepedianus, Risso. Body silvery, with some black and round 
spots ; dorsal fin purple red; pectorals rose-coloured, and the caudal fin carmine. 3 to 4 feet long. Inhabits Mediterranean sea. -Risso, pl. v. fig. 17 .

According to M. Risso, this is one of the most beautiful fishes of the Mediterranean.

Gen. 5. Trachy pterus, Gouan.

Dorsal fin very long, supported by round rays, the anterior ones dentated; no anal fin; lateral line armed with spines; tail strongly serrated below.

T. tania, Schn. (Cepola trachyptera, Gmel.) Body elongated, silvery. 2 feet long. Inhabits Mediterranean sea.-Shaw, iv. 191.

Gen. 6. Gymnogaster, Brunnich.-Bogmarus, Schn.

One long dorsal fin; pectoral fins small; destitute of anal and ventral fins; teeth sharp and pointed.

G. arcticus, Brun. (B. Islandicus, Schn.) Body elongated, silvery; lateral line armed with small spines. 4 feet long. Inhabits Northern seas.-Cuv. Reg. An. ii. 246.

\section{Snout pointed.}

Gen. \%. Trichiurus, Lin.

Body elongated, flattened, ensiform; jaws pointed, with long and curved teeth; dorsal fin extending along the whole body; no ventral or anal fins; tail terminated by a slender filament.

T. lepturus, Bloch. Body bright silvery, extremely compressed and elongated; the lower jaw longer than the upper. 3 feet long. Inhabits South American rivers and lakes._Shaw, iv. pl. 12.

T. Indicus, (A. Indica, Will.) Body pale brown, with shades of deeper colour; jaws of equal length.-Shaw, iv. 92.

Gen. 8. Lepidopus, Gouan.

Body elongated and flattened; dorsal fin long; jaws pointed, with sharp teeth; caudal and anal fins distinct; two pointed moveable scales in place of ventral fins.

L. tetradens, (Ziphotheca, Mont.-Vandellius Lusitanicus, Shaw.) Body silvery, without scales, carinated on the back and belly; pectoral fins pointed; under jaw longest; four larger teeth in the upper jaw; tail lunated. 5 feet long. Inhabits European seas. B.-Wern. Mem. i. pl. $2,3$.

Gen. 9. Stylephorus, Shaw.

Body very long, compressed; eyes pedunculated; snout lengthened, directed upwards, retractile towards the head by means of a membrane; pectoral fins small; no ventral or anal fins; tail terminating in a filament longer than the body.

S. chordatus, Shaw. Body silvery, marbled with brown; candal process very long. 2 feet long without the filament. Inhabits Gulf of Mexico.-Shaw, iv. pl. 11. 


\section{Family II.-Gobioides.}

This family is distinguished by their slender and flexible dorsal spines. All have the viscera of nearly the same form; a large equal intestinal canal without cœcums; and no swimming-bladder.

\section{Gen. 10. Blennius, Lin.}

Head obtuse; snout short ; teeth long, equal, crowded, and in one row in each jaw; body elongated, compressed, with one dorsal fin of simple and flexible rays; ventral fins placed before the pectorals, and composed of two rays ; head with fimbriated appendages.

The Blennies possess a marked character in their ventral fins being placed before the pectorals, and composed of only two rays. Their body is elongated, compressed, with but one dorsal fin of simple and flexible rays. They associate together among the rocks near the shores. The skin is covered with a mucous secretion, from which circumstance they derive their generic name. Many are viviparous; and all have near the anus a tubercle conceived to be concerned in the act of generation.

B. ocellaris, Bloch. Ocellated Blenny. Body bluish green, deeper on the back, and marked with a few large distant clouds or bands ; first ray of the dorsal fin longest; a round blackish spot surrounded by white on the dorsal fin. 6 or 8 inches long. Inhabits European seas. B.-Shaw, iv. pl. 24.

B. gattorugine, Lin. Body rufous; first ray of the dorsal fin short; crest fimbriated on both sides. 7 inches long. Inhabits European seas. B.-Mont. Wern. Mem. ii. 447.

B. galerita, Lin. Crested Blenny. Body long, compressed, smooth, and slimy, yellowish brown, with darker coloured spots; coronal appendages oblique, with an intervening conical wart. 5 inches long. Inhabits European seas. B.-Pen. Brit. Zool. iii. pl. 39.

This species is found, though not frequently, on our rocky shores. Its crest is capable of erection and depression.

B. Montagui, Fleming. Body above olive green, with blue spots; belly white; crest transverse, fleshy, fimbriated; lateral line curved near the head ; first rays of the dorsal fin on the neck, detached. 12 inches long. British seas.-British Animals, 207.

Montagu considered this species as a variety of the crested Blenny; but Dr Fleming regards it as a separate species.

\section{Gen. 11. Pholis, Artedi.-Blennius, Lin.}

Body elongated; head obtuse, and destitute of crest or appendages; lips thick; nostrils round and terminating in cylinders; dorsal fin long, waved, and appearing as if divided into two parts; ventral fin with two rays.

P. lavis, (B. Pholis, Bloch.) The Smooth Blenny. Body olivaceous, marbled with black and white; lateral line bent behind the pectoral fins. 6 to 8 inches long. Inhabits European seas. B.-Pen. Brit. Zool. iii. pl. 40.

This species is found lurking among stones and sea-weeds; is able, with the as. sistance of its ventral fins, to creep up the slopes of stones; and, according to Ray, is so tenacious of life that it will live for twenty-four hours out of the water. 
Gen, 12. Salarias, Cuv.-Blennius, Lin.

Head compressed above, and broad transversely below; lips fleshy and tumid; body elongated; teeth in enormous number, crowded, in one row, but very slender, compressed laterally, and hooked at their extremity.

S. simus, Cuv. With a small appendage over the eyes; dorsal united to the caudal fin; lateral line bent. $3 \frac{1}{2}$ inches long.Shaw, iv. 172.

\section{Gen. 13. Curnus, Cuv.-Blennius, Lin.}

Body elongated, compressed; head less obtuse than the preceding; dorsal fin long; teeth short and pointed, disposed in many rows, of which the first is the longest.

C. superciliosus, Cuv. Body golden yellow, with numerous reddish spots; first rays of the dorsal fin separated from the rest of the fin by a notch; a palmated appendage above each eye; lateral line bent. 12 inches long. Inhabits Indian seas.-Bloch, pl. 168. This species is viviparous.

C. mustelaris, Cuv. Three rays in the first part of the dorsal fin. -Shaw, iv. 182.

Gen. 14. Gunnelius, Cuv.-Murcenoides, Lacep.-Blennius, Lin.

Body elongated, compressed; dorsal fin long, equal, with all the rays spinous; ventral fins very small, and oftea with only a single ray; teeth short, pointed, and in many rows.

G. vulgaris, (B. Gunnellus, Lin.) Body yellowish brown, clouded with deeper spots; a row of ten or twelve black ocellated spots at the base of the dorsal fin. 6 to 10 inches long. Inhabits European seas.-Shaw, iv. pl. 24.

G. viviparus, (B. viviparus, Lin.) Body subcylindrical anteriorly; yellowish brown above, marbled with darker spots and streaks, yellow beneath; margin of the dorsal fin suddenly waved near the tail. 12 to 13 inches long. Inhabits European seas.Shaw, iv. pl. 24.

G. lumpenus, Cuv. Body subcylindric, palish brown above, marked with brown spots, whitish beneath. Inhabits Mediterranean sea._Shaw, iv. 183.

\section{Gen. 15. Opistognathus, Cuv.}

Body elongated, compressed; snout short; maxillary bones very large, and prolonged behind; three rays in the ventral fins, which are placed immediately under the pectorals.

O. Sonneratii, Cuv. Inhabits Indian seas.-Cuv. Reg. An. ii. 252.

Gen. 16. Anarchicas, Lin.

- Body long, smooth; head thick and obtuse; anterior teeth long 
and conical; the others bony tubercles with small enamelled teeth on their summits; six rays in the branchial membrane.

A. lupus, Lin. The Wolf-Fish. Body and sides grayish, beneath yellowish; dorsal fin extending along the whole back; tail small and rounded. 2 to 6 feet long. Inhabits Northern seas. B.Shaw, iv. pl. 13.

This species feeds on univalve molluscous and crustaceous animals; and the teeth are so strong as, according to Schonfelde, to leave their marks on an anchor. From its forbidding appearance it is not much used as food, though said to be excellent. The Greenlanders, however, eat it both fresh and dried.

\section{Gen. 1\%. Goвıus, Lacepede, Lin.}

Body elongated; head of medium size, rounded; cheeks tumid; two dorsal fins, the posterior long; ventral fins thoracic, united towards their base into a hollow disk; four rays in the branchial membrane.

The fishes of this genus are middle sized or small, and are found among the rocks where the water is shallow. Their ventral fins, united into a hollow disk, is their chief distinguishing character. They are able to live for some time out of the water. The males have an appendage behind the anus; and the greater part are provided with a swimming-bladder.

G. niger, Lin. Common Goby. Body brownish black above, white beneath; dorsal and anal fins pale blue, the rays marked with minute black spots; tail rounded. 6 inches long. Inhabits European seas.-Shan, iv. pl. 34.

G. minutus, Lin. The Spotted Goby. Body whitish, obscurely spotted with ferruginous; streaks of dots of the same colour across the fins; tail even. $2 \frac{1}{2}$ inches long. Inhabits European seas. -Don. Brit. Fishes, pl. 38.

G. Plumerii, Bloch. Body yellowish brown above, paler on the sides, and whitish below; upper jaw projecting; tail rounded. 3 to 4 inches long. American seas.-Bloch, pl. 175, fig. 3.

G. lanceolatus, Bloch. Body elongated, yellowish brown; the scales increasing in size towards the tail, which is broad, elongated, and sharp pointed; sides compressed, of a pale yellow; belly gray; a black spot on each side where the dorsal fins meet. Inhabits rivers in West India Islands.-Shaw, iv. pl. 34.

G. lagocephalus, Pall. Body round, compressed towards the tail, gray or dark brown; head short, thick, without scales; lips cleft in the middle, the upper one very thick; tail oval, rounded. 3 inches long.-Shaw, iv. 239.

G. Boddaerti, Pall. Body bluish brown above, with longitudinal spots, reddish white beneath; head varied with brown and white; vent surrounded by a black ring, and terminated by a fleshy protuberance; first dorsal fin blackish blue, spotted with white, and furnished with long projecting filaments. 5 or 6 inches long. Inhabits Indian seas.-Shaw, iv. 238. 
Gen. 18. Gobroides, Lacepede.-Gobius, Lin.

Body elongated; head small; ventral fins thoracic and united; one dorsal fin.

G. Broussonetii, Cuv. Body very long, much compressed, with transparent skin; pectoral fins small; rays of the dorsal and anal fins projecting; tail lanceolate. Indian seas.-Shaw, iv. 236.

\section{Gen. 19. Tenioides, Lacep.-Gobius, Lin.}

Body much elongated and compressed; upper lip with cirri ; pectoral fins in the form of a disc, and composed of many rays; eyes scarcely perceptible; no caudal fin.

T. Hermanii, Lacep. (Cepola caecula, Schn.) Dorsal fin commencing near the head, and running to the extremity of the tail ; three or four cirri at the mouth.-Shaw, iv. pl. 26.

Gen. 20. Periophthalmus, Schn.-Gobius, Pall.

Head covered with scales; eyes approximated, with an eyelid at their inferior margin; pectoral fins covered with scales more than half their length; ventral fins more or less united; branchial openings narrow.

The species of this genus are able to live for some time out of the water, and are often seen crawling on the mud to avoid their enemies or to procure food.

P. Schlosseri, Cuv. Body dusky above, covered with coriaceous rounded scales; head longish, much broader than the body; eyes protuberant ; ventral fins forming a concave disk. 6 to 8 inches long. Inhabits fresh waters in India.-Shaw, iv. 246.

P. Kolreuteri, Cuv. Body grayish white, with the ventral fins attached to a kind of fleshy arm or process, and separated almost to their base; lateral line as if compressed; upper jaw with a tooth on each side larger than the rest. About a span long.Shaw, iv. 251.

\section{Gen. 21. Eleotris, Cuv.-Gobius, Gmel.}

First dorsal fin with flexible rays; an appendage behind the anus; thoracic ventrals perfectly distinct; head obtuse, slightly depressed; eyes separated; branchial membrane with six rays.

E. Pisonis, Cuv. Under jaw longer than the upper; ventral fins separate; tail rounded. Waters of Brazil._Shaw, iv. 252.

E. strigatus, Cuv. Body compressed, elongated, of a greenish blue on the back, white beneath, with brown and reddish lines and spots; fins greenish, varied with red and yellow; scales square; upper jaw longest; tail rounded. Inhabits Southern ocean.Shaw, iv. 249.

Gen. 22. Sillago, Cuv.

Snout slightly elongated, with a protractile mouth, and fleshy lips; teeth small, crowded, with a larger row exteriorly; 
head scaly; two dorsal fins, the first short, but elevated, with flexible rays; the second long and low; operculi armed with a small spine.

S. acula, Cuv. Body fawn-coloured. About a foot long. Inhabits Indian seas-Reg. An. ii. 258.

S. domina, Cuv. First ray of the dorsal fin as long as the body. Inhabits Indian seas.-Reg. An. ii. 258.

These two species are accounted delicate eating.

\section{Gen. 23. Callionxmus, Lin.}

Head oblong, depressed, thicker than the body; eyes approximated, vertical; branchial openings on each side of the neck; ventral fins under the throat, and larger than the pectorals; first dorsal fin supported by setaceous rays; body naked.

C. Lyra, Lin. The Gemmeous Dragonet. First dorsal fin lyreshaped, the first ray reaching to the tail ; last rays of the second dorsal and anal fins longest; body rounded, smooth, splendidly coloured with blue, yellow, and white. 12 inches long. Inhabits European seas. B.-Shaw, iv. pl. 19.

The $C$. dracunculus, or Sordid Dragonet of Pennant, which differs from the preceding, chiefly in the colours being less brilliant, the first ray of the dorsal fin shorter, and the body in general smaller, Mr Neill conjectures to be the female. He found all the specimens of the Lyra from the Frith of Forth which he examined to be males.

C. ocellatus, Pall. Body variegated above with cinereous and brown, with white spots, white beneath ; first dorsal fin minute, black, with four dusky spots and setaceous rays; pectoral fins hyaline, spotted with white at their base, the two middle rays longest; tail rounded. 3 inches long. Indian seas.-Shaw, iv. 120.

C. pusillus, Laroche. Head large, flattened snout pointed; body tapering, grayish brown, with scattered white spots above; gray below, and the sides marked with transverse bands of the same colour; second dorsal fin with six rays, and thrice higher than the first. 3 inches long. Inhabits Mediterranean sea.An. Mus. xiii. pl. 25, fig. 16 .

C. sagitta, Pall. Head triangular; body brownish, variegated with gray, whitish beneath; operculi with a long subulate spine serrated within; tail rounded. 3 inches long. Inhabits Indian seas.-Shaw, iv. 122.

Gen. 24. Comephorus, Lacep.-Callionymus, Lin.

Body elongated and compressed; head and opening of the mouth large; snout broad and depressed; branchial membrane with seven rays; very long pectoral fins; two dorsal and no ventral fins.

C. Baikalensis, Cuv. Body soft and oily, slender, slightly compressed; head large, somewhat quadrangular at the base ; pectoral fins lax and long; tail bilobate. 8 inches long. Inhabits Lake Baikal in Tartary.-Shaw, iv. 119. 


\section{Family III.-Labroides.}

The fishes of this family have an oblong body covered with scales; a single dorsal fin supported before by strong spines, and generally furnished with a membranous appendage; jaws covered by fleshy lips; the pharyngeal bones all armed with flat or pointed teeth.

The genus Labrus of Linnæus, forming a numerous group of fishes resembling one another in their oblong form and double fleshy lips, in their branchial membrane with five rays, their conical maxillary teeth and their cylindrical and blunt pharyngeal ones, is the type of this family.

\section{Gen. 25. Labrus, Cuv.}

Body oblong; lips double, fleshy ; maxillary teeth conical, pharyngeal ones blunt; cheeks and operculi covered with scales, but destitute of spines and dentations; lateral line nearly straight.

L. Vetula, Bloch. Anile Labrus. Head reddish; body yellowish, with lead-coloured spots ; ventral, anal, and caudal fins margined with black. 10 to 12 inches long. Inhabits Northern seas.Bloch, pl. 293.

\section{* Without pores on the head.}

L. guttatus, Bloch. Head bluish, with oblong silvery spots; back brown; sides blue; belly whitish; spots on the sides and anal fin silvery, those on the dorsal fin yellow.-Bloch, pl. 287, fig. 2.

L. carneus, Bloch. Head narrow; body red, brightest on the sides; with three black spots, two on the posterior part of the back, and the third near the caudal fin. Northern seas.-Bloch, pl. 289.

L. fasciatus, Bloch. Head compressed ; body covered with large scales, and surrounded by four broad brown bands; lateral line nearer the back than the belly; eight spines in the dorsal fin. Inhabits sea of Japan.-Bloch, pl. 290.

L. punctatus, Bloch. Body thin, broad, and covered with large round scales; back brown; belly and sides paler; sides marked with nine longitudinal yellow lines, and dotted with brown points; soft rays of all the fins long and forked ; four spines in the anal fin; head, sides, and end of the tail marked with a round black spot; tail rounded. Inhabits rivers of Surinam.-Bloch, pl. 295.

L. loevis, Cuv. Body covered with very small scales, and with five large spots or transverse bands; fifteen spinous rays in the dorsal fin; lower jaw longer than the upper; teeth large ; tail crescentshaped. Inhabits Indian seas.-Lacep, iii. pl. 23, fig. 2.

\section{** With pores on the head.}

L. tesselatus, Bloch. Head compressed, sloping ; mouth small ; back violet; sides silvery; ventral fin black; pectoral and caudal fins blue, the anal yellowish; four to six pores below the nostrils; operculi and breast marked with small brown spots, with larger ones of the same colour on the body; anal fin with three spines and the ventral one. Inhabits Northern seas.-Bloch, pl. 291.

L. maculatus, Bloch. Head obtuse ; lips thick; jaws of equal length; 
pores at the anterior operculi ; body yellowish, deeper on the back; all the fins yellowish, with brown spots; twenty spines in the dorsal fin. 12 to 15 inches long. Northern seas.-Bloch, pl.294.

L. Bodianus, (Bodianus, Bloch.) Head small, obtuse; jaws equal; body golden coloured, the scales margined with red; part of the back purple, and the scales with a blue border; pectoral and ventral fins purple; anal yellowish; twelve spines in the dorsal fin. 8 inches long. Inhabits S. American seas.-Bloch, pl. 223.

Gen. 26. Jucis, Cuv.-Labrus, Lin.

Body oblong; lips thick, fleshy ; maxillary front teeth conical, the pharyngeal blunt; head entirely smooth and without scales; lateral line strongly bent towards the end of the dorsal fin.

J. vulgaris. (L. Julis, Lin.) Body bluish or violet above, with an undulating orange stripe on each side towards the back; abdomen whitish; pectoral, ventral, and caudal fins pale; dorsal fin fulvous or orange-coloured at its origin, with a brown or purplish stripe along the base. 8 inches long. Inhabits Mediterranean sea. B.-Don. Brit. Fishes, pl. 94.

\section{* Without pores on the head.}

J. Braziliensis, Cuv. Head smooth, with vermicular lines; body golden yellow, with oblong blue spots near the back; dorsal and anal fins yellow, with three blue lines on each, the other fins blue, and all pointed. 12 inches long. Inhabits Brazil.-Bloch, pl. 280.

J. lunaris, Cuv. Head small, compressed, with a number of pores ; body violet, and the dorsal fin with eight spines, and bordered with white above and below; tail lunated. Indian seas.-Bloch,pl. 281.

J. viridis, Cuv. Head small, compressed, with green stripes; body narrow, compressed, fine green, covered with large smooth scales, bordered with yellow and green; eight spines in the dorsal fin; dorsal and anal fins yellow, with a green border at the base and extremity; the others yellow in the middle and green on the edges. 12 inches long. Inhabits Japan.-Bloch, pl. 282.

J.cyanocephalus, Cuv. Head and back deep blue; sides silvery; dorsal fin with nine spines; lateral line interrupted.-Bloch, pl. 286.

J. chloropterus, Cuv. Body greenish ; the back deep green, shading to lighter below ; fins green; projecting front teeth in each jaw; two spines on the anal and nine on the dorsal fin. Inhabits $\mathrm{Ja}_{\mathrm{a}}$ pan.-Bloch, pl. 288.

J. malapterus, Cuv. Body narrow and compressed, whitish, shading to blue on the back; five black spots on the sides; all the rays of the fins, except a spine on the ventrals, soft. Inhabits Japan.-Bloch, pl. 286.

J. Hebraicus, Cuv. (Labre Hebraïque, Lacep.) With twenty-one articulated rays in the dorsal fin; thirteen in the anal; stripes on the head and operculi resembling Hebrew characters. Inhabits Indian seas.-Lacep. iii. pl. 29, fig. 3. 
J. hortulanus, Cuv. (Labre parterre, Lacep.) Body and tail marked by decussated stripes, with a spot in each division; five spinous rays in the dorsal fin. Indian seas.-Lacep. iii. pl. 29, fig. 2.

\section{** With marked pores on the head.}

J. bifasciatus, Cuv. Head violet; body gray, with two broad brown bands on the fore part; caudal fin brown at the edges and base, bluish in the middle; ventral and pectorals yellow, dorsal and anal reddish, bordered with blue; head with small openings exuding a viscid matter. 10 inches long. Inhabits Indian seas. Bloch, pl. 283.

J. bivittatus, Cuv. Back and belly red; sides yellowish, the yellow of the fins shaded by violet; two brown longitudinal stripes along the body; tail rounded, violet, with yellow spots.-Bloch, pl. 284, fig. 1 .

J. microlepidotus, Cuv. Head and back yellowish brown; sides and belly silvery; scales very small, and covering the operculi ; fins brownish.-Bloch, pl. 284, fig. 2.

J. annulatus, Cuv. (Labre annelé, Lacep.) With minute scales, subtrilobate tail, and body surrounded by nineteen dusky bands. Inhabits Indian seas.-Shaw, iv. pl. 70.

\section{Gen. 2\%. Crenilabrus, Cuv.}

Body oblong; lips thick and fleshy ; front teeth conical, the pharyngeal blunt; margins of the pre-operculi dentated; cheeks and operculi furnished with scales.

C. rupestris, Cuv. (Lutianus, Bloch.) Head without scales before, but with blue lines on each side, and truncated; back yellowish green, belly white; body with transverse brown bands, and longitudinal reddish lines; top of the caudal, commencement of the dorsal fin, and sides of the head marked with a black spot. 4 to 5 inches long. Inhabits Northern seas.-Bloch, pl. 250.

C. bidens, Cuv. Body rose-coloured, darker on the back; abdomen silvery; chin and fins greenish; a black spot at the base of the pectoral fin, and each row of scales with a line of pale yellow; two teeth in the upper jaw. 6 inches long. Inhabits Northern seas.-Bloch, pl. 251, fig. 1.

C. Norvegicus, Cuv. Nape and back violet; sides and belly yellow, spotted with violet; pectoral and ventral fins blue; extremities of the anal and caudal fins pale violet, the other parts yellowish; sixteen spines in the dorsal fin. Norwegian seas.-Bloch, pl. 256.

C. Tinca, (Labrus Tinca, Lin.) The Wrasse. Body reddish, often varied with blue, red, and yellow ; pectoral fins large and rounded; dorsal fin with sixteen spinous rays. About a foot long. Inhabits European seas. B.-Donov. Brit. Fishes, pl. 72.

C. gibbus. (Sparus gibbus, Shaw.) The Gibbous Wrasse. Back arched, carinated, sloping to the mouth; sides spotted with blue and orange, and above each eye a dusky semilunar spot; sixteen 
spinous rays in the dorsal fin. 8 inches long. Inhabits British seas.-Penn. Brit. Zool. iii. pl. 56.

C. chrysops, Cuv. (Lutianus, Bloch.) The Golden-eye. Head wedgeshaped; sides, belly, and head silvery, shading to violet at the lateral line, and deep violet on the back; dorsal fin with eleven spinous rays, the anal with three; fins pale yellow, violet on the margin ; iris golden. Inhabits American seas.-Bloch, pl. 248.

C. erythropterus, Cuv. (Lutianus, Bloch.) Head compressed; back brown; the sides and head silvery, and the fins red ; the pectoral fins pointed, the caudal slightly notched, the others rounded; eleven spinous rays in the dorsal fin. 8 inches long. Inhabits seas of Japan.-Bloch, pl. 249.

C. notatus, Cuv. (Lutianus, Bloch.) Body yellowish, spotted with brown, a black spot on each of the base of the tail; dorsal fin with fourteen spinous rays. 5 inches long. Inhabits Indian seas. -Bloch, pl. 251, fig. 2.

C. Linkii, Cuv. (Lutianus, Bloch.) Head narrow before, grayish ; body pale violet coloured; fifteen spinous rays in the dorsal fin. 12 inches long.-Bloch, pl. 252.

C. virescens, Cuv. (Lutianus, Bloch.) Head elongated and obtuse; body yellowish, with longitudinal brown lines and greenish fins; twelve spinous rays in the dorsal fin. 8 inches long.-Bloch, pl. 254.

C. lapina, Cuv. (Labrus, Gmel.) Body ovate, oblong, brown above, white beneath; sides marked by a triple red spotted line; pectoral fins yellow, ventrals blue, the others violet. Inhabits Mediterranean sea._Shaw, iv. 459.

C. merula, Cuv. (Labrus, Gmel.) Body blackish blue, with large scales. 12 inches long. Inhabits European seas._Shan, iv. 507.

C. viridis, Cuv. (Labrus, Gmel.) Body green, yellowish beneath, with a longitudinal blue stripe on each side. Inhabits Mediterranean sea.-Shaw, iv. 501 .

Gen. 28. Coricus, Cuv.-Lutianus, Risso.

Body oblong; lips thick and fleshy; mouth protractile; front teeth conical and pharyngeal, teeth blunt ; margins of the preoperculi dentated; cheeks and operculi furnished with scales.

C. virescens, Cuv. Body deep green on the back, passing into golden yellow on the belly; head and throat traversed by violet lines; snout prolonged into a bent tube; lateral line bent. $3 \frac{1}{2}$ inches long. Mediterranean sea.-Risso, Ich. de Nice, 280.

C. Lamarckii, Cuv. Body flattened, bluish on the back; sides silvery pink with black points; belly silvery with red points; snout. elongated, tubular, and of a copper red. 4 inches long. Inhabits Mediterranean sea.-Risso, pl. 9, fig. 29.

Gen. 29. Cheilinus, Lacepede.

Head scaly; front teeth conical, the pharyngeal blunt; upper 
lip extensible; branchial operculi without spines or dentations ; lateral line interrupted opposite the dorsal fin; terminating scales of the tail advancing upon the base of the rays.

C. trilobatus, Cuv. Body bluish brown, spotted with white, yellow and reddish; two lateral lines, and the caudal fin trilobed. About a foot long. Inhabits Indian seas.-Lacep. iii. pl. 31. fig. 3.

C. fasciatus, Cuv. (Sparus fasciatus, Bl.) Body broad, compressed, yellowish, with six brown bands; lateral line interrupted; dorsal fin with nine spinous rays. Seas of Japan.-Bloch, pl. 257.

\section{Gen. 30. Epibulus, Cuv.-Sparus, Pall.}

Body and head covered with large scales; the last row advancing on the anal and caudal fin; mouth extremely extensible ; two longer conical teeth before in each jaw, and smaller pharyngeal ones; lateral line interrupted.

E. insidiator, Cuv. Snout elongated in form of a tube ; back red, and the sides yellowish; nine spinous rays in the dorsal fin; tail crescent-shaped. 12 inches long. Indian seas.-Shaw, iv. 445.

Gen. 31. Gomphosus, Lacep.

Body oblong; head entirely smooth; jaws prolonged into a tubular snout; teeth in front large, conical, those on the pharynx blunt.

G. caruleus, Lacep. Body entirely blue ; lateral line bent, marked with small streaks. 12 inches long. South seas._Shaw, iv. pl. 67.

G. variegatus, Lacep. Body variegated with red, yellow, and blue. Smaller than the preceding. South seas._Shaw, iv. pl. 67.

\section{Gen. 32. Novacula, Cuv.-Coryphana, Lin.}

Forehead almost vertical; body covered with large scales; lateral line interrupted; jaws armed with a row of conical teeth, of which the middle ones are longest, and the palate paved with hemispherical ones.

N. Rondeletii. (C. novacula, Lin.) Body carinated, reddish yellow; head, jaws, and branchial membrane with numerous blue lines; anal and caudal fins variegated with green and yellowish lines; dorsal fin red, with scattered blue spots. 8 inches long. Inhabits Mediterranean sea.-Shaw, iv. $21 \%$.

N. carrulea, Cuv. Body deep, compressed vertically, of a uniform blue colour; tail crescent-shaped. 18 inches long. Inhabits American seas.-Catesby, ii. pl. 18.

N. pentadactyla, Cuv. Head much truncated; body brownish above, silvery below; dorsal fin bluish, bordered with yellow orange, the nine first rays hard; caudal, pectoral, and ventral fins orange, with a violet border; anal bluish; tail even. 12 inches long. Inhabits Indian seas.-Bloch, pl. 173.

N. psitlacus, Cuv. Head and body variegated with green, yellow, 
and blue; on the middle of the body towards the back a rhomboid purple spot; dorsal and anal fins linear; tail even. Inhabits American seas.-Shaw, iv. 221.

N. lineata, Cuv. Head, dorsal and anal fins marked by coloured streaks ; tail round. Inhabits American seas.-Shaw, iv. 224.

Gen. 33. Chromis, Cuv.

Body oblong; lips thick and fleshy; mouth protractile; teeth numerous, crowded, equal in both jaws and larynx; vertical fins filamentous, those of the ventral fin often prolonged into filaments; lateral line interrupted.

C. castaneus, (Sparus Chromis, Lin.) Body chestnut brown, with longitudinal streaks of a lighter colour; a black spot at the base of the ventral fins. Inhabits Mediterranean sea.-Shaw, iv. 446.

C. Niloticus, Cuv. (Labrus, Gmel.) Body whitish, with the dorsal, anal, and caudal fins clouded. Inhabits the Nile.-Shaw, iv. 506.

C. saxatilis, Cuv. (Sparus, Lin. Perca, Bloch.) Head broad behind, and narrow before; body elongated, brown above, paler on the sides, and whitish below; two black spots with white borders at the pectoral and caudal fins. S. American seas.-Bloch, pl. 309.

C. punctatus, Cuv. Head small and sloping; body broad, thin, and covered with round scales, brown above, paler below; the sides marked with nine longitudinal yellow lines and spotted with brown points ; dorsal, anal, and caudal fins with black lines; anal fin with four spines. Rivers of Surinam.-Bloch, pl. 295, fig. 1.

C. Surinamensis, Cuv. Body yellowish, with transverse red spots; three large black spots on each side; fifteen spinous rays in the dorsal and three in the anal fin; tail crescent-shaped. Inhabits seas of South America.-Bloch, pl. 277, fig. 2.

The species with the head compressed and eyes approximated, and with very long ventral fins, form the geius Plesiops of Cuvier.

Gen. 34. Scarus, Lin.

Body oblong, with large scales; jaws convex, rounded, furnished with teeth disposed like scales on their margin and anterior surface; two pharyngeal plates above and one below, furnished with laminar teeth ; lips fleshy; lateral line interrupted; one dorsal fin.

Cuvier, in his Règne Animal, doubted the existence of the fish in the Mediterranean Sea, known to the ancient Romans by the name of Scarus; but later investigation has ascertained not only its existence, but that it is known by the name of Scaros among the modern Greeks. The fish, which.M. Cuvier has procured from the coast of Greece, possesses all the characters attributed to it by the ancient naturalists; the same colour, the same form, and the same delicate flesh which made it to be so much prized among the epicures of Rome. This fish, it is said, was transported in the reign of Claudius from the coasts of Greece to those of Tuscany by Elipertius Optatus.

S. rivulatus, Lin. Body bluish, spotted with black, with longitudinal yellow undulations; thirteen spinous rays in the dorsal fin. Inhabits the Red Sea.-Shan, iv. 395.

VOL. I.

F $f$ 
S. croicensis, Bloch. The Red Scarus. Body red, shaded with silvery; belly white; dorsal fin with nine spinous rays; tail rounded; base of the upper jaw with projecting points. 10 inches long. Inhabits Indian seas.-Shaw, iv. pl. 57.

S. Cretensis, Bloch. The Cretan Scarus. Back and head greenish-brown; sides greenish-yellow; belly yellowish; fins yellow and green at the end; dorsal fin without spinous rays. 12 inches long. Inhabits Indian seas.-Bloch, pl. 220.

S. viridis, Bloch. The Green Scarus. Body yellowish-green; scales large, bordered with deeper green; caudal fin straight, with thirteen green rays. 10 or 12 inches long. Inhabits $\mathrm{Ja}$ panese seas.-Shaw, iv. pl. 56.

S. sordidus, Lacep. Sordid Scarus. Body slender, brown; dorsal fin of a deeper colour; pectoral fins and tail yellowish; tail even. Inhabits Arabian seas.-Shaw, iv. 400.

S. trilobatus, Lacep. Trilobate Scarus. Two spinous rays and sixteen soft ones in the dorsal fin; tail distinctly trilobate. Inhabits American seas.-Shan, iv. 400.

S. purpureus, Forsk. Purple Scarus. Body abruptly lanceolate, with three longitudinal purple stripes on each side; pectoral fins green, marked at the tip by a large lunated, marginal, purple spot; abdomen and ventral fins blue. Arabian seas.-Sham, iv. 397.

Gen. 35. Labrax, Pallas.

Head small; lips fleshy; teeth small, conical, unequal; body furnished with ciliated scales, and rows of lateral pores; dorsal fin composed of slender spines, prolonged on the back.

This genus was instituted by Pallas for some species found in the sea of Kamtschatka.

\section{Family IV.-Percoides.}

The Perches, as the Labroides, have the dorsal and anal fin slightly scaly, and supported before by strong and sharp spines, the spines of the dorsal fin being sometimes capable of being folded back and concealed among the scales of the base. The body of these fishes is scaly, and the scales generally large; their intestines are large and provided with cocums; and they have almost always the swimming-vessel without communication with the stomach. This family Cuvier divides into two sections or series, so parallel in their structure, that most of the same characters are repeated in both. The first, which he terms Sparoides, has but one dorsal fin running along the greater part of the back; the second, which he terms Perseques, have two dorsal fins; or at least the spinous and soft portions are divided to their base. Both series may be divided further, according to the structure of their jaws and teeth.

\section{Section I.-Dorsal fin continuous. \\ 1. Jaws protractile.}

\section{Gen 36. Smaris, Cuv.-Sparus, Lin.}

Body narrow; jaws extensible into a kind of tube, with one row of fine pointed teeth, behind which are rows of smaller ones.

S. mana, Cuv. Body silvery-gray, banded longitudinally with bluish ; a black spot on each side. 10 inches long. Inhabits Mediterranean sea._-Shaw, iv. 418. 
S. vulgaris, Cuv. (Sp. Smaris, Lin.) Body grayish-red above, silvery below, with a black spot on each side. 10 inches long. Inhabits Mediterranean sea.-Shaw, iv. 418.

S. erythrurus, Cuv. (Sparus, Bloch.) Back blue, head and sides silvery ; fins red. 15 inches long. Seas of Japan.-Bloch, pl.26.

S. bilobatus, Risso. Body flattened, silvery, traversed with light bluish and golden bands; snout pointed; nape and sides diaphanous; lateral line bent; branchial membrane with six rays. 8 inches long. Mediterranean sea.-Risso, Ich. de Nice, 252.

\section{Teeth edged and in one row.}

Gen. 37. Boops, Cuv.-Sparus, Lin.

Body oblong, compressed, with pretty large scales; teeth in one row, edged, sometimes notched; jaws slightly extensible.

B. salpa, Cuv. Body silvery, and banded longitudinally with yellow; teeth in the upper jaw bifid, in the lower pointed. 6 to 10 inches long. Inhabits Mediterranean sea.-Bloch, pl. 265.

B. chrysurus, Cuv. (Sparus, Bloch.) Gold-tailed Sparus. Body long and slender, bright rose-red, deepest on the back; a golden yellow longitudinal stripe on each side, from the gills to the tail; a second on each side of the base of the abdomen; pectoral and ventral fins dusky violet; tail sharply forked, golden yellow. 12 inches long. Inhabits South American seas.-Shan, iv. pl. 60.

B. melanurus, Cuv. Body silvery gray, banded longitudinally with brown, and marked with a black spot on each side of the tail ; teeth in the middle notched, the lateral ones fine and pointed. 6 inches long: Inhabits American seas.-Shaw, iv. 429.

B. vulgaris, Cuv. (Sp. Boops, Lin.) Body elongated, silverygray, banded longitudinally with golden brown streaks; lateral line yellow; upper incisive teeth dentated, the under ones pointed. Inhabits Mediterranean sea.-Shan, iv. 417.

\section{Molar teeth rounded and fiattened.}

Gen. 38. Sargus, Cuv.-Sparus, Lin. Bloch.

Jaws slightly extensible, furnished on the sides with round or flat teeth, similar to molars; incisive teeth large, like those of man.

S. argenteus, Laroche. (Sp. Sargus, Lin.) Body silvery, streaked longitudinally with yellow, and with black transverse bands. 15 inches long. Inhabits Mediterranean sea.-Bloch, pl. 264.

S. annularis, Laroche. Body oval, compressed ; molar teeth rounded; incisors broad, truncated; body and ventral fins golden yellow, the other fins gray; a black ring round the tail, which is forked. 6 to 8 inches long. Inhabits Mediterranean sea.-An. Mus. xiii. pl. 24, fig. 13.

S. acutirostris, Laroche. Body extremely compressed, oval, grayish, with eight or nine transverse black lines, and a broader band 
surrounding the tail; snout pointed; incisive teeth truncated; molars hemispherical ; ventral fins black, and the others margined with the same colour. 6 inches long. Inhabits Mediterranean sea.-An. Mus. xiii. pl. 24, fig. 12.

\section{Gen. 39. Daurada, Cuv.-Sparus, Lin.}

Head compressed; jaws slightly extensible, with four or six conical teeth in one row; the others flat.

D. auratus, Cur. The Gilt-head. Back bluish; head and trunk silvery; a golden-coloured spot on the eye brows, and a purple spot on each side of the head; teeth in age sometimes very large. 15 inches long. Mediterranean sea. B.-Bloch, pl. 266.

This fish was well known to the Greeks and Romans, and was highly prized by the latter when fed on oysters. By the Greeks it was consecrated to Venus. It is not now in much estimation.

D. spinifer, Cuv. Body ovate, reddish-silvery, with the back and lines on the body dusky; five middle spines of the dorsal tin elongated. 18 inches long. Inhabits Red Sea.-Shan, iv. 416.

D. Mylio. (Sparus, Lacep.) Body yellowish, with interrupted longitudinal brown bands, and the fore part marked by a double transverse black band. 12 to 16 inches long. Inhabits Indian seas.-Lacep. iii. pl. 26, fig. 2.

D. mylostomus, Cuv. (Sparus, Lacep.) Body deep yellow, paler on the pectoral fins, and mixed with green on the dorsal fin and tail ; a black spot on each side of the tail ; scales slightly crenated on the edges. Inhabits Indian seas.-Shan, iv. 427.

D. psittacus, Cuv. (Sparus, Lacep.) Snout resembling the bill of a parrot; occiput and back arched and elevated; body longitudinally striated. Inhabits Indian seas.-Shan, iv. 436.

D. bilobatus, Cuv. (Sparus, Lacep.) With eleven spinous rays in the dorsal fin, and four in the anal; caudal fin divided into two rounded lobes. Inhabits Indian seas.-Shaw, iv. pl. 61.

Gen. 40. Pagrus, Cuv.-Sparus, Lin.

Head compressed; teeth small, numerous, in bundles or brushes, those of the first row being largest.

P. argenteus, Cuv. Body shaded with rose-colour, and silvery ; nostrils tubular, and a black spot on the dorsal fin. Inhabits American seas.-Shaw, iv. 438.

P. erythrinus, Cuv. Back carinated, and the belly round; sides rose-coloured, shaded with silvery scales ; abdomen silvery ; dorsal fin paler than the body, but edged with deep rose-red. 6 inches long. Mediterranean and Indian seas.-Bloch, pl. 274.

P. mormyrus, Cuv. Body silvery, with numerous transverse black bands; tail bordered with black at the tip. 5 or 6 inches long. Inhabits Mediterranean sea.-Shan, iv, 422.

P. roseus. ( $S p$. pagrus, Bloch.) Back carinated; belly round; body rose-coloured, with numerous longitudinal reddish lines; 
abdomen silvery, with yellowish longitudinal streaks; a black spot on each side at the base of the pectoral fins. 12 inches long. Inhabits Mediterranean sea.-Bloch, pl. 267.

4. Jaws with hooked irregular teeth, and crowded ones behind; branchial membrane with seven rays.

This group is composed of those genera with wider mouth and jaws, armed with hooked irregular teeth, having others behind them very small and crowded. The bent teeth in the upper jaw are generally longest. The branchial membrane has seven rays. The characters derived from the operculi, as armed with spines or dentated, has afforded to M. Cuvier indications for the subdivision of this numerous group.

\section{Gen. 41. Dentex, Cuv.-Sparus, Lin.}

Jaws armed in front with long hooked teeth; and on the sides with one row of conical ones; behind the hooked teeth are small and crowded ones.

D. vulgaris, Cuv. (S. dentex, Lin.) Head compressed; eight long curved teeth before; body silvery, shaded with yellow; back reddish brown; vertical and anal fins deep yellow; pectorals reddish; dorsal and caudal yellowish, terminating in a bluish tinge; tail slightly forked. 12 inches long. Inhabits Mediterranean sea. -Bloch, pl. 268.

D. anchorago, Cuv. Head and fins reddish; body yellowish, with transverse brown bands; teeth of the lower jaw bent outwards and curved inwards. 12 inches long. 13 spinous rays in the dorsal fin.-Bloch, pl. 276.

D. cynodon, Cuv. Head and sides yellow; belly silvery, inclining to yellow; pectoral, ventral, and caudal fins red; dorsal fin yellow before, and reddish behind, with eleven spinous rays. 12 inches long. Inhabits Mediterranean sea.-Bloch, pl. 278.

D. macrophthalmus, Cuv. Body yellowish, shaded by white and ciliated scales, with longitudinal streaks of a deep red towards the back, and yellowish towards the belly; eyes very large, and four large teeth in the upper jaw. 6 inches long.-Bloch, pl. 272.

Gen. 42. Lutianus, Cuv. Bloch, Lacep.

Preoperculum dentated, and no spines on the operculum.

L. Lutianus, Bloch. Back round; belly carinated, and the sides compressed; body silvery gray ; back yellowish brown, with transverse blue streaks above the lateral line, and below this line yellow ones; nine spinous rays in the dorsal fin. Inhabits Japanese seas.-Bloch, pl. 245.

Gen. 43. Diacope, Cuv.-Holocentrus, Bloch.

Preoperculum with a large notch for the articulation of the interoperculum.

D. Bengalensis, Cuv. Head and body compressed, with four longitudinal bluish bands, margined with black; scales small and ciliated; back and top of the head reddish; belly and sides white; tail slightly lunated. 6 inches long. Indian seas.-Bloch, pl.246. 
D. quinquelineatus, Cuv. Body yellowish; head and fins violet, shading to red, with five longitudinal blue lines on each side; tail lunated. 12 inches long. Japanese seas._Bloch, pl. 259.

Gen. 44. Cirrhitrs, Lacepede.

Seven rays in the branchial membrane, the last widely separated from the others; preoperculum finely dentated; inferior rays of the pectoral fins thicker and longer than the others, and free at their extremity.

C. marmoratus, (Labrus marmoratus, Shaw.) Body almost entirely covered with small dark spots, accompanied by larger whitish ones, so as to appear marbled; ten spinous rays in the dorsal fin. Inhabits Indian seas.-Shan, iv. 509.

C. pantherinus, Cuv. (Sparus pantherinus, Lacep.) Body gray, with the head and abdomen speckled with unequal round black spots. Inhabits Indian seas.-Shan, iv. 456.

Gen. 45. Bodianus, Cuv. Bloch, Lacep.

Preoperculum without perceptible dentations; operculum with spines.

\section{* With one spine on the operculum.}

B. aya, Bloch. Body bright red above, shading to white on the belly; dorsal fin rounded at the tip; tail lunated. 2 to 3 feet long. Inhabits lakes in South America.-Bloch, pl. 227.

B. apua, Bloch. Body blood-red, silvery towards the abdomen, strewed with black spots, of which those on the back are largest; fins rounded; seven spinous rays in the dorsal fin. 12 to 14 inches long. Inhabits South American seas.-Bloch, pl. 229.

* With two spines on the operculum.

B. argenteus, Bloch. Head long and narrow; body silvery ; fins tinged with yellow, pointed; 14 rays in the anal fin. 6 inches long. Inhabits Mediterranean sea.-Bloch, pl. 231, fig. 1.

\section{*** With three spines on the operculum.}

B. guttatus, Bloch. Body fleshy, brownish yellow; dorsal, ventral, and anal fins with a violet border; the whole fish sprinkled with brown round spots, with a paler central point. 1 foot long. Inhabits Indian and American seas.-Bloch, pl. 224.

B. Banac, Bloch. Body circular, brownish, paler on the sides and belly, with seven longitudinal brown bands; head narrow and pointed; tail rounded. Japanese seas.-Bloch, pl. 226.

B. maculatus, Cuv. (Perca, Bloch.) Body elongated, whitish, with red spots, and covered with silvery scales; fourteen spinous rays in the dorsal fin; fins rounded. American seas.-Bloch, pl. 313.

Gen. 46. Serranus, Cuv.-Epinephelus, Holocentrus, Bloch.

Head scaly; operculum with spines, and the preoperculum with dentations; jaws armed with small teeth, those in the 
upper jaw largest; body elongated, with a long and partly spinous dorsal fin.

* With one spine on the operculum.

S. cceruleo-punctatus, Cuv. (Holocentrus, Bloch.) Body bluish, with pale yellow spots ; fins brown, with numerous round blue spots ; operculi with one spine, and eleven spinous rays in the dorsal fin. 3 inches long.-Bloch, pl. 242, fig. 2.

S. striatus, Cuv. (Holocentrus, Bloch.) Body compressed, dirty white, with five transverse brown bands; ten spinous rays in the dorsal fin. 6 inches long.-Bloch, pl. 235, fig. 1 .

S. punctatus, Cuv. Body compressed, yellowish, thickly spotted with black and red spots and points; eleven spinous rays in the dorsal fin. Inhabits South American seas.-Bloch, pl. 241.

S. afer, Cuv. Body ovate, brown, deeper on the bak ; pectoral fins sulphur yellow, ventrals orange. 12 inches long. Inhabits African seas.-Bloch, $\mathrm{pl} .327$.

\section{** With two spines on the operculum.}

S. lanceolatus, Cuv. Body compressed and broad, silvery, banded and spotted with brown ; fins pointed; eleven spinous rays in the dorsal fin. 6 inches long. Indian seas.-Bloch, pl. 242, fig. 1.

S. maculatus, Cuv. Body grayish, with white spots; pectoral, cau= dal, and dorsal fins rounded; eleven rays in the dorsal fin. Inhabits Indian seas.-Bloch, pl. 242, fig. 3.

S. ruber, Cuv. Head narrow, and with the back and sides deep red; belly pale red, and the base of the fins yellow; eleven spines in the dorsal fin. Japanese seas.-Bloch, pl. 331.

S. siagonotus, Cuv. (Holocentrus, Laroche.) Body oblong, compressed, whitish gray or silvery, deeper on the back; lower jaw dotted below, with small transverse furrows; caudal fin notched ; a round black spot on the dorsal fin. 5 inches long. Inhabits Mediterranean sea. $-A n$. Mus. xiii. pl. 22, fig. 8.

\section{*** With three spines on the operculum.}

S. ongus, Cuv. Head long; body brown, greenish towards the belly, and marked transversely by elongated spots; dorsal, caudal, and anal fins spotted with yellow; tail rounded. Inhabits Japanese seas.-Bloch, pl. 234.

S. tigrinus, Cuv. Brownish on the back, bluish on the sides, and the belly silvery, marked by numerous black spots and bands, those on the fins being rounded. 12 inches long. Inhabits Indian seas.-Shaw, iv. pl. 81.

S. argentinus, Cuv. Ground colour of the body yellowish, top of the head violet, and the sides silvery ; fins pale blue; tail truncated. 5 inches long. - Bloch, pl. 335, fig. 2.

S. marginalis, Cuv. Head large, covered with small scales; four large teetl and small ones on the sides ; preoperculi finely dentated, and the operculum with three spines; body bluish, with brownish back, and red fins. 6 inches long.-Bloch, pl. 328, fig. 1 . 
S. gigas, Cuv. Body ovate, compressed, grayish, with brownish clouds; teeth sharp, and in several rows; dorsal fin with eleven spinous rays. 3 feet long. Mediterranean sea._Shaw, iv. 560.

S. anthias, Cuv. Head short, compressed; teeth very small; body fine red; third ray of the dorsal fin long; ventral fins very long; tail much forked. Inhabits Mediterranean sea-Bloch, pl. 315. Rondeletius conceives this fish to be the Anthias of the ancients.

S. brunneus, Cuv. Body elongated, deep yellow, with brown spots and bands; fins yellow at the base, with black margins; ten spinous rays in the dorsal fin. Norwegian seas.-Bloch, pl.328, fig. 2.

S. merra, Cuv. Body elongated ; back brownish ; belly white, spotted on all parts with brown subhexagonal spots ; fins transparent, and spotted in the same manner. 12 inches long. Inhabits $\mathrm{Ja}$ panese seas.-Shaw, iv. pl. 82.

Gen. 4\%. Plectropomus, Cuv.-Holocentrus, Bodianus, Bl. Base of the operculi with large teeth or spines, directed forwards.

P. calcarifer, Cuv. Head flattened above, compressed on the sides; back brownish, shading to violet; body compressed and covered with silvery scales, with yellow borders, each row being marked by a longitudinal line; anal and caudal fins rounded with brown streaks. 12 inches long. Japanese seas.-Bloch, pl. 244.

P. maculatus, Cuv. Head thick and short; body yellowish, with blue oblong spots of unequal size; seven spinous rays in the dorsal fin; tail slightly lunated. 12 inches long. Inhabits Japanese seas.-Bloch, pl. 228.

P. cyclostomus, Cuv. (Bodianus, Lacep.) Body with four or five irregular transverse bands; eight spinous rays in the dorsal fin; tail lunated._Lacep. iii. pl. 20, fig. 3.

\section{Teeth small and crowded.}

\section{Gen. 48. Cantharus, Cuv.}

Numerous rows of small close-set teeth; body oval; mouth narrow, snout slightly protractile; destitute of spines or dentations on the operculi.

C. vulgaris, Cuv. (Sparus Cantharus, Lin.) Body silvery gray, striped longitudinally with yellowish; teeth in the first row largest; those in the last blunt and rounded.-Bloch, pl. 270.

C. brama, Cuv. (S. brama, Bloch.) Body broad and thin; back carinated, and belly round; scales rough; sides whitish golden; belly white; back gray; lateral line broad, with a row of black points on each side. 12 inches long. Inhabits European seas. -Bloch, pl. 269.

C. macropterus, Cuv. (Labrus, Lacep.) Rays of the dorsal and anal fins long, and furnished with filaments ; tail lunated; a black spot at the posterior angle of the operculi. Inhabits Indian seas. -Lacep. iii. pl. 24, fig. 1. 
C. sparoides, Cuv. (Labrus, Lacep.) Body as deep as long, covered with irregular lunated spots on each side; a concavity above the eyes; tail rounded. Indian seas.-Lacep. iii. pl. 24, fig. 2.

C. centrodontus, Cuv. (Sparus, Laroche.) Body elevated, grā,, with an irregular black spot at the commencement of the lateral line; teeth subulate; tail forked. 18 inches long. Inhabits Mediterranean sea.-An. Mus. xiii. pl. 23, fig. 11 .

\section{Gen. 49. Cichla, Schn.-Labrus, Lacepede.}

Body ovate; mouth wide, protractile; teeth numerous, small and crowded; operculi destitute of spines and dentations.

C. furcata, Cuv. With nine spinous and ten articulated rays in the dorsal fin; last ray of the dorsal and anal fins very long; two pointed and prolonged lobes in the caudal fin. Inhabits Indian seas._Lacep. iii. pl. 21, fig. 1 .

C. hololepidota, Cuv. With eleven spinous and twenty-seven articulated rays in the dorsal fin; two spinous and ten articulated rays in the anal fin; tail rounded. Inhabits Indian seas.Lacep. iii. pl. 21, fig. 2.

\section{Gen 50. Pristopomus, Cuv._Lutianus, Bloch.}

Body compressed, deep; mouth small; teeth numerous, small, crowded; margin of the preoperculum dentated; scales large.

P. hasta, Cuv. Head yellowish brown; sides compressed, yellowish above the lateral line, grayish silvery below it, with numerous cinereous spots, forming irregular lines; pectoral, ventral, and caudal fins red, the others bluish, inclining to yellow; twelve spinous rays in the dorsal fin; tail truncated. Inliabits Japanese seas.-Bloch, pl. 246, fig. 1 .

P. luteus, Cuv. Body broad and thin, silvery, with longitudinal lines of golden colour; fins yellow; tail forked. Inhabits American seas.-Bloch, pl. 247.

P. Surinamensis, Cuv. Body broad before, tapering posteriorly, reddish, with stripes and spots of a deep gray; fins blue, rounded, the tail fin red above. South American seas.-Bloch, pl. 253.

P. Virginicus, Cuv. Body marked by numerous blue parallel longitudinal streaks, with two black transverse bands; tail bilobate and obtuse. Inhabits American seas.-Shaw, iv. 436.

Gen. 51. Scolopsis, Cuv.

Body compressed and deep; mouth small; teeth numerous, small, crowded; margin of the preoperculum dentated; scales large; the suborbitary bone dentated and spinous behind.

This genus was instituted by Cuvier for the reception of the species Kurite and Botche of Russell._Coroman. ii. pl. 105, 106.

Gen. 52. Diagramma, Cuv.-Anthias, Bloch. Body oblong; head rounded; mouth slightly cleft; teeth small, 
numerous, crowded; preoperculum slightly dentated; six large pores under the lower jaw.

D. vulgaris. (A. diagramma, Bloch.) Body compressed, whitish, with brown lougitudinal bands and spots; pectoral, ventral, and anal fins brown, those of the back and tail black and white. 1 foot long. Inhabits Indian seas.-Bloch, pl. 320.

D. Orientalis, Cuv. Body fulvous; dorsal, anal, and caudal fins variegated with blackish brown; twelve spinous rays in the dorsal fin. 4 inches long. Inhabits Japanese seas.-Bloch, pl. 326, fig. 3 .

\section{Gen. 53. Cheilodactylus, Lacep.}

Body and tail compressed; upper lip double and extensible; last rays of the pectoralfins prolonged beyond the uniting membrane ; one dorsal fin ; preoperculum without dentations, and teeth small and crowded.

C. fasciatus, Lacep. With seven brown bands on the body and five on the caudal fin. Inhabits Indian seas.-Lacep. v. pl. 1. fig. 1.

Gen. 54. Micropterus, Lacep.

Mouth cleft ; teeth crowded; a flat spine at the operculum; last soft rays of the dorsal fin detached, and forming a small separate fin.

M. Dolomieui, Lacep. Ten spinous rays and seven jointed ones in the first part of the dorsal fin, four in the second ; caudal fin lunated.-Lacep, iv. pl. 3.

\section{Gen. 55. Grammistes, Cuv.}

Mouth cleft; teeth crowded; scales scarcely perceptible, with two or three spines at the preoperculi and as many at the operculi; no spine at the anal fin.

G. Orientalis, Schn.-Seba, iii. pl. 27, fig. 5 .

Gen. 56. Priacantuus, Cuv.-Anthias, Bloch.

Body covered with rough scales to the point of the snout; lower jaw projecting; mouth obliquely directed upwards; teeth crowded; preoperculum dentated, and terminated towards the base by a dentated spine.

P. macrophthalmus, Cuv. Eyes very large; back deep yellow, lighter on the sides, and shading to white on the belly; pectoral and ventral fins red; base of the dorsal and anal fins bluish, with the extremities yellow; tail yellow, bordered with blue. Inhabits Japanese seas._Bloch, pl. 319.

\section{Gen. 5\%. Polyprion, Cuv.}

Body and head covered with hard ciliated scales; numerous dentations on the head, and a strong scale on the shoulder bone; a dentated ridge under the operculum; spine of the ventral fins serrated; teeth crowded, very small, in both jaws, the vomer, the palate, and base of the tongue. 
P. Americanus, Cuv. (Amphiprion Americanus, Schn.) The only species of the genus. American seas.-Reg. An. ii. 282.

Gen. 58. Holocentrus, Artedi.

Snout short, slightly extensible; teeth small ; scales thick, hard, and dentated; a strong spine at the base of the preoperculum, and the operculum with one or two at its upper margin; soft part of the dorsal fin elevated above the spinous part; occiput without scales, osseous, and striated.

H. sogo, Bloch. Body compressed and rectangular, silvery red, with longitudinal yellow lines on each side; fins long, bright red; eyes large ; tail very much forked. 1 foot long. Inhabits seas of both hemispheres.-Shav, iv. pl. 80.

H. angularis, Cuv. (Labrus angularis, Lacep.) Twelve spinous and nine articulated rays in the dorsal fin, the articulated rays longest ; five or six rows of small points on each side; second piece of the operculum notched and angular. Inhabits Indian seas.Lacep. iii. pl. 22. fig. 3.

H. diadema, Cuv. Body black, with a longitudinal white band; eleven spinous rays and ten articulated ones in the dorsal fin. Inhabits South sea.-Lacep. iii. pl. 23, fig. 3.

\section{Gen. 59. Acerina, Cuv.-Perca, Bloch.}

Mouth slightly cleft ; teeth small, crowded; head without scales and furrowed; margin of the preoperculum armed with eight or ten small spines or hooks; a pointed spine at the operculum, and another at the shoulder bone; margin of the scales dentated.

A. cernua, Cuv. The Ruffe. Head thick and flattened; body long and slimy, subolivaceous, with numerous dusky spots; first fifteen rays of the dorsal fin hard and pointed; tail forked. 8 inches long. Inhabits rivers of Europe. B.-Pen. Brit. Zool. iii. 350.

A. Schraitzer, Cuv. Body somewhat elongated, brownish, with four longitudinal black lines on each side; abdomen silvery. 10 inches long. Inhabits the Danubeand its tributary streams.-Bloch, pl. 332 , fig. 1.

Gen. 60. Stelliferus, Cuv.

Head naked and cavernous; suborbitaries, preoperculi, and operculi furnished with spines; snout tumid; teeth small and crowded; four rays in the branchial membrane.

S. Capensis. (Bodianus stellifer, Bloch.) Head short and truncated; iris white, surrounded with a stellated silvery ring, body compressed and silvery; back and fins yellowish brown; tail ovate. 5 inches long. Seas near the Cape of Good Hope.-Bloch, pl. 231.

Gen. 61. Scorpana, Schn.

Head rough with spines, chiefly above the orbits, on the occi- 
put, and cheeks; preoperculum with three or four spines, and the operculum with two, prolonged in ridges.

The genus Scorpæna of Linnæus, including fishes with tuberculated or spinous naked heads with cirri, of a singular and often frightful appearance, has been subdivided by Cuvier and others into more distinctly characterized groups. The genus Scorpæna of Linnæus may therefore be considered as the type of a family in which these characters are variously combined. Their jaws are much cleft; teeth small and crowded; and the pectoral fins very large, embracing a part of the throat.

S. porcus, Lin. Head of large size, with cirri under the eyes and along the lateral line; body dusky, variegated with black above, pale beneath, with a reddish tinge; dorsal fin with very strong spinous rays; scales small, rough. 12 to 15 inches long. Inhabits European seas.-Shaw, iv. 267.

This species was well known to the ancients, and various accounts of its supposed use in medicine are given by Hippocrates and later writers. It has now, however, lost its reputation; and itsflesh, which is coriaceous, is only eaten by the poorer people. When taken it erects its dorsal spines, and the wounds inflicted by these were formerly considered very dangerous.

S. scrofa, Lin. Body rufous, with brown variegations; cirri under the eyes and along the lateral line; soft dentated processes attached to the cheeks, to the angles of the jaws, and to the sides; scales larger than in the preceding. 2 to 4 feet long. Inhabits European seas.-Shaw, iv. pl. 38.

S. dactyloptera, Laroche. Spines of the head simple, and without cirri or soft dentated appendages. Inhabits European seas.An. $d u$ Mus. xiii. pl. 22, fig. 9.

S. gibbosa, Cuv. Head large, with the spines cleft at their extremity into many points; pectoral fins broad; mouth turned up. Inhabits European and American seas.-Cuv. Reg. An. ii. 285.

S. Plumieri, Cuv. Body blackish brown, with feathered cirri on the head and lateral line. American seas.-Shan, iv. pl. 40.

\section{Gen. 62. Synanceia, Schn.-Scorpona, Lin.}

Head covered with unequal tubercles, more or less projecting; mouth and eyes directed upwards; no swimming-bladder.

S. horrida, Cuv. Head large, abrupt in front, and marked by numerous tubercles, depressions, and spines; a semilunar cavity on the top; body ferruginous brown, deepest above, without scales, and marked by callous tubercles. 12 to 15 inches long. Inhabits Indian seas.-Shaw, iv. pl. 39.

This singular fish is of a very forbidding appearance, and realizes to the eye all that a vivid imagination could consider as monstrous. The head is very large, abrupt in front, and marked by numerous tubercles, depressions, and spines. On the top is a semilunar cavity; the mouth opens upwards and resembles a horse shoe; and the head, body, pectoral, and dorsal fins are strewed with numerous tubercles. All the fins are thick and fleshy, and furnished with strong rays.

S. didaclyla, Cuv. Head depressed and furnished with several abrupt depressed cirri; eyes large, on two protuberances; body dusky brown, with transverse yellow streaks above, and roundish spots below; fins with the rays very long; two digitated pro= 
cesses at the pectoral fins. 12 inches long. Inhabits Indian seas.-Shav, iv. 279.

\section{Gen. 63. Pterois, Cuv.}

Head covered with unequal tubercles and fleshy appendages; rays of the dorsal and pectoral fins very long, surpassing the membranes; a swimming-vessel.

P. volitans, Cuv. Head truncated, broad before and compressed on the sides, furnished with spines and broad dentated cirri; body brownish yellow, with deep brown transverse bands; pectoral fins extremely large, deep violet, spotted with white. 12 inches long. Inhabits rivers of Japan.-Bloch, pl. 184.

P. antennata. Head rough, spinous; two cylindric tentacula over the eyes, surrounded by fibrous brown bars; body variegated with brown and yellow transverse stripes, and a brown band across the eyes; rays of the pectoral fins white, simple, and very long. 12 inches long. Rivers of Amboyna._Shaw, iv. pl. 39.

Gen. 64. Tenianotus, Lacep.

One or more spines and no dentations on the operculi; body much compressed vertically; dorsal fin long, the spinous part not distinguished from the soft, but forming an extended vertical riband along the back, commencing between the eyes.

T. triacanthus, Lacep. With cirri on the eyelows.-Lacep. iv. 306.

T. latovittatus, Lacep. General colour blue, with a longitudinal black and very broad band on each side; dorsal and anal fins spotted with brown. 2 feet long. Inhabits Indian seas.- Lacep. iv. pl. 3 , fig. 2.

\section{Sectron II.-Dorsal fin deeply divided, or two distinct dorsal fins.}

This section have the dorsal fin divided, or two distinct fins. Their teeth are generally very small, crowded and hooked. Cuvier divides this section into tribes.

\section{Head without spines.}

Gen. 65. Athentna, Lin.

Body oblong; intermaxillaries extensible, with very small teeth; lower jaw and tongue smooth; five rays in the branchial membrane; cheeks and operculi scaly; two small dorsal fins ; a silvery band on the sides.

A. hepsetus, Lin. Body brownish above, silvery below, and gray on the sides, diaphanous; with a broad longitudinal silver band on each side ; fins and tail white. 6 or 7 inches long. Inhabits Mediterranean sea.-Bloch, pl. 393, fig. 3.

A. Sihama, Cuv. Body bluish green, lanceolate, subpellucid; silvery band obscure. 9 inches long. Red Sea.-Shaw, v. 132.

\section{Gen. 66. SphyrenA, Lacepede.}

Body elongated; snout pointed; jaws much cleft; under jaw 
longest, with a row of conical teeth, of which the two anterior are largest; intermaxillaries with two strong teeth before, followed by a row of smaller ones, and a row of strong ones on each palate bone; cheeks and operculi scaly.

S. argenteus, (Esox sphyrana, Lin.) Head narrow, oblong, broad above, and covered with thin scales; body greenish above, silvery on the sides and belly; pectoral, ventral, and anal fins reddish; dorsal and caudal bluish. 3 feet long. Inhabits Mediterranean sea.-Bloch, pl. 389.

\section{Gen. 6\%. Paralepis, Cuv.}

Lower jaw surpassing the upper, forming a cone, and armed with a row of conical teeth, of which the two anterior are the strongest; the ventral fins and first dorsal much behind; and the second dorsal scarcely visible.

The two species which form this genus are the Coregonus paralepis and the Osmerus sphyrenoides of Risso.

Gen. 68. Mullus, Lin.

Head sloping ; two long cirri under the chin; large scales on the head and body, which fall easily ; body oblong; eyes contiguous; three rays in the branchial membrane; two dorsal fins.

M. barbatus, Bloch. The Red Surmullet. Back fine red, brilliant silvery on the belly; head broad, truncated. 8 to 9 inches long. Inhabits European seas.-Bloch, pl. 348, fig. 2.

This is considered a very delicate fish for the table. It was in high repute among the ancient Romans; and one of the refinements of luxury in ancient Rome was to have this fish in artificial rivulets under the tables of the great, that they might enjoy the pleasure of seeing its colours fade as it expired.

M. surmuletus, Bloch. The Surmullet. Body reddish silvery, with golden yellow longitudinal bands. 12 to 14 inches long. Inhabits Northern seas.-Shan, iv. pl. 88.

M. auriflamma, Lacep. Back bronze-coloured; a broad longitudinal and red band on each side of the body; a black spot towards the extremity of the lateral line; cirri white; tail yellow. Inhabits Indian seas._Lacep. iii. pl. 13.

M. vittatus, Forsk. Body whitish, with two longitudinal brown and three yellow bands on each side ; fins whitish. Inhabits Arabian seas.-Shaw, iv. pl. 89.

M. trifasciatus, Lacep. Whitish, with three transverse brown bands on each side. Inhabits Indian seas.-Shaw, iv. pl. 89.

M. bifasciatus, Lacep. Whitish, with two transverse brown bands on each side. Inhabits Indian seas.-Lacep. iii. pl. 14.

\section{Gen. 69. Poмatomus, Lacep. Cuv.}

Body elongated ; two dorsal fins; scales large, deciduous ; snout short; teeth crowded; eyes very large; preoperculi more or less notched; seven rays in the branchial membrane. 
P. telescopus, Risso. Body black, variegated with blue, red, and violet. Inhabits the Mediterranean.-Risso, pl. ix. fig. 31 .

\section{Gen. 70. Mugru, Lin.}

Head depressed, broad and scaly; ventral fins under the abdomen, and two short distant dorsal fins, of which the first or spinous is further back than the ventrals, and the second answers to the anal; mouth with fleshy and crenulated lips; lower jaw with a carination in the middle, entering into a corresponding groove in the upper; no teeth; branchial membrane with three rays.

M. Cephalus, Lin. The Common Mullet. Body grayish, banded longitudinally with brownish parallel lines; belly silvery; fins bluish ; first dorsal fin with four spinous rays. Inhabits the European, Indian, and Atlantic seas.-Shaw, v. pl 114.

This fish, the Mugil or Mugilus of the ancient Romans, and highly esteemed as food, is very abundant in the Mediterranean on the coasts of Spain. It is much used in the southern countries of Europe. Of the roes a kind of caviar, named pontargue or bontarge is made, much esteemed for the table.

M. auratus, Risso. (M. tang, Bloch.) Head narrow and sloping; mouth small; back brown; sides white, banded with yellow, and the fins brownish yellow; first dorsal fin with four and the second with nine rays. 12 inches long. Inhabits Mediterranean sea._Bloch, pl. 395 .

\section{With spines or dentations on the head.}

This group comprehends those genera which have dentations or spines on the operculum or pre-operculum, or any other part of the head, but where the cheek is not covered by the suborbitary bones. Their two dorsal fins are generally contiguous.

\section{Gen. 71. Perca, Cuv.}

Snout without scales, not advancing beyond the lips; second dorsal fin not sensibly longer than the first; ventral fins on the thorax; pre-operculi dentated; operculi spinous.

P. fluviatilis. The Common Perch. Body brownish olive, of a golden tinge, with broad transverse bands of a deeper colour; first dorsal fin a little longer than the second, and marked behind by a black spot; the other fins and tail red. 8 to 15 inches long. Rivers and lakes in Europe. B.-Penn. Brit. Zool. iii. pl. 59.

The Perch is found in all the lakes of Europe and Northern Asia. It spawns in spring and is very prolific; for in one taken in the lake of Geneva there were 992,000 ova; but the numberless enemies to which the young are exposed make it probable that not a hundredth part reach maturity. They swim with much rapidity, keep near the surface, and feed on small fishes, reptiles, insects, \&c. In attempting to swallow the stickleback, however, this animal erects its dorsal spines in such a manner that, fixed in its mouth, the perch is unable to shut it, and dies of hunger. The spines on the dorsal fin of the perch in like manner protect it from the voracity of the pike. The perch was well known to the Greeks and Romans, and is thus mentioned by Ausonius :

Nec te delicias mensarum, perca, sileho Amnigenos inter pisces dignande, marinis Solus puniceis facilis, contendere mullis.

The Laplanders make a kind of glue with the skins of perches, not inferior to the isinglass which is produced from the sturgeon. 
P. labrax, Lin. (Sciana diacantha, Bloch.) The Basse Perch. Body silvery: with the fins reddish, first dorsal fin the same length as the second; two spines at the operculum; tail slightly lunated. 12 inches long. Inhabits the Mediterranean sea. B.-Penn. Brit. Zool. iii. pl. 60.

P. punctata, Cuv. (Scicena, Bloch.) Back bluish; belly and sides silvery; ventral and pectoral fins brown red, those of the anus and tail reddish at the base and blue at the margin, body marked with black spots or points from the back to the lateral line. 12 inches long. Inhabits Mediterranean sea.-Bloch, pl. 305.

P. lineata, Cuv. (Scicena Bloch.) Back violet; sides and belly silvery, with longitudinal yellow lines along the body; first dorsal fin with eight spinous rays. 12 inches long. Inhabits $\mathrm{Me}$ diterranean sea.-Bloch, pl. 304.

Gen. 72. Centrofomus, Lacepede.

Snout without scales; teeth crowded; pre-operculi dentated; operculi without spines, or with the points flattened; the suborbitary bone generally dentated.

C. Niloticus, Cuv. (Perca Nilotica, Gmel.) Body brown, with eight spinous rays in the first dorsal fin; one spinous and eight articulated ones in the second. Inhabits the Nile and Caspian sea.-Geoff. Pois. du Nil.pl. 9, fig. 1.

This fish is conceived by Geoffroy to be the Lotus of the ancients, the name by which it is still known in upper Egypt.

C. undecimalis, Cuv. (Scicena, Bloch.) Body red, with silvery abdomen; fins of the tail and back yellow at their base, and blue towards the extremity; eight spinous rays in the first dorsal fin, and one spinous and ten articulated ones in the second. 12 inches long. Inhabits American seas.-Bloch, pl. 303.

Gen. 73. Exoplosus, Lacep.

Teeth flexible and small; body and tail much compressed; dorsal fins high vertically and prolonged; suborbitaries dentated; pre-operculi dentated and spinous towards the base.

E. armatus, Cuv. (Choctodon armatus, Shaw.) Body silvery white, darker, and with a bluish tinge on the back, with seven transverse black bands; tail slightly lunated. 4 inches long. Inhabits Indian seas-Shan, iv. 373.

Gen. 74. Prochrlus, Cuv.-Sciana, Bloch.

Body oblong; scales pretty large ; head short ; teeth crowded; no dentations on the preoperculi; snout without scales.

P. macrolepidotus, Cuv. Body yellow, with transverse brownish violet bands; scales large; dorsal, anal, and caudal fins spotted with brown; pectoral fins yellow; ventrals brick-red. 12 inches long. From India.-Bloch, pl. 398.

P. maculatus, Cuv. Body deep yellow, spotted with brown; fins bluish at the base, the other parts yellowish, marked with black 
points, except those of the breast and belly. $5 \frac{1}{2}$ inches long.Bloch, pl. 299, fig. 2.

\section{Gen. 75. Sandrus, Cuv.}

Headentirely destitute of scales; jaws armed with pointed and distant teeth; preoperculi dentated, but operculi without spines.

S. lucioperca. (Perca, Bloch.) Back round, with ten to twelve brown transverse bands ; sides silvery, and belly white ; pectoral fins yellowish, the others whitish; dorsal fins of equal length. 1 to 3 feet long. Rivers and Lakes of Europe.-Bloch, pl. 51 .

S. coro, Cuv. (Scicena, Bloch.) Body bluish-silvery, with brownish back, and body marked on each side with eight transverse brown bands; tail slightly forked. 6 to 12 inches long. Inhabits South American seas.-Bloch, pl. 307, fig. 1.

\section{Gen. 76. Terapon, Cuv.}

Body and head oblong; snout obtuse; scales small; mouth small, with a row of equal close-set teeth in each jaw, behind which are others smaller and crowded; preoperculi dentated, and the operculi spinous; strong dentations at the shoulder bone; branchial membrane with six rays.

T. servus, Cuv. (Holocentrus, Bloch.) Body silvery, with brownish back, and four longitudinal black lines on each side; caudal fin brownish, forked, the two points black, and three bands of the same colour in the middle. 5 inches long. From Japan.Bloch, pl. 238, fig. 1 and 2.

\section{Gen. $7 \%$. Apogon, Lacep.}

Summit of the head elevated, two dorsal fins; no cirri under the lower jaw ; scales large and easily detached; preoperculi dentated ; teeth crowded.

A. ruber, Lacep. (Mullus imberbis, Gmel.) Body of a fine red colour; mouth wide. Inhabits Mediterranean sea.-Cuv. Reg. An. ii. 296.

A. radiatus, Cuv. (Cheilodipterus, Lacep.) Nine spinous rays in the dorsal fin ; tail lunated; a large transverse band near the caudal fin, and eight longitudinal bands on each side._L Lacep. iii. pl. 34 .

Gen. 78. Cingla, Cuv.

Snout scaly, projecting ; scales rough ; teeth crowded; operculi spinous; preoperculi dentated; two nearly equal dorsal fins.

C. zingel, Cuv. (Perca, Bloch.) Body yellowish, with transverse brown bands and spots; belly white ; lateral line near the back, straight. 14 to 16 inches long. The Danube.-Bloch, pl. 106.

C. asper, Cuv. (Perca, Bloch.) Head large; body elongated, and covered with large hard scales; colour yellowish, with three or four transverse bands; belly white. Inhabits Rivers of Europe. -Bloch, pl. 107. 
Gen. 79. Umbina, Cuv.

Snout less projecting than the preceding genus; second dorsal fin longer than the first; preoperculi dentated; teeth small, crowded; pores under the lower jaw.

U. cirrhosa, Cuv. (Scicena, Lin.) Body pale-yellow, brownish on the back, subargenteous beneath, with oblique yellow and blue longitudinal lines, and a short cirrus on the lower jaw. 1 to 2 feet long. Inhabits the Mediterranean sea.-Shaw, iv. pl. 77.

Gen. 80. Lonchurus, Bloch.

Head scaly; ventral fins separate; tail lanceolate.

This genus differs from the preceding only in having the tail lanceolate.

L. barbatus, Bloch. Body ferruginous brown; ventral fins sharp, and placed at some distance from each other; two cirri at the lower jaw, and the first ray of the ventral fin elongated into a bristle. 12 inches long. From Surinam.-Bloch, pl. 359.

Gen 81. Screna, Lacepede.

Snout scaly, blunt, and more or less prominent; dentations of the preoperculi almost insensible ; spines of the operculi wellmarked; teeth elongating with age, and forming a row of unequal hooks.

S. nigra, Bloch. Black Sciæna. Body blackish-brown, silvery towards the belly, with black fins; tail rounded. 10 to 12 inches long. Inhabits Mediterranean seas.-Bloch, pl. 297.

S. aquila, Cuv. Body silvery gray, remarkable for its large branched swimming-vessel. Upwards of three feet long. Inhabits Mediterranean sea.-Cuv. Reg. An. ii. 298.

S. carutta, Cuv. (Johnius, Bloch.) Back and sides steel blue; belly and lateral line yellow; dorsal and caudal fins bluish, the others reddish-brown. 18 inches long. Inhabits Indian seas.Bloch, pl. 356.

S. aneus, Cuv. (Johnius, Bloch.) Head compressed, scaly ; body elongated; back black; sides white; pector:ll and ventral fins reddish-brown; anterior part of the dorsal fin blackish; tail bluish at the point. Indian seas. $-B l o c h, \mathrm{pl} .357$.

\section{Gen. 82. Pogonias, Lacep.}

Snout obtuse; bones of the head cavernous ; operculi scaly, but without dentations; teeth crowded; pores under the lower jaw ; spinous part of the dorsal fin separated from the other to the base; numerous small cirri at the lower jaw.

P. fasciata, Lacep. (Labrus grunniens, Mitchell.) Head thick; eyes large; under jaw with about twenty short filaments; dorsal fin slightly notched. 12 inches long. Inhabits American seas. -Lacep. iii. pl. 138.

\section{Gen. 83. Otolithes, Cuv.}

Dorsal fin in two parts; dentations of the preoperculi scarcely 
sensible; external row of teeth largest, and two long ones in the upper jaw ; snout not tumid.

The Johnius ruber and regalis of Schneider are the types of this genus.

Gen. 84. Ancylodon, Cuv.

Head naked, compressed, armed with dentations and spines; mouth cleft; the teeth, particularly those below, in the form of long projecting hooks; second dorsal fin long, and tail pointed.

The Lonchium ancylodon of Schneider is the rype of this genus.

Gen. 85. Percis, Schn.-Scicena, Bloch.

Body elongated; head depressed ; teeth hooked; first dorsal fin with a few rays, the second running along almost the whole back; anal fin without spines; preoperculi slightly dentated, and the operculi spinous.

P. cylindrica, Cuv. Body cylindrical, yellowish-brown above, silvery below, marked with eleven brown transverse bands, and two pale brown longitudinal lines ; five spinous rays in the first dorsal fin. 6 inches long.-Bloch, pl. 249, fig. 1 .

Gen. 86. Trachinus, Lin.

Body and tail elongated, compressed; head compressed laterally; eyes approaching vertically; a strong spine on the operculi, and two small ones before each eye; shoulder-bones dentated; second dorsal fin very long; no swimming-bladder; ventral and anal fins very much forward.

T. draco, Lin. The Dragon Weever. Body brownish-yellow ; first dorsal fin black, and five-rayed. 10 to 12 inches long. Inhabits Northern seas. B.-Shaw, iv. pl. 21.

The spines of the first dorsal fin of this fish are conceived by the fishermen to be poisonous. It is, however, esteemed as an article of food on the Continent. It is very tenacious of life, and can exist many hours out of the water. The skin is remarkably tough.

\section{Head Mailed.}

This tribe comprehends those genera which have the head mailed by the extension, solidity, and hardness of the suborbitaries. Their dorsal fins are sometimes contiguous, sometimes separated. Some have the ventral fins jugular.

Gen. 8\%. Uranoscopus, Lin.

Head depressed, almost cubical, thicker than the body, with the eyes above, and directed upwards; lower jaw longer than the upper, and the mouth cleft vertically; preoperculi crenated below; a strong spine on each shoulder; first dorsal fin small, with striated rays; the second as well as the anallong and soft; no swimming-vessel.

U. scaber, Bloch. Brown on the back, gray on the sides, white on the belly; a membranous process with a long filament at the interior tip of the lower jaw ; lips with smaller cirri. 12 inches long. Inhabits Northern seas.-Shaw, iv. pl. 20.

This fish generally conceals itself in the mud or fuci, with the tip of the head 
up, and feeds on small fishes and insects, the movement of the cirri in this situation probably attracting them.

$$
\text { Gen. 88. Trigla, Lin. }
$$

Head cubical, covered with a bony plate, formed by the enormous suborbitaries; operculi, preoperculi, occiput, and shoulder generally terminating behind in a spine; teeth pointed, crowded like the pile of velvet; scales small; lower rays of the pectoral fins detached from the others; swimming-vessel bilobate.

T. cuculus, Lin. The Cuckow Gurnard. Body slender, red above, more or less marked by whitish transverse bands; belly silvery; lateral line of broad silvery scales; fins of the breast and tail, which is forked, reddish; ventral, anal, and dorsal fins white, the last spotted with yellow; a black spot on the first dorsal fin. 12 inches long. Inhabits European seas.-Shaw, iv. pl. 90.

T. gurnardus, Bloch. The Gray Gurnard. Body above deep gray, with blackish and red spots, beneath silvery ; lateral line composed of rounded whitish scales, with a dusky central spot. 1 to 2 feet long. Inhabits European seas. B.-Shan, iv. pl. 90.

T. lineata, Bloch. Lirieated Gurnard. Head black, and sides deep red, with numerous transverse lines and deeper spots; on each side of the dorsal fins a row of broad serrated processes of a yellow colour; lateral line similar; pectoral and first dorsal fins with black spots; anal and second dorsal fins bluish; tail slightly lunated. Inhabits Mediterranean sea. B.-Bloch, pl. 354.

T. hirundo, Lin. Body brown, rounded; snout slightly notched ; pectoral fins equal in length to the third of the body, and spotted with bluish. 1 to 2 feet long. Inhabits European seas. B.Bloch, pl. 60.

T. lyra, Lin. Body rose-red, silvery beneath; snout strongly divided into two dentated lobes. 1 to 2 feet long. Inhabits European seas. B.-Bloch, pl. 350 .

T. pini, Bloch. Body reddish, except the belly, which is yellowish; ventral tins red, the others bluish; lateral line with thin transverse processes like the leaves of the pine.-Bloch, pl. 355.

T. punctata, Bloch. Body dotted with numerous red points; pectoral fins very large, blue; the others yellow. Inhabits American seas. - Bloch, pl. 353.

Gen. 89. Peristedion, Lacep-Trigla, Lin.

Body completely mailed with osseous plates ; suborbitary prolongations forming a forked snout; jaws without teeth, and branched cirri under the lower; two dorsal fins, united at their base, the anterior with longest rays.

P. cataphractum, Cuv. Body pale-red, octagonal, completely mailed with bony plates; ventral fins gray, the pectorals blackish; rays of the first dorsal fin terminating in filaments. 12 inches long. Inhabits Mediterranean sea.-Bloch, pl. 349. 
Gen. 90. Dactrlopterus, Lacep.-Trigla, Lin.

Detached rays below the pectoral fin numerous, and united by a membrane, so as to form distinct pectorals ; rays of the supernumerary pectorals as long as the body, forming a species of wings; snout short; occiput and preoperculi prolonged behind into long spines; jaws with small rounded teeth; scales carinated.

D. volitans, Cuv. Body crimson-red above, whitish beneath, covered with strong carinated and sharp-pointed scales ; first dorsal fin pale-violet, crossed by deeper lines, the two first rays separate and longest ; supernumerary pectoral fins very large, transparent, olive-green, with numerous bright blue spots; tail pale violet. 12 inches long. Inhabits Mediterranean, Indian, and Atlantic seas.-Shaw, iv. pl. 91.

This species is capable of supporting itself out of the water in the manner of the common flying-fish for some seconds, by means of its large pectoral fins.

Gen. 91. Cephalacantrus, Lacep-Gasterosteus, Lin. Head furnished on each side with two dentated and very long spines ; no isolated rays before the first dorsal fin ; fins of ordinary proportions.

C. Spinarella, Lacep. The only species known. Inhabits the Indian seas.-Shaw, iv. 608.

Gen. 92. Monocentris, Schn.

Body short and thick, entirely mailed with enormous angular, sharp, and carinated scales ; first dorsal fin composed of four or five free spines, and the ventral fins of one, in the angle of which are some soft rays; head short, thick, mailed.

M. carinata, Schn. Forehead projecting; mouth large; teeth small, crowded; eight rays in the branchial membrane. 5 inches long. Inhabits Japanese seas.-Shaw, iv. 610.

Gen. 93. Cotrus, Lin.

Head thicker than the body, spinous, and flattened horizontally ; first dorsal fin spinous, distinct from the second soft one; pectoral fins large; ventral fins thoracic.

The fishes of this genus are found on rocky shores, can live for some time out of the water, and, when irritated, inflate their head by filling their gills witb air. The fresh water species have the head almost smooth, and only one spine at the preoperculi.

C. gobio, Lin. River Bullhead. Body yellowish-olive, deepest on the head and back, variegated with black; a hooked spine on each side of the head. $3 \frac{1}{2}$ inches long. Inhabits clear rivers of Europe.-Penn. Brit. Zool. iii. pl. 43.

C. quadricornis, Bloch. Four-Horned Bullhead. Head thick, flattened below; body olivaceous, marbled with brown above, whitish beneath, with four bony tubercles on the head; ventral 
fins and first rays of the pectorals red. 6 inches long. Inhabits Mediterranean sea. B.-Shaw, iv. pl. 36.

C. Scorpius, Lin. The Father-Lasher. Head large, with a small spine before each eye ; two strong ones at the operculi, and two on the shoulder ; body brown, marbled with gray and white ; fins and tail transparent, clouded with brown, and the rays banded regularly with deep brown. 8 to 10 inches long. Inhabits European seas. B.-Penn. Brit. Zool. iii. pl. 44.

Gen 94. Aspidophorus, Lacep.-Agonus, Schn.-Phalan-

$$
\text { gites, Pall.-Cottus, Lin. }
$$

Body octagonal, completely covered with scaly plates; two dorsal fins; head thicker than the body, with points and depressions above, flattened below.

A. cataphractus, Cuv. Armed Bullhead. Head large, bony, and very rugged; nose armed with four upright short spines, and on the throat a number of cirri ; body octagonal ; first dorsal fin of six spinous rays; colour brown above, with three or four transverse blackish bands, whitish beneath. 5 inches long. Inhabits European seas. B.-Penn. Brit. Zool. iii. pl. 43.

A. Japonicus, Lacep. Body yellowish-brown; plates disposed into eight prominent lines; no cirri on the throat. 12 inches long. Inhabits sea about the Kurile Islands.-Shaw, iv. 264.

A. monopterygius, Cuv. (Aspidophoroides, Lacep.) Body narrow, elongated, octagonal, brown on the back, gray on the sides, with brown spots and bands; belly spotted with white; only one dorsal fin. Inhabits Indian seas.-Bloch, pl. 178, fig. 1, 2.

Gen. 95. Platycephalus, Bloch.-Cottus, Lin.

Head flattened; suborbitaries spinous, large and broad; body flattened, and ventral fins situate behind the pectorals and much separated.

P. spatula, Bloch. Body depressed, grayish, with dusky clouds and spots; head marked above by sharp lines, and on each side by two spines. 12 inches long. Arabian seas.-Bloch, pl. 424.

P. scaber, Bloch. Back bluish ; sides and belly silvery, with six reddish brown transverse bands; head with four rows of small spines; lateral line spinous. 12 inches long. Indian seas._Bloch, pl. 180.

\section{Gen. 96. Batrachus, Schn.}

Head flattened horizontally, broader than the body; mouth large ; operculi spinous ; first dorsal fin short, with three spinous rays; the second soft and long, as well as the anal; lips often furnished with cirri.

This group conceal themselves in the sand to watch their prey, and make dangerous wounds by their spines.

* With cirri.

B. tau, Cuv. (Gadustau, Lin.) Body yellowish brown, paler be- 
neath, the whole, as well as the fins, variegated with numerous irregular blackish spots; tail with two or three transverse bands; lower lip fringed with cirri. 1 foot long. Inhabits American and Indian seas.-Bloch, pl. 6, fig. 2, 3 .

B. grunniens, Cuv. (Cottus, Lin.) Body brown, smooth, with white variegations, and exuding a mucous fluid; fins pale, spotted with brown; sides of the head and lower jaw furnished with cirri. 6 to 8 inches long. Indian and American seas.-Bloch, pl. 179.

\section{** Without cirri.}

B. Surinamensis, Cuv. S. American seas._Cuv. Reg. An. ii. 308.

\section{Skin without scales, and pectorals supported by arms.}

Gen. 97. Lophius, Cuv.

Head extremely broad and depressed, spinous in many parts; mouth wide, with pointed teeth; lower jaw with numerous cirri ; two distinct dorsal fins, and some free and moveable rays on the head; branchial membrane with six elongated rays, and the opening behind the pectorals; ventral fins placed before the pectorals; skin without scales; no swimming.vessel.

The fishes of this genus are said to conceal themselves in the sand, moving the rays upon their head, which being taken for worms by the smaller fishes, are thus brought within their reach.

L. piscatorius, Lin. The Angler or Frog-Fish. Head extremely large, rounded; pectorals supported as by two arms ; mouth excessively wide; body brown, with deeper and paler variegations; ventral fins short, stiff; two or three long tentacula on the top of the head, and sides fringed with similar processes. 2 to 4 or 6 feet long. Inhabits European seas.--Shaw, v. pl. 161.

This species grows to a large size, some having been taken measuring six or seven feet in length. In shape it bears some resemblance to a tadpole. The head is extremely large, rounded in front, and the mouth very wide. The Frog-Fish frequents shallows, lying in ambush half covered by sea weeds for its prey.

Gen. 98. Antennarius, Commers.-Lophius, Bloch. Body and head compressed; mouth opened vertically; branchial membrane with four rays; free rays on the head, the first slender, often terminated by a tuft, the two following augmented by a membrane, sometimes tumid, sometimes united like a fin; dorsal fin long; and often fleshy appendages over all the body.

This genus are able to inflate their large stomach in the manner of the tetrodons, like a balloon. On land their fins assist them to crawl almost like a quadruped, their pectoral fins on account of their position acting as hind feet; and they are able to live out of the water for two or three days. They are found in tropical seas.

A. histrio, Cuv. Body thick, much compressed, rough and unequal, yellowish brown, irregularly marked or marbled with deep brown or blackish variegations; pectoral and ventral fins resembling short arms ; upper lip and head with cartilaginous appendages, 
terminated by fleshy and elongated processes. 10 or 12 inches long. Inhabits Indian and American seas._Shaw, v. pl. 164.

A. Commersonii, Cuv. Body entirely black, with a milk white round spot on each side; a long and slender filament with an elevated tip above the eyes. A few inches long. Inhabits Indian seas.Shaw, v. 387.

A. Chironectes, Cuv. (L. variegatus, Shaw.) Body reddish, with some black spots; a long filament above the upper lip, terminated by a very small fleshy mass._Lacep. i. pl. 16, fig. 2 .

A. marmoratus, Cuv. Body oval,slightly compressed, blackish above, with bluish clouds or spots, whitish beneath and marbled; dorsal fin simple. 5 inches long. Pacific Ocean._Shaw, v. pl. 165.

A. striatus, Cuv. Body compressed, yellowish brown, marked all over, chiefly in a transverse direction, by very numerous and closely placed narrow black streaks; pectoral and ventral fins resembling short arms ; a long filament dilated into an oval-shaped tip on the top of the mouth, and beyond this two strong and thick processes. 5 inches long. Inhabits Southern seas.-Shaw, Nat. Mis. v. pl. 175.

A. hirsutus, Cuv. (Lophius, Lacep.) Body compressed laterally, with scattered very small blackish spines; upper lip extensible; a filament terminated by a small fieshy mass above the snout; two rays in the first dorsal fin, nineteen in the second. Inhabits seas of New Holland.-An. Mus. iv. pl. 55, fig. 3.

A. lavis, Cuv. (Lophius, Lacep.) Body compressed laterally, smooth; filament above the snout terminating in a slender point; two rays in the first dorsal fin, seventeen in the second. Inhabits seas of New Holland.-An. Mus. pl. 55, fig. 4.

\section{Gen. 99. Malthe, Cuv.-Lophius, Lin.}

Head extraordinarily broad and depressed; eyes much before; mouth under the elongated and pointed snout, protractile; branchiæ supported by six or seven rays, and opening on the dorsal surface above the pectoral fins; one soft dorsal fin; body rough with osseous tubercles; cirri along the sides.

M. vespertilio, Cuv. Ventral fins resembling feet and the pectorals hands; body reddish, tuberculated, the tubercles yellow; above the nostrils a cartilaginous filament with a dilated tip. 10 to 18 inches long. Inhabits S. American seas.-Shaw, v. pl. 163.

\section{Family V.-Scomberoides.}

This family are distinguished by their small scales, often imperceptible, except towards the end of the lateral line, where they form sometimes a projecting ridge. In others this carina is formed by the skin itself, independently of the size of the scales, supported by the transverse processes of one or two vertebræ. The soft part of the dorsal and anal fins is sometimes a little thickened before by the scales, but never completely connected by them; on the contrary, the menbrane which unites the rays behind is often very slender, and even wanting entirely in some genera, when these rays, being then isolated, take the name of spurious fins. Cuvier divides 
the family into four sections or tribes, characterized from the structure of their dorsal fins.

\section{With two dorsal fins, the spinous one not divided.}

Gen. 100. Scomber, Lin.

A projecting ridge on each side of the tail, and a row of pointed teeth in each jaw; anal and dorsal fins with the posterior part divided into spurious fins; the second dorsal distant from the first.

S. scomber, Lin. The Mackerel. Back blue, marked with small round black lines; five spurious fins above and below. 12 to 16 inches long. European seas. B.-Pen. Brit. Zool. iii. pl. 62.

The Mackerel visits the British shores annually in vast shoals, and is highly esteemed as an article of food. The colours of this fish when taken are very brilliant, and it is one of the most beautiful of the British fishes. It was greatly esteemed by the Romans, who used it in the preparation of their garum, a sort of pickle for their sauces. The preparation of the anchovy for a similar purpose has long superseded this ancient condiment.

S. Colias, Gmel. Body bluish green; no swimming-bladder. Smaller than the preceding. Mediterranean sea._Shaw, iv. 580.

Gen. 101. Thy nus, Cuv.-Scomber, Lin.

A projecting ridge on each side of the tail ; and a row of pointed teeth in each jaw; anal and second dorsal fins subdivided; first dorsal fin prolonged almost to the second, and sometimes touching it.

T. vulgaris, Cuv. The Tunny. Back steel-coloured; sides and belly silvery, with eight or nine spurious fins. 2 to 8 or 10 feet long. Inhabits Mediterranean sea. B.-Pen. Brit. Zool. iii. pl. 63.

The Tunny was well known to the ancients; and formerly, as at present, the Tunny fisheries in the Mediterranean were an object of great commercial importance. It is a gregarious fish, and often appears in large shoals; and Pliny relates that the fleet of Alexander the Great was impeded by a shoal of Tunnies so closely impacted that the ships had to make their way through them in order of battle. They are occasionally taken on the British shores, and have been frequently seen in the arms of the sea on the west coast of Scotland in pursuit of the shoals of herrings.

T. Sarda, Bloch. Back bluish, banded obliquely with black; six or seven spurious rays. 2 feet long. Inhabits Mediterranean sea.-Bloch, pl. 334.

T. Pelamis, Cuv. Back blue; belly silvery, marked by bands prolonged longitudinally on the sides; eight or nine spurious fins. -Shan, iv. 588.

T. Mediterraneus, Rondelet. Back blue, marked by broad transverse blackish bands; six or seven spurious fins; teeth strong and pointed. Inhabits Mediterranean sea.-Rondelet. 248.

T. Commersonii, Lacep. Body elongated, with brownish back, and sides marked with irregular brown spots; lateral line undulated; ten spurious fins above and below. Inhabits Pacific Ocean.Shan, iv, pl. 85. 
Gen. 102. Orcynus, Cuv.-Scomber, Lacep.

A row of pointed teeth in each jaw ; anal and second dorsal fins subdivided; first dorsal fin prolonged to near the second; pectoral fins very long, extending beyond the anus.

O. Germon, Cuv. Blackish blue on the back; silvery blue on the abdomen; eight or nine spurious fins above and below. 3 or 4 feet long. Inhabits Mediterranean sea._Cuv. Reg. An. ii. 314.

O. Alatunga, Cuv. With seven spurious finsabove and below; twelve rays in each dorsal fin; pectoral fins long. Inhabits Mediterranean sea.-Shan, iv. 590.

Gen. 103. Caranx, Lacep.-Scomber, Bloch.

Carina of the lateral line formed by a row of imbricated ridged scales; a small fin before the anal supported by two spines; pectorals long and pointed; teeth generally crowded, but in a very narrow band, sometimes scarcely perceptible.

\section{* With spurious fins.}

C. Rotleri, Cuv. Sides, head, and back blue; ventral and pectoral fins red, the others violet and yellowish; ten spurious fins above and below; lateral line marked by broad acuminated scales. 14 inches long. Inhabits Indian seas.-Bloch, pl. 346.

\section{** Fins not divided.}

C. trachurus, Lin. The Sand Mackerel. Body elongated, compressed laterally; back fine blue; sides and belly silvery ; lateral line bent, marked by a row of thick strong scales. 18 inches long. Inhabits European seas.-Pen. Brit. Zool. iii. pl. 62.

C. Chloris, Cuv. Body pale yellowish green, with a brownish tinge on the back; lateral line with rounded scales; pectoral fins lanceolate, reddish at the base; tail forked. 12 inches long. Inhabits African seas.-Bloch, pl. 339.

C. ruber, Shaw. Body beautiful rose red, silvery on the sides and abdomen; lateral line with large scales as it approaches the tail; tail deeply forked. 12 or 14 inches long. Inhabits Indian and American seas._Shaw, iv. pl. 86.

\section{Gen. 104. Citula, Cuv.}

Carina of the lateral line formed by a row of imbricated scales; a small fin before the anal, with two spines; first rays of the dorsal and anal fins elongated; pectoral fins elongated.

This genus was instituted by Cuvier for a new species.

Gen. 105. Seriola, Cuv.-Caranx, Risso.

Lateral line with small imbricated scales scarcely forming aridge; a fin with two spines before the anal; pectoralslong and pointed.

S. Dumerili, Cuv. Body silvery, with the back violet, and fins bluish. Grows to a large size. Mediterranean sea.-Risso, pl. 6, fig. 20. 
S. fasciatus, Cuv. Body silvery, with brownish back, and banded transversely by narrow brown lines; ventral fins yellow at the base, and the rest violet; the other fins blue and sputted with brown. 12 inches long.-Bloch, pl. 341.

\section{Gen. 106. Nomeus, Cur.}

Body broad, with small scales; the small fin before the anal with two spines; ventral fins extremely large and broad, attached to the belly by their internal margin.

N. Gronovii, Cuv. Head with large scales; body silvery, dusky on the back; sides spotted with black; tail forked. Inhabits South American seas.-Shan, iv. 251.

\section{Gen. 10\%. Selene, Lacep.}

Body much compressed, of a tetragonal or pentagonal form, as broad as deep; line of the forehead almost vertical, and edged; scales almost imperceptible; jaws edged with minute teeth ; two dorsal fins, with one or more spines between them; first rays of the second dorsal fin falcate, extending beyond the extremity of the tail.

S. argenteus, Cuv. Body pentagonal, silvery ; first dorsal fin small, with four spinous rays ; pectoral fins large ; tail cylindrical, forked. Inhabits S. American seas._Lacep. iv. pl. 9, fig. 2.

\section{Gen. 108. Gallus, Lacep.}

Body and head compressed; teeth in both jaws; two dorsal fins, with spines along each side, and many of the rays with long filaments; a transverse vertical membrane below the upper lip; ventral fins long.

G. vulgaris. (Zeus gallus, Lin.) Body rhomboidal, thin, silvery; greenish on the back; scales very small; tenth ray of the dorsal and second of the anal fin extending beyond the membrane. 6 to 8 inches long. Inhabits Indian seas.-Bloch, pl. 192, fig. 1.

\section{Gen. 109. Argyreiosus, Lacep.-Zeus, Lin.}

Body much compressed; ventral fins elongated; one dorsal fin in two divisions, the second falcate; spines of the first part of the dorsal and anal fins with long filaments.

A. vomer, Cuv. Body thin, silvery, tinged with bluish above ; second ray of the dorsal and anal fins very long; tail forked. 6 or 8 inches long. S. American and northern seas._Shan, iv. pl. 41.

\section{Gen. 110. Vomer, Cuv.}

Body much depressed, and without scales, except on the lateral line ; front edged, and teeth very small; belly also edged; all the fins short, the first dorsal and anal scarcely distinguishable.

V. Brownii, Cuv. (Rhomboida alepidota, Brown.) Brown's Jamaica, 455 . 
Gen. 111. Tetragonurus, Risso.

Body elongated; lower jaw elevated vertically, with a row of pointed cutting teeth locking between those of the upper jaw ; a small row of pointed teeth on each palatine and two on the vomer; two dorsal fins, and two projecting crests on each side of the tail.

T. Cuvieri, Risso. Blackish brown, and all the scales deeply striated and dentated. 2 feet long. Mediterranean sea.-Risso, pl. x. fig. 37.

\section{With distinct spines in place of the first dorsal fin.-} Rhynchobdella, Schn.

Gen. 112. Macrognathus, Lacep.

Body elongated, destitute of ventral fins; dorsal spines numerous, and two before the anal fins; snout prolonged into a flattened cartilaginous point, longer than the lower jaw; second dorsal and anal opposite, distinct from the caudal fin.

M. ocellatus, Hamilton. (Ophidium aculeatum, Gmel.) Rufous brown above, below silvery; fourteen spines before the dorsal fin, and at its base from three to seven ocellated spots with a yellow ring. 6 inches long. Fresh waters in India.-Shaw, iv. 73.

Gen. 113. Mastacembelus, Gronov.

Body elongated, destitute of ventral fins; jaws nearly equal ; dorsal and anal fins almost united to the caudal.

M. halepensis, Cuv. (Rhynchobdella, Schn.)-Gronov. Zooph. pl. 8.

Gen. 114. Gasterosteus, Lacep. Lin.

One dorsal fin, with free spines before; ventral fins with one strong spine, and destitute of other rays ; bones of the pelvis forming a shield pointed behind.

G. aculeatus, Lin. Banstickle or Stickleback. Three spines on the back; lateral scales occupying almost all the breadth of the sides; colour of the back and sides olive green; belly white ; in some the lower jaw and belly bright crimson. 2 inches long. Inhabits streams in Europe. B.-Penn. Brit. Zool. iii. pl. 61.

The Stickleback is extremely common in the waters of Britain, but nowhere in greater quantities tinan in the fens of Lincolnshire, and the rivers connected with them. "At Spalding," says Pennant, " there are once in seven or eight years amazing shoals that appear in the Welland, and come up the river in the form of a vast column. They are supposed to be the multitudes that have been washed out of the fens by the floods of several years, and collected in some deep hole, till, overcharged with numbers, they are periodically obliged to attempt a change of place. The quantity is so great that they are used to manure the land. A notion may be had of this vast shoal by saying, that a man employed by the farmer to take them has got for a considerable time four shillings a day by selling them at a halfpenny the bushel." The G. pungitius is conjectured to be the young of this species.

Gen. 115. Sirinachia, Cuv.-Gasterosteus, Lin.

Body elongated; lateral line broad, composed of bony plates, 
forming a ridge ; ventrals placed behind the pectorals, composed of two spines and a small membrane; dorsal spines numerous.

S. marina, (G. Spinachia, Lin.) Body deep brown above; belly white; head produced and tubular; fifteen dorsal spines. 6 inches long. European seas. B.-Penn. Brit. Zool. iii. pl. 61.

Gen. 116. Centronotus, Lacep.-Gasterosteus, Lin.

One dorsal fin, with spines before; ventral fins supported, as in general, by some rays, the most of which are short; sides of the tail carinated; anal shorter than the dorsal fin, with sometimes free spines.

C. ductor, Lacep. The Pilot-Fish. Body bluish, with broad transverse bands of deeper blue; four dorsal spines; tail forked. 18 inches long. American and Indian seas.-Bloch, pl. 338.

This is the fish so well known to mariners, and to which they ascribe the custom of swimming before the shark to indicate its prey. Two of this species some years ago accompanied a ship from the Mediterranean into Falmouth, and were taken in a net. Other species of the family have the same habit.

C. niger, Cuv. (Scomber, Bloch.) Head short, rounded; eight strong spines before the dorsal fin; ventral fins white, with black edges ; tail forked. Inhabits African and American seas. 2 to 6 feet long.-Bloch, pl. 377.

\section{Gen. 11\%. Lichia, Cuv.-Scomber, Bloch.}

Body deep and compressed; lateral line not carinated; ventral fins with some rays; one or two free spines before the anal fin; first dorsal spine often bent forwards and immoveable.

\section{* With spurious dorsal and anal fins.}

L. saliens, Cuv. Body smooth, compressed, darkish blue on the back; silvery on the sides and abdomen; four strong spines before the dorsal fin ; eight spurious fins above and below. 18 inches long. Inhabits American seas.-Bloch, pl. 335.

L. aculeata, Cuv. Head small, compressed; back brownish; sides and belly silvery; eight spines before the dorsal fin; eleven spurious fins above and below. 7 or 8 inches long. Inhabits European and American seas.-Bloch, pl. 336, fig. 1.

\section{** Without spurious fins.}

L. calcar, Cuv. Body silvery, with brownish back, and four diverging spines before the dorsal fin; two strong spines before the anal fin, connected by a membrane. 10 or 12 inches long. Inhabits African seas.-Bloch, pl. 336.

*** Points of the dorsal and anal fins prolonged.-TRACHINOTUs, Lacepede.

L. falcatus, Cuv. Second dorsal and anal fins falcate; body broad, brownish on the back, silvery on the sides; glaucous and yellow on the caudal fin; lateral line undulated. 12 inches long. Inhabits Red sea.-Forsh. 57. 
L. rhomboides, Cuv. (Choetodon, Bloch.) Body rhomboidal, gray or greenish blue above, yellowish beneath, with two or three deeper blue bands on the sides; five spines before the dorsal, and two before the anal fin. Inhabits American seas.-Bloch, pl. 209.

Gen. 118. Blepharis, Cuv.-Zeus, Bloch.

Body deep, rhomboidal; dorsal spines very short ; first soft rays of the dorsal and anal fins soft, and elongated into filaments exceeding the body in length; free spines before the anus.

B. ciliaris, Cuv. Body rhomboidal, thin, without scales, bright silvery, with a bluish or greenish tinge on the back; soft rays of the dorsal and anal fins extended into long filaments. 6 inches long. Inhabits Indian seas.-Bloch, pl. 191.

\section{With one dorsal fin; teeth crowded.}

Gen. 119. ZEus, Lin.

Body oval, compressed; jaws strongly protractile ; teeth crowded; spinous portions of the dorsal and anal fins separated from the other by a deep notch; scales projecting, or spinous scales at the base of the vertical fins, and between the ventral and anal fins.

Z. faber, Lin. Common Dory. Head and mouth large; body yellow, marked with a black spot on each side; forked spines along the dorsal and anal fins, and long membranous filaments behind each dorsal spine. 15 inches long. Inhabits European seas. B.Shaw, iv. pl: 41.

The black spot on each side of the Dory has been attributed to a similar cause with that whicli is said to have occasioned the haddock bearing analogous marks. The latter, according to the legend, was the fish out of whose mouth St Peter took the tribute money, and the marks of his finger and thumb on its sides perpetu:te the miracle. St Christopher, in wading through an arm of the sea, having caught a stray Dory in his passage, left indubitable evidence of the fact on its sides by the two opposite marks of a finger and thumb. The Dory, notwithstanding its appearance not being very prepossessing, is said to be an excellent fish for the table. It was chiefly brought into reputation in England by $\mathrm{Mr}$ Quin the actor, who, to talents of a high order in his profession, joined a most consummate taste in the luxuries of the table.

$$
\text { Gen. 120. Capros, Lacep.-Zeus, Lin. }
$$

Body and tail much compressed vertically; no teeth; two dorsal fins; scales small and rough; no spines before the dorsal or anal fins.

C. aper, Lin. Snout narrow, produced; body reddish, covered with rough ciliated scales. 3 inches long. Inhabits Mediterranean sea.-Shaw, iv. 292.

Gen. 121. Equula, Cuv.-Zeus, Lin.

Body compressed, covered with small scales, except towards the end of the lateral line, where they are carinated ; snout protractile, and mouth with small crowded teeth; one continuous dorsal fin, the spinous part projecting; a row of spines on 
each side of the anal and caudal fins; two spines above each eye, and base of the operculi dentated; a rounded plate before the ventrals.

E. insidiator, Cuv. (Centrogaster equula, Gmel.) Body bright silvery, bluish green above, spotted with black. Of small size. Inhabits rivers of India._Shaw, iv. pl. 41.

From the structure of the mouth of this animal it is enabled to contract it into a kind of syringe, to propel the water on the insects resting on aquatic plants within its reach, and by this means to secure its prey.

\section{Gen. 122. Mene, Lacep.}

Body compressed, with one dorsal fin; belly carinated and semicircular; back and shoulder raised; ventral fins narrow and elongated.

M. maculatus, Schn. (M. Anne Caroline, Lacep.) Body silvery.Lacep. v. pl. 14.

Gen. 123. Atropus, Cuv.-Brama, Schn.

Body compressed; forehead sloping; snout very short; lower jaw projecting; one dorsal fin with two or three spines, and a part of the soft rays prolonged into filaments ; lateral line carinated towards the end; two free spines before the dorsal fin.

A. Brama. (B. atropus, Sch.) Body blue above; sides silvery; belly black, with yellow spots. Inhabits Indian seas.-Schn. pl. 23.

\section{Gen. 124. Trachichthys, Shaw.}

Head rounded in front ; mouth wide ; teeth crowded; one elevated and pointed dorsal fin; sides, upper and under part of the tail with large strongly carinated scales; and similar scales forming a dentation between the ventral and anal fins; branchial membrane with four rough rays.

T. Australis, Shaw. (Amphiprion carinatus, Schn.) Body bright pink, ferruginous or reddish brown, the middle of the fins deeper, and the margins paler; tail strongly furcated. 6 inches long. Inhabits seas of New Holland.-Shaw, v. pl. 92.

\section{Gen. 125. Chrysotosus, Lacep.-Zeus, Gmel.}

Body and tail compressed, oval, without perceptible scales; forehead gibbous, rounded; snout short; mouth without teeth ; six rays in the branchial membrane; anterior part of the dorsal fin elevated and pointed, the middle part very small; sides of the tail carinated; ventrals more behind than the pectorals.

C. luna, Lacep. The Opah or Moon-fish. Back bluish, spotted with silvery; fins and tail bright scarlet. Inhabits European seas. 5 feet long.-Shan, iv. pl. 42.

This splendid fish, of which the colour varies from silvery green to bright golden, with azure reflections, has always the body variegated on the sides with oval white spots. Specimens are occasionally met with on the British coasts. 
Gell. 126. Xiphias, Lin.

Snout prolonged, resembling the blade of a sword; strong asperities in the jaws in place of teeth; body elongated, rounded, with scarcely perceptible scales; a projecting carina on each side of the tail; pectoral fins long and pointed; two or three anterior rays of the dorsal fin spinous; no ventral fin.

X. gladius, Lin. The Sword-Fish. Snout very long, flattened, and edged; first dorsal fin commencing near the nape, high and pointed anteriorly, sinking along the back, and terminated by a smaller point ; anal fin with two points, short; tail lunated; body brownish, shaded with steel blue above, silvery white below. 12 to 20 feet long. Snout 2 to 3 feet. Inhabits European seas. B.Shan, iv. pl. 14.

The snout of this fish has been supposed hard enough to penetrate the planks of ships; and Mr Scoresby relates an instance of a ship from the coast of Africa, the bow of which had been penetrated by a bone, which he considered as the snout of the Sword-fish. This fish is used as food in Sicily.

X. Makaira, Shaw. Snout not so long as the preceding; lower jaw about half the length of the upper; first dorsal fin large; tail large, lunated, marked by numerous black spots, with two bony prominences on each side the base. Size of the preceding. Inhabits European seas.-Shan, iv. pl. 16.

Gen. 12\%. Istiophonus, Lacepede.-Scomber, Bloch.

Upper jaw prolonged like the blade of a sword; ventral fins with two slender and very long rays; first dorsal fin large and elevated, forming a kind of vertical sail, with which they catch the wind when swimming at the surface.

I. platypterus. (Xiphias platypterus, Shaw.) Body bluish silvery; the back, head, fins, and tail deeper, fading to brown when dried. 20 feet long. Inhabits tropical seas.-Shaw, iv. pl. 15.

As an instance of the amazing strength which this fish is able to exert, it may be mentioned that a plank of an East Indiaman, in which the sword was driven nearly to its base, is preserved in the British Museum.

Gen. 128. Centrolophus, Lacep.-Coryphcena, Lin.

Body elongated, with small scales; head oblong, obtuse; teeth fine and in one row; head edged above, and a row of very short spinous prominences before the dorsal fin; anal shorter than the dorsal fin.

C. niger, Lacep. (C. pompilus, Lin.) Body dusky, with transverse yellowish stripes over the curved lateral line. Inhabits Mediterranean and Atlantic seas.-Shan, iv. 220.

Gen. 129. Ouigoponus, Risso.

Body elongated; covered with small scales; head edged above; dorsal prominences sensible only to the finger; dorsal and anal fins united to the caudal, which terminates in a point; one ray in the ventral fins. 
O. niger, Risso. Body tinted with ebony black on a reddish violet ground; lateral line double ; firs deep black. 5 inches long. Inhabits the Mediterranean sea.-Risso, pl. 12, fig. 41.

Gen. 130. Coryphena, Cuv.

Body elongated, covered with small scales; head compressed, edged above, and the forehead vertical; teeth very small, crowded; dorsal fin extending from the nape.

C. Hippuris, Lin. Body of a fine blue silvery colour, spotted with yellow; almost all the fins yellow; tail forked. 3 to 4 feet long. Inhabits Mediterranean, Atlantic, and Indian seas.-Shaw, iv. pl. 32.

The beautiful and varying colours in this species are very evanescent. When taken out of the water, the colour fades as the fish expires, till at last it becomes of a dull grayish or cinereous appearance.

Gen. 131. Pteraclis, Gronov.-Ogliopodus, Lacep.

Body elongated, much compressed ; teeth in one row above and two below ; scales large, and notched at the margin to receive the small spine of the following scale; dorsal fin very elevated, commencing above the head and extending to the caudal fin; anal fin of equal size; ventrals before the pectorals.

P. velifer, Cuv. (Coryphana, Pall.) Body much elongated, much compressed, and almost surrounded by two immense dorsal and anal fins ; fins brown, with white spots.-Cuv. Reg. An. ii. 329.

4. With one dorsal fin; teeth edged and in a single row.

Gen. 132. Amphacanthus, Schn.-Scarus, Gmel.

Jaws convex, with a single row of small flat and dentated teeth along their edge; a curved spine before the dorsal fin, a spine at each side of the ventrals, and the internal margin attached to the abdomen; scaies small.

A. rivulatus, Forsk. Body bluish, spotted with black, and marked by longitudinal yellowish undulations; tail forked. Inhabits Red Sea.-Shaw, iv. 395.

Gen. 133. Acanthurus, Lacep.-Theutis, Lin.

Body compressed, broader than long; front vertical; teeth in one row, and their edges crenulated; a strong spine on each side the base of the tail ; scales small.

A. nigricans, (Chotodon, Bloch.) Body black above, brown on the sides, and whitish towards the belly; pectoral fins gray, those of the belly black; a curved spine on each side of the tail. Inhabits South American seas.-Bloch, pl. 203.

A. chirurgus, Lacep. Body ovate, orange-yellow, crossed in the hind part by transverse brown stripes; a strong curved spine capable of erection on each side of the tail. 9 or 10 inches long. Inhabits American seas._Shan, iv. pl. 52.

voL. I.

H h 
Gen. 134. Aspisurus, Lacep.-Chatodon, Lin.

Body compressed, higher than broad; snout projecting; mouth small; teeth crenated; dorsal fin covered with small scales; a hard plate on each side of the tail.

A. Sohal, Cuv. Body ovate, dusky, with longitudinal violet streaks; abdomen whitish ; fins violet-coloured; pectoral fins with a yellow spot; tail lunated, with a carinated plate on each side. 15 inches long. Inhabits Red Sea.-Shaw. iv. 382.

\section{Gen. 135. Prionurus, Lacep.}

Body compressed; teeth crenated, with many spines on each side of the tail.

P. microlepidotus, Lacep. Opening of the mouth small; body silvery, with nine transverse waved irregular bands of a bluish black colour; fins transparent, and bluish white. Inhabits seas of New Holland.-An. Mus. iv. 205.

Gen. 136. NAseus, Lacep.-Monoceros, Will.

Body and tail covered with a rough shagreened skin; teeth crowded and in a single row; a protuberance in the form of a horn on the nose; two plates or shields on each side of the extremity of the tail.

N. unicornis, Lacep. Body gray brown, deep, compressed, with a strong conical horn-shaped process extending from the forehead; two plates on each side the tail. 3 feet long. Inhabits Indian seas.-Shan, iv. pl. 50.

This species is found in large shoals in the Arabian seas; and Forskal relates that he saw an eagle dart among a crowd of these fishes, and, happening to seize two at once in his claws, was, in consequence of their sudden and violent separation, torn asunder and destroyed.

\section{Family VI.-Squamipennes.}

Scales encrusting the soft part of the dorsal and anal fins, and often a portion of the spinous part.

\section{Teeth crowded, like hairs or bristles.}

Gen. 137. Chrtodon, Cuv.

Body much compressed, oval, high vertically; dorsal and anal fins covered with scales; teeth crowded, bristly; dorsal spines nearly equal; no dentations or spines on the operculi.

C. striatus, Bloch. Body ovate, yellowish on the back and whitish towards the belly, with four distant brown bands, and narrow longitudinal dusky streaks ; tail rounded ; thirteen spines in the dorsal fin. Inhabits Indian and American seas.-Bloch, pl. 205, fig. 1.

C. unimaculatus, Bloch. Head small, with a black band passing over the eye; back gray; sides white, with transverse yellow lines; fins yellowish; a round black spot on the lateral line; thirteen spines in the dorsal fin. Indian seas.-Bloch, pl. 201, fig. 1. 
C. setifer, Bloch. Body ovate, pale yellow, with a tinge of crimson on the back, and marked with numerous oblique crimson stripes ; a broad black band across the head passing over the eyes; and on the hinder part of the dorsal fin a large round black spot bordered with white, over which a long setiform ray. 6 inches long. Inhabits Indian seas. - Bloch, pl. 426, fig, 1 .

\section{Gen. 138. Chelmon, Cuv.}

Body much compressed, high vertically; dorsal and anal fins covered with scales; teeth crowded, bristly; snout prolonged, forming a narrow cylindrical beak.

C. rostratus, Cuv. Body broad, whitish, with longitudinal brown lines and four transverse black bands, bordered with white; a black spot on the back bordered with white. 6 to 8 inches long. Inhabits fresh waters in India.-Bloch, pl. 202.

This species possesses the power of syringing water from its tubular mouth to a distance for the purpose of stunning the insects upon which it feeds.

C. longirostris, Cuv. Body oblong, rhomboidal ; head brown; snout elongated; body yellowish or citron-coloured; dorsal and anal fins citron-colour, with a black streak behind, margined with white; a black spot towards the tip of the anal fin. Inhabits Pacific Ocean.-Shaw, iv. 368.

Gen. 139. Platax, Cuv.-Chotodon, Bloch.

Body much deeper than long; snout obtuse; teeth small, crowded; dorsal and anal fins excessively long and pointed; spines of the dorsal fin concealed in the rising edge of the fin, and the first rays much elongated.

P. Teira, Cuv. Body silvery whitish, with three black bands; dor * sal and anal fins extremely elongated; ventral fins black. 4 inches long. Inhabits Indian and Arabian seas.-Shaw, iv. pl. 48.

P. pentacanthus, Cuv. Body orbicular; lower jaw projecting, with five spinous rays in the dorsal fin; vertical fins less elevated than the preceding. Inhabits South seas._Lacep. iv. pl. 11, fig. 2.

Gen. 140. Heniochus, Cuv.-Chatodon, Bloch.

Body compressed; teeth small ; scales large ; rirst dorsal spines prolonged into a long whip, behind these shorter spines, and then the ordinary soft rays.

H. macrolepidotus, Cuv. Body silvery, with two broad brown bands; fourth ray of the dorsal fin very long, filamentous. Inhabits waters in India.-Bloch, pl. 200, fig. 1 .

Gen. 141. Ephippus, Cuv.

Body compressed; teeth small; dorsal fin with a notch between the spinous and soft portion.

E. Argus, Cuv. Back violet, shading to white towards the belly, marked with round brown spots ; fins short and yellow, the dorsal one with eleven spines. Inhabits waters in India.-Bloch, pl. 204. 
Gen. 142. Chetodipterus, Lacep.

Teeth small, flexible; body and tail compressed, as deep as long; snout projecting; separation of the dorsal fin so deep as to make two dorsal fins.

C. Plumieri, Lacep. Body greenish, mixed with yellow, with six transverse narrow bands of a deeper green; tail lunated. Inhabits fresh waters of India.-Bloch, pl. 211, fig. 1.

Gen. 143. Holocantuus, Lacep-Chotodon, Bloch, Lin.

Body compressed, oval; teeth minute; preoperculum dentated or smooth, with a strong spine towards the base; vertical fins not much elevated at their commencement; soft rays of the dorsal and anal fins elongated and falciform.

\section{* Dorsal and anal fins falciform.}

H. aureus, Cuv. Body bright golden yellow, shaded with orange on the upper parts; dorsal and anal fins falciform; extremities of the fins green. 12 incheslong. American seas.-Bloch, pl.193, fig.1.

H. paru, Cuv. Body black, silvery on the sides; scales with a yellow border; pectoral and caudal fins short and rounded; dorsal and anal fins extended, falciform; 12 spines in the dorsal fin. 12 inches long. Inhabits S. American seas._Bloch, pl. 197.

H. ciliaris, Cuv. Body gray, deeper on the back; belly white ; fins gray, with a yellow border; scales ciliated; dorsal and anal fins extending in a semilunar form. 12 inches long. Inhabits Indian seas.-Bloch, pl. 214.

** Dorsal and anal fins rounded or angular.

H. imperator, Cuv. Body golden yellow, with longitudinal bright blue parallel rays; anal and dorsal fins thick, stiff and rounded; fourteen spines in the dorsal fin. 12 inches long. Inhabits $\mathrm{Ja}$ panese seas.-Bloch, pl. 194.

H. bicolor, Cuv. Body oblong; head, half of the body, and tail white, the rest reddish brown. Inhabits Indian and American seas.Bloch, pl. 206, fig. 1.

Gen. 144. Acanthopodus, Lacep.

Body much compressed, as deep as long; opening of the mouth small; teeth short and crowded; dorsal fin covered with small scales; two short spines in place of the ventral fins.

Cuvier includes in this group the genus Monodactylus of Lacepede.

A. falciformis, Cuv. Body much compressed, silvery, with brownish back ; two short spines in place of ventral fins; dorsal and anal fins falciform, extending to near the tail, which is lunated. 12 inches long. Inhabits Indian seas.-Shaw, iv. 392.

\section{Gen. 145. Osphronemus, Commers.}

Head and branchial membrane scaly, as well as the bases of the vertical fins; mouth small, and teeth crowded, but very short; 
preoperculi and suborbitars dentated on their margin; one of the rays of the ventrals forming an articulated bristle as long as the body; one spine at each anal fin.

O. olfax, Commers. Body much compressed and deep, covered with large scales; belly and posterior part carinated; brown, with reddish tints on the fins and back; tail rounded. 6 feet long. Inhabits rivers in Java, \&c.-Lacep. iii. pl. 8, fig. 2.

This fish, the flesh of which is much esteemed, has been transported to the rivers of the Isle of France from Java, and now forms at the latter place an important article of food.

Gen. 146. Trichopodus, Lacep.-Trichogaster, Schn.

Head and bases of the vertical fins scaly; teeth short and crowded; preoperculi and suborbitars dentated on their margin; one of the rays of the ventrals extended into a filament; no spines at the anal fin.

T. trichopterus, Lacep. Head small ; mouth narrow; lips extensible; body variegated with brown, and two large round black spots; dorsal fin small and anal very long. 6 inches long. Inhabits Indian seas.-Bloch, pl. 295, fig. 2.

T. satyrus, (Trichopus satyrus, Shaw.) Body deep, much compressed; dorsal and anal fins nearly equal ; ventral fins consisting of a single filament; chin much produced. Inhabits Indian seas.-Shaw, iv. pl. 55.

Gen. 14\%. Toxotes, Cuv.-Labrus, Shaw.

Body compressed, with large scales; snout obtuse, flattened horizontally; teeth like a fine file; inferior margin of the preoperculi and suborbitars finely dentated; dorsal fin short, commencing opposite the beginning of the anal fin.

T. jaculator, Cuv. Body yellowish, with five brown spots on the back; lower jaw longer than the upper; first spines of the dorsal, anal, and ventral fins very strong. 6 to 8 inches long. Inhabits Indian seas.-Shaw, iv. pl. 68.

This species has the singular faculty of darting drops of water at insects within its reach.

\section{Gen. 148. Kurtus, Bloch.}

Head and body much compressed; back elevated; dorsal fin much shorter than the anal fin, and placed more forwards ; teeth crowded.

K. Indicus, Bloch. Body broad, short, and covered with small silvery plates; back and belly carinated; back tinged with gold colour, and three or four black spots on its ridge. 10 inches long. Inhabits Indian seas.-Sham, iv. pl. 25.

$$
\text { Gen. 149. Ana bas, Cuv.-Anthias, Bloch. }
$$

Snout blunt and short; head and body covered with large scales; both jaws with rasp-like teeth, but strong and conical on 
the pharynx ; an apparatus of complicated Iaminæ at the base of the branchiæ.

A. scandens, Cuv. (A.testudineus, Bloch, Perca scandens, Daldorf.) Head short and covered with scales; body brown, the fins of a deeper colour; ten spines in the anal fin. Inhabits Indian seas. -Bloch, pl. 322.

Gen. 150. Cessio, Commerson.

Body oblong; upper jaw slightly protractile; a row of small pointed teeth in each jaw, and behind these minute and scarcely perceptible teeth; dorsal and anal fins scaly; two long scales at the side of the ventrals and one between them; seven branchial rays.

C. azuror, Lacep. Back blue, and a longitudinal yellow band on the sides ; belly silvery ; a spot of pure black at the base of each dorsal fin. 12 inches long. Inhabits Indian seas.-Nouv. Dict. iv. 549.

Gen. 151. Brama, Schn.

Snout truncated, the mouth when shut directed upwards; head covered with scales; teeth hooked, the external row largest, dorsal and anal fins very scaly, rising in front and sloping to the tail.

B. Raii, Cuv. (Sparus Raii, Bloch.) Body silvery bluish, with dusky back; head sloping abruptly downwards. 15 inches long. Inhabits Mediterranean sea.-Bloch, pl. 273.

2. Teeth in one regular row; not like hairs or bristles.

Gen. 152. Stromateus, Lin.

Body oval, flattened; teeth very fine, edged, pointed, and in one row; no ventral fins.

S. paru, Bloch. Body bright golden colour above, shading to silvery below; fins long, white in the middle, and blue on the margins. Inhabits S. American seas.-Bloch, pl. 160.

S. niger, Bloch. Body entirely of a blackish colour; jaws equal. Inhabits Indian seas.-Bloch, pl. 422.

Gen. 153. Fratola, Cuv.-Stromateus, Lin.

Body oval, compressed; teeth very small, pointed, in one row ; scales very minute; dorsal and anal spines concealed in the anterior margin of the fins.

F. subfasciata. Body silvery, with many longitudinal or waved spots of a golden yellow colour; double lateral line; lips red ; tail forked. Inhabits Mediterranean sea.-Shaw, iv. pl. 17.

\section{Gen. 154. Seserinus, Cuv.}

Body ovate, compressed; teeth very small, pointed, in one row ; scales minute; first dorsal and anal spine bent forwards, and two spines in place of ventral fins; double lateral line. 
S. alepidotus, (Chotodon alepidotus, Gmel.) Body bluish above, whitish beneath; tail bifid. American seas.-Shaw, iv. 370.

\section{Gen. 155. Pimelepterus, Lacep.}

Body oval, compressed; teeth equal, edged obtuse, and crowded; soft part of the vertical fins thickly covered with scales; branchial membrane scaly, with four rays.

P. Boscii, Lacep. Head small ; lips extensible; scales broad, round, and silvery. 6 inches long. American seas.-Lacep, iv. pl.9, fig. 1.

Gen. 156. Ky Phosus, Lacep.

Back elevated; a prominence on the neck before the dorsal fin, and another between the eyes; operculi scaly; pectoral fins elongated and pointed; tail forked.

This genus is founded upon a species from the South Sea, observed and figured by Commerson.

\section{Gen. 15\%. Plectorhy nchus, Lacep.}

Body ovate, compressed; preoperculi dentated; a row of minute teeth scarcely piercing the jaws; ventral fins broad, with numerous rays.

P. chatodonoides, Lacep. Indian seas.-Bloch, pl. 198, fig. 1.

Gen. 158. Gryphisodon, Lacep.-Chatodon, Bloch.

Body and tail much compressed; head scaly; teeth edged, and in a single row, often notched; Iateral line terminating opposite the dorsal fin.

G. maculatus, Cuv. Body yellow, with a longitudinal row of five or six large round brown spots, and crossed with bands of paler brown ; fins yellow. Inhabits fresh waters in India and S. America.-Bloch, pl. 427.

\section{Gen. 159. Pomacentrus, Lacep.}

Preoperculi dentated; otherwise the same as the preceding.

P. pavo, Lacep. Body dull orange, with numerous brown lines and undulations ; head spotted and streaked with blue ; tail forked. Inhabits Indian seas.-Bloch, pl. 198, fig. 1 .

P. aruanus, Cuv. (Chatodon, Bloch.) Body ovate, whitish, shading to brown above, with three transverse black bands ; suborbitars dentated. Inhabits Indian seas.-Bloch, pl. 198, fig. 2.

\section{Gen. 160. Амphiprion, Cuv.}

Body oval, compressed ; teeth edged, and in a single row ; lateral line terminating at the dorsal fin; suborbitars and the four pieces of the operculi dentated.

A. ephippium, Cuv. (Lutianus, Bloch.) Head short, much sloped and compressed; mouth small and oblique; body compressed, reddish, the back black, extending on the sides into a large black spot. Inhabits Indian seas.-Bloch, pl. 250. 
Gen. 161. Premnas, Cuv.

Head very obtuse ; teeth fine, short, in a single row ; strong spines under the suborbitars; preoperculi and suboperculi dentated; lateral line terminating before reaching the tail.

P. biaculeatus, Bloch. Body elongated; the back blue; belly silvery, with three distant, narrow, ferruginous bands; two spines under the eye. Inhabits Indian seas.-Bloch, pl. 219, fig. 2.

\section{Two dorsal fins, without the scaly thickening.}

Gen. 162. Temnodon, Cuv.

Body oblong and scaly, without spines or dentations on the head; a row of compressed and pointed teeth in each jaw, behind them a row of smaller ones, and five crowded teeth on the vomer and palate; second dorsal and aral fins scaly; branchial membrane with seven rays.

T. heptacanthus. Seven spinous rays in the first dorsal fin; tail forked. Inhabits South seas.-Lacep. iii. pl. 21, fig. 3.

Gen. 163. Eques, Bloch.

Body elongated; tail terminating in a point; head blunt, and the rays of the dorsal fin prolonged; teeth small, crowded; swimming bladder large and strong.

E. Americanus, Bloch. Head rounded and scaly ; back brown ; sides and belly yellow, with three oblique black bands, the first passing over the eyes, the second over the operculi and breast, and the third commencing at the dorsal fin and running to the point of the tail; first dorsal fin elevated, with prolonged separate rays. 12 inches long. Inhabits American seas.-Shaw, iv. pl. 54.

Gen. 164. Polynemus, Lin.

Snout gibbous; head scaly ; preoperculi dentated ; teeth crowded; vertical fins more or less scaly ; five rays under the pectoral fins, exceeding the length of the body in some species.

P. paradiseus, Lin. Mango Fish. Body yellowish; seven free rays or long filaments on each side of the throat ; tail forked. 12 to 15 inches long. Indian and American seas.-Shaw, v. pl. 118. P. quinquarius, Cuv. Body silvery, with five long thoracic filaments, the three superior ones exceeding the length of the fish. Inhabits American seas.-Shaw, v. 149.

\section{Family VII.-Fistularide.}

This family is characterized by a long tube formed by the prolongation of the ethmoid bone, the vomer, the preoperculi, the pterygoid and tympanal bones, at the end of which the mouth is placed. Their intestinal canal has no great inequalities. The body in some is cylindrical, and in others of an ovate and compressed form.

Gen. 165. Fistularia, I Lacep.

Head much elongated; jaws very narrow, much produced and tubular; mouth terminal; teeth small; body much elongated 
and slender ; fins small, one dorsal fin placed opposite the anal, and between the lobes of the tail a filament sometimes as long as the body; seven rays in the branchial membrane.

F. tabacaria, Lin. Slender Fistularia. Body smooth, scales imperceptible, of a liver colour, marked above and on the sides by a row of blue spots and greenish ones intermixed; tail bifid, with a long bristle in the centre tapering to a point. 3 to 4 feet long. Inhabits S. American seas.-Shaw, v. pl. 107.

\section{Gen. 166. Aulostomus, Lacep.-Fistularia, Lin.}

Jaws narrow, much elongated and tubular ; body much elongated, scaly; a row of free spines in front of the dorsal fin; tail terminated by ân ordinary fin.

The tube of the snout is shorter in this than the preceding genus, and the body less slender.

A. Chinensis, Cuv. Body pale reddish brown, with several deep or blackish spots, and three or four pale longitudinal stripes on each side; fins pale yellow. 3 to 4 feet long. Inhabits Indian seas.Bloch, pl. 388.

\section{Gen. 16\%. Centriscus, Lin.}

Body oval or oblong, compressed on the sides and carinated below ; mouth extremely small and cleft obliquely; first dorsal fin spinous, the first spine long, and supported by an apparatus with larger scales; ventral fins small, behind the pectorals.

C. scolopax, Lin. Snout greatly elongated ; body covered with numerous small scales; colour rufous brown above, paler beneath, silvery on the sides; first dorsal fin subtriangular, the first spine strong and serrated. 4 to 8 inches long. Inhabits Mediterranean and Indian seas:-Shaw, v. pl. 181.

Gen. 168. Amphisile, Klein.-Centriscus, Lin.

Back mailed with long scaly plates, of which the anterior spine of the first dorsal fin has the appearance of being a continuation.

A. scutatum, Cuv. Upper part of the body formed into a kind of mail, divided into broad segments to the number of twelve on each side, and terminating in a projecting point at the end of the back ; head oblong, terminating in a lengthened tubular snout. 6 or 8 inches long. Inhabits Indian seas.-Shan, v. pl. 181.

A. velitare, Cuv. Body silvery yellowish gray on the back, which is mailed by a rhombic shield for half its length, marked by four oblique lines; a strong recumbent serrated spine in the middle; tail slightly rounded. 2 inches long. Indian seas.-Shaw, v. 460. 


\section{FOSSIL FISHES.}

Fossil remains of Fishes, in the form of bones, casts, or impressions, are met with in various strata, from those of the transition rocks to the latest alluvial formations. The greater part of these remains, however, like the other remains of vertebral animals found in a fossil state, cannot be identified with the existing species; and though many resemble in their generic characters the groups of the present races, so as to be conveniently referred to these, yet there appear to be some which present typical forms possessing no identity with the more recent individuals. These animal remains have been termed Ichthyolites.

Among the more ancient marine formations, the fossil remains of fishes near the town of Glaris in Switzerland have long attracted attention. The place where they are found is in the bottom of a small valley named Sernft, about 1000 metres above the village of Lengi, and surrounded by the mountains called Plattenberg. The rock which includes the Ichthyolites is a kind of transition or schistose rock, containing mica slate and limestone in parallel beds; and the skeletons of the fishes occur in relief on the slaty laminæ. The specimens are rare, and never accompanied by fragments of shells. The valley of Sernft opens into another valley hollowed out of mountain limestone. Species of the genus Anenchelum, (A. Glarisianum, Blainv.- the eel of Glaris,) of Palceorhyncum, Clupea, and Zeus, have been met with in this locality.

In the canton of Lucerne, near the top of Mont Pilat, and in the slaty schistus of which it is composed, are also found remains of fishes. The hard parts of the skeletons, however havedisappeared, and the impressions of the animals only remain. Large quantities of the teeth of fishes occur in this locality.

In the metalliferous rocks of Germany, as at Mansfeld, Thuringia, near Madgeburgh, and in the Palatinate, fossil remains of fishes are numerous, and in very complete preservation. The soft parts of the animals, as the skin, appear to be here preserved, the body being found on splitting up the stones in relief on one side, with a corresponding hollow on the other. The 
skeletons are never met with in this locality. They occur in all attitudes. The substance in which these remains are found is a coppery and marly schistus, bituminous, strewed with argentiferous pyrites, and sometimes mercury in the state of cinnabar. This strata occurs under limestone containing Belemnites, Entrochi, and Arnmonites. The remains are numerous, but not of any great variety of species, of the genera Palceoniscum, Palceothrissum, Clupea, Esox, and Stromateus of Blainville.

Ichthyolites or fossil fishes occur in the compact limestone of France and Italy. In the former country at Granmont, four leagues from Beaune in Burgundy, two species have been found, which M. Blainville names Elops macropterus, and Esox incognitus; and others in Italy at Pietra Roya. In the chalk formations, Ichthyolites have been met with at Brussels, Maestricht, and Paris. The remains at Brussels belong, besides teeth, to the genera Pleuronectes and Squalus. In the calcareous formations below the gypsum in the quarries near Paris, a species of Labrus has been found ; and in the marine limestone above the gypsum, isolated vertebræ, teeth, operculi, and spines. In the well known locality of Pappenheim, in the quarries near Aichstedt, many remains of fish have been observed in the calcareous fissile strata of that district. These quarries have been worked for slates; and the remains appear in relief, or impressed on the surface of the plates. Species of the genus Clupea, Esox, Stromateus, and Pocilia, have been found in these quarries, along with remains of Crustacea.

The most celebrated locality for remains of fossil fishes, and which has furnished the greatest quantity to collections, is the basin of the Mediterranean, and particularly at Monte Bolca, or Vestena Nuova, on the confines of the Veronese territory, and the Vicentine. The mountain of Vestena Nuova is volcanic, and rises 1000 feet above the limestone. It is composed of two species of stones; the first, named in the country il Zengio, is a very hard marl, forming thick beds, but which contains no organic remains; the second, called il Lastra, is a fissile fetid marl, which splits easily into laminæ, in which the fossil remains are discovered in a bed of two feet in thickness. This stone is almost entirely calcareous, with a little clay, and mixed with a bituminous substance. The Ichthyolites consist of skeletons, sometimes in very perfect preservation, fragments of bones, 
and impressions or casts; and some remains of crustaceous animals have been found in the same place. Shells are extremely rare. Many genera and species of fishes which occur in this stratum have been described by Dr Volta, brother of the celebrated physician of the same name, in a work published at $\mathrm{Ve}$ rona in 1796, and by Blainville in the twenty-seventh volume of the New Dictionary of Natural History. Fossil remains of fishes have also been found in the Vicentine, at Frioul, in Dalmatia, Cerigo, Malta, Sicily, and Barbary, in strata of a similar kind.

In what have been called the fresh water formations, fossil remains of fishes have been met with in various parts of the continent of Europe. In the gypseous formations at Aix, and in the neighbourhood of Paris, are species of the genera Mugil, Perca, Cyprinus, Sparus, Pccilia, Salmo, and other fresh water fishes. At the village of OEningen, on the right bank of the Rhine, as it leaves the lake of Constance, in a quarry 500 feet above the level of the lake, and on the southern slope of a mountain, called Schienerberg, many species of fishes have been discovered. The substance in which they are inclosed is a kind of fetid slate or schistus, coloured white or gray, containing a great quantity of clay and fragments of vegetables. The specimens found here, often very complete and even with the scales, are of the genera Petromyzon, Murana, Cobitis, Salmo, Esox, Cyprinus, Clupea, Pleuronectes, Scomber, and Trigla.

Other remains of fishes occur in various parts of the world, and in very different formations. These, consisting of detached vertebræ and teeth, are found in transition rocks, compact limestone, chalk, gypsum, and alluvial strata. Fossil teeth or ichthyodontes occur in great quantity in Malta and Sicily. They are common in Calabria, Tuscany, the teritory of Sienna, the Plaisantine, and probably in all the subapennine hills; in the neighbourhood of Brussels, in the hill of St Peter near Maestricht, the environs of Montpellier, in the neighbourhood of Paris, London, \&c. These teeth are often of their natural colour, or tinged with yellow; but sometimes they are coloured bluish black, or ochreous red, according, it is thought, to the nature of the strata in which they are imbedded; and even some have undergone a change in their chemical composition, as those which have been converted into the gem named the turquoise. Those of a flat. 
tened form, named glossopetro, are the teeth of a species of Squalus; and those more or less rounded, which have been termed bufonites, batrachites, \&c. are, according to Blainville, to be considered as having belonged to the Spari or some congenerous family. The glossopetro, or petrified tongues, as they have been termed, found in quantities at Malta, were supposed by the ignorant to be the tongues of the serpents which St Paul was said to have destroyed when in that island. These are teeth of Squali, and often occur so large, (four inches in height and five on the sides) that M. Lacepede conjectures the individuals to which they belonged must have been at least seventy-one feet long. The teeth and spines of rays are also frequently met with in a fossil state.

Bufonites, batrachites, or toad-stones, so named, because it was formerly believed they were engendered in the head of the toad, are found in numbers in various places, on the continent, and in England. Though generally confounded under the same name, there are evidently many different species. Lluid divides them after their forms, as orbicular, flattened, or hemispherical ; and figures of many are given in his work entitled Lithophylacii Britannici Ichnographia, and in the second volume of Knorr's large work on petrifactions. 
(as .

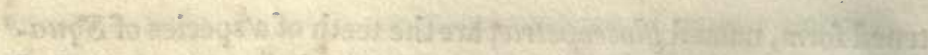

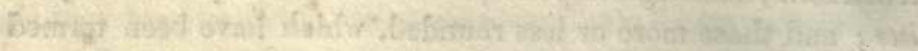
-

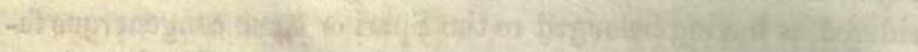

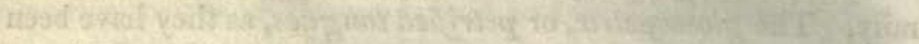

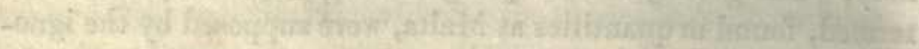

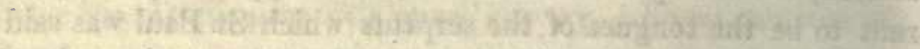

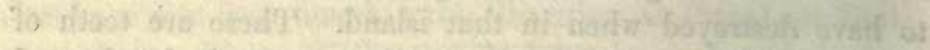

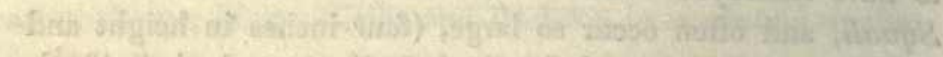

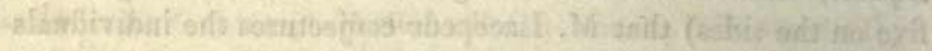

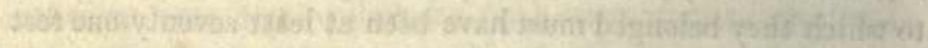

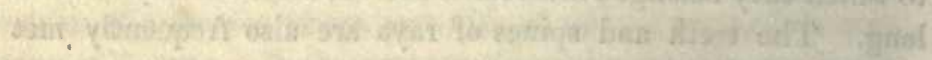

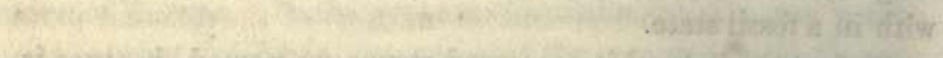

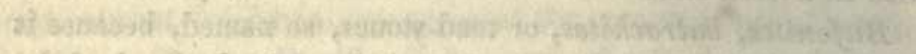

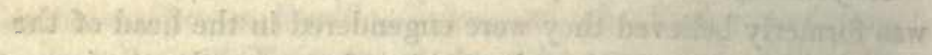

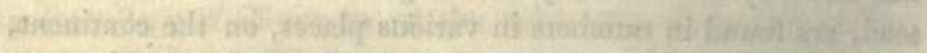

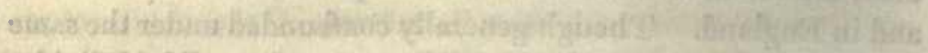

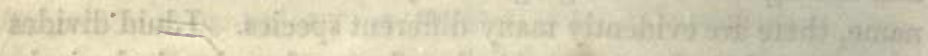

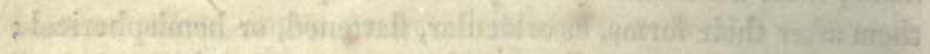

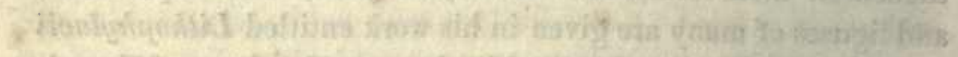

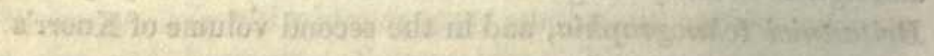

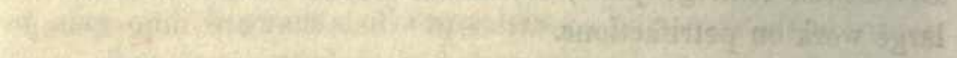

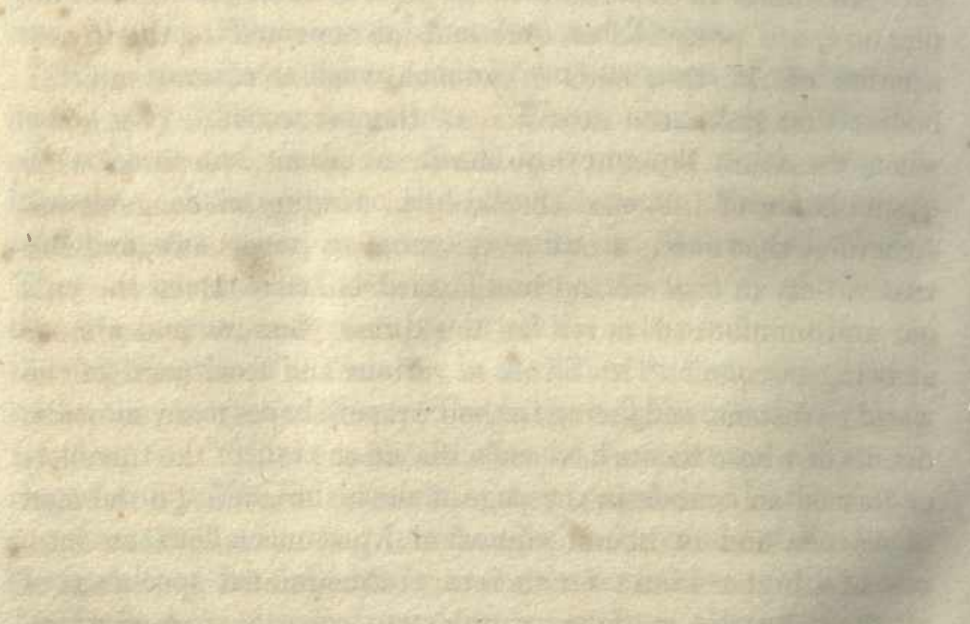




\section{PREPARATION AND PRESERVATION}

OF

OBJECTS IN NATURAL HISTORY.

THE use of Museums or Collections of objects in Natural History to the successful prosecution of the study is very apparent; and it has lorig been an object of scientific men to collect the animal, vegetable, and mineral productions of the different parts of the world, for comparison and examination. Besides the knowledge of the family characters and structure of the individuals which such collections afford, and the facility of comparing that structure with what is related of the habits of the animals themselves, and their uses, even as a matter of general interest, a Museum of Natural History affords to the most casual observer much of what he desires to know. It is not every one who has an opportunity of examining the productions of nature in the respective countries to which they are indigenous; few can have seen very many of them in their native haunts; and still fewer in visits to distant places, either on business or pleasure, are possessed of time and talents equal to the investigation of the thousands of animal, vegetable, and mineral bodies that claim the attention of the naturalist. It is only when these are brought together in museums, prepared with a simulation of life, and displayed in families of congenerous structure, that one is aware of the number, importance, and the vast variety of organic and inorganized bodies. Even the vulgar and uninformed never fail to express pleasure and wonder at being in contact with forms so various and from parts of the world so distant, and seeing in their proper shapes many animals, details of whose habits have embellished the tale of the traveller, or formed an episode in the page of the historian. To the man of science and of liberal education Museums afford an interest of a higher kind ; for there are accumulated specimens of all those articles in their natural state, an exchange of which between distant nations constitutes the chain that connects 
them together, and forms the commerce of the world. The effects of soil, climate, or food on these, are exhibited in the productions of the torrid, the temperate, and the frigid zones, in animals or plants common to all; and the geographical range of organized bodies in general is brought within the reach of observation and comparison. In examining productions of different countries, there is something besides which excites general curiosity in no ordinary degree. The terror of the forests, the lion, the tiger, the rattlesnake, - the gigantic and the minute in animal forms-all that is dreaded for ferocity or magnified for the danger of their approach when living and in their native haunts, are here innocuous; and, however much the effect may be lost by contemplating such animals without the power to hurt, yet curiosity is gratified in beholding the identical beings, relations connected with which have so powerfully increased the interest of the traveller's narrative.

Unfortunately for the perpetuity of such collections, however, the resources of man have proved but a feeble barrier against the universal law of decay, which reduces all organized bodies to their original elements; and though care may for a while arrest the progress of decomposition, yet it is found that even in the best regulated Museums many portions become useless or ultimately disappear. Theelements of air, heat, and moisture, though no other causes operated, gradually but infallibly destroy the finest specimens; and when to these are conjoined the ravages of thousands of minute animals which find their food in these preparations, human care proves but of limited avail in counteracting the effect of these natural causes. Hence a museum, unless constantly kept up by the addition of new specimens, is gradually falling away, in so far at least as regards most of the organized bodies of which its parts are composed; and hence the disappearance of collections once celebrated for their riches in animal remains.

By proper and incessant care, however, even the most perishable objects of a Museum may be preserved for a considerable length of time; and as the causes of destruction are investigated counteracting agents may be discovered, in so far at least as to preserve for a long period the acquisitions of science in animal structures.

Next to Museums good Figures of the objects are important 
to the successful study of Natural History. But the number and consequent expence of these make their acquisition within the reach of but very few. Many splendid works of this kind have been published; but where the artist is not himself a naturalist, or has not worked under the immediate superintendence of one intimately acquainted with the objects represented, the chance of error in the delineation of minute or characteristic parts is much increased. Hence the small comparative value of those collections of engraved figures which generally accompany popular compilations on Natural History; and the value of original works where the objects have been figured from Nature, by a person qualified to copy the minute particulars of the original. But after all, in the study of Natural History, nothing can compensate for the want of a museum, where the structure of the individuals themselves can be studied, and frequent observation of the native species. One animal, or plant, or mineral, observed in its native habitat is worth a thousand figures; and gives a more accurate idea of the structure and manners of congenerous objects than volumes of description, unaccompanied by reference to the great field of practical study.

Since the study of Nature has become of general interest, Museums of objects in Natural History have been established in all the capitals of Europe. In Britain, however, notwithstanding the possession of extensive colonies and commercial establishments in every quarter of the globe, little advantage has hitherto been taken of the means in the power of government for procuring exotic specimens; and while in a neighbouring country expeditions have been set on foot, under the superintendence of qualified men, to investigate the natural and other products of distant countries, objects of a similar kind have occupied but a small portion of attention in Britain. The Royal Museum at Paris is an example of what can be achieved when the pursuit of science is patronized by the State; and from the Professors of that Institution, the greater portion of the accurate information in Natural History has been derived. In Britain, the largest public collection is the British Museum; and a Society has been lately established in the Metropolis, for supporting a menagerie for the study of living animals. In Edinburgh, the College Museum, under

voL. I. 
the superintendence of the able Professor of Natural History, has within a few years become an extensive and valuable collection. There existed, indeed, in that seminary, a very considerable museum for the time, formed by Sir Andrew Balfour and Sir Robert Sibbald, about a century ago ; but long before the present Professor was called to the chair, it had disappeared, and Professor Jameson has the sole merit of establishing this $\mathrm{Mu}$ seum by his personal exertions, and of extending a taste for the Science of Nature, which has rendered the University of Edinburgh in this particular the first in the kingdom.

Preparatory to giving a short account of the manner in which the different objects described in this and the following volume may be prepared or kept, it may be necessary, for the use of those visiting distant countries, to state at what a trifling expence of time and labour many interesting objects may be put up, so as to insure their transmission home without injury. For this purpose, we avail ourselves of a paper of directions which the eminent Professor above alluded to drew up some years ago for the use of his pupils, as conveying in a few sentences, most of what is in this respect desirable to be known.

"Quadrupeds and Birds.-Quadrupeds and birds to be preserved by taking off their skins, which may be easily done, by making an incision in a straight line, from the vent to the throat, and removing the skin by means of a blunt knife. The skull and bones of the legs and feet are to be left. The brain, eyes, and tongue, ought also to be extracted. The skin, in order that it may be preserved from decay, should be also rubbed on the inside with some one of the following compositions : 1st, tanners' bark well dried and pounded, one part ; burnt alum, one part ; and in a hot climate one part of sulphur; to be well mixed together. $-2 d$, tanners' bark well dried and pounded, one part ; tobacco, perfectly dried, one part; burnt alum, one part: add to every ounce of these ingredients one ounce of camphor, and half an ounce of sulphur. (N. B. No sublimate or arsenic ought to be put on the skins, as both substances destroy their texture.) These compositions to be kept for use in well corked bottles or jars.

"Skins, when thus prepared, and perfectly dry, must be packed carefully in boxes, the lids of which ought to be pasted up, and in the paste used in fixing the paper, a little corrosive sublimate must be put, which prevents insects from eating through the paper. 
"Reptiles and Fishes.-Reptiles and fishes are best preserved in spirit of wine, rum, or whisky, some of which must be injected into the stomach, through the mouth, and into the other intestines through the anus. Before putting them into bottles, jars, or barrels, they ought to be washed clean of slimy matter. If long kept in spirits before they are sent, the spirits should be changed two or three times. The jars or bottles ought to be closed by means of sheet-lead and bladders. The larger reptiles, as crocodiles, and the larger fishes, may be preserved in the same manner as quadrupeds and birds.

"Animal Concretions.-Concretions of various kinds are occasionally found in the brain, lungs, heart, liver, kidneys, gall-bladder, intestines, and urinary bladder. The stomachs of many animals afford concretions of different kinds, particularly those known under the name of Bezoar Stones; and travellers inform us, that stones are met with in the eggs of the ostrich. All of these bodies are interesting and valuable to the natural historian.

"Skeletons.-Collectors ought not to neglect to preserve the skelètons of the different species of animals. Of man, the skull is the most interesting part, as it varies in the different races of the human species, and is also frequently singularly altered by the practices of savage tribes. The best way of cleaning bones, is to expose them to the air, and allow the insects to eat off the flesh. This being done, they ought to be washed with sea water, and afterwards freely exposed to the sun. The best skulls are obtained by putting the whole head in rum or whisky, or a strong solution of alum; and both male and female heads ought if possible to be preserved.

"Molluscous Animals,_Vermes and Zoophytes.-Molluscous animals, such as cuttle-fish, the inhabitants of shells, \&c. Vermes or worms, and Zoophytes, or animals of the coral and other allied kinds, ought all to be preserved in spirits ; and in the two former classes, viz. the Mollusca and Vermes, the spirit of wine should be injected into the intestines, by means of a syringe, to prevent the putrefaction of the internal parts, and the consequent destruction of the organs of digestion, respiration, and of the nervous system. Many Zoophytes or Corals, or rather their houses, may be preserved dry ; but fragments of every species ought to be put into spirits, that the real structure of the animal may be discovered.

"Shells.-Shells, or the coverings of Molluscous animals, are anxiously sought after by the naturalist, not only on account of their great beauty, but also from their intimate connection with the various fossil species met with in rocks of different kinds. The best live shells are collected by means of a trawling-net, such as is used 
by fishermen, if the depths are not too great; they are also brought up by the cable in weighing anchor, the log-line, and in sounding.

"After a storm, good shells may be picked up on sea beaches or shores, as the violent agitation of the ocean in a tempest separates them from their native beds, and often casts them on the shore: Shells that have been much tossed about by the waves, are of less value than fresh ones; but these, when other specimens are not to be got, ought to be carefully collected. Many interesting shells are found in rivers and lakes; and numerous species occur on the surface of the land.

- "Fresh shells, or those in which the animal is still alive, ought to be thrown into hot water, the temperature of which may be gradually brought to the boiling point, by the repeated additions of hotter portions, by which means the animal will be killed. The shells are allowed to cool for two or three minutes, and then the animal is picked out.

" Insects.-Beetles of every kind are speedily deprived of life by putting into boiling water, which does not injure those having black, brown, or any dark colour; but those which are covered with fine down, or have brilliant colours and lustre, should not be exposed to moisture, but are easily killed, if put into a phial, and placed in a vessel of boiling water for some time. When the insects are quite motionless, such as have been in the water should be exposed to the air and sun for a day or two, until perfectly dry. In this state, they are to be placed in boxes with cotton-wool, along with camphor. Beetles may also be preserved in spirit of wine.

" Butterflies, moths, and many other tribes of insects, with delicate and tender wings, may be easily killed, by pressing the thorax or breast betwixt the finger and thumb; and it is preferable to have the wings closed, because they thus occupy less space, their colour and lustre are better preserved, and they can be expanded afterwards by the steam of hot water. Care should be taken that the antennæ or feelers and legs are not injured. A pin should be stuck through them, by means of which they are fastened to the bottom of a box lined with cork, or to one of deal, or other soft wood. Camphor ought to be put into the box.

"The Arachnides or Spiders are best preserved in spirits.

"In collecting insects, we use either the forceps or a net. The forceps are about ten or twelve inches in length, provided with fans of a circular or other form, and are covered with fine gauze. They are held and moved as a pair of scissors. The net is very easily made. It is of gauze, or any very fine open muslin, made upon a piece of cane of four feet long, split down the middle about the half 
of the length : the split part is tied together, so as to form a hoop, upon which the gauze is sewed in the form of a bag; the lower part serves as a handle, and with this, all flying insects may be very easily caught. When the insect is once within the rim of the net, by turning it on either side, its escape is completely prevented by the pressure of the gauze or muslin against the edge of the hoop.

"Crabs.-Crabs, Lobsters, \&c. may be suffocated in spirits of wine or turpentine, and then dried in an oven.

"Crustaceous Animals.-Sea Stars, after washing in fresh water, may be extended on boards by means of pins, and when dry, laid between folds of paper, and packed in a box with a little camphor.

"In Echini or Sea Eggs, the soft internal parts are to be extracted by the anus : they are then to be stuffed with cotton, and carefully packed with tow or cotton. Particular attention should be paid to the preserving of the spines.

"Seeds.-In collecting seeds, it is desirable that they should be well ripened, and dried in the sun. Large quantities should never be put together, but only a few, and these well selected. They retain their vegetative powers much better if tied up in linen or cotton cloth, than in any other substances; and if then packed up in small boxes, and placed in an airy part of the ship, there is every probability of their arriving in a sound state. The same remark applies to bulbous roots. Bulbs should never be put in the same box with seeds. . The boxes with seeds, and with bulbs, ought never to be put into the ship's hold.

“ Dried Plants.-The greater part of plants dry easily between leaves of books, or other paper. If there be plenty of paper, they often dry best without shifting; but if the specimens are crowded, they must be taken out frequently, and the paper dried before they are replaced. Those plants which are very tenacious of life, ought to be killed by the application of a hot iron, such as is used for linen, after which they are easily dried. The collections to be carefully packed in boxes with camphor, and closed in the same manner, as directed for quadrupeds and birds.

"Minerals.-1. Every mineral, from the most common clay or sand, to the gem, ought to be collected.

" 2. Specimens of rocks, such as granite, porphyry, limestone, \&c. should, if possible, be broken from tixed rocks, and not from loose masses, which are generally decayed. In selecting the specimens, one set ought to represent the different varieties of appearance presented by the rock in the fresh state, another, the rock in its different states of decomposition.

" 3 . When the specimens of simple minerals, or rocks, contain 
crystals, they ought to be wrapped in gauze-paper, then in cotton, and afterwards in several folds of strong wrapping-paper.

" 4 . The specimens of rocks ought, if possible, never to be less than four inches square, and one inch in thickness, and of a square form. As soon as they have been prepared, they should be labelled, and wrapped in several folds of strong wrapping-paper. When paper cannot be procured, moss, or other soft vegetable substance, may be substituted for it.

" 5 . The sands of deserts, steppes, and rivers, ought to be carefully collected. The sands of rivers often contain precious stones and metals, and hence become very interesting objects to the naturalist. The sands of deserts and steppes throw much light on the nature of the surrounding country, and are much prized by the geologist.

"6. Numerous mineralized animal and vegetable remains occur imbedded in strata of different kinds; all these ought to be very carefully collected, and preserved. Abundance of shells in a fossil or petrified state, are met with in limestone; of vegetables in slate-clay, sandstone, \&c. ; and numerous bones, and even whole skeletons of quadrupeds, birds, amphibious animals, fishes, and even of insects, occur in rocks of various descriptions.

“7. The mineralogist ought to provide himself with hammers of various sizes. One for common use of two pounds weight; others, three, four, and six pounds weight. He ought also to provide himself with chisels of various sizes and forms, and with a set of small boring-irons. A miner's compass, small magnifying glass, goniometer, and blowpipe, ought also to form part of his equipment. The two first are indispensably necessary for the travelling mineralogist. Nor should he neglect to provide himself with a strong bag; the form that of a fowling-bag, lined with strong leather, covered with wax-cloth, and the outside of some durable cloth."

The art of preparing and mounting the skins of animals for preservation in a Museum has been denominated Taxidermy. Many methods to attain the desired end in the best manner have been proposed. Reaumur published a Memoir on the subject of preserving the skins of birds sent from distant countries, and formed a beautiful collection in his own house, which after his death became the basis of that in the Museum at $\mathbf{P a}$ ris. According to the instructions he had given, he received birds from all quarters in spirit of wine. On taking them from the liquid, he simply introduced two ends of an iron wire into 
the body behind the thighs, fastened the wire to the claws, the ends serving to fix the specimen to a board, and put in glass beads for the eyes. The larger animals, such as the shark and crocodile, were stuffed with straw.

The plan of skinning and stuffing with soft materials was afterwards attempted. Schœffer, after skinning a bird, cut the skin longitudinally in two, and filled one-half with plaster moulded to the shape of the bird ; fixed the skin thus prepared to a board in a frame, represented the beak or claws by painting, and covered the whole with glass.

The early modes of preserving animals, however, having been found very imperfect, the attention of the French naturalists was for many years directed to the subject, and many treatises on Taxidermy, as it is now called, were written. In 1786, the Abbé Manesse published a Treatise on the manner of stuffing and preserving animals and skins, which contained some very useful directions ; but as the Abbé excluded the use of poisons, and trusted chiefly to alkaline preparations, the affinity of these for moisture soon destroyed the lustre of the preparations, particularly of birds. In the Memoir of Mauduyt for preparing birds for collections, his attention seems chiefly to have been directed to the destruction of the parasital insects which feed on such preparations. Fumigation of sulphur he found very efficacious for this purpose ; but the use of this mineral, while it had the desired effect in this respect, totally destroyed the skins themselves. Daubenton, adopting the use of sulphur in the Museum of Natural History at Paris, found that the sulphurous vapour changed the red into a dirty yellow, blackened the blue colours, soiled the cases, and even burnt the upper parts of the more delicate specimens. In 1802, M. Nicholas, a chemist, and M. Henon, published works on Taxidermy, the first, after detailing the previous modes, recommending a soapy composition and a tanning liquor to be used in mounting the specimens. The oil of turpentine is the chief article trusted to by the latter. But the first method, excluding poisonous ingredients, was not found to answer completely ; and turpentine has been found to injure the colours. M. Dufresne, whose great experience in the Museum at Paris makes his observations of consequence, finds the arsenical soap invented by M. Becour, an apothecary of Metz, indispensable. 
The articles necessary for mounting animals are, according to Dufresne, an assortment of iron wire of different sizes; flax, or cotton ; scalpels, scissors, and forceps of various sizes; a hammer, files, and brushes, and an assortment of eyes in enamel. The arsenical soap is composed of the following ingredients :-

\begin{tabular}{|c|c|}
\hline Camphor, - & 5 ounces. \\
\hline Arsenic in powder, & 2 lbs. \\
\hline White soap, & 2 lbs. \\
\hline $\begin{array}{l}\text { Salt of tartar, } \\
\text { Chalk in powder, }\end{array}$ & $\begin{array}{r}12 \text { ounces. } \\
4 \text { ounces. }\end{array}$ \\
\hline
\end{tabular}

The soap is cut in thin slices, and melted over a gentle fire in a small quantity of water, care being taken to stir it often. When all is dissolved, the salt of tartar and powdered chalk is added. It is then taken from the fire, the arsenic is added, and the whole gently triturated. Lastly, the camphor reduced to powder in a mortar with a little spirit of wine is mixed with the previous ingredients ; and the whole is then put aside in convenient pots for use. When wanted, the necessary quantity is put into another vessel, and diluted to a proper consistency with cold water. Gum Paste, made of gum-arabic, in the proportion of one pound to two ounces of white sugar-candy, and a spoonful of starch or hair powder, is also of use in the mounting of animals. M. Dufresne also uses a paper paste, formed of the pulp of unsized paper pounded in a mortar and dried, with the addition of melted gum-arabic.

Skeletons of animals are prepared when under the size of a fox, by macerating the body after the skin, muscles, intestines, \&c. are removed, in water, to which a little quicklime has been added. After two or three days maceration, it is extended on a table, and the fragments of flesh scraped off with a scalpel, taking particular care to preserve all the ligaments which attach the bones together. These ligaments when dried are in general sufficient to keep the skeleton upright; but when this is not the case, an iron wire passed through or under the vertebral column fixes the head to the cervical vertebra at the anterior end ; and two forks of similar wire support the extremities. In larger animals, the bones are separated at the joints before maceration, whitened in the sun after being properly cleaned, and afterwards fixed in their natural order by wires 
passed through holes drilled at their junction. When all the bones are attached in this manner, two perpendicular iron rods are fixed to the board upon which it is placed for the support of the skeleton. In very large animals the connection at the articulations is formed with nuts and screws.

In mounting a quadruped, the general plan is to lay the animal on its back, after having filled its mouth and any wounds in the skin with cotton or chopped flax, to prevent the soiling of the hairs. An incision is then made in the middle of the abdomen, turning back the hairs to right and left, and taking care not to cut the muscles of the belly. The incision is carried longitudinally from the arch of the pubis to the stomach, or further if necessary, and the skin separated to the right and left, placing pads of tow or cotton between it and the body as the skinning proceeds. The anus is separated at the rectum, and each thigh at its junction with the bones of the pelvis. For quadrupeds of middling size it is sufficient to take the skin in one hand, and the body in the other, and, by pulling in contrary directions, remove the skin as far as the shoulders. When this is done, the fore legs are cut at the shoulder joint. The neck is skinned by passing the skin over the head, and detach-ing it from the cranium by means of a scalpel. The ears are cut as near as possible to the bone, and the eyelids preserved. The head is skinned as far as the nose, the cellular matter removed from the cranium, and the bone anointed with the arsenical mixture. The occipital hole being now enlarged, the brain is scooped out by means of a spatula ; and the bones of the head being cleaned are replaced under the skin. The forelegs are skinned in the same manner, by turning over the skin downwards, and dissecting away all the soft parts except the ligaments. The other legs are done in the same manner to the claws and replaced. The tail is then skinned, only being more difficult, it is found necessary sometimes after clearing two or three joints, to fix a cord to these, attached to a hook in the wall, and by means of a cleft stick free the skin from its attachments. The body being completely removed, the skin is spread upon a table, and all the fleshy portions scraped off.

An iron wire is now procured of such thickness that four picces introduced into the legs will support the animal. A 
piece of smaller wire, the length of the tail, with an oval bending at the anterior end, is now to be rolled round with flax, increasing the quantity of flax as the tail thickens, towards the oval. When of the proper size, moistened with a little flour paste to make it retain the form, and dried, it is inserted into the skin of the tail, both being previously rubbed with the preservative mixture by means of a brush. The oval bending of the tail wire serves to fix that which replaces the vertebral column.

A long wire now fixed in the cranium, and extending to the loop of the tail wire, is made to support the body longitudinally. Loops bent on this wire at the shoulder serve for fixing the wires which support the legs. After the inner side of the skin has been anointed with the mixture, the body is then either formed of chopped flax, or if the animal be large, straw or hay, and the head and legs stuffed by means of forceps to the requisite thickness. The wires of the limbs are pointed and inserted behind the bone. When the body is formed as nearly as possible of the natural size, the skin is brought together and sewed neatly, taking care not to include the hairs in the stitches. The enamel eyes are put in while the eyelids are still fresh, and any want of stuffing to imitate the muscles of the head is inserted by the eyes, ears, and nose, by means of a small probe. The lips are then placed properly, and fastened with pins till dry. The opening of the nostrils is prevented from shrinking by inserting a peg into them covered with cotton; and the ears are supported in their proper state of erection by slips of card and pins. The ends of the wires inserted at the feet are left long for fastening the preparation to a board by corresponding holes made in the wood; and the bendings of the legs and attitude are given before putting the specimen aside to dry. When the internal anointing with the preservative mixture or powder is not judged sufficient, such parts as the nose, lips, and feet, are anointed by means of a brush with spirit of turpentine, and afterwards wiped with cotton.

A large elephant mounted in Paris for the Museum, had a wooden model of accurate dimensions formed for the internal frame. The skin of this animal when taken from the body weighed 576 French lbs. 
BrRDs.-Birds are skinned nearly in the same manner as quadrupeds; that is, an incision is made from the breast bone to beyond the middle of the belly, after separating the feathers of the belly to right and left. The skin is then freed from the muscles by means of a scalpel, putting chopped cotton on the skin and body to prevent the soiling of the feathers; the wings detached at the junction of the humerus with the body; and the skin turned over the head and legs after dividing the joints. The brain is now removed by an enlargement of the occipital hole, the tongue taken out, and the bill tied close; and after scraping off with a scalpel all the muscular and cellular substance, and anointing the inside of the skin and bones of the head and legs, the skin is returned to its natural position. A body formed of straw, flax, or cotton, is inserted, and the skin drawn over it. A piece of wire of a forked form supports the tail ; a second fixed in the cranium, and extending to this, gives strength to the body; and two wires, run up the back of the legs from the sole of the foot, are attached to the ring on the tail wire irside the body. When finished, and the incision sewed up, the proper attitude is to be given, the wires projecting from the soles serving to fix the specimen on a board or perch. In large-headed birds, such as ducks, as the skin of the neck will not pass over the head, an incision is often necessary in the nape of the neck.

As many skins of birds are sent home from foreign countries dried and temporarily preserved, the stuffing ought to be carefully taken out, and the skin made pliant by wet linen or cotton inserted, and in a short time it will be ready for mounting as in the fresh-killed bird. In specimens, however, which are much decayed, there is a mode of mounting feather by feather, when the rarity of the bird is such as to make its preservation an object. The mode adopted by the French naturalists to effect this is to form a body as like the original as possible on a piece of soft wire, with flax and paste; the head and legs are then fitted; and the feathers placed in their order, beginning with those nearest the tail, and working forwards. The feathers are fastened singly by gum; the wings attached by pins ; the tail inserted in a hole made for the purpose, and fixed by gum. 
Reptiles. - Lizards are mounted in the same manner as quadrupeds; but much precaution is necessary in taking off the skin of the tail, which easily breaks. The smaller species, which lose their colours in preparation, are generally preserved in spirits.-Frogs are mounted by cutting the first cervical vertebra through the opening of the mouth; separating the attachments of the mouth, taking out the viscera by this opening, folding back the skin, and pushing the body out. After being wholly detached, the skin is filled by means of a funnel with very fine sand. When the body and feet are perfectly full, the frog is placed on a board, in the proper attitude, its mouth shut, and put to dry. When completely dried, it is coated with varnish, and the sand removed by boring small holes under the belly. The small species are preserved in spirits.-Serperts are prepared by an opening made in the side, so as not to divide the ventral plates, and mounted by passing a long wire twisted round with flax of the proper thickness into the skin, and afterwards varnished; but the smaller species are best preserved in spirits.

Fisues.-The larger fishes are skinned by a longitudinal opening made in the belly, and stuffed as quadrupeds, but varnished when dry. The smaller ones are sometimes mounted by forming a cork body the size of the fish, but flattened on one side ; and the skin being carefully dissected off the specimen, is applied over the cork body, preserving the dorsal and ventral fins. The preparation is then varnished and fixed to a board. The very small species are preserved in spirits. - Lampreys and Eels are skinned by the mouth as frogs, and the skin filled with sand.

Mot.lusca.-Molluscous animals without shells can only be preserved in spirits. The shells of the others require merely brushing with soap and water after the animal is removed by boiling water, to fit them for the cabinet. The soft parts of the Crustacea require to be carefully removed. This is effected in the claws by making a small opening and picking out the flesh. The smaller species may be preserved as Insects, by passing a pin through them, and affixing them to cork.

The Arachnides generally lose their colour and shrivel up in drying, and are therefore best preserved in spirits. 
INSECTs.-Insects are found everywhere, and as the mode of procuring specimens in their various localities is different, it may be necessary to mention the several modes in which they are procured. The apparatus necessary is, 1. a pasteboard or slight box about ten inches long, four wide, three deep, and of an oval form, for carrying home the specimens, the larger being affixed with pins to the bottom, the smaller to the lid, both of which are lined with cork. 2. A net to catch butterflies and other winged insects. This has the head, about ten inches in diameter, formed of wire of an oval form, and fixed in a socket affixed to a stick four feet long. Round the wire is attached a bag of gauze from fifteen to eighteen inches long. This net is used for catching butterflies, \&c. in flight, on the ground, or on flowers. When the insect is in the net it is turned, the butterfly forced to the bottom, and the thorax passed between the fingers without touching the wings. It will then easily drop out, and is transfixed with a pin through the thorax and stuck into the box. Another net of stronger consistence is used for fishing aquatic insects in rivulets, ditches, and ponds. The net is dipped into the water, to the bottom even in many cases, and into the mud, the mouth then turned to a side, and the bag passed quickly through the water several times to wash away the mud. By use of this net, many species of aquatic Coleoptera are procured. Coleopterous insects are conveniently carried home in a small bottle partly filled with spirits.

To prepare butterflies a groove is made in a piece of soft wood or cork the size of the body, and so deep, that the body is received into the groove to the insertion of the wings. Being pinned in this situation, the wings are then placed horizontally by means of slips of card or paper fastened by pins ; and when the specimen is dried it preserves the position thus given. When insects have been dried in an improper position, they

- are easily softened so as to make their members flexible, by placing them on a piece of cork floated in water for a few hours.

The caterpillars of insects are sometimes preserved by pressing the skin after making an opening at the anus for the passage of the intestines. When empty, a pipe of straw is introduced, and the specimen being held over a chafing dish till 
partially dried, the body is blown up to its common size, and the straw cut off.

The finest specimens of Phalenæe are procured by rearing the caterpillars. These are gathered along with the leaves of the plant upon which they feed, and are kept in a box covered with gauze, taking care that the leaves are kept fresh by being placed in a small vessel of water. When done feeding, they form their cocoon, and remain in their pupa state till the period of their complete developement.

Messrs Kirby and Spence recommend the drawers for keeping insects to be about eighteen inches square, the bottom covered with cork, the top with glass, and about an inch and a half in depth from the glass to the corked bottom. These can be arranged at pleasure in a double row in a cabinet with folding doors.

Polypi, \&c.-The greater portion of the calcareous Polypi, as the corals, lose their animal matter upon being taken out of the water, and the stony axis or body requires no further preparation. The flexible or horny species, as the Sertulariæ, \&c. are, after being freed of salt by dipping in fresh water, dried and preserved in the manner of plants. To preserve the polypi in a recent state spirits are necessary. 


\section{LIST OF BOOKS.}

Æliani, Claud. de vi et natura Animalium.

Albin, E. A Natural History of Birds, 3 vols. 4to. Lond. 1738.

History of Esculent Fish. 4to. Lond. 1794.

Icones Piscium. 4to. Lond. 1735.

Aldrovandus, Ulysses, de Piscibus. Folio. Bonon. 1638.

de Quadrupedibus. Folio. Bonon. 1637, \&c.

Annales du Museum d'Histoire Naturelle de Paris, 20 vols. 4 to. Paris, 1802-1813.

This work is continued under the title of Mémoires du Museum.

- des Sciences Naturelles, publiées par M M. Audouin, Al. Brongniart et Dumas. 8vo. Paris, 1824, \&c.

Aristotelis Historia Animalium. Folio. Venet. 1513.

Artedi, Pet. Ichthyologia, cura Linnæi, 8vo. Lugd. Bat. 1738 -cura Walbaum. Gryp. 1788-cura Schneider. 4to. Leips. 1789.

Audebert, Histoire Naturelle des Singes et des Makis. Folio. Paris, 1800.

- et L. P. Vieillot, Histoire Naturelle des Colibris, Oiseaux Mouches, Ja. camars et Promerops, aussi des Grimpereaux et des Oiseaux des Paradis, 2 vols. folio. Paris, 1822.

Azzara, Don Felix, Essai sur 1'Histoire Naturelle des Quadrupedes du Paraguay, 2 vols. 8vo. Paris, 180 J. And Voyages dans l'Amerique Meridionale, 4 vols. 8vo. Paris, 1809.

Bellonius de Aquatilibus. Folio. Paris, 1553.

Bewick, T. History of British Birds, with figures on wood. 8vo. Newcastle, 1797. History of Quadrupeds. 8vo. Newcastle, 1820.

Bloch, Marc. El. Ichthyologie, ou Histoire Naturelle des Poissons. Folio. Berlin, 1785-97. - A small copy published at Paris, in 10 vols. $18 \mathrm{mo}$.

Blumenbach, J. F. Manual of Comparative Anatomy, translated by Lawrence. 8vo. Lond. 1828.

Brissoni, Regnum Animale. 4to. Paris, 1756.

Ornithologia, 6 vols. 4 to. Paris, 1760.

Brongniart, A. Essai d'une Classification Naturelle des Reptiles. 4to. Paris, 1805.

Brown, Patrick, Illustrations of Zoology. 4to. Lond. 1760.

Brunichii, M. T. Ornithologia Borealis. 8vo. Hafn. 1764.

Buffon, Histoire Naturelle, par Sonnini, 127 vols. 8vo. Paris, 1798-1807. - A complete edition of Buffon, in 40 vols. $8 \mathrm{vo}$, by Lamouroux and Desmarest, is nearly completed.

Catesby, M. Natural History of Carolina, Florida, and the Bahama Islands, 2 vols. folio. Lond. 1731.

Church's Quadrupeds, 2 vols. folio. Lond. 1805.

Cuvier, G. Leçons d'Anatomie Comparée, 5 vols. 8vo. Paris, \&c. An 7-14.

Recherches sur les Ossemens Fossiles des Quadrupedes, 7 vols. 4to. Paris, 1822-24:

Le Règne Animal, 4 vols. 8vo. Paris, 1817.

- Discours sur les Revolutions de la surface du globe, et sur les Changements qu'elles ont produits dans le Règne Animal. 8vo. Paris, 1825.

- F. Des Dents des Mammifêres considerées conıme caractères zoologiques. 8vo. Paris, 1825. 1819, \&c.

Fr. et Geoffroy St Hilaire, Histoire Naturelle des Mammifères. Paris,

Daudin, F. M. Histoire Naturelle des Quadrupedes Ovipares. 4to.

1800. 
Desmarest, Mammalogie, ou Description des espéces de Mammifères. 4to. Paris, 1822.

Paris, 1805.

Histoire Naturelle des Tangaras, des Manakins et des Todiers. Folio.

Dictionnaire Classique d'Histoire Naturelle, par MM. Audouin, Brongniart, \&c. 8vo. des Sciences Naturelles par les Professeurs du Jardin du Roi. 8vo. V. Y.

Paris, 1816-19.

(Nouveau) d'Histoire Naturelle appliques aux Arts, \&c., 36 vols. 8 vo.

Donovan, E. History of British Birds, 10 vols. 8vo. Lond. 1794-1818.

. The Natural History of British Fishes, 5 vols. 8vo. Lond. 1808.

Dumeril, Elemens des Sciences Naturelles, 2 vols. 8vo. Paris, 1825.

Zoologie Analytique. 8vo. Paris, 1806.

Edwards, George, A Natural History of Birds, 4 vols. 4 to. Lond. 1743, \&c.

Encyclopédie Metliodique. 4to. Paris, V. Y.

Erxleben, C. P. Systema Regui Animalis, Classis I. Mammalia. 8vo. Lips. 1777.

Fabricius, O. Fauna Groenlandica. 8vo. Hafn. 1779.

Fleming's Philosophy of Zoology, 2 vols. 8vo. Edin. 1822.

- British Animals. 8vo. Edin. 1828.

Forskal, P. Descriptiones Animalium quæ in itinere Orientali observavit. 4 to. Hafn. 1775.

Forster, J. R. A Catalogue of the Animals of North America. 8vo. Lond. 1771.

Gesner, Conr. Historia Animalium, 4 vols. folio. Tigur. 1551.

Gouan, Ant. Historia Piscium. 4to. Strasb. 1770.

Griffith's Animal Kingdom, translated from Cuvier. 8vo. Lond. 1825.

General and Particular Descriptions of Vertebrated animals. 4 to. Lond. 1821.

Gronovii, Laur. 'Theod. Museum Icthyologium, 2 vols. folio. Lud. Bat. 1745.

Zoophylacium, exhibens Quadrupeda, Amphibium, et Fisces. Folio. Lugd.

Bat. 1763 , \&c.

Harlan, Dr Richard, Fauna Americana. 8vo. Philad. 1825.

Huet, Collection de Mammifères du Museum d'Histoire Naturelle, desinées d'apres Nature. 4to. Paris, 1808.

Illiger, J. C. W. Prodromus Systematis Mammalium et Avium. 8vo. Berlin, 1811.

Klein, J. T. Historiæ Avium Prodromus. 4to. Lubec. 1750.

- Historia Piscium. 4to. Gedan, 1742.

Stemmata Avium. 4to. Lips. 1759.

Kramer, Elenchus Animalium, \&c. 8vo. Vien. 1756.

Lacepede, Comte de, Histoire Naturelle des Quadrupedes Ovipares et des Serpens, 2 vols. 4to. Paris, 1788.

Histoire Naturelle des Poissons, 5 vols. 4to. Paris, 1798.

Latham, J. General Synopsis of .Birds, 7 vols. 4 to. Lond. 1789.-New edition, Lond. 1821, \&c. Index Ornithologicus, 2 vols. 4to. Lond. 1790.

Latreille, P. A., Familles Naturelles du Règne Animal. 8vo. Paris 1825.

Laurenti, Jos. Nic. Specimen exhibens Synopsin Reptilium emendatum. 8vo. Vindob. 1786.

Leach, Dr W. E., Zoological Miscellany. 8vo. Lond. 1814, \&c.

Leske, N. G., Ichthyologia Lipsiensis. 8vo. Lips. 1794.

Lewin, W. Birds of Great Britain with their eggs, 3 vols. 4to. Lond. 1789.

Birds of New South Wales. 4to.

Linnæi, Car. Fauna Suecica. 8vo. Stockh. 1761.

- Systema Naturæ, 12th edit. 2 vols. 8 vo, in 4 parts. Holmiæ, 1766.

Lord's History of British Birds. Folio. Lond. 179 I.

Merrem, Blas. Vermischte Abhandlungen aus der Thiergeschichte. 4to. Goett. 1781 .

4to. Leips. 1786, \&c.

4to. Leips. 1786,

Monro, Dr A., Structure and Physiology of Fishes, compared with those of Man and other animals. Folio. Edin. 1785.

Montagu's Ornithological Dictionary, 2 vols. 8vo. Lond. 1802.-Supplement to ditto. Exeter, 1813. 
Muller, O. F., Zoologica Danica. Folio. Hafn. 1777.

Naumann, J. F., and Dr C. A. Buhle, Die Eier der Vogel Deutschlands. 4to. Halle, 1818.

Oken, Lor. Lehrbuch der Natur-Geschichte, 3ter Th. 8vo. Leipz. 1816.

Pallas, P. S., Spicilegia Zoologica, 2 vols. 4 to. Berlin, 1761.

Novæ Species Quadrupedum e Glirium Ordine. 4to. Erlang. 1778.

Pennant, Thomas, British Zoology. 4 to ard 8vo, 4 vols. Lond. 1768.

Synopsis of Quadrupeds. 8vo. Lond. 1771.

_- General History of Quadrupeds, 2 vols. 4to. Lond. 1792.

Indian Zoology. Folio. Lond. 1779.

Arctic Zoology, 2 vols. 4to. Lond. 1792.

Petiver, J. Gazophylacii Naturæ et Artis. Folio. Lond. 1702.

Plinii Historia Naturalis, 3 vols. Folio. Paris, 1723.

Pultene5, Richard, Catalogue of the Birds, Shells, \&c. of Dorsetshire. Folio. Lond. 1799.

Raii, J. Synopsis Animalium Quadrupedụm et Serpentini generis. 8vo. Lond. 1693.

Synopsis Methodica Piscium. 8vo. Lond. 1713.

Avium. 8vo. Lond. 1713.

Reaumur, Art de faire eclorer et d'elever en toute saison des Oiseaux Domestiques de toutes espèces, 2 vols. 12mo. Paris, 1751.

Ridinger, J. E., Betrachtung der Wilden Thiere. Folio. Augsb. 1736, \&c.

Risso, A. Ichthyologie de Nice. 8vo. Paris, 1810.

8vo. Haris, 1826.

Roesel, Aug. Jo. Historia Naturalis Ranarun Nostratium. Folio. Nurnb. 1758.

Rondeletius, G. Libri de Piscibus Marinis in quibus veræ Piscium effigies expressæ sunt. Folio. Lugd. 1554.

Russel's Account of Indian Serpents collected on the coast of Coromandel, together with experiments and remarks on their several poisons. Folio. London, 1796.

Salerne, Ornithologie, ou Traité des Oiseaux de Terre, de Mer, et de Rivière. 4 to. Paris, 1767.

Schæffer, Elementa Ornithologica Iconibus vivis coloribus expressis illustrata. 4to. Ratisb. 1764.

Museum Ornithologicum, exhibens Enumerationem et Descriptionem Avium. 4to. Ratisb. 1789.

Schneider, J. G. Algemeine Naturgeschichte der Schildkroten nebst einen systematisches Verzeichnisse der einzelnen arten. Leip. 1783.

-Historiæ Amphibiorum Naturalis et Literariæ. 8vo. Jen. 1799, \&c.

Schœffer, J. C. Piscium Bavarico Ratisbonensium pentas. 4to. Ratisb. 1761.

Schœpff, J. D. Historia Testudinum iconibus illustrata. 4to. Erlang. 1792.

Schreber, C. D. Die Saugthiere in Abbildungen, nach der natur, met Beschreibungen, 4to. Erlang. 1775, \&c.

Seba, Alb. Rerum Naturalium Thesaurus, 4 vols. folio. Amst. 1734-1765.

Selby, P. J. Illustrations of British Ornithology. Folio. Lond. 1821, \&c.

Sepp, C. Nederlandsche Vogelen. Folio. Amst. 1770.

Shaw, Dr George, General Zoology, 14 vols. 8vo. Lond. 1800, \&c.

Smith, J. E. Zoology of New Holland. 4to. Lond. 1798.

Sonnini et Latreille, Histoire Naturelle des Reptiles, avec figures dessinées d'apres Nature, 4 vols. $18 \mathrm{mo}$. Paris, 1802.

Storr, G. C. Prodromus Methodi Mammalium, 4to. Tubing. 1780.

Sturm, J. Deutschland's Fauna, 2 vols. 8vo. Nurn. 1807.

Temminck, C. J. Histoire Narurelle Générale des Pigeons et des Gallinacés, accom. pagné avec planches anatomiques, 3 vols. 8vo. Amst. 1813.

Hist. Nat. des Pigeons, Folio. Paris, 1808. Manuel d'Ornithologie, 2 d edit. 2 vols. 8vo. Paris, 1820.

Turton, Dr W. British Fauna. 12mo. Swans. 1807.

Translation of Gmelin's Edition of the Systema Naturæ of Linnæus,

7 vols. 8vo. Lond. 1805.

Vaillant, Histoire Naturelle des Oiseaux d'Afrique. folio, 4to, and 8vo. Paris 1798.

Histoire Naturelle des Peroquets, 2 vols. 4to. Paris, 1784.

Vieillot, Galerie des Oiseaux du Cabinet d'Hist. Nat. du Jardin du Roi. 8vo. Paris,

V. Y.

vor. I.

K k 
Vieillot, Ornithologie Française. 4to. Paris, 1823, \&c.

Virey, Histoire Naturelle du genre Humain, 3 vols. 8vo. Paris, 1825.

Walbaum, D. Chelonographia, oder Beschreibung einiger Schildkroten nach naturlichen Urbilden. 4to. Leips. 1782.

Walcott, J. Synopsis of British Birds, 2 vols. 4to. Lond. 1792.

Werner, Atlas des Oiseaux d'Europe, pour servir de complement à l'ouvrage de $\mathbf{M}$. Temminck. 8vo. Paris, 1826, \&c.

Willughby, F. Ornithology by John Ray. Folio. Lond. 1678.

\section{De Historia Piscium. Folio. Oxf. 1686.}

Wilscn's American Ornithology, 9 vols. 4to. Philad. 1808, \&c.

Wulff, Jo. Christ. Ichthyologia Regni Borussici. 8vo. Regiom. 1765.

Zoological Journal. 8vo. Londun, 1825, \&c. 


\section{DESCRIPTION OF PLATES.}

The Figures in the Plates have been selected to exhibit the general characters and forms of the different classes; and in most cases from objects of frequent occurrence, that the details of structure may be more easily verified.

\section{PLATE I.-MAMMALIA.}

Fig. 1. Human Scull.

2. Incisive and canine teeth of Man.

3. Molar tooth of Man.

4. Scull of the Orang Outang.

5. Scull of the Hedgehog, Erinaceus Europceus, showing the structure of jaws and teeth in an insectivorous quadruped.

6. Molar teeth of the Hedgehog.

7. Scull of the Beaver, Castor fiber, showing the structure of the jaws and teeth of a gnawing quadruped.

8. Scull of the Cat, Felis catus, showing the teeth and jaws of a carnivorous quadruped.

9. Incisors and canines of the Lion, Felis Leo.

10. Scull of a Dog.

11. Molar tooth of a Dog.

12. Scull of a Sheep, Ovis aries, to show the structure of the teeth and jaws in a ruminating quadruped.

13. Molar tooth of the Sheep.

14. Scull of the Horse, Equus caballus.

15. Wing and feet of a Bat, to show the disposition of the fingers connected by membranes.

16. Feet of the Elephant, Elephas Indicus.

17. Hands of the Orang Outang, as exemplifying the structure of Quadrumanous animals.

18. Feet of the Hog, Sus scrofa.

19. Feet of the Bear, Ursus Arclos, as exemplifying the mode of walking in a plantigrade quadruped.

20. Feet of the Lion, showing the mode of walking in a digitigrade quadruped. 


\section{PLATE II.-BIRDS.}

Fig. 1. Bill and Cere of Golden Eagle, Falco fulvus.

2. Bill of Peregrine Falcon, $F$. peregrinus.

3. Bill and Head of the Great Horned Owl, Strix bubo.

4. Bill of the Carrion Crow, Corvus corone.

5. Head of the Nightingale, Sylvia luscinia.

6. Head of the Bulfinch, Pyrrhula vulgaris.

7. Head of the Crossbill, Loxia curvirostra.

8. Head of the Green Parrot, Psittacus cyanotis.

9. Head of the Nuthatch, Sitta Europea.

10. Head of Turtle-Dove, Columba turtur.

11. Head of Wild Goose, Anas Anser.

12. Head of the Great Auk or Penguin, Alca impennis.

13. Foot of the Golden Eagle, exemplifying the talons of a bird of prey.

14. Foot of the Great Horned Owl.

15. Foot of the Starling, Sturnus vulgaris.

16. Foot of the Nuthatch, showing the structure of the feet in an Anisodactylous bird.

17. Foot of the Green Finch, Fringilla Chloris.

18. Foot of the Green Woodpecker, to show the structure of a Zygodactylous foot.

19. Foot of the Lark.

20. Foot of the Pheasant, Phasianus Colchicus, showing the general structure of the foot in gallinaceous birds.

21. Foot of the Plover, Charadrius pluvialis, to show the structure of the foot among the Grallatores.

22. Foot of the Little Bustard, Otis tetrax, to exemplify the structure of the foot in the Cursores.

23. Foot of the Ostrich, Struthio Camelus.

24. Foot of the Red Phalarope, Phalaropus hyperboreus, to show the structure of the foot in the Pinnatipedes.

25. Foot of the Common Gull, Larus canus, to show the foot of a Palmipede. 


\section{PLATE III.-REPTILES.}

Fig. 1. Testudo Græca.

2. Head of the Rattlesnake.

3. Ventral and transverse plates of a Boa.

4. Poison Fang of the Rattlesnake.

5. Head of the Cæcilia, or Naked Serpent.

6. Head of a Coluber, exhibiting the arrangement of the plates.

7. Head of a Serpent with the head covered with scales.

8. Head of the Siren, exhibiting the external branchiæ.

9. Foot of the Iguana vulgaris.

10. Foot of a Lizard.

11. Foot of a Gecko.

12. Foot of a Frog.

13. Under part of the tail of a Boa, showing the arrangement of the plates.

14. Under part of the tail of a Coluber.

15. Anolius principalis, exhibiting the gular pouch.-P. 349, line 10. Instead of five rays read fifteen.

16. Anguis fragilis, or Blind Worm.

17. Vipera Berus, or Common Viper.

18. Rana esculenta, or the Green Frog.

19. Spawn of the Green Frog.

20. Bufo calamita, or the Mephitic Toad.

\section{PLATE IV.-FISHES.}

Fig. 1. Gymnotus electricus, or the Electric Gymnotus.

2. Head of the Carcharias vulgaris, or White Shark.

3. Diodon atinga.

4. Syngnathus typhle.

5. Salmo salar. The Salmon.

6. Morrhua vulgaris. The Cod-fish.

7. Platessa vulgaris. The Plaise.

8. Conger vulgaris. The Conger Eel.

9. Mullus surmuletus. The Surmullet.

10. Aspidophorus cataphractus. The Armed Bullhead.

11. Scomber scomber. The Mackerel.

12. Zeus faber. The Dory.

13. Chetodon setifer.

14. Centriscus scolopax.

15. Xiphias gladius. The Sword-fish. 


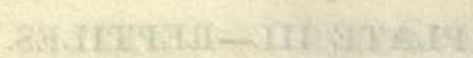

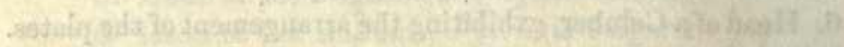

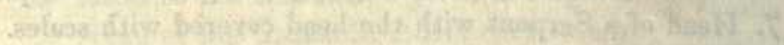

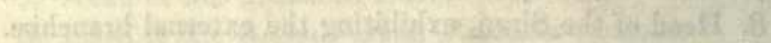

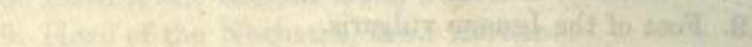

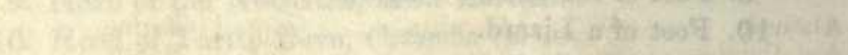

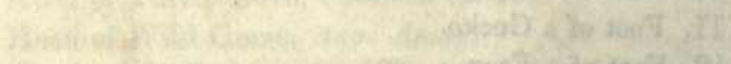

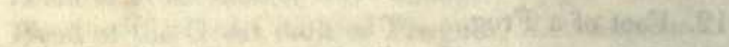

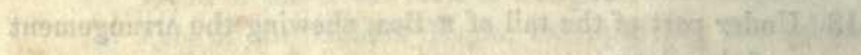

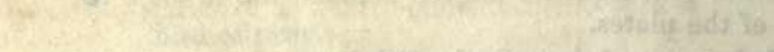

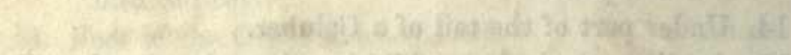

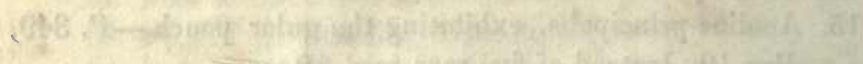

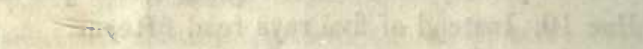




\section{N D E X.}

The names of the Classes and Orders are printed in Capital Letters, the Families in Small Capitals, and the Genera in the ordinary type.

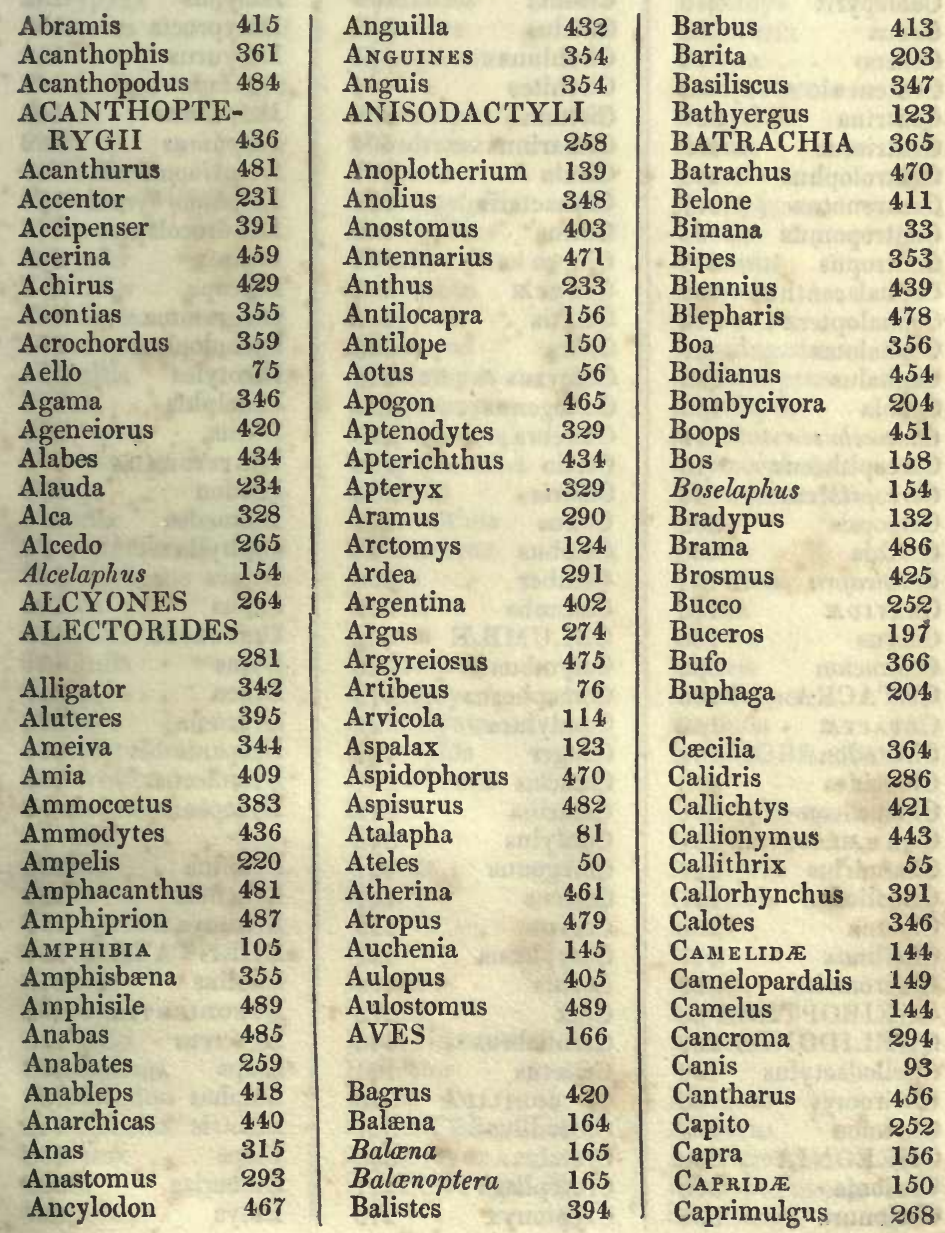




\begin{tabular}{|c|c|c|c|c|}
\hline Capros & Chelys & 339 & Curimata & 402 \\
\hline Caracara & Chersydrus & 360 & CURSORES & 283 \\
\hline Carapus & Chetodipterus & 484 & Cursorius & 285 \\
\hline Caranx & CHIM在压 & 390 & Cuculus & 248 \\
\hline Carbo & Chimæra & 391 & Cyclopterus & 430 \\
\hline Carcharias & Chionis & 308 & CYCLOSTOMI & 382 \\
\hline Carnivora $\quad 86$ & Chirocentrus & 409 & Cymindi & 193 \\
\hline CARTILAGINOUS & Chironectes & 109 & Cynocephalus & 49 \\
\hline FISHES $\quad 382$ & Chirotes & 353 & CYPRINIDEE & 413 \\
\hline asmarhynchos & Chlamyphorus & 134 & Cyprinodon & 418 \\
\hline Castor & Chromis & 449 & rinus & 413 \\
\hline Casuarius & Chrysochloris & 84 & Cypselus & 268 \\
\hline Cathartes & Chrysotosus & 479 & & \\
\hline Catodon & Cichla & 4.57 & Dacelo & 266 \\
\hline Cavia & Cin & 465 & Dactylopterus & 469 \\
\hline Ceblepyris & Cicc & 292 & Das & 132 \\
\hline Cebus & Cinclus & 213 & Dasyprocta & 130 \\
\hline Celæno & Cirrhinus & 4.15 & Dasyurus & 109 \\
\hline Centenes & Cirrhites & 4.54 & Irada & 4.52 \\
\hline Centrina & uda & 338 & Delphinus & 162 \\
\hline entriseus & Citharinus & 404 & Delphinus & 162 \\
\hline Centrolophus & Citula & 474 & Delphinopterus & 163 \\
\hline Centronotus & Climacteris & 262 & Delphinorhyncus & 162 \\
\hline Centropomus $\quad 4.64$ & Clinus & 440 & Dendrocolaptes & 259 \\
\hline Centropus & Clupea & 406 & Dentex & 453 \\
\hline Cephalacanthus 4.69 & Clupe & 406 & pe & 453 \\
\hline Cephaloptera $\quad 390$ & Cobitis & 417 & ramma & 457 \\
\hline Cephalotes $\quad 67$ & Cobra & 363 & olophus & 281 \\
\hline Cephalus & Coccyzus & 249 & tyles & 139 \\
\hline Cepola & Cœlogenus & 131 & elphis & 108 \\
\hline Cercocebus & Cœrebra & 260 & Dic & 330 \\
\hline Cercopithecus & Cœsio & 486 & TIGRADA & 389 \\
\hline Cercopithecus & Colaris & 205 & lon & 392 \\
\hline Cereopsis & Col & 246 & gedea & 315 \\
\hline Certhia & Colobus & 44 & Diphylla & 76 \\
\hline Cervicapra $\quad 151$ & Coluber & 358 & Dipsas & 358 \\
\hline Cervide $\quad 145$ & Imba & 269 & $\mathrm{Di}$ & 122 \\
\hline Cervus & COLUMBA & 269 & COBOLI & 429 \\
\hline Cestracion & bus & 325 & & 421 \\
\hline CETACEA & horus & 443 & & 347 \\
\hline CEE & lura & 85 & cœna & 343 \\
\hline xtodon & & 432 & anis & 264 \\
\hline Chalcides & ias & 204 & hiceus & 284 \\
\hline Chamæleon $\quad 351$ & cina & 219 & Dysopes & 76 \\
\hline CHAMALEONIDE 351 & ylus & 345 & & \\
\hline drius $\quad 287$ & gonus & 401 & & 135 \\
\hline liodus & & 447 & heneis & 431 \\
\hline 282 & & 199 & & 117 \\
\hline Cheilinus & phæna & 481 & ENTATA & 131 \\
\hline Cheiromeles $\quad 69$ & & 469 & lolius & 218 \\
\hline CHEIROPTERA 63 & Crax & 275 & EFFODIENTIA & 132 \\
\hline LIDONES 266 & Crenilabrus & 446 & Egocerus & 155 \\
\hline odactylus $\quad 4.58$ & Cricetus & 121 & & 363 \\
\hline Cheiromys & CROCODILIDAE & 340 & Elephas & 136 \\
\hline Chelmon & Crocodilus & 341 & Eleotris & 442 \\
\hline CHELONIA $\quad 336$ & Crotalus & 360 & & 408 \\
\hline $\begin{array}{ll}\text { Chelonia } & 338\end{array}$ & Crotophaga & 251 & Emberiza & 237 \\
\hline $\begin{array}{ll}\text { Chelonura } & 338\end{array}$ & Cryptonyx & 279 & Emys & 337 \\
\hline
\end{tabular}


INDEX,

\begin{tabular}{|c|c|c|c|c|c|}
\hline Fingraulis & 407 & Gobioides & 442 & \multirow{2}{*}{\multicolumn{2}{|c|}{ Istiophorus $\quad 480$}} \\
\hline Enicurus & 233 & Gobius & 441 & & \\
\hline Enoplosus & 464 & Gomphosus & 448 & \multicolumn{2}{|c|}{ Jacchus $\quad 57$} \\
\hline E.phippus & 483 & Gonorhynchus & 417 & \multirow[t]{2}{*}{ Julis } & 44.5 \\
\hline Ephibulus & 448 & Gracula & 203 & & \\
\hline Epimachus & 263 & \multicolumn{2}{|c|}{ GRALLATORES } & \multirow{4}{*}{\multicolumn{2}{|c|}{$\begin{array}{ll}\text { Kangurus } & 112 \\
\text { Kurtus } & 485 \\
\text { Kyphosus } & 487\end{array}$}} \\
\hline Eques & 488 & & .285 & & \\
\hline Equula & 478 & Grammistes & 4.58 & & \\
\hline Equus & 142 & GRANIVORA & 234 & & \\
\hline Erinaceus & 82 & Grus & 290 & \multicolumn{2}{|c|}{ Labeo $\quad 415$} \\
\hline Erix & 357 & Gulo & 88 & \multicolumn{2}{|c|}{ Labrax $\quad 450$} \\
\hline Erpeton & 357 & Gunnellus & 440 & \multirow{2}{*}{\multicolumn{2}{|c|}{$\begin{array}{ll}\text { LABROIDES } & 444 \\
\text { Labrus } & 444\end{array}$}} \\
\hline Erythrinus & 4.09 & Gymnetrus & 437 & & \\
\hline EsOCES & 410 & GYMNODONTES & 392 & \multirow{2}{*}{\multicolumn{2}{|c|}{$\begin{array}{ll}\text { Lacerta } & 344 \\
\text { LACERTINIDEE } & 342\end{array}$}} \\
\hline Esox & 410 & Gymnogaster & 438 & & \\
\hline Eurypyga & 301 & Gymnotus & 434 & \multicolumn{2}{|c|}{$\begin{array}{ll}\text { Lagomys } & 130\end{array}$} \\
\hline Exocetus & 412 & Gypaetus & 183 & \multirow{2}{*}{\multicolumn{2}{|c|}{$\begin{array}{lr}\text { Lagothrix } & 51 \\
\text { Lamna } & \mathbf{3 8 5}\end{array}$}} \\
\hline & & Gypogeranus & 184 & & \\
\hline Falcinellus & 286 & & & \multicolumn{2}{|c|}{ Lamprotornis $\quad 209$} \\
\hline Falco & 184 & Hæmatopus & 287 & \multirow{2}{*}{\multicolumn{2}{|c|}{$\begin{array}{ll}\text { Langaha } & 362 \\
\text { Lanius } & 216\end{array}$}} \\
\hline Felis & 100 & Haladroma & 314 & & \\
\hline FERE & 81 & Halicore & 161 & \multirow{2}{*}{\multicolumn{2}{|c|}{$\begin{array}{lr}\text { Larus } & 310 \\
\text { Lasiopyga } & \mathbf{4 6}\end{array}$}} \\
\hline Fiatola & 486 & Hemidactyli & 350 & & \\
\hline Fiber & 114 & Hemipodius & 280 & \multicolumn{2}{|c|}{ Lebias 418} \\
\hline Fierasfer & 436 & Hemiramphus & 412 & \multicolumn{2}{|c|}{ Lemmus $\quad 116$} \\
\hline FISHES & 371 & Heniochus & 483 & \multicolumn{2}{|c|}{ Lemur $\quad 60$} \\
\hline Fistularia & 488 & Herpestes & 98 & LEMURES & 59 \\
\hline Fistut.ARIDEE & 488 & rodon & 163 & Lepadogaster & 429 \\
\hline Fringilla & 243 & Himantopus & 287 & doleprus & 426 \\
\hline Fulica & 305 & Hippocampus & 399 & Lepidopus & 438 \\
\hline & & oglossus & 427 & isosteus & 4.09 \\
\hline Gadites & 423 & Hippopotamus & 137 & Leptocephalus & 435 \\
\hline Galago & 62 & Hirundo & 266 & Leptosomus & 250 \\
\hline Galbula & 257 & Holocanthus & 484 & Lep & 129 \\
\hline Galeopitheci & 64 & Holocentrus & 459 。 & Lestris & 312 \\
\hline Galeopithecus & 64 & $\mathrm{Hol}$ & 33 & Leuciscus & 415 \\
\hline Galeus & 385 & Hurria & 357 & Lichia & 477 \\
\hline GALLINA & 271 & Hyء & 99 & Limosa & 299 \\
\hline Gallinula & 302 & Hydrochærus & 130 & Lip & 430 \\
\hline Gallus & 475 & Hydromys & 118 & Lonchurus & 4.66 \\
\hline Gallus & 272 & Arocynus & 404 & Lophius & 471 \\
\hline Gasteropelecus & 405 & Hydrophis & 359 & LOPHOBRANC & HII \\
\hline Gasterosteus & 476 & Hypostomus & 422 & & 398 \\
\hline Gastrobranchus & 383 & Hyrax & 141 & Lophophorus & 273 \\
\hline Gaviala & 340 & Hyreus & 246 & Lophotes & 437 \\
\hline Gazella & 151 & Hystrix & 128 & Lophyrus & 347 \\
\hline Gecko & 349 & Hyla & 366 & Loricaria & 422 \\
\hline Geckotide & 349 & & & Loris & 61 \\
\hline Gerbillus & 122 & Ibis & 295 & Lota & 424 \\
\hline Glareola & 281 & Icterus & 206 & Loxia & 241 \\
\hline Glaucopis & 203 & Iguana & 348 & Lutianus & 453 \\
\hline GLIRES & 113 & IGUANIDE & 345 & Lutra & \\
\hline Glossophaga & 71 & Indicator & 248 & & \\
\hline Glyphisodon & 487 & Indris & 59 & Macacus & \\
\hline Gnathobolus & 408 & INERTES & 329 & Macacus & \\
\hline Gobiesox & 430 & INSECTIVORA & 81 & Macrognathus & \\
\hline Gobio & 414 & INSECTIVOR & & Macropteronotus & 421 \\
\hline Gobioides & 439 & & 210 & Macrourus & \\
\hline
\end{tabular}


MAMMALIA
MALACOPTER.
ABDOMINA-
LES
MALACOPTER.
APODES
MALACOPTER.
SUBRACHIATI

Malapterurus $\quad 422$

Malthe

Malurus

472

Manatus

224

Manis

MARSUPIALIA

107

Martes 90

Mastacembelus $\quad \mathbf{4 7 6}$

Mastigura $\quad 346$

Mastodon $\quad 137$

Medateus $\quad 72$

Megaderma $\quad 72$

Megalops $\quad 407$

Megatherium 132

Meleagris $\quad 274$

Meliphaga 264

Mene $\quad 479$

Menura 213

Mephitis $\quad 91$

Mergus 321

Merlangus $\quad 424$

Merluccius $\quad 424$

Merops 265

Micropterus $\quad 4.58$

Microstoma 411

Molossus $\quad 67$

Monitor $\quad 343$

Monocanthus 395

Monochirus $\quad 429$

Monocentris $\quad 469$

Monodon $\quad 163$

Monophyllus $\quad 76$

Monotrema 135

Mormoops 72

Mormon $\quad 327$

Mormyrus $\quad 412$

Morrhua $\quad 423$

Moschus $\quad 145$

Motacilla 232

\begin{tabular}{l} 
Mugil $\quad 463$ \\
\hline
\end{tabular}

Mullus $\quad 462$

Muræna $\quad 433$

Mus $\quad 118$

Muscicapa $\quad 223$

Muscipeta 223

Musophaga $\quad 247$

Mustela $\quad 425$

Mustela

$\begin{array}{lr}\text { Mustelus } & 386 \\ \text { Mycetes } & 52 \\ \text { Mygale } & 83 \\ \text { Myiothera } & 214 \\ \text { Myletes } & 403 \\ \text { Myliobatis } & 390 \\ \text { Myopteris } & 75 \\ \text { Myoxus } & 117 \\ \text { Myrmecophaga } & 134\end{array}$

Naked Serpents

Naia

364

363

Nasalis $\quad 46$

Naseus $\quad 482$

Nasua

Nectarinia 262

Noctilio $\quad 69$

Nomeus $\quad 473$

Notidanus $\quad 386$

Notopterus $\quad 408$

Novacula $\quad 448$

Nucifraga 202

Numenius $\quad 296$

Numida $\quad 275$

Nycteris 74

Nycticebus $\quad 61$

Nyctinomus $\quad 68$

Nyctophilus $\quad 76$

Ocypterus $\quad 218$

CEdicnemus $\quad 286$

Oligopodus $\quad \mathbf{4 8 0}$

OMNIVORE 197

Opetiorhynchus 260

Opisthocomus $\quad 197$

Opistognathus $\quad \mathbf{4 4 0}$

Ophicephalus 431

OPHIDIA $\quad 353$

Ophidium $\quad 435$

Ophisaurus $\quad 354$

Ophisurus $\quad 432$

Orcynus $\quad 474$

Oreas ${ }^{\circ} \quad 154$

Oriolus 205

Ornithorynchus 135

Orthonyx 258

Orcyteropus 133

Oryx

Osmerus $\quad 401$

Osphronemus 484

OSSEOUS FISHES

$\begin{array}{ll} & 392 \\ & 396\end{array}$

Ostracion $\quad 396$

$\begin{array}{ll}\text { Otaria } & 106 \\ \text { Otis } & 284\end{array}$

Otolithes $\quad \mathbf{4 6}$

Ouistiti
Ovibos

158

Ovis 157

Oxyrhynchus 258

\section{PACHYDERMA}

Pachyderma 135

Pachyptila $\quad 314$

Pagrus 4.52

Palæotherium 141

Palamedea 282

PALMIPEDES 307

Paradisea 208

Paradoxurus $\quad 98$

Paralepis $\quad 462$

Pardalotus 222

Parus 236

Parra $\quad 303$

Pastor $\quad 207$

Pauxi 275

Pavo 271

Pedetes 123

Pegasus $\quad 399$

Pelamis $\quad 360$

Pelecanus 322

Penelope $\quad 276$

Perameles $\quad 110$

$\begin{array}{ll}\text { Perca } & 463\end{array}$

Percis $\quad 467$

Percoldes $\quad 4.50$

Perdix 278

Periophthalmus 4.42

Peristedion 4.68

Petaurista 111

Petromyzon 382

Phæton 325

Phalaropus $\quad 305$

Phaleris 327

Phalangista $\quad 110$

Phascolarctos 113

Phascochærus 139

Phascolomys $\quad 113$

Phasianus 273

Phibalura 221

Phoca 105

Phoca 105

Phocæna 163

Phœnicophaus 250

Phœnicopterus 291.

Pholis 439

Phycis 425

Phyllostoma $\quad 70$

Phylluri $\quad 350$

Physeter $\quad 164$

Physeter 164

Phytotoma $\quad 246$

Piabucus 403

Picus 256 


\begin{tabular}{|c|c|c|c|c|}
\hline Pimelodus & 419 & Procyon & Sciæna & 466 \\
\hline Pimelepterus & 487 & Proteus & ScINCIDE & 352 \\
\hline \multicolumn{2}{|c|}{ PINNATIPEDES } & Psaris & Scincus & 352 \\
\hline & 304 & Pseudoboa & Sciurus & 125 \\
\hline Pipa & 368 & Psittacus & Schilbe & 419 \\
\hline Pipra & 221 & Psittirostra & Sclerot)ermi & 394 \\
\hline Pithecia & 56 & Psophia & Scolopax & 300 \\
\hline Pithecus & 41 & Pteraclis & Scolopsis & 457 \\
\hline Pitta & 213 & Pterocles $\quad \mathbf{2 7 7}$ & Scomber & 473 \\
\hline \multicolumn{2}{|c|}{ PLAGIOSTOMI } & Pteroglossus & Scomberesox & 411 \\
\hline & 383 & Pterois & SCOMBEROIDES & 472 \\
\hline Plantigrada & 286 & Pteromys & Scopelus & 405 \\
\hline Platalea & 295 & Pteropus & Scopus & 293 \\
\hline Platax & 483 & Ptilonorynchus 204 & Scorpæna & 4.59 \\
\hline Platessa & 427 & Ptyodactyli & Scotophilus & 76 \\
\hline Platurus & 362 & Putorius & Scyllium & 384 \\
\hline Platycephalus & 470 & Pyrrhocorax & Scymnus & 387 \\
\hline Platydactyli & 349 & Pyrrhula & Scythrops & 250 \\
\hline Platyrhynchos & 222 & Python & Scytalus & 361 \\
\hline Platysomi & 388 & & Selache & 386 \\
\hline Platystacus & 422 & QUADRUMANA & Selene & 475 \\
\hline Plecotus & 80 & $\begin{array}{r}215 \\
39\end{array}$ & Semnopithecus & 4.5 \\
\hline \multicolumn{2}{|c|}{ PLECTOGNATHI } & 1721 & Seps & 352 \\
\hline & 392 & Raia & SERPENTES & 355 \\
\hline Plectorhynchus & 487 & Rallus & Serranus & 454 \\
\hline Plectropoinus & 4.56 & Ramphastos & Serrasalmus & 403 \\
\hline Pleuronectes & 4.26 & Rana & Seriola & 474 \\
\hline Ploceus & 240 & Raniceps & Seserinus & 486 \\
\hline Plotosus & 421 & RAPACES & Sillago & 442 \\
\hline Plotus & 324 & Recurvirostra & SILURIDAE & 418 \\
\hline Podargus & 269 & Regalecus & Silurus & 418 \\
\hline Podiceps & 306 & Regulus & SIMINE & 40 \\
\hline Podoa & 305 & REPTILIA & Siren & 369 \\
\hline Pœcilia & 418 & Rhea & Sirenia & 160 \\
\hline Pogonias & 253 & Rhinobatus & Sitta & 258 \\
\hline Pogonias & 466 & Rhinoceros & Smaris & 450 \\
\hline Polychrus & 348 & Rhinolophus & Solea & 428 \\
\hline Polynemus & 488 & Rhinopoma & Solenostomus & 399 \\
\hline Polyplectron & 273 & Rhombus & SOLIDUNGULA & 142 \\
\hline Polyprion & 458 & Rhynchops 308 & Sorex & 82 \\
\hline Polypterus & 410 & RUMINANTIA & Sparactes & 217 \\
\hline Pomacentrus & 487 & 144 & Spatularia & 392 \\
\hline Pomatomus & 402 & Rupicapra & Sphagebranchus & 433 \\
\hline Porphyrio & 304 & Rupicola & Spheniscus & 328 \\
\hline Potorous & 112 & Rynchæa & Sphyræna & 461 \\
\hline Potos & 88 & & Spinachia & 476 \\
\hline Premnas & 488 & Sagrus & Spinax & 386 \\
\hline Priacanthus & 4.58 & Salamandra & SQUALIDES & 384 \\
\hline Prionites & 198 & Salanx & SQUAMIPENNES & 482 \\
\hline Prionurus & 482 & Salarias & Squatina & 387 \\
\hline Pristigaster & 408 & Salmo & Stelliferus & 4.59 \\
\hline Pristis & 387 & SALMONIDES & Stellerus & 161 \\
\hline Pristopomus & 457 & Sandrus & Stellio & 345 \\
\hline Proboscidea & 77 & SAURIA & Stenoderma & 69 \\
\hline Proboscidea & 135 & 405 & Sterna & 308 \\
\hline Procellaria & 313 & 230 & Sternarchus & 435 \\
\hline Prochilus & 464 & Scalops & Sternoptix & 406 \\
\hline Procnias & 220 & Scarus & Stomias & 411 \\
\hline
\end{tabular}


INDEX.

\begin{tabular}{|c|c|c|c|c|c|}
\hline Strepsilas & 289 & Testudo & 336 & Troglodytes & 41 \\
\hline Strix & 194 & Tetragonopterus & 403 & Trogon & 251 \\
\hline Stromateus & 486 & Tetragonurus & 476 & Trygon & 389 \\
\hline Struthio & 283 & Tetrao & 276 & Tupaia & 84 \\
\hline STURIONES & 391 & Tetraodon & 393 & Turdus & 210 \\
\hline Sturnus & 206 & Thamnophilus & 215 & Typhlops & 355 \\
\hline Stylephorus & 438 & Thecadactyli & 350 & & \\
\hline Suclis & 409 & Thrissa & 4,08 & Umbrina & 4.66 \\
\hline Sula & 324 & Thyr & 473 & Upupa & 263 \\
\hline Suricata & 99 & ptera & 77 & Uranoscopus & $46 \gamma$ \\
\hline & 138 & Ticl & 262 & Uria & 326 \\
\hline Sylvia & 225 & Tin & 280 & Ursus & 86 \\
\hline Synanceia & -460 & Tin & 415 & & \\
\hline chus & 434 & Tod & 222 & Vampyrus & 71 \\
\hline Syng & 398 & & 385 & & 288 \\
\hline Synodontis & 419 & & 356 & & 215 \\
\hline \multirow{2}{*}{ Syrrhaptes } & 278 & & 298 & rtilio & 77 \\
\hline & & Tox & 485 & Vespertilio & 77 \\
\hline ach & 323 & ypterus & 4,38 & VESPERTILIONES & s 65 \\
\hline Tænia & 461 & Trac & 479 & Vipera & 363 \\
\hline TEN & 436 & & 467 & Vive & 97 \\
\hline Tæn & 442 & Tra & 154 & Vomer & 475 \\
\hline Takydromus & 34.5 & & 346 & Vultur & 181 \\
\hline Talpa & 85 & Tria & 395 & & \\
\hline Tamarin & 58 & Tric & 107 & Xen & 259 \\
\hline Tan & 239 & Tric & 438 & Xiphias & 480 \\
\hline Tan & 295 & & 485 & & \\
\hline zous & 74 & phorus & 218 & Yunx & 257 \\
\hline Tapir & 142 & & 468 & & \\
\hline RADA & 132 & Trig & 362 & & 478 \\
\hline GADA & 62 & & 359 & Zorilles & 90 \\
\hline Taxus & 88 & & 297 & Zygæna & 385 \\
\hline Teius & 344 & Trio & 339 & ZYGODACTIL & \\
\hline Temnod & 488 & & 261 & & 247 \\
\hline Terapon & 465 & Troglodytes & 230 & & \\
\hline
\end{tabular}




\section{ENGLISH INDEX.}

\begin{tabular}{|c|c|c|c|c|c|}
\hline ACCENTOR & 232 & Bunting & 7,239 & Darter & 325 \\
\hline Agama & 346 & Burbot & 425 & Deer & 148 \\
\hline Agouti & 131 & Bustard & 284 & Diodon & 392 \\
\hline Albatross & 315 & Butcher-bird & 216 & Dipper & 213 \\
\hline Alligator & 342 & Buzzards & 192 & Diver & 325 \\
\hline Ameiva & 344 & & & Dodo & 330 \\
\hline Anaconda & 356 & Cachalot & 164 & Dogs & 93 \\
\hline Anchovy & 407 & Camel & 144 & Dog-fish & 386 \\
\hline Angel-físh & 387 & Camelopard & 149 & Dolphin & 162 \\
\hline Angler & 471 & Canary-finch & 245 & Dormouse & 117 \\
\hline Ant-eater & 134 & Capercail zie & 276 & Dorse & 423 \\
\hline Antelopes & 150 & Caracal & 103 & Dory & 478 \\
\hline Apes & 41 & Carp & 413 & Dragon & 347 \\
\hline Apteryx & 330 & Cat & 104 & Dragonet & 443 \\
\hline Argali & 157 & Centriscus & 489 & Ducks & 318 \\
\hline Armadillo & 133 & Chacal & 96 & Dugong & 161 \\
\hline Arnee & 159 & Chætodon & 482 & & \\
\hline Aspic & 363 & Chaffinch & 244 & Eagles & 187 \\
\hline Ass & 143 & Chalcides & 353 & Echidna & 135 \\
\hline Auk & 326 & Chamæleons & 351 & E.el & 432 \\
\hline \multirow{2}{*}{ Aye-aye } & 63 & Chamois & 156 & Efts & 352 \\
\hline & & Chatterer & 220 & Egret & 292 \\
\hline Baboons & 49 & Chimæra & 391 & Eider duck & 319 \\
\hline Badger & 88 & Chimpansé & 41 & Electric gymnot & 434 \\
\hline Band-fish & 437 & Chinche & 91 & Elephant & 136 \\
\hline Banstickle & 476 & Civet & 97 & Elk & 146 \\
\hline Barbel & 413 & Coal-fish & 424 & Emu & 284 \\
\hline Basilisk & 347 & Coaita & 51 & Ermine & 90 \\
\hline Bats & 65 & Coati & 87 & & \\
\hline Bears & 86 & Cock & 272 & Falcons & 185 \\
\hline Beaver & 114 & Cock of the wood & 276 & Father-lasher & 470 \\
\hline Bee-eater & 265 & Cockatoos & 254 & Ferret & 89 \\
\hline Beluga & 163 & Cod & 423 & Field mouse & 115,119 \\
\hline Bintourong & 98 & Condor & 183 & Fieldfare & 211 \\
\hline Bird of Paradise & 208 & Coney & 141 & File-fish & 394 \\
\hline Bison & 159 & Conger & 432 & Fistularia & 489 \\
\hline Blackbird & 211 & Coot & 305 & Flamingo & 294 \\
\hline Black-cock & 277 & Cormorant & 323 & Flounder & 427 \\
\hline Black fish & 421 & Coucal & 249 & Flycatcher & 223 \\
\hline Bleak & 415 & Cranes & 290 & Flying-fish & 412 \\
\hline Blenny & 439 & Creeper & 260 & Fossil birds & 330 \\
\hline Blind-w orm & 354 & Crocodile & 341 & Fossil fishes & 490 \\
\hline Boa & 356 & Cross-bill & 241 & Fossil reptiles & 370 \\
\hline Boat-bill & 295 & Crows & 199 & Fox & 96 \\
\hline Bohemian chatterer & 204 & Cuckoo & 248 & Frogs & 365 \\
\hline Bonnet Fluke & 428 & Curassou & 275 & Frog-fish & 471 \\
\hline Bream & 415 & Curlew & 296 & & \\
\hline Brill & 428 & Curlew, pigmy, & 287 & Galago & 62 \\
\hline Buffalo & 159 & & & Gannet & 324 \\
\hline Bulfinch & 242 & Dab & 427 & Gar-fish & 411 \\
\hline Bullhead & 469 & Dace & 415 & Garganey & 319 \\
\hline
\end{tabular}




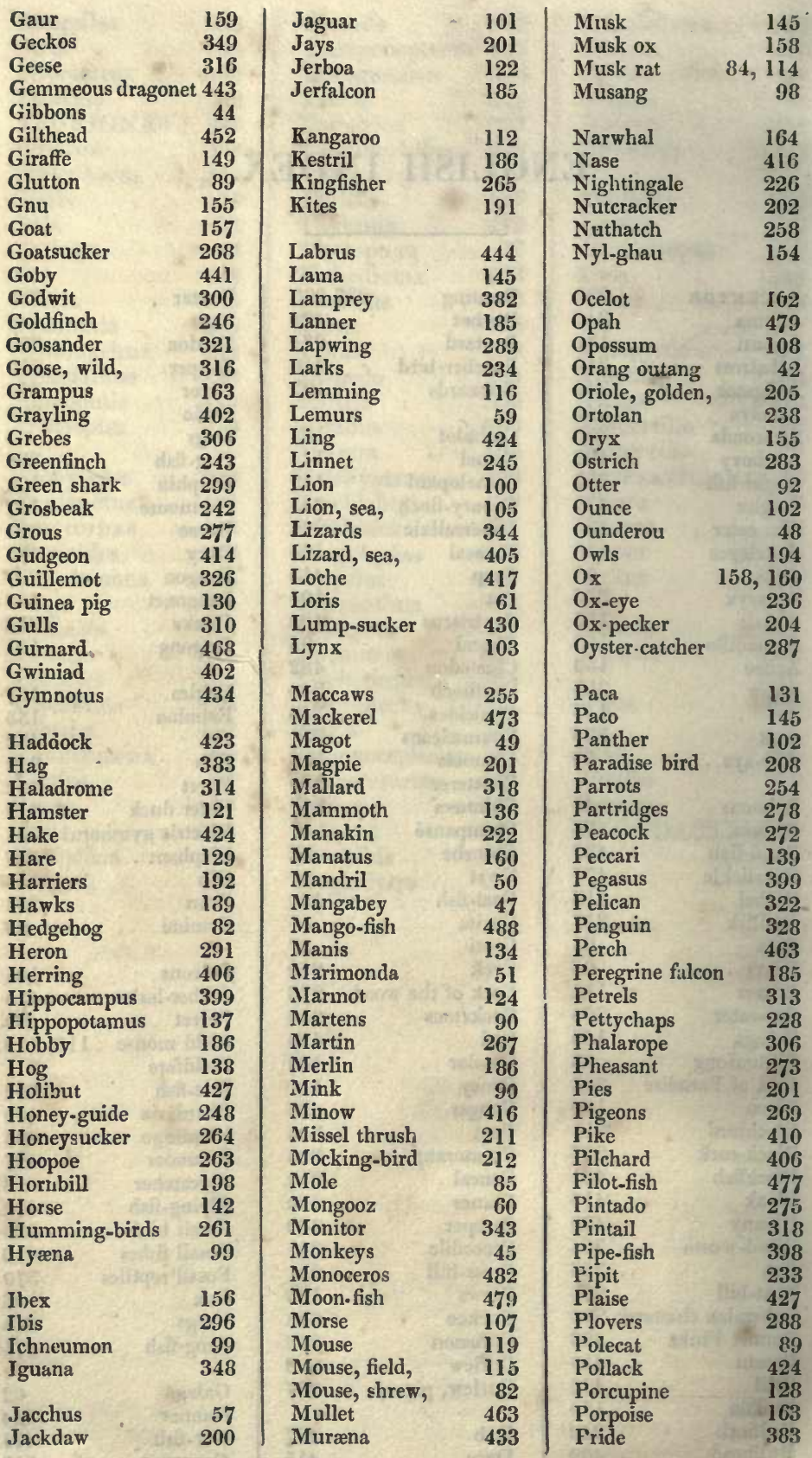


ENGIISH INDEX.

\begin{tabular}{|c|c|c|c|c|c|c|}
\hline Ptarmigan & 277 & Sheep & 158 & Torpedo & & 388 \\
\hline Puffin & 326 & Sheldrake & 318 & Torsk & & 425 \\
\hline Puffin petrels & 313 & Snipe & 300 & Tortoises & & 337 \\
\hline \multirow[t]{2}{*}{ Puma } & 101 & Shoveler & 319 & Toucan & & $25 \mathrm{i}$ \\
\hline & & Shrew-mouse & 82 & Tropic bird & & 325 \\
\hline Quagga & 143 & Shrike & 216 & Trout & & 401 \\
\hline \multirow[t]{2}{*}{ Quail } & 279 & Siamang & 44 & Trumpeter & & 281 \\
\hline & & Siren & & Trunk fish & & 396 \\
\hline Rabbit & 129 & Skate & 389 & Tunny & & 473 \\
\hline Raccoon & 87 & Skua gull & 312 & Turbot & & 428 \\
\hline Rails & 302 & Skylark & 235 & Turkey & & 274 \\
\hline Rats & 118 & $\begin{array}{l}\text { Sloth } \\
\text { Smelt }\end{array}$ & 132 & Turnstone & & 289 \\
\hline Rat, musk, & 84,114 & $\begin{array}{l}\text { Smelt } \\
\text { Smew }\end{array}$ & $\begin{array}{l}401 \\
322\end{array}$ & Turtle-dove & & 270 \\
\hline Rat, water, & $\begin{array}{l}114 \\
360\end{array}$ & Snakes & 358 & Vampyre & & 71 \\
\hline $\begin{array}{l}\text { Rattlesnake } \\
\text { Rays }\end{array}$ & 389 & Soland goose & 324 & Vicugna & & 145 \\
\hline Redbreast & 228 & Sole & 428 & Viper & & 364 \\
\hline Rein-deer & 146 & Sparrow & 244 & Vulture & 181, & 183 \\
\hline Remora & 431 & Sparrow-hawk & 190 & & & \\
\hline Reptiles, fossil, & 370 & Sparus & 457 & Wagtail & & 232 \\
\hline Rhinoceros & 140 & Spoonbill & 295 & Wapiti & & 147 \\
\hline Ring-dove & 269 & Sprat & 407 & Warblers & & 225 \\
\hline Ring-ouzel & 211 & Squirrel & 125 & Water-hen & & 303 \\
\hline Roach & 415 & Stag & 147 & Water-rat & & 114 \\
\hline Roebuck & 148 & Starling & 206 & Weasel & & 90 \\
\hline Rook & 200 & Stellio & 346 & Weaver & & 240 \\
\hline Roller & 205 & Stickleback & 476 & Weever & & 467 \\
\hline Rud & 416 & Stock-dove & 270 & Whale & & 165 \\
\hline Ruff & 298 & Stork & 293 & Wheat-ear & & 230 \\
\hline \multirow{2}{*}{ Ruffe } & 459 & Sturgeon & 391 & Whimbrel & & 296 \\
\hline & & Sucker & 429 & Whin-chat & & 231 \\
\hline Sable & 91 & Sun-fish & 393 & White-throat & & 227 \\
\hline Salamander & 368 & Surmullet & 462 & Whiting & & 424 \\
\hline Salmon & 400 & Swallows & 266 & Widgeon & & 319 \\
\hline Sanderling & 286 & Swallow Petrels & 314 & Wolf & & 95 \\
\hline Sand-launce & 436 & Swans & 317 & Wolf-fish & & 441 \\
\hline Sand pipers & 297 & Swift & 268 & Wolverene & & 88 \\
\hline Saury pike & 411 & & & Wombat & & 113 \\
\hline Scarus & 449 & Tapir & 142 & Woodcock & & 300 \\
\hline Sciæna & 466 & Teal & 319 & Woodlark & & 235 \\
\hline Scink & 352 & Tench & 414 & Woodpeckers & & 256 \\
\hline Screamer & 282 & Terns & 309 & Wrasse & 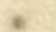 & 446 \\
\hline Seals & 106 & Tetraodon & 393 & Wren & & 230 \\
\hline Sea Lion & 105 & Thornback & 389 & Wren, wood, & & 228 \\
\hline Secretary & 184 & Thrush & 211 & Wryneck & & 257 \\
\hline Sapajous & 50,53 & Tiger & 101 & & & \\
\hline Serpents & 355 & Tinamoo & 280 & Yapock & & 109 \\
\hline Serval & 103 & Titmouse & 236 & & & \\
\hline Shad & 407 & Toads & 366 & Zebra & & 143 \\
\hline Shark & 384 & Tope & 385 & & & \\
\hline
\end{tabular}

ENI OF VOLUME FIRST. 
12807

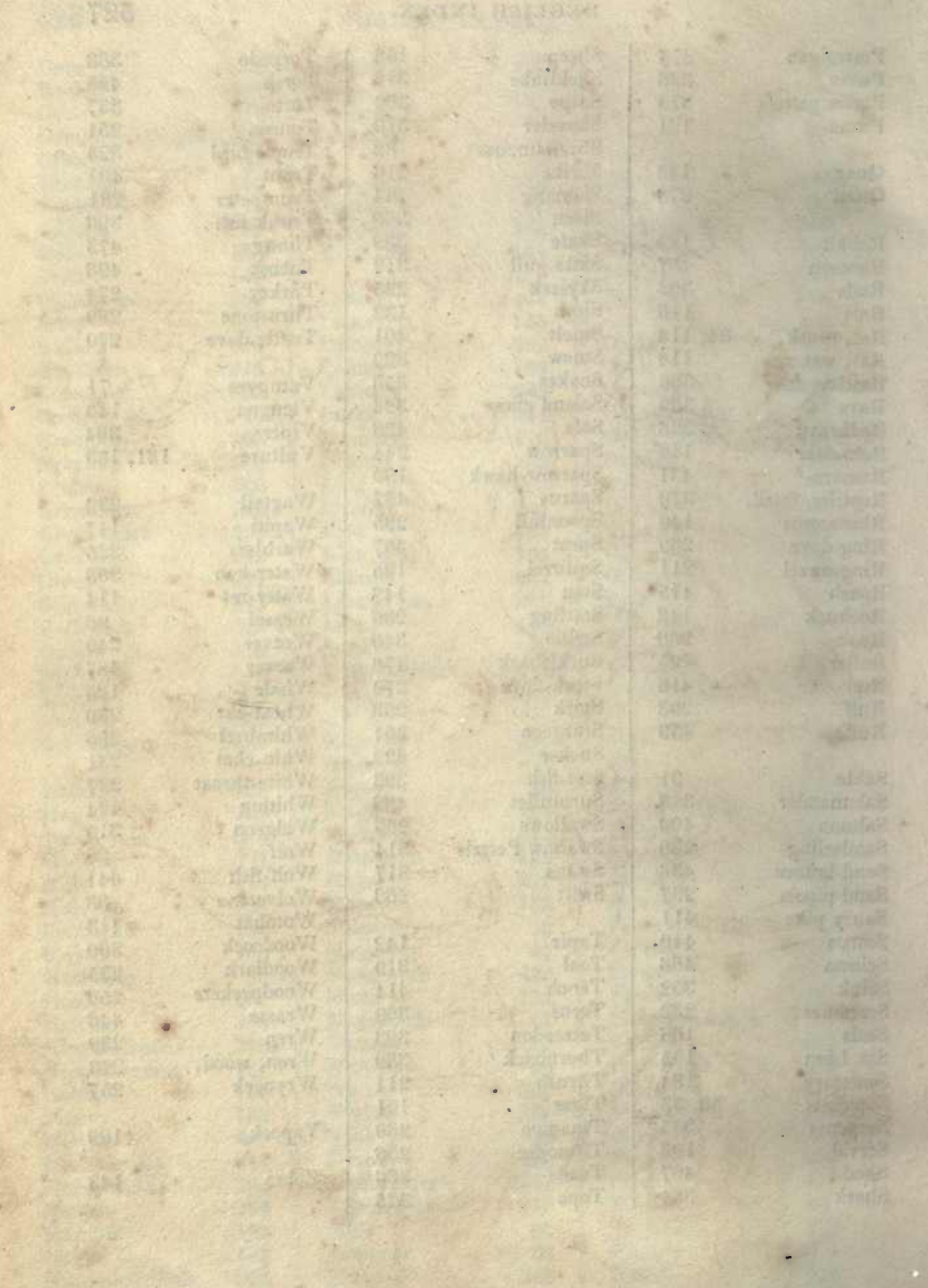

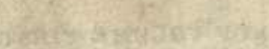

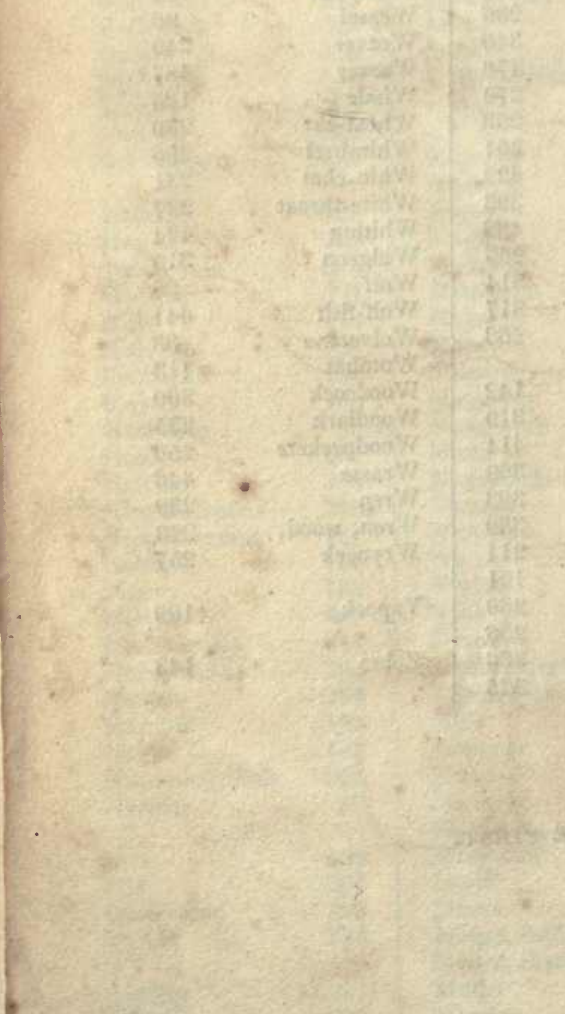



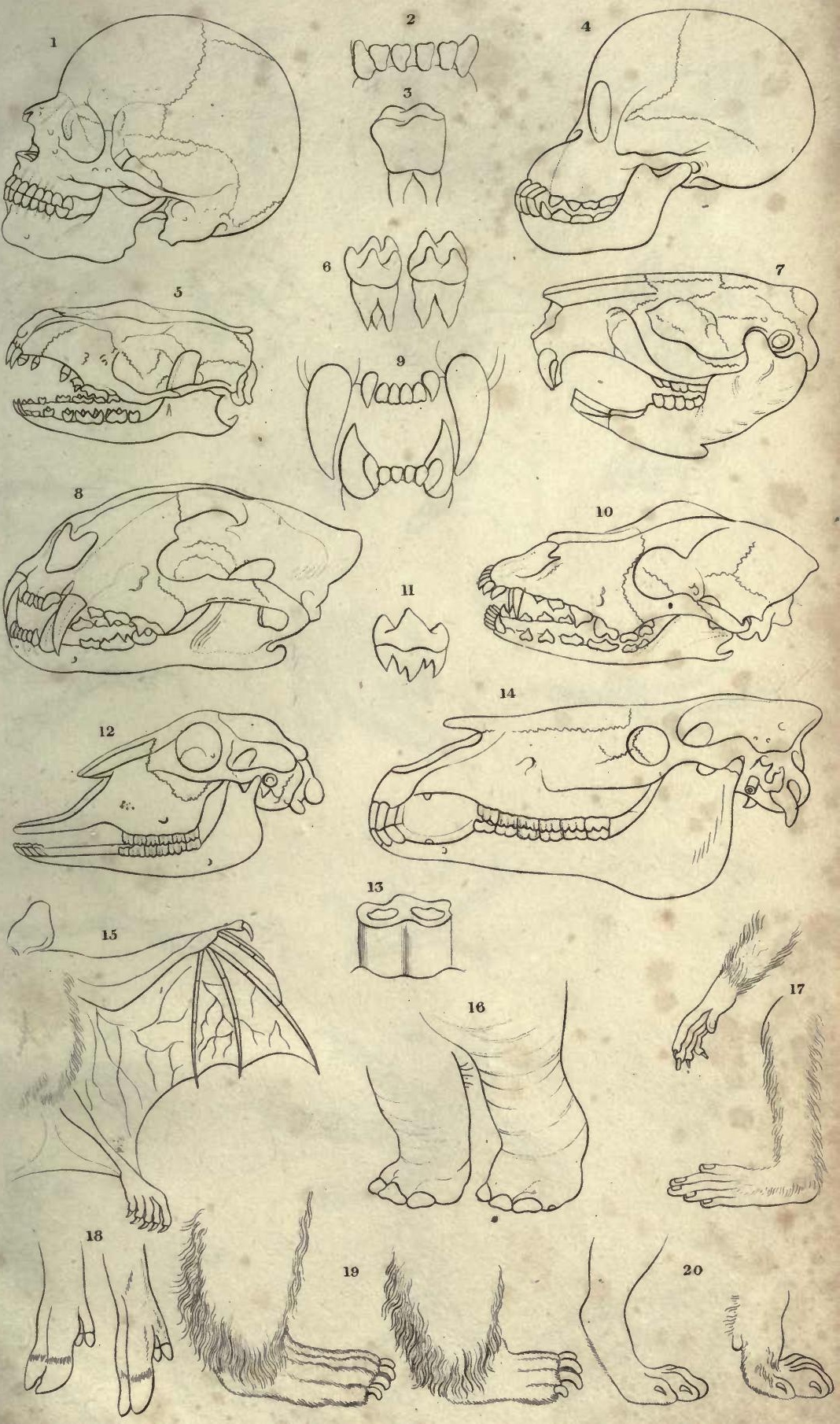


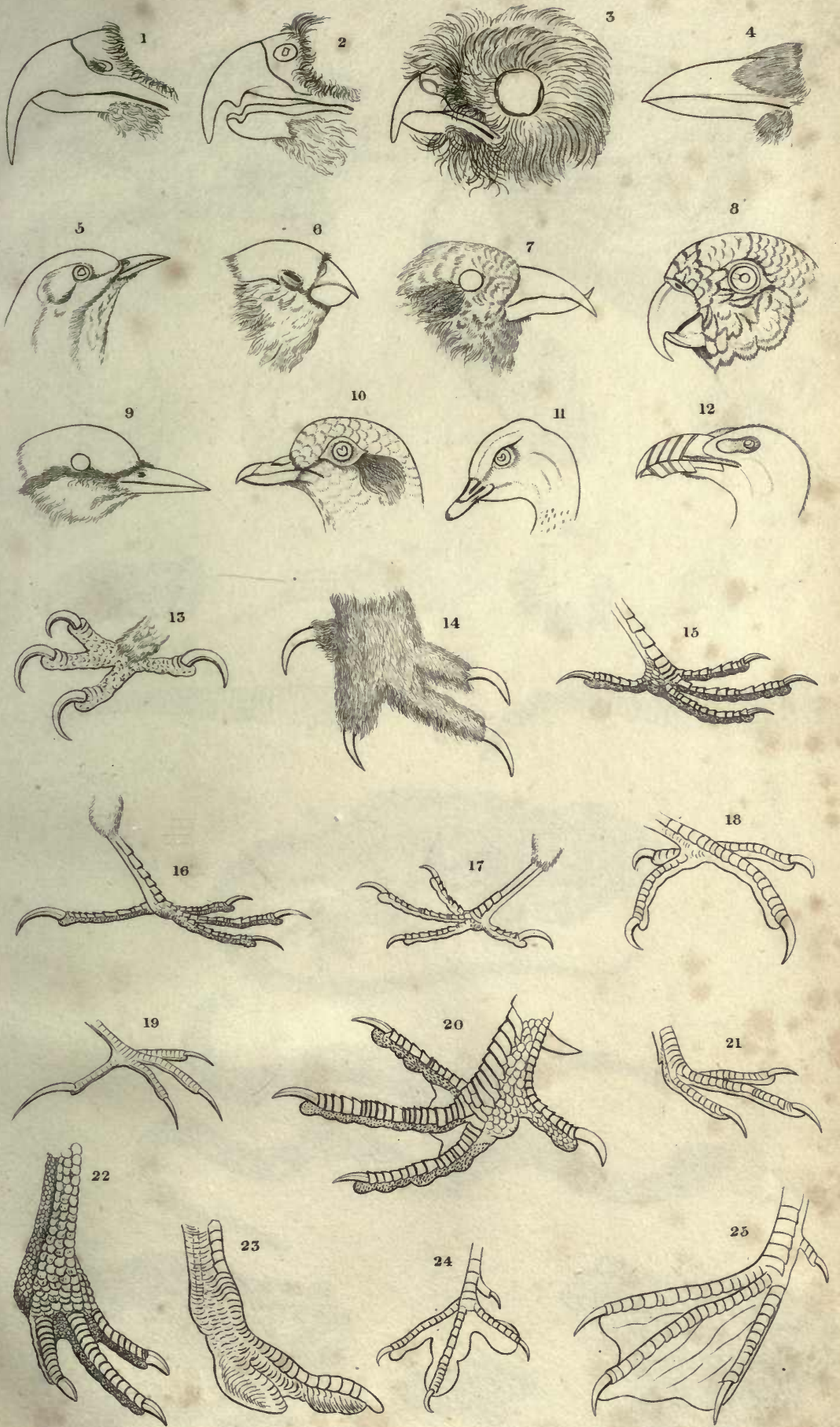
$4 x-17 \times=$

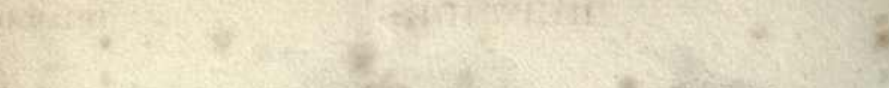

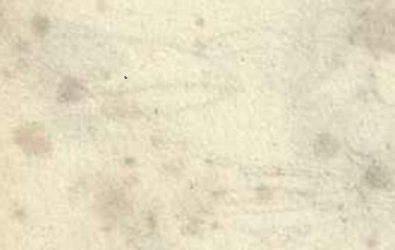
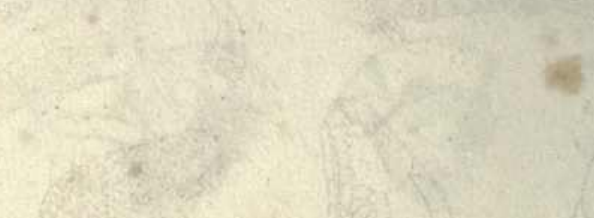

$$
\begin{aligned}
& x^{3}
\end{aligned}
$$

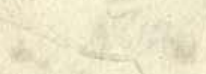

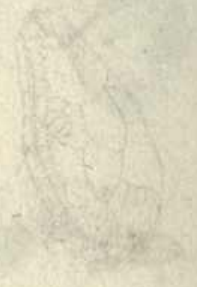

(46)

$$
\begin{aligned}
& 34 x+3 y^{4} \\
& 4
\end{aligned}
$$

3

a 2

3

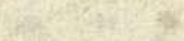

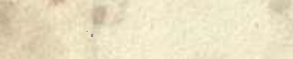

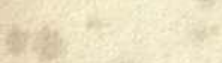
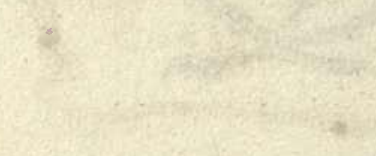


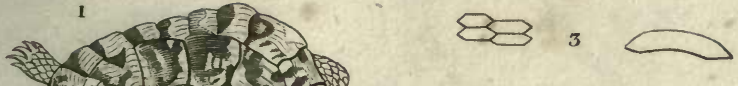

c. 0.15

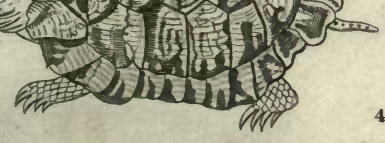
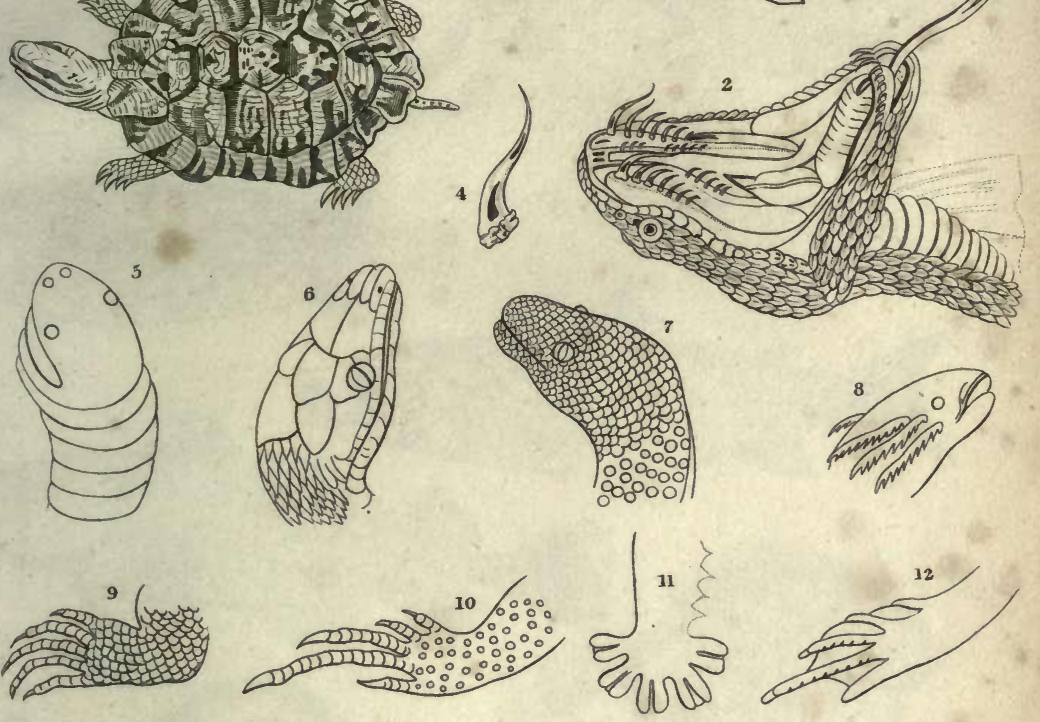

13

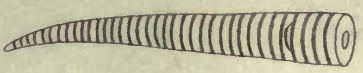
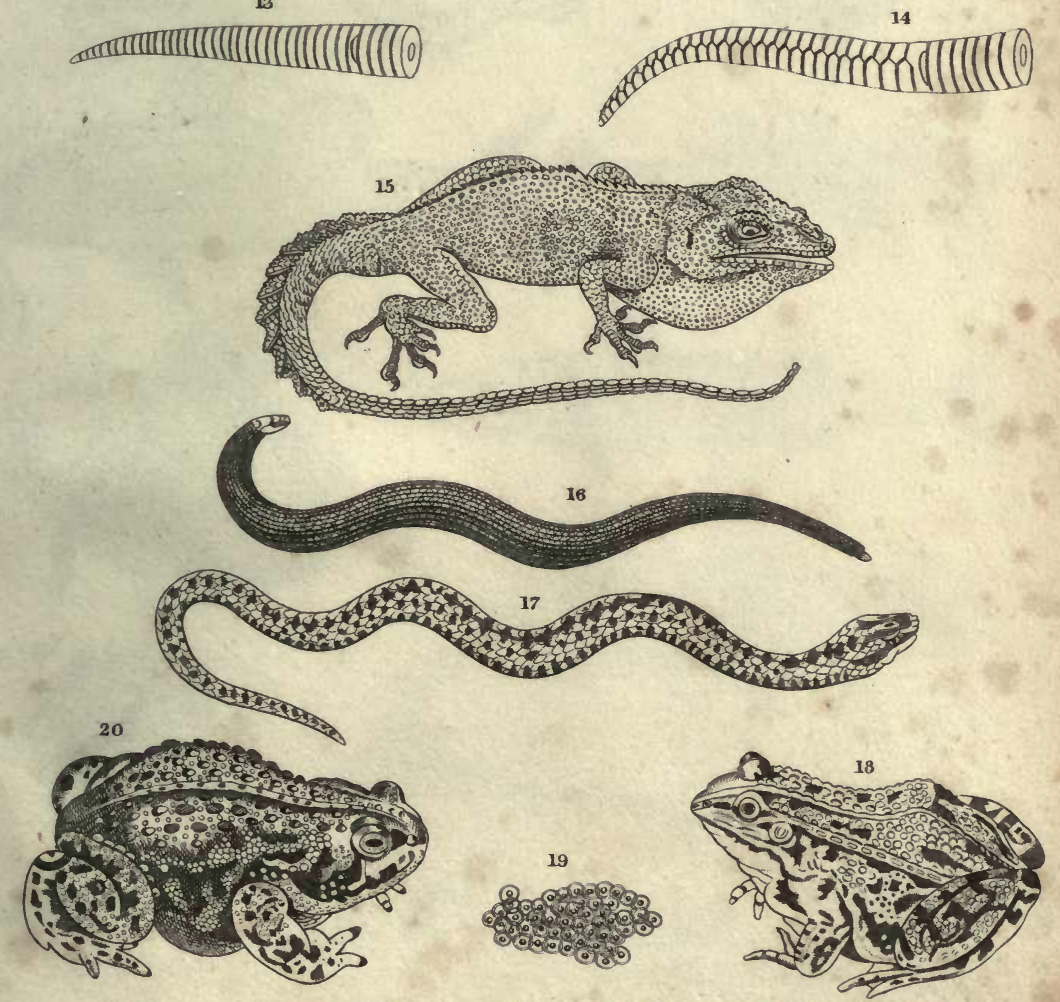


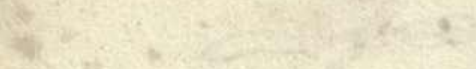

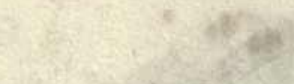

3

x-5

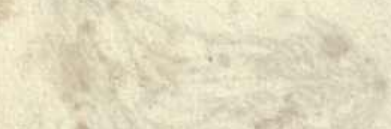

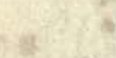

Ding

(4) -1.2

in

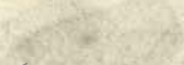

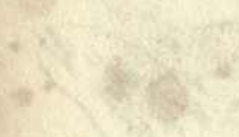

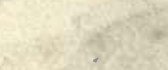

48

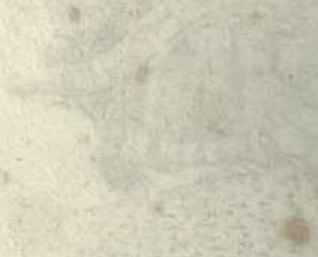

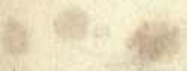

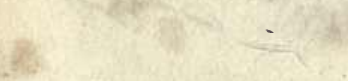

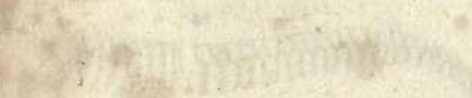

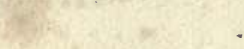

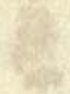

$\cdot$

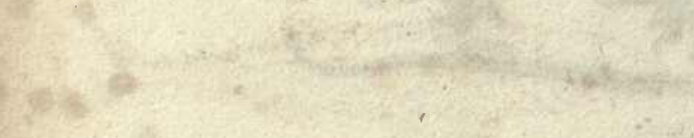

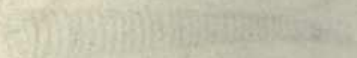
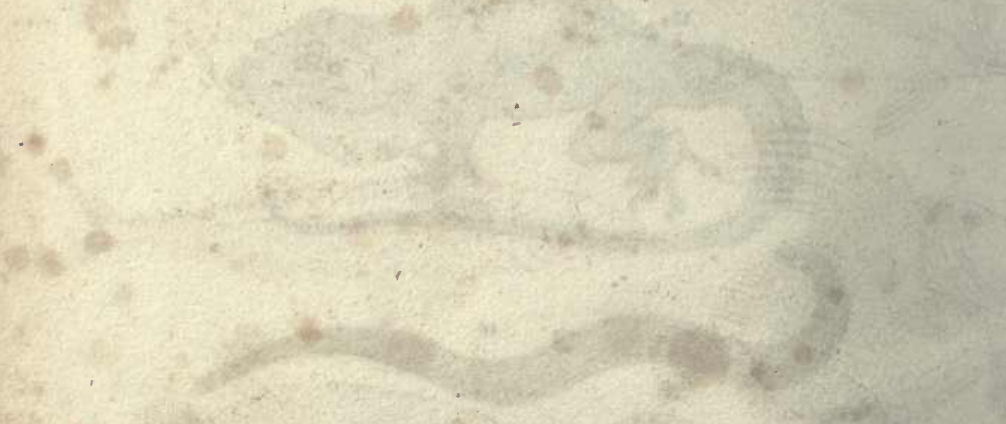

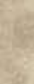

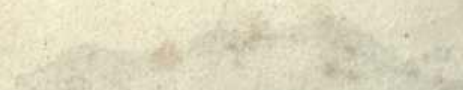

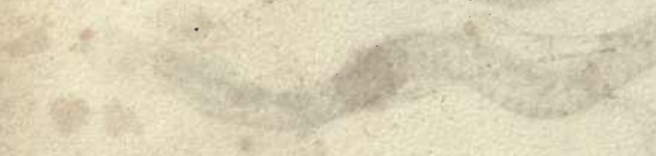

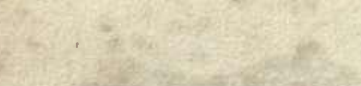

W.

sols

$y^{6}+48$ 

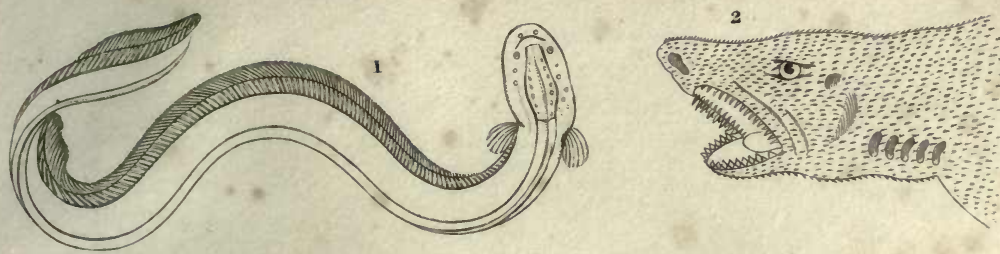

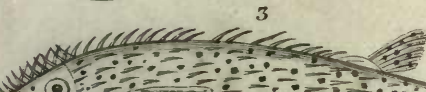

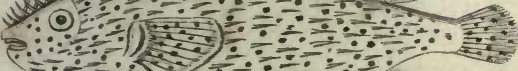

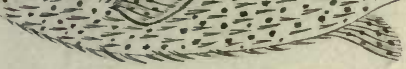

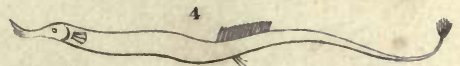

5

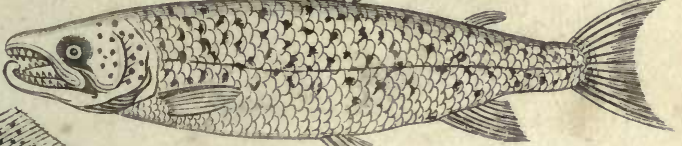

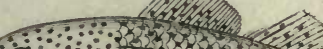
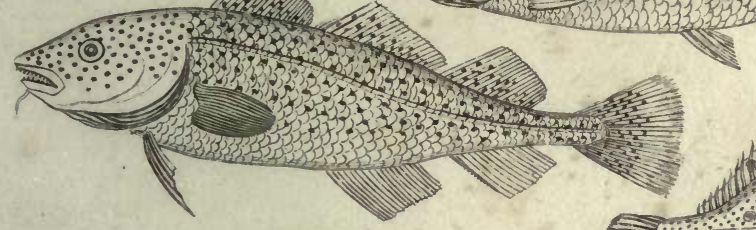

1

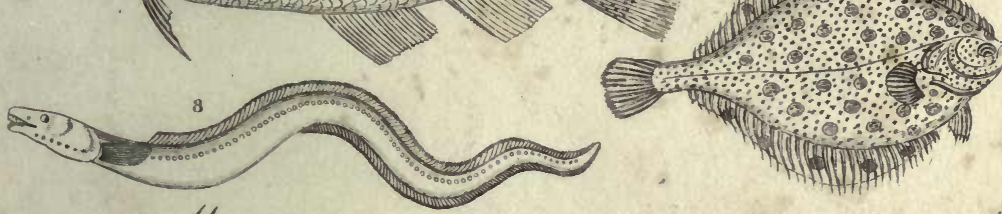

$\int_{1}^{2}$

Ifluming

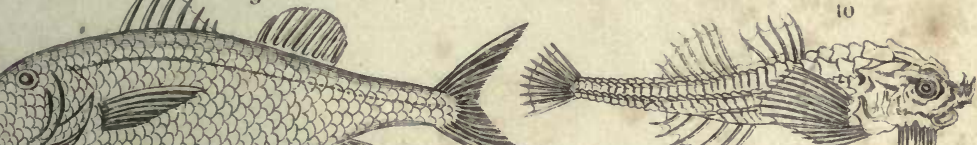
(3)
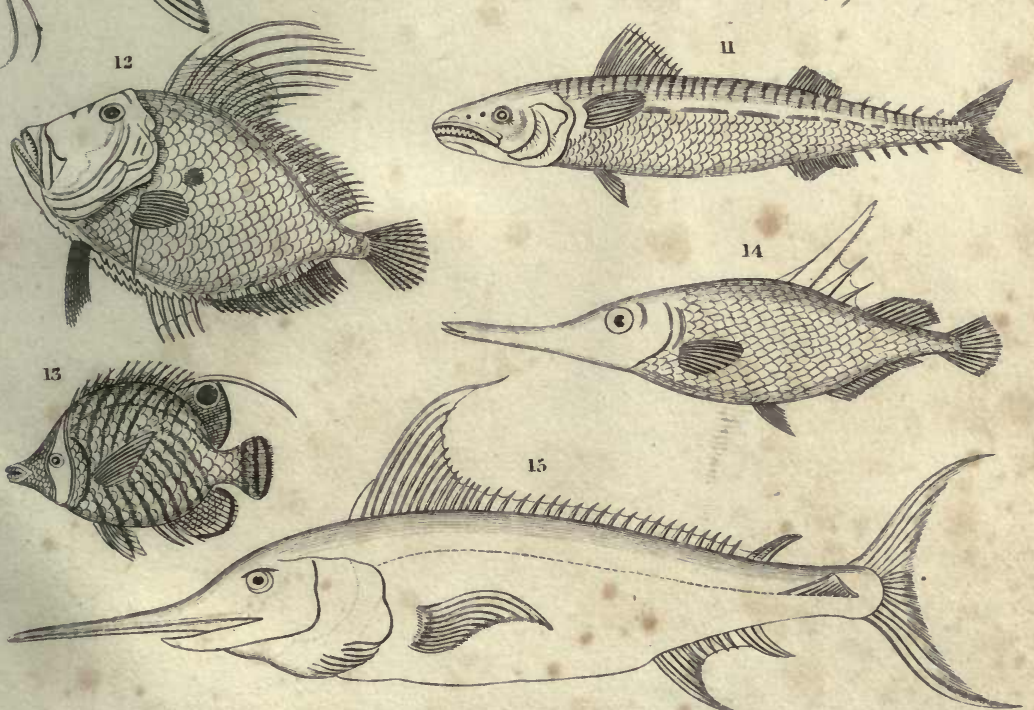

- (a) )

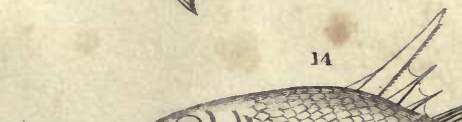








\section{FOURTEEN DAY USE}

\section{RETURN TO DESK FROM WHICH BORROWED}

\section{Biollogy [cilbrousy}

This book is due on the last date stamped below, or on the date to which renewed.

Renewed books are subject to immediate recall.

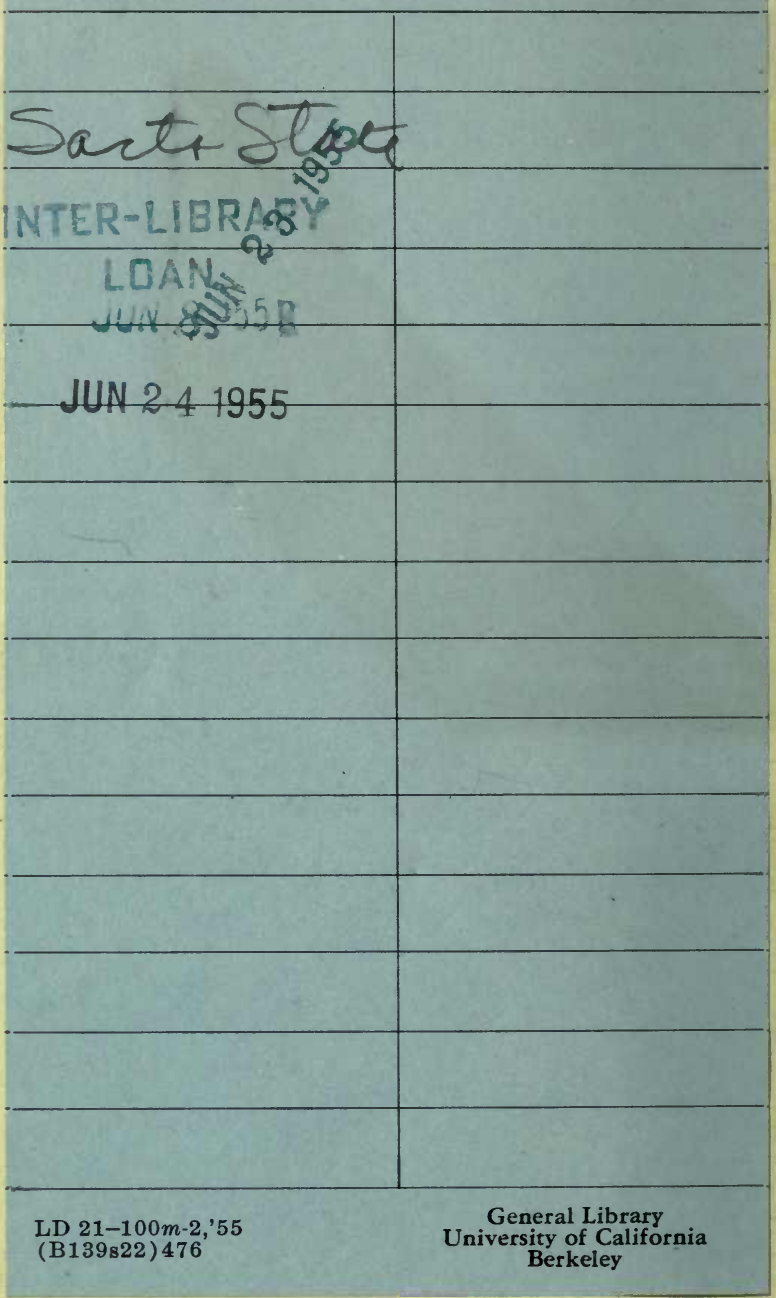


$\because$

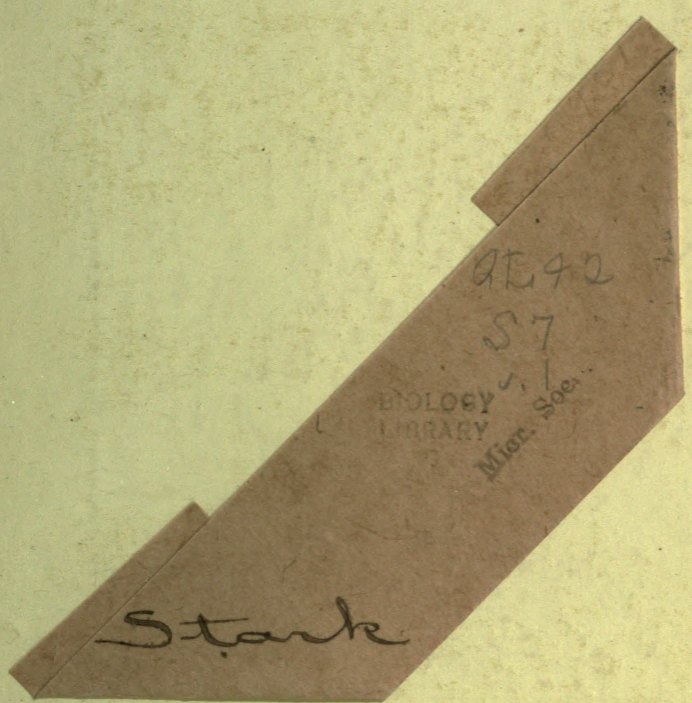

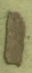


